\title{
Legitimacy of 'humanitarian military intervention'
}

Citation for published version (APA):

Eisenhamerová, L. (2011). Legitimacy of 'humanitarian military intervention'. [Doctoral Thesis, Maastricht University]. Maastricht University. https://doi.org/10.26481/dis.20111221le

Document status and date:

Published: 01/01/2011

DOI:

10.26481/dis.20111221le

\section{Please check the document version of this publication:}

- A submitted manuscript is the version of the article upon submission and before peer-review. There can be important differences between the submitted version and the official published version of record.

People interested in the research are advised to contact the author for the final version of the publication, or visit the DOI to the publisher's website.

- The final author version and the galley proof are versions of the publication after peer review.

- The final published version features the final layout of the paper including the volume, issue and page numbers.

Link to publication

\footnotetext{
General rights rights.

- You may freely distribute the URL identifying the publication in the public portal. please follow below link for the End User Agreement:

www.umlib.nl/taverne-license

Take down policy

If you believe that this document breaches copyright please contact us at:

repository@maastrichtuniversity.nl

providing details and we will investigate your claim.
}

Copyright and moral rights for the publications made accessible in the public portal are retained by the authors and/or other copyright owners and it is a condition of accessing publications that users recognise and abide by the legal requirements associated with these

- Users may download and print one copy of any publication from the public portal for the purpose of private study or research.

- You may not further distribute the material or use it for any profit-making activity or commercial gain

If the publication is distributed under the terms of Article $25 \mathrm{fa}$ of the Dutch Copyright Act, indicated by the "Taverne" license above, 


\title{
LEGITIMACY OF 'HUMANITARIAN MILITARY INTERVENTION’
}

\author{
Dissertation
}

to obtain the degree of Doctor at the Maastricht University, on the authority of the Rector Magnificus, Prof.dr. G.P.M.F. Mols in accordance with the decision of the Board of Deans, to be defended in public on Wednesday 21 $1^{\text {st }}$ December 2011 at 12.00 hours by

\section{Lenka Eisenhamerová}


Supervisors:

Prof.dr. Chris de Neubourg

Prof.dr. Jan Hanousek (CERGE-EI Institute, Czech Republic)

Co-supervisor:

Prof. Sara Cobb (George Mason University, USA)

Assessment Committee:

Prof.dr. Theo van Boven, chairman

Dr. Hakan Edstrom

Prof.dr. Evžen Kočenda, CERGE-EI Institute, Czech Republic

Dr. Fabian Raimondo 


\section{ACKNOWLEDGEMENTS}

This thesis owes a gratitude for its existence to many people who somehow contributed either by an inspiration, advice, or a support on the path to its finalization. My deepest gratitude belongs to my family, whose support and belief in me have made all my up-to-date studies and this entire accomplishment possible. I would also like to express my gratefulness to my supervisors Prof. Dr. Jan Hanousek and Prof. Dr. Sara Cobb, and to my promoter Prof. Dr. Chris Neubourg, who scrutinized and commented on individual chapters to turn them into a valuable contribution to the existing academic literature. While listing the people who deserve being acknowledged, I cannot omit the role of administrative stuff of the Maastricht Graduate School of Governance, especially the personal approach and support of Mindel and Chris, who much helped me in the difficult moments of my $\mathrm{PhD}$ and gave me a feeling that each single research fellow actually matters to them. The last but not the least, I would like to thank to all the cohort researchers, especially to Cheng, my dear office-mate, who were great friends and who managed to create a joke of even the most boring theory that we have come across during the $\mathrm{PhD}$ program. Only thanks to this entire broad network of people, where each individual contributed its little though important part, this thesis has been finished and has made it to the printer to become published. I sincerely hope, it will be read, understood, and used as an indication of how to make the functioning of the international system at least a bit more effective. 


\section{TABLE OF CONTENTS}

1. CHAPTER: INTRODUCTION - A NEW EMPIRICAL APPROACH TO THE LEGITIMACY OF HMI …..................................................

1.1. The complexity of 'humanitarian military intervention' (HMI)...............1

1.2. Empirical evaluation of the legitimacy of HMI in the existing literature...4

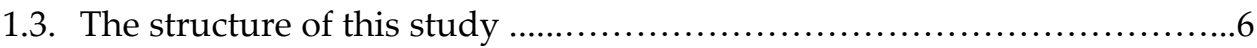

1.4. Limitations of the study and its approach...................................

2. CHAPTER: THE CONCEPT OF HMI - ITS LEGALITY AND LEGITIMACY..10

2.1. Complexity of the HMI concept..........................................10

2.2. Definition of the HMI concept.............................................11

2.3. Historical development of the HMI concept................................12

2.4. Difference between legality and legitimacy................................ 14

2.5. Legality of HMI..............................................................

2.5.1. Theoretical approaches toward the legality of HMI.....................14

2.5.2. Key legal provisions relevant for the right of HMI......................15

2.5.3. Alternative sources of the legal status of the right of HMI ...........16

2.5.3.1. International human rights law ..............................17

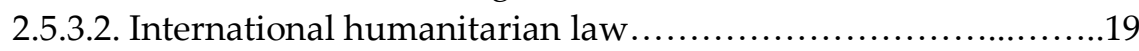

2.5.3.3. International customary law .....................................21

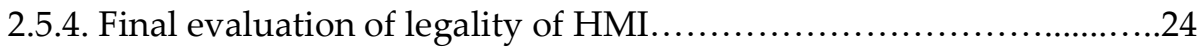

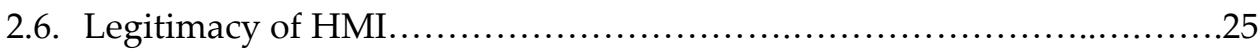

2.6.1. Mainstream approaches toward the legitimacy of HMI................25

2.6.2. Moral arguments supporting the legitimacy of HMI...................26

2.6.3. Moral arguments opposing the legitimacy of HMI....................28

2.6.4. Final evaluation of legitimacy of HMI.....................................32

2.7. Gap between legality and legitimacy - 'responsibility to protect' concept .33

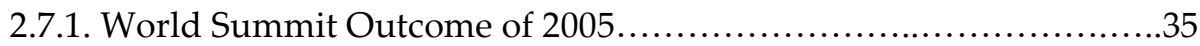

2.7.2. Legal interpretation of the 'responsibility to protect' ....................36

2.7.3. Impact of the 'responsibility to protect' concept on future policy

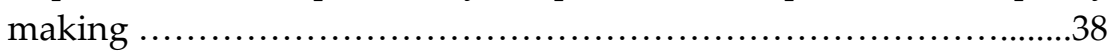

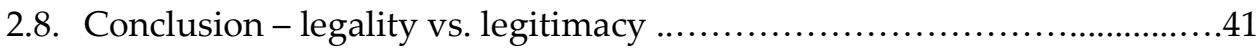

3. CHAPTER: THEORETICAL FRAMEWORK FOR EVALUATING THE

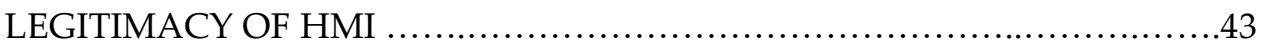

3.1. Controversy about 'motives and means' versus 'outcomes' ..................43

3.2. JWT as an evaluation framework of the legitimate 'motives and means' of

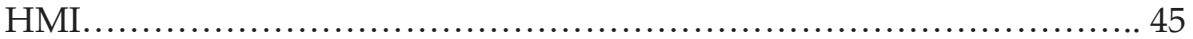

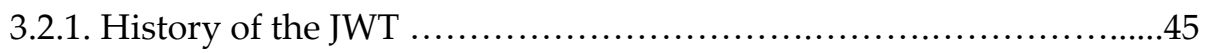


3.2.2. Applicability of the JWT to modernity..............................47

3.2.3. Description of the JWT criteria ....................................48

3.2.3.1. JWT criteria of 'jus ad bellum' .......................................49

3.2.3.1.1. JWT criterion of 'just cause' ................................49

3.2.3.1.2. JWT criterion of 'just intent' ...............................50

3.2.3.1.3. JWT criterion of 'just authority' ............................51

3.2.3.1.4. JWT criterion of 'last resort' .................................52

3.2.3.1.5. JWT criterion of 'proportionality'............................52

3.2.3.1.6. JWT criterion of 'probability of success' .......................53

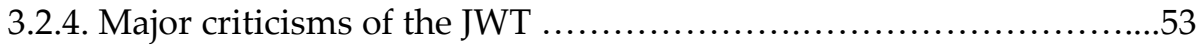

3.3. Consequentialism as an evaluation framework of the legitimate

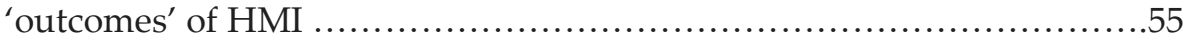

3.3.1. Strengths of the consequentialist approach ...........................56

3.3.2. Weaknesses of the consequentialist approach ........................58

3.4. Adopted theoretical framework in a summary .............................60

4. CHAPTER: QUANTIFICATION OF THE 'MOTIVES AND MEANS' OF MILITARY INTERVENTIONS BASED ON THE JWT …........................62

4.1. Quantification of the JWT criteria - conceptualization .....................62

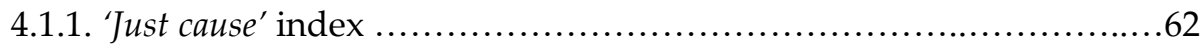

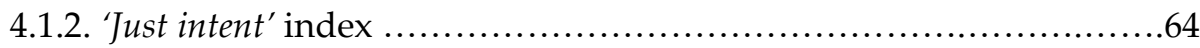

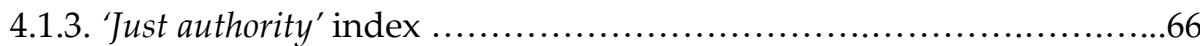

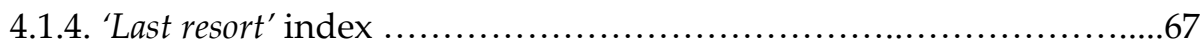

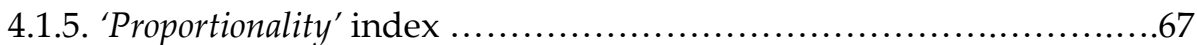

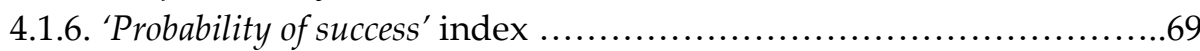

4.2. Quantification of the JWT criteria - factor analysis .......................70

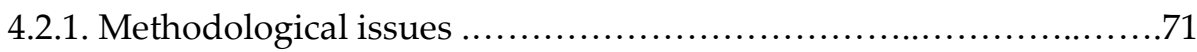

4.2.1.1. Choice of a factor model - principal component analysis (PCA) .71

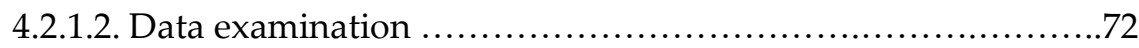

4.2.1.3. Number of the retained components ............................73

4.2.1.4. Method of rotation - orthogonal ................................ 75

4.2.1.5. Construction and labeling of the components ....................76

4.2.2. Interpretation of the results ........................................

4.2.2.1. Summary tables of the generated components constituting the

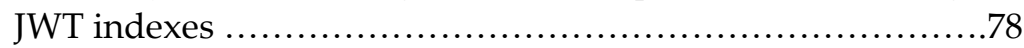

4.3. Weighting of the components and of the individual JWT criteria...........80

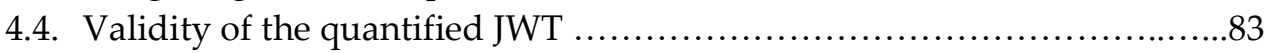

5. CHAPTER: LEGITIMACY OF HMI - MIXED CONSEQUENTIALIST AND JUST WAR THEORY PERSPECTIVE 
5.1. Introduction - an empirical assessment of the legitimacy of HMI...........85

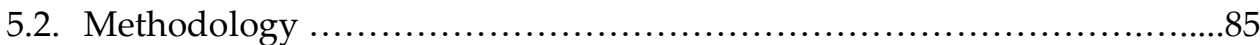

5.2.1. Definition of the 'HMI' ............................................85

5.2.1.1. Conceptualization of the 'humanitarian motives and means' ( $\left.\mathrm{X}_{\mathrm{it}}\right)$ 87

5.2.1.1.1. The 'humanitarian motives and means'- control version .87

5.2.1.1.2. The 'humanitarian motives and means'- first version (

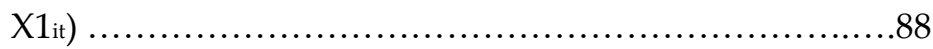

5.2.1.1.3. The 'humanitarian motives and means'- second version

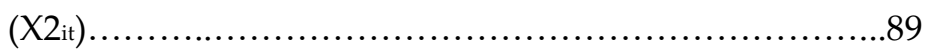

5.2.1.1.4. The 'humanitarian motives and means'- third version

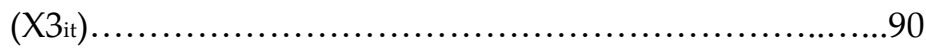

5.2.1.2. Conceptualization of a 'humanitarian outcome' (- $\left.\mathrm{Y}_{\mathrm{it}}\right) \ldots . . . . . .991$

5.2.1.2.1. A 'humanitarian outcome' - battle deaths indicator ( $\mathrm{Y} 1_{\text {it }}$ )

.96

5.2.1.2.2. A 'humanitarian outcome' - conflict deaths indicator

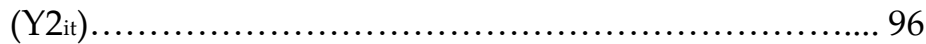

5.2.1.2.3. Common features of both dependent variables $\left(\mathrm{Y}_{1 \mathrm{it}}+\mathrm{Y} 2_{\mathrm{it}}\right)$

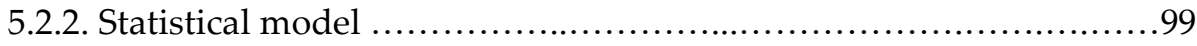

5.2.2.1. Time frame and unit of observation ..........................100

5.2.2.2. Statistical method ........................................101

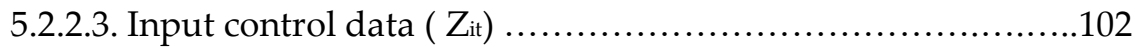

5.2.2.3.1. Characteristics of the target country (time-constant

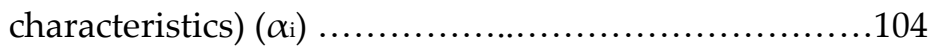

5.2.2.3.2. Characteristics of the target country (time-variant characteristics) $\left(\mathrm{Z}_{\mathrm{it}}\right)$...................................................104

5.2.2.3.2.1. Economic factors: GDP per capita level and GDP per capita change ......................................104

5.2.2.3.2.2. Political factors: polity level and polity change .........105

5.2.2.3.2.3. Ethno-religious factors: ethnic fractionalization and excluded population ................................107

5.2.2.3.2.4. Cultural factors: culture of violence ....................108

5.2.2.3.3. Characteristics of the conflict ........................108

5.2.2.3.3.1. Existence of a conflict ............................109

5.2.2.3.3.2. Previous conflict ....................................109

5.2.2.3.3.3. Internal conflict ..................................109

5.2.2.3.4. Characteristics of the military intervention .............110

5.2.2.3.4.1. Previous military intervention .........................110

5.2.2.3.4.2. 'Third-party' military intervention ....................110

5.2.2.3.4.3. Use of force by the intervener .........................110 
5.2.2.3.4.4. Military intervention targeting: supporting the government, supporting the rebels, mixed ..............111

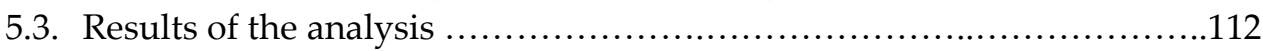

5.3.1. Hausman test .................................................112

5.3.2. Output of the fixed effects regression method ......................113

5.3.2.1. Legitimacy of the HMI based on the aggregate JWT ...........113

5.3.2.1.1. Control variables of the 'humanitarian motives and means' ..............................................114

5.3.2.1.2. Variables approximating the 'humanitarian motives and means' ..................................................115

5.3.2.1.3. Resulting effect of the 'humanitarian motives and means'

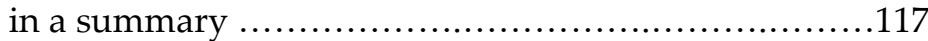

5.3.2.2. Legitimacy of the HMI based on the individual JWT criteria .118

5.3.2.3. Role of the remaining control variables in the legitimacy model 121

5.3.3. Sample of the candidates for a 'legitimate HMI' ....................122

5.4. Conclusion - an empirical assessment of the legitimacy of HMI .........123

6. CHAPTER: CONCLUSION - AN EMPIRICAL ASSESSMENT OF THE LEGITIMACY OF HMI................................................124

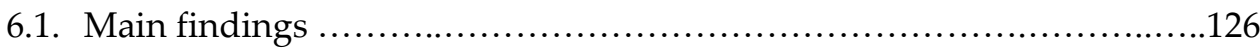

i. TECHNICAL APPENDUM TO CHAPTERS 4 AND 5: A NEW DATA COMPILATION ON CONFLICTS AND MILITARY INTERVENTIONS.............131

i.1. Rationale behind a new data compilation .............................131

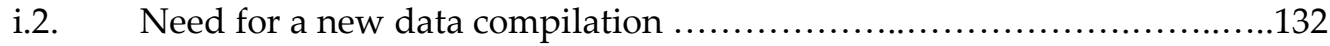

i.2.1. Lack of the comprehensive data .............................132

i.2.2. Differences in conflict operationalization .........................134

i.3. Academic contribution of the data compilation ...........................135

i.4. Data compilation structure .......................................136

i.4.1. Typology of the input data....................................136

i.4.2. Data structure of the compilation................................139

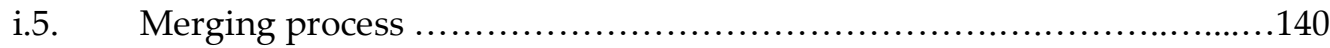

i.5.1. Creation of a common unit of analysis..........................140

i.5.1.1. Time-unit of analysis...................................141

i.5.1.2. Event-unit of analysis..................................142

i.5.1.3. Object-unit of analysis.................................143

i.5.1.3.1. Object coding.................................143

i.5.1.3.2. Object identification........................ 144 
i.5.1.4. Advantages of the adopted units of analysis. 145

i.5.1.5. Multiple entries resolution ..............................147

i.5.2. Merging of the adjusted datasets..................................149

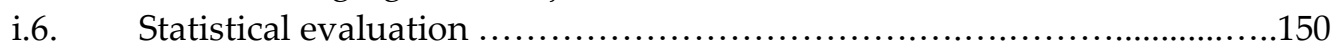

i.6.1. 'Consistency' of the merged data..................................150

i.6.2. 'Correctness' of the merged data................................151

i.6.3. 'Completeness' of the merged data..................................152

i.7. Attachment of the newly generated quantified JWT ....................153

i.8. Conclusion ...........................................................156

BIBILIOGRAPHY ..................................................... 158

TECHNICAL APPENDICES ............................................... 181

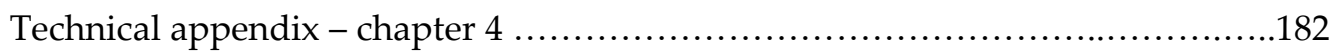

List of variables used for the quantification of the JWT criteria.............182

Results of the factor analysis ............................................208

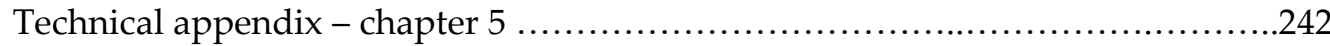

Regression model input variables: description and adjustments..........242

Results of the regression analysis.....................................261

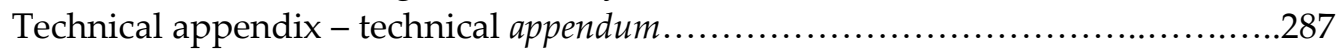

Technicalities of the data compilation................................287

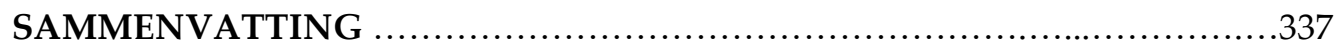

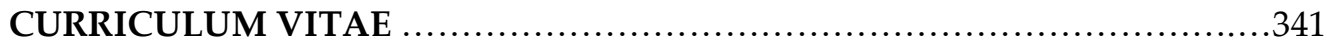




\section{LIST OF TABLES}

Table 1: Variables-to-observations ratio .73

Table 2: Results of Kaiser and Catell tests and the related decisions about

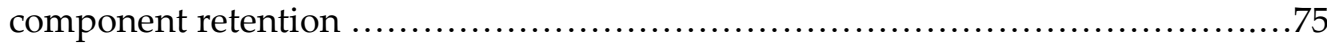

Table 3: Assessment of strength of the generated component loadings...............78

Table 4: PCA output - 'just cause' index ...............................................

Table 5: PCA output - 'just intent' index ..............................................

Table 6: PCA output - 'just authority' index ............................................

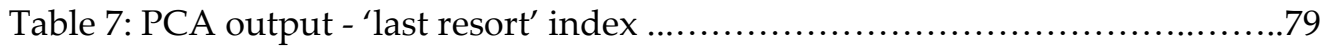

Table 8: PCA output - 'proportionality' index..........................................

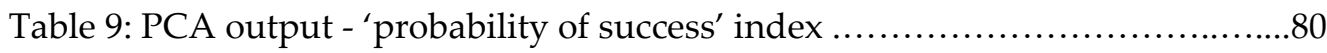

Table 10: Quantified JWT in a summary (input variables, generated components,

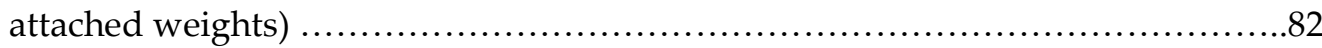

Table 11: Statistical description of JWT criteria indexes and the aggregate JWT index .83

Table 12: Approximation of the 'humanitarian outcomes' of military interventions

Table 13: Summary of the statistical model empirically assessing the legitimacy of

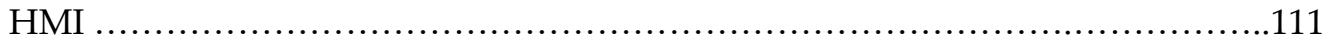

Table 14: Evaluation of the results of empirical analysis............................114

Table 15: Results of the fixed effects analysis - the control variables ................114

Table 16: Results of the fixed effects analysis - the aggregate JWT .................116

Table 17: Results of the fixed effects analysis - the individual JWT criteria (Y1)...119

Table 18: Results of the fixed effects analysis - the individual JWT criteria (Y2)...119

Table 19: Results of the fixed effects analysis including the control variables .....121

Table 20: Samples of the candidates for being awarded a label 'legitimate HMI'..122

Table 21: Input datasets into the new data compilation ............................137

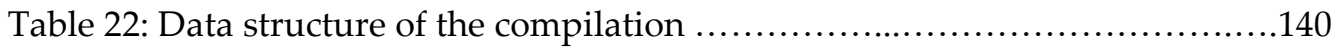

Table 23: Event definitions in the data compilation ...............................146 
Table 24: Event identification overlap in the data compilation (in country-years) .150

Table 25: Event identification overlap in the data compilation (in percentage)....151

Table 26: Overview of the 'correctness' of the data compilation ....................152

Table 27: Overview of the 'completeness' of the data compilation (percentage of

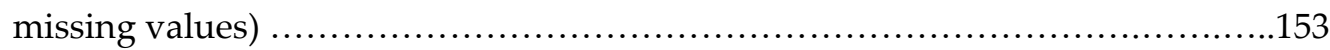

Table 28: Coding of the variables quantifying the JWT ...........................153 


\section{CHAPTER}

\section{INTRODUCTION - A NEW EMPIRICAL APPROACH TO THE LEGITIMACY OF HMI}

"War, to be abolished, must be understood. To be understood, it must be studied." Karl Deutsch in introduction of Quincy Wright's Study of War (1965)1

This study empirically analyses the 'humanitarian military interventions' (HMI's) between the years 1946 and 2005 by assessing a degree of 'humanitarianism' of the interventions in their 'motives and means' as well as in their 'outcomes'. The analysis adds radically new elements in the debates and controversies that are raised on every occasion a HMI is undertaken.

\subsection{The complexity of 'humanitarian military intervention' (HMI)}

Justifying the so-called 'humanitarian military interventions' (HMI's) and defending the underlying concept in international debates are highly problematic undertakings. Despite the very poor and contested legal status of the very concept of HMI within the current international law ${ }^{2}$, it is impossible to simply disregard the concept and define its related applications as not being justifiable. If $\mathrm{HMI}$ as a concept was accepted to be legitimate, it would have a power to challenge its presumed illegality. ${ }^{3}$ It would put pressure on the accepted norms and (gradually) lead to the acceptance of HMI within the framework of the international legal order in the future. ${ }^{4}$ Therefore, it is important to study whether the underlying virtue of morality of HMI and thus its legitimacy is not so robust that it could overcome the burden of its claimed illegality, providing the interveners with a legitimate right to intervene for the 'humanitarian' purposes despite the presumed illegality.

There are strong and valid arguments both supporting and condemning the HMI as a legitimate action, reflecting thus a tension between two moral perspectives. On one hand, it is argued that the respect of the ban on use of force in the international relations for the virtue of preserving peace and stability is an imperative and should make HMI not only illegal but also illegitimate. On the other hand, it is argued that guaranteeing international justice and protection of human rights provide interveners with the legitimate right to intervene for the

\footnotetext{
1 Wright, 1965.

2 The legal perspectives on the HMI will be discussed in detail in the second chapter of this study.

${ }^{3}$ Legitimacy represents the 'validity' of a given social order. See: D'entrèves, 1963.

4 Popovski \& Turner, 2008.
} 
'humanitarian' purposes outside their own territory. Should the predominant concern be the respect for the political and territorial integrity and sovereignty of the nation states, or should the main concern be the preference of human rights? This basic question about the legitimacy of HMI has gained importance particularly since the end of Cold War when the system of collective UN security became revitalized and the 'humanitarian' interventionism started to be used more frequently in practice. Among the most debated events from this time period that greatly influenced the discourse of HMI and added controversy to its application belong the crises in Rwanda in 1994 and in Kosovo in 1999. On one hand, the international community failed to prevent the genocide in Rwanda. On the other hand, the NATO decided to bomb Kosovo to end the ethnic cleansing and other mass atrocities without receiving an authorization by the UN Security Council. ${ }^{5}$ In fact, HMI is controversial both when it happens and when it does not. When a particular HMI is launched, there are serious doubts and debates about its legitimacy; however, when the international community remains inactive in the light of ongoing massive human rights violations, it is accused of a moral failure. Due to the strong moral positions of both supporters and opponents of HMI, the question, whether the HMI can be justified as a tool of crisis management or whether its use forms merely an illegal act, leads to inevitable disagreements not only among lawyers, moralists, and political scientists, but also within the public opinion worldwide.

The recent behavior and attitudes of the international actors seem to be increasingly inclined toward acceptance of legitimacy of the HMI and the acceptance of the underlying concept. The fact that the concept is frequently used to justify military actions indicates that legal considerations are less predominant and that international law is often disregarded in the politically sensitive questions in favor of the moral arguments. ${ }^{6}$ In spite of the increasingly supportive attitudes towards legitimacy of HMI's, unauthorized HMI's have so far been just 'silently' tolerated and the countries intervening for the 'humanitarian' purposes act on an ad hoc basis without having any framework available to rely on. ${ }^{7}$ More recently, new legal developments try to fill the discrepancy between the existing legal doctrines and between what the states and international organizations defend as morally right and legitimate. The international community has been pushing interpretation and development of the existing legal doctrines regulating the HMI step-by-step further to catch up with the actual behavior of the countries. The most remarkable step in this respect has been the adoption of a 'responsibility to protect' at the UN level as a new concept encouraging the international community to act in cases when the nation states fail to prevent or to stop serious violations of

\footnotetext{
5 Simma, 1999; or Independent International Commission of Kosovo, 2000.

6 Caplan, 2000.

7 See: Simma, 1999; Independent International Commission of Kosovo, 2000; or Franck, 2001.
} 
human rights within their territories. In spite of the fact that the 'responsibility to protect' does not represent a legally binding prescription and that it is still labeled only as an 'emerging legal norm', 8 the concept represents a significant tool of a moral pressure on the countries to react to the human rights violations abroad. ${ }^{9}$ These developments, however, do not imply that the relaxation of the principle of non-interventions continues without passionate debates. This is demonstrated by the fact that none of the attempts to restrict in a legally binding way the scope of the non-intervention norm embedded in the UN Charter or to enlarge the number of its allowed exceptions has so far managed to generate a consensus within the international community. ${ }^{10}$

This study proposes a radical departure from the difficult and sensitive moral and legal debates surrounding the HMI concept and its application. As an alternative to putting weights to a variety of moral claims defending or rejecting the legitimacy of HMI, this study intends to clarify the debate by empirically assessing the degree of 'humanitarianism' behind 1114 cases of military interventions in the time period between 1946 and 2005. The novelty of this approach is based on a systematic evaluation of the 'humanitarianism' behind the 'motives and means' of military interventions on the one hand and of the 'humanitarianism' behind the 'outcomes' of military interventions on the other hand. Based on the empirical evidence, it assesses how much are the 'humanitarian motives and means' actually decisive for the achievement of the 'humanitarian outcomes' at the end; it proposes an empirically validated version of a 'legitimate $\mathrm{HMI}^{\prime}$ and it filters out a resulting sample of historical cases of military interventions that represent potential candidates for receiving a label 'legitimate $\mathrm{HMI}^{\prime}$. If the findings of this study discover that it is possible to improve the humanitarian situation in the target state by waging a military intervention for 'humanitarian' purposes, it would serve as an empirically supported illustration of an existing gap between legitimacy and legality of HMI, and it would provide an argument for claiming that the legal framework should catch up. If the results of this study, however, suggest that the military interventions - though intended to be 'humanitarian' - tend to make the humanitarian suffering even worse, it would be an indication that the moral arguments calling for the legalization of the right of HMI are blind toward the actual negative effects of such interventions on the target state and that the legal obstacle to such interventionism makes sense and should be legitimately kept. Taming this normative debate about legitimacy of HMI into a long-run empirical analysis assessing its actual applications on the ground represents a new perspective that could move the scientific community a step

\footnotetext{
${ }^{8}$ See: International Commission on Intervention and State Sovereignty, 2001; MacFarlane, Thielking \& Weiss, 2004; Barbour \& Gorlick, 2008; or Bellamy, 2009.

${ }^{9}$ Weiss, 2004.

${ }^{10}$ Reisman, 1990.
} 
further while solving this dilemma. In spite of its novelty, the study builds on the insights provided by a limited number of earlier empirical studies.

\subsection{Empirical evaluation of the legitimacy of HMI in the existing literature}

The scholarly debate about legitimacy of HMI is very rarely of a quantitative nature. Due to the fact that HMI has traditionally been primarily a concept for theologians and legal theorists, a great majority of the existing literature about HMI is dominated by the single qualitative studies theoretically dealing either with the moral or legal aspects of the interventions ${ }^{11}$ or with the more technical issues of implementation and coordination failures of individual military missions. ${ }^{12}$ A new stream of research efforts focusing on the problem of legitimacy of HMI has been initiated by the increased capability of the UN Security Council to act in cases of the massive human rights violations after the end of Cold War. Only between April 1990 and March 1999, there were over 330 new articles published under the subject heading 'United Nations Armed Forces'.13 Among the most important recent triggers stimulating the research efforts on the legitimacy of HMI belong the NATO intervention in Kosovo in 1999,14 and obviously the US operations in Iraq in $2003,{ }^{15}$ which were both openly presented as 'humanitarian' but both lacked a clear mandate from the UN Security Council. The controversial legal standing and the debated morality of the two above mentioned interventions have resulted in a massive production of studies devoted to the issue of HMI. ${ }^{16}$ Despite the recent attention, only few studies have dealt with the concept of HMI using a quantitative approach.

There are just some empirical studies quantitatively addressing the impacts of HMI on the target state. Unfortunately, most of these impact assessments do not examine HMI in general, but rather focus on a certain sub-part of it. ${ }^{17}$ They can be classified into a number of categories. First, there are existing studies evaluating the crisis management activities of a single actor - typically the UN. ${ }^{18}$ Some of them conclude that the UN has a limited short-term success in settling the conflicts; ${ }^{19}$ while others claim that there is no difference in the success rate of the UN-led interventions if compared to the non-UN-led ones. ${ }^{20} \mathrm{~A}$ second stream of

\footnotetext{
11 For example: Hoffmann, 1995; Mandelbaum, 1996; Bloom, 1999; Wheeler, 2000; Murphy, 2000; Maull \& Stahl, 2002; Crawford, 2003; Brock \& Müller, 2004 or Waltzer, 2004.

12 For example: Yannis \& Levy, 1999; Traub, 2000; Counsens \& Cater, 2001; or Smith \& Dee, 2003.

13 This statistic was measured using the Social Sciences Index. See: Paris, 2000.

${ }^{14}$ For example: Henkin, 1999; Byers \& Chesterman, 2003; Clark, 2005; or Handrick, 2005.

${ }^{15}$ For example: Farer, 2003; or Bulley, 2010.

${ }^{16}$ For example: Stein, 2004; or Bellamy, 2006.

17 Pickering \& Kisangani, 2006.

18 For example: Haas, 1986; Meernik, 1996; Hermann, 1998; or Doyle \& Sambanis, 2000.

19 For example: Bercovitch \& Diehl, 1997; or Hartzell, Hoddie \& Rothschild, 2001.

${ }^{20}$ For example: Heldt, 2004.
} 
research specializes on the management of a particular type of conflict, notably only genocide or politicide, excluding the other types of humanitarian crises. ${ }^{21}$ Their conclusions suggest that the most effective way to intervene into ongoing instances of the state-sponsored mass murder is to directly challenge the perpetrator or to aid the target group of a brutal policy, suggesting a conclusion that an impartial intervention is ineffective. Thirdly, some studies focus merely on a particular type of the crisis management technique such as mediation, peacekeeping or peacemaking. ${ }^{22}$ In general, the conclusions of these studies are heterogeneous, depending on the aspect of HMI being researched and the adopted methodology. In spite of shedding some light on the problematic of HMI, these studies do not evaluate systematically all types of HMI so as to generate a comprehensive picture about the broader impacts of the HMI's on the target states and thus to serve as an indication of their overall legitimacy.

The scholarly debate dealing with the general consequences of wars does not offer a particularly fertile ground for theory building in relation to the HMI, since military interventions are a distinct and presumably much less destructive phenomenon than the full-blown wars. However, the literature on a narrower subject of a 'third-party' intervention focusing on one type of conflict while controlling for the occurrence of another represents an interesting source of an inspiring research related to the HMI. Even though, the theory of a 'third-party' military intervention does not provide an integrated approach, it could be a foundation for the future theoretical development describing the issue of HMI. ${ }^{23}$ There are two major works attempting to explain the effects of the 'third-party' interventions on the target state. The study by Elbadawi and Sambanis models a relationship between the 'third-party' intervention and the duration of a civil war. ${ }^{24}$ The authors distinguish among the military, economic, and the mixed interventions waged in favor of either a government or a rebel movement involved in a civil war. The main findings of this study point to the importance of targeting for the resulting conflict duration. More particularly, the study indicates that the interventions in favor of the government tend to shorten the conflict, while the interventions in favor of the rebels tend to prolong the conflict. ${ }^{25}$ Another major

\footnotetext{
${ }^{21}$ For example: Krain, 2005.

${ }^{22}$ For example: Haas, 1993; or Bercovitch \& Diehl, 1997.

${ }^{23}$ For example: Raknerud \& Hegre, 1997; Hegre, Ellingsen, Gates \& Gleditsch, 2001; or Hess \& Blomberg, 2002.

${ }^{24}$ Elbadawi \& Sambanis, 2000.

25 'Third-party' interventions supporting the target government have a higher probability of ending the conflicts than the interventions opposing the target government. This phenomenon is explained by the fact that any intervention reduces the cost of sustaining a rebellion. It not only increases a likelihood of success of the rebellion, but it also lowers the rebels' costs of fighting and facilitates a recruitment of more rebels. Without existence of such an intervention, the rebellion would be much more quickly suppressed by the government.
} 
study dealing with the effects of 'third-party' interventions on the dynamics of civil war was conducted by Regan. ${ }^{26}$ He concludes by listing four major criteria influencing the probability that the intervention is waged and the probability of its success: a strategic environment of the ongoing conflict; existence of a humanitarian crisis; number of fatalities; and intensity of the conflict. Regan confirms the conclusions of Elbadawi and Sambanis by a finding that the 'thirdparty' military interventions can be successful in achieving their goals, if waged in support of the target state's government. ${ }^{27}$

As indicated above, none of the empirical studies has attempted to evaluate impacts of the HMI's over a large number of conflicts and interventions in general. This is caused mainly by the lack of agreement on what cases of military interventions should belong to the sample of HMI's. This study overcomes this classification challenge by making a systematical quantification of a degree of 'humanitarianism' behind the 'motives and means' of individual interveners. By doing that the study is capable to generate a comprehensive empirical evaluation of HMI's, contributing thus with a new perspective on this controversial issue.

\subsection{The structure of this study}

Chapters 1 and 2 elaborate on the complexity of the HMI concept. They discuss its historical development and provide an overview of the theoretical debate about its legality and legitimacy. The chapters point to the tension between legality and legitimacy of the concept that is illustrated by the efforts of the international community to introduce and to formalize the concept of 'responsibility to protect'. The main question discussed in these chapters is whether the vague legal status of the right of HMI can be overcome by its accepted legitimacy, and the right of HMI should thus be incorporated into the legal framework; or whether the legitimacy of the right of HMI is dubious and the status quo of an illegal HMI should not be challenged. The chapters then propose an innovative approach trying to judge the legitimacy of HMI based on the empirical evidence.

The first step in the process of empirically assessing the legitimacy of HMI is choosing a theoretical framework to be used as a basis for the quantification of the multi-layered aspects of HMI. Chapter 3 describes a rationale for selecting a particular theoretical framework together with an acknowledgment of its possible weaknesses. The entire model is built on an assumption that so as to be acknowledged as 'legitimate', a HMI has to have both the 'humanitarian motives and means' as well as a positive 'humanitarian outcome' on the target state, reflecting thus a controversy between the 'motives and means' versus the 'outcomes' of any action. The ethical considerations found in the Just War ethics

\footnotetext{
${ }^{26}$ Regan, 2000 \& 2002.

27 Regan, 2002.
} 
and the consequentialist ethics serve as the main inspiration for the quantification of these two complementary criteria of a 'legitimate HMI'. While the Just War Theory (JWT) serves as the leading theoretical framework for evaluating a degree of 'humanitarianism' behind the 'motives and means' of individual interveners, the existence of a positive 'humanitarian outcome' is assessed by counting the lives saved by the intervention using the consequentialist approach.

Having selected the most appropriate theoretical framework, the $4^{\text {th }}$ chapter takes up a next challenge to quantify each of the six JWT criteria of 'jus ad bellum': 'just cause', 'just intent', 'just authority', 'last resort', 'proportionality' and a reasonable 'probability of success'. Level of fulfillment of the individual JWT criteria is evaluated on the scale of 0-100, assigning to each identified yearly record of a military intervention a single score for every criterion. Consequentially, the JWT criteria are weighted according to their relative importance within the theory as a whole. Being assigned a corresponding weight, they can be used to generate an aggregate JWT index approximating a degree of 'humanitarianism' behind the 'motives and means' of each intervention. To the knowledge of authors of this study, the JWT criteria have not yet been quantified in a systematic way in the earlier studies and their use for the empirical evaluation of the legitimacy of HMI represents an innovative approach.

Having quantified the 'humanitarian motives and means' of the interveners; the $5^{\text {th }}$ chapter confronts the 'humanitarian motives and means' with the 'humanitarian outcomes' of the interventions using a regression analysis. First, the aggregate JWT index is studied in association with the 'humanitarian outcomes', in order to assess the legitimacy of the HMI concept if defined according to the JWT theory of 'jus ad bellum' as a whole. Next, each quantified JWT criterion is also studied separately so as to compare, which JWT criterion is more and which less relevant for the 'humanitarian outcome' of these military undertakings. This process allows us to identify, which JWT criteria are most crucial for defining a 'legitimate HMI'.

The last $6^{\text {th }}$ chapter then presents the concluding remarks about the legitimacy of HMI, if evaluated by the quantitative model used in this study. This chapter introduces an empirically validated definition of a 'legitimate HMI' that fulfills both set conditions of having 'humanitarian motives and means' but also resulting in a 'humanitarian outcome'. Additionally, the chapter presents a sample of military interventions between the years 1946-2005 that constitute potential candidates for being awarded the label 'humanitarian'. Based on the presented empirical findings, it assesses whether the concept of HMI is legitimate and thus whether the gap between legality and legitimacy of the HMI concept really exists. This chapter concludes by discussing the derived appropriateness of introducing the right of HMI as a legal norm. 
The technical appendum of this study then introduces a huge database systematically compiling data on conflicts and military interventions from the post-WWII period. The data are organized two-dimensionally: the first dimension captures the relationship between the intervener and the target state; and the second one traces the developments in the target state only. Apart from bringing the heterogeneous data from many different sources together under the unified coding rules, the major added value of this compilation is represented by the newly created indexes quantifying the JWT. The data compilation not only served as a prerequisite for the above described research, but it is made available on-line together with a detailed codebook with a hope that it will serve as a useful input data source also for the other researchers working in the field of conflict management and conflict studies in general.

Summarizing the above, this study attempts to formulate answers to the following questions:

- What should be an appropriate definition of a 'legitimate HMI' based on the empirical evidence?

- Which cases of military interventions fulfill the adopted definition and represent the candidates for a 'legitimate HMI'?

- Does the concept of HMI have legitimacy if evaluated on the basis of the theoretical frameworks of 'Just War' ethics and consequentialitst ethics?

- Are the 'humanitarian motives and means' of military interventions associated with their 'humanitarian outcomes' on the target state and under what conditions?

\subsection{Limitations of the study and its approach}

The use of an empirical approach for the assessment of legitimacy of HMI has one major advantage that forms at the same time also its major weakness. It is capable of generating one-number answers to the complex set of questions in a seemingly exact way. Nevertheless, this exactness is obviously just an illusion. The empirical approach really enables the researchers to draw broader, empirically grounded generalizations that are validated across many cases; but a quantification of any such a complex issue as the legitimacy of HMI requires many painful simplifications of the reality. Due to the highly interdisciplinary nature of the HMI concept, it is necessary to ease many complicating assumptions from each of the touched upon field. This imperfection of the information inserted into the model then logically influences the exactness of the one-number solution that comes out of the analysis. The study acknowledges this weakness, but it adopts an approach that there would be no answer to any question without allowing for a certain 
degree of simplification. Therefore, it treats the simplification of complexity of the issue as a necessary price for reaching any conclusion.

Apart from the above described imperfection of the model, the study also faces a problem of reliability of the input data, which is a typical feature of all the data collected in the conflict zones. Even with the best efforts of the data collectors; the countries experiencing violence suffer from the sudden population movements, a lack of governmental control, and an inadequate census data, which greatly complicate an effective data collection. In addition to that, the statistics generated in the war-torn countries are often intentionally manipulated, since the officially published numbers have a power of sending important political and military messages. ${ }^{28}$ As a result of that, all the conflict-related data are inherently exposed to uncertainty, which is reflected in the existing differences among records indicated in the individual datasets that were compiled by different researchers. Uncertainty is, however, not unique to this study; and as long as the standard rules of inference are used, this uncertainty should not detract from a validity of the applied empirical research. ${ }^{29}$

After bringing attention to the most problematic aspects of this study, there is one more disclosure to be made. While reading this study, it is necessary to bear in mind that the findings of the analysis are not intended to represent 'the' answers to the question of legitimacy of HMI. The findings should be viewed and understood just as a very first attempt to evaluate this sensitive issue on a more systematic empirical basis. It is a pioneering trail to classify the multidimensional problem and to bring its variously overlapping dimensions together to provide some interpretable conclusions. As a result of that, the generated empirical model will be kept as simple as possible so as to preserve both a reasonable interpretability and a logical coherence. It can be viewed as an invitation for the other scholars from many different relevant fields to focus on the sub-parts of the model, and to further develop and purify it in the subsequent studies. We hope that our study and the generated database will serve other researchers to make different assumptions, to seek alternative theoretical tracks and potentially to arrive at different conclusions all with the intention that has guided this study as well, namely to shed another light on the complex problem of legitimacy of the HMI concept.

\footnotetext{
${ }^{28}$ Typical examples of such manipulation are when the leaders of the fighting groups inflate a number of their followers to demonstrate their strength; when the separatist movements blow up a degree of their suffering in a hope of attracting an external help; or when the countries planning to intervene or actually intervening into some crisis manipulate information describing the character of the crisis in a way to gain a public support for their operations. See: Seybolt , 2007.

${ }^{29}$ Seybolt, 1994.
} 


\section{CHAPTER}

\section{THE CONCEPT OF HMI - ITS LEGALITY AND LEGITIMACY}

\subsection{Complexity of the HMI concept}

The concept of 'humanitarian military intervention' (HMI) is in each respect problematic. Its controversial nature is reflected already by the fact that it is attempting to bridge two instinctively incompatible words: 'humanitarian' and 'military'. Nevertheless, this concept has already become established in the field of research and the in minds of general public and it appears to be too late to try rejecting it. ${ }^{30}$ Appropriateness of its label represents, however, just a minute problem in comparison to the actual implications that this concept casts. Impacts of HMI entail serious ethical problems targeting the basic consciousness and fears of not only the international actors but also of the general public. HMI is easily associated with the concrete images of humanitarian suffering and imposed military violence, which evoke in each individual strong opinions and emotional reactions to the question of its justice or injustice. This highly normative nature of HMI complicates the scholarly debate about the concept and keeps the international society short of any consensus on the most basic questions of its definition, legality or legitimacy.

How should such a complicated concept be approached by the scholars? Is it possible to declare it illegal or illegitimate? Use of the HMI as a tool of last resort crisis management cannot be supported or condemned merely by an assessment of its legality. In such complicated cases, when the major ethical concerns surrounding the concept cannot be ignored; it is necessary to get to the very basic question of a general justice, focusing plainly on evaluation of its legitimacy. ${ }^{31}$ Only after concluding whether such a concept is or is not legitimate, it is possible to confront its assessed legitimacy with its existing legal status, and to call for a potential revision of law in case of a discovered non-compliance of the legal interpretation with the carried out legitimacy judgment.

So as to allow for an assessment of this normatively complex concept, this chapter will begin by discussing a definition and historical development of the HMI concept. Afterwards, it will introduce a comprehensive overview of all the main approaches toward its legality and legitimacy. The last section of this chapter will present the latest legislative effort at the UN level, which serves as a good indication of an existing gap between legality and legitimacy that the policy makers are trying to correct, and thus also as an indication of the direction of

\footnotetext{
30 Verwey, 1992; or Ryter, 2003.

31 Smith, 2006.
} 
where the next legislative initiative are going to be heading in this respect and what are the possibilities of its correction.

\subsection{Definition of the HMI concept}

Given the considerable normative implications of the HMI concept, it is difficult for the international community to find a generally accepted consensus on its definition. Some of the studies understand and interpret this notion broadly to cover all the military interventions waged for the 'humanitarian' purposes; while other - especially legal studies, reserve this term exclusively for the military interventions for 'humanitarian' purposes that take place both without the authorization by the UN Security Council and without an invitation by the target state's government. ${ }^{32}$ For the purpose of this study, the term HMI will be used broadly, attaching the word 'unauthorized' in front of the term, if necessary to stress the absence of authorization by the UN or of the invitation by the target state government. Nevertheless this legal technicality is not the main problematic aspect in defining the concept.

The main problem rests in finding an agreement on the conditions, which change the concept of a regular military intervention that is generally perceived as being associated with an increased level of violence and humanitarian suffering in a way that it can be awarded a label 'humanitarian' or 'just'. What constitutes a sufficient reason to send a HMI? Who should be intervening with which purity of motives? What means and ends are necessary? Who evaluates fulfillment of all these criteria and thus grants the label? There is more or less a general agreement only on when the HMI should be waged, if at all. Most of the authors agree that a legitimate HMI should take place only in cases that 'shock the conscience of mankind', which should constitute the cases of large-scale and gross violations of human rights such as genocides, massacres, mass murders, or ethnic cleansing. ${ }^{33}$ Nevertheless, that is where the agreement ends. There are, for example major disagreements on the required motivation of the interveners. Classical definitions of HMI tend to stress that the motive of HMI should be strictly 'humanitarian'. ${ }^{34}$ In contrast to that, liberal perspectives tend to be much more permissive regarding the motivation, and they often refer merely to the existence of a persuasively strong 'humanitarian' motive of a various degree of 'purity'. ${ }^{35}$ There are many different versions of the definition setting various criteria. However, most of the

\footnotetext{
32 Wil Verwey proposed a classic legalist definition of HMI: "A threat or use of force by a state or states abroad, for the sole purpose of preventing or putting to halt a serious violation of fundamental human rights, in particular the right to life of persons, regardless of their nationality, such protection taking place neither upon authorization by relevant organs of the UN nor with permission by the legitimate government of the target state." See: Verwey, 1992, p.114.

33 Wheeler, 2001; Lepard, 2002; or Finnemore, 2003.

34 Verwey, 1992.

35 Parekh, 1997.
} 
definitions share a same common base line....the sense of the definition is the use of force to save lives.

\subsection{Historical development of the HMI concept}

HMI doctrine owes its origin to the Just War tradition that is based on the Christian conception of the Just War Theory (JWT). Foundations of this justicebased JWT rhetoric can be traced back to the Roman Empire and the influence of the St. Augustine's notion of 'the Two Cities'. Augustine offered a formula for the restoration of peace that includes the commonly cited theme of a 'just war' as one limited by its purpose, authority and conduct. Following on Augustine's thoughts, Thomas Aquinas concretely specified in his Summa Theologica three main conditions for labeling a war as being 'just': 'just cause', 'just intent', and 'just authority'. ${ }^{36}$

A modern and secular conception of the JWT was framed into the HMI concept by the Dutch jurist Hugo Grotius in the 17th century, when he introduced an idea of intervening militarily for the 'humanitarian' purposes. He proposed in his book De jure belli ac pacis libri tres that the outside countries can legitimately intervene to stop the human rights abuses in a neighboring state. ${ }^{37}$ In the $18^{\text {th }}$ century, among other scholars promoting and further developing these thoughts belonged, for example, the Swiss philosopher Emmerich de Vattel who defended a solidarist tradition recognizing that the governments have not only a right but even a duty to defend the humanitarian values wherever they were threatened in the name of international justice. ${ }^{38}$ As Vattel argued, the natural society of states could not continue unless the rights belonging to each by nature were respected. In line with this reasoning, he further claimed that it was lawful for any state to support an uprising in another country, if the people had been exposed to a tyranny. ${ }^{39}$ Scholars such as Hugo Grotius, Emmerich de Vattel and other their colleagues and followers have attempted to dissociate the notion of 'just war' from its religious origins by arguing that the Sovereigns were bound by the fundamental principles of humanity and have thus duty to treat their subjects with respect for human dignity. ${ }^{40}$ If updated to the modern realities, this would suggest that states are all bound by the natural law of the human society that obligates them to treat their own nationals in accordance with the principle of humanity and also to ensure that

\footnotetext{
${ }^{36}$ For a more detailed overview of historical development of the Christian conception of JWT, see, for example: Waltzer, 1977; Atwood, 2003; or Butler, 2003.

37 Grotius (transl.), 1625.

38 Vattel (transl.), 1758.

39 Vattel (transl), 1758.

${ }^{40}$ Other scholars debating the legitimacy of HMI based on the JWT in the 18th and 19th century were: Christian Wolff, Henry Wheaton, Robert Phillimore, John Stuart Mill, Moutague Bernard, or William Edward Hall. For a more detailed description of the development of the concept, see: Knudsen, 2009.
} 
the other states do. ${ }^{41}$ These propositions immediately started heated debates among theologians and legal theorists about the right of HMI that have not been resolved until now.

In spite of the fact that the concept of HMI has been a subject of scholarly debates for about 1600 years, a first acknowledged recorded case of HMI occurred only in 1827, when France was authorized by the other European powers to intervene into the Ottoman Empire to save the Maronite Christians in Syria from being suppressed in practicing their traditional religion. This precedent was followed by two other cases of interventions in $19^{\text {th }}$ century that were generally considered to be 'humanitarian': the Russian intervention in Bosnia-Herzegovina and Bulgaria (1977-1830), and the US intervention in Cuba (1898). There were also some acknowledged instances of HMI during the Cold War. Among the most cited belong, for example: the Indian intervention in East Pakistan (1971), the Vietnamese invasion to Cambodia (1978), or the Tanzanian intervention in Uganda (1979). Even though, none of the above listed interventions was directly called 'humanitarian', their humanitarian motives, means and effects were clearly apparent. $^{42}$

The end of the Cold War has brought new threats of terrorism, genocides and failed states that forced the international community to reexamine the notion of 'sovereignty' and the reasonability of blindly following the legally established norm of non-interventionism into the other states' internal affairs. This trend has been further encouraged by the strengthened role of the UN, which has catalyzed the idealist thoughts about the international ability to protect the human rights violations globally. The readiness and the capacity to promote human rights abroad have certainly grown over the past two decades, which is visible on a growing number of interventions labeled 'humanitarian' that took place in this time period: Iraq (1991), Somalia (1993), Bosnia (1993-1995), Rwanda (1994), Haiti (2004), Sierra Leone (1998), East Timor (1999), Kosovo (1999), Liberia (2003), or Congo (2003). Nevertheless, the use of HMI in practice has been complicated by the unresolved legality and legitimacy of the concept, which remain to be a topic of the heated academic and political discussions. Among the strongest recent manifestations of the international disagreements about the concept belong: the NATO's intervention in Kosovo in 1999, the US intervention in Iraq in 2003, the latest intervention in Libya in 2011, and the ongoing debates about appropriateness of waging a HMI in Darfur. The questions regarding what criteria actually constitute an HMI and whether it can represent a legal and/or a legitimate tool of crisis management still continue being unanswered.

\footnotetext{
41 Secularization of the JWT is described in greater detail in, for example Haar, 2000; Harhoff, 2001; or Kabia, 2009.

42 Kabia, 2009.
} 


\subsection{Difference between legality and legitimacy}

Having gone through the problem of definition of HMI and the historical development of the concept, the chapter will move to a more analytical section devoted to the assessment of its legality and legitimacy. First of all, it is necessary to bear in mind that the evaluation of legality and legitimacy are two completely different activities. Evaluating legality of some action or policy is usually carried out by referring to the existing legal texts and customary law, and the answers tend to be relatively straightforward declaring the act or the policy as being either legal or illegal. In contrast to that, evaluation of legitimacy is much more subjective, depending on the complex normative decisions of what is desirable and appropriate. Legitimacy judgment loosens the constraints of legality, and evaluates the actions using the more sensitive ethical and political considerations. As a result of that, legitimacy is a much more fluid category that can be easily gained and lost. It always stays open-ended and evolves over time. ${ }^{43}$

Under the ideal circumstances, what is legal should be legitimate and what is legitimate should be legal. However, this is usually not the case. If compared with legality, legitimacy has a broader perspective based in basic morality. It suggests that nobody should be obliged to follow blindly a rule of law, if it runs counter to what is generally considered to be just. It means that legitimacy has a power to both reinforce the existing law, but also to challenge it based on the legitimacy of some higher rationale, so as to ensure that laws serve their fundamental purpose of improving the lives of those whom they govern. ${ }^{44}$ This corrective mechanism of legitimacy is particularly important in case of the international law, which is often a compromise between the demands for regulation on one hand and a desire of governments to keep their hands free on the other. ${ }^{45}$ If simplified, it is possible to claim that legitimacy exerts a constant corrective pressure on the legality to evolve in its direction. This struggle between legitimacy and legality is thus a never ending process of conversion with the ultimate utopist goal of a synthesis of the two doctrines. Therefore, while evaluating the concept of HMI, it is necessary to explore both these perspectives and to identify a potential gap that is to be corrected.

\subsection{Legality of HMI}

\subsubsection{Theoretical approaches toward the legality of HMI}

Scholarly debate about legality of HMI is divided into two opposing camps. First one is represented by the so-called 'restrictionists't6 who defend the legalist

\footnotetext{
43 Popovski \& Turner, 2008.

44 Popovski \& Turner, 2008.

${ }^{45}$ Haar, 2000.

46 Jackson, 2000.
} 
position coming out of the realist tradition of state sovereignty and noninterference. This position considers unauthorized HMI to be illegal based on the ban on use of force in the international relations as imbedded in the Article 2(4) of the UN Charter. Second stream is represented by the so-called 'counter-

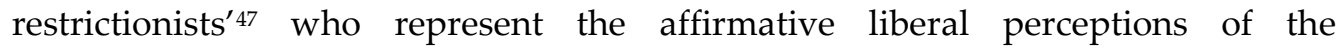
international politics. Proponents of this position claim that there is an established customary right of HMI regardless of existence or absence of authorization, which is based on the commitment of the UN Charter to protect human rights globally. ${ }^{48}$

\subsubsection{Key legal provisions relevant for the right of HMI}

So as to prevent other international violence and to protect the international order after WWII, international community codified a basic principle of the 'non-use of force', which has committed all the member states of the UN not to use force in their international affairs. This principle has become a cornerstone of the UN Charter regulating the use of force in the international arena. The exact text of the key Article 2(4) stipulates: "All Members shall refrain in their international relations from the threat or use of force against the territorial integrity or political independence of any State, or in any other manner inconsistent with the Purposes of the United Nations. "49 Importance of this rule is generally acknowledged by most of the legal scholars and this particular provision has become considered to be a part of 'jus cogens' - a legal norm that has become accepted by the international community as a principle from which no derogation is permitted. ${ }^{50}$ The UN Charter mentions only two possible qualifications to this rule. The first one is the right to use force in selfdefense, which is stipulated in the Article 51: "Nothing in the present Charter shall impair the inherent right of individual or collective self-defense if an armed attack occurs against a Member of the United Nations, until the Security Council has taken measures necessary to maintain international peace and security."51 The second exception imbedded in the UN Charter relates to the use of force under the authorization by the UN Security Council in the cases of an existing threat to or a breach of collective peace and security. It is well described by the following extractions from the Articles 39 and 42 of the Charter. The Article 39 states: "The Security Council shall determine the existence of any threat to the peace, breach of the peace, or act of aggression and shall make recommendations, or decide what measures shall be taken ...... to maintain or restore international peace and security." 52 , while the Article 42

\footnotetext{
47 Bull, 1966; Arend \& Beck,1993; Tesón, 1997; or Linklater, 1998.

48 To gain more detailed overview about the division of the theoretical approaches toward the HMI concept, see, for example: Wheeler \& Bellamy, 2001\& Rytter, 2001; or Atwood, 2003.

49 UN Charter, 1945, art. 2(4).

50 'Jus cogens' is regulated by the Articles 53 and 64 of the 1969 Vienna Convention on the Law of

Treaties. For an interesting discussion about the issue, see: Gray, 2008.

51 UN Charter, 1945, art. 51.

52 UN Charter, 1945, art. 39.
} 
stipulates: "Should the Security Council consider that measures provided for in Article 41[non-forcible measures] would be inadequate or have proved to be inadequate, it may take such action by air, sea, or land forces as may be necessary to maintain or restore international peace and security." 53

If simplified, the legal interpretation of the UN Charter regarding the legality of any type of military intervention can be summarized by the following single sentence. The use of force in the international relations is prohibited ${ }^{54}$, but there are two accepted exceptions to this rule: a use of force in self-defense $e^{55}$, or a use of force to maintain or restore international peace and stability if authorized by the UN Security Council ${ }^{56}$. Codification of this rule delegitimized individual acts of war, leaving the UN Security Council as a sole authority with a capability to provide a legal status to any non-defensive use of force. Main rationale behind its adoption was to limit interventionism into the internal affairs of individual states with the goal to provide not only peace and security but also to ensure protection of the values such as national independence, diversity or mutual restraint. ${ }^{57}$ Internally, it has endowed the states with the right to organize their internal affairs according to their own preference; and externally, it has provided them with a protection against international aggression and with a possibility to participate in the international relations on an equal level with the others.

Should the legality of right of HMI be evaluated based on the explicit meaning of the above listed key legal provisions of the UN Charter, the judgment would be quite straightforward. In case that a military intervention - even for the 'humanitarian' purposes - is not granted an authorization by the UN Security Council, the act of intervention would be based on the Article 2(4) clearly unlawful. A HMI could be considered as legal only if authorized by the UN Security Council. ${ }^{58}$ In addition to that, HMI remains legally controversial even after being authorized by the UN Security Council, since using force for the 'humanitarian' purposes does not qualify as fulfilling any of the accepted exceptions to the ban on the use of force. HMI is clearly not an act of self-defense, neither is it reasonable to assume that that the framers of the UN Charter intended to treat human rights violations as a threat to the international peace and security.

\subsubsection{Alternative sources of the legal status for the right of HMI}

\footnotetext{
53 UN Charter, 1945, art. 42.

54 See: Article 2(4) of the UN Charter.

55 See: Article 51 of the UN Charter.

56 See: Article 39 and 42 of the UN Charter.

57 Reisman, 1984.

58 Alternatively, HMI could be legal if being waged based on the invitation of the target state's government.
} 
Nevertheless, there are also other alternative sources of law that could potentially provide the right of HMI with a legal status. The above presented legal interpretation of the Article 2(4) of the UN Charter and the related articles has become complicated by the development of international human rights law and humanitarian law, as well as by the way the states have used the HMI in practice. These developments allow viewing the legality of the right of HMI also from a different angle. Those arguing in support of the right of HMI view the Article 2(4) as being open to a changing interpretation over time and not as having a fixed meaning. This position is based on the argument that the UN Charter is not a historical will, which the states are obliged to follow in its original meaning, but that the subsequent practice gives expression to the reality of the Treaty. ${ }^{59}$ It does not mean to suggest that the drafters of the UN Charter meant the HMI being legal in the year 1945, but rather that the right of HMI has been gradually emerging and developing over time. This idea is supported by the Nicaragua Case, which stated that Article 2(4) is potentially subject to change as a result of a customary law development. ${ }^{60}$ If these arguments are acknowledged to be valid, it is possible to identify three major possible alternative sources of legality of a general right of HMI that have been gradually formed alongside the Article 2(4) since 1945: 1) the international human rights law; 2) the international humanitarian law; and 3) the international customary law.

\subsubsection{International human rights law}

Proponents of legality of the right of HMI point to the fact that the UN Charter has also other dimensions than only ensuring international peace and security, and point to the obligation of a worldwide protection of human rights that was anchored into the UN Charter in reaction to the massive violations of the fundamental human values during the World War II. The UN effort to establish a legal framework for the international human rights protection has crystallized into a formation of the new body of law - international human rights law - whose basic stone represents the Universal Declaration of Human Rights adopted in the year 1948. ${ }^{61}$ A current legal trend is undeniably heading toward a greater international authority in promoting and protecting international human rights, where the states still maintain a primary responsibility but the international community has a subsidiary one. The claim that promotion and protection of human rights is a legitimate concern of international community was confirmed in the UN report of the World Conference on Human Rights. ${ }^{62}$ It is increasingly becoming the case that

\footnotetext{
${ }^{59}$ Hilpold, 2001.

${ }^{60}$ Hargrove, 1987.

${ }^{61}$ The Universal Declaration defined the meaning of terms: 'fundamental freedoms' and 'human rights' appearing in the UN Charter, and established a bases for the obligation of the states to respect human rights of all persons. See: Reisman, 1990.

62 The World Conference on Human Rights, 1993.
} 
when the principles of human rights and sovereignty come into conflict, the human rights tend to be given preference. ${ }^{63}$

As the Universal Declaration of Human Rights has gradually advanced to a universal acceptance, it started to represent a powerful tool in applying diplomatic and moral pressure on the governments violating any of its articles. ${ }^{64}$ There seems to be a broad agreement among the legal scholars that certain provisions of the international human rights law have gradually evolved into a customary law, which means that the states are bound by all their legal provisions regardless of their ratification of the treaty that has originally introduced them. ${ }^{65}$ Some legal theorists go even so far as to claim that some key human rights provisions have evolved into the 'ius cogens' - just as the Article 2(4) prohibiting the use of force in the international relations. ${ }^{66}$ Would the theory that certain human rights provisions are 'ius cogens' be accepted as correct; it would be theoretically possible to argue that they could override the 'ius cogens' prohibition on the use of force in the international system, providing thus the general right of HMI with legality. Nevertheless, this argument is refused by a majority of legal scholars and states; since its acceptance would require not only a demonstration that human rights are accepted and recognized by the international community as a rule from which no derogation is permitted - which is highly debatable, but also that the international community accepts the right to use force to protect these rights in a similar manner - which is not the case. ${ }^{67}$

Another argument of the proponents of the right of HMI based on the international human rights law brings attention to the last part of the key sentence outlawing the use of force in the Article 2(4), which stipulates that states should refrain from the use of force "...in a manner inconsistent with the Purposes of the United Nations." 68 They argue that given the above mentioned growing importance of the human rights' protection within the UN system and the international law in general; military intervention for the protection of human rights could be treated as being consistent with the 'purposes' of the UN. Nevertheless, such an interpretation of Article 2(4) would go against the UN General Assembly resolution on the use of force, which outlawed a forcible intervention in absolute terms making no provision for HMI69; and additionally against the UN General Assembly resolution dealing with the definition of 'aggression' that explicitly states that: "no consideration of whatever nature, whether political, economic, military or

\footnotetext{
63 Atwood, 2003.

${ }^{64}$ Reisman, 1990.

${ }^{65}$ Meron, 1983; or Orakhelashvili, 2007

${ }^{66}$ Gray, 2008.

${ }^{67}$ Gray, 2008.

68 UN Charter, 1945, art. 2(4).

${ }^{69}$ General Assembly Declaration, 1970.
} 
otherwise, may serve as a justification for aggression"..$^{70}$ It is necessary to recognize that the violations of the human rights provisions - however severe - do not provide an explicit legality for waging a HMI - neither authorized nor unauthorized. This is caused by the fact that even though the international human rights law sets sanctions for the human rights violations, it does not mention a forcible action by en external party as a lawful remedy. ${ }^{71}$

\subsubsection{International humanitarian law}

Another potential source of legal status of a general right of HMI arises from the international humanitarian law that is based on the old tradition of 'jus in bello' defining the conduct and responsibilities of the states and individuals engaged in the warfare. A legal corpus of international humanitarian law is comprised of the Geneva Conventions ${ }^{72}$ that provide a legal protection to the specified classes of people during wartime; the Hague Conventions ${ }^{73}$ that govern the overall methods of combat; and the Genocide Convention ${ }^{74}$ requiring the states to undertake all appropriate measures to prevent and to punish a genocide; as well as of the subsequent treaties, case law, and customary international law that have gradually emerged since the Nuremberg Trails. ${ }^{75}$

The main purpose of the humanitarian law is to restraint violence by protecting the lives and dignity of the non-combatants in the armed conflict - either civilians, refugees or prisoners of war, and to ensure that combatants and their political leaders respect these norms. ${ }^{76}$ As stated in the Hague Convention, there should be a desire "to diminish the evils of war, as far as military requirements permit."77 Therefore, the parties are bound by the humanitarian law to the extent that such compliance does not interfere with achieving their legitimate military goals. For example, they are obliged to make every effort to avoid killing and wounding of civilians or damaging their property, if these are not involved in the combat; but they are not guilty of a war crime, if a bomb mistakenly hits a residential area. The Genocide Convention is more concrete, it directly relates to one of the crimes against humanity directed against non-combatants. It stipulates that genocide is a crime under the international law that should be punished, giving the parties to the Convention right to demand the UN to take such an action as they "consider

\footnotetext{
70 General Assembly Declaration, 1974, art. 5.

${ }^{71}$ For a more detailed discussion on the legitimacy of HMI based on the international human rights law and the humanitarian law, see: Haar, 2000; or Atwood, 2003.

${ }^{72}$ Geneve Conventions were adopted in 1864, 1929, 1949, and in 1977 (Geneva Protocol I+II), 2005

(Geneva Protocol III).

73 Hague Conventions were adopted in 1899, 1907, and in 1954.

${ }^{74}$ Convention on the Prevention and Punishment of the Crime of Genocide, 1948.

75 Meron, 2000; or Smith, 2002.

${ }^{76}$ Hubert \& Bonser, 2001.

77 Convention No. IV on the Laws and Customs of War on Land, 1907, pmbl. 36, p. 1.
} 
appropriate for the prevention and suppression of acts of genocide", which can implicitly suggest also the potential use of military force. ${ }^{78}$

Over the past two decades, the international humanitarian law has been invoked more frequently than ever, especially in the area of human rights and war crimes. A growing importance of the humanitarian law has been demonstrated by the establishment of the International Criminal Tribunal for the Former Yugoslavia (1993), the International Criminal Tribunal for Rwanda (1994), and most importantly by the establishment of the International Criminal Court (1998)..$^{79}$ The legal framework of the International Criminal Court has criminalized "intentionally directing attacks against the civilian population as such" and "extensive destruction ... of property, not justified by military necessity". ${ }^{80}$ Creation of these courts has served to reinforce the position that those who are responsible for the massive and systematic violations of human rights such as genocide, war crimes or crimes against humanity within the state borders, are not immune from the international law and can be punished. ${ }^{81}$ This means that the above listed crimes could theoretically constitute a legal ground for waging a HMI under certain limited circumstances, even for an unauthorized one.

The legalizing effect of the international humanitarian law has been enhanced by the recent development of the international human rights law. Due to the fact that the international human rights law and the international humanitarian law are greatly interconnected by their common basis in humanity; a gradual recognition of the evolvement of the international human rights law into the customary law has affected a parallel acceptance of the international humanitarian law. ${ }^{82}$ In 1996, the International Court of Justice held regarding a compliance with the international humanitarian law that "a great many rules of humanitarian law applicable in armed conflict are so fundamental to the respect of the human person and 'elementary considerations of humanity'......that... these fundamental rules are to be observed by all States whether or not they have ratified the conventions that contain them, because they constitute intransgressible principles of international customary law". ${ }^{83}$ Nevertheless, it is still important not to ignore the significant differences between these two bodies of law that persist in spite of their growing convergence. While the humanitarian law regulates a struggle of the equal combatants for life and death that tolerates killings, wounding, or deprivations of personal freedom for the purpose of achieving a victory as long as certain rules of basic concern minimizing the unnecessary human suffering are being followed; human rights law protects a

\footnotetext{
${ }^{78}$ Convention on the Prevention and Punishment of the Crime of Genocide, 1948, art. 8.

${ }^{79}$ Haar, 2000.

${ }^{80}$ Rome Statute of the International Criminal Court, 1998, art. 8, sec. 2.

${ }^{81}$ Hubert \& Bonser, 2001.

82 Meron, 2000.

${ }^{83}$ International Court of Justice Report, 1996, par. 79.
} 
physical integrity and a human dignity under all circumstances and it is applicable mainly to the relationships of the unequal parties such as the citizens and the governments. ${ }^{84}$

\subsubsection{International customary law}

The last relevant source of law that could serve as a potential legal framework for the right of HMI is represented by the international customary law developed in reaction to the state practice. As is codified in the Article 38(1) of the Statue of the International Court of Justice; in addition to the codified doctrines, treaties and court judgments, the international law is also based on the established customary behavior. ${ }^{85}$ Customary rules can be by their origin illegal; but they can become subsequently accepted as lawful, if the states continuously act in such a manner, and if they believe they are legally obliged to act in such a manner - existence of 'opinio juris'. To prove that states continuously act in a certain manner is the easier task of proving the existence of a customary law, since the state practice is more objectively measurable than the subjective believes of the states. Therefore, the requirement of a consistent and generally accepted international practice represents a necessary element of the customary law. In contrast to that, the second requirement of 'opinio juris' can be lessened, if there is a consistent state practice over a longer period of time. It is only in cases of just a few applications of the emerging norm in practice that the presence of the belief becomes more important. ${ }^{86}$

Some legal scholars representing the affirmative position to the right of HMI point to the process of how the customary law is developing, and they claim that the interpretation of the Article 2(4) can be changed by a state practice that is gradually becoming transformed into the customary law. They argue that a state practice of the repeatedly launched military interventions for the 'humanitarian' purposes that has been running and developing parallel to the codified nonintervention legal instruments, has gradually established a legal norm of HMI. ${ }^{87}$ They bring attention to the fact that HMI has been increasingly used as a last resort conflict management tool in extreme situations, when the UN Security Council was paralyzed by a veto power of some of its permanent member states and when the traditional non-military tools of conflict management seemed to be incapable of dealing effectively with the large-scale human rights violations. ${ }^{88}$ They cite numerous cases of state practice as evidence supporting the crystallization of a legal right. For example, Nicholas Wheeler identifies six cases of military

\footnotetext{
${ }^{84}$ Meron, 2000.

85 Rome Statute of the International Criminal Court, 1998.

86 Bederman, 2001.

87 Greenwood, 2000; or Harhoff, 2001.

88 Bellamy, 2002; or Walzer, 2004.
} 
interventions in the post-WWII era that could because of the grave and extensive human rights abuse in the target state be labeled as HMI: India's intervention into Bangladesh in 1971, Vietnam's intervention in Cambodia in 1979, and Tanzania's intervention in Uganda in 1979, UN intervention into Northern Iraq in 1991, the US and UN intervention in Somalia in 1992, late intervention to Rwanda in 1994, and the UN and NATO's interventions in Bosnia in 1995 and in Kosovo and Serbia in 1999. ${ }^{9}$ Nevertheless, it would be also possible to add other interventions to this list, such as: the Economic Community of West African States' interventions into Liberia in 1990, UN intervention in Haiti in 1994, UN intervention in East Timor in 1999 and the British and UN interventions in Sierra Leone in 2000; or the highly controversial US interventions/wars in Afghanistan in 2001 and Iraq in 2003, or the intervention in Libya in 2011.90

The advocates of the existence of the customary right of HMI not only relate to the existing state practice, but also to the gradually established 'opinio juris'. According to the affirmative position, there is a partial consensus among the liberal states that there is a moral right to intervene in the extreme cases of humanitarian suffering even without authorization by the UN Security Council. This would suggest that while intervening for the declared 'humanitarian' purposes, the interveners could have reasonably acted with a defendable feeling of being legally obliged to stop the ongoing human rights violations based on the universally accepted international human rights law and the international humanitarian law. ${ }^{91}$

If both assumptions of the existing consistent state practice and a sufficient 'opinio juris' were accepted as being valid, both conditions for the emergence of the international customary law would have been fulfilled and it would be possible to declare existence of the customary right of HMI. This position is defended, for example, by the former President of the International Criminal Tribunal for the former Yugoslavia who stated that the customary law could provide a legal basis to intervene militarily for the limited humanitarian purposes and, indeed, that international law was moving in this direction. Similarly, the judge Antonio Cassesse concluded that: "Based on these nascent trends in the world community, I submit that, under certain strict conditions, resort to armed force may gradually become justified, even absent any authorization by the Security Council."92 Validity of this affirmative argument that there has been a sufficient amount of cases of HMI that could be reasonably considered as representing a consistent and a generally accepted practice and that the actors have acted with a necessary 'opinio juris' is, nevertheless, highly contested. ${ }^{93}$

\footnotetext{
${ }^{89}$ Wheeler, 2000.

${ }^{90}$ Kurth, 2006.

${ }^{91}$ Bellamy, 2002; or Walzer, 2004.

${ }_{92}$ Cassese, 2000, p. 27.

${ }^{93}$ Welsh, 2002.
} 
The affirmative position is being challenged by the legalist one, which refuses both the existence of a general acceptance of the right of HMI within the international community, and its consistent usage in practice that could jointly transform the illegal HMI into a legal custom. ${ }^{94}$ Legalist position points to the absence of a consensus about the existing right of HMI that is demonstrated by the behavior and declarations of both states and international organizations. It emphasizes that the right of HMI tends to be perceived predominantly as a Western driven principle, which is strongly opposed not only by the weaker developing countries that tend to be the most typical targets of such interventions, but also by the stronger powers such as China or Russia that follow the lower human rights standards and fear a possible interventionism into their domestic affairs. ${ }^{95}$

The legalist position also criticizes the inconsistent usage of the concept of HMI, which arises from the fact that states intervening militarily for 'humanitarian' purposes have appeared to be reluctant citing the human rights protection as an indicated reason for the interventions - even if the consequences of the conflict seemed to provide a ready-made justification for doing that. In spite of an increasing willingness to address the tragic humanitarian consequences of the conflicts while justifying some military intervention; claiming to be acting on the basis of self-defense is still considered to be an easier way of relating to the UN Charter in most of the cases. ${ }^{96}$ A similar reluctance has been notable on the behavior of the UN Security Council, when it tried authorizing interventions for 'humanitarian' purposes. Due to a lack of legal basis for exempting the HMI from a general ban on use of force as stipulated in the UN Charter, the UN Security Council often artificially stretched the definition of the legally allowed exception to the ban on use of force - the 'threat to international peace and security', which in spite of the severity of the humanitarian crisis could not have been reasonably evaluated as such a threat. ${ }^{77}$ The UN Security Council defended this interpretation of the UN Charter by a statement that a mere absence of military conflict among states does not itself ensure 'the international peace and security'; rather that the intrastate humanitarian crises can also become threats to peace and security. ${ }^{98}$ What is important to note is that while giving its consent to the military interventions for 'humanitarian' purposes, the UN Security Council usually described the situation as having a 'unique character' or being of an 'extraordinary

\footnotetext{
94 Arend \& Beck, 1993; or Hilpold, 2001.

${ }^{95}$ Holbrook, 2002.

${ }^{96}$ For example, while justifying the generally acknowledged cases of HMI, such as the Indian invasion of East Pakistan in 1971, Vietnamese invasion of Cambodia in 1978, or Tanzanian invasion of Uganda in 1979; the intervening governments claimed 'self-defense' rather than 'humanitarian motive' as a main reason behind the interventions. See: Roberts, 1993.

97 Tesón, 1997; or Welsh, 2008.

${ }_{98}$ UN Security Council Summit Statement, 1992.
} 
nature' and thus requiring an 'exceptional response'. ${ }^{99}$ This reluctance to explicitly acknowledge the 'humanitarian' purposes as a main motive for interventions reveals a clear unwillingness on the side of the UN Security Council to set an explicit precedent for mandating a HMI, which has had a secondary effect of an inconsistent application of the HMI concept and has thus complicated its acceptance as a customary law. ${ }^{100}$ It is just recently, that the UN Security Council has started to refer to the 'humanitarian motives' more directly, by referring to the 'responsibility to protect' framework that will be debated in detail in the later parts of this chapter.

To sum the legalist position up, it suggests that there is a lack of a sufficient evidence of state practice of a genuinely 'humanitarian' military intervention based upon the 'opinio juris'. ${ }^{101}$ As a leading international lawyer noted facing the United Kingdom House of Commons Foreign Affairs Committee following the Kosovo air campaign: "The proponents of humanitarian intervention are distinctly in a minority. More significant, however, is the position in customary international law, which depends upon the practice of States based upon 'opinio juris', that is to say, a belief that the action is in accordance with international law. There can be no doubt that the UN Charter can be modified by the congruent practice of the Member States crystallizing as a new principle of customary law. But there is a burden of proof upon proponents of a change in the customary law. The central point is the absence of evidence of a change of view by a majority of States." 102

The final and maybe the most important argument opposing the existence of a customary right of HMI views this dilemma from a different angle by weighting the relative legal strength of the treaty law versus the customary law. In support of the legalist objections, it suggests that privileging the custom over the treaty whose provisions are additionally 'jus cogens' such as the Article 2(4) - would be a dangerous approach potentially leading to the serious misuses of the customary law due to the shifting perspectives and controversies of what constitutes a custom.

\subsubsection{Final evaluation of legality of HMI}

While evaluating the legality of HMI, it is necessary to start with the interpretation of the UN Charter and to determine, "whether the application of an agreement to a particular situation is or is not in accordance with the shared intentions, expectations and objectives of the parties." 103 In spite of some disagreements about the interpretation of the Article 2(4), the above presented analysis clearly shows that the legalist

\footnotetext{
${ }^{99}$ See, for example: UN Security Council Resolution 940, or UN Security Council Resolution 929.

100 Roberts, 1993; or Hilpold, 2001.

101 Arend \& Beck, 1993.

102 Brownlie, 2000, p. 894.

${ }^{103}$ Lissitzyn, 1967, pp. 895-896.
} 
position refusing the existence of the right of unauthorized HMI has much more support within the scholarly legal debate about the concept. It is thus possible to conclude that there is a majority legal opinion that the general right of HMI does not exist within the current international law, and that there are only two legally acceptable versions of HMI - the one authorized by the UN Security Council or the one waged on the invitation by the target state's government. Under the current state of international law, any suggestion to violate sovereignty of any state using a military force without the UN Security Council authorization would be unlawful.

Nevertheless, in spite of the fact that the alleged cases of HMI still lack a legal standing that would transform the exceptions into the norm ${ }^{104}$; it would be difficult to ignore the importance and moral validity of the affirmative arguments that have managed to divide the scholars in their opinion about the legality of the concept. It is necessary to take into consideration that the poor legal status of the unauthorized HMI and a foreseeable condemnation by the international community have not prevented the countries to intervene anyway in many cases of humanitarian disasters in spite of the lacking mandate by the UN Security Council. It is necessary to admit that it is not uncontroversial to denounce any of the two approaches toward the legality of the general right of HMI as being completely wrong, since both the legalist and the affirmative positions have their strengths and inherent problems. Problem of the legalist position is that it fails to provide a legal basis for taking a firm action to prevent the ongoing atrocities against the civilians, degrading thus the international human rights law and humanitarian law. Similarly, it is problematic to fully adhere to the affirmative liberal position and to advocate the legality of unauthorized HMI plainly by referring to the universal human rights and the custom, while ignoring the existing legal structure. Opting for anyone of them would entail serious moral implications that need to be taken into consideration.

\subsection{Legitimacy of HMI}

In case of such a morally loaded legal trap, it is usually a habit to retreat a step back and to return to the basic legitimacy of the concept, letting the legitimacy to shape the interpretation of its legal status.

\subsubsection{Mainstream approaches toward the legitimacy of HMI}

There are three key works framing the debate about legitimacy of HMI in the existing literature. First work Just War or Just Peace? written by Simon Chesterman supports a legalist perspective in the debate about legitimacy of HMI. Chesterman frames the dilemma of HMI as a choice between "the just war or just peace"105 and

\footnotetext{
${ }^{104}$ Chesterman, 2001.

${ }^{105}$ Chesterman, 2001, p. 236.
} 
concludes by rejecting the legitimacy of the right of HMI.106 Second key work Saving Strangers written by Nicholas Wheeler represents a more permissive liberal perspective on the problem. He describes cases of the use and misuse of HMI in practice, and traces the justifications declared as a ground for individual cases of HMI and their actual goals. Wheeler concludes by recognizing the norm of HMI as a legitimate exception to the rule of nonintervention, calling for a solidarist approach of a "guardianship of human rights everywhere". ${ }^{107}$ The final key document is the UN-contracted report produced by the International Commission on Intervention and State Sovereignty (ICISS) that is positioned theoretically somewhere in-between the legalist and the liberal positions. Authors of the report try to reconcile conflict between the norms of nonintervention and the respect for human rights; and attempt to create some guidelines for responding to the massive human rights violations. ${ }^{108}$ Conclusions of this study support legitimacy of the emerging HMI norm by introducing a concept of 'responsibility to protect'. The report bases its reasoning on the shifted understanding of state's sovereignty in the international system. It entails that states no more possess an unlimited control over their delimited territory. Instead, it interprets sovereignty as being conditional upon the states' respect for a minimum standard of human rights: "...sovereignty implies a dual responsibility: externally to respect the sovereignty of other states, and internally, to respect the dignity and basic rights of all people within the state". 109

\subsubsection{Moral arguments supporting the legitimacy of HMI}

Moral principles supporting existence of legitimacy of the right of HMI are based mainly on the natural law and the related Just War ethics. Natural law represents a set of rules with a universal character regulating the behavior of states in their international relations. What is unique about the natural law is that it has a primacy over and exists independently of both treaty and customary law. ${ }^{110}$ Natural law accepts existence of the right to use force in case of a moral imperative of protecting the innocents, even if the suffering occurs in another state. As Grotius stated in his De jure belli ac pacis libri tres: "According to the new understanding of international relations that was emerging together with the idea of sovereign state, any sovereign state has the right to enforce natural law against any other sovereign who is

\footnotetext{
106 Chesterman, 2001.

107 Wheeler, 2000, p. 12.

${ }^{108}$ ICISS was launched at the UN Millennium Assembly in September 2000 in response to Kofi Annan's challenge to push the international community to act when facing the massive human rights violations. ICISS had three ambitious goals: to promote a comprehensive debate on the issue of HMI, to foster a new global consensus on how to move forward of the issue, and to find a way how to reconcile the clashing principles of human and humanitarian rights with the nonintervention norm. See: Welsh, 2002. The ICISS report and its conlusions and implications will be discussed later in this chapter.

${ }^{109}$ International Commission on Intervention and State Sovereignty, 2001, p. 8.

110 See, for example: George, 1999.
} 
guilty of violating it....providing the offence is very atrocious and very evident."111 Natural law constitutes a major inspiration for the foundations of the Just War Theory (JWT), which deals with the justification of HMI much more specifically, concretizing the exact conditions for both waging and conducting a 'just war'.112 Based on the JWT, an act of war can be classified as 'just' when the following six criteria become fulfilled: 1) 'just cause'; 2) 'just intent'; 3) 'just authority'113; 4) 'last resort'; 5) 'proportionality' of the used force to the ends it seeks to achieve; and 6) a reasonable chance of 'success'. 114

There is a powerful moral intuition at work in thinking of those who advocate legitimacy of the right of HMI that apparently goes beyond the current international law. Coming out of the natural law, the supporters of legitimacy of HMI argue that a complete prohibition of use of force outside the framework set in the UN Charter is clearly incapable of protecting the inviolable human rights of individuals. They claim that the UN Charter should be treated as a living instrument that needs to be interpreted in its contemporary context to allow dealing effectively with the cases of humanitarian suffering. Michael Walzer wrote in support of this position: "Any state capable of stopping the slaughter has a right at least, to try to do so. The legalist paradigm indeed rules out such efforts, but that only suggests that the paradigm, unrevised cannot account for the moral realities of military intervention." 115 These affirmative thoughts have crystallized into the elaboration of the ICISS report, which has introduced new concepts such as a 'limited sovereignty' and the derived 'responsibility to protect' that have been conceptually adopted at the UN level in 2005, and that have served as a major legitimizing factor supporting the legitimacy of HMI so far.

The ICISS report points to the existing shift in understanding of the notion of 'sovereignty', which is no more perceived merely as an 'authority', but also as a 'responsibility'.116 While the former treats the state sovereignty as an unrivaled control over a delimited territory and the population residing within it, the later suggests that sovereignty is conditional upon the state's responsibility for respecting the dignity and basic human rights of all its citizens. This suggests that sovereignty should no more serve as a protective shell for the governments committing massive human rights violations against their citizens, but should be interpreted as being bound by certain limitations. As the former UN Secretary General, Kofi Annan, repeatedly declared; the sovereignty should not be meant to

\footnotetext{
111 Grotius (transl.), 1625, sec. II.20.43.3.

112 Williams \& Caldwell, 2006.

113 The original criterion of 'a lawfully declared war' was adjusted and transformed into a modern reality of 'just authority' requirement.

114 Harhoff, 2001.

115 Walzer, 1977, p. 108.

116 Welsh, 2002.
} 
leave governments free to persecute their citizens. Only good governance and the consequent international recognition can fully establish a sovereignty of the state. ${ }^{117}$ In 1999, Kofi Annan publically proclaimed that: "Emerging slowly, but I believe surely is an international norm against the violent repression of minorities that will and must take precedence over concerns of State sovereignty. No government has the right to hide behind national sovereignty in order to violate the human rights or fundamental freedoms of its peoples."118

Introduction of the concept of a 'limited sovereignty' has constituted grounds for challenging the nonintervention norm with the new concept of 'responsibility to protect'. Its basic idea is set on an assumption that functioning of the international system is dependent on the willingness of states to play by the system rules. If this fundamental condition is not respected and some state completely disregards the fundamental human rights, such a moral collapse is outside the law and so can be the tool used by the international community to deal with it. From this follows that HMI can be perceived as a legitimate response of the international community to such an abnormal behavior - though illegal in principle, which provides the individuals living under oppressive regimes with a hope that an abusive government may confront international action. ${ }^{119}$

\subsubsection{Moral arguments opposing the legitimacy of HMI}

Moral concerns motivate not only the supporters but also the opponents of the HMI concept. Negative arguments represent a mix of realist, colonialist, pluralist and consequentialist perspectives that point to the institutional and practical limitations for controlling the use of HMI in practice. There are about five major ethical objections to the legitimacy of the right of HMI. First objection follows the realist way of thinking by claiming that the establishment of such a right would endanger international peace and stability that could unleash an uncontrollable anarchy. ${ }^{120}$ This argument is based on an assumption that the world peace is better preserved and international stability is more effectively guaranteed, if the states respect each other's sovereignty without any reservations. It puts an emphasis on the moral obligation to maintain order at the expense of the moral obligation to promote human rights and democracy elsewhere. It points to the fact that the value of an international peace should be given a particular weight; since it is in the situations of war, when the humanitarian values are most likely to be threatened. Therefore, based on this argument, standing firm on the prohibition of use of force should represent a lesser evil.

\footnotetext{
117 See: Reisman, 1990; or Ryter, 2003.

118 UN Press Release, 1999, SG/SM/6949.

119 Cassese, 2000.

${ }^{120}$ Jackson, 2000.
} 
Second criticism of the HMI concept questions the real motivations of the interveners and the related abuses of the right of HMI mainly for the national interests. As Michael Walzer suggests in his publication Just and Unjust Wars, interventions intended mainly to protect the human rights are rare, since states are not willing to use own military forces unless having some substantial national interests at stake. ${ }^{121}$ In fact, demanding a purity of humanitarian motives to qualify some military intervention as being 'humanitarian' is not a very realistic option; since under such conditions, there would hardly ever be any. It is necessary to take into consideration that any type of a military endeavor is politically risky and has real costs - both in terms of finances and death soldiers. If no national interests are involved, it is obviously more rational for the political leaders to remain inactive and to wait until some other country takes the burden of bearing the costs of HMI on itself. Political leaders are thus confronted with a need to justify their decision to send young men into the distant conflict zones not only by referring to the morality of such an operation, but also by referring to the existing national interests to justify the entailed risks that the country would undergo. ${ }^{122}$ This necessity is demonstrated by the fact that if a conflict appears in some economically and politically uninteresting region, the international community faces a totally opposite problem than having to stop the fighting willing countries from sending their troops. Just to the contrary, it is often very difficult to find the volunteers that would be willing to contribute the troops. Low willingness to fight for merely moral reasons often leaves the main global governor of human rights the UN - paralyzed from stopping the humanitarian suffering in the politically or economically unattractive areas. Having no own military capabilities to act and having no troop contributions from the member states without direct interests in the conflict region; the UN is often incapable of waging any operation no matter how severe the ongoing humanitarian crisis is. In such cases, the UN is left with two possibilities: either to remain inactive and to let the suffering continue; or to give the mandate to intervene even to the states with the obvious side interests but to the only ones willing to act. This argumentation explains also the other often criticized aspect of the HMI concept in practice, which is its selectivity in targeting. As argued above, it is just a logical consequence of the necessity of intervening countries to count the possible risks and costs associated with each military endeavor, and thus a necessity to carefully considerate when and where these risks and costs will be born based on the other strategic interests. It is just a logical consequence of the limited resources that even with the best will in the world, it would be just impossible to take action in every single case of the human rights violations. ${ }^{123}$

\footnotetext{
121 Walzer, 1980.

122 Hehir, 1995; or Buchanan, 1999.

${ }^{123}$ Ramsbotham \& Woodhouse, 1996.
} 
Next critical argument suggests that establishment of the right of HMI could be extremely prone to the potential abuses for the sake of power politics of those countries, which have the sufficient financial and military means to actually conduct such endeavors. ${ }^{124}$ Given the imbalanced power relations among states and within the entire institutional framework at the international level, there is no body capable of controlling the great powers from misusing the HMI. There are about two scenarios of how the control mechanism over the use of the potential right of HMI could be possibly carved. Assuming that the decision to intervene for 'humanitarian' purposes would be left upon the sensitivity of individual countries, it would potentially lead to an uncontrollable unilateralism by the strongest powers. Similarly, assuming that the UN Security Council would be given the authority to decide upon legitimacy of the launched HMI, which is the most probable scenario; its militarily strong permanent members entitled with a veto power would be capable of stopping any legitimate HMI from happening, while themselves enjoying a de facto immunity regarding their own acts of aggression. Critics of the right of HMI thus argue that the nonintervention norm needs to be preserved, since it is intended to be applied to all states equally, representing thus a protection of the weaker states from being violently exploited by the stronger powers that seek to further their selfish interests or to impose their views on how the weaker states should be internally organized. ${ }^{125}$

Third criticism of the right of HMI represents a mix of pluralist and neocolonialist perspectives that follows from the previously debated abuses of such a right by the great powers. Pluralists argue that there is no common universalist agreement on the political, social and cultural values; and stress that each society cherishes different religious, ethnic, and civilization habits. As a result of that, it is very subjective to evaluate certain policies as being oppressive toward the human rights and thus as being a viable reason for a breach of some state's sovereignty. They point to the fact that a majority of the militarily strong states that tend to be the most frequent interveners, as well as most of the permanent members of the UN Security Council belong among the representatives of the Western culture. Human rights as understood in the West differ from those valued in the developing world, which makes the concept of the 'universal' human rights questionable. It suggests that introducing the right of HMI into the current international system that is so imbalanced in the power-values distribution would put the Western countries in a position and in power to evaluate and punish other states for the claimed noncompliance with the subjective human rights standards, forcing a majority of the mankind to accept the ideological hegemony of the Western establishment. Without clearly separating a minimalist conception of the

\footnotetext{
124 Köchler, 2000.

125 International Commission on Intervention and State Sovereignty, 2001.
} 
human rights' protection from a maximalist intention to reshape societies according to the Western liberal-democratic image; the right of HMI would be highly probably portrayed as a Western-driven norm reflecting the Western ability to manipulate the international opinion and to construct an illusory 'consensus' ${ }^{126}$

Similarly as pluralists, the neocolonialists perceive the right of HMI as a mere cover for legitimization of the Western power politics. They claim that the concept of HMI bears the shades of the medieval crusades or the later European colonial imperialism that is just veiled in the 'modern' clothes of human rights protection and democracy. They present the concept of HMI as being built on the traditional stereotypes and hegemonial discourses in favor of the right to intervene, by which the Western powers authoritatively present their own moral and civilization superiority. They argue that even if the now-a-days motivations and objectives of the interveners were of a substantially different nature form those during the colonial period; separating substance and symbols for those being intervened upon may be a difficult task. These concerns seem to be supported by the fact that most of the typical targets of HMI tend to have a post-colonial character. ${ }^{127}$

Fourth major objection to the right of HMI follows the argumentation of consequentialist ethics. It states that - no matter how well intentioned - HMI can easily produce more problems than it solves, resulting in a negative humanitarian outcome. Intervention could, for example, provoke a violent resistance by the government of the target country; may provoke a violent reaction of the government in the neighboring state; alternatively, it may also prolong or intensify the conflict by injecting the new weapons and men-power into the conflict zone or by increasing the prospects and willingness to fight of the conflict party in those support the intervention was carried. ${ }^{128}$ Nevertheless, conflict environment is highly complex, which makes any speculation about the possible effects of HMI highly problematic. Results of any such evaluation can be strikingly different depending on which set of consequences and which time frame are taken into consideration, or by whom and on the basis of which data are the evaluations carried out. It is impossible to evaluate precisely in advance whether some HMI can succeed or not, since there are simply too many unknown and unpredictable factors outside the control of the intervener.

Last major argument criticizing the concept of HMI is a product of the practical experience with usage of this term. Combining the words 'humanitarian' and 'military' within one term creates undesired associations between the two, which complicates and endangers work of the non-military humanitarian workers stationed in the conflict zones. In contrast to the practices of the military personnel,

\footnotetext{
126 For a further discussion, see: Bull, 1984; or Laughland, 2000.

127 See, for example: Köchler, 2000; or Welsh, 2002.

128 Kissinger, 2001.
} 
humanitarian workers typically tend to follow three guiding principles in their work: neutrality, impartiality, and independence. These principles not only symbolize the core values of their mission; but most importantly, they represent a practical tool for their own protection. Being perceived as representatives of the neutral charitable organization serves as a guarantee that humanitarian workers are not attacked upon by any side of the conflict. Nevertheless, when the humanitarian organization operates in a close proximity to the military forces that call themselves 'humanitarian'; all sides inevitably view also the non-military humanitarian workers as political actors driven by the strategic goals of the military planners. These allegations about their interconnectedness are often correct, since humanitarian aid is sometimes openly manipulated by the intervening forces in an attempt to build a local support for their military and political goals. This happens particularly when the intervening states are at the same time also the major funders of humanitarian activity in the target state so as to win the support of the civilian population by demonstrating a goodwill and power of the donor. An unfortunate consequence of such practices is a rapid increase in the number of humanitarian workers killed in the battle fields ${ }^{129}$, and open accusations of the military sector of 'devouring' the humanitarian space. ${ }^{130}$

\subsubsection{Final evaluation of legitimacy of HMI}

Question about existence of a sufficient moral ground for legitimizing the right of HMI seems to have no clear answer. HMI cannot be from the moral perspective declared neither plainly legitimate nor illegitimate. On one hand, it would be possible to question morality of the international system, in which the states can massacre their people without having to fear a punishment, and in which the oppressed people have no hope of receiving external assistance. On the other hand, apart from the unsure positive humanitarian outcomes of HMI; establishing the right of HMI could potentially increase the risk of new conflicts and could serve as a cover for the powerful states to impose their power and subjective human rights standards on the weaker ones. Even though, the above provided list of moral arguments seems to indicate more criticism of HMI relative to the arguments supporting the concept; it is just an overview of as many possible perspectives on the concept as possible. It is important to critically assign the weights of moral importance to individual arguments that justify or denounce the concept before making any final judgment.

Nevertheless, what appears to be obvious from the above carried out analysis is that the arguments against legitimacy of the right of HMI cannot be dismissed merely by a claim that sovereignty is not absolute. It cannot be ignored that any

\footnotetext{
${ }^{129}$ According to the study carried out by the John Hopkins University, there were at least 320 humanitarian workers killed in the field between the years 1997 and 2006. See: Lischer, 2007. 130 Stoddard, 2003.
} 
type of warfare destroys lives, health, property, infrastructure, and natural and cultural environment in a degree that far overreaches any alternative diplomatic or economic tools of crisis management. Due to the fact that any military intervention - including the 'humanitarian' one - involves deliberate killing and destruction; a resort to it logically demands a heavy burden of justification. As a result of that, it would be necessary to provide really reasonable and solid reasons why waging a military intervention can be justified and under which criteria to award the concept of HMI with legitimacy.

\subsection{Gap between legality and legitimacy - 'responsibility to protect' concept}

As is visible from the historical development of the HMI concept that was presented at the beginning of this chapter, the international community seems to be adopting an increasingly affirmative approach toward the right of HMI. The behaviour of the international actors suggests that the right of HMI is gradually becoming accepted as legitimate, and that there is an effort to correct its illegality by providing it with an increasingly solid legal status. The main impulse to institutionalize the right of HMI was initiated by the former UN Secretary-General, Kofi Annan. He addressed the issue of HMI in the Millennium Report to the General Assembly in 2000, posing a question: "If humanitarian intervention is, indeed an unacceptable assault of sovereignty, how should we respond to a Rwanda, to a Srebrenica - to gross and systematic violations of human rights that offend every percept of our common humanity?". ${ }^{131}$ As a reaction to his appeal, the International Commission on Intervention and State Sovereignty (ICISS) was established to approach the problem of HMI in a comprehensive manner with the task of finding a global consensus about how and when the international community should respond to the emerging humanitarian crises. ${ }^{132}$ In 2001, the ICISS released a report introducing a new concept of 'responsibility to protect', which commits states to take action to prevent genocide, war crimes, crimes against humanity, and ethnic cleansing when they know or should know that populations are at grave risk. ${ }^{133}$ The main declared purpose of the ICISS report was to introduce a broad doctrine of crisis prevention. It stated: "prevention is the single most important dimension of the responsibility to protect". ${ }^{134}$ In spite of this original goal, the ICISS report has been mainly discussed in relation to the potential legalization of the right of HMI, since it allows for a possibility of waging a HMI as a last resort solution when dealing with a humanitarian crisis. ${ }^{135}$

\footnotetext{
131 UN Secretary General Report, 2000, p. 35.

132 Bellamy, 2009.

133 International Commission on Intervention and State Sovereignty, 2001.

134 International Commission on Intervention and State Sovereignty, 2001, p. xi.

135 Evans, 2008.
} 
The entire 'responsibility to protect' concept is based on a two-dimensional understanding of responsibility: (1) the responsibility of a state to protect its citizens from atrocities; and (2) the responsibility of the international community to prevent and to react to the massive human rights violations. The ICISS report argues that states have the primary responsibility to protect their citizens. When they are unable or unwilling to do so, "the principle of nonintervention yields to the international responsibility to protect" 136 , and "it becomes the responsibility of the international community to act in its place". ${ }^{137}$ The concept shifts the debate away from the controversial 'right to intervene' to the 'responsibility to protect' meaning to a perspective focused on the victims of human rights violations. ${ }^{138}$ Based on this perspective, human rights are not perceived as limitations to the sovereignty, but rather as their inherent elements. According to this logic, HMI does not contradict the principle of sovereignty, but rather complements it, where a state does not fulfill its responsibility. ${ }^{139}$ Nevertheless, as is emphasized in the ICISS report; a resort to a military intervention should only be acceptable in the extreme cases of large-scale human rights violations or ethnic cleansings - 'just cause', and only when all of the additional four criteria are met: (1) 'just intent'; (2) 'last resort'; (3) 'proportionality'; and (4) a reasonable 'probability of success'. ${ }^{140}$

In answering who can authorize a HMI, the ICISS report adopts a rather cautious approach leaving a key role with the UN Security Council as is stipulated in the UN Charter. ${ }^{141}$ Nevertheless, in case that the HMI is blocked by a veto vote by some permanent member of the UN Security Council; the report suggests a possibility to obtain legitimization from the General Assembly, or alternatively through authorization by a relevant regional organization. ${ }^{142}$ The drafters of the report justify this position by a statement that scenario, in which "one veto can override the rest of humanity on matters of grave humanitarian concern" is unacceptable. ${ }^{143}$ They admit that there is no realistic prospect for passing an amendment of the UN Charter abolishing the veto power in cases of ongoing humanitarian emergencies, but they urge the permanent members of the UN Security Council to adopt a "formal, mutually agreed practice" of giving it up in these exceptional situations. ${ }^{144}$ Concerning the legal status of an unauthorized HMI; the ICISS report mentions a lack of global consensus on this controversial question, but

\footnotetext{
${ }^{136}$ International Commission on Intervention and State Sovereignty, 2001, p. 2.29.

${ }^{137}$ International Commission on Intervention and State Sovereignty, 2001, p. xi.

${ }^{138}$ International Commission on Intervention and State Sovereignty, 2001.

${ }^{139}$ Levitt, 2003.

${ }^{140}$ International Commission on Intervention and State Sovereignty, 2001, p. 4.19, 4.32-4.43.

${ }^{141}$ International Commission on Intervention and State Sovereignty, 2001.

142 International Commission on Intervention and State Sovereignty, 2001; or Wheeler, 2005.

${ }^{143}$ International Commission on Intervention and State Sovereignty, 2001, p. 6.13, 6.20.

${ }^{144}$ International Commission on Intervention and State Sovereignty, 2001, p. 6.21.
} 
it avoids explicitly calling such an intervention illegal. ${ }^{145}$ It explains this seemingly confusing position by pointing out a potential damage to the international order if the UN Security Council is bypassed; but at the same time, it also emphasizes a "damage to that order if human beings are slaughtered while the UN Security Council stands by". ${ }^{146}$ It warns that if the UN Security Council fails to live up to its responsibility, the states might take the law into their own hands and might intervene either in the ad hoc coalitions or unilaterally, which could have negative consequences for both international order and justice. ${ }^{147}$ The ICISS report concludes by suggesting a following hierarchy of responsibility for the management of the severe human rights violations: host state, the UN Security Council, the General Assembly, regional organizations, coalitions of the willing, and finally individual states external to the violations.

\subsubsection{World Summit Outcome of 2005}

The 'responsibility to protect' doctrine has been elevated to the global level by being endorsed by the UN General Assembly at the World Summit in 2005. The state representatives explicitly acknowledge in the World Summit Outcome Document that each state has a responsibility to protect its populations from genocide, war crimes, ethnic cleansing, and crimes against humanity; and if some state bearing the primary responsibility for its population "manifestly" fails to live up to its responsibility, they agree on the existence of a collective responsibility to help protecting such populations using the peaceful means. ${ }^{148}$ Concerning a possibility of initiating a collective military operation to protect these populations; the proclamation is phrased more vaguely stating that the states are prepared to act in a timely manner and on the basis of a case-by-case evaluation. ${ }^{149}$

There are some notable differences between the ICISS Report of 2001 and the World Summit Outcome Document of 2005 that were a price for gaining a sufficient support for approving the Document within the UN framework, since a number of states voiced serious concerns about a potential of the 'responsibility to protect' concept for being abused, equating the concept with the highly controversial right of HMI.150 Critical remarks were voiced across a whole spectrum of the international arena. While the great powers feared losing their privileged position within the UN Security Council and thus a power to decide when and where the force can be used; ${ }^{151}$ other countries also adopted a generally cautious approach, suggesting that a failure to act in the past was more caused by a

\footnotetext{
${ }^{145}$ International Commission on Intervention and State Sovereignty, 2001.

${ }^{146}$ International Commission on Intervention and State Sovereignty, 2001, p. 6.37.

${ }^{147}$ International Commission on Intervention and State Sovereignty, 2001.

148 UN General Assembly Resolution, 2005, p. 139.

149 UN General Assembly Resolution, 2005.

${ }^{150}$ Global Centre for the Responsibility to Protect, 2009.

${ }^{151}$ Chesterman, 2004; or Cushman, 2006.
} 
lack of political will rather than by a lack of authority. ${ }^{152}$ As a result of these doubts, the original ideas from the ICISS report had to go through some significant changes so as to persuade the states to adopt the concept at least in an adjusted form. In particular, the proposal to include criteria governing the use of force was dropped, and it was agreed that any HMI under the 'responsibility to protect' framework would require an authorization by the UN Security Council. The World Summit Outcome Document also dropped the possibility of appealing to other bodies such as the UN General Assembly in case of the veto being applied to block a potential HMI, as well as the possibility of waging a HMI outside the UN framework. ${ }^{153}$ The UN Secretary-General defended a lack of discussion about the possibility of unauthorized HMI by stating: "The task is not to find alternatives to the Security Council as a source of authority but to make it work better." 154

Since the endorsement of the World Summit Outcome Document, the UN Security Council has five times successfully included the 'responsibility to protect' concept into the resolutions - once in the resolution to protect the civilians in armed conflicts in general ${ }^{155}$, and four times in reference to the concrete situations in Sudan ${ }^{156}$, Libya ${ }^{157}$ and Ivory Coast ${ }^{158}$. In 2009, the UN Secretary-General asked the UN General Assembly to further develop the World Summit Outcome Document, and to provide the concept of 'responsibility to protect' with a more concrete legal basis. ${ }^{159}$ In 2009, the UN General Assembly started a debate about a potential strategy for implementing the 'responsibility to protect'. The outcome was a resolution reaffirming the principles listed in the UN Charter and the World Summit Outcome Document, and declaring its interest in further considerations on the 'responsibility to protect'. ${ }^{160}$

\subsubsection{Legal interpretation of the 'responsibility to protect'}

Endorsement of the 'responsibility to protect' principle by the UN General Assembly in 2005 has triggered continuous academic and political debates about its legal content. 161 There are ongoing disagreements about whether the 'responsibility to protect' constitutes only a conceptual framework for political discourse, or whether it has some more concrete legal implications. In fact, a legal status of the concept that is challenging the key provisions on the non-use of force

\footnotetext{
152 Global Centre for the Responsibility to Protect, 2009.

153 Wheeler, 2005.

154 UN Secretary-General, 2005, p. 126.

155 See: UN Security Council Resolution, 2006a.

156 See: UN Security Council Resolution, 2006b.

157 See: UN Security Council Resolution, 2011a \& 2011b.

158 See: UN Security Council Resolution, 2011c.

159 UN General Assembly Letter, 2009.

160 UN General Assembly Resolution, 2009.

161 Alvarez, 2007.
} 
in the UN Charter has been supported merely by the declaration of the World Summit and by the UN General Assembly resolution, none of which has a legally binding effect under the international law. ${ }^{162}$ Even though, the World Summit Outcome Document remained silent regarding the legal status of the 'responsibility to protect'; most of the scholars qualify it as an 'emerging norm' not yet included in any legally binding international document but that might gradually develop into the international customary law. ${ }^{163}$ They argue that in its current form, the 'responsibility to protect' concept is still not a suitable candidate for a legal norm. It is constructed as a comprehensive framework without a sufficient degree of precision, which causes that not all of its aspects are fit to be translated into the legal rights and obligations. It is only in conjunction with other more concrete rights or duties that such a broad concept could gain a legal significance. ${ }^{164}$

To sum it up, based on the majority legal opinion; the 'responsibility to protect' concept is constructed primarily as a non-legal concept introducing a more concrete set of criteria and procedures for determining when the responsibility of the international community to intervene should be triggered; ${ }^{165}$ nevertheless, the concept has a generally acknowledged potential to gradually evolve into a customary law, which allows for categorizing it among the 'emerging legal norms'. It is thus possible to claim that its legal content can be summarized as evolutionary rather than as revolutionary. ${ }^{166}$

One of the most controversial topics touched upon by the 'responsibility to protect' concept is the question of legality of HMI without authorization by the UN Security Council. Some authors argue that endorsement of the concept supports the claim that unilateral military intervention could be legal even in absence of the authorization by the UN Security Council. ${ }^{167}$ Nevertheless, such an interpretation would go too far. In spite of the fact that the original ICISS report does not explicitly deem the unilateral HMI without a Security Council mandate illegal, its drafters were unable to find a consensus with regard to its legality. The ICISS report solves this question by describing a potential bypass of the UN Security Council as a "damage to international order". ${ }^{168}$ The World Summit Outcome Document is even more skeptical regarding the legality of the unauthorized HMI.

\footnotetext{
162 Simma, 1994.

163 See: International Commission on Intervention and State Sovereignty, 2001; MacFarlane, Thielking \& Weiss, 2004; Barbour \& Gorlick, 2008; or Bellamy, 2009;. Other authors describe it as a 'soft law', for example: Welsh, 2006. Moreover, there are also propositions that it is already firmly grounded in the international law, for example: UN Secretary General, 2009.

164 Payandeh, 2010.

165 Winkelmann, 2010.

166 Luck, 2008..

167Hart, 1994; Amerasinghe, 2006; or Verlage, 2009

168 International Commission on Intervention and State Sovereignty, 2001, p. 6.37.
} 
Due to the fact that the majority of the states explicitly refused to accept legality of the unauthorized HMI during the negotiations about the final draft of the Document ${ }^{169}$, it entirely places the 'responsibility to protect' within the institutional framework of the UN, which means as being conditional upon the authorization by the UN Security Council. ${ }^{170}$

A surprising endorsement of the 'responsibility to protect' concept at the UN level can be explained by the fact that its adoption has not added anything substantially new to the international law regulating the use of force in the international relations. The concept has not created any legally binding criteria for the UN Security Council to act, it has not managed to legally restrict the use of veto power by the permanent members, and it has not legalized an unauthorized HMI. The powers and competences of the General Assembly as well as of the other international actors have remained legally unchanged. It was possible to push through the concept of 'responsibility to protect' at the UN level, because it is not as radical as the HMI concept. Building a similar support for the general right of HMI would have been much more improbable.

\subsubsection{Impact of the 'responsibility to protect' concept on future policy making}

The main contribution of the ICISS report are its conceptual insights into the relationship among sovereignty, responsibility, and intervention. The report presents a rather affirmative perspective on the right of HMI, forming a convincing argument in favor of the legality and legitimacy of such an action. By endorsing the 'responsibility to protect' at the UN level during the World Summit of 2005, the international community for the first time formally declared that the sovereignty might sometimes give way to the concerns about human rights. The international community has thus moved from away from tolerating the practice of authorizing the HMI by the UN Security Council to explicitly approving it. Endorsement of the 'responsibility to protect' can thus be understood as a codification of the emerging HMI norm that has been gradually developing especially since 1990s. Seemingly degrading fact that the concept represents just a mix of political and moral responsibilities and cannot be equated with a legal obligation should not diminish its significance. Political and moral implications may often have an even greater impact on the behavior of international actors than the legal norms. ${ }^{171}$ The concept should be perceived as a tool of political and moral pressure preventing the world from standing aside the mass killing and ethnic cleansing like it happened in Rwanda or, more recently, in Darfur - as a tool making the governments more

\footnotetext{
169 Brownlie, 2003.

170 UN General Assembly Resolution, 2005.

171 Payandeh, 2010.
} 
likely to act. ${ }^{172}$ To sum it up, in spite of a weak legal standing of the concept ${ }^{173}$; it has had and will have a tremendous impact on the political discourse of HMI. ${ }^{174}$

Obviously, it is necessary to be critical regarding the use and misuse of the concept in practice. The desired effects repeatedly mentioned by the proponents of the concept could be just a wishful thinking that will be far from reality. It is always necessary to bear in mind that the application of the agreed-upon criteria to the real cases is always open to interpretation. Skilled lawyers and diplomats can use the criteria entailed in the concept to construct the convincing arguments both for and against particular cases of HMI. ${ }^{175}$ A biased interpretation of the concept could go in various directions. This study will mention just two most probable ones.

First possible misinterpretation could be used to argue for a more restricted use of collective security within the UN framework. This scenario can be caused by the fact that the concept assigns a key responsibility to safeguard the massive human rights violations to the states themselves. It is then a subjective question to decide whether a state has already failed to live up to its responsibility, and whether a responsibility of the international community has thus already been triggered. This suggests that the concept of dual responsibility might prove to be a political obstacle for waging a collective action, which could greatly hinder an effective and timely reaction to the cases of genocide or other massive human rights violations. ${ }^{176}$ There have already been instances of applying the 'responsibility to protect' concept in this way. For example, when the UN Security Council members discussed about the Darfur crisis in 2005, they were unable to find an agreement whether or not the Sudanese government had indeed proven itself 'unable and unwilling' to protect its people. During the discussions, states emphasized the primary responsibility of Sudan, claiming that a collective response would be premature. ${ }^{177}$ Without an authoritative judge to determine such matters, the criteria contained in the concept will always be debatable. On the other hand, it is necessary to point out that it was exactly this potential restraint on interventionism that facilitated a consensus on the 'responsibility to protect' at the World Summit. ${ }^{178}$

Another possible way how the 'responsibility to protect' concept could be applied against its original purpose is, if misused to justify the unauthorized unilateral military interventions with the various self-interested motives -

\footnotetext{
172 Weiss, 2004.

173 Smyser, 2003.

174 Weiss \& Hubert, 2001.

175 Bellamy, 2005

176 Wheeler, 2005.

177 Bellamy, 2005.

178 Wheeler, 2005.
} 
especially by the big powers. It is unfortunately a reality that interpretation of the norms by the powerful states with a capacity to reward and punish others is likely to have a greater weight in the deliberations of governments than the arguments of the states that do not possess these incentives and disincentives to steer the negotiations in their preferred direction. The most recent international practice unfortunately confirms these fears. For example, the USA and the UK invoked the 'responsibility to protect' by referring to the serious human rights violations committed by Saddam Hussein and the Ba'ath regime in order to legitimize the invasion of Iraq. ${ }^{179}$ Similarly, Russia employed the 'responsibility to protect' in the context of Russia's use of force in Georgia. ${ }^{180}$ Although scholars have convincingly argued against this kind of misuse of the concept, ${ }^{181}$ these incidents show how susceptible to abuse it is. Obviously, there have been many states skeptical about the concept already since its introduction; nevertheless, there are also states that have withdrawn their support later on as a result of the perceived misuse of the humanitarian rationales in the Iraqi war. ${ }^{182}$ Kenneth Roth of the Human Rights Watch commented the situation concerning the use of humanitarian justifications in relation to Iraq by stating that "it will be more difficult next time for us to call on military action when we need it to save potentially hundreds of thousands of lives". ${ }^{183}$ This worrying development was manifested by a failure of the international community to prevent or end the humanitarian catastrophe in Darfur.

Based on the above listed weaknesses, it is obvious that the concept of 'responsibility to protect' needs a clarification that would decrease not only the existing uncertainty surrounding its meaning and legal status, but that would also decrease its potential for abuse. It should not be possible to justify a forcible breach of sovereignty by simply claiming to act in the fulfillment of some vague concept. To make the concept effective, it is necessary to control its employment outside the intended framework. The concept needs to be clearly interpreted and the justifications of the military actions based on this concept must be located within the established rules of international law. Otherwise, the concept would be a dangerous tool threatening stability within the international system. Nevertheless, no matter how many problematic aspects the concept seems to have at its current stage; a general acceptance of the concept - no matter how interpreted, the increasing UN tendency to refer to the concept, and the claims by the international lawyers equating it with an emerging customary law make it clear that the concept

\footnotetext{
179 Nanda, 2007.

180 Barbour \& Gorlick, 2008.

181 Bannon, 2006; or Evans, 2006.

182 The Iraqi intervention fuelled a resentment of states such as Cuba, Venezuela, Sudan, Pakistan, and Nicaragua, which prominently voiced their criticism toward the concept during the session of the UN General Assembly in 2008. See: Payandeh, 2010.

183 Roth, 2004, pp. 2-3.
} 
of 'responsibility to protect' will play a key role in the debates about legality and legitimacy of HMI in the future.

\subsection{Conclusion - legality vs. legitimacy}

The above elaborated analysis of legality and legitimacy of the HMI concept does not provide a clear-cut answer to the justification of the concept. From the legal point of view, an overwhelming majority of academic opinion seems to be inclined toward a conclusion that an unauthorized HMI is based on the Article 2(4) of the UN Charter an illegal act. In spite of its illegality, HMI has been increasingly used as a last resort crisis management tool by the states in case that many lives were immediately in danger. Based on this state practice and a gradual development of international human rights and humanitarian law, some legal scholars have started to suggest a possibility that the right of HMI could have evolved as a part of the international customary law. Nevertheless, the majority legal opinion refuses this position, claiming that there is an absence of a sufficient evidence of a coherent state practice based upon 'opinio juris' - the necessary ingredients for a customary international legal right to emerge.

Facing the absence of a solid legal status for the right of HMI, the proponents of its existence point to its morality and claim its legitimacy based on a higher moral rationale. Nevertheless, is it possible to claim that the concept though being illegal is legitimate? Could it be the case that legitimacy of the concept is so strong that it could overweight its illegality? Is there a gap between legality and legitimacy that should be filled in by adjusting the international law? Answering these questions is a normatively controversial and extremely complicated task. The existing academic debate seems to be equally divided regarding the question of legitimacy of HMI, presenting strong moral arguments that both support and condemn the concept. The whole debate rotates around assigning the relative weights of importance to the following two clashing moral concerns. On one hand, should the general right of HMI be legitimized; it would put into question a value of state sovereignty, which provides the states with a right to manage their own affairs, and which represents a main tool for maintaining peace and stability in the international system. On the other hand, there are also undoubtedly good reasons for being suspicious about an absolute right of states to be left immune from a possible outside intervention in case that they mistreat their own populations. It seems apparent that the question, whether the legal interpretation of the Article 2(4) of the UN Charter should be brought into compliance with a legitimate concern of preventing or stopping the huge humanitarian suffering or whether it should be rather left untouched due to the concerns of international peace and stability, entails a very difficult moral weighting.

The current trend in the international law suggests that the customary law is increasingly driven much more by a concern for protecting the human rights than 
by the traditional Westphalian respect for sovereignty of the state. This trend has been demonstrated by the endorsement of the new concept of 'responsibility to protect' at the UN level in 2005. The introduction of 'responsibility to protect' has significantly changed the political discourse of HMI, and has greatly influenced the ongoing debates about its legality and legitimacy by moving the debate to focus on the perspective of victims of the human rights violations. The concept represents an interesting solution to the tensions between sovereignty and human rights by embedding the notion of human rights within the idea of state sovereignty. It suggests that intervention within a state that fails to protect its citizens from the massive human rights violations does not constitute a violation of that state's sovereignty, but rather that it constitutes a realization of the responsibility that is shared by the state and by the international community. In spite of the fact that the 'responsibility to protect' still does not have a binding legal status, it seems to take a more affirmative stance pushing the international community toward an increasing legalization of the HMI concept. Its endorsement seems to imply that the political opinion is inclined toward the option that there is an existing gap between legality and legitimacy regarding the right of HMI that needs to be corrected. Nevertheless, it is necessary to point out that this revisionist enthusiasm is not globally shared, and that it is very difficult to neglect the morally significant objections that are raised against the introduction of such a right.

After reading this chapter, the reader could gain an impression that it has not given clear answers to the questions stated at its very beginning. This impression is partially correct, since it was not the main purpose to provide the reader with the black or white answers. The aspiration was to present the entire academic debate about the concept of HMI in such a comprehensive picture as possible, and to present how extremely complicated it is to take sides in this normative argument. The chapter should have motivated the reader to assess independently his position toward the concept without presenting any of the approaches as being right or wrong. The only apparent message that this chapter should have transmitted to the reader is the paralysis of the moralists and lawyers in solving the dilemma surrounding the right of HMI. Particularly this indecisiveness of the normative sciences has served as a main impetus for initiating an effort to evaluate the concept of HMI on the empirical basis, making a daring attempt to tame the justice-based rhetoric into the more structural and measurable terms. So as to achieve this goal, the following chapters of this study will be devoted to the empirical evaluation of the HMI by assessing its actual impacts on the target states. 


\section{CHAPTER}

\section{THEORETICAL FRAMEWORK FOR EVALUATING THE LEGITIMACY OF $\underline{\text { HMI }}$}

Debate about legitimacy of HMI is part of a broader question of morality of war, inheriting much of what is morally problematic about war and other uses of political violence. Similarly as in case of war, the most frequent way of evaluating the legitimacy of HMI in the existing literature is by a reference to a commonsense morality. ${ }^{184}$ The arguments of the authors draw from the morally reasoned ethics that is familiar to everybody and that - in spite of some disagreements about particular details - tends to be widely accepted. ${ }^{185}$ There are also some studies that have approached the question of legitimacy of HMI more theoretically and systematically, drawing from the various theoretical traditions such as realism, liberalism, or applied ethics. ${ }^{186}$ Nevertheless, the existing literature still lacks an analysis encompassing the entire ethical discourse related to the issue of HMI legitimacy. This study will attempt to fill in this gap by introducing a combined theoretical framework that would not only represent a balanced ethical perspective, but that would also enable a really systematic evaluation of the concept by quantifying its aspects and by making an empirical comparison over many historical cases. The goal of this chapter is to present a solid theoretical framework for the quantification of the complex issue of HMI legitimacy that would ensure preservation of a theoretical validity and relevance of the simplified empirical findings of this study within the existing ethical discourse.

\subsection{Controversy about 'motives and means' versus 'outcomes'}

While constructing a theoretical framework for the planned empirical analysis, this study begins with a basic assumption that evaluation of legitimacy of any action is connected with a controversy about 'motives and means' versus its 'outcomes'187, which is derived from the inevitable gap between even the best intentions of the actors and the resulting effects of their activity. Therefore, while evaluating the legitimacy of HMI, it is necessary to pose a question whether the 'motives and means' justify the 'outcomes', or whether it is the other way round. In other words, which of the two main ethical models - whether the intrinsicist or the consequentialist one - represents a better tool for evaluating the 'justice' of HMI. Inherent problem with both these ethical models is that when it comes to war, they

\footnotetext{
184 See, for example: Kagan, 1989; Pogge, 1992; Adelman, 1992; Moore, 1998a; Hooker, 2000; Cook, 2000; Portmore, 2000, Lango, 2001; Nardin, 2002; Bellamy, 2003; or Buchanan, 2003.

185 Harbour, 1995; or Kagan, 1998.

186 Mason, \& Wheeler, 1996; Hoffmann, 1997; Walzer, 2000; Wheeler, 2000; Nardin, 2002; Holzgrefe \& Keohane, 2003; Tesón, 2003; or Jokic \& Wilkins, 2003.

${ }_{187}$ Bellamy, 2004.
} 
become either too vague or too restrictive. Intrincist model puts the main emphasis on the 'motives and means', permitting a little flexibility in the rules of war. The extremist intrincist position claims that possessing a 'just motive' constitutes the only condition of moral activity, regardless of the consequences envisioned or caused. Based on this approach, a 'legitimate HMI' should have either a sole or a primary 'humanitarian motivation', suggesting that the 'humanitarian' component of the intervention should not be an unintended by-product of an otherwise unjust act perpetrated for the self-interested reasons. Apart from the motivation of the interveners, intrinsicism regulates the actual conduct of the intervention. It restrains a military operation to the targeting of permissible targets only, which can be very complicated given the messiness of conflict environment, in which military targets are often dispersed among the civilian population or even covered by the civilian centers. ${ }^{188}$ On the other hand, consequentialism is an open-ended model oriented on the 'outcomes' of the use of force that is highly vulnerable to the pressing military or political needs to adhere to any code of conduct in war. This approach assumes that the rules can be broken, if it is necessary for achieving a better result. It considers the 'humanitarian outcomes' of HMI to be the only legitimizing criteria, even if the intervention was actually not motivated by any 'humanitarian concerns'. ${ }^{189}$ Both of these approaches have own relevance and moral weight. Nevertheless, it is obvious that a narrow focus solely either on the 'motives and means' or on the 'outcomes' oriented approach does not represent a sufficiently encompassing theoretical framework for evaluating such a complex issue as the HMI. ${ }^{190}$

So as to avoid a necessity of making a normative decision about a greater validity of one of the above described ethical approaches, this study will introduce a theoretical framework situated in the intersection of the two. The adopted theoretical framework will neither be tied to the intrinsicist's absolutism nor to the consequentialist's open-endedness; instead, it will bridge the main arguments of these two perspectives by explicitly acknowledging that the 'motives and means' as well as the 'outcomes' represent the relevant parts of the equation of legitimacy. So as to qualify a military intervention as a legitimate HMI, the study will not only set a requirement of 'humanitarian motives and means', but it will additionally extend the legitimating function to include merely such operations that resulted in a positive 'humanitarian outcome'. To situate this definition within a theoretical framework, a degree of humanitarianism behind the 'motives and means' of the interveners will be evaluated by employing the Just War ethics, while existence of

\footnotetext{
188 Parekh, 1997.

189 Tesón, 1997; or Wheeler, 2000.

190 For a broader discussion about the division of these two ethical approaches, see: Welsh, 2002; or Ryter, 2003.
} 
a positive 'humanitarian outcome' will be evaluated using the consequentialist ethics.

\subsection{IWT as an evaluation framework of the legitimate 'motives and means' of HMI}

The primary and generally acknowledged ethical model for considering whether the 'motives and means' of any act of war can be considered 'just' is the Just War Theory (JWT). ${ }^{191}$ JWT is a justice-based rhetoric concerned on the theoretical ground with a moral justification of planning and prosecuting wars of any kind. It attempts to distinguish between the justifiable and unjustifiable uses of organized armed forces, aiming to make the use of arms as restrained and humane as possible with the goal of establishing a lasting peace and justice. ${ }^{192}$ When trying to situate the JWT between the two traditional schools of thought of the International Relations - realism and idealism, JWT is located somewhere in-between the two extremes. ${ }^{193}$ While realists focus on how to avoid a mistake of fighting when one should not; idealists deal with a failure of not fighting when one should. JWT skips this moral dilemma and rather combines sensitively both these approaches - it represents a moral restraint of war together with a readiness to accept that war may sometimes be necessary. ${ }^{194}$ Criteria constituting the JWT are neither unrestricted nor too restrictive. On one hand, this provides the JWT with an advantage of flexibility; on the other hand, a lack of a strict ethical framework makes its criteria open to the broad interpretations. ${ }^{195}$ All together, a generally acknowledged complexity of the JWT makes it a robust theoretical framework for examining legitimacy of the 'motives and means' of any military endeavor that balances main moral arguments both supporting and opposing the concept. JWT thus represents an adequate starting base for any research trying to capture the ethical essence of the HMI. ${ }^{196}$

\subsubsection{History of the JWT}

Historically, the JWT tradition is based on the natural law and has evolved over 1600 years. Its purpose is to regulate and to restrain the use of violence by establishing the widely recognized moral guidelines for waging a war. ${ }^{197}$ Origins of the JWT have their roots in the Christian theology, and can be traced to the Romanized Berber philosopher and theologian, St. Augustine (354-430), and his

\footnotetext{
191 International Commission on Intervention and State Sovereignty, 2001; or Coady, 2002.

192 Janzekovic, 2006. For an insightful analysis of the JWT tradition, see also: Christopher, 1994; or

Butler, 2003.

193 Bull, 1979; or Christopher, 1994.

194 Crawford, 2003; Janzekovic, 2006.

195 Christopher, 1994; Welsh, 2002; or Ryter, 2003.

196 Christopher, 1994; or Coady, 2002.

${ }^{197}$ While both natural law and JWT deal with the justification of resort to war, JWT is much more concrete about when and how the force can be used. See: Johnson, 1981.
} 
notion of 'the Two Cities'. St. Augustine claimed that violence was sometimes justified, referring to the concept of 'just' war as one limited by its purpose, authority, and conduct. He shifted the understanding of 'justice' in relation to warfare by suggesting that the use of force for own self-protection was not so much noble or legitimate when compared with legitimacy of employing force for the sake of defending other innocent parties unable to defend themselves. ${ }^{198} \mathrm{He}$ was the first one to formalize the JWT within the Christian Church. His proposition that killing the human beings could sometimes be justified represented a significant shift away from the pacifism of the early Church, and this proposition was later adopted as a justifying tool for the 'Holy just war' of the Christians against the 'infidels'- the Crusades.199 In the 13th century, following on Augustinian thoughts; the Italian priest, Thomas Aquinas (1225-1274), specified in his Summa Theologica a general outline of what has gradually developed into a coherent JWT. He introduced first three concrete criteria for waging a 'just' war: 'just cause', 'just intent', and 'just authority'; which have become known as the 'jus ad bellum'. ${ }^{200}$

Inspired by the work of Aquinas a couple of centuries later, Hugo Grotius (15831645), a Dutch jurist; Francisco de Vitoria (1486-1546), a Spanish Dominican priest; or Francisco Suarez (1548-1617), a Spanish Jesuit priest, subsequently dissociated the notion of 'just' war from its religious origins and helped to spread the idea of JWT beyond the Christendom. They argued that even the Sovereign was bound by the fundamental principles of humanity, and could thus not lawfully defy the duty to treat his subjects with a respect for their human dignity. In Grotius' view, the emerging Nation States were all bound by the law and morals of human society, and they were obliged not only to treat their own nationals in accordance with the principle of humanity but also to ensure that others did. Grotius and his contemporaries extended the three already established JWT criteria of 'jus ad bellum' by adding three additional ones: 'last resort', 'proportionality', and 'probability of success'. ${ }^{201}$

The Reformist Movement in the $16^{\text {th }}$ century and the Peace of Westphalia of 1648 opened a new era of a modern state that has brought many dramatic changes into the development of Just War ethics. The increasing secularization of power within individual states has caused that there ceased to be the only 'just' authority represented by the Pope, but that there appeared many of them having both secular and religious character. Therefore, so as to preserve the international peace and stability among the newly emerging power actors, an emphasis began to be

\footnotetext{
198 Reichberg \& Syse, 2002.

199 Butler, 2003.

200 Aquinas (transl.), 1952.

${ }^{201}$ Harhoff, 2001.
} 
placed on order over justice. ${ }^{202}$ The sovereignty of individual countries was acknowledged and respected as a guarantee of order, and the questions of justice were left to be decided within the national boundaries. JWT has started to experience a new revival at the end of $20^{\text {th }}$ century. This revival was marked by a gradual shift away from the paradigm that states should never intervene into the internal affairs of the other states. In this period, a debate about whether a HMI can be considered 'just' has again started to be evolving, referring to the arguments from the JWT.

\subsubsection{Applicability of the JWT to modernity}

JWT has been refined and clarified throughout the centuries. It has developed into a broadly acknowledged actor-oriented approach, which conceptually represents a synthesis of both idealist and realist conceptions of war utility. This proposition is demonstrated by the repeated acknowledgments of its preserved relevance and validity for evaluating the justice of any military endeavor not only by the Church, but also by the UN, and by many respected scholars. The Roman Catholic Church reconfirmed a continuous relevance of the JWT in the pastoral letter The Challenge of Peace: God's Promise and Our Response ${ }^{203}$, which states that the methods of precaution imbedded in the JWT remain a valid source of concern regardless of the evolution of war making and the occurred structural changes within the international system. The letter is concluded by a statement that the JWT offers a set of principles to objectively examine and to guide the decisions and the conduct of any type of a military endeavor. More recently, the Pope John Paul II issued the Catechism of the Catholic Church, which lists four strict conditions for a legitimate use of military force that directly reflect the traditional JWT criteria. ${ }^{204}$

Similarly, a modern applicability of the JWT has been repeatedly confirmed outside the Christian Church. For example in September 2000, the UN Millennium Assembly launched the International Commission on Intervention and State Sovereignty (ICISS) with the aim to explore particularly the question of legitimacy of HMI. The appointed Commission considered various perspectives on the issue of HMI ranging from the legal, moral, operational, to the political ones; covering the widest possible range of opinions so as to assist the UN in finding a common ground in this debate. The Commission introduced in its final ICISS report a new concept of 'responsibility to protect', which overtakes with just minor adjustments all the traditional JWT 'jus ad bellum' criteria. This conclusion of the Commission

\footnotetext{
202 Atwood, 2003.

${ }^{203}$ United States National Conference of Catholic Bishops, 1983.

${ }^{204}$ Catechism of the Catholic Church listed the following conditions: "1) the damage inflicted by the aggressor on the nation or community of nations must be lasting, grave, and certain; 2) all other means of putting an end to it must have been shown to be impractical or ineffective; 3 ) there must be serious prospects of success; 4 ) the use of arms must not produce evils and disorders graver than the evil to be eliminated." See: Chapman, 1994.
} 
serves as a confirmation that the JWT can still represent a legitimate tool for evaluating the justice of HMI. ${ }^{205}$ The fact that the JWT is generally accepted by the academic circles is also demonstrated by its frequent use as an evaluative framework of the warfare by the scholars. ${ }^{206}$ Although, these studies reflect some differences in opinion over the meaning of individual JWT criteria and over their implementation ${ }^{207}$; all share a basic assumption that the JWT remains applicable to the modern realities and that it represents a legitimate and a robust tool for evaluating justice of any type of military intervention, including the HMI. ${ }^{208}$

\subsubsection{Description of the JWT criteria}

JWT theorists distinguish between the rules that govern the 'justice' of waging a war ('jus ad bellum') from those that govern a 'just' conduct of war ('jus in bello'), and from the most recently added rules governing the responsibility and accountability of the warring parties after the war ('jus post bellum'). ${ }^{209}$ Each of the above listed set of JWT rules corresponds to a certain stage of military operation, and fixes exact conditions that must be fulfilled to preserve 'justice' of any military endeavor. This study will be focused merely on the most traditional 'jus ad bellum' JWT criteria, which are within the humanitarian context of a primary interest. ${ }^{210}$ Nevertheless, so as to get an overall picture of how comprehensively constructed the JWT is while considering the 'justice' of the use of force, all sets of the JWT rules are listed below.

\section{'Jus ad bellum' JWT criteria:}

- 'Just cause'

- 'Just intent'

- 'Just authority'

- 'Last resort'

- 'Proportionality'

- 'Probability of success'211

\footnotetext{
${ }^{205}$ ICISS kept the criterion of 'just authority' represented by the existence of the UN authorization only conditionally, calling for a reform of the UN Security Council to make it work better. See: International Commission on Intervention and State Sovereignty, 2001.

206 Ramsey, 1968; Walzer, 1977; O’Brien, 1979; Phillips, 1984; Johnson, 1999; Coady, 2002; or Butler, 2003.

207 Among the typical disagreements belong, for example, the questions of first strikes, involvement in wars of national liberation or secessionist movements, or the role of non-state bodies in prosecuting a 'just war'.

208 See, for example: Waltzer, 1977; or Butler, 2003.

${ }^{209}$ Williams \& Caldwell, 2006.

${ }^{210}$ Coady, 2002.

${ }^{211}$ Barcalow, 1994; or Ryter, 2003.
} 
'Jus in bello' JWT criteria:

- 'Target discrimination'

- 'Proportionality'

- 'Responsibility'212

\section{'Jus post bellum' JWT criteria:}

- 'Just war resolution'213

\subsubsection{IWT criteria of 'jus ad bellum'}

Due to the fact that this study will frame the identification procedure of the HMI cases on the 'jus as bellum' JWT criteria, it is crucial to describe in detail the original meaning of these criteria and how has been their meaning adjusted to the modern realities. First of all, each of the criteria will be discussed in general - referring to any act of war; and then they will be related to the concept of HMI, debating what implications and what practical complications could follow from setting such criteria as an evaluative framework of the 'humanitarian motives and means' of a military intervention.

\subsection{JWT criterion of 'just cause'}

The first JWT criterion of 'just cause' requires the intervener to justify the cause of the waged military operation. It is arguably the most important condition for evaluating the justice of any military endeavor. ${ }^{214}$ Originally, the JWT theorists considered self-defense against a physical aggression as the only sufficient 'just' reason for waging a war. In fact, moral right of self-defense represents almost universally accepted justification for using force. ${ }^{215}$ Nevertheless, the acceptance of 'justice' of using the violence in case of self-defense has recently been extended to cover also the more controversial cases such as a preemptive intervention when an act of aggression is just being anticipated ${ }^{216}$, or for our study more relevant external intervention aimed at assisting the oppressed civilians in a severe humanitarian

\footnotetext{
212 The criterion of 'discrimination' deals with the problem of legitimate targets in the war, while the criterion of 'proportionality' deals with how much force is morally appropriate. Apart from the first two traditional criteria, a third criterion of 'responsibility' is sometimes added, which demands an examination of where responsibility lies in the war. See: Barcalow, 1994.

${ }^{213}$ In more recent years, a third category of 'jus post bellum' has been added to govern the justice of war termination, peace agreements, and the prosecution of war criminals. See: Walzer, 1997; or Stahn \& Kleffner, 2008.

214 Walzer, 1997.

215 Janzekovic, 2006.

${ }^{216}$ Critics of this extension of the 'just cause' criterion complain that the preemptive strikes are based on the conjectured rather than the impending aggression, suggesting that a mere posturing and building up of armaments should not constitute a sufficient reason for an aggression. In such cases, a preemptive intervention would denounce the moral principle of the 'presumed innocence' of the actor.
} 
crisis. ${ }^{217}$ The JWT theorists generally agree that a military intervention for 'humanitarian' purposes is acceptable in some special cases; when it is aimed at preventing, stopping, or correcting the 'wrong behavior' that entails the massive human rights violations 'shocking the conscience of mankind'. ${ }^{218}$ These special cases are usually interpreted as referring to genocide or ethnic cleansing. Nevertheless, there is no agreement among the JWT theorists, on what the 'wrong behavior' that 'shocks the conscience of mankind' should exactly entail, and this proscription thus remains rather open-ended. The imprecise specification of the special cases is further complicated by a highly political nature of the HMI. First of all, full information is extremely difficult to obtain and verify in the conflict zones. Moreover, the issue of HMI is easily subjected to a political and media manipulation. Whether, when and how the politicians and especially the media report about the humanitarian crisis makes an enormous difference in the subjective perceptions about a degree of justice entailed in a possible military intervention, creating a corresponding public pressure in favor or against a possible dispatch of the troops.

\subsection{JWT criterion of 'just intent'}

The second JWT criterion of 'just intent' stipulates that the use of force can be considered 'just', only if waged for the purpose of justice and not for the reasons of self-interest. Therefore, while evaluating the legitimacy of HMI; correction of a suffered wrong is considered to represent a 'just intent'; while material gains, maintaining economies, or extending the sphere of influence are not. ${ }^{219}$ However theoretically reasonable this criterion might seem, it is very problematic to apply it in practice. First of all, it is impossible to objectively evaluate someone's intent. There can be a huge difference between a stated and a real motivation of the intervener, and the real intentions of any actor can always be doubted and questioned. The second main criticism reflects the realist way of thinking by claiming that it is irrational for a country to commit its troops to a military intervention on behalf of the human rights protection without having some complementary economic or other military side-interests to intervene. Sending the troops to some distant unknown country without any attached national interests might be reasonably considered too expensive and/or too politically risky in the eyes of the political decision-makers, regardless how just the cause may be. ${ }^{220}$ Unfortunately, the fact that the self-interested motives cannot be excluded from

\footnotetext{
217 Walzer, 1997.

${ }^{218}$ Harhoff, 2001.

${ }^{219}$ Harhoff, 2001.

${ }^{220}$ For example, in case of the ongoing genocide in Rwanda where no of the great powers had major national interests, there was a reluctance to call the genocide by its name, since applying the term would create a demand for a concerted action based on the Convention on the Prevention and Punishment of the Crime of Genocide of 1948. See: The United Nations General Assembly, 1948.
} 
any foreign policy act greatly complicates the requirement of a purely 'humanitarian motivation' of the intervener. ${ }^{221}$ For these reasons, most of the JWT theorists interpret this requirement in a way that it is sufficient, if there is a minimum level of 'humanitarian' motivation to qualify some military intervention as fulfilling the JWT criterion of 'just intent'. Other JWT theorists claim that the criterion of 'just intent' is reasonably fulfilled; if the motivation to create or restore peace, to correct damages, or to assist the victims of aggression are paramount or overwhelm the reasons of national interest. ${ }^{222}$ Some scholars even consider a mere absence of territorial acquisition, intimidation, coercion, cruelty, hate, and vengeance constitutes a sufficient fulfillment of this criterion. ${ }^{223}$ Nevertheless, acceptance of this position would suggest that the criterion of 'just intent' refers more to a notion of the limited wars, whose conduct is regulated by the 'jus in bello' JWT criteria.

\subsection{JWT criterion of 'just authority'}

The third JWT criterion of 'just authority' stipulates that an act of war can be considered 'just' only if backed up by a legitimate authority. The traditional JWT notion of 'just authority' resided in the concept of a state sovereignty, and was originally interpreted as a lawfully declared war. The basic argument rested on an assumption that if a government was 'just', then giving the officers of the state right to declare war was reasonable and justifiable. ${ }^{24}$ Nevertheless, the traditional interpretation of the criterion has become old-fashioned in a contemporary world, and has been gradually transformed into a requirement of authorization by a more globally acknowledged authority that should optimally function as a control mechanism deciding about a 'justice' of such operations. ${ }^{225}$ Nowadays, the only institution with the sufficient legal powers and an adequate authority to evaluate justice of the use of force in the international relations is the UN Security Council. Nevertheless, neither this updated interpretation of the criterion is unproblematic. In spite of the fact that the UN Security Council was established to serve as 'a guardian of international peace and security', and as 'a protector of human rights'; the veto power possessed by its permanent members disqualifies its decisions as

\footnotetext{
${ }^{221}$ For example, the most frequent intervener for the 'humanitarian' purposes in the post-Cold War period, the USA, directs its operations according to the Presidential Decision Directive 25 (1994). It states that the US soldiers can participate only in such peacekeeping operations, where the US national interests are at stake, and where the US would keep command of its troops. Similarly, British Prime Minister Blair declared in his speech in Chicago in 1999 that there is no contradiction in defending both humanitarian and national interests, since there is a need to justify the costs involved in any military operation to the citizens of the country. See: Ramsbotham \& Woodhouse, 1996.

222 Harhoff, 2001.

223 Butler, 2003.

${ }^{224}$ Hubert \& Weiss et al., 2001.

${ }^{225}$ Hurd, 2002.
} 
being influenced by the national interests. ${ }^{226}$ The veto power provides the permanent members not only with a protection from being targets of any UNauthorized military intervention; moreover, it provides them with a possibility to block authorization of any intervention - however 'just' - for their own narrow political interests. As a result of the anticipated use of veto power by some of the permanent members, the HMI often had to take place without being consulted at the UN level; and though being unauthorized, some cases of HMI are generally acknowledged to be legitimate. For example, Harhoff identified ten unauthorized interventions, whose legitimate 'humanitarian purpose' cannot be doubted, which brings into question the ability of the UN to decide about the 'justice' of such military operations. ${ }^{227}$

\subsection{JWT criterion of 'last resort'}

The following JWT criterion stipulates that war should always be used only as a 'last resort' tool, and only after all peaceful and viable alternatives have been seriously tried and exhausted. Originally, it meant that all peaceful alternatives had to be tried according to the escalating logic, and that war was only to be started if all these alternatives had failed. This approach has been, however, challenged; since it has proved to be problematic in practice. In many cases, negotiations were utilized as a mere delaying tactic, in spite of knowing that the party will not make any meaningful concessions anyway. Requirement of using force only in a 'last resort' is problematic especially in case of dealing with the humanitarian crises. If many lives are immediately endangered due to the severe humanitarian conditions, the effectiveness of the HMI is usually a question of a timely reaction. Under such circumstances, it is generally considered to be sufficient and also more 'just', if all the other alternative escalating acts have been at least honestly considered before waging a military intervention. ${ }^{228}$

\subsection{JWT criterion of 'proportionality'}

The fifth JWT criterion of 'proportionality' stipulates that the desired ends of war should be proportional to the means used to achieve them, as well as to be proportional to those applied by the aggressors. This criterion commonly entails a general balance of power consideration and an effort to minimize the destruction of war by using a minimum amount of force necessary to achieve one's objectives. ${ }^{22}$ This principle overlaps with the 'jus in bello' criteria, which require the force to be directed only against the legitimate targets, and which consider any

\footnotetext{
${ }^{226}$ Wheeler, 2000.

227 To the list of unauthorized HMI belong: Congo (1964), the Dominican Republic (1965), East Pakistan (1971), Kampuchea (1978), Uganda (1979), Central African Republic (1979), Grenada (1983), Liberia (1990), Northern Iraq (1991), and Sierra Leone (1998). See: Harhoff, 2001.

228 Ryter, 2003.

${ }^{229}$ Hubert \& Weiss et al., 2001.
} 
excessive or unnecessary use of military force to be morally unacceptable. ${ }^{230}$ Critics of this criterion point to the subjective nature of the criterion that is dependent on what the intervener considers to be proportional and how high personal price the intervener is prepared to pay. It is, for example, implausible to expect that the intervener would ignore its technological supremacy and would use only arsenal that is similar to the one possessed by the enemy, putting thus its own soldiers into danger.

\subsection{JWT criterion of 'probability of success'}

The last JWT criterion sets a requirement that any 'just' war must have a reasonable 'probability of success'. There must be solid grounds for believing that the desired outcome can be achieved.231 This criterion suggests that while evaluating the 'justice' of a military endeavor such as the HMI, a possible resistance in the target country should be taken into consideration so that the intervention does not cause more harm that it relieves. For example, if the intervention is waged against the government of a militarily strong state, or if the military resistance by the indigenous people is expected to be large relative to the scale of human rights violations that the intervention is intended to end; the prospects of success of the HMI are deemed to be low. As stated in the ICISS report: "some human beings simply cannot be saved except at an unacceptable cost...".232 This criterion thus imposes a moral obligation to carefully assess a balance between the risk entailed by the military intervention and the relief it can bring, before waging it. The criterion refers to the outcome of military operations only theoretically - based on the reasonable assessment of the situation and not based on their actual effects. Obviously, such a weighting of costs and benefits also poses a moral problem, because it suggests that the massive human rights violations should be ignored, if there is no conceivable chance of success. ${ }^{233}$ The opponents of such an interpretation argue that in the cases of a huge injustice, it is necessary to intervene for the sake of moral justice and for the sake of national pride, even if the 'probability of success' is very low.

\subsubsection{Major criticisms of the JWT}

In spite of many advantages of the balanced approach of the JWT, the Theory clearly remains a normative account those propositions can be easily challenged by billions of global citizens in a variety of different settings. As a result of that any conclusions made on the basis of such a normative account that aspire to claim a global validity can only be presented, if accompanied by an acknowledged list of

\footnotetext{
230 Cannizzaro, 2006.

${ }^{231}$ Hubert \& Weiss et al., 2001.

232 International Commission on Intervention and State Sovereignty, 2001, p. 37.

233 Harhoff, 2001.
} 
the major criticisms of a given approach and by an overview of the other competing theories that challenge the assumptions of the selected approach. ${ }^{234}$

The main criticism of using the JWT as a theoretical framework for evaluating the legitimacy of 'motives and means' of the HMI is coming from the supporters of nonintervention norm such as the realists, anti-imperialists or pluralists, who point to the fact that the flexible JWT criteria are too permissive, which could lead to a growing interventionism in the international relations. The realists base their argument on the Westphalian tradition of respecting states' sovereignty and mutual noninterference into the internal affairs. They emphasize the primacy of the order represented by the international peace over the justice represented by the human rights. Anti-imperialist and pluralist, on the other hand, fear the weakened role of the nonintervention rule entailed in the JWT logic, since this rule protects the small and weak states from being dictated upon by the great powers how to rule within their own territory. They claim that the nonintervention rule should be respected in order to preserve order, self-determination, and justice. ${ }^{235}$

Next often debated criticism of the JWT is directed against its historical roots. Theory is often rejected because of its solely Western-Christian cultural background. This criticism, however, refers just to the origin of this Theory, but says nothing about its validity or its concrete relevance to the parallel theories from the other cultures. In fact, similar moral considerations about a 'justice' of war as those set in the JWT are to be found not only in the Christianity, but also in most of the other religions. ${ }^{236}$ For example, the Chinese philosophical tradition addresses almost identical questions regarding a resort and a conduct of war as the JWT does. ${ }^{237}$ Universality of the Theory is confirmed by the fact that the secular humanists who specifically reject whatever religious dogma as a basis of morality and decision-making accept the JWT based on the universal ethics without making any reference to the Christianity. ${ }^{238}$

Other critique of the JWT invokes a plethora of practical problems that stem both from the vagueness and from the inherent subjectivity of its criteria. The fact that there is no definite answer to the issues of 'just cause', 'just intent', 'just authority', 'last resort', let alone a reasonable 'proportionality' or 'probability of success' greatly complicates their practical usability as tools for legitimizing the HMI. Flexibility of the JWT criteria enables both a too narrow and a too broad interpretation, which makes them easily subjected to a political manipulation and

\footnotetext{
234 Austin, Fischer \& Ropers, 2004.

235 Atwood, 2003.

236 Ryter, 2003.

237 Tzu, 1967.

238 Kurtz, 1995; or Seidman, 2003.
} 
abuse. ${ }^{239}$ For example, it is extremely difficult to identify a presence of 'just cause' for a military intervention into an internal conflict, where some fighting ethnic group keeps referring to a real or imagined wrong committed centuries ago, and where the ethnic hatred has escalated into a vicious circle of mutual violence making it impossible to identify the actual wrong-doer. ${ }^{240}$ Vagueness and subjectivity of the JWT criteria have thus resulted in the numerous historical cases of misapplication of the Theory by both the interveners and the actors in the target states. The most famous case of misuse of the Theory by the intervener was the 'Holy war' of the Christians against the 'infidels'. A similar misapplication was often displayed by the countries intervening militarily for the sake of own national interests, but officially declaring 'just cause' or 'just intent' as a mere cover for an act of aggression. Sometimes, the JWT criteria were also misinterpreted reversely, as an excuse for not intervening when a real humanitarian crisis was actually taking place. ${ }^{241}$ In spite of the criticized existence of a too wide space for maneuver in interpreting the criteria, given the extreme political sensitivity of the issue; this flexibility is also a question of necessity, since having the precisely stated criteria would make it often difficult to expound the Theory in particular conflict situations, and the Theory would lose its universal applicability. ${ }^{242}$

As a final critical remark against the use of the JWT as a framework for assessing the legitimacy of HMI, it is necessary to take into consideration that establishing any concrete criteria legitimizing the use of force may represent a potential danger of producing the perverse reactions from the conflict actors. For example, if the existence of a supreme humanitarian emergency - JWT criterion of 'just cause' - represents a criterion of a legitimate HMI; the rebel groups desiring the outside assistance might trigger the large scale human right abuses themselves and might intentionally provoke the mass killing. Similarly, if the established criterion stipulates a possibility to use force merely against the legitimate targets - JWT criterion of 'proportionality', the opponents might put the civilians next to the military targets so as to protect themselves from the possible air attacks by the interveners.

\subsection{Consequentialism as an evaluation framework of the legitimate 'outcomes' of HMI}

Given the aspiration of this study to introduce an encompassing empirical model of a legitimate HMI, the adopted theoretical framework will not be based solely on the existence of the 'humanitarian motives and means' in accordance with the JWT ethics, but this condition will be also complemented by the requirement of a

\footnotetext{
239 Welsh, 2002.

240 Janzekovic, 2006.

241 Welsh, 2002.

242 Butler, 2003.
} 
positive 'humanitarian' outcome of these military interventions as follows from the consequentialist logic. Why is it necessary to complement the legitimacy model with an additional criterion? It is possible to answer this question by posing two different ones with a self-evident inner message. Could a military intervention be legitimately labeled 'humanitarian', if the 'motives and means' of the intervention were 'humanitarian', but its effects actually increased the humanitarian suffering of the local population in the target state? What if the military interventions though being sent for the 'humanitarian purposes' - do not tend to produce the positive 'humanitarian outcomes'? If this was the case, the concept of HMI as such would not be justifiable, and there would be no reason to make an exception to the nonintervention norm in the existing international law when dealing with the humanitarian emergencies. These concerns and a logical sequence of the arguments follow from the consequentialist ethics. Consequentialism evaluates morality of the acts solely in terms of the 'goodness' of their consequences, meaning in terms of their contribution to the aggregate sum of general welfare. ${ }^{243}$ According to its logic, a right act is the one that is expected to yield the greatest net good or, in case of no realistic prospect of achieving any good, the one yielding the least net evil. ${ }^{244}$ Based on the consequentialist perspective, a 'legitimate $\mathrm{HMI}^{\prime}$ should not cause more damage than it is intended to correct - meaning that a net 'humanitarian outcome' should end up being positive.

\subsubsection{Strengths of the consequentialist approach}

The first major advantage of integrating the consequentialist approach into the theoretical framework of legitimacy of HMI is that the 'outcomes' of actions are relatively objectively measurable, which could enhance a practical usability of the proposed model in practice. So as to be able to claim a status of legitimacy, the actors would be encouraged to evaluate and rank the possible options based on their morality, opting for the most moral way of acting. It means that when, for example, political decision makers would consider whether to wage a HMI, they should count the expected moral costs and benefits, and weigh them against each other. Assuming existence of rationality and good intent, this weighting should prevent them from waging a military operation that has a high probability of causing a net increased humanitarian suffering. ${ }^{245}$ Moreover, putting an emphasis on the 'outcomes' of military interventions would compel the political leaders to carefully consider strategies employed during the conduct of these interventions in an effort to maximally prevent the unnecessary bloodshed. ${ }^{246}$ This suggests that

\footnotetext{
${ }^{243}$ Hopkinson, 1993.

244 Grisez, 1978.

245 Grisez, 1978.

${ }^{246}$ In spite of agreeing with relevance and validity of most of the JWT criteria, Wheeler rejects a necessity of two out of six criteria, leaving only: 'just cause', 'last resort', 'proportionality' and 'probability of success'. See: Wheeler, 2000; or Wheeler \& Bellamy, 2001.
} 
employing methodological key of consequentialism as a criterion of legitimacy of HMI provides easily understandable guideline and promotes measurable efficiency and effectiveness of the actors in their aspiration of achieving a global welfare.

In contrast to the measurable consequentialist rationale, the inherently subjective 'jus ad bellum' JWT criteria are sentenced to the never-ending disagreements about a degree of their fulfillment. For example, does the amount of fifty killed people represent a sufficiently 'just cause' for waging a military intervention? Or to what degree was the military intervention really waged as a 'last resort' given the generally unstable and unpredictable developments in any conflict zone? The always present doubts and reluctance of the JWT theorists to identify some military intervention as 'humanitarian' is a logical consequence of the fear that the concept of HMI could be abused to hide a violence that is motivated by the other self-interested objectives. Nicholas Wheeler - one of the main proponents of using the consequentialist approach for evaluating the legitimacy of HMI - recognizes this weakness of the JWT and argues that it is implausible to insist on the existence of a purely 'humanitarian motive' of any military intervention because of the inevitable mix of interests shaping the behavior of the states in the international arena. Instead, he advocates an emphasis on evaluating the legitimacy of HMI using their quantifiable effects on the target state. He claims that as long as the 'motives and means' of the intervention do not undermine the 'just outcome' of the intervention in a form of an improved humanitarian situation; the intervention could be considered 'legitimate', even if its 'motives' were accompanied by some more strategic rationale. ${ }^{247}$ Therefore, it is possible to argue that consequentialism is gaining plausibility from the weakness of the available alternative theories that are too subjective to be utilized for the practical decision-making. Its measurability generates a promising potential for reaching at least some consensus while assessing even such normatively complex concepts as the one of HMI.

Another major positive aspect of the consequentionalist approach follows from its universal appeal. In spite of the fact that many philosophical approaches criticize consequentialism and do not perceive it as a complete theory for all moral judgments per se, most philosophers conceptually accept its logic as an appropriate method in general, acknowledging its undisputed complementary function in the other theories of moral judgments. In fact, virtually all the ethical theories give the consequences of an act a considerable weight while evaluating its moral status. ${ }^{248}$

\footnotetext{
${ }^{247}$ In spite of agreeing with relevance and validity of most of the JWT criteria, Wheeler rejects a necessity of two out of six criteria, leaving only: 'just cause', 'last resort', 'proportionality' and 'probability of success'. See: Wheeler, 2000; or Wheeler \& Bellamy, 2001.

248 Janzekovic, 2006.
} 
What makes consequentialism so universally plausible is, first of all, the basic idea that it is impossible to morally criticize its effort to aspire for the maximalization of an overall welfare. Secondly, there seems to be no good alternative to it, because any ethical approach not based on the human well-being seems to be inhuman. Even those who reject consequentialism are thus forced to admit that a greater good of society outweighs the private interests, or that a proportionate reason can justify doing an act with negative side effects. This general acceptance gives consequentialism an irreducible and indispensable role in assessing morality of any action. ${ }^{249}$ And finally, a fundamental importance of consequentialism to the HMI discourse is also reflected by the appearance of its ethical arguments for and against the legitimacy of HMI in the public debates and the scholarly literature. ${ }^{250}$

\subsubsection{Weaknesses of the consequentialist approach}

In spite of many undisputable advantages of having the consequentialist approach integrated into the theoretical framework of legitimacy of HMI, it has also some major drawbacks. One of its main weaknesses is that it assumes the welfare to be measurable. ${ }^{251}$ This assumption is controversial, because it presupposes existence of a general agreement on the desirable consequences of any action, which is not the case. There is no consensus about what makes the outcome 'good', neither about who should determine the resulting 'goodness' in individual instances. Reaching agreement on such normative accounts is an unrealistic task. Assume, for example, that the society decides to save resources for building a protected house for the mothers exposed to domestic violence by the means of euthanizing your 10year old daughter who is lying in the coma in hospital for two months without any sign of improvement. If a general welfare was evaluated, your daughter really represents a severe economic burden with no guarantee of a positive effect, and the money would surely be much more effectively spent elsewhere. But would you consider such a decision to be moral?

Another major weakness of the consequentialist approach is that our foresight is radically limited. The approach incorrectly presumes that actors direct their actions by a cool logic, have extreme analytical skills, and are able to radically abstract from their emotions, or cultural and historical experience. In fact, it is often difficult to accurately predict outcomes of even the short-term simple actions, because the actors are incapable of performing calculations of all possible scenarios and their respective probabilities. This limitation is growing exponentially while analysing possible consequences of action in such a complex, unstable, and nontransparent political setting as a violent conflict that exposes actors to a pressure of

\footnotetext{
${ }^{249}$ Grisez, 1978.

250 Bellamy, 2004.

251 Anscombe, 2005.
} 
making quick uninformed decisions. Consequentialists recognize this problem, but they offer no adequate solution of how to overcome it. ${ }^{252}$

Additional objection to the consequentialist ethics raises a question, which 'motives and means' are justifiable by which 'outcomes'. Those being abused would say that any means - even the violent ones - to stop the abuse are acceptable, but the international community sill needs to consider the wider ramifications of the use of force. ${ }^{253}$ In relation to the problem of warfare, consequentialists tend to be inclined toward adopting the arguments of 'military necessity', claiming that if a military victory is sought then all methods should be employed to ensure it is gained at a minimum of lost lives, injuries, and lowest possible expenditures. For example, while they would surely agree that using the nuclear weapons in Hiroshima and Nagasaki was a tragic event and that the death of so many civilians was very unfortunate, they would also add that bombing of the civilian centres in Japan was necessary to finish the WWII. They would defend this stance on the moral grounds, claiming that this seemingly 'inhuman' decision to sacrifice so many civilians probably saved in its result much greater amount of lives, since it removed the need of a full invasion of Japan that would lead to the death of many soldiers and to an immense suffering of hundreds of thousands and perhaps millions of Japanese. From the consequentialist perspective, the goal of ending the WWII justified the means of employing the weapons of mass destruction. It is possible to criticize this argument as being based on the 'cold utilitarian calculations', since it only takes into consideration the aggregate human suffering, which justifies the commitment of certain great evils for the sake of promoting an overall good. For these reasons, it is for many scholars unacceptable to adopt a purely consequentialist approach as a basis for evaluating the legitimacy of HMI. They accuse consequentialism of permitting too much, making nothing unthinkable - not even a deliberate killing of the innocent civilians as an instrumental mean to achieve the strategic objective of an overall net positive 'humanitarian outcome'. ${ }^{254}$

Next criticism of using the outcome-oriented consequentialist approach as a sole tool for assessing the legitimacy of HMI stipulates that it could legitimize also such type of military interventions that were carried out purely for the sake of national interests, but which just accidently happened to have a fortunate but unintended 'positive outcome'. There is a broad opposition against allowing that the fortunate indirect consequences could transform a 'wrong' act into a 'just' one. Opponents of this scenario claim that adoption of such a permissive approach could be misused

\footnotetext{
252 Curran, 1979.

253 Blume, Junk, Schöndorf \& Steibel, 2006.

254 Pettit, 1991.
} 
for the legitimization of a massive use of force without any control.255 For these reasons, many scholars seem to be reluctant making an explicitly consequentialist argument in relation to the legitimization of the HMI concept. ${ }^{256}$

Last criticism of the consequentialist approach relates less to its moral validity but rather more to its practical usability as a tool for evaluating the legitimacy of HMI. It points to the fact that the approach enables legitimization of any action only retrospectively, based on the occurred results, but not beforehand.257 Therefore, this approach cannot serve as a prescriptive tool for the political leaders when deciding about the legitimacy of a planned HMI. On the other hand, this fact does not degrade usability of this approach as a tool for evaluating the legitimacy of the historical cases of military interventions for the purposes of learning from the past experience and adjusting the current policies, which is the goal of this study.

\subsection{Adopted theoretical framework in a summary}

This chapter has presented various concerns that have been taken into consideration while constructing the theoretical framework for assessing a legitimacy of HMI that will be used in the later chapters of this study. Due to the highly normative nature of the HMI concept, there has been an effort to construct such a theoretically balanced evaluative framework as possible so as to allow for a transformation of this sensitive issue into the quantified empirical model without losing too much of the theoretical validity. The adopted theoretical framework reflects a controversy between the 'motives and means' versus the 'outcomes' of any activity and their respective relative weights. This controversy divides the scholars regarding the assessment of legitimacy of any action into two major ethical approaches: intrinsicism and consequentialism. This study does not want to take sides in the debate, which of these two approaches has a greater moral validity, since both of them are grounded on the very strong moral arguments that cannot be easily ignored. Instead, this study will utilize strengths of both these perspectives by transforming them into two complementary parts constituting a legitimizing function of HMI. It means that for the purposes of this study, a 'legitimate HMI' will need to possess both the 'humanitarian motives and means' that will be evaluated based on the JWT, as well as to result in a net positive 'humanitarian outcome'. By combining the both opposing ethical approaches, their main weaknesses will become balanced out and mutually controlled for. Making such a sensitive choice of a theoretical framework should help bringing the highly emotive, controversial, and politically charged issue of the use of force in the name

\footnotetext{
${ }^{255}$ Blume, Junk, Schöndorf \& Steibel, 2006.

256 Frost, 1986.

257 Kagan, 1998.
} 
of humanitarianism into a balanced evaluative framework that would enable the applied empirical model to generate theoretically robust results. 


\section{CHAPTER}

\section{QUANTIFICATION OF THE ‘MOTIVES AND MEANS’ OF MILITARY INTERVENTIONS BASED ON THE JWT}

Main foal of this chapter will be to quantify the 'humanitarian motives and means' of military interventions based on the theoretical propositions of the JWT. Quantification of the JWT criteria of 'just cause', 'just intent', 'just authority', 'last resort', 'proportionality' and a reasonable 'probability of success' represents a very complex theoretical assignment that requires major simplifications of the reality that could obviously result in much criticism from many sides. The fact that there are no final true or false solutions to this assignment makes this chapter the most controversial part of the whole study. Nevertheless, however subjective the presented results can be; it is necessary to stress the importance of this empirical assignment for the whole debate about legitimacy of HMI. Existence of the 'humanitarian motives and means' represents a key part of the legitimizing function of HMI. Therefore, a quantification of 'humanitarianism' behind 'motives and means' of military interventions is a necessary prerequisite for enabling an evaluation of HMI on any more systematic basis. The presented model is a very first attempt to quantify this highly normative issue, and should be read and understood as a pioneering work that needs to be further developed and improved. This chapter will begin with description and justification of the variables that were selected to approximate individual JWT criteria. Afterwards, the chapter will present outputs of the factor analysis that was utilized to reduce the amount of variables quantifying the JWT criteria by classifying the input variables into the related components based on their common variation. The final part of this chapter will be devoted to the issue of weighting and index building.

\subsection{Quantification of the JWT criteria - conceptualization}

In spite of the subjective nature of the JWT criteria and the related impossibility of making any definite judgment about their fulfillment; it is possible to at least approximate a degree of their fulfillment based on a systematic and coherent, though simplified evaluation. Therefore, this study has developed six indexes that represent the simplified proxies for each of the JWT criterion. Composition of the below described indexes always reflects various perspectives on how the concept could be evaluated, often including various control indicators weakening a possible 'humanitarianism' behind the military intervention.

\subsection{1. 'Just cause' index ${ }^{258}$}

\footnotetext{
${ }^{258}$ Index approximating JWT criterion of 'just cause' - “jwt_cause”.
} 
Variables used for quantification of the JWT criterion of 'just cause' evaluate the severity of humanitarian crisis in the target state. The more severe the humanitarian crisis is, the greater legitimacy is awarded to a potential intervention for 'humanitarian purposes'. First four variables composing the 'just cause' index are focused on the degree of humanitarian suffering experienced by the local population due to the ongoing violence in the target state. One measure simply counts the scaled number of civilians and combatants killed in the course of battle. ${ }^{259}$ This variable alone would not be sufficient to capture the amount of violent deaths, since it counts only fatalities resulting from the conflicts that involve government as one of the warring parties. It does not cover ethnic massacres that occurred without the coordinated involvement of any governmental forces. Therefore, the second variable was introduced to estimate a scaled number of fatalities resulting from the ongoing genocide or politicide in the target state. ${ }^{260}$ This variable covers all types of coherent actions against the unarmed civilians causing a complete or partial destruction of that people's existence.

Obviously, counting the number of violent deaths is not a sufficient measure of humanitarian suffering. Most of the people do not die as a direct result of violence in the conflict zones; but rather indirectly as a result of starvation, exhaustion and diseases. Therefore, it could be possibly argued that a simple change in crude mortality should have been used instead of the two above listed input variables. Nevertheless, due to the fact that this study attempts to justify the use of military personnel to manage the humanitarian crises, the crisis management should be of such a complicated nature to necessarily require a presence of soldiers to become successful. In the poor but otherwise peaceful countries suffering from hunger; the civilian sector of NGOs and humanitarian aid should be given the stage in managing the humanitarian crisis instead of the military sector. In such cases, deployment of soldiers would not be defendable. Therefore, this study rather put an emphasis on the deaths that could have been prevented only by establishing the security either with a mere demonstration or an actual use of force. From the less battle-related indicators of humanitarian suffering, the 'just cause' index includes only the scaled number of forcibly displaced people who can be reasonably assumed to be exposed to the severe humanitarian conditions due to the violence in the target state. ${ }^{261}$ This indicator was included into the index, since a forcible displacement of the local population is something that can be either prevented or at least logistically better managed with the presence of intervening troops in the war zone. None of the three above listed variables describing the complexity of humanitarian crisis was adjusted by the number of population, since the study

\footnotetext{
259 Variable "battle_deaths_x".

260 Variable "genoc_deaths_x".

261 Variable "refug_x".
} 
attempted to avoid attaching a lower value to the lives lost in the more populous countries. Due to the very imprecise statistics on fatalities and refugees from the conflict zones, the included indicators were constructed by compiling the data from more sources and by scaling them to control for the potential outliers. Furthermore, the imprecise statistics were controlled for by incorporating one additional variable into the model, which evaluates the scaled level of ethnic and civil violence in the target state that is not dependent on the count of fatalities, but rather determines the type of violence in general. ${ }^{262}$

The remaining two variables constituting the 'just cause' index reflect a concern that a mere existence of the internal conflict and the resulting humanitarian crisis should not by itself represent a sufficient reason for an external party to legitimately break a sovereignty of another state. Each country should be given an opportunity to solve its internal matters without an external intrusion; and the legitimacy of the 'cause' for an intervention can be considered 'just' only if the treatment of the humanitarian crisis from inside is improbable. Therefore, a second group of indicators building the 'just cause' index is more structural, looking at the ability and willingness of the local government to manage the humanitarian crisis on its own. There are two possible scenarios that could provide justification for waging a military intervention into a humanitarian crisis taking place in a sovereign country, and which are approximated by the last two variables. The first situation occurs in case that the local government is unable to manage the ongoing crisis by itself. So as to control for this scenario; a variable indicating a joint magnitude of state failure, degree of collapse of democratic institutions, and violence associated with adverse regime transition in the target country was introduced. ${ }^{263}$ The higher the summed scale, the less probable it is that the government is capable of handling the violence on its own without any external assistance. The second scenario takes place when the violence is perpetuated by the government itself, suggesting that the oppressed population has no reasonable prospects of being assisted from inside. In such cases there is typically at least some manifestation of an active domestic rebellion against the government that explicitly demonstrates a dissatisfaction of the local population with the current political situation and a willingness of the people to fight for a change. To control for this possibility, the last variable capturing the most serious manifestation of rebellion of the local population against the government was added.264

\subsection{2. 'Just intent' index ${ }^{265}$}

\footnotetext{
262 Variable "viol_x".

263 Variable "state_fail_x".

264 Variable "rebel_x".

${ }^{265}$ Index approximating JWT criterion of 'just intent' - "jwt_intent".
} 
JWT criterion of 'just intent' aspires to evaluate 'humanitarian motivation' behind the military interventions. Evaluating the intent of the intervener was a problematic assignment, since the declared reasons can be completely different from the real motivation of the actor. Therefore, the real motivation can always be questioned. Bearing this in mind, this study divided the variables building the 'just intent' index into two subgroups - one serving as an indicator of 'humanitarian intent' of the intervener, the other serving as a control group for the other possible economic and political side motives. The first variable composing the index evaluates the existence of a 'just intent' behind the interventions on a binary scale. ${ }^{266}$ Obviously, such a simplified binary indicator needs to be treated only as a very rough approximation of the real motives. To make the argument more persuasive, this binary variable is accompanied by three other indicators of 'just intent'; one indicating a degree of intervener's expected utility from waging an intervention into the target country ${ }^{267}$, and the other two indicating a degree of mutual solidarity symbolized by the existing ties between the intervener and the target state, such as a joint historical relationship ${ }^{268}$ or a similarity of the two states' alliance portfolios 269 .

The second group of variables building the 'just intent' index controls for the possible side motives of the interveners. Its first four variables evaluate the possible economic side motives of the intervener. They establish whether the military intervention attempts to protect own economic or resource interests ${ }^{270}$, whether the target state represents a potentially interesting economic partner for the intervener 271 , whether the economic attractiveness of the target state has an increasing or decreasing potential272; and finally, whether there are some lootable resources present in the target country - such as gemstones or oil ${ }^{273}$. Last four variables in the control group reflect the possible political, strategic and territorial concerns that the intervener could have toward the target state. They indicate whether the intervention has political motives aimed at affecting domestic policies ${ }^{274}$; whether the intervention is aimed at acquisition or retention of the territory, delineation of frontiers, or specification of sovereign status ${ }^{275}$; whether the intervention attempts to restore a regional balance of powers, stability, or is led by

\footnotetext{
266 Variable "hum_int_x".

267 Variable "util_AchB_t_x".

268 Variable "joint_hist_type_x".

${ }^{269}$ Variable "alliance_glob_x".

${ }^{270}$ Variable "econ_int_x".

271 Variable "tot_trade_x".

272 Variable "trade_growth_x".

273 Variables "gemstones_x" and "oil_gas_x".

274 Variable "pol_int_x".

275 Variable "territ_int_x".
} 
the ideological motives ${ }^{276}$; and finally, whether the intervention is aimed at protecting own interests and property inside or outside of the target state ${ }^{277}$. By doing that it is possible to assume that the resulting 'just intent' index represents a balanced estimate of a real 'humanitarian motivation' of the intervener.

\subsection{3. 'Just authority' index ${ }^{278}$}

Quantification of the JWT criterion of 'just authority' was based on two major assumptions. The first assumption stipulates that if the government of the intervening state is 'just'; then giving its officers the right to declare war is reasonable and justifiable. 'Just authority' criterion can thus be approximated by the level of democracy in the intervening country; since the more democratic the country is, the more political support the politicians need from the citizens to be able to wage the military operation. Therefore, the first variable building the index measures a level of democracy in the intervening country. ${ }^{279}$ Nevertheless, evaluation of justice of a military intervention should not be left solely up to the decision of one country, regardless of how democratic the country is. Due to the global implications of HMI authorization, existence of a 'just authority' also requires the international consent with the operation. While examining the presence of such consent, this study assumed that an active involvement of the international organization should increase an authorization of the intervention due to its internationally recognized status. Therefore, two additional variables evaluating the participation of some international organization in the leadership of the intervention were added to the model. While the first one treats all the internationally recognized organizations at equal footing and evaluates merely a participation of whatever international organization ${ }^{280}$; the second variable looks solely on the active participation by the $\mathrm{UN}^{281}$, since the $\mathrm{UN}$ is generally considered to be an institution with the highest authority in matters of evaluating justice of any military endeavor.

The second assumption is set on a similar logic as the first one, but turns the argument the other way round. It focuses on the level of democracy in the target state, arguing that the sovereignty of an undemocratic country could justifiably be questioned under certain extreme circumstances. To put it more specifically, an undemocratic government lacks accountability for its actions or inactions, which could provide an implicit authorization for some external party to correct a potential misbehavior or a lack of action of such an undemocratic government if

\footnotetext{
276 Variable "strat_int_x".

277 Variable "protect_int_x".

${ }^{278}$ Index approximating JWT criterion of 'just authority' - "jwt_auth".

279 Variable "dem_A_x".

280 Variable "io_int_x".

281 Variable "un_int_x".
} 
the consequences entail a humanitarian suffering. Therefore, there were two additional variables added to form the 'just authority' index - one assessing a degree of democracy in the target state ${ }^{282}$; the other one indicating whether the country currently undergoes the process of autocratization. ${ }^{283}$ While the first one is concerned merely with the level of democracy as such, the second one wants to complicate authorization of intervention that would be waged into the target country currently experiencing a process of democratization regardless of the actual level of democracy.

\subsection{4. 'Last resort' index ${ }^{284}$}

JWT criterion of 'last resort' requires that the military intervention is waged only in a last resort, after all the non-violent escalatory acts have been at least honestly considered. Nevertheless, there are practical difficulties in satisfying this otherwise rational criterion when dealing with the humanitarian crises. Requiring the fulfillment of all the prerequisite steps of escalatory tactics of diplomatic or economic interventions usually does not make sense in case of a humanitarian emergency, in which time tends to be of essence. It would be too time consuming to wait for the UN to pass escalatory resolutions and then to wait whether the target country is going to comply with it or not, especially if some big massacre is taking place or many lives are immediately endangered. Therefore, this study quantifies the 'last resort' criterion in a way that an immediate forcible reaction by an external party becomes justified, if the humanitarian situation escalates dramatically in the target state. For this purpose, the study uses the already constructed JWT index of 'just cause' that approximates the severity of humanitarian crisis by capturing its percentage change from the previous to the current year. This means that the same variables that quantify the 'just cause' are also used for the quantification of 'last resort', just in a slightly adjusted way. ${ }^{285}$

\subsection{5. 'Proportionality' index ${ }^{286}$}

Ranking high on 'proportionality' index requires that a military intervention uses forcible means proportionally to its 'humanitarian' objective of bringing a humanitarian relief to the target state. This suggests that the intervention should be waged in a manner that the negative effects of using force should not overweight the improvement of humanitarian situation brought by the presence of the intervening forces, and that the use of force by the intervener should be as minimal as possible just as to stop the violence. To quantify whether individual

\footnotetext{
282 Variable "dem_B_x".

283 Variable "autocratiz_A_x".

${ }^{284}$ Index approximating JWT criterion of 'last resort' - “jwt_last".

285 Input variables for the 'last resort' index measure the number of battle deaths, genocide deaths, displaced population; and measure the level of internal violence, state failure and rebellion.

286 Index approximating JWT criterion of "proportionality' - "jwt_prop".
} 
interventions fulfill this JWT criterion, there were two types of indicators selected that should be weighed against each other. The severity of the existing or the perceived threat is compared to the type of military strategy actually applied by the interveners to manage that threat. By comparing the two, this study attempts to approximate how 'proportional' the intervention is.

One side of the equation constituting the 'proportionality' index approximates the severity of security threat that is to be encountered by the intervener both internally coming from the violent resistance against the intervention from the target state and externally from the possible third-parties intervening into the conflict. Security of the threat is quantified by eight variables. First four variables count the number of lives lost in the course of battle to indicate to what degree are the warring parties willing to shed blood for their goals. Two of them measure an overall number of battle-related deaths. ${ }^{287}$ They do not distinguish among individual interveners and the target state, but count all the fatalities regardless of who was dying and who caused it, as long as the deaths resulted out of violence and occurred in the target state. Additional two variables reflect even more closely the security concerns of the interveners, taking into the consideration a pressure that the politicians sending the troops are exposed to from their domestic electorate. They capture exclusively the battle-related deaths suffered by the interveners. ${ }^{288}$ This information plays a crucial role during selection of an appropriate military strategy, since the interveners need to minimize own losses in the external battle-field so as to maintain a domestic political support for the operation.

Next variable assessing the threat estimates the strength of opposition that the intervener could face in the country. ${ }^{289}$ This estimate combines information about the military capability index of the target state with the intended target of intervention. It distinguishes among the cases, when all the interventions in particular country-year are intended to support government, cases when all support the rebels and cases when the interventions clash in targeting. The estimated value is calculated based on the two simplified assumptions influencing the multiplier effect of the estimate. First of all, the interventions against the government are assumed to result in a greater amount of opposition than the interventions supporting the government against a rebel movement. Secondly, the mixed target interventions are assumed to be the most dangerous type of endeavor for the interveners, since they tend to be most complex and least predictable regarding the behavior of individual conflict actors.

\footnotetext{
287 Variables "battle_deaths_1 1 " and "battle_deaths_2x".

288 Variables "battle_deaths_A1x" and "battle_deaths_A2x".

289 Variable "opp_strength_x".
} 
Last three variables complementing the information about the expected military threat to the intervener bring an international perspective into the consideration. They refer to the potential of the conflict to draw additional third-party actors and to the related increase in complexity of the security threat. First variable is more theoretical, evaluating how vulnerable the target country is to be intervened into in general. ${ }^{290}$ This evaluation is based on the alliance portfolio of the target state and the summed utilities of the other states toward this country. The remaining two variables describe the already existing internalization of the conflict, serving as an indicator of how much the conflict actually draws attention and activity of the other external parties. While the first variable provides a total number of foreign soldiers that intervened into the target country in a given year ${ }^{291}$; the second variable counts the number of intervening countries currently present. 292

The second side of the equation constituting the 'proportionality index' represents a better measurable counterweight to the first, more subjective one. It does not describe how the threat could have been perceived by the interveners; instead, it is composed of three variables describing a robustness of the forcible strategy actually employed by the interveners during the operations. First two variables in this group provide information about a level of violence used by the interveners. One indicates the most violent troop activity employed by any intervener ${ }^{293}$, while the second one takes into consideration a number of interveners and sums the highest degree of violence employed by each of them. ${ }^{294}$ The last variable measures the size of the waged military operation by counting the number of troops sent to the target state. 295

\subsection{6. 'Probability of success' index ${ }^{296}$}

Last JWT criterion of 'probability of success' stipulates that there should be a reasonable hope of success in achieving the desired goals when deciding about waging an intervention or about extension of presence of the troops in some foreign country. Existence of this hope was roughly approximated by two groups of variables in this study. First group of variables derives the expected 'probability of success' from the military strength of the target state. It is assumed that a military intervention waged into a militarily strong country has a higher probability to fail, because the powerful countries have a higher potential of a forcible counterreaction, meaning that the intervention could easily result in a greater bloodshed than it was intended to prevent. First variable in this group is very simple,

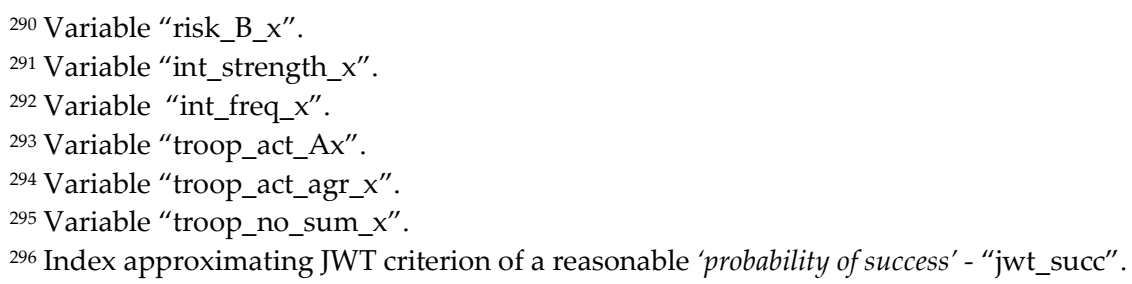


indicating whether the target country does or does not belong among the so-called 'big powers' ${ }^{297}$ Countries denoted as 'big powers' are capable of a relatively quick mobilization of massive military and economic resources, and represent thus a difficult target of any military endeavor. Next variable evaluates a level of the expected military strength of opposition in the target country that is adjusted depending on existence or absence of the mixed targeting. ${ }^{298}$ Following variable relates to the fact that the military strength of the state hosting the conflict diminishes a tendency of the conflict to draw new external parties, which could further destabilize the conflict situation. Therefore, it indicates how the alliance portfolio of the target state leaves it vulnerable or invulnerable to a possible involvement by the other third parties. ${ }^{299}$ Last variable in this group compares the distance data, national military capability data, and regional risk attitude scores between the intervener and the target state; and transforms them into a joint score capturing a general 'probability of success' of their potential mutual military confrontation. ${ }^{300}$

The second group of variables evaluates the 'probability of success' of the intervention in the light of complexity of the conflict and its pervasiveness. First included indicator captures a culture of political violence in the target country, which is quantified as a number of violent years relative to those peaceful ones that the target state experienced since the year 1946 till the year of concern. ${ }^{301}$ Inclusion of this variable is based on an assumption that the more permanently present the violence is in the society, the more difficult it is to succeed in stopping it. Second included indicator is in fact the newly generated 'just cause' index, which is approximating the conflict severity and thus also a difficulty in succeeding in its management. ${ }^{302}$ The very last variable again looks at how much the conflict is drawing attention of the third parties; nevertheless, this time not theoretically in relation to the general characteristics of the target state, but more concretely in relation to the particular conflict. It measures the number of ongoing interventions in the target state and thus a growing number of actors in the field and the related unpredictability of the conflict development. ${ }^{303}$

\subsection{Quantification of the IWT criteria - factor analysis}

So as not to create the JWT indexes arbitrarily a statistical method of exploratory factor analysis (EFA) was used to classify the variables composing individual JWT indexes into the linear clusters with a similar variance and with the attached

\footnotetext{
297 Variable "big_pow_B_x".

298 Variable "opp_strength_x".

299 Variable "risk_B_x".

300 Variable "succ_A_x".

301 Variable "viol_cult_x".

302 Variable "just_cause_x".

${ }^{303}$ Variable "int_freq_x".
} 
weights within a relevant linear function. Factor analysis is a data reduction technique that makes the large amount of data better descriptively and analytically manageable without losing much information about their variance. ${ }^{304}$ It disentangles the complex interrelationships among the variables and reveals a latent structure that causes them to co-vary in space and time. Factor analysis is thus capable of explaining the input manifest variables in terms of a much smaller set of empirically based latent variables, which contain interrelated data with similar characteristics, and which are expressed as relatively simple linear expressions with the assigned respective weights. ${ }^{305}$ Before presenting results of the analysis; it is necessary to discuss several methodological decisions, which could have major impact on the presented findings, and which need to be explicitly acknowledged to allow for a critical evaluation of this research. ${ }^{306}$ Therefore, the following paragraphs will be discussing issues such as a choice of the factor model; data examination; component retention, rotation, and labeling.

\subsubsection{Methodological issues}

\subsubsection{Choice of a factor model - principal component analysis (PCA)}

Modern factor analysis is divided into two different approaches: principal factor analysis (PFA) and principal component analysis (PCA). The major assumption that distinguishes the two relates to the nature of variance of the variables, how they are distributed relative to each other. While PFA defines the patterns of common variation only among the set of variables, ignoring the variation unique to a variable; the PCA patterns all the variation in a set of variables, both common and unique. This study adopted the more common PCA model, which is especially convenient for the purposes of data reduction with the aim to maximize the described variance of the observed variables, which corresponds with the desired goal of this study. PCA takes the manifest data and seeks their linear combinations, the so-called latent variables or components, so that the maximum variance in the manifest variables is extracted. Afterwards, it removes this identified variance $\left(1^{\text {st }}\right.$ component) and seeks a second strongest linear combination ( $2^{\text {nd }}$ component) in the remaining variance, and so on. The number of so extracted components is equal to the number of manifest variables in the analysis. The resulting components presented in this study are orthogonal, uncorrelated, and they analyze the total variance - both common and unique. ${ }^{307}$

\footnotetext{
304 Among the competing techniques belong, for example, a cluster analysis or a multidimensional scaling. See: Rummel, 1970.

${ }^{305}$ It is important not to stretch the interpretation of factor analysis behind of what it is capable of doing. The below presented results are thought of as heuristics rather than being interpreted in absolute terms. 306 See: Weiss, 1976; or MacCallum, 1983.

${ }^{307}$ For a more detailed description of factor analysis, see, for example: Tucker, Koopman \& Linn, 1969; or Truxillo, 2003.
} 
In spite of a general acceptance of validity of the PCA model by most of the statisticians ${ }^{308}$; as in case of any other statistical model, appropriateness of the PCA for generating the JWT indexes could be questioned. ${ }^{309}$ The major critique of the PCA is directed to the fact that component model does not differentiate between common, unique and error variance. The original set of manifest variables is just transformed into a new set of latent variables, which are linear composites of the original ones. Due to this fact, PCA is criticized for producing merely the convenient groupings of variables rather than the theoretical constructs. ${ }^{310}$ However, this criticism can be opposed with a counterargument that PCA does not base its conclusions on an assumption that the causal model actually underlies the data. ${ }^{311}$

\subsubsection{Data examination}

Having chosen a statistical model, it was necessary to review whether the model fits the capabilities of the data. The main rule regarding the appropriateness of the data for PCA is that the stability of component loadings is a direct function of the sample size. ${ }^{312}$ Without a sufficiently large data sample, PCA might produce seemingly 'meaningful' components even from the randomly generated numbers, based on a mere sampling variability. ${ }^{313}$ In spite of an existing agreement that a larger sample size is considered desirable for any type of factor analysis; there is no agreement about the minimally required observations-to-variables ratio. For example, while one study suggests five observations per variable ${ }^{314}$, another study recommends a minimal ratio of ten observations per variable. ${ }^{315}$ Below presented table that lists number of observations and variables used for the quantification of individual JWT indexes in this study shows that data samples are sufficiently large, satisfying even the strictest requirements.

\footnotetext{
${ }^{308}$ PCA is a generally accepted statistical tool. Some statisticians claim that there is almost no difference between PFA and PCA, or that PCA is preferable. (See, for example: Arrindell \& Ende, 1985;

Schonemann, 1990; Steiger, 1990; Velicer \& Jackson, 1990.) For example, a survey in PsycINFO found that out of over 1700 studies using some form of explanatory factor analysis in years 2003 and 2004, more than half of the studies applied PCA method. See: Costello \& Osborne, 2005.

${ }^{309}$ For a criticism of PCA, see, for example: MacCallum \& Tucker, 1991; Widaman, 1993; or Floyd \& Widaman, 1995.

310 See: Hakstian \& Muller,1973; or Kim \& Mueller, 1978.

311 Kim \& Mueller, 1978.

312 Arrindell \& Ende, 1985.

313 Cliff \& Pennell, 1967.

314 Gorsuch, 1974.

${ }^{315}$ Nunnally, 1978.
} 
Table 1: Variables-to-observations ratio

\begin{tabular}{|c|c|c|}
\hline JWT CRITERIA & Number of variables & Number of observations \\
\hline Just cause & 6 & 12000 \\
\hline Just intent & 12 & 1695 \\
\hline Just authority & 5 & 1695 \\
\hline Last resort & 6 & 12000 \\
\hline Proportionality & 11 & 1695 \\
\hline Probability of success & 7 & 1695 \\
\hline
\end{tabular}

Even though, most of the data requirements were solved by the fact that the tested samples of observations are relatively large; neither the large data samples must guarantee valid components. Component invalidity can be caused also by an inconvenient input data distribution. For example, categorical variables with similar splits tend to correlate with each other regardless of their content. ${ }^{316}$ The most problematic in this sense are the dichtonomous variables. Regardless of the sample size, dichtonomous data often tend to yield the loaded components even for the randomly generated data. ${ }^{317}$ For these reasons, the input data are rarely structured into the clearly cut scales or dichtonomous variables in this study. Instead, observations in most of the variables were divided by a number of interveners in particular country-year, making thus the categories more fluid. In addition to that, in case that some higher underlying metric correlation was discovered between a pair of input variables; it is discussed whether the discovered correlation is defendable on the theoretical grounds in the technical appendix of this study.

\subsubsection{Number of the retained components}

The outcome of PCA heavily depends on how many principal components are retained prior to the rotation. A general theory states that only the components accounting for a maximal variance should be retained and that the rest should be dropped. Nevertheless, there are no precise variance thresholds for the component retention, and the researchers use various rules-of-thumb that often lead to the different solutions. ${ }^{318}$ So as to identify a correct number of components to be retained, this study used two methods. First of them was the most typically used Kaiser test ${ }^{319}$, which retains all the components explaining more than 1.0 of variance (eigenvalues $\lambda>1.0$ ). ${ }^{320}$ A rationale behind this threshold is that since PCA

\footnotetext{
316 Gorsuch, 1983.

317 Kim \& Mueller, 1978.

318 Humphreys \& Montanelli, 1974.

319 Kaiser, 1960.

${ }^{320}$ Eigenvalue is not a percent of variance but rather a measure of amount of variance in relation to the total.
} 
standardizes each variable to have a mean of 0.0 and a standard deviation of \pm 1.0 , variance of each variable ends up as being 1.0. It is thus logical that a useful component should account for more than 1.0 unit of variance; otherwise, the extracted component would explain no more variance than a single variable, which would contradict the PCA goal of explaining multiple variables by a lesser amount of components. Therefore, the Kaiser test stipulates that the components contributing less than 1.0 to the explanation of variance in the variables may be ignored as redundant. ${ }^{321}$

Second method used in this analysis for the purpose of assessing the number of components to retain took into consideration the main criticism of the Kaiser test for its tendency to overestimate the true number of components. ${ }^{322}$ Therefore, so as to ensure a correct decision about the retained number of components; the study applied an additional control Cattell scree test ${ }^{323}$ that retains components located above the point of inflection on a plot of eigenvalues ordered by a diminishing size. Cattell scree test plots the components on the $X$ axis and the corresponding eigenvalues on the $\mathrm{Y}$ axis. While moving toward the later components, the eigenvalues drop. When the curve makes an elbow toward a less steep decline, the test suggests that all further components including the one starting the elbow should be dropped. The major weakness of this method is that picking the right elbow is again a subjective decision, since there are often more of them on the curve. ${ }^{324}$

This study used both these tests to complement each other. In case that the number of factors suggested by the Kaiser test was different from the number suggested by the Cattell test; the number of components was set manually and the analysis was run to test both possibilities. After component rotation, the loading tables representing both possibilities were compared and the one with a 'cleaner' component structure - loadings above 0.40 , no or few 'cross-loadings' 325 , and no components with fewer than two variables - was retained as having the best fit to the data. In addition to that, before dropping any controversial component; the study tested its correlation with the dependent variables that are to be used in the subsequent analysis for assessing the 'humanitarian' effects of military interventions. Even if the component seemed to be of a lesser importance; the component was retained, if it was highly correlated with any of the dependent variables.

\footnotetext{
${ }^{321}$ For a more detailed debate about the Kaiser test, see: Weiss, 1976; or Costello \& Osborne, 2005.

${ }^{322}$ In spite of the fact that the evidence suggests that it is better to overestimate rather than underestimate the number of factors; Kaiser test is sometimes criticized for this tendency. See: Guertin, Guertin \& Ware, 1981; Velicer \& Jackson, 1990; or Lance, Butts \& Michels, 2006.

${ }^{323}$ Cattell, 1966.

324 See: Zwick \& Velicer, 1982.

${ }^{325} \mathrm{~A}$ 'cross-loading' item is an item that loads at 0.32 or higher on two or more components.
} 
Table 2: Results of Kaiser and Catell tests and the related decisions about component retention

\begin{tabular}{|c|c|c|c|c|}
\hline JWT CRITERIA & $\begin{array}{c}\text { Kaiser } \\
\text { test }\end{array}$ & Cattell scree test & $\begin{array}{c}\text { Number of } \\
\text { components } \\
\text { retained }\end{array}$ & $\begin{array}{c}\text { Cummulative } \\
\text { variance } \\
\text { explained }\end{array}$ \\
\hline Just cause & 1 & 1 & 1 & $\mathbf{6 0 , 1 9 \%}$ \\
\hline Just intent & 4 & unclear result - 4 possible & 4 & $\mathbf{5 8 , \mathbf { 1 8 } \%}$ \\
\hline Just authority & 2 & 1 & 2 - cleaner structure & $\mathbf{6 9 , 6 4 \%}$ \\
\hline Last resort & 1 & 1 & 1 & $\mathbf{6 0 , 1 9 \%}$ \\
\hline Proportionality & 3 & 3 & 3 & $\mathbf{6 2 , 4 6 \%}$ \\
\hline Probability of success & 2 & 2 & 2 & $\mathbf{5 1 , 1 6 \%}$ \\
\hline
\end{tabular}

\subsubsection{Method of rotation - orthogonal}

PCA method produces components in more possible forms. Due to the fact that the simplest form of the unrotated PCA solutions tends to load on multiple components, and is thus hard to be interpreted; the components are usually rotated until the distinct clusters of interrelated variables are defined. Rotation is a linear data transformation that changes the loadings and the eigenvalues of individual components, and produces a basis for imputing their weights and labels. In its result, component rotation facilitates interpretation, meaningfulness, reliability and reproducibility of the PCA analysis. ${ }^{326}$ There are two main types of component rotation: orthogonal ${ }^{327}$ and oblique ${ }^{328}$. While the orthogonal rotation produces uncorrelated components; the oblique rotation produces both correlated and uncorrelated patterns of variables. ${ }^{329}$

For the reasons of greater conceptual clarity and better suitability for a subsequent regression analysis, this study gave a preference to the orthogonal method that produces statistically uncorrelated components. It rotates the total set of components as a rigid frame around the origin until the system becomes maximally aligned with the separate clusters of variables. The more correlated the separate clusters are, the less capable the orthogonal rotation is to identify them. The adopted orthogonal approach has two major advantages for the realization of the aims of this study. First of all, it is suitable for the purposes of index building, since the generated component loadings are equivalent to the correlations between

\footnotetext{
326 Weiss, 1976.

327 Orthogonal rotation means a 90 degree angle rotation.

328 Oblique rotation means other than a 90 degree angle rotation.

${ }^{329}$ If correlation of oblique rotated factors is 0 , the patterns are in fact orthogonal (= uncorrelated to each other). See: Nunnally, 1978.
} 
manifest variables and components. The second main advantage of the orthogonal approach is that by producing the statistically uncorrelated components, it transforms the data in a way to meet the assumptions of a multiple regression technique, which is the method to be used to test the relevance of individual JWT criteria for the 'humanitarian outcomes' of military interventions in the following chapter.

Nevertheless, the study cannot completely ignore the theoretical weakness of the orthogonal approach that arises from the fact that behavior in the social sciences can rarely be described as being partitioned into the clusters that function independently of one another. Therefore, relying merely on the orthogonal rotation results could result in a loss of valuable information. Taking this potential weakness into consideration, in spite of a methodological decision to draw the component loadings from the orthogonally rotated solutions; a control oblique rotation was always run to check the effect of letting the rotated components being correlated and thus to better reflect the correlated realities of the real world. In case that the preferred orthogonal rotation discovered some cross-loadings of the input variables over more components, assigning the variable to a correct pattern was reconciled or verified based on the results of oblique rotation.

\subsubsection{Construction and labeling of the components}

In the final step of PCA analysis, the generated component loadings, which are in fact the estimated weights for each variable building the component, were used to calculate the component scores. The component scores were obtained by multiplying each input variable by its respective component loading and by summing the results for the component together. The only remaining task was to assign the identified components the adequate labels. Labeling of the identified components is a highly subjective process that depends on the earlier methodological choices, and that is influenced by the expectations of the researchers. 330 So as to minimize subjectivity of the labeling process; it is often recommended to adopt the symbolic labels without any substantive meaning on their own, in spite of the awareness that such a labeling would become less intuitive for the reader and would complicate the orientation in the presented results. This study adopted the more controversial approach of assigning the identified components the descriptive labels, while risking that they could have different connotations for different people and that they might potentially result in adding an unintended surplus meaning. The selected labels reflect the joint characteristics of the variables constituting each component. In spite of their obvious subjectivity; this choice enables a better communication of the research

330 Comrey, 1978. 
findings, which was a preferable option for this study given the complexity of the JWT.

\subsubsection{Interpretation of the results}

Having discussed the most important methodological decisions, it is possible to present the results of the carried out PCA analysis. While the more detailed output of the analysis can be found in the technical appendix, this chapter presents just the summarizing tables for each of the JWT criterion. Rows in the tables list the input manifest variables, and the columns of the tables show the generated components or the so called latent variables that explain as much of the variance in the manifest variables as possible. The colored cells are the component loadings, which show the correlation coefficients between the manifest variables and the retained components. There are various arbitrarily set rules for evaluating the importance of the manifest variables for the component that vary by the research context. Ideally, the goal is to have all the main component loadings greater than 0.70 ; since such a loading threshold corresponds to about half of the variance in the variable being explained. However, this rule is generally considered to be too strict when dealing with the field of social sciences. The common social science practice generally uses a minimum cut-off loading of $0.30,0.35$ or 0.40 , depending on the subject being researched. 331 This study adopted a relatively strict evaluation framework for the social sciences standards, where a loading is considered to be 'weak' if being lower than 0.4 ; it is considered to be 'moderate' if being in the range between 0.4 and 0.6 ; and is considered to be 'strong' if being higher than 0.6. The results of the analysis indicate that if evaluated based on the above described scale; out of 47 input variables approximating the JWT criteria, 37 load strongly, 10 moderately, and 0 weakly on the component models. The presented models show very low number of cross-loadings above 0.30 , none of which exceeds 0.40 .

Apart from the columns representing individual retained components, the below presented tables show also two additional columns indicating communality and uniqueness for the each manifest variable row. Communality counts the percentage of variance in each manifest variable explained by all the components jointly, and may be interpreted as a reliability of the variable in the component model. ${ }^{332}$ Low communality suggests that the component model is not working well for the variable and that the variable should be possibly removed from the model. Ideally, communality should be higher than 0.3 , but lower than 1.0. Communality in a range between 0.2 and 0.3 is lower, but it may be still meaningful if the variable is contributing to a well-defined factor. Communality exceeding 1.0 suggests existence of a spurious solution caused by retaining of too

\footnotetext{
${ }^{331}$ Hair, Anderson, Tatham, \& Black, 1998; or Raubenheimer, 2004.

332 Communality (h2) is computed as a sum of the squared component loadings for the variable row. Uniqueness of a variable is calculated as 1-h2.
} 
many or too few components. The presented component models for the JWT criteria show that no input variable has a communality below 0.2 , and just a couple of them falls within the lowly performing range of $0.2-0.3$. Total communality percentage presented in the right bottom part of the table shows the joint variance in all the variables accounted for by each component. ${ }^{333}$ The average percentage explained by the six component models describing individual JWT criteria is $60.31 \%$.

\subsubsection{Summary tables of the generated components constituting the IWT indexes}

Table 3: Assessment of strength of the generated component loadings

\begin{tabular}{|l|l|}
\hline$* * *$ & 'strong' loadings $(|x|>0,6)$ \\
\hline$* *$ & 'moderate' loadings $(0,4 \leq|x| \leq 0,6)$ \\
\hline$*$ & 'weak' loadings $(|x|<0,4)$ \\
\hline
\end{tabular}

Table 4: PCA output - 'just cause' index ${ }^{334}$

\begin{tabular}{|c|c|c|c|}
\hline \multicolumn{4}{|c|}{ JUST CAUSE } \\
\hline Variables & C1: Just cause index & Communality & Uniqueness \\
\hline battle_deaths_x & $* * * \quad 0,8597$ & 0,7391 & 0,2609 \\
\hline genoc_deaths_x & ** $\quad 0,5870$ & 0,3446 & 0,6554 \\
\hline displaced_pop_x & $* * * \quad 0,6417$ & 0,4118 & 0,5882 \\
\hline viol_x & $* * * \quad 0,9115$ & 0,8308 & 0,1693 \\
\hline state_fail_x & $* * * \quad 0,8039$ & 0,6463 & 0,3537 \\
\hline rebel_x & $* * * \quad 0,7992$ & 0,6387 & 0,3612 \\
\hline Total $=60,19 \%$ & & 0,6019 & \\
\hline
\end{tabular}

Table 5: PCA output - 'just intent' index

\begin{tabular}{|c|c|c|c|c|c|c|}
\hline \multicolumn{7}{|c|}{ JUST INTENT } \\
\hline Variables & $\begin{array}{l}\text { C1: Hum. } \\
\text { motivation }\end{array}$ & $\begin{array}{c}\text { C2: } \\
\text { Economic } \\
\text { motivation }\end{array}$ & $\begin{array}{c}\text { C3: } \\
\text { Political } \\
\text { motivation } \\
\text { I }\end{array}$ & $\begin{array}{c}\text { C4: } \\
\text { Political } \\
\text { motivation } \\
\text { II }\end{array}$ & Communality & Uniqueness \\
\hline hum_int_x & *** $-0,8016$ & $-0,0969$ & 0,0847 & $-0,1795$ & 0,6913 & 0,3087 \\
\hline util_achb_x & *** $\quad 0,6771$ & $-0,0544$ & 0,1587 & 0,1669 & 0,5145 & 0,4855 \\
\hline joint_hist_x & ** 0,5900 & $-0,1737$ & 0,3804 & $-0,1344$ & 0,5410 & 0,4590 \\
\hline alliance_x & *** $-0,8710$ & 0,0239 & 0,0483 & 0,1358 & 0,7800 & 0,2200 \\
\hline tot_trade_x & $-0,0350$ & *** 0,8312 & $-0,0479$ & $-0,0840$ & 0,7015 & 0,2985 \\
\hline
\end{tabular}

333 Total percent of variance is calculated as a sum of communalities for each manifest variable that is divided by the number of variables. (Number of variables equals the sum of their variances, since the variance of a standardized variable is 1.0.)

334 'Just cause' index was used to construct the 'last resort' index by calculating a yearly change in the 'just cause' index from the previous to the current year. 


\begin{tabular}{|l|r|rr|r|r|r|r|} 
oil_gas_x & $-0,0302$ & $* * *$ & 0,8078 & 0,1825 & 0,0510 & 0,6894 & 0,3106 \\
\hline gemstones_x & 0,0633 & $* *$ & 0,4617 & $-0,1487$ & $-0,0364$ & 0,2406 & 0,7594 \\
\hline trade_growth_x & 0,0959 & $* *$ & 0,4313 & $-0,1289$ & $-0,1606$ & 0,2376 & 0,7624 \\
\hline pol_int_x & $-0,1134$ & $-0,0546$ & $* * *$ & 0,7867 & 0,0769 & 0,6407 & 0,3593 \\
\hline territ_int_x & 0,1914 & 0,2632 & $* * *$ & 0,6778 & 0,0275 & 0,5661 & 0,4339 \\
\hline strat_int_x & 0,4212 & $-0,1099$ & $-0,3293$ & $* *$ & 0,5714 & 0,6244 & 0,3756 \\
\hline protect_int_x & $-0,0588$ & $-0,0112$ & 0,1310 & $* * * 0,8566$ & 0,7545 & 0,2455 \\
\hline Total =58,18\% & & & & & & 0,5818 & \\
\hline
\end{tabular}

Table 6: PCA output - 'just authority' index

\begin{tabular}{|c|c|c|c|c|}
\hline \multicolumn{5}{|c|}{ JUST AUTHORITY } \\
\hline Variables & $\begin{array}{l}\text { C1: Legitimacy of } \\
\text { intervener }\end{array}$ & $\begin{array}{c}\text { C2: Absence of } \\
\text { legitimacy of target state }\end{array}$ & Communality & Uniqueness \\
\hline dem_a_x & *** 0,7426 & $-0,0972$ & 0,5609 & 0,4391 \\
\hline io_int_x & $* * * \quad 0,9404$ & $-0,0383$ & 0,8858 & 0,1142 \\
\hline un_int_x & *** 0,9134 & $-0,0141$ & 0,8345 & 0,1655 \\
\hline dem_b_x & 0,2635 & $* * * \quad-0,6577$ & 0,5020 & 0,4980 \\
\hline aurocratization_x & 0,0674 & *** 0,8332 & 0,6988 & 0,3012 \\
\hline Total $=69,64 \%$ & & & 0,6964 & \\
\hline
\end{tabular}

Table 7: PCA output - 'last resort' index

\section{LAST RESORT}

'Last resort' index is calculated as a yearly change in the 'just cause' index.

Table 8: PCA output - 'proportionality' index

\begin{tabular}{|c|c|c|c|c|c|}
\hline \multicolumn{6}{|c|}{ PROPORTIONALITY } \\
\hline Variables & $\begin{array}{l}\text { C1: Security } \\
\text { threat in } \\
\text { target state I }\end{array}$ & $\begin{array}{l}\text { C2: Force used } \\
\text { by intervener }\end{array}$ & $\begin{array}{c}\text { C3: Security } \\
\text { threat in target } \\
\text { state II }\end{array}$ & Communality & Uniqueness \\
\hline battle_deaths_1x & $* * * \quad 0,7027$ & 0,0152 & $-0,1092$ & 0,5059 & 0,4941 \\
\hline battle_deaths_2x & $* * * \quad 0,6234$ & 0,3424 & $-0,1189$ & 0,5200 & 0,4800 \\
\hline battle_deaths_a1x & *** 0,7997 & 0,0031 & $-0,0714$ & 0,6446 & 0,3554 \\
\hline battle_deaths_a2x & $* * * \quad 0,6445$ & 0,3745 & $-0,1194$ & 0,5699 & 0,4301 \\
\hline int_strength_x & *** 0,8508 & 0,1560 & 0,1431 & 0,7687 & 0,2314 \\
\hline int_freq_x & *** 0,8381 & $-0,0725$ & 0,1208 & 0,7223 & 0,2777 \\
\hline troop_act_x & $-0,0770$ & $* * * \quad 0,8758$ & 0,0350 & 0,7742 & 0,2258 \\
\hline troop_act_agr_x & 0,1769 & *** 0,8847 & 0,0616 & 0,8178 & 0,1822 \\
\hline troop_no_ax & 0,2684 & ** 0,4702 & 0,1337 & 0,3110 & 0,6890 \\
\hline opp_strength_x & $-0,0272$ & $-0,0033$ & *** $\quad-0,7833$ & 0,6143 & 0,3857 \\
\hline risk_b_x & 0,0192 & 0,1212 & *** 0,7789 & 0,6217 & 0,3783 \\
\hline Total $=62,46 \%$ & & & & 0,6246 & \\
\hline
\end{tabular}


Table 9: PCA output - 'probability of success' index

\begin{tabular}{|c|c|c|c|c|}
\hline \multicolumn{5}{|c|}{ PROBABILITY OF SUCCESS } \\
\hline Variables & $\begin{array}{l}\text { C1: Strength of the } \\
\text { target state }\end{array}$ & $\begin{array}{l}\text { C2: Conflict } \\
\text { complexity }\end{array}$ & Communality & Uniqueness \\
\hline succ_a_x & ** $-0,4573$ & $-0,0426$ & 0,2110 & 0,7890 \\
\hline risk_b_x & ** $\quad-0,5384$ & $-0,1359$ & 0,3083 & 0,6917 \\
\hline big_power_b_x & $* * * \quad 0,8498$ & $-0,0147$ & 0,7225 & 0,2775 \\
\hline opp_strength_x & *** 0,8821 & 0,0755 & 0,7838 & 0,2162 \\
\hline viol_cult_x & 0,1693 & *** 0,7781 & 0,6340 & 0,3660 \\
\hline int_freq_x & $-0,1614$ & $* * \quad 0,4437$ & 0,2229 & 0,7771 \\
\hline just_cause_x & $-0,0202$ & *** 0,8359 & 0,6991 & 0,3009 \\
\hline Total $=51,17 \%$ & & & 0,5117 & \\
\hline
\end{tabular}

\subsection{Weighting of the components and of the individual JWT criteria}

Having identified how the data quantifying individual JWT criteria are interrelated and having simplified their complexity by grouping the input variables with similar underlying functions into the labeled components ${ }^{335}$; the study needed to assess a relative theoretical importance of those components within the individual JWT criteria to be able to assign them respective weights. Due to the fact that this task required many normative decisions; the process of weighting was carried out in a way to allow for a ready-made possibility to readjust the weights based on an alternative perspective, accepting thus a possibility that the adopted decisions could be opposed by different researchers using the data in the future. To enable this flexibility, all the generated components are kept both in their unadjusted as well as the unadjusted forms in the data compilation that is presented in the last chapter of this study, and each change to the data for the distributional purposes is described in detail in the technical appendix of this chapter.

While attaching particular weights to the components, this study was drawing inspiration from the current academic debate about the JWT criteria, looking at how the academic texts interpret a relevance of different aspects of the criteria for the legitimacy of HMI and what are the existing criticisms of these aspects. After selecting the appropriate weights for the components and after transforming the scores accordingly; the components constituting individual JWT indexes were merged together. The process of merging of the weighted components had to take into consideration that not all of the generated components are of a complementary nature, that some of the components have legitimizing and some delegitimizing effect on the HMI. Therefore, the components increasing the 'humanitarianism'

\footnotetext{
335 Components: “just_cause_x", “hum_motive_x", “econ_motive_x", "pol_motive_1x", "pol_motive_2x", "legit_a_x", "legit_b_x", "last_resort_x", "threat_1x", "force_used_x", "threat_2x", "strength_b_x", and "conf_compex_x".
} 
behind 'motives and means' of the military operations were summed together; while the negative components controlling for the possible side 'motives' and inappropriate 'means' were subtracted from the final scores. ${ }^{336}$ The resulting quantified indexes approximate individual JWT criteria, with 0 indicating the lowest possible score of 'humanitarian motives and means' that the military operation can possibly achieve on each criterion. ${ }^{337}$

After generating indexes for all the JWT criteria, it was necessary to create an aggregate JWT index that would be capable of determining an overall 'humanitarianism' behind 'motives and means' of each military intervention. Therefore, the next stage of weighting required that the quantified JWT criteria were also assigned the weights based on their relative importance within the JWT as a whole. The Theory itself does not mention much about the differences in relevance of the six JWT criteria, not directly indicating which one is more and which less crucial for the legitimizing effect. The only indication is that the criteria of 'jus ad bellum' initially included only the first three criteria of 'just cause', 'just intent' and 'just authority', and that the remaining ones were added just later on so as to further develop the Theory. This very basic fact allows a reasonable assumption that the first three criteria represent the basic stones for provision of legitimacy to the military operations.

The underlying assumption of a greater relevance of the first three criteria is confirmed by the scholarly debate about the applicability of JWT for the evaluation of legitimacy of HMI. In fact, most of the existing studies stress the importance of the first three criteria. The most privileged position within the Theory is typically assigned to the criterion of 'just intent'. Its primacy follows from a general definition of the HMI concept, in which 'humanitarian intent' is a decisive aspect in distinguishing the HMI from the other types of aggressive military interventions. Therefore, it is primarily the 'just intent' that is being scrutinized and only then the remaining JWT criteria. ${ }^{338}$ The second position in ranking the three basic JWT criteria was assigned to the criterion of 'just cause', since the criterion of 'just authority' is sometimes being questioned on the practical grounds of lack of a generally acknowledged authority capable of effectively proving and awarding the legitimate status to the military operations. Taking all these aspects into consideration, the JWT criteria were attached weights in the following order of a decreasing importance: 'just intent' (30\%); 'just cause' (25\%); 'just authority' (15\%); and then last three criteria of 'last resort' (10\%), 'proportionality' $(10 \%)$, and a reasonable 'probability of success' $(10 \%)$. After recalculating the scores for the

\footnotetext{
${ }^{336}$ Control components with the negative weights: "econ_motive_x", "pol_motive_1 $1 x^{\prime \prime}$, "pol_motive_2x", "force_used_x", "strength_b_x", and "conf_compex_x".

337 Variables approximating the JWT criteria: "jwt_cause_x", "jwt_intent_x", "jwt_auth_x", "jwt_last_x", "jwt_prop_x" and "jwt_succ_x".

${ }^{338}$ Coady, 2002.
} 
individual JWT criteria based on the adopted weights; the scores were summed together to construct the final aggregate index approximating the quantified 'humanitarian motives and means' based on the propositions of the JWT.

Table 10: Quantified JWT in a summary (input variables, generated components, attached weights)

\begin{tabular}{|c|c|c|c|}
\hline \multicolumn{4}{|c|}{ OVERVIEW OF THE QUANTIFIED JWT CRITERIA } \\
\hline \multicolumn{2}{|c|}{ INPUT VARIABLES } & \multicolumn{2}{|c|}{ OUTCOME COMPONENTS } \\
\hline \multicolumn{4}{|c|}{ JUST CAUSE INDEX (+25\%) } \\
\hline Battle deaths - target state & battle_deaths_x & \multirow{6}{*}{$\begin{array}{l}\text { Just cause index } \\
\qquad(+100 \%)\end{array}$} & \multirow{6}{*}{ just_cause_x } \\
\hline Genocide deaths - target state & genoc_deaths_x & & \\
\hline Displaced population - target state & displaced_pop_x & & \\
\hline Internal violence - target state & viol_x & & \\
\hline State failure - target state & state_fail_x & & \\
\hline Rebellion - target state & rebel_x & & \\
\hline \multicolumn{4}{|c|}{ JUST INTENT INDEX $(+30 \%)$} \\
\hline Humanitarian intervention & hum_int_x & \multirow{4}{*}{$\begin{array}{c}\text { Humanitarian } \\
\text { motivation } \\
(+\mathbf{1 0 0} \%)\end{array}$} & \multirow{4}{*}{ hum_motive_ג } \\
\hline Intervener's utility & util_achb_x & & \\
\hline Joint history & joint_hist_x & & \\
\hline Alliance & alliance_x & & \\
\hline Trade importance - target state & tot_trade_x & \multirow{4}{*}{$\begin{array}{c}\text { Economic } \\
\text { motivation (- } \\
30 \%)\end{array}$} & \multirow{4}{*}{ econ_motive_x } \\
\hline Oil and gas - target state & oil_gas_x & & \\
\hline Gemstones - target state & gemstones_x & & \\
\hline Trade growth - target state & trade_growth_x & & \\
\hline Political intervention & pol_int_x & \multirow{2}{*}{$\begin{array}{c}\text { Political } \\
\text { motivation I (- } \\
10 \%)\end{array}$} & \multirow[b]{2}{*}{ pol_motive_1x } \\
\hline Territorial intervention & territ_int_x & & \\
\hline Strategic intervention & strat_int_x & \multirow{2}{*}{\begin{tabular}{|c|} 
Political \\
motivation II (- \\
$10 \%)$
\end{tabular}} & \multirow[b]{2}{*}{ pol_motive_2x } \\
\hline Protective intervention & protect_int_x & & \\
\hline \multicolumn{4}{|c|}{ JUST AUTHORITY INDEX (+15\%) } \\
\hline Democracy level - intervener & dem_a_x & \multirow{3}{*}{$\begin{array}{c}\text { Legitimacy of } \\
\text { intervner }(+60 \%)\end{array}$} & \multirow{3}{*}{ legit_a_x } \\
\hline International organization leadership & io_int_x & & \\
\hline UN leadership & un_int_x & & \\
\hline Democracy level - target state & $d e m \_b \_x$ & \multirow{2}{*}{$\begin{array}{c}\text { Lack of } \\
\text { legitimacy of } \\
\text { target state } \\
(+40 \%)\end{array}$} & \multirow[b]{2}{*}{ legit_b_x } \\
\hline Autocratization - target state & aurocratization_x & & \\
\hline \multicolumn{4}{|c|}{ LAST RESORT INDEX $(+10 \%)$} \\
\hline Battle deaths - target state & battle_deaths_x & \multirow{6}{*}{$\begin{array}{l}\text { Last resort index } \\
(+\mathbf{1 0 0 \% )}\end{array}$} & \multirow{6}{*}{ last_resort_x } \\
\hline Genocide deaths - target state & genoc_deaths_x & & \\
\hline Displaced population - target state & displaced_pop_x & & \\
\hline Internal violence - target state & viol_x & & \\
\hline State failure - target state & state_fail_x & & \\
\hline Rebellion - target state & rebel_x & & \\
\hline \multicolumn{4}{|c|}{ PROPORTIONALITY INDEX $(+10 \%)$} \\
\hline
\end{tabular}




\begin{tabular}{|c|c|c|c|}
\hline Aggregate battle deaths on both sides I & battle_deaths_1x & \multirow{6}{*}{$\begin{array}{c}\text { Security threat } \\
\text { in target state I } \\
(+70 \%)\end{array}$} & \multirow{6}{*}{ threat_1x } \\
\hline Aggregate battle deaths on both sides II & battle_deaths_2x & & \\
\hline Battle deaths - interveners I & battle_deaths_a1x & & \\
\hline Battle deaths - interveners II & battle_deaths_a2x & & \\
\hline International troops strength - target state & int_strength_x & & \\
\hline Intervention frequency - target state & int_freq_x & & \\
\hline Most violent troop activity - intervener & troop_act_x & \multirow{3}{*}{$\begin{array}{c}\text { Force used by } \\
\text { intervener (- } \\
50 \%)\end{array}$} & \multirow{3}{*}{ force_used_x } \\
\hline $\begin{array}{l}\text { Aggregate violent troop activity - } \\
\text { interveners }\end{array}$ & troop_act_agr_x & & \\
\hline Troop number - interveners & troop_no_ax & & \\
\hline $\begin{array}{c}\text { Military strength of opposition - target } \\
\text { state }\end{array}$ & $o p p \_s t r e n g t h \_x$ & \multirow{2}{*}{$\begin{array}{c}\text { Security threat } \\
\text { in target state II } \\
(+30 \%)\end{array}$} & \multirow[t]{2}{*}{ threat_2x } \\
\hline Alliance risk score - target state & risk_b_x & & \\
\hline \multicolumn{4}{|c|}{ PROBABILITY OF SUCCESS INDEX $(+10 \%)$} \\
\hline Probability of success - intervener & succ_a_x & \multirow{4}{*}{$\begin{array}{c}\text { Strength of the } \\
\text { target state (- } \\
60 \%)\end{array}$} & \multirow{4}{*}{ strength_b_x } \\
\hline Risk score - target state & risk_b_x & & \\
\hline Big power - target state & big_power_b_x & & \\
\hline $\begin{array}{l}\text { Military strength of the opposition - target } \\
\text { state }\end{array}$ & $o p p \_s t r e n g t h \_x$ & & \\
\hline Political culture of violence - target state & viol_cult_x & \multirow{3}{*}{$\begin{array}{c}\text { Conflict } \\
\text { complexity (- } \\
40 \%)\end{array}$} & \multirow{3}{*}{ conf_complex_x } \\
\hline Intervention frequency - target state & int_freq_x & & \\
\hline Just cause index & just_cause_x & & \\
\hline \multicolumn{4}{|c|}{ JUST WAR THEORY INDEX $=100 \%$} \\
\hline
\end{tabular}

Table 11: Statistical description of JWT criteria indexes and the aggregate JWT index

\begin{tabular}{|c|c|c|c|c|c|}
\hline \multicolumn{7}{|c|}{ INDEXES APPROXIMATING JWT } \\
\hline Variables & Obs. & Mean & Std. Dev. & Min. & Max. \\
\hline jwt_cause_x & 1200 & 6,39 & 12,77 & 1,09 & 99,99 \\
\hline jwt_intent_x & 1695 & 53,69 & 24,59 & 0,00 & 98,85 \\
\hline jwt_auth_x & 1695 & 48,77 & 16,92 & 3,78 & 102,23 \\
\hline jwt_last_x & 1200 & 46,61 & 3,03 & 0,01 & 100,00 \\
\hline jwt_prop_x & 1695 & 38,73 & 8,82 & 0,00 & 134,14 \\
\hline jwt_succ_x & 1695 & 41,40 & 7,22 & 0,01 & 51,72 \\
\hline jwt_x & 1965 & 21,33 & 8,05 & 0,06 & 47,14 \\
\hline
\end{tabular}

\subsection{Validity of the quantified JWT}

This chapter has attempted to quantify a highly normative and complex issue of 'Just War'. It would be possible to question each single step of this analysis, starting with the selection of variables approximating individual JWT criteria, continuing with their conceptualization and data adjustments, and ending with the choice of method used for assigning these variables with respective weights. This study acknowledges that the presented JWT indexes greatly simplify the reality and do not manage to encompass all the possible relevant aspects of the Theory. Nevertheless, these indexes should be perceived as a mere trail to overcome the 
multidimensionality and subjectivity of this difficult issue. The main contributions of this chapter can thus be summarized in three points. First of all, it has attempted to quantify the JWT in a systematic and coherent way. Secondly, it has suppressed the subjectivity of how the individual input variables theoretically describing the JWT criteria correlate with each other, but has rather classified them based on their actual variance. And finally, it has generated the approximated JWT indexes by weighting the individual aspects of JWT based on their relevance within the Theory. By doing that, the study has provided a tool for approximating a degree of 'humanitarianism' behind 'motives and means' of military interventions. This daring trail has enabled to expose the controversial doctrines of JWT and HMI to a critical empirical evaluation that could bring more light into the question of legitimacy of HMI. 


\section{CHAPTER}

\section{LEGITIMACY OF HMI - MIXED CONSEQUENTIALIST AND JWT PERSPECTIVE}

\subsection{Introduction - an empirical assessment of the legitimacy of HMI}

Due to the fact that the issue of legitimacy of HMI traditionally belongs to the field of expertise of moralists and lawyers, most of the existing academic debate deals with the HMI concept exclusively qualitatively. This study will take an alternative approach and will attempt to situate the normative debate about legitimacy of HMI into a more quantitative perspective. The aim will be to provide the empirically grounded answers to several key questions, which are still pending in the vague and confused debate about the concept. This study will evaluate legitimacy of HMI by assessing a degree of 'humanitarianism' behind the 'motives and means' and the 'outcomes' of military interventions from the post-WWII era. 'Motives and means' of the interveners will be evaluated based on the theoretical framework of the classical Just War Theory (JWT) of 'jus ad bellum' that was quantified for individual cases of military interventions in the previous chapter. The identified level of 'humanitarianism' behind the 'motives and means' will then be compared with the existence of the 'humanitarian outcomes' of these interventions in the light of consequentialist ethics.

Due to the fact that this attempt to evaluate legitimacy of HMI on such a systematic basis is a first of its kind, the study will test the various definitions of the concept as well as the significance of individual JWT criteria so as to generate a comprehensive picture of the functioning and relationships within the concept based on the empirical evidence. The goal will be to draw an empirically sound judgment whether the 'humanitarian motives and means' tend to be empirically associated with the positive 'humanitarian outcomes' of military interventions and under which conditions, how an adequate definition of a legitimate HMI should be phrased, and what are the possible candidates for being awarded a label 'legitimate HMI'. All these findings should build up a solid basis for making a proposition about the legitimacy of HMI at the end of this study.

\subsection{Methodology}

\subsubsection{Definition of the 'HMI'}

So as to empirically assess the legitimacy of HMI, the first major task is to formulate a definition of a "legitimate HMI' and to rephrase it into the measurable conceptualizations based on the chosen theoretical frameworks of JWT and consequentialism. Due to the fact that there is no agreement on the basic defining aspects of the HMI, this study starts by adopting a very basic working definition of 
a legitimate HMI, which is framed by an attempt to answer a question of what is 'humanitarian' about HMI. Most authors agree that the expression of HMI refers to a primary 'humanitarian motive' behind the intervention accompanied by a usage of the sensitive 'means'. However, there is also a tendency to understand the concept in terms of a positive 'humanitarian outcome' of these interventions, claiming that the outcome of an action rather than rather than its purpose are crucial for assigning the legitimacy. ${ }^{339}$

This study will adopt a combined approach. In spite of acknowledging ethical strength of the JWT for evaluating legitimacy of any military endeavor, it will not identify a 'legitimate HMI' merely based on the 'motives and means' of the intervener as defined by the JWT criteria. Instead of giving a preference to the 'motives and means' over the 'outcomes'; it will set them on a equal footing as being two complementary parts of legitimacy. It will define a working definition of a 'legitimate HMI' as a use of force by state (or states) against another state for the humanitarian purposes that attempts and manages to prevent or to put to halt the gross violations of human rights or international humanitarian law. On one hand, this definition suggests that a mere reliance on the subjective 'humanitarian motives and means' is not a sufficient criterion of a 'legitimate $\mathrm{HMI}^{\prime}$; on the other hand, it states that the society should not blindly legitimize interventions that just happened to have 'humanitarian outcomes'. Based on this definition, a legitimization should be reserved only for such military interventions that were inspired at least to some degree by the 'humanitarian' concerns and that resulted in the 'humanitarian outcomes'. This definition thus represents a balanced approach combining the tools of 'Just War' ethics and consequentialist ethics that successfully overcomes the traditional controversy between the 'motives and means' and the 'outcomes' of any action.

Incorporating the less traditional 'outcomes-oriented' approach into the definition of a 'legitimate HMI' brings many advantages. First of all, it relieves the burden of finding a consensus on the existence of the subjective motivations of the interveners, overcoming thus the inherent subjectivity of the 'motive-oriented' approach. Instead, it allows the researchers to set an empirically measurable benchmark for evaluating the improvement or alternatively the worsened humanitarian situation in the target state. Moreover, incorporating the 'outcomeoriented' approach provides an incentive for the intervening states to engage in the prudential considerations about the applied military strategies and their broader impacts on the target state.

Another feature of the adopted definition is its purposeful vagueness. Given the existing disagreements about the details of the HMI definition in the academic

\footnotetext{
339 Wheeler, 2000; or Tesón, 2005.
} 
literature; this definition does not specifically state anything about the requirement of authorization by the UN, neither anything about the requirement that the intervention must be waged against the will of the government of the target state, neither any other specification that often appears in various definitions of the concept. Instead of incorporating various contested criteria into the working definition of a 'legitimate HMI' on an ad hoc basis, this study will first of all test how their incorporation influences the existence of a positive association between 'humanitarian motives and means' of the military interventions and their 'humanitarian outcomes' on the target state. Therefore, the exact details of the definition of a legitimate HMI will be concretized based on the carried out tests of the different adopted operationalizations of the concept.

$$
\begin{aligned}
& \Rightarrow \text { A 'legitimate } H M I^{\prime}=f \text { ('humanitarian motives and means' behind military } \\
& \text { intervention = Just War ethics; 'humanitarian outcome' of intervention on the } \\
& \text { target state = consequentialist ethics) }
\end{aligned}
$$

\subsubsection{Conceptualization of the 'humanitarian motives and means' ( $\left.\mathrm{X}_{\mathrm{it}}\right)$}

Conceptualizing a definition of the HMI concept requires a number of difficult theoretical and methodological decisions that have significant implications for the final assessment of its legitimacy. Coming out of the above presented working definition of a legitimate HMI, three types of conceptualizations of 'humanitarian motives and means' of an increasing complexity will be tested regarding their 'humanitarian outcomes' on the target state. Each of these conceptualizations is based on an assumption that the higher JWT score a military intervention achieves, the more 'humanitarian motives and means' the intervention entails. What differentiates the individual conceptualizations is their increasing complexity. Each successive conceptualization adds an additional criterion that the military intervention must fulfill so as to qualify its 'motives and means' as being 'humanitarian'.

\subsection{The 'humanitarian motives and means'- control version ${ }^{340}$}

In order to make whatever propositions about influence of the 'humanitarian motives and means' on the 'humanitarian outcomes' of military interventions plausible, the study will begin with testing the impact of all the military interventions on the target state in general; and only afterwards, it will proceed with testing solely the effects associated with the 'humanitarian motives and means'. Therefore, the first tested concept will simply cover all the cases of military interventions, which are defined as a movement of regular troops or forces of one

\footnotetext{
340 This dummy variable will represent a control version of the main tested independent variables approximating the 'humanitarian motives and means'. It will indicate the occurrence of a military intervention based on the identification procedure of the Military Intervention dataset. It will be denoted as "mil_int...". Input data source: Pearson \& Baumann, 1992; and Kisangani \& Pickering, 2007.
} 
country inside another. ${ }^{341}$ This definition apparently does not distinguish among the levels of 'humanitarianism' hidden behind individual interventions, but only evaluates their presence or absence on a binary scale. Therefore, all cases of military interventions will be identified into the sample regardless of how 'humanitarian' their 'motives or means' were and will be tested regarding their 'humanitarian outcomes' on the target state, so as to serve as a control in the subsequent interpretation of the main tested operationalizations of the 'humanitarian motives and means'.

\section{$\Rightarrow$ Control of 'humanitarian motives and means' behind military intervention $=f$ (military intervention)}

5.2.1.1.2. The 'humanitarian motives and means'- first version ( $\left.\mathrm{X} 1_{\text {it }}\right)^{342}$

First tested operationalization of the 'humanitarian motives and means' of military interventions will also cover all the cases of military interventions; this time, however, not defined merely by their presence or absence as in case of the previous control variable, but rather by a degree of 'humanitarianism' behind the 'motives and means' of the intervener. So as to establish how 'humanitarian' the 'motives and means' of the military interventions are, this study will utilize the quantified JWT. Previous two chapters devoted to the JWT not only explained its relevance for the concept of HMI, but also quantified how each individual military intervention scored on the aggregate JWT index as well as on its constituting criteria of 'just cause', 'just intent', 'just authority', 'last resort', 'proportionality' and a reasonable 'probability of success'. ${ }^{343}$ The JWT scores will be transformed into the positive values, so that they indicate a presence of a military intervention expressed as a degree of 'humanitarianism' behind its 'motives and means'. All the observations without presence of any military intervention will be assigned a JWT score of zero, depicting thus absence of any military efforts for conflict management. 'Humanitarian motives and means' of military interventions will be expressed by using each JWT criterion separately as well as by using the aggregate JWT index combining all the weighted criteria together. By doing that it will become possible to establish, which of the JWT criteria is and which is not

\footnotetext{
341 This definition is overtaken from the Military Intervention dataset. See: Pearson \& Baumann, 1992; and Kisangani \& Pickering, 2007.

342 This will be a first version of the main tested independent variable approximating the 'humanitarian motives and means' behind a military intervention. It will indicate a score of 'humanitarianism' entailed in the military intervention being waged into the target country, if any, based on the JWT. The variable will be denoted as "jwt_...x".

343 The quantified JWT scores were created by producing the orthogonally rotated component scores from the original input data, and by multiplying them by their relative weights according to the mainstream interpretation of the JWT in the academic literature. See the chapter 4 for the details of this quantification.
} 
associated with a positive 'humanitarian outcome' of military operations and to frame the resulting definition of a 'legitimate $\mathrm{HMI}^{\prime}$ accordingly.

\section{$\Rightarrow$ 'Humanitarian motives and means' behind military intervention $=f(J W T$ index)}

5.2.1.1.3. The 'humanitarian motives and means'- second version $\left(\mathrm{X} 2_{\mathrm{it}}\right)^{344}$

Second tested conceptualization of the 'humanitarian motives and means' of military interventions will not only be set on the JWT scores as in the previous case, but will also include a control requirement that the military intervention is 'third-party'. A main rationale behind including this additional conditionality arises from the fact that the military interventions as defined in this study cover not only the interventions into ongoing conflicts, but also the acts of aggression catalyzing completely new conflicts. ${ }^{345}$ Without eliminating the acts of aggression, it would be possible that an aggressive military intervention could still receive a relatively high aggregate JWT score by scoring high on all the other JWT criteria than the one of 'just cause'. So as to ensure that the acts of aggression are not candidates for a 'legitimate $\mathrm{HMI}^{\prime}$, the requirement of being 'third-party' will be incorporated into the second operationalization of the 'humanitarian motives and means'.

Requiring that a military intervention should be 'third-party' to become nominated as potentially 'humanitarian' has also another strong theoretical rationale. It rests on a general assumption that regardless of its real motives; each 'third-party' military intervention represents some form of a conflict management ${ }^{346}$, having a core motivation to end the hostilities rather than to exacerbate them. Even though, the intervener may, for example, prefer its ally to prevail; one would think that prevailing at an acceptable human cost is a key consideration while making a decision to intervene. 347 Therefore, in its essence, each 'third-party' military intervention should represent an attempt to decrease severity of the conflict.

\footnotetext{
344 This will be a second version of the main tested independent variable approximating the 'humanitarian motives and means' behind a military intervention. It will indicate a degree of 'humanitarianism' entailed in the 'third-party' military intervention being waged into the target country, if any; that will be evaluated based on the JWT ('third-party' military interventions are those being waged into the internal conflicts or those being waged into the ongoing conflicts of any type). It will be denoted as "jwt_...x1".

${ }^{345}$ A sample of military interventions will be drawn from the Military Intervention dataset that codes all the military interventions waged by regular armed forces of independent states across the international boundaries in the period of 1946-2005. See: Pearson \& Baumann, 1992; and Kisangani \& Pickering, 2007. 346 'Third-party' actors: UN, regional organization, state or a coalition of the states.

347 Regan, 2002.
} 
The study will define a 'third-party' military intervention as the one that takes place into the target state that suffered at least 25 battle-related deaths in the year previous to the intervention or as the one that was waged into internal conflict. Existence of a previous conflict or alternatively the intervention into internal conflict are assumed to represent scenarios guaranteeing that the intervener is a 'third-party' and not a 'direct-party' to the conflict. The newly introduced requirement of being 'thirdparty' will decrease the sample of military interventions that could become candidates for being classified as 'humanitarian'. ${ }^{348}$ Only the 'third-party' military interventions will be assigned the JWT score, while the remaining observations without any military intervention at all or the observations capturing the 'directparty' military interventions will be assigned the zero JWT score.

\section{$\Rightarrow$ 'Humanitarian motives and means' behind military intervention $=f(J W T$ index; 'third-party' military intervention)}

5.2.1.1.4. The 'humanitarian motives and means'- third version $\left(\mathrm{X}{ }_{\mathrm{it}}\right)^{349}$

Last tested operationalization of the 'humanitarian motives and means' of military interventions will preserve both of the two previous defining factors - a degree of fulfillment of the JWT and a requirement of being 'third-party'. In addition to that, however, the definition will also introduce a condition that the intervention must be waged in support of the target state's government. In spite of the fact that this new condition is not directly relevant to the 'motives or means' of the intervener; it reflects the conclusions of the existing studies about the effects of 'third-party' military interventions on the target state, which suggest that interventions can be successful in achieving their goals if waged in support of the government. ${ }^{350}$ Due to the fact that this characteristic of the 'third-party' military interventions has been repeatedly confirmed by more researchers, it seems to be a very important for understanding of what type of HMI can really bring a humanitarian relief, if any. Therefore, this study will include this criterion as a additional condition limiting the sample of military interventions that are going to be assigned the JWT score.

\footnotetext{
${ }^{348}$ See the technical appendix for the changes in the number of observations that are awarded the JWT score depending on the adopted conceptualization.

${ }^{349}$ This will be a third version of the main tested independent variable approximating the 'humanitarian motives and means' behind a military intervention. It will indicate a degree of 'humanitarianism' entailed in the 'third-party' military intervention supporting the government of the target state, if any; that will be evaluated based on the JWT ('third-party' military interventions are those being waged into the internal conflicts or those being waged into the ongoing conflicts of any type). It will be denoted as “jwt_...x2".

350 See the second chapter of the study dealing with the empirical evaluation of HMI in the existing literature. The positive effects of the 'third-party' military interventions were confirmed by: Elbadawi \& Sambanis, 2000; Regan, 2000; or Regan, 2002.
} 
Inclusion of this criterion creates, however, also a theoretical controversy related to the meaning of the word 'intervention'. The word 'intervention' refers to the breach of sovereignty of a state, which literally means that an external military operation taking place with the consent of the target state's government does not represent an intervention per se. ${ }^{351}$ Including the requirement that the military intervention must be waged in support of the target state's government thus logically violates the condition of absence of the government's consent, since it is possible to assume that the government that is to be assisted by the intervention has given its consent to the presence of the external troops. In spite of this fact, concept of HMI is very often used to refer also to the cases when the intervention takes place on the invitation of the target state's government or in the absence of an effective government in the target state. Moreover, it is necessary to take into consideration a fact that the consent is not always voluntary or genuine. It requires proving whether the authority giving it was really a representative body or what exactly the consent constituted. Its presence or absence can often be just a mere rhetoric claim, or the initial consent may gradually turn into resentment and hostility later on. ${ }^{352}$ And finally, it would be from the ethical point of view not reasonable to require that the military intervention can be carried out only against the will of the government to become qualified as a 'legitimate HMI'. Such a requirement would suggest that only the military interventions supporting the rebels can be considered 'legitimate', which would be counterintuitive to the idea of what makes any military intervention 'humanitarian'. Based on the above presented considerations, this study will make a proposition that the existence or the absence of the target state's government consent with the external military operation will not be determinative for whether it can be considered an intervention or not; since the question of consent is probably more relevant to the legality of the intervention and not to the inquiry, whether the military operation can be assessed as legitimately 'humanitarian'. 353

$\Rightarrow$ 'Humanitarian motives and means' behind military intervention $=f(J W T$ index; 'third-party' military intervention; military intervention supporting the target state's government)

\subsubsection{Conceptualization of a 'humanitarian outcome' (- $\left.\mathrm{Y}_{\mathrm{it}}\right)$}

Estimating a 'humanitarian outcome' of military interventions on the local population is a complex problem whose results proved to be very much dependent on the adopted conceptualization of the 'humanitarian outcome'. In spite of the fact that there has been a couple of studies attempting to quantify the broader

\footnotetext{
351 Damrosch, 1993.

352 Hoffmann, 1998.

353 Voon, 2002.
} 
effects of warfare on normal social dynamics and societal systems ${ }^{354}$, this effort still remains an abstract and challenging goal for the scientists. There is a broad agreement among the scientists that an optimally designed measure should be maximally comprehensive, capturing so wide spectrum of the effects of military interventions on the in the target state as possible. The problem with introducing such a measure is that there is not only a lack of theory on how to estimate a full 'humanitarian' impact of military interventions, but especially a serious lack of cross-national data that would allow estimating and comparing such impacts over a longer time period. ${ }^{355} \mathrm{In}$ fact, very few of the indirect effects of warfare have been systematically measured or consistently recorded outside the advanced industrial OECD countries since the end of WWII. The statistical data for the Third World where most of the conflicts in the post-WWII era have taken place are in most cases completely missing - particularly for the chaotic periods of ongoing violent conflict. As a result of that, it is extremely complicated to empirically assess the 'humanitarian outcome' of military operations in a sufficiently long time frame that would encompass enough cases of conflicts to be able to draw the statistically valid conclusions.

Even if it happened in the future that there would be some precise and theoretically comprehensive measure developed and the respective data would be systematically recorded in each country, it would be impossible to apply the measure retrospectively to the historical cases, in which no measurement was taken in an identical coherent manner. Therefore, it would be impossible to evaluate the warfare in the long-run using this hypothetical smart measure anyway. This leaves the scientific community with very few means how to make some generalizable conclusions about the past experience that would allow the political decision-makers to learn from the previous mistakes and to correct the possibly wrong assumptions about the actual effects of the used conflict management measures. The researchers have to find alternative, even if suboptimal, ways how to get around the absence of appropriate model and data. They have to attempt interpreting the data that are available and to draw at least rough conclusions while accepting their theoretical limitations.

There are many possible ways how to capture impact of military intervention on the humanitarian situation in the country. One possible extreme how to measure the 'humanitarian outcome' would be by looking merely at the changes of mortality in the battle field or alternatively conflict duration, while completely ignoring the impact of the interventions on the civilian population. The second extreme would be an adoption of the Johan Galtung's approach that a mere cessation of violence without removing the roots of conflict is not a sufficiently

\footnotetext{
${ }^{354}$ Cranna, 1994; or Brown \& Rosecrance, 1999.

355 Lacina \& Gleditsch, 2005.
} 
positive outcome, claiming that a successful intervention should achieve a positive peace without presence of any indirect and structural violence.356 Conceptualization of the 'humanitarian outcome' in this study has been influenced by the fact that the results of this study could potentially serve as a justification for a wider use of force in the international relations, though limited by 'motives', 'means' and 'outcomes'; which is under the existing international law either a legality bordering or as more generally considered an illegal activity. Therefore, the adopted conceptualization has to provide a clear and persuasive justification for the necessity of using military force, which would effectively challenge the nonintervention norm that currently governs the behaviour of the states in the international system and that serves as a guarantee of international peace and stability.

This study adopts a position that should the concept of HMI be acknowledged as 'legitimate', humanitarian relief brought by the military intervention should be of a type that the civilian sector would not be able to manage on its own; otherwise, a necessity of questioning the nonintervention norm would not be morally defendable. Therefore, waging a military intervention for 'humanitarian' purposes can be from the ethical point of view defendable only in such cases that there are immediate lives in danger to be saved, and if directed solely against an existing military threat in the target country with the aim to mitigate the humanitarian suffering that the violence is causing. It should be credited and thus also evaluated merely for its ability to directly decrease severity of this violence, which is a goal not reasonable achievable using any softer tools. As a result of this theoretical assumption, the other seemingly relevant possible 'humanitarian' effects of military interventions, such as the longer-term political stability or conflict reoccurrence will not be covered by this analysis. Waging a military intervention, though for 'humanitarian' purposes, cannot be reasonably expected to heal the root causes of the conflict by itself. Its mission should be to stop the bloodshed and to provide security for the distribution of humanitarian aid. Afterwards, however, it should provide a space to the non-military sector to come in that is much better trained and equipped for assisting the target country with the long-term peace-building efforts. Therefore, if the humanitarian crisis can be effectively managed by other means than by breaking a sovereignty of an independent state by sending the troops, these means should always be given preference. In accordance with these assumptions, this study will evaluate the 'humanitarian outcomes' of military interventions merely by their ability to decrease conflict severity.

\footnotetext{
${ }^{356}$ Galtung refers to the necessity of achieving a positive peace with the absence of any indirect or structural violence. See: Galtung \& Jacobsen, 2000.
} 
Second consideration framing the conceptualization of 'humanitarian outcome' of military interventions relates to the problem of attribution. Particularly, under what conditions can the changed humanitarian situation in the target state be attributed to the presence of the intervening troops. It is necessary to be decent in the propositions about the actual influence of military interventions on the local developments, and to attach to the interventions only the reasonably attachable effects. Due to the impossibility of running the controlled experiments in historical political events, it is necessary to use the counterfactual reasoning by posing a question of how severe the crisis would have been, had the military intervention not taken place. This task requires isolating the effects of military interventions from the broader internal processes in the target state, as well as from the effects of other non-military interventions that might have engined the observed changes in the target country. ${ }^{357}$ To achieve this goal, the study will consistently compare country-years with and without any crisis, and with and without any military intervention, so as to enable a reliable prediction of the 'humanitarian' impacts of military interventions on the target state. The counterfactual reasoning in the model will not necessitate any enabling counterfactuals, since it is easy to imagine a possibility of nonintervention in all the cases of intervention without having to change the context of the crises.

Another concern of this study is the selection of the most suitable time-spam for estimating the effects of military interventions on the target state. The longer time period of the changed history is allowed to elapse, the more problematic the counterfactual assessments become, since the long-term developments in the target country are subjected to many influences going far beyond the control of the already left troops. ${ }^{358}$ As a result of that, the indicators of 'humanitarian outcome' that are measurable directly as the military intervention is ongoing or shortly afterwards are the most attributable ones, and enable making the most plausible 'counterfactual judgments'. Logically, it is much more reliable to claim that the presence of external armed troops influenced hostilities in the target state in the same or in the following year, than trying to assume some deeper societal changes that took place in the long-run, long after the intervening troops left the country. As Rantner claimed, the long-term failures of stability in the target state should not be used as an indicator of success of the military interventions. In his opinion, a return to chaos after a longer period of time does not make the earlier intervention a failure, since there can be too many new developments that occurred despite of the successful earlier intervention. ${ }^{359}$ Therefore, in spite of the awareness that not

\footnotetext{
357 A sound counterfactual argument should be explicit about its undertakings; should maintain a logical, theoretical, and historical consistency; should avoid using of too many enabling counterfactuals; and should rewrite a minimal amount of history. See: Fearon, 1991; or Lebow, 2000.

358 Seybolt, 2007.

359 Rantner, 1995.
} 
all the humanitarian costs of violence are revealed immediately, and that the indirect effects of violence such as dying from wounds, illnesses, famine or poverty can continue teasing the local population long after the actual violence stopped; this study will evaluate the impacts of military interventions only in the short-run. Due to this methodological decision, the other typical problematic feature of counterfactual reasoning - interconnectedness should also become unproblematic, since even though a theoretical absence of military intervention might lead to a different type of compensatory event such as to the imposition of an economic embargo; non-military types of interventions do not tend to have direct but rather longer-term influence on the fighting and should thus not violate the conclusions of the model.

The last aspect influencing the conceptualization of the 'humanitarian outcomes' of military interventions is obviously the availability of the data. Capturing the 'true' humanitarian costs caused by the intervening troops represents a very complex problem that can be expressed in many ways. The most straightforward approach is to count the number of fatalities resulting of violence either directly in the course of battle, or indirectly as a result of illnesses or famine, or both. Nevertheless, there are also other considerable human costs of violence than the pure fatalities - such as non-fatal injuries, disability, reduced life expectancy, sexual violence, psychological trauma, displacement, loss of property, damage to capital and infrastructure, or degradation of environment. ${ }^{360}$ Unfortunately, data on most of these indicators are available only for the most recent conflicts, which makes it impossible to empirically assess the 'humanitarian outcomes' of military interventions in its whole complexity in the long-run. Given the limited scope of available data, this study will have to adjust its aspirations and to use the indicators that that would cover all the countries throughout the whole time spam of the study and that would allow at least a rough approximation of the changes in humanitarian suffering related to the activities of the intervening forces.

The adopted conceptualization will thus approximate the 'true' humanitarian costs of conflict by counting the lost lives in the short-run. More precisely, humanitarian effects of military interventions will be quantified using two types of indicators: battle deaths (a number of soldiers and civilians killed in the battle) and conflict deaths (an aggregate number of conflict-related fatalities covering both battle and non-battle deaths - approximated by a change in crude mortality). These two indicators have been selected, since the dying people represent undoubtedly the most severe demonstration of an ongoing humanitarian crisis, and prospects of saved lives provide in comparison with, for example, loss of property or psychological trauma a much more robust justification for breaking the sovereignty of an independent state. Another advantage of these indicators is that

${ }^{360}$ Lacina \& Gleditsch, 2005. 
they constitute a very strict test of legitimacy of HMI, since many people who received the humanitarian assistance due to the security established by the intervening troops would not have died anyway; while many people that were assisted died in spite of this assistance. Counting the number of saved lives thus represents the lowest common denominator in the confused debate about legitimacy of HMI.

\subsection{A 'humanitarian outcome' - battle deaths indicator $\left(\mathrm{Y} 1_{\mathrm{it}}\right)^{361}$}

First indicator approximating the 'humanitarian outcomes' of military interventions will simply indicate a yearly change in the number of battle-related deaths in the target state, covering both soldiers and civilians killed in the course of battle. This indicator is limited in its capability to capture the humanitarian suffering of local population in its whole complexity; nevertheless, it has an advantage of being relatively easily attributable to the presence of the external troops. A probably surprising structural decision to merge military and civilian battle deaths into one category follows the realities of the modern conflicts, in which the distinction between soldiers and civilians is often unclear or even entirely fluid if compared to the traditional wars fought formally between the organized armies. Therefore, a mere focus on the military battle deaths could seriously underestimate the scope of fighting. ${ }^{362}$ Therefore, in spite of the fact that counting the battle deaths represents a rather superficial indicator of the 'true' humanitarian costs of the conflicts; it is probably the best measure of combat intensity and scale, and thus also a theoretically sound approximation of the level of war-related hardships that the local population is facing.

$\Rightarrow \quad$ 'Humanitarian outcome' $=f$ (yearly change in battle deaths)

5.2.1.2.2. A 'humanitarian outcome' - conflict deaths indicator $(\mathrm{Y} 2 \mathrm{it})^{363}$

Second indicator approximating the 'humanitarian outcomes' of military interventions will be more encompassing. It will not count solely the people who died violently in the course of battle as in the case of the first indicator; instead, it

\footnotetext{
361 This will be the first dependent variable approximating the 'humanitarian outcome' of a military intervention. It will indicate a yearly change in the number of battle-related fatalities (including both civilians and combatants killed in the course of combat) measured from the previous to the current target country-year (abs. num.). This indicator will not include the one-sided violence, though it will include terrorism. It will be denoted as "b_deaths_ch...".

${ }^{362}$ Lacina \& Gleditsch, 2005.

363 This will be the second dependent variable approximating the 'humanitarian outcome' of a military intervention. It will indicate a yearly change in the number of deaths per year for both sexes combined measured from the current to the following year. It will be expressed as a proportion of the daily dying people out of 1.000. Keeping the indicator as a proportion will enable comparability between more and less populous countries. It will be denoted as "deaths_ch...".
} 
will also cover the battle-indirect deaths resulting of the conflict-related hardships. Precisely, it will indicate a yearly change in the conflict deaths approximated by a yearly change in crude mortality that is recognized as one of the three indicators that are rated as being the 'highest' in terms of their validity as the measures of health impact of a humanitarian crisis. ${ }^{364}$ The second selected indicator has in contrast to the first one both some advantages and disadvantages. On one hand, it covers a greater spectrum of the possible humanitarian costs of violence and is thus theoretically a more appropriate; on the other hand however, it brings some attribution problems requiring several simplifying assumptions.

Theoretical advantage of this indicator arises out of its ability to capture the most serious negative externalities of the conflict. It takes into consideration the fact that conflicts kill people in less direct ways than just in the battle fields. In fact, violent conflicts usually take place in poor countries, in which poorly equipped and organized armies have relatively limited capacity to cause a larger number of battle deaths. Nevertheless, due to the fact that such countries typically suffer from the collapse of society's economy, bad infrastructure, and limited medical and safety public facilities; presence of conflicts has a potential to produce a high number of battle indirect deaths resulting from unorganized violence (such as rioting), one-sided violence (such as genocide), criminality, displacement, illnesses, deprivation and starvation. The number of battle-indirect deaths often even much surpasses the number of lives lost in the battle in some conflicts. For example, the International Rescue Committee estimated a ratio of battle to non-battle deaths at roughly one to six. 365

Suitability of this indicator is, however, slightly mitigated by the problem of attribution that this indicator entails. While attributing the changed number of battle deaths to the effects of military intervention sounds unproblematic; a similar attribution to the non-battle deaths is more controversial, and needs to be interpreted with some underlying assumptions. Even after controlling for the characteristics of the target state and of the crisis, attributing all the changes in the number of conflict deaths to the effects of an on-going or of a recently left military intervention could be questionable due to the presence and activities of the nonmilitary humanitarian NGOs in the conflict zones. In spite of acknowledging the important role of these organizations in mitigating the humanitarian suffering in the war torn societies, this study will make a simplifying assumption that no matter who brings the humanitarian assistance - whether the NGOs or the intervening military forces; security is a prerequisite for its successful delivery. Therefore, any possible improvement in humanitarian situation in the war-zones

\footnotetext{
364 The other two indicators measuring the health impacts of the humanitarian crises are mortality of children under five years of age and case fatality rate. See: Roberts \& Hofmann, 2004.

365 Lacina \& Gleditsch, 2005.
} 
with an on-going military intervention is thus attributable to the security established by these military forces. This assumption is based on two arguments. First of all, the well-intended humanitarian assistance by the NGOs can paradoxically encourage and prolong the violence in the unsecured war zones; since the humanitarian resources distributed by the NGOs are often appropriated by the war lords to feed their militias instead of being delivered to the desiring population. ${ }^{366}$ Secondly, unlike the intervening military forces; humanitarian aid organizations maintain a presence in virtually all the conflicts, which allows the model to neglect their individual effects. Therefore, in accordance with the adopted assumption; if, for example, the incidence of a deadly diarrhea declined in a time period when the external troops were present, it will be the military intervention that will receive the credit for saving the lives, since it established and safeguarded the security on the roads enabling the transport of medicines and fresh water.

$\Rightarrow$ 'Humanitarian outcome' $=f$ (yearly change in conflict deaths)

Table 12: Approximation of the 'humanitarian outcomes' of military interventions

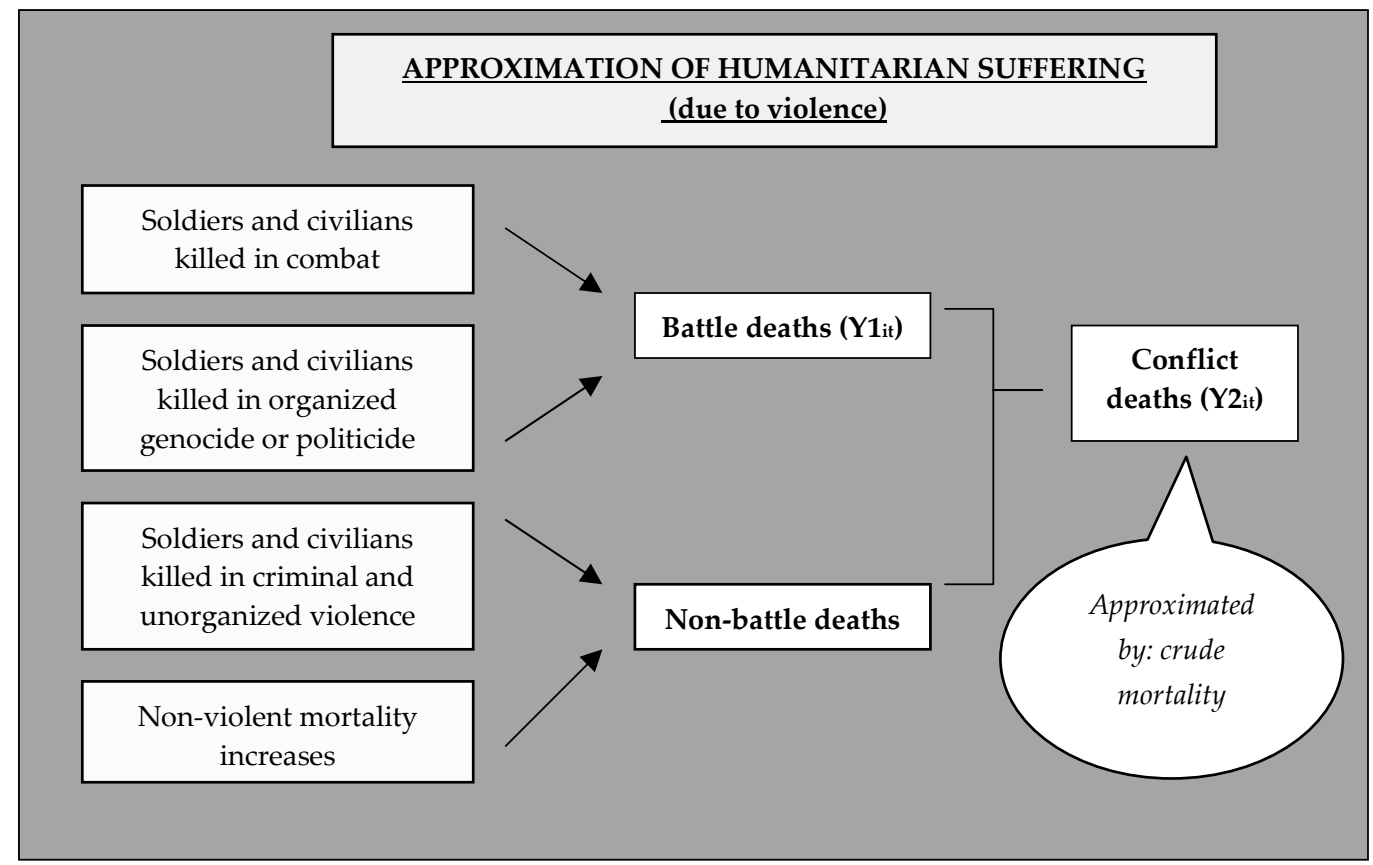

5.2.1.2.3. Common features of both dependent variables $\left(Y 1_{i t}+Y 2_{i t}\right)$

366 Seybolt, 2007. 
Two selected indicators of 'humanitarian outcome' of military interventions will be adjusted to correct for a common statistical problem of temporal dependence of the units of observations that is generally associated with the panel data. ${ }^{367}$ Temporal dependence implies that a measurement of $Y_{i t}$ is correlated with a measurement $\mathrm{Y}_{\mathrm{it}+1}$, which causes that the resulting correlation ( $\mathrm{t}$-value) appears to be artificially stronger than it is in reality. Clearly, if the country has a history of zero record of the battle-related deaths on its territory over last twenty years, the effect of time on the risk of emergence of a bloody conflict appears to be declining monotonically until the curve approaches zero. ${ }^{368}$ So as to prevent a possibility that the results of analysis are spoiled by the temporal dependence among the units of observations, none of the two dependent variables in the model will be kept in absolute values, but both will be rather expressed as yearly changes from the previous to the current year.

The last common theoretical concern shaping the form of both dependent variables has been focused on when to measure the changes in the dependent variables. First of all, it is theoretically plausible to assume that the effects of military intervention do not reveal immediately, but are much better traceable with a one- or two-year delay. The necessity of lagging the dependent variables at least by one year is confirmed by the fact that all the input data in the model are structured on a yearly basis. Therefore, in case that some military intervention took place at the end of the year, the observation actually fully captures a year prior to the military intervention and not the effects of the intervention. The theoretical necessity for lagging the dependent variables is especially strong in case of the dependent variable measuring the conflict deaths. The indirect causes of deaths are slower to reveal, since many people die only gradually as a result of wounds, starvation, or illnesses. So as to present a fully comprehensive picture, the study will first of all test the effects of the control independent variable capturing presence or absence of a military intervention on the immediate, one year lagged, and two years lagged changes in the two dependent variables; and then also the effects of the three definitions of the main independent variables capturing the 'humanitarian motives and means' of military interventions on the immediate, one year lagged, and two years lagged changes in the dependent variables. Based on the results of this analysis, it will become possible to reasonably assess, when the effects of the military interventions on the target state are the most significant and thus best measurable.

\subsubsection{Statistical model}

\footnotetext{
367 Benoit, 1996; Beck \& Katz, 1997; or Heagerty, Ward \& Gleditsch, 2002.

368 Bauhaug, 2005.
} 
Having completed the conceptualization of the tested concepts and the dependent variables, it is necessary to describe the construction of the statistical model that will be used in this analysis to evaluate legitimacy of HMI.

\subsubsection{Time frame and unit of observation}

The analysis will work with the panel data covering all the country-years in the time spam of 1946-2005. Rationale behind choosing particularly this time period is a product of several methodological and practical reasons that reflect the goal of this study is to establish the empirically grounded generalizations about legitimacy of HMI that would hold up across a variety of contexts. For that purpose, it will be necessary to make a systematic comparison over a large number of cases covering the country-years with and without a conflict, and with and without a presence of a military intervention into the conflict. So as to gather a sufficiently large pool of cases, data in the model will be structured in a way to cover as long time period as the theoretical concerns arising from the data comparability and data availability allow for. First major concern limiting the covered time period is an effort to compare just comparable. The international arena, its rules, and the meaning of different concepts such as democracy have been changing and developing over time. So as to guarantee some consistency of the rules within the system and the understanding of the concepts being evaluated by the model, this study will follow an universal ban on use of force in the international relations codified by the UN Charter after the end of WWII that established norms governing the behavior of the states in the international arena that have remained valid until now. The second time-frame limiting aspect is the data availability constraint for the preWWII period. In fact, a consistently collected high quality data are usually available only from the year 1946 onwards.

Country identification procedure of the sample of states in the data will also reflect an effort to maximize the number of observations by tracing a continuity of developments in each country regardless of absence of that state's sovereignty in some of the years. Countries will be identified based on the adjusted Quality of Government (QoG) project country list, which covers all the countries in the world recognized by the United Nations as of the year 2002 plus an addition of 9 historical nations. This makes together 200 nations that are included throughout the whole time period of 1946-2005..369 Data will thus cover 200 counties and nations $(\mathrm{n})$ over 60 time periods $(\mathrm{t})$, which makes a total of 12.000 observations $\left(\mathrm{n}^{*} \mathrm{t}\right)$ organized in a long form of the panel data. ${ }^{370}$ This selected panel data structure has

\footnotetext{
${ }^{369}$ QoG country list is described in: Teorell, Holmberg \& Rothstein, 2007. For the adjustments of the original version, see the technical appendix of chapter 6 dealing with the country identification procedure.

${ }^{370}$ Panel data are also called longitudinal data or cross-sectional time series data.
} 
a major advantage of enabling to isolate the time constant and potentially also the country constant effects during the data analysis.

\subsubsection{Statistical method}

To explore the association between the 'humanitarian motives and means' and the 'humanitarian outcomes' of military interventions, this study will apply a regression method investigating how a change in the predicting independent variables affects the dependent variables. Nevertheless, the regression method will be adjusted to reflect an extreme complexity of the issue of HMI that makes it impossible to successfully include all the relevant independent variables into the model. So as to avoid a mistake of appearance of some unknown variable or variables that would not be controlled for and that would affect the dependent variable, the study will not use an ordinary multiple regression technique that is easily subjected to an omitted variable bias and thus also to the wrongly estimated coefficients.

The study will first of all test the fixed effects regression method that is capable to control for the potential omitted variables that differ between the cases but are constant over time even without observing them or including them explicitly into the model. This method observes changes in the variables over time to consistently estimate the effects of independent variables on the dependent ones. ${ }^{371}$

$$
\begin{aligned}
& \text { Fixed effects: } \quad Y i t=\beta X_{i t}+\beta Z_{i t}+\alpha_{i}+u_{i t} \\
& Y_{i t}=\text { dependent variable }(i=\text { country, } t=\text { year }) \\
& \beta=\text { coefficient for independent variable } \\
& \left.X_{i t}=\text { main independent variable ( } i=\text { country, } t=\text { year }\right) \\
& Z_{i t}=\text { control independent variable }(i=\text { country, } t=\text { year }) \\
& \alpha_{i}=\text { unknown intercept for each country }(i=1 \ldots n) \Rightarrow \text { includes time-constant } \\
& \text { characteristics of the country } \\
& u_{i t}=\text { error term }
\end{aligned}
$$

Fixed effects method is always consistent but is not necessarily the most efficient one to run. It is possible that there could be not only the omitted variables that are constant over time but vary between cases, but also those that are fixed between cases but vary over time. It is possible to control for both these types of omitted variables by using a random effects regression method. ${ }^{372}$ Given it is statistically

\footnotetext{
${ }^{371}$ It is a method equivalent to generating dummy variables for each of the cases and including them in a standard linear regression to control for these fixed 'case effects'.

372 Stata's random effects estimator is a weighted average of the fixed effects and the in-between effects.
} 
consistent, random effects method is a more efficient ${ }^{373}$ and thus also a preferable method to run.

Random effects: $\quad Y i t=\beta X i t+\beta Z_{i t}+\alpha+u_{i t}+\varepsilon_{i t}$

$\alpha=$ includes time-constant and country-constant characteristics

$u_{i t}=$ between-country error

$\varepsilon_{i t}=$ within-country error

Assumptions:

$$
\begin{aligned}
& \operatorname{Cov}\left(\alpha_{i}, u_{i}\right)=0 \\
& \operatorname{Cov}\left(\alpha_{i}, x i\right)=0
\end{aligned}
$$

So as to assist with a decision, which of the two methods - whether the fixed effects or random effects - would statistically be more appropriate to test the legitimacy of HMI; the study will run the Hausman test, which tests a more efficient random effects model against a less efficient but always consistent fixed effects model to make sure that the more efficient model would also generate the consistent results.

\section{Hausman test:}

$H_{0:} \alpha_{i} \perp X_{i t}, V_{i}$

$H_{a}: \alpha_{i} \pm X_{i t}, V_{i}$

$X_{i t}=$ time-variant independent variable

$V_{i}=$ time-invariant independent variable

$\alpha_{i}=$ unobserved country effect

Assumptions:

If $\mathrm{H}_{0}$ is true, both estimates from $F E$ and $R E$ are consistent, but only $R E$ is efficient.

If $H_{a}$ is true, estimates from FE are consistent and from RE not.

\subsubsection{Input control data ( $Z_{\text {it) }}$ )}

It is impossible to evaluate effects of military interventions without controlling for the fact that onset of conflicts, external military interventions, and conflict escalations do not happen at random. In fact, if a military intervention for 'humanitarian' purposes is waged, it usually attempts to manage conflicts that are the most escalated and perhaps inherently intractable. These conflicts tend to be

\footnotetext{
${ }^{373}$ Random effects method generates better p-values than the fixed effects method.
} 
more resistant to the exogenous pressures, since the violence is already deeply embedded in the society, and the willingness to use military force is too high. Due to the fact that the main goal of this study is to attach the escalatory or deescalatory tendencies of an ongoing conflict to the presence or absence of the external military troops, it is necessary to isolate all the other conflict driving and conflict mitigating factors than the presence of the evaluated military intervention. Without controlling for a degree of difficulty that the interveners have to face during conflict management in the target state, even the best intended military intervention would surely end up as being detrimental to the humanitarian situation in the target state. ${ }^{374}$

While selecting the most appropriate control variables, the study has taken into consideration that the motives for political violence are very complex, ranging from the pure economic motives, struggle for power, persuasiveness and persistence of ideological beliefs, and existence of political and other forms of inequality. ${ }^{375}$ After inspecting the existing literature dealing with the issue of conflict escalation, it is possible to make a simplified statement that there are two main engines behind the conflict escalation: 'motivation' and 'opportunity'. These two major factors are reflected in various variations in all the major theories of conflict dynamics. Most of the researchers emphasize importance of 'motivation'; however, there is no agreement among them whether the motive-driven escalation is pushed more by the 'grievance' or the 'greed'.376 'Grievance' motivated escalation of conflicts is formed by the groups' perceptions of an unbearable extent of injustice and the resulting hatred, which is usually framed by the ethnic and religious divisions within the society and the related repressions. ${ }^{377}$ On the other hand, 'greed' motivated escalation takes place, if some group perceives a possibility to gain power or economic advantages by initiating or catalyzing the conflict. Apart from the 'motivation' of the conflict actors, the second major engine of conflict escalation is represented by an 'opportunity' of parties to escalate the violence. A typical 'opportunity' occurs if the government becomes militarily or politically weak - such as during the periods of a political change; if the finances or lootable resources are available to the warring parties; if some additional actors enter the conflict bringing in new weapons and manpower; or if some charismatic leader promoting a further violence takes the lead. ${ }^{378}$ Therefore, so as to control for the selection effects; the model will include three groups of control variables capturing the most crucial 'motivation' and 'opportunity' factors. It will not only

\footnotetext{
374 Betts, 1994; Goertz \& Diehl, 1995; Regan, 2000; Regan, 2002.

375 Herbst, 2000.

376 Berdal \& Malone,2000; Collier \& Hoeffler, 2000; Mueller, 2000; or Collier, 2001.

377 Lichbach, 1987; Moore, 1998b; Ellingsen, 2000; Hegre et.al., 2001; Reynal-Querrol, 2002; or Elbadawi \& Sambanis, 2002.

378 Collier \& Hoeffler , 2000; Sambanis, 2002; or Fearon \& Laitin, 2003.
} 
include control variables describing the type of military intervention as such; but also the control variables describing the characteristics of the target country, and the nature of the conflict. By doing that a degree of difficulty of managing the conflict will be controlled for, and that the 'humanitarian' effects of military interventions on the target state will be much more precisely estimated.

\subsection{Characteristics of the target country (time-constant characteristics) $\left(\alpha_{\mathrm{i}}\right)^{379}$}

Due to the panel structure of the data, the time-constant characteristics influencing a propensity of each individual country for conflict escalation will be automatically captured by the adopted fixed effects regression method, without a necessity of incorporating them as extra control variables into the model. Among the most typical time-constant characteristics of the country influencing the conflict dynamics belong, for example: appreciation of the local population for a peaceful or reversely coercive conflict resolution, geographical location, lootable natural resources endowment for financing the conflict, or dominance of a rough terrain facilitating insurgency.

\subsection{Characteristics of the target country (time-variant characteristics) ( $\left.Z_{i t}\right)$}

Time-variant characteristics of the target country influencing the escalatory tendencies of the conflict will be approximated by four control variables corresponding to four main categories of the motive- and opportunity-driven factors: economic, political, ethno-religious and cultural.

\subsection{Economic factors: GDP per capita level ${ }^{380}$ and GDP per capita change381}

First control variable in this model will indicate the target state's GDP per capita. GDP level refers to both motive- and opportunity-driven factors. Low GDP per capita is a strong predictor of conflict, since it proxies the incapacity of the state to attract and contain both internal and external violence. ${ }^{382}$ First of all, countries with a low level of economic development tend to suffer from poverty and high unemployment. Due to the lack of alternative prospects of supporting their families; young unemployed men are motivated to join either the regular army or militias, which would provide them with at least some guarantee of food and income provision, and with a respectable status. Opportunity cost of fighting is

\footnotetext{
379 Fixed effects will be denoted as " $\alpha \mathrm{i}_{\mathrm{i}}$ "

380 This variable will indicate a GDP per capita in 1000 USD and will be denoted as "gdp_lev".

381 This variable will indicate the averaged change in level of GDP per capita (in 1000 USD) over the last three years and will be denoted as "gdp_gr".

382 Collier \& Hoeffler , 2000; Fearon \& Laitin, 2001; Collier \& Sambanis, 2002; or Fearon, \& Laitin, 2003.
} 
thus extremely low in such countries. ${ }^{383}$ Another conflict driving aspect related to the GDP level is rather surprising. The conducted research suggests that the smaller the economic surplus in the poor countries is, the more intensively the leaders compete with each other to control it. ${ }^{384}$ In addition to that, the lower economic position the country has, the higher is the probability that it becomes challenged either internally or externally, since a lower GDP level increases the opportunity-driven tendencies of the unsatisfied parties to change the status quo by resorting to violence. Low GDP level is thus the most salient determinant of both insurgency and probability of being intervened into. ${ }^{385}$

Nevertheless, the effects of GDP level on the conflict dynamics are not so straightforward as might seem, and could be reflected differently depending on the choice of dependent variable. On one hand, economically weak states have limited technologies and organizational capacity, which leaves them with a minimal military strength and poorly organized combatant groups. As a result of that economically weak states are assumed not to produce a larger number of battle deaths. ${ }^{386}$ On the other hand, conflicts in the economically weak states are anarchic, disorganized, and are typical with warlordism. Such disorganized conflicts usually cause large number of battle indirect deaths and result in severe humanitarian crises, which can be assumed to become reflected in the increased crude mortality and thus a number of conflict deaths. ${ }^{387}$

Apart from capturing a mere level of economic development, this study will also include a control variable indicating an averaged change of GDP per capita over the last three years. The main incentive behind adding this control variable is to capture an actual change in economic factors strengthening or weakening the 'motivation' and 'opportunity' of the actors to drive the conflict depending on whether the country currently experiences a period of economic growth or a recession. Particularly, the variable will control for how the economic 'grievance' and 'greed' of the local population increased or alternatively how the 'opportunity' for conflict escalation increased because of the weakened economic position of the target state or vice versa.

\subsection{Political factors: polity level 388 and polity change389}

\footnotetext{
${ }^{383}$ Collier \& Hoeffler, 2002.

${ }^{384}$ Collier \& Hoeffler, 2000.

${ }^{385}$ Collier \& Hoeffler, 2000; Blomerg \& Hess, 2002; or Fearon \& Laitin, 2003.

386 Kalyvas, 2005.

${ }^{387}$ Herbst, 2004.

388 This variable will show the polity scale evaluating a level of democracy. The score will be indicated within a value range of 2-20, with the score 20 reaching the highest quality of the democracy. The variable will be denoted as "polity_lev".
} 
Next control variable in the model will be related to the level of democracy in the target state, since different regime types have different inherent characteristics that either mobilize or inhibit both motive- and opportunity-driven factors driving the conflict dynamics. First of all, the theory suggests that some regimes are more and some less willing to use the harshest measures or to inflict a great collateral loss of lives among civilians, since the institutional structure provides them with completely different 'opportunities' for conflict escalation. In contrast to the autocracies, democracies are better equipped to peacefully contain any rebellion and to negotiate with the rebels, and have available institutional settings that make the concessions less costly. Similarly, if compared with the autocratic political leaders, democratic leaders are much more constrained in a resort to violence by the established institutional check and balances, and by the norm of internalization that makes them more inclined toward minimizing causalities in an effort to avoid being condemned by the public. ${ }^{390}$ A similar difference appears, if the bottom-up approach is adopted. The unsatisfied groups living in the democratic regimes have in comparison with those living in the autocratic regimes a possibility to express their dissatisfaction peacefully during the regular elections or by using some more direct and immediate tools such as protests or referenda, rather than by engaging in a violent rebellion. Just oppositely, the unsatisfied groups in the autocracies have no other option than using a rebellion instead. ${ }^{391}$

A seemingly transparent theoretical rule that the autocracies are more violent is, however, more complicated than it may seem. It is theoretically true that democracies do not tend to produce 'motivation' for its citizens to escalate the conflict, since they have other means how to express their dissatisfaction nonviolently; nevertheless, democracies provide its citizens with a much greater 'opportunity' to rebel due to the developed human rights protection mechanisms. Autocracies, on the other hand, produce a 'motivation' to rebel, since there is no other way how to express a dissatisfaction; however, the repressive regimes do not provide much 'opportunity' to rebel because of punishing harshly whatever expression of dissatisfaction. In addition to that, recent empirical studies suggest that the countries in the middle of the autocracy-democracy spectrum could be the ones most inclined toward conflict escalation, since they are neither autocratic enough to control for the 'opportunity' of rebellion, nor democratic enough to prevent a significant 'grievance' and thus a 'motivation' for a rebellion from happening. 392

\footnotetext{
389 This variable will indicate an average movement on the polity scale over the last three years. A positive sign will denote an ongoing democratization, while a negative sign will denote autocratization. The variable will be denoted as "polity_gr".

${ }^{390}$ Harff, 2003; Valentino, Huth, \& Balch-Lindsay, 2004; or Carey, 2005.

391 Gurr, 2000; or Gurr \& Harff , 2004.

392 Jaggers \& Gurr, 1995; Collier \& Hoeffler, 2000; or Hegre, Ellingsen, Gates \& Gleditsch, 2001.
} 
The complicated influence of the regime type on conflict dynamics leads to the contradictory results of the empirical tests of the political 'grievance'. On one hand, there are well acknowledged researchers arguing that the political 'grievance' is a primary motive driving the civil violence ${ }^{393}$ On the other hand, most of the major empirical studies on civil war have found no significant relationship between a lack of democracy and the conflict escalation; since most of the proxies for political 'grievance' end up as being insignificant or in the best case as having a very low explanatory power. ${ }^{394}$ It is possible to conclude that thus far, there is only mixed evidence about the role of regime type on conflict dynamics, and the current academic opinion remains divided about the effects of political 'grievance' and 'opportunity' indicators on the propensity of countries to resort to the use of violence. Therefore, so as to make the controversial political-related 'grievances' and 'opportunities' better interpretable in the model, this study will disentangle the political factors into two indicators. As in the case of their economic counterpart, the study will include apart from a control variable capturing a level of democracy in the target state, also a dynamic version of this variable capturing an increased or decreased 'motivation' and 'opportunity' for conflict escalation resulting from the observed change in a political regime over the last three years. ${ }^{395}$

\subsection{Ethno-religious factors: ethnic fractionalization ${ }^{396}$ and excluded population ${ }^{397}$}

Next two indicators of 'grievance' constituting the model will be of an ethnoreligious nature. The first one will evaluate how ethnically fractionated the target country is. Ethnic divisions within the society should theoretically make the conflicts much bloodier, since they enable mobilization along the collective identities that are derived from the fundamental, incontrovertible and nonnegotiable values such as language, history and religion. Identity-related conflicts should thus be particularly strong and difficult to resolve, since the parties are more willing to bear the costs of violence for achieving a common goal. ${ }^{398}$ Nevertheless, in spite of the fact that ethnic fractionalization is generally assumed to have a conflict escalating effect, and is thus a typically used control variable in the studies dealing with conflict onset and escalation; the statistical significance of

\footnotetext{
${ }^{393}$ Esty et al., 1995, 1998; Gurr, 2000; Elbadawi \& Sambanis, 2000, 2002; Hegre et al., 2001; or ReynalQuerrol, 2002.

${ }^{394}$ Collier \& Hoeffler, 2000; Fearon \& Laitin, 2001.

${ }^{395}$ Most of the existing empirical studies focused on the association of the regime change and the escalatory tendencies of the conflicts are concentrated on international wars. See: Mansfield \& Snyder, 1995; Snyder, 2000; Russett, Oneal \& Cox, 2000. There is no clear evidence yet on the effects of democratization and the likelihood of civil war. See: Sambanis, 2001.

396 This variable will indicate the ethnic fractionalization index based on the ESEG data that covers only the ethno-politically relevant groups. It will be denoted as "ethn_fract".

397 This variable will indicate the percentage of excluded population. It will be denoted as "excl_pop". ${ }^{398}$ Huntington, 1997; or Fortna, 2003.
} 
this indicator greatly varies across the studies. Results of the recent empirical studies suggest a more complicated relationship between ethnic divisions and propensity to use violence than assumed by a general discourse. Some studies have identified that ethnic dominance, not diversity, is more likely to drive the violence, suggesting that countries with very high levels of ethnic diversity may be as safe as ethnically homogeneous countries. ${ }^{399}$ The results of the studies describing the effects of ethnic fractionalization are clearly mixed.

Another theoretically strong control indicator of 'grievance' included into the model will indicate a percentage of population excluded from the participation in central government of the target country. This indicator will be located among the ethno-religious factors, since most of the cases of political and economic stratification and discrimination occur along the ethno-religious divisions within the society. ${ }^{400}$ It will cover, first of all, people who have no central power but have some influence at the subnational level; then elite representatives who hold no political power at the national or regional levels without being explicitly discriminated against; and finally, those who are subjected to active, intentional, and targeted discrimination with the intent of excluding them from both regional and national power. This indicator will accompany the typically used measure of ethnic heterogeneity, since existence of a heterogeneous population alone does not necessarily suggest existence of a 'grievance'. Ethnic heterogeneity must be accompanied by an oppression to become a potential common 'grievance' that would join and mobilize the excluded group or groups in fighting for a change of power distribution. This indicator will thus describe a percentage of apparently dissatisfied and oppressed population locked out of power that is prone to rebel.

\subsection{Cultural factors: culture of violence ${ }^{401}$}

Another added variable controlling for a degree of difficulty of conflict management will measure how much is the violence imbedded in the society of the target state. The main idea behind including this variable is that once the violence is initiated, it tends to follow a path-dependent process, often generating a conflict trap. Hatred is accumulated in the society and makes a further violence more viable. Culture of violence in the target state is thus another motive-driven factor influencing the tendencies of conflict to escalate. This theoretical concept will be approximated by making an average of number of battle deaths over the last three years.

\subsection{Characteristics of the conflict}

\footnotetext{
399 Horowitz, 1985; Rothschild \& Foley, 1988; Collier \& Hoeffler, 2000; Elbadawi \& Sambanis, 2000. 400 Esty et al., 1995, 1998; or Gurr, 2000.

401 This variable will indicate an averaged number of battle deaths over the last three years (using the best guess estimate). The variable will be denoted as "viol_cult".
} 


\subsection{Existence of a conflict ${ }^{402}$}

First control variable describing the conflict will merely indicate existence of a violent conflict in the target state. This variable should capture the changes in the number of battle deaths and conflict deaths, and thus to enable isolating only those changes in mortality that are associated with the presence of a military intervention, if any takes place.

\subsection{Previous conflict 403}

Next control variable will indicate existence of a conflict in the previous year. This variable will relate to the lagged effect of conflict on the target state, suggesting whether the conflict is new or whether the violence is already present in the society. This variable partially relates to the timing of military intervention, since it is assumed that a conflict management military intervention into the country with an already settled violence should be more complicated than settling a short-term dispute. The longer the conflict, the more complicated is it for the intervening military troops to achieve some conflict mitigating effect. In case that the conflict occurred only in particular year, it is still in its beginning stage when a possibility of reaching a quick settlement has not yet been prevented by much bloodshed and suffering on both sides. Therefore, this variable will control for the difficulty of managing the already established conflict, while bringing attention to the effect of timing of interventions on their outcome.

\subsection{Internal conflict $t^{404}$}

The last control variable in this group will describe type of the conflict, if any; particularly, whether the conflict is internal or not. There are two reasons for distinguishing between internal and international conflicts. First of all, based on the findings of the existing research; conflict management seems to be much more difficult for internal than for interstate conflicts. In contrast to the traditional wars fought between the sovereign states, belligerents in the internal conflicts cannot retreat to the opposite sides of an established cease-fire line and to agree to disagree indefinitely with each party staying on its side of the border. In addition to that, combatants in the internal conflicts face the problem of disarming and of creating a single national army, which makes it much harder for them to reach a

\footnotetext{
402 This dummy variable will indicate occurrence of a crisis based on the identification threshold of more than 25 battle-related deaths per year (using the best guess estimate from the ACD dataset). The variable will be denoted as "confl".

403 This dummy variable will indicate a presence of conflict in the previous year based on the identification threshold of more than 25 battle-related deaths per year (using the best guess estimate from the ACD dataset). The variable will be denoted as "prev_confl".

404 This dummy variable will indicate whether the conflict was internal. The variable will be denoted as "intern_confl".
} 
stable negotiated settlement. ${ }^{405}$ From this follows that internal conflicts tend to have much stronger escalatory tendencies than the international ones. The second concern supporting the decision to incorporate the control variable capturing the type of conflict is that the processes that influence conflict escalation in internal and interstate conflicts do not operate in similar ways. If these two types of conflicts were merged together, the explanatory strength of the analysis would be weakened.

\subsection{Characteristics of the military intervention}

\subsection{Previous military intervention ${ }^{406}$}

First control variable describing the characteristics of the military intervention will indicate presence of the external troops in the target state in the previous year. Main incentive behind including this variable is to control for the fact, whether the evaluated military intervention is already ongoing or whether it is a new event radically changing the conflict dynamics. The effects of an ongoing established military intervention on the yearly change in battle and conflict deaths are expected to be weaker than the effects of the fresh intervention entering the scene.

\subsection{2. 'Third-party' military intervention 407}

Additional control variable will differentiate between the military interventions that are 'third-party' and those that are 'direct-party'. It is assumed that each 'third-party' intervention represents some form of conflict management with a core motivation to end the hostilities rather than to escalate them. ${ }^{408}$ Even though, the intervener may have a preference for one of the parties to prevail; intervention at an acceptable human costs is assumed to be a key consideration. ${ }^{409}$ Therefore, in its essence, each 'third-party' military intervention should represent an attempt to decrease severity of the conflict.

\subsection{Use of force by the intervener 410}

It would be very difficult to evaluate the effects of military interventions on conflict dynamics without adequately differentiating between the various mandates assigned to the different interventions, or the resource and manpower limitations that individual interventions faced. Differently mandated and equipped

\footnotetext{
405 Fortna, 2003.

406 This binary variable will indicate a military intervention taking place in the previous year, regardless of the degree of 'humanitarianism' entailed. The variable will be denoted as "prev_mil_int".

407 This binary variable will indicate presence of a 'third-party' military intervention. The variable will be denoted as "third_party_int".

408 'Third-party' actors: UN, regional organization, state or coalition of the states.

${ }^{409}$ Regan, 2002.

410 This binary variable will indicate presence of an aggressive troop activity by some intervener. The variable will be denoted as "viol_mil_int".
} 
interventions are logically able to achieve differently significant results. So as to control for this differentiation, this study will include a variable indicating use of force by the interveners, which should reflect both the allocated mandate and the strength of the operations. Therefore, while evaluating an overall 'humanitarian' effectiveness of the military interventions, the study will be able to control for the use of a forcible military strategy.

\subsection{Military intervention targeting: supporting the government ${ }^{411}$, supporting the rebels ${ }^{412}$, mixed ${ }^{413}$}

Next three control variables in the model will indicate a type of targeting of the military interventions. Reason for distinguishing between interventions that target the rebels and those that target the government is based on the existing research, which suggests that interventions in favor of the government appear to make the conflicts less severe than the interventions in favor of the rebels. ${ }^{414}$ This phenomenon is interpreted using an argument that external interventions in favor of the rebels drive the conflict, since such interventions reduce the cost of sustaining a rebellion, facilitate a recruitment of more rebels, and increase the willingness of the rebels to proceed with the fighting due to the improved prospects of success. Without existence of an intervention in their support, the rebellion would highly probably be more quickly crushed by the government. ${ }^{415}$ Therefore, the model will, first of all, distinguish among the pro-governmental and the pro-rebel military interventions. Additionally, the model will include one more control variable indicating existence of a mixed targeting supporting both the government and the rebels that is assumed to have the most profound escalatory tendencies on the conflict development, since it increases the military strength of both parties and thus also their capacity to drive the conflict.

Table 13: Summary of the statistical model empirically assessing the legitimacy of HMI

\footnotetext{
411 This dummy variable will indicate presence of a military intervention supporting the government of the target state. The variable will be denoted as "int_supp_gov"..

${ }^{412}$ This dummy variable will indicate presence of a military intervention supporting the rebels. The variable will be denoted as "int_supp_reb".

${ }^{413}$ This dummy variable will indicate that the targeting of military interventions was mixed - the intervention/s targeted both the rebels and the target state's government. The variable will be denoted as "target_mixed".

414 Betts, 1994; or Regan, 2000, 2002.

${ }^{415}$ Elbadawi \& Sambanis, 2000; or Regan, 2000, 2002.
} 


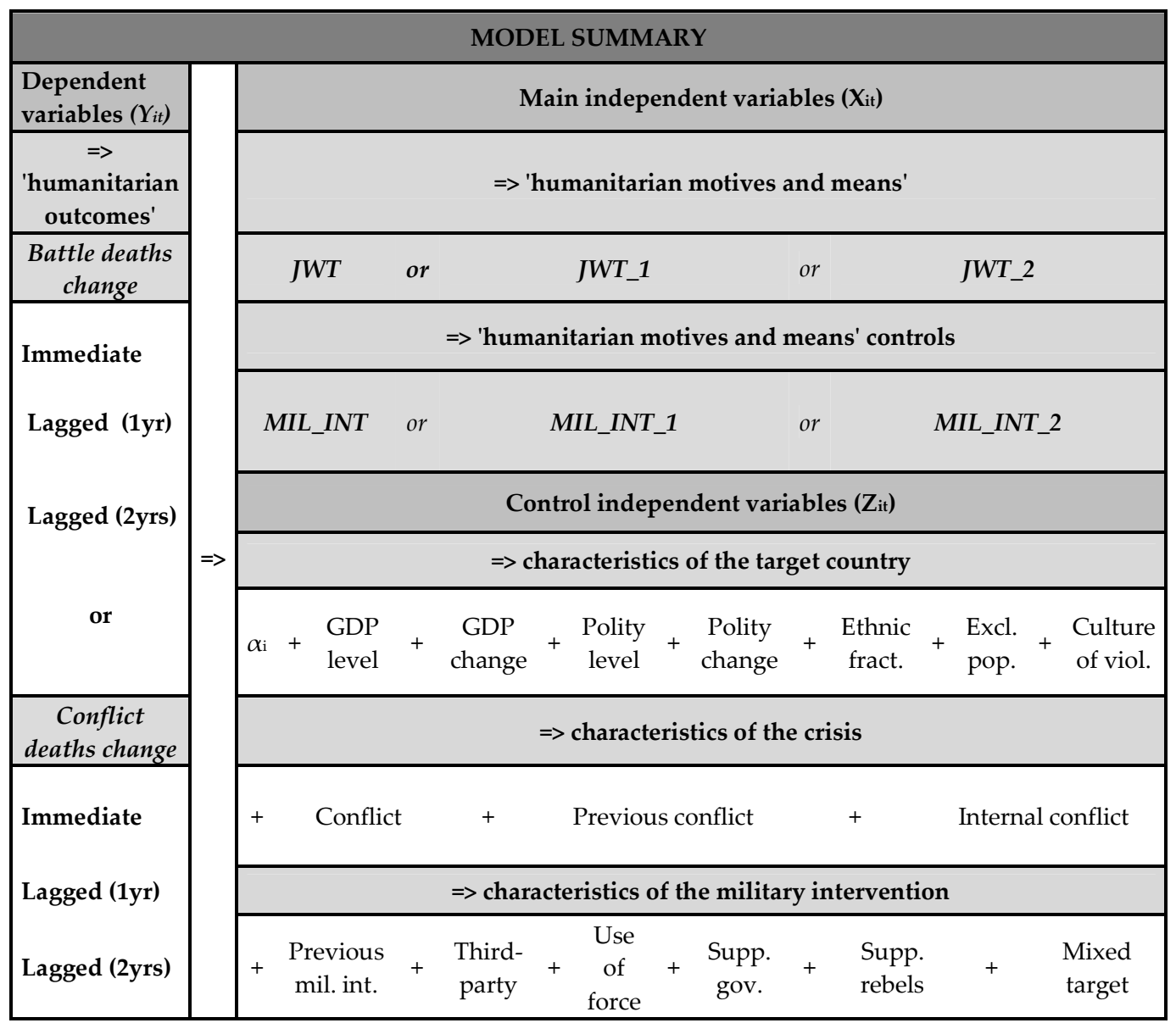

\subsection{Results of the analysis}

The rest of the chapter is going to be devoted to the presentation of the results of the analysis. It will present just a summarizing overview of the most important features. The detailed output tables covering each step of the analysis and all the estimations are to be found in the technical appendix of this chapter.

\subsubsection{Hausman test}

Hausman test was applied to test the hypothesis that the coefficients estimated by the efficient random effects estimator are the same as the ones estimated by the consistent fixed effects estimator. The test was carried for all the possible combinations of regression models testing the effects of the three HMI definitions and their control version on the variously lagged dependent variables. While evaluating the results of the Hausman test, the study used a commonly accepted procedure establishing that if the p-value is significant $(<0,05)$, the fixed effects method should be used; but if the p-value is insignificant $(>0,05)$, then it is safe to 
use the random effects method. The output of the Hausman test indicated the mixed results. Out of the 36 outputs of the Hausman test, 17 supported the fixed effects method and 16 supported the random effects method. In three cases, the Hausman test failed, since the data failed to meet the asymptotic assumptions of the test. Nevertheless, the results for the most theoretically sound version of lagging that captures the effects of military interventions with a one year delay indicated that the fixed effects method should be given preference. ${ }^{416}$ Due to the fact that the Hausman test resulted in a very weak trust in usage of the more efficient random effects method for testing the model, the study adopted a more careful approach of the fixed effects method. First of all, the fixed effects method is not constrained by the complicating assumptions, which if violated produce invalid results. Moreover, it is necessary to take into consideration that countries experiencing a crisis are not a randomly chosen sample, which could again violate the results, if the random effects method was applied instead.

\subsubsection{Output of the fixed effects regression method}

Due to the fact that this study has been a very first attempt to systematically evaluate the 'humanitarianism' behind military interventions, the structure of the study has largely been of an exploratory nature. Nevertheless, it has managed to discover a number of significant patterns, and to verify or disconfirm some of the original hypotheses. First of all, the study tested the correlations of both conceptualizations of the 'humanitarian outcomes' with all the definitions of 'humanitarian motives and means' based on the aggregate JWT index, so as to assess a legitimacy of the HMI concept if defined based on the JWT of 'jus ad bellum' as a whole. Afterwards, each quantified JWT criterion was also tested separately, so as to evaluate which JWT criterion is more and which less relevant for the 'humanitarian outcomes' of military interventions. By testing the individual aspects of 'humanitarian motives and means' separately, it is possible to make an empirically sound judgment, which of the JWT criteria is from the consequentialist perspective actually crucial for defining a 'legitimate $\mathrm{HMI}^{\prime}$ and which not.

\subsubsection{Legitimacy of the HMI based on the aggregate IWT}

The two below presented tables show, first of all, the estimated coefficients for all the tested control definitions of 'humanitarian motives and means' in relation to the two adopted conceptualizations of 'humanitarian outcomes' of military interventions; as well as the coefficients for all the tested definitions of 'humanitarian motives and means' based on the aggregate JWT.

\footnotetext{
416 Out of 12 carried out Hausman tests, 8 outputs suggested using the fixed effects method, while only 2 outputs suggested using the random effects. Two Hausman tests failed.
} 
Table 14: Evaluation of the results of empirical analysis

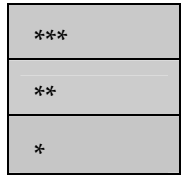

$1 \%$ significance level

$5 \%$ significance level

$10 \%$ significance level

\subsection{Control variables of the 'humanitarian motives and means'}

Table 15: Results of the fixed effects analysis - the control variables

\begin{tabular}{|c|c|c|c|c|c|c|c|c|c|}
\hline \multicolumn{10}{|c|}{ JWT INDEX } \\
\hline \multirow{2}{*}{ Y1: deaths_ch.... } & \multicolumn{3}{|c|}{ Y1a: deaths_ch } & \multicolumn{3}{|c|}{ Y1b: deaths_ch_lag } & \multicolumn{3}{|c|}{ Y1c: deaths_ch_lag2 } \\
\hline & Coef. & St. Err. & $P>t$ & Coef. & St. Err. & $P>t$ & Coef. & St. Err. & $\mathbf{P}>t$ \\
\hline mil_int & 0,001 & 0,058 & 0,99 & 0,004 & 0,058 & 0,95 & $-0,015$ & 0,058 & 0,80 \\
\hline mil_int_1 & * 0,113 & 0,064 & 0,08 & ** 0,140 & 0,065 & 0,03 & ** 0,150 & 0,065 & 0,02 \\
\hline mil_int_2 & 0,016 & 0,093 & 0,87 & $-0,027$ & 0,094 & 0,77 & $-0,067$ & 0,094 & 0,47 \\
\hline \multirow{2}{*}{ Y2: b_deaths_ch.... } & \multicolumn{3}{|c|}{ Y2a:b_deaths_ch } & \multicolumn{3}{|c|}{ Y2b: b_deaths_ch_lag } & \multicolumn{3}{|c|}{ Y2c: b_deaths_ch_lag2 } \\
\hline & Coef. & St. Err. & $P>t$ & Coef. & St. Err. & $P>t$ & Coef. & St. Err. & $P>t$ \\
\hline mil_int & 307 & 487 & 0,53 & -187 & 463 & 0,69 & -141 & 474 & 0,77 \\
\hline mil_int_1 & -153 & 545 & 0,78 & * -926 & 519 & 0,07 & 494 & 531 & 0,35 \\
\hline mil_int_2 & -145 & 789 & 0,85 & * -1286 & 750 & 0,09 & -34 & 768 & 0,97 \\
\hline
\end{tabular}

The tested control independent variables (table 14) indicate merely presence of a military intervention on a binary scale, without taking into account how the intervention is scoring on the JWT. The identification procedure of the control variables varies similarly as in case of the main tested variables specifying a degree of 'humanitarianism' behind the military interventions. While the first control variable captures presence of all military interventions, ${ }^{417}$ the second control variable captures only the 'third-party' military interventions, ${ }^{418}$ and the third one identified only the 'third-party' military interventions supporting the target state's government. ${ }^{419}$

\footnotetext{
${ }^{417}$ Control variable "mil_int".

418 Control variable "mil_int_1".

${ }^{419}$ Control variable "mil_int_2".
} 
The effects of military interventions on the target state without taking a degree of 'humanitarianism' into account are not much significant. As theoretically expected, the effects of military interventions are best reveled if the dependent variables are lagged by one year, so that the observations really capture the situation after the military intervention took place and not beforehand. Similarly, the assumption that the effects of military interventions on the indirect conflict deaths should be spread more gradually than the effects on the direct battle deaths was confirmed by the results of the analysis. As indicated in the table, while the effects on the battle deaths are significant only in the short-run, if lagged by one year; the effects on the conflict deaths are significant both, if lagged by one and if lagged by two years. These results serve as a control for whether the indexes approximating the 'humanitarian motives and means' are really capturing the effects of military interventions, and whether a HMI as defined in this study actually achieves a more 'humanitarian outcome' if compared with a generally defined military intervention.

The most important information in the table that should assist with answering the key questions of this study are the coefficients describing the effects of the generally defined military interventions on the target state and their relative strengths. The results support the assumption that each 'third-party' military intervention represents a sort of crisis management. Nevertheless, this proposition was found to be valid only if the crisis management activity is evaluated by the changes in the number of battle-related deaths. In that case, both the second and the third definition of the control variable covering the military interventions that are 'third-party', and the interventions that are 'third-party' plus supporting the government of the target state decrease the severity of the conflict. Nevertheless, this assumption seems to fail, if the crisis management activity is being evaluated by the overall changes in conflict deaths. The results suggest that no matter whether the military intervention was 'third-party' or not, the intervention increases the number of conflict deaths and thus has a negative 'humanitarian' impact on the local population. The only possible exception to this rule represents the third control definition covering the military interventions that are 'third-party' and support the government, which seems to result in a positive 'humanitarian outcome', but has an insignificant coefficient. So as to make a final conclusion about the effects of the control variables of the 'humanitarian motives and means' of military interventions; the generally defined military interventions tend to produce the most significant positive 'humanitarian outcomes', if they are 'thirdparty' and being waged in support of the government.

5.3.2.1.2. Variables approximating the 'humanitarian motives and means' 
Table 16: Results of the fixed effects analysis - the aggregate JWT

\begin{tabular}{|c|c|c|c|c|c|c|c|c|c|}
\hline \multicolumn{10}{|c|}{ JWT INDEX } \\
\hline \multirow{2}{*}{ Y1: deaths_ch.... } & \multicolumn{3}{|c|}{ Y1a: deaths_ch } & \multicolumn{3}{|c|}{ Y1b: deaths_ch_lag } & \multicolumn{3}{|c|}{ Y1c: deaths_ch_lag2 } \\
\hline & Coef. & St. Err. & $P>t$ & Coef. & St. Err. & $P>t$ & Coef. & St. Err. & $P>t$ \\
\hline jwt_x & 0,004 & 0,003 & 0,16 & $* 0,005$ & 0,003 & 0,06 & $* * * 0,007$ & 0,003 & 0,01 \\
\hline jwt_x1 & $* * 0,006$ & 0,003 & 0,02 & $* * * 0,008$ & 0,003 & 0,00 & $* * * 0,011$ & 0,003 & 0,00 \\
\hline jwt_x2 & $* * *-0,012$ & 0,003 & 0,00 & $* * *-0,015$ & 0,003 & 0,00 & $* * *-0,015$ & 0,003 & 0,00 \\
\hline \multirow{2}{*}{ Y2: b_deaths_ch.... } & \multicolumn{3}{|c|}{ Y2a:b_deaths_ch } & \multicolumn{3}{|c|}{ Y2b:b_deaths_ch_lag } & \multicolumn{3}{|c|}{ Y2c: b_deaths_ch_lag2 } \\
\hline & Coef. & St. Err. & $P>t$ & Coef. & St. Err. & $P>t$ & Coef. & St. Err. & $P>t$ \\
\hline jwt_x & $* * * 119$ & 22 & 0,00 & -28 & 21 & 0,17 & -16 & 21 & 0,44 \\
\hline jwt_x1 & $* * * 96$ & 22 & 0,00 & $* * *-65$ & 21 & 0,00 & -1 & 21 & 0,95 \\
\hline jwt_x2 & $\begin{array}{ll}* * * & 96\end{array}$ & 27 & 0,00 & $* * *-67$ & 26 & 0,01 & ${ }^{*}-48$ & 27 & 0,07 \\
\hline
\end{tabular}

The next presented table (table 15) evaluates the effects of the variously defined 'humanitarian motives and means' behind the military interventions on the two possible operationalizations of the 'humanitarian outcomes' on the target state. While the first definition captures a presence of all military interventions by a degree to which they score on the aggregate JWT, ${ }^{420}$ the second tested definition awards the aggregate JWT score merely to the cases of military interventions that are 'third-party', ${ }^{421}$ and the last definition only the cases of military interventions that are 'third-party' and waged in support of the target state's government. ${ }^{422}$ During interpretation of the results, a major attention is to be devoted to the effects that are lagged by one year, and potentially also to those lagged by two years in case of the first dependent variable measuring the changes in conflict deaths. Appropriateness of this choice of lagging follows not only from the theoretical rationale described at the beginning of the analysis, but has also been confirmed by the results of the regression analysis using the control variables.

When evaluating the directions and significance of the identified effects, the results seem to confirm the tendencies that were localized already by the control variables, but this time with a much more robust significance. The lagged effects of 'humanitarian motives and means' behind military interventions on conflict deaths generally do not tend to improve the humanitarian situation in the target state, but rather deteriorate it. ${ }^{423}$ The only definition that came out of the analysis as decreasing the number of conflict deaths and thus the humanitarian suffering of the local population in general is the third definition requiring that the intervention must score high on the JWT, that it must be 'third-party', and must be

\footnotetext{
${ }^{420}$ Main independent variable "jwt_x".

${ }^{421}$ Main independent variable "jwt_x1".

422 Main independent variable "jwt_x2".

${ }^{423}$ Dependent variable Y1 ("deaths_ch_lag").
} 
waged in a support of the target state's government. Otherwise, the results suggest that regardless of 'motivations and means", the interventions end up as being harmful for the population of the target state. In contrast to that, the lagged effects of 'humanitarian motives and means' behind military interventions on the changes in battle deaths significantly improve the humanitarian situation in the target country regardless of the definition adopted. ${ }^{424}$ Nevertheless, even here, the interventions with the most positive 'humanitarian outcomes' are those that are 'third-party', and even more those that are 'third-party' and support the government of the target state.

5.3.2.1.3. Resulting effect of the 'humanitarian motives and means' in a summary

Before drawing any conclusions about a degree of legitimacy of HMI that could be derived from the results of this analysis, it is necessary to bring attention to how comparable the two dependent variables actually are. While the first dependent variable capturing the conflict deaths refers to the change in crude mortality out of 1000 people, ${ }^{425}$ the second dependent variable capturing the changes in battle deaths relates to the absolute number of fatalities. ${ }^{426}$ Therefore it is not possible to sum them together to get an overall result. Instead, it is very beneficial to think of them separately.

The above presented results suggest that military interventions no matter how well intended tend to increase the amount of conflict deaths and thus tend to have a negative 'humanitarian outcome' on the population in the target state. ${ }^{427}$ The only exception is represented by the interventions that are at the same time 'third-party' and being waged in support of the target state's government, which is the only definition with a potential to improve the humanitarian situation in the target state. This positive effect of the third tested definition is insignificant for the control variable capturing the military interventions in general; however, it is highly significant if the interventions are recorded by the achieved JWT score of 'humanitarian motives and means'.

Effects of military interventions on the second theoretically more limited dependent variable capturing the changes in battle deaths present a similar story. ${ }^{428}$ The outcomes have confirmed the anticipated beneficial humanitarian effect of the 'third-party' military interventions and of the interventions supporting

\footnotetext{
${ }^{424}$ Dependent variable Y2 (“b_deaths_ch_lag”).

425 Dependent variable Y1 ("deaths_ch_lag").

${ }^{426}$ Dependent variable Y2 (“b_deaths_ch_lag").

427 Dependent variable Y1 ("deaths_ch_lag").

${ }^{428}$ Dependent variable Y2 (“b_deaths_ch_lag").
} 
the government of the target state. ${ }^{429}$ A rather surprising conclusion of the analysis is that all types of military interventions actually decrease the number of battle deaths in the target state. Nevertheless, as demonstrated in the above presented table, the increasing 'humanitarian considerations' of the intervener tend to further increase the positive effect of reducing the battle-related fatalities. Moreover, in contrast to the control variables indicating merely a presence or absence of the military interventions in general, the military interventions defined by the JWT score have much more significant effect on the target state, in most of the cases reaching a $0.01 \%$ significance level. Therefore, if the humanitarian costs were to be measured merely by the fatalities on the battle field, any type of 'third-party' military intervention significantly decreases the humanitarian suffering and the increasing JWT considerations make their beneficial 'humanitarian outcome' even bigger.

Should the above presented findings be applied to the existing rules in the international system, the confirmed finding that the 'third-party' military interventions tend to decrease the number of battle-related deaths in general, regardless of a degree of 'humanitarianism' entailed, should not serve as an empirical legitimization for a broader use of violence in the behavior of the states, since the 'third-party' military interventions - unless being waged in support of the local government - tend to have a negative 'humanitarian impact' on the local population in general. So as to legitimize any military endeavor other than selfdefense - meaning that we talk about an illegal activity under the current international law - much more would be needed than an unintended effect of decreasing the number of fatalities in the battle field. A 'legitimate HMI' would have to possess both the 'humanitarian motives and means' as well as the 'humanitarian outcomes', with the 'outcomes' being preferably measured by both tested definitions of battle and conflict deaths. Based on the results of this study, such conditions of a 'legitimate HMI' can be fulfilled only if the HMI follows the rules of JWT, if it is 'third-party', and waged in support of the target state's government.

\subsubsection{Legitimacy of the HMI based on the individual JWT criteria}

The following two tables decompose the JWT definition of 'humanitarian motives and means' into individual JWT criteria so as to distinguish, which of the criteria is crucial for reaching a positive 'humanitarian outcome' of military interventions and which not. Such a defragmentation should enable a better understanding of the JWT index and will assist in framing of the definition of a 'legitimate HMI' at the end of this chapter. Based on the results of the tested control variables capturing a presence of the military interventions, the effects of individual JWT

429 The positive effects of the 'third-party' military interventions supporting the government have been confirmed by some of the studies. See: Elbadawi \& Sambanis, 2000; or Regan, 2000, 2002. 
criteria on the dependent variables were tested only in a one-year lagged form. As suggested from the results testing the aggregate JWT, most of the JWT criteria significantly decreased the humanitarian suffering in the target state, if the criteria were defined by the third definition requiring the intervention to be 'third-party' and waged in support of the government.

Table 17: Results of the fixed effects analysis - the individual JWT criteria (Y1)

\begin{tabular}{|c|c|c|c|c|c|c|c|c|c|}
\hline \multirow{3}{*}{$\begin{array}{c}\text { Y1: } \\
\text { deaths_ch_la } \\
\text { g }\end{array}$} & \multicolumn{9}{|c|}{ JWT CRITERIA } \\
\hline & \multicolumn{3}{|c|}{$\begin{array}{l}\text { HMI DEFINITION 1: } \\
\text { jwt_x }\end{array}$} & \multicolumn{3}{|c|}{$\begin{array}{c}\text { HMI DEFINITION 2: } \\
\text { jwt_x1 }\end{array}$} & \multicolumn{3}{|c|}{$\begin{array}{l}\text { HMI DEFINITION 3: } \\
\text { jwt_x2 }\end{array}$} \\
\hline & Coef. & St. Err. & $P>t$ & Coef. & St. Err. & $P>t$ & Coef. & St. Err. & $P>t$ \\
\hline jwt_cause... & *** 0,005 & 0,001 & 0,00 & ${ }^{* * *} 0,005$ & 0,001 & 0,00 & $* * *-0,013$ & 0,002 & 0,00 \\
\hline jwt_intent... & 0,000 & 0,001 & 0,96 & ${ }^{*} 0,002$ & 0,001 & 0,08 & ** $-0,002$ & 0,001 & 0,05 \\
\hline jwt_auth... & 0,001 & 0,001 & 0,13 & $* * * 0,003$ & 0,001 & 0,01 & 0,001 & 0,002 & 0,49 \\
\hline jwt_last... & $-0,001$ & 0,001 & 0,38 & 0,001 & 0,001 & 0,27 & $-0,002$ & 0,002 & 0,21 \\
\hline jwt_prop... & 0,000 & 0,001 & 0,81 & ${ }^{* *} 0,004$ & 0,001 & 0,02 & 0,003 & 0,002 & 0,16 \\
\hline jwt_succ... & $-0,001$ & 0,001 & 0,53 & 0,002 & 0,002 & 0,17 & $-0,002$ & 0,002 & 0,48 \\
\hline
\end{tabular}

Table 18: Results of the fixed effects analysis - the individual JWT criteria (Y2)

\begin{tabular}{|c|c|c|c|c|c|c|c|c|c|}
\hline \multirow{3}{*}{$\begin{array}{c}\text { Y2: } \\
\text { b_deaths_ch_1 } \\
\text { ag }\end{array}$} & \multicolumn{9}{|c|}{ JWT CRITERIA } \\
\hline & \multicolumn{3}{|c|}{$\begin{array}{c}\text { HMI DEFINITION 1: } \\
\text { jwt_x }\end{array}$} & \multicolumn{3}{|c|}{$\begin{array}{c}\text { HMI DEFINITION 2: } \\
\text { jwt_x1 }\end{array}$} & \multicolumn{3}{|c|}{$\begin{array}{c}\text { HMI DEFINITION 3: } \\
\text { jwt_x2 }\end{array}$} \\
\hline & Coef. & St. Err. & $P>t$ & Coef. & St. Err. & $P>t$ & Coef. & St. Err. & $P>t$ \\
\hline jwt_cause... & 1 & 11 & 0,91 & -10 & 11 & 0,36 & -16 & 14 & 0,28 \\
\hline jwt_intent... & 5 & 8 & 0,49 & -8 & 9 & 0,38 & -7 & 10 & 0,47 \\
\hline jwt_auth... & $* * *-21$ & 7 & 0,00 & $* * *-34$ & 8 & 0,00 & $* * *-54$ & 13 & 0,00 \\
\hline jwt_last... & -12 & 9 & 0,20 & $* * * \quad 33$ & 11 & 0,00 & $*-26$ & 15 & 0,09 \\
\hline jwt_prop... & -15 & 10 & 0,13 & $* * *-43$ & 12 & 0,00 & $* * *-83$ & 18 & 0,00 \\
\hline jwt_succ... & -16 & 10 & 0,13 & $* * *-44$ & 13 & 0,00 & $* * *-51$ & 17 & 0,00 \\
\hline
\end{tabular}

What is interesting about these results is the striking difference in the relative importance of individual JWT criteria within the Theory for guaranteeing a positive 'humanitarian outcome' of military interventions, depending on the choice of the dependent variable. The two dependent variables set almost opposite priorities in ranking importance of the criteria. While the first two JWT criteria of 'just cause' and 'just intent' are the strongest and the most significant in decreasing 
the humanitarian suffering in the target state, if measured by the changes in conflict deaths; 430 the last four JWT criteria of 'just authority', 'last resort', 'proportionality', and 'probability of success' are the most important for achieving a positive 'humanitarian outcomes' of military interventions if evaluated by the changes in battle deaths. ${ }^{431}$ Improvement of the humanitarian situation in the target state thus seems to be driven by different aspects of the JWT in the two dependent variables.

Therefore, before evaluating the relative importance of individual JWT criteria for assessing a legitimacy of HMI, it is necessary to rank the underlying priorities. What is more decisive for awarding the HMI with legitimacy? A positive 'humanitarian outcome' that is related to the population of the target state as a whole, but which is less attributable to the role of military intervention; or a better attributable positive 'humanitarian outcome' covering only the battle deaths? This study opts to risk a lower attributability and argues for a greater priority of the overall conflict deaths. First of all, this indicator is theoretically stronger and casts a much greater legitimacy on the concept. Secondly, this decision is supported by the results of the analysis, which show that the military interventions ended up as decreasing the number of battle deaths in general, no matter of the actual 'motives or means' of the interveners. Moreover, all the coefficients estimating the effects of individual JWT criteria on the changes in battle deaths, though not having the same level of significance, have a same negative sign. Therefore, all of them contribute to a certain degree to an improvement of the 'humanitarian outcome'. This finding suggests that no matter how the ranking of the key JWT criteria constituting a 'legitimate $\mathrm{HMI}^{\prime}$ would end up, the military intervention can be defined by whatever combination of the criteria and would still most probably end up as decreasing the number of the battle deaths. The same cannot be said about the coefficients describing the effects of individual JWT criteria on the conflict deaths. Due to the fact that two of the criteria ended up as increasing the number of conflicts deaths, though insignificantly; it is necessary to differentiate carefully in ranking the JWT criteria. It is very crucial to emphasize the importance of the first two JWT criteria of 'just cause' and 'just intent' for the ability of the military intervention to decrease the number of conflict deaths and thus to achieve an overall positive 'humanitarian outcome'. Therefore, in spite of acknowledging, that the JWT represents a very complex theoretical construct that is difficult to get disaggregated into the separate criteria; this study concludes that the criterion of

\footnotetext{
${ }^{430}$ Only the third HMI definition is being considered, since it is the only definition resulting in a significant positive 'humanitarian outcome' if measured by the number of conflict deaths. ${ }^{431}$ All three HMI definitions are taken into consideration, since all of them produce significant results. Nevertheless, the second and especially the third HMI definition relating merely to the 'third-party' military interventions are the more robust.
} 
'just cause' followed by the criterion of 'just intent' are the most crucial in awarding a legitimacy of HMI.

\subsubsection{Role of the remaining control variables in the legitimacy model}

The first surprising finding regarding the control variables that were added to the model to safeguard for the conflict driving and conflict mitigating effects other than that of the military interventions concerns a weak significance of the role of economic indicators in case of both tested dependent variables. A second feature deserving attention is the positive 'humanitarian' effect of the use of force by the intervener. All the remaining control variables were at least closely significant for some of the HMI definition, generally confirming the expected effects.

Table 19: Results of the fixed effects analysis including the control variables

\begin{tabular}{|c|c|c|c|c|c|c|c|c|c|c|}
\hline \multirow{2}{*}{\begin{tabular}{|c|} 
Y1b: \\
deaths_ch_la \\
$\mathrm{g}$ \\
\end{tabular}} & \multicolumn{3}{|c|}{ HMI definition 3} & \multirow{2}{*}{$\begin{array}{c}\text { Y2b: } \\
\begin{array}{c}\text { b_deaths_ch_ } \\
\text { lag }\end{array} \\
\end{array}$} & \multicolumn{3}{|c|}{ HMI definition 2} & \multicolumn{3}{|c|}{ HMI definition 3} \\
\hline & Coef. & $\begin{array}{l}\text { St. } \\
\text { Err. }\end{array}$ & $P>t$ & & Coef. & $\begin{array}{c}\text { St. } \\
\text { Err. }\end{array}$ & $P>t$ & Coef. & $\begin{array}{c}\text { St. } \\
\text { Err. }\end{array}$ & $P>t$ \\
\hline jwt_x & - & - & - & jwt_x & - & - & - & - & - & - \\
\hline jwt_x1 & - & - & - & t__x1 & $* * *-65$ & 21 & 0,00 & - & - & - \\
\hline jwt_x2 & ${ }^{* * *}-0,015$ & 0,003 & 0,00 & jwt_x2 & - & - & - & $* * *-67$ & 26 & 0,01 \\
\hline polity_lev & 0,005 & 0,003 & 0,07 & polity_lev & -16 & 23 & 0,49 & -15 & 23 & 0,50 \\
\hline polity_gr & $-0,061$ & 0,013 & 0,00 & polity_gr & 140 & 103 & 0,17 & 140 & 103 & 0,17 \\
\hline gdp_lev & 0,002 & 0,002 & 0,30 & gdp_lev & -2 & 17 & 0,88 & -1 & 17 & 0,94 \\
\hline gdp_gr & 0,006 & 0,024 & 0,81 & gdp_gr & -24 & 189 & 0,90 & -17 & 189 & 0,93 \\
\hline excl_pop & 0,479 & 0,080 & 0,00 & excl_pop & -1154 & 641 & 0,07 & -1183 & 641 & 0,07 \\
\hline ethn_fract & $-0,213$ & 0,143 & 0,14 & ethn fract & -635 & 1147 & 0,58 & -654 & 1147 & 0,57 \\
\hline viol_cult & 0,115 & 0,041 & 0,01 & viol_cult & 280 & 166 & 0,01 & 259 & 85 & 0,00 \\
\hline confl & 0,069 & 0,042 & 0,10 & confl & 1088 & 341 & 0,00 & 1060 & 340 & 0,00 \\
\hline prev_confl & 0,089 & 0,078 & 0,25 & prev_confl & 3120 & 621 & 0,00 & 3120 & 627 & 0,00 \\
\hline intern_confl & 0,220 & 0,077 & 0,00 & intern_confl & 4694 & 678 & 0,00 & 4163 & 615 & 0,00 \\
\hline prev_mil_int & 0,107 & 0,035 & 0,00 & prev_mil_int & 566 & 281 & 0,05 & 497 & 281 & 0,08 \\
\hline 3rd_party_int & $-0,001$ & 0,078 & 0,99 & 3rd_party_int & -2998 & 610 & 0,00 & -3198 & 623 & 0,00 \\
\hline viol_mil_int & $-0,117$ & 0,050 & 0,02 & viol_mil_int & -141 & 399 & 0,72 & -273 & 397 & 0,49 \\
\hline int_supp_go & 0,066 & 0,077 & 0,39 & int_supp_go & -820 & 521 & 0,12 & -97 & 619 & 0,88 \\
\hline int_supp_reb & 0,242 & 0,059 & 0,00 & int_supp_reb & -390 & 477 & 0,41 & -884 & 474 & 0,06 \\
\hline mixed_target & 0,355 & 0,103 & 0,00 & mixed_target & -340 & 814 & 0,68 & 162 & 822 & 0,84 \\
\hline _cons & 0,171 & 0,070 & 0,02 & cons & 678 & 561 & 0,23 & 693 & 561 & 0,22 \\
\hline
\end{tabular}




\subsubsection{Sample of the candidates for a 'legitimate $\mathrm{HMI}^{\prime}$}

The study has adopted the following methodology to identify a sample of potential candidates for being awarded a lable 'legitimate HMI'. The candidates had to have both the 'humanitarian motives and means' as well as to have the 'humanitarian outcomes'. They were filtered out of the entire sample of military interventions recorded in the time period of 1946-2005 in a way that the interventions had to achieve more than half of the maximum awarded aggregate JWT score, and they had to result in a decreased number of either the battle deaths, but more preferably of the conflict deaths in general. The number of the qualified cases varied depending on the adopted HMI definition. The results are presented in the below table, while a complete list of the cases fulfilling both of the conditions is to be found in the technical appendix of this chapter.

Table 20: Samples of the candidates for being awarded a label 'legitimate HMI'

\begin{tabular}{|l|r|r|r|r|}
\hline \multicolumn{5}{|c|}{ CANDIDATES FOR A 'LEGITIMATE HMI' } \\
\hline \multirow{2}{*}{} & \multicolumn{5}{|c|}{ Positive 'humanitarian.. } \\
\cline { 2 - 5 } & ..motives and means' (X) & ..outcomes' (Y1) & ..motives and means' + ..outcomes' (Y1) \\
\hline JWT & 623 & 148 & 57 \\
\hline JWT_1 & 525 & 94 & 49 \\
\hline JWT_2 & 275 & 39 & 18 \\
\hline & & Positive 'humanitarian.. & 179 \\
\cline { 2 - 6 } & ..motives and means' (X) & ..outcomes' (Y2) & ..motives and means' + ..outcomes' (Y2) \\
\hline JWT & 623 & 287 & 162 \\
\hline JWT_1 & 525 & 251 & 81 \\
\hline JWT_2 & 275 & 109 & \\
\hline
\end{tabular}

Based on the findings of the empirical model that only the third definition of the 'humanitarian motives and means' (JWT_2) requiring that the military intervention is 'third-party' and waged in support of the target states' government, achieved a significant positive 'humanitarian outcome', it would be fair to consider only the cases identified by this conceptualization of the 'humanitarian motives and means' as being the potential candidates of a 'legitimate HMI'. When considering just the JWT_2 conceptualization, the analysis identified 18 cases of military interventions as fulfilling the above set conditions - subjected that the 'humanitarian outcome' was evaluated using the aggregate conflict deaths, and 81 cases were identified - subjected that the 'humanitarian outcome' was evaluated 
using only the battle deaths indicator. Obviously, the presented sample of the suggested candidates for a 'legitimate $\mathrm{HMI}^{\prime}$ is a product of the adopted conceptualizations during the quantification process, and the result needs to be interpreted with an awareness that it has been generated using a macro approach.

\subsection{Conclusion - an empirical assessment of the legitimacy of HMI}

The findings of this chapter provide a structured overview of the empirical findings surrounding the question of HMI legitimacy. The generated model has tested variously framed definitions of HMI so as to discover a dynamics behind its individual defining criteria and thus to provide a comprehensive picture of their empirically validated associations. The outputs of the model should help clarifying the logics behind the controversial concept of HMI by shifting the debates about its legitimacy into the right direction of what really matters. A detailed interpretation of the model in relation to the individual research questions posed at the beginning of this study together with the practical implications of these findings will be discussed in the concluding chapter of this study. 


\section{CHAPTER}

\section{CONCLUSION - AN EMPIRICAL ASSESSMENT OF THE LEGITIMACY OF} $\underline{\text { HMI }}$

"In the case of intervention as that of revolution, its essence is illegality, and its justification is its success."

Sir William V. Harcourt (1863) ${ }^{432}$

Military intervention of any kind has been for a long time considered an outlawed concept violating the sovereignty of the state. The legally established norm of nonintervention is based on the deeper insights of limiting the resort to war and of preserving the right of national self-determination. Even though, the formal principle of sovereignty remains the basic norm in the international relations, the content of the principle has shifted. Over last thirty years, a legacy of state sovereignty has occurred under a strong pressure, especially from the side of human rights protection. ${ }^{433}$ There has appeared almost a universal agreement that a military intervention for 'humanitarian' purposes could be under some extreme circumstances of human rights violations - though debated ones - justified. This has created a demand for a revision of the outdated concept of HMI. 434

In spite of these developments, the international community has not managed to achieve a consensus neither on the definition of HMI, nor on its legality or legitimacy. This means that there is no commonly accepted doctrine regarding when and how the HMI should be used, if ever; and the interventions for 'humanitarian purposes' thus continue to take place merely on an ad hoc basis. So as to move this controversial debate a step further, this study has set a goal of assessing, whether the right of HMI cannot be endowed with such an overarching legitimacy that would overweight the majority claims about its illegality. Due to the fact that the moral debates about a relative importance of individual arguments either supporting or refusing the legitimacy of HMI do not seem to provide any concrete results; this study has attempted to approach this controversial issue from a different perspective. It has carried out a daring trail to evaluate the legitimacy of HMI by employing quantitative methodologies and empirical evidence, which should provide the new valuable insights into the problem.

While evaluating the legitimacy of HMI, the study has overcome the controversy between the 'motives and means' versus the 'outcomes' of any action

\footnotetext{
432 Harcourt (transl.), 1863, p. 41.

433 Hehir, 1995.

${ }^{434}$ Laughland, 2000; or Köchler, 2000.
} 
by setting them on an equal footing as two complementary parts of legitimacy. The main and guiding assumption of the study was that a 'legitimate HMI' must entail both the 'humanitarian motives and means' as well as the 'humanitarian outcome' on the target state. Existence of the 'humanitarian motives and means' has been evaluated based on the Just War ethics, which stipulates that to be morally defensible; HMI should have no hidden self-interest, should be waged for a just cause and as a last resort, should receive a proper authorization, should use only the minimal violence necessary, and should be waged only with a reasonable probability of success. In spite of the ethical strength of the JWT criteria, their inherent subjectivity leads to the never-ending disagreements about a degree of their fulfillment, and this uncertainty weakens the possibility of a practical usage of the JWT as a tool for assessing the legitimacy of HMI. Therefore, the outcomesoriented consequentialist approach has been used to complement the more traditional motives- and means-oriented approach of the Just War ethics. Existence of a 'humanitarian outcome' has been evaluated using the consequentialist ethics of looking at the impacts of military interventions on the level of humanitarian suffering of the local population in the target state by counting the number of 'saved lives'. Counter-balancing the subjective JWT criteria with the consequentialist approach has enabled to overcome many practical problems of relying solely on the subjective JWT criteria, and has resulted into a plausible normative framework for addressing the dilemmas involved in the HMI concept. The theoretical framework used for the empirical model in this study is thus capable of producing results that would greatly substantiate the existing ethical discourse of HMI.

A daring attempt to quantify the morality behind a complex concept such as the HMI is obviously very problematic. This study is aware of it and it would like to encourage the readers to understand the results of the adopted empirical approach as representing just a very rough approximation of reality. The study explicitly acknowledges that it had to carry out many simplifying assumptions and approximations in the process of quantifying the concept. First of all, the entire study was based on a macro perspective that does not explore the concrete details of each individual conflict, and thus omits often very important shades of the different humanitarian crises. It has sacrificed precision by aiming for universality. It made a systematic comparison over a large sample of cases that allowed it to draw the generalized conclusions regarding the legitimacy of the concept and to adopt an empirically validated definition of a 'legitimate HMI'. Second major weakness of this study is that any of its assumptions and conceptualizations used for the construction of the empirical model for the assessment of legitimacy of HMI can be easily declared problematic. This is, however, something that must be counted with when quantifying such a normatively loaded concept. Whichever methodological approach would have been used for this sensitive topic, 
subjectivity would always appear as being a difficult issue to be addressed. ${ }^{435} \mathrm{In}$ order to minimize this weakness as much as possible, the study clearly described and recorded all the methodological and conceptual decisions in its technical section to allow for the potential readjustments based on a different conception of the problem. This study adopts a position that as long as the presented model remains clear about each step being taken and accepts subjectivity of its conclusions, the quantitative approach can reasonably represent a significant contribution to the current controversial debate about the HMI concept. It claims that without existence of similar empirical efforts, the world of policy practitioners would continue to rely on the rules-of-thumb, making the decisions for the purposes that the used political tool cannot reasonably achieve based on the past practical experience. Nevertheless, it also accepts the reality, which discourages from being over-optimistic about the potential of the outputs of this study to be really utilized by the political decision makers. It is necessary to admit that regardless of the conclusions of this study, HMI is most of all a political decision that is generally not done based on the empirical evidence of its effectiveness, but rather based on the broader political implications of the action.

\subsection{Main findings}

The systematically organized empirical information as presented in the previous chapters and the appendices allow us to answer the research questions posed in the introductory part of the study.

- $\quad$ Are the 'humanitarian motives and means' of military interventions associated with their 'humanitarian outcomes' on the target state and under what conditions?

Assuming that all the methodological decisions adopted during the construction of the model are accepted as being theoretically valid; it is possible to draw an empirically validated statement that in contrast to the insignificant 'humanitarian outcomes' associated with the generally defined military interventions; the military interventions defined by the extensiveness of the 'humanitarian motives and means' entailed do achieve the significant positive 'humanitarian outcomes' on the local population in the target state under certain restricted conditions. Nevertheless, the results of the analysis differ for the two tested dependent variables. If a positive 'humanitarian outcome' is measured by a decrease in the number of overall conflict deaths including those who died outside the battle fields due to the war-related hardships; a military intervention for the 'humanitarian purposes' 436 must be: 1) 'third-party'; and 2) waged in support of the target state's government so as to achieve a significant positive result. This suggests that only

\footnotetext{
435 Robinson, 1998; or Parker, 1999.

436 The 'humanitarian motives and means' were tested based on the aggregate HMI index.
} 
'third-party' military interventions with the 'humanitarian motives and means' waged in support of the target state's government tend to be associated with a positive 'humanitarian outcome' on the entire population of the target state. If just the battle-related fatalities and not the overall conflict fatalities are taken into account while evaluating the effects of military interventions; the results of the study suggest that any type of a 'third-party' military intervention is capable of decreasing a number of lives lost in the course of battle in the target state and that this positive 'humanitarian outcome' is growing by each marginal increase in the level of 'humanitarianism' behind the 'motives and means' of the intervener. ${ }^{437}$ This study has concluded that under certain conditions, it is really possible to achieve 'humanitarian ends' by using 'military means'. These results are significant and represent a valid product of a systematic comparison over many cases.

The results of the analysis confirm the conclusions of the already existing studies exploring the effects of military interventions. They have confirmed the proposition by Regan that each 'third-party' military intervention represents some form of a conflict management with a core motivation to end the hostilities rather than to exacerbate them. ${ }^{438}$ Regan assumed that any intervener carefully considers the potential risks while intervening into ongoing conflict, assessing whether his goals are reachable at an acceptable human cost. This assumption has proved to be valid, especially if the 'humanitarian outcome' of military interventions was evaluated by the changes in the number of battle deaths in the target country. Similarly, the results of the carried out analysis seem to be consistent with the conclusions reached by Regan, and by Elbadawi and Sambanis who also discovered a significant effect of targeting on the 'outcome' of a military intervention in their empirical studies. ${ }^{439}$ They have discovered that any intervention in favor of a rebel movement reduces the cost of sustaining a rebellion. It not only increases a likelihood of success of the rebellion, but it also lowers the rebels' costs of fighting, and it facilitates a recruitment of more rebels. Without existence of such an intervention, the rebellion would be much more quickly suppressed by the government. Therefore, they have in harmony with findings of this study concluded that the interventions in favor of the target state's government tend to result in a positive 'humanitarian outcome'.

- What should be an appropriate definition of a 'legitimate HMI' based on the empirical evidence?

The proposed definition of a 'legitimate HMI' is framed by a guiding assumption that in order to receive a label 'legitimate', the HMI should have both the 'humanitarian motives and means' as well as it should achieve the 'humanitarian

\footnotetext{
${ }^{437}$ The 'humanitarian motives and means' were tested based on the aggregate HMI index

438 Regan, 2000.

${ }^{439}$ Elbadawi \& Sambanis, 2000; and Regan, 2000 \& 2002.
} 
outcomes'. This assumption must be reflected in the resulting definition, since it was adopted during the construction of the theoretical framework for the empirical model and it was then used throughout the entire analysis as a leading working definition. In addition to that, the resulting shape of the definition is shaped by the choice between the two operationalizations of the 'humanitarian outcome'. The study has opted for giving a priority to the broader version that measures the 'humanitarian outcome' as a decrease in the overall conflict fatalities, covering both those who died directly in the battle field and those who died indirectly due to the conflict-related hardships. This choice seems to have theoretically greater weight, since it is more sensitive and more relevant to the general foals of the HMI. Moreover, based on the empirical results of individual tests, the chosen dependent variable is less generous in awarding the 'legitimacy' label and represents thus a stricter threshold. And finally, the proposed definition of a 'legitimate $\mathrm{HMI}^{\prime}$ incorporates the findings not only from the tests of the aggregate JWT but also from the part of the analysis disaggregating the JWT into the individual JWT criteria. The idea is that the JWT criteria with the greatest potential for increasing the 'humanitarian outcomes' of the military interventions should be explicitly listed in the proposed definition, so as to carve it with the highest possible precision.

As was already indicated, a military intervention for 'humanitarian' purposes must be 'third-party' and waged in support of the target state's government to achieve a significant positive 'humanitarian outcome' on the overall population in the target state. The more specific tests of the individual JWT criteria suggest that the criteria of 'just cause' and 'just intent' appear to be the most significant ones in generating the desired 'humanitarian outcome'. Based on these results, the study proposes a following definition of a 'legitimate $\mathrm{HMI}^{\prime}$ : a 'third-party' military intervention by state (or states) for the humanitarian purposes to prevent or to stop the gross violations of human rights or international humanitarian law (preferably waged in support of the target state's government) that attempts and manages to decrease the suffering for the population in the target state. This definition relates both to the 'humanitarian motives and means' by requiring the existence of the JWT criterion of 'just cause' ("..gross violations of human rights or international humanitarian law..") and by requiring the JWT criterion of 'just intent' ("..humanitarian purposes.."), as well as it relates to the 'humanitarian outcome' by requiring that the intervention decreases the conflict severity ("..manages to decrease the suffering..").

The requirement of targeting ("..preferably waged in support of the target state's government..") represents the most problematic aspect of the definition. In spite of the fact that the interventions for 'humanitarian' purposes must be waged in support of the target state's government to be empirically associated with the increased 'humanitarian outcomes', it is very problematic to include this 
requirement as a necessary condition into the definition, since such a condition would be difficult to be morally defended. It would imply that in case that the human rights violations are being conducted by the government itself, the international community would have to remain inactive and to ignore the humanitarian suffering. Due to these facts, the question of targeting is left in the proposed definition only as a recommendation and not as a requirement ("..preferably.."). It is left up to the careful consideration of the political decision makers, whether the risks entailed in the military intervention waged in support of the rebel movement should be taken in a particular situation, given they know that there is - based on the empirical evidence - a high probability of an increased net humanitarian suffering as a result of such an intervention. This discovered condition for the existence of a 'humanitarian outcome' represents the greatest challenge that the concept of HMI faces, and it should be carefully considered before drawing some substantial decisions about the legitimacy of the concept and its implications.

\section{$\Rightarrow$ Legitimate HMI $=f$ ('humanitarian motives and means'; 'humanitarian outcome') \\ $\Rightarrow$ 'Humanitarian motives and means' $=f(J W T$ criteria of 'just cause'+'just intent'; 'third-party' military intervention; recommended intervention in support of the government) \\ $\Rightarrow$ 'Humanitarian outcome' $=f$ (decrease in battle deaths/decrease in conflict deaths)}

- Which cases of military interventions fulfill the adopted definition and represent the candidates for a 'legitimate HMI'?

The study has identified a sample of potential candidates for being awarded a label 'legitimate HMI' that achieved in the quantified model both the 'humanitarian motives and means' 440 as well as the 'humanitarian outcomes'. Each selected case had to achieve more than half of the maximum awarded aggregate JWT score, and had to result in a decreased number of battle deaths, but most preferably of the overall conflict deaths that were selected as theoretically more appropriate. Out of the entire sample of 1114 military interventions recorded in the time period of 1946-2005, the analysis has identified 18 cases of military interventions as fulfilling the above set conditions - subjected that the 'humanitarian outcome' is evaluated using the aggregate conflict deaths, and 81 cases have been identified - subjected that the 'humanitarian outcome' is evaluated using only the battle deaths indicator. Nevertheless, in spite of the fact that the identified cases are the product of a systematic comparison, they represent just an output of the simplified identification formula and of numerous conceptualizations associated with the

440 The 'humanitarian motives and means' were tested based on the aggregate HMI index. 
selected macro approach that should serve merely as an indication of general tendencies and characteristics. As a result of that, the sample needs to be subjected to a deeper qualitative investigation before drawing some final conclusion about legitimacy of the individual cases of HMI.

- Does the concept of HMI have legitimacy if evaluated on the basis of the theoretical frameworks of 'Just War' ethics and consequentialitst ethics?

The findings of this study suggest that HMI can be claimed to represent a legitimate concept, when evaluated based on the theoretical frameworks of the 'Just War' ethics and the consequentialitst ethics, and when all the conditions of the proposed definition of a 'legitimate $\mathrm{HMI}^{\prime}$ are fulfilled. Having reached a conclusion that the empirical evidence confirms the existence of a gap between legality and legitimacy of the concept, the question remains whether the evidence is persuasive enough to create a pressure on the legality to adjust. Are the results of this study strong enough to represent a solid argument for introducing a right of HMI as a legal norm?

In spite of the fact that the presented results are significant and that the positive 'humanitarian outcomes' have been discovered testing both dependent variables, the coefficients indicating the number of 'saved lives' were relatively low in the tests. Moreover, there is another complicating aspect in a form of the targeting condition that has come out of the analysis. It seems that in spite of the fact that the conclusions of the study tend to support more the affirmative position toward the right of HMI (or the emerging 'responsibility to protect' norm) by showing that it is possible to achieve humanitarian ends by using military means; the results still indicate many hidden risks by demonstrating that bringing new manpower and new weapons into the conflict zones can be regardless of the 'humanitarian' character of the 'motives and means' of the interveners very counterproductive to the positive 'humanitarian outcome' without a careful targeting of such interventions.

It means that in spite of the significant positive results of this study, it still does not provide a really persuasive answer to the question, whether the effects of the HMI's are worth the potential risks entailed, and whether the right of HMI should really be introduced. It is necessary to conclude that even with the pro-affirmative conclusions of this study, a resort to the HMI or the decision to take up the 'responsibility to protect' remains to be an extremely dangerous and volatile enterprise. It will always require very sensitive political analysis of its potential short-run and long-run implications in the context of each newly emerging humanitarian crisis. 


\section{i. TECHNICAL APPENDUM TO CHAPTERS 4 AND 5}

\section{A NEW DATA COMPILATION ON CONFLICTS AND MILITARY INTERVENTIONS}

The main purpose of this technical appendum is to introduce a new comprehensive data compilation on conflicts and military interventions covering the period of 1946-2005 that served as a source of input data for the analysis presented in the previous two chapters. The main motivation behind this initiative is to generate a harmonized pool of data that would reduce the amount of work that the researchers in the field of conflict studies have to spend on compiling the data from many different sources. Moreover, this compilation introduces the quantified Just War Theory (JWT) and its constituting criteria, making these new variables accessible to the research community, and providing a fresh data basis for starting a completely new type of research in the field of conflict management. First of all, this section of the study will introduce a rationale behind this compilation initiative and why is it needed. Afterwards, it will describe a content of the new compilation, it will explain the methodological and theoretical concerns that shaped its construction, and will continue by providing a statistical evaluation of the 'consistency', 'correctness' and 'completeness' of the merged data. All the technical details of the merging process, together with a codebook capturing the adjustments applied to the original variables, and the descriptions of the newly generated variables will be presented in the attached technical appendix.

\section{i.1. Rationale behind a new data compilation}

The international community has started to shift normatively away from the nonintervention norm that regulates the use of force in the behavior of the states in the international arena. The interference in domestic affairs has increasingly started to be considered as a legitimate mean for not only the maintenance or reestablishment of international peace and stability, but increasingly also for stopping the excessive human rights violations or human suffering caused by the conflicts abroad. ${ }^{441}$ This trend of a weakening state sovereignty has been demonstrated by a growing number of the UN Security Council resolutions regulating the domestic affairs of the states. A growing interventionism, especially the military one; has, however, also brought many moral and legal questions that need to be deeply researched and evaluated. One of these questions has stood as a basic motivation behind the initiative to create this data compilation. Particularly, it was a question whether the use of force for 'humanitarian' purposes can be considered legitimate. If rephrased... whether the negative humanitarian impacts of internal conflicts can be decreased by employing the additional military means

${ }^{441}$ International Commission on Intervention and State Sovereignty, 2001. 
in a form of military intervention. Finding the answer to this question could represent an important factor in assessing the appropriateness of the gradually increasing legitimacy of military interventionism for the declared 'humanitarian' purposes.

Even though, some researchers have already tried to explore the potential effects of a wide variety of interventions into the conflicts, and have attempted to detect the underlying processes; the linkage between interventions and their effects on the humanitarian crises is still imperfectly understood. ${ }^{442}$ It is questionable, which theoretical models and what kind of data can actually be used for measuring the conflict mitigating effects of military interventions. ${ }^{43}$ With a lack of theory, the econometric models arrive at widely different conclusions, depending on the underlying assumptions and a concrete choice of variables. ${ }^{44}$ Which of these conclusions are more accurate is an empirical question that can only be resolved by systematically confronting the hypotheses emerging from the different models with the actual data. Therefore, so as to move the search for the scientifically grounded answer to the above stated question a step further, there is a need for a comprehensive and easily manageable data covering the problem of military interventionism and the related conflict dynamics in its whole complexity.

\section{i.2. Need for a new data compilation}

\section{i.2.1. Lack of the comprehensive data}

While analyzing the impacts of military interventions, it is important to treat the conflict evolution as a complex and dynamic process. Conflict dynamics is composed of more discrete but mutually related stages: conflict onset, escalation, and potential military intervention; each of them being influenced by various factors, whose causations do not necessarily work in the same directions. ${ }^{445}$ Conflict dynamics is outcome of many different structural and event 'causes' driving its onset, escalation, and shaping a possible decision to intervene; but also outcome of many structural and event 'preventors' encouraging a peaceful conflict resolution and a nonintervention. ${ }^{446}$ Some of the typical 'causes' of violence identified by the earlier studies are, for example: ethnic heterogeneity, political or economic discrimination, or bad neighborhoods. On the other hand, among the typical conflict 'preventors' that make the state conflict-aversive belong, for example: economic development, full democratization, societal resources, or power sharing. ${ }^{447}$ Nevertheless, it is very difficult to establish that a particular bunch of

\footnotetext{
442 Deininger, Klaus \& Lyn Squire, 1996.

443 Miall, 2001.

${ }^{444}$ Deininger, Klaus \& Lyn Squire, 1996.

${ }^{445}$ Lacina \& Gleditsch, 2005.

446 Most \& Starr, 1989.

447 Miall, 2001.
} 
factors represents the sufficient conditions for a violence onset, escalation, or for a decision to intervene. In fact, all these factors are substitutable and work differently in the various complex combinations. ${ }^{448}$

Given the fact that conflicts do not occur, escalate, neither are intervened into by chance; so as to succeed in evaluating the effects of military interventions, the researchers need an access to the data that would be comprehensive enough to enable capturing the conflict dynamics in its whole complexity. Optimal data should cover all major conflict driving and mitigating factors for each individual conflict stage, and where possible these data should be included for both peace and conflict periods. Having such data available, the researchers can not only identify the most important conflict driving and mitigating determinants other than the military intervention; moreover, they can isolate these effects by comparing their developments in countries with and without conflicts to control for the conflict onset; and having set some controls for a decision to intervene, they can compare the evolution of conflicts with and without interventions so as to get the real effects of these interventions. Without going through all these steps, the researchers would be unable to isolate the effects of military interventions from the other factors influencing conflict dynamics, and would face a serious problem of attribution.

The existing datasets are typically not organized in such a comprehensive way. First of all, they are not encompassing enough to enable setting the relevant controls for the individual conflict stages without a substantial data merging and data transformation efforts. Moreover, the datasets often cover only the time periods in which the event of conflict or intervention was identified. A sample of non-event cases - meaning a period without any conflict in case of the conflict data or a period without any intervention in case of the intervention data - is usually omitted. Absence of non-event cases brings a potential risk that restricting the empirical inquiries into conflict dynamics exclusively on the events with certain high levels of violence or interventions could impose severe limits on understanding the conflict development and the related intervention decisions, and could result in severe attribution problems and one-dimensional conclusions, that could fail to uphold on the theoretical grounds. ${ }^{449}$ And finally, the datasets usually focus solely either on the conflict situation in the target states or on the activity of the interveners, and it is often difficult to bridge these two types of information. 450 Obviously, it is always possible for the researchers to merge all the data they need for an effective evaluation of conflicts and military interventions,

\footnotetext{
448 Most \& Starr, 1989.

449 Pfetsch \& Rohloff, 2000; Miall, 2001; or Lacina \& Gleditsch, 2005.

${ }^{450}$ Regan, 2001.
} 
but it is a much time demanding activity distracting the researchers from their actual research focus.

\section{i.2.2. Differences in conflict operationalization}

Another complicating aspect of the existing datasets results from the divergent conceptualizations and operationalizations of conflict in a quantitative research. 451 As is typical for any other type of empirical research, there is a gap between the theoretical concepts and the observable phenomena, which forces the researchers to form some arbitrary operational definitions of the concepts they are exploring. ${ }^{452}$ Existing datasets dealing with conflicts are built based on the various operationalizations of the event, measuring the conflict occurrence and intermittency differently. A logical consequence of this operationalizational heterogeneity is that there is a low overlap of the conflict samples identified by individual datasets, and from that resulting low comparability of the results of the applied analysis depending on the particular conflict sample being used. ${ }^{453}$

Most of the datasets formulate a definition of the conflict based on some arbitrary threshold of the estimated conflict-related fatalities that must be achieved so that the event is identified and included into the conflict sample. Nevertheless, there is no consensus on the exact level of this threshold, neither on the conceptualization of this threshold. First of all, each data collection project identifies conflict based on a different threshold level ranging from 25 to even 1000 of conflict-related fatalities per year or sometimes per entire conflict, which logically causes considerable differences in the identified samples. In addition to that, individual data collection projects adopt a different operationalization of the conflict-related fatalities, meaning that each threshold actually counts something slightly different. Thresholds in some data projects cover only the military battlerelated deaths, some add also the civilian battle-related deaths, and some add also the fatalities caused by the indirect effects of the conflict. Another complicating consequence of the incoherent identification procedures is the same conflicts are being assigned different starting and ending dates, depending on the choice of applied threshold level and intermittency coding. This logically leads to a problem of uncoordinated conflict aggregation and disaggregation; in which the same conflict is treated as ongoing in one dataset, but is divided into more separate ones in another. This causes additional deviances in the conflict samples, and greatly complicates any applied conflict duration analysis on the data. ${ }^{454}$ Additionally, inconsistencies in some conflict samples are partly caused by the unclearly divided

\footnotetext{
451 Pfetsch \& Rohloff, 2000.

452 Collier \& Hoeffler, 2001.

453 This low overlap of the datasets is also partially caused by the shockingly imprecise fatality estimates.

454 See: Fordman \& Sarver, 2001.
} 
lines between the different conflict types in the data collection projects. For example, if some internal conflict experienced an external third-party intervention; is it still an internal conflict, an internationalized internal conflict, or an international conflict? Each dataset approaches this dilemma differently and attaches a different conflict sample to each category. And finally, the fatality data as well as all the other conflict-related data are inherently imprecise and exposed to uncertainty, which is reflected in the existing differences among the records describing the same characteristic in the different data collection projects. ${ }^{455}$ Therefore, the identified samples can be different even if a perfectly harmonized identification procedure would have been adopted by all the data collecting projects, depending on the source of fatality data being used for assessing the fulfillment of the threshold.

A price paid for this operationalizational pluralism is that each dataset depicts a different representation of the world of violence. ${ }^{456}$ For example, a study by Eberwein and Chojnacki compared a degree of convergence of some well-known datasets dealing with internal and interstate conflicts. While evaluating the datasets based on the quantitative thresholds for event identification, the study came up with a disappointing result of less than $50 \%$ of the overlap. This heterogeneity in the identified data samples represents one possible explanation behind the conflicting results of the empirical analyses exploring similar issues. Therefore, it is important to account for these quantitative effects of definitional differences in any empirical research by doing the robustness checks for the different operationalizations. ${ }^{457}$ Nevertheless, proving a validity of the results based on the different operationalizations of the event again requires an extra data work associated with the new data merging.

\section{i.3. Academic contribution of the data compilation}

So as to target the above described inconveniences of the existing datasets on conflicts and military interventions, this section of the study will introduce a new integrated overarching data compilation allowing for a comprehensive analysis of these two events. Data in the compilation will be structured in a way to bridge the information about crisis dynamics in the target countries with the motivation and the strategy of the interveners to be able to analyze the resulting effects of the military interventions on the conflict development in the target states. For that purpose, the compilation will be constructed in a way to take into account the entire complexity of the conflict dynamics. It will combine the data describing all the major conflict driving and mitigating factors relevant for each individual conflict stage, and for a possible decision to intervene; and there possible, it will

\footnotetext{
455 Seybolt, 2007.

456 Collier \& Hoeffler, 2001.

${ }^{457}$ Eberwien \& Chojnacki, 2001.
} 
include the data describing both peace and conflict periods so as to enable isolation of the effects of military interventions from the other conflict driving and mitigating factors without having to engage in a complex data manipulation and merging. Such a comprehensive data structure will enable both the analysis of each individual conflict stage separately, as well as jointly together within a multi-stage analysis. In addition to that this data structure will allow to assess the motivations behind individual interventions and to compare them with their resulting effects on the target state. Another major contribution of this new data compilation will be that it will assist the researchers with addressing the operationalizational heterogeneity of conflict event within the existing datasets. The compilation will be structured in a way to keep an operational definition of conflict as flexible as possible. Different conflict thresholds will be kept in the compilation to provide the researchers with a possibility to choose the most appropriate one, depending on their theoretical assumptions. Joining the conflict samples filtered out based on the various definitions within one data compilation will allow the researchers to switch their choice of the definition easily so as to double-check the correctness of their hypotheses based on the alternative conceptualization, without having to undergo the additional obstacles of structuring and merging new data.

To sum it up, it is possible to claim that the major contribution of this new data compilation will be to help the researchers saving time spent on the routine tasks of data manipulation and merging. These tasks are usually cumbersome, forcing many researchers to turn into technicians for the substantial periods of time, rather than allowing them staying focused on the research design improvements. The second major contribution of this data compilation will be that it will introduce the newly quantified JWT that evaluates the 'motives and means' of the interveners. By making the quantified JWT and its constituting criteria accessible to the research community, the compilation could open a space for answering a new type of research questions using the empirical methods of evaluation. In general, a comprehensive structure of the data compilation should enrich and boost the empirical analysis in the field of conflict studies and especially of conflict management, contributing thus to a broader discussion and further research on these critical issues. ${ }^{458}$

\section{i.4. Data compilation structure}

\section{i.4.1. Typology of the input data}

Structural division of this data compilation has required many theoretical and methodological considerations so that the final output really becomes a flexible and versatile instrument broadly usable in the field of conflict studies. The data in

\footnotetext{
458 The entire data compilation together with a detailed codebook will be accessible at the webpage of the Maastricht Graduate School of Governance.
} 
the compilation are divided into two general categories. The first data type is represented by the so-called 'event data' (ED). It covers only such observations, in which any or both of the following two events occurred: conflict and/or military intervention. The second type of the data is represented by a variety of the socalled 'structural data' (SD). Structural variables represent the typical conflict and intervention 'causes' and 'preventors' that are added into the compilation to enable setting controls for the attribution problem. Whenever possible, the structural variables cover the whole period of 1946-2005, regardless of the existence of a conflict or intervention. In some cases, the compilation includes more structural variables with a similar meaning but differently operationalized; allowing the researchers to make an optimal choice based on their theoretical model.

The input data for this data compilation were not searched from the scratch. Instead of engaging in own data collection activity, which would be extremely time consuming and financially demanding; the study combines data from the existing and freely available datasets with various focus and applicability. Some input variables were obtained from the famous existing data collection projects on conflicts and interventions, other variables were provided by the different international organizations or personally by the researchers. The compilation attempts to combine the best possible mix of variables describing the events of conflict and military intervention, which come from the reliable data sources, and which are available in a longer time-frame. The following table represents a complete list of the input datasets constituting this compilation. Apart from the original citation of the individual input datasets and the working names attached to the datasets to simplify any reference to them; the table indicates the actually included time coverage of the data, a description of the general focus of the data, and an indication of the data type.

Table 21: Input datasets into the new data compilation ${ }^{459}$

\begin{tabular}{|l|l|l|l|l|l|}
\hline \multicolumn{7}{|c|}{ INPUT DATASETS } \\
\hline \multicolumn{1}{|c|}{ Input dataset name } & Original citation & $\begin{array}{l}\text { Incl. time } \\
\text { coverage }\end{array}$ & \multicolumn{1}{|c|}{ Data focus } & $\begin{array}{l}\text { Data } \\
\text { type }\end{array}$ & $\begin{array}{c}\text { New dataset } \\
\text { name }\end{array}$ \\
\hline $\begin{array}{l}\text { COW National Military } \\
\text { Capabilities (NMC v.3.0) }\end{array}$ & $\begin{array}{l}\text { Singer, Bremer \& } \\
\text { Stuckey, 1972 }\end{array}$ & $1946-2001$ & $\begin{array}{l}\text { Military } \\
\text { capabilities }\end{array}$ & SV & EUGene SV \\
\hline $\begin{array}{l}\text { COW State System } \\
\text { Membership List } \\
\text { (v.2008.1) }\end{array}$ & $\begin{array}{l}\text { Correlates of War } \\
\text { Project, 2008 }\end{array}$ & $1946-2005$ & $\begin{array}{l}\text { State system } \\
\text { membership }\end{array}$ & SV & EUGene SV \\
\hline
\end{tabular}

459 The data compilation was a first prerequisite step of the whole study presented in the previous chapters. Due to the fact that it was complied already in years 2007-2008, the age of some datasets may already seem slightly outdated. 


\begin{tabular}{|c|c|c|c|c|c|}
\hline $\begin{array}{l}\text { COW National Trade } \\
\text { (v.2.0) }\end{array}$ & \begin{tabular}{|l} 
Barbieri, Keshk \& \\
Pollins, 2008
\end{tabular} & 1946-2005 & National trade & SV & EUGene SV \\
\hline $\begin{array}{l}\text { COW Colonial Contiguity } \\
\text { (v.3.0) }\end{array}$ & $\begin{array}{l}\text { Correlates of War } \\
\text { Project }\end{array}$ & 1946-2005 & Colonial ties & SV & EUGene SV \\
\hline $\begin{array}{l}\text { COW Minimum Distance } \\
\text { (v.0.97) }\end{array}$ & $\begin{array}{l}\text { Gleditsch \& } \\
\text { Ward, } 2001\end{array}$ & 1946-1998 & $\begin{array}{l}\text { Geographic } \\
\text { data }\end{array}$ & SV & EUGene SV \\
\hline COW Alliances (v.3.0) & \begin{tabular}{|l} 
Gibler \& Sarkees, \\
2004
\end{tabular} & $1946-2000$ & Alliances & SV & EUGene SV \\
\hline Polity III (v.96) & \begin{tabular}{|l|} 
Marshall \& \\
Jaggers, 2002
\end{tabular} & 1946-2004 & $\begin{array}{l}\text { Political } \\
\text { regimes }\end{array}$ & SV & EUGene SV \\
\hline EUGene (v.3.2) & $\begin{array}{l}\text { Bennett \& Stam, } \\
2000\end{array}$ & 1946-2005 & $\begin{array}{l}\text { Expected } \\
\text { utilities }\end{array}$ & SV & EUGene SV \\
\hline $\begin{array}{l}\text { UN World Population } \\
\text { Prospects }\end{array}$ & \begin{tabular}{|l|} 
UN World \\
Population \\
Prospects, 2006 \\
\end{tabular} & $1946-2005 *$ & $\begin{array}{l}\text { Demographic } \\
\text { data }\end{array}$ & SV & UN Pop \\
\hline $\begin{array}{l}\text { UN Food and Agriculture } \\
\text { Organization (FAO) }\end{array}$ & FAOSTAT & 1961-2005 & $\begin{array}{l}\text { Geographic } \\
\text { data }\end{array}$ & SV & UN FAO \\
\hline $\begin{array}{l}\text { UNSD Demographic } \\
\text { Statistics }\end{array}$ & \begin{tabular}{|l|} 
UN Statistics \\
Division \\
\end{tabular} & 1995-2005 & Demographics & SV & UN SD \\
\hline $\begin{array}{l}\text { Forcibly Dislocated } \\
\text { Populations (FDP v.2006a) }\end{array}$ & Marshal, 1999 & 1946-2005 & \begin{tabular}{|l}
$\begin{array}{l}\text { Forced } \\
\text { migration }\end{array}$ \\
\end{tabular} & SV & FDP \\
\hline Democratization (v.07) & $\begin{array}{l}\text { Cederman, Hug } \\
\text { \& Krebs, } 2007\end{array}$ & 1946-2005 & $\begin{array}{l}\text { Political } \\
\text { regimes }\end{array}$ & SV & DEM \\
\hline $\begin{array}{l}\text { Minorities at Risk Project } \\
\text { (MAR) }\end{array}$ & $\begin{array}{l}\text { Minorities at Risk } \\
\text { Project, } 2005\end{array}$ & $1946-2005 *$ & $\begin{array}{l}\text { Ethno- } \\
\text { politicized } \\
\text { conflict } \\
\end{array}$ & SV/ED & MAR \\
\hline $\begin{array}{l}\text { Quality of Government } \\
\text { (QoG v.07) }\end{array}$ & \begin{tabular}{|l|} 
Teorell, \\
Holmberg \& \\
Rothstein, 2007 \\
\end{tabular} & $1946-2005 *$ & Government & SV & QoG \\
\hline $\begin{array}{l}\text { Major Episodes of } \\
\text { Political Violence (MEPV } \\
\text { v.2006) }\end{array}$ & $\begin{array}{l}\text { Marshall, 1999, } \\
2002\end{array}$ & 1946-2005 & $\begin{array}{l}\text { Violent } \\
\text { conflicts }\end{array}$ & ED & MEPV \\
\hline $\begin{array}{l}\text { Political Instability Task } \\
\text { Force (PITF v.06) }\end{array}$ & Bates et al., 2003 & $1955-2005$ & State failures & ED & PITF \\
\hline $\begin{array}{l}\text { UCDP/PRIO Armed } \\
\text { Conflict Dataset (ACD } \\
\text { v.4-2007) }\end{array}$ & $\begin{array}{l}\text { Gleditsch et al., } \\
2002\end{array}$ & 1946-2005 & $\begin{array}{l}\text { Violent } \\
\text { conflicts }\end{array}$ & ED & $A C D$ \\
\hline $\begin{array}{l}\text { Regan - Third Party } \\
\text { Interventions (v.2002) }\end{array}$ & Regan, 2002 & 1946-1999 & Interventions & ED & Regan 1 \\
\hline $\begin{array}{l}\text { Regan \& Aydin - } \\
\text { Intrastate Conflicts } \\
\text { (v.2004) }\end{array}$ & $\begin{array}{l}\text { Regan \& Aydin, } \\
2004\end{array}$ & 1946-1999 & $\begin{array}{l}\text { Intrastate } \\
\text { violent conflicts }\end{array}$ & ED & Regan 2 \\
\hline $\begin{array}{l}\text { Regan - Intrastate } \\
\text { Conflicts (v.2000) }\end{array}$ & Regan, 2000 & 1946-1999 & $\begin{array}{l}\text { Intrastate } \\
\text { violent conflicts }\end{array}$ & ED & Regan 3 \\
\hline $\begin{array}{l}\text { COW Military Interstate } \\
\text { Dispute (MID v.2.1) }\end{array}$ & \begin{tabular}{|l|} 
Jones, Bremer \& \\
Singer, 1996 \\
\end{tabular} & 1946-1992 & \begin{tabular}{|l|} 
Interstate \\
violent conflicts \\
\end{tabular} & ED & \begin{tabular}{|l|} 
EUGene \\
MID \\
\end{tabular} \\
\hline $\begin{array}{l}\text { COW Military Interstate } \\
\text { Dispute (MID v.3.0) }\end{array}$ & $\begin{array}{l}\text { Ghosten, Glen \& } \\
\text { Bremer, 2004 }\end{array}$ & 1993-2001 & $\begin{array}{l}\text { Interstate } \\
\text { violent conflicts }\end{array}$ & ED & $\begin{array}{l}\text { EUGene } \\
\text { MID }\end{array}$ \\
\hline
\end{tabular}




\begin{tabular}{|l|l|l|l|l|l|}
$\begin{array}{l}\text { International Crisis } \\
\text { Behavior (ICB II v.8) }\end{array}$ & $\begin{array}{l}\text { Brecher \& } \\
\text { Wilkenfeld, 1997, } \\
2000\end{array}$ & $1946-2005$ & $\begin{array}{l}\text { Interstate } \\
\text { violent conflicts }\end{array}$ & ED & $\begin{array}{l}\text { ICB II \& } \\
\text { EUGene ICB }\end{array}$ \\
\hline $\begin{array}{l}\text { International Crisis } \\
\text { Behavior (ICB Dyad v.2.0) }\end{array}$ & Hewitt, 2003 & $1946-2001$ & $\begin{array}{l}\text { Interstate } \\
\text { violent conflicts }\end{array}$ & ED & ICB Dyad \\
\hline $\begin{array}{l}\text { International Military } \\
\text { Intervention (ICPSR 6035) }\end{array}$ & $\begin{array}{l}\text { Pearson \& } \\
\text { Baumann, 1992 }\end{array}$ & $1946-1989$ & $\begin{array}{l}\text { Military } \\
\text { interventions }\end{array}$ & ED & Mil Int I \\
\hline $\begin{array}{l}\text { International Military } \\
\text { Intervention (ICPSR } \\
\text { 21282) }\end{array}$ & $\begin{array}{l}\text { Kisangani \& } \\
\text { Pickering, 2007 }\end{array}$ & $1989-2005$ & $\begin{array}{l}\text { Military } \\
\text { interventions }\end{array}$ & ED & Mil Int II \\
\hline Peacebuilding (v.2000) & $\begin{array}{l}\text { Doyle \& } \\
\text { Sambanis, 2000 }\end{array}$ & $1946-1999$ & Interventions & ED & Peace \\
\hline
\end{tabular}

* Different time coverage for individual variables

\section{i.4.2. Data structure of the compilation}

So as to make the data compilation a usable instrument for studying both the development of the conflict itself, and the motivations and effects of the interventions; the data compilation is constructed using two different units of analysis, which are mutually combinable without any undesired data losses. The first part of the data compilation is structured in the country-years (CC), where each line of the data contains information about a country in a year. This data section gathers, first of all, the 'structural data' (SD) that can be flexibly attached as explanatory or control variables both to the intervening state (side A) and to the target state (side $B$ ), depending on the research question being asked. The countryyear part of the data compilation also includes the 'event data' (ED) that traces the development of the conflict or intervention in the target state only (side B).

The second part of the data compilation is created based on the directed country dyad-year (DD) unit of analysis, where each line of the data contains information about a pair of two states in a year, describing the position of a potential or actual intervener (side A) vis-à-vis a target state (side B) in individual years. ${ }^{460}$ The main reason for adding the second unit of analysis is an attempt to incorporate the role of the intervener into the theoretical framework of the conflict dynamics, and thus to broaden a possible scope of the analysis being carried out using the data. The dyadic part of the data is composed, fist of all, of the various 'structural variables' (SD) capturing the mutual relations and ties between the interveners and the target states. The dyadic section of the compilation includes also the 'event data' (ED) that capture different motivations behind the decisions to intervene, and that describe a form and structure of these interventions.

460 In the directed dyadic data, for example, Britain vs. Somalia in 1994 is treated as distinct from Somalia vs. Britain in 1994. 
Table 22: Data structure of the compilation

\begin{tabular}{|l|l|}
\hline \multirow{4}{*}{$\begin{array}{c}\text { Structural data } \\
\text { (SD) }\end{array}$} & Country-year (CD) \\
\cline { 2 - 3 } & Conflict onset driving factors (side B, potentially side A) \\
\cline { 2 - 3 } & Conflict escalation driving factors (side B, potentially side A) \\
\cline { 2 - 3 } & Conflict severity driving factors (side B, potentially side A) \\
\cline { 2 - 3 } & Directed dyad-year (DD) \\
\hline \multirow{4}{*}{\begin{tabular}{l} 
Event data (ED) \\
\cline { 2 - 2 }
\end{tabular}} & Decision for intervention driving factors (side A-B) \\
\cline { 2 - 3 } & Country-year (CD) \\
\cline { 2 - 3 } & Intervention development (side B) \\
\cline { 2 - 3 } & Directed dyad-year (DD) \\
\cline { 2 - 3 } & Intervention strategy (side A-B) \\
\hline
\end{tabular}

* Side $\mathrm{A}=$ intervener, side $\mathrm{B}=$ target state

\section{i.5. Merging process}

Integration of the heterogeneous datasets always represents a problematic task. Due to the fact that individual datasets are typically developed, deployed, and maintained independently to serve the specific needs; they tend to suffer from a huge structural heterogeneity causing various overlaps and contradictions of the data in many dimensions. The merging process of such heterogeneous data thus requires deeper thoughts about a complexity of the matching process, and many important methodological decisions about the coding of individual variables that have a substantial influence on the resulting output. ${ }^{461}$ The most important encountered methodological issues will be shortly discussed below; since the future users of this data compilation will need to be aware of them, and will have to address them when using the data. The process of merging will be described in the following three steps:

- $\quad$ STEP 1: Creation of a common unit of analysis

- $\quad$ STEP 2: Multiple entries resolution

- $\quad$ STEP 3: Merging of the adjusted datasets

\section{i.5.1. Creation of a common unit of analysis}

Taking into account the existing differences in the units of analysis used in the individual input dataset, their harmonization was a precondition for being able to

${ }^{461}$ Naumann \& Häussler, 1999; or International Standards Organization, 1999. 
proceed with the data merging itself. Such a harmonization requires that the same objects/events in each dataset become coded and identified in a same way to make the observations in each dataset describing the same story; otherwise, the merging could result in the undesired mistakes. Each input dataset introduced some kind of obstacle to the data transformation, whose particularities can be traced in the technical appendix of this appendum. Nevertheless, there were some common issues that will be briefly discussed below.

\section{i.5.1.1. Time-unit of analysis}

Year was selected as a common time-unit of analysis in both parts of the data compilation. This choice seemed to be the most appropriate given the fact that a majority of scholars in the field of political sciences rely on the annual data. The main advantage of the annual data is that they represent a natural political break between the budget and electoral cycles. Therefore, they are commonly used by the data collecting institutions, and are thus also widely available. Having assigned the year as a preferred time-unit of analysis, it was necessary to select an appropriate time-spam. Due to the fact that conflicts and interventions are relatively rare events, this data compilation does not focus just on the most recent cases but rather on a longer time spam of 1946-2005 to be able to gather a sufficiently large amount of cases. Limiting the beginning of the selected time frame by the year 1946 is based on two pragmatic reasons. First of all, most of the larger data collection projects do not gather data for a period before WWII; and therefore, there are not enough existing data available for these years. Secondly, it did not seem to be wise comparing the conflicts and interventions that happened before WWII with the more recent ones. Not only that the political situation in the international arena has changed dramatically, but also the concepts that are measured by the variables have gradually changed their meaning and status throughout the years.

Harmonization of the time-unit of analysis in individual input datasets differed for the 'structural' and for the 'event data'. Transformation of the 'structural data' into the yearly indicators was a relatively simple task, since most of the data were already in their original form recorded in the country-years. Nevertheless, there were some 'structural data' that were originally country-constant, or recorded in the various time intervals. Such data were either expanded into constant yearly values, or were interpolated within the original time intervals so as to indicate the estimated values for each year. ${ }^{462}$ Transformation of the 'event data' had less of the

\footnotetext{
462 Smoothing function used for the interval based data took a difference between the nearby known values of the five-year measurements and divided it by five. The result was then added to the first known value in an additive way for each successive year. It is a natural approach that shows the average growth tendencies of the data. The main disadvantage of this approach is its assumption of linearity of development throughout the five-year intervals. It causes that the data lack the peaks associated with the various shocks such as a conflict or violent intervention within the intervals. The effects of such events can be traced only gradually and not anyhow strongly, if the data are smoothed in
} 
common traits, since the input datasets applied many different ways of keeping track of events in time. While some datasets recorded the developments of the event each month or year, the other treated the event as discrete information with one record regardless of its duration. So as to harmonize this incoherent time-unit of analysis, the monthly data were merged into the yearly data, while event constant data have been extended into the constant yearly ones.

\section{i.5.1.2. Event-unit of analysis}

The most complicated part of the process of unit of analysis harmonization was to find a common identification procedure for the 'event data', which were in their original form based on many different units of analysis. The handiest option how to approach the incoherent identification of the events of conflicts and interventions in individual datasets seemed to be by tying the events to the place of their location. By doing that it is possible to use the transformed data most flexibly - both for the studies focusing on the conflict development and for the studies evaluating the effects of military interventions on the target state. Therefore, the first part of the data compilation was transformed into a homogenous country-year unit of analysis (CC), which enables evaluating the developments in countries with and without a conflict, and developments with and without various types of third party interventions. The second part of the data compilation was structured based on the directed country dyad-year unit of analysis (DD), which makes it possible to trace the mutual relationships between the intervener and the target. By tying the events to their respective countries, the problem of finding a coherent identification procedure for conflicts or interventions in both parts of the data compilation became solved by itself by shifting it away from the original event (conflict and intervention) identification task to the easier task of object (country) identification.

The obstacles of tying the events to the country of their location were different for the country-year data and for the country dyad-year data. The least problematic transformation of the 'event data' into the country-based observations was when the data were structured on the country-event level, such as the MEPV dataset; which treat individual countries involved in the conflict/intervention separately, while explicitly acknowledging the location of the event. However, some of the input datasets were originally recorded at the event level, such as ACD dataset. Such a type of data brings all the countries engaged in the conflict/intervention under one observation, without describing the development of the event in each participating country separately. These data had to be disaggregated into the country-event level data by attaching the events to the countries of location based

such a way. Due to these disadvantages, interpolation was used only in cases that there were no alternative reliable data covering the entire time period of the data compilation. 
on the information available in other datasets or based on the information from the secondary sources.

Transformation of the input data into the country-dyadic form that distinguishes between the target state and the intervener represented another complicated task. Even though, some input datasets were in their original form constructed as dyadic, such as the COW Colonial Contiguity dataset, these represented more an exception than a rule. Some datasets were originally available in some type of a hybrid from, such as the MID or the ICB datasets, coming distributed in more files, which had to be first merged together to create the dyads. However, most of the input datasets were originally not created with the intent to support a dyadic form, and had to be converted into the dyadic interactions manually. The necessary merges and conversions that were carried out while transforming the data were not always straightforward; since some of the datasets did not provide easily extractable identification of the interveners, or did not distinguish among individual parties of the conflict to enable division of the intervener from the target state. Due to the fact that it was not always possible to identify both sides of the dyad in some of the input datasets, the dyadic data represent just a smaller sub-section in this compilation.

\section{i.5.1.3. Object-unit of analysis}

After tying all the events to the countries of their location, a country has become the main object of analysis unifying the both parts of the data compilation. Nevertheless, before merging the data together; it was necessary to harmonize the coding and identification procedures for the countries in individual datasets. The existing inconsistencies are caused by the disagreements among the political scientists about the exact procedure of how to code and identify the countries; especially those that historically changed their status as a result of either country mergers or splits. Due to the lack of the overarching rules regulating the country coding and identification procedure, each data collection project applied its own method. Therefore, the process of harmonization of the object-unit of analysis required an explicit acknowledgement of how the new data compilation approached the coding and inclusion of these problematic cases.

\section{i.5.1.3.1. Object coding}

The system of coding rules for the countries was selected with a main consideration to the compilation with the maximum possible flexibility for the applied research. For that purpose, both the country-year and the country dyadyear data were assigned with two identical types of country coding that belong among those most frequently used in the existing data collection projects. Such a choice of coding procedure made both parts of the data compilation not only mutually combinable among themselves without any data losses, but also easily 
combinable with most of the other existing data collections for the potential additional merges. The two adopted coding systems are based on the three-digit identification numbers: the one adopted by the Correlates of War Project (COW) the so called COW ccode; 463 and the one adopted by the United Nations Statistics Division (UNSD) -the so called UN ccode. ${ }^{464}$ A complete list of country codes together with all the adjustments carried out in the process of coding harmonization in each individual input dataset are presented in the technical appendix of this chapter.

\section{i.5.1.3.2. Object identification}

While the country coding rules used in both parts of the data compilation are identical; each compilation part was constructed based on a different country identification procedure. Country identification procedure in the country-year data was based on the Quality of Government (QoG) project country list that includes all countries in the world recognized by the United Nations as of the year 2002 plus an addition of 13 historical nations. This makes together 204 countries included throughout the whole time period of 1946-2005. ${ }^{465}$ The main advantage of the QoG country list is that it includes all countries in all years throughout the whole time spam of the data compilation, regardless of existence or absence of their sovereignty. Such a data structure enables analyzing the situation in the countries more consistently, by allowing to assess a relative importance of the observed changes in a certain indicator. For example, it is crucial to have the data on crude mortality, migration rate, or presence of violence within the society available for a period as long as possible; to be able to draw some conclusions about the escalatory tendencies of a conflict, and to be able to isolate the effects of a potential intervention given a general situation in the target country.

Countries in the directed country dyad-year data part of the compilation were, on the other hand, identified based on the Correlates of War (COW) state membership list, which identifies only such countries that have a population greater than 500000, and that are "sufficiently unencumbered by legal, military, economic, or political constraints to exercise a fair degree of sovereignty and

\footnotetext{
${ }^{463}$ COW country code is a homogenous three-digit identification number for each country adopted by the Correlates of War Project (COW). To see a complete list of the COW ccodes, see the last version of the COW State System Membership List for years 1816-2008 that is available online at http://www.correlatesofwar.org/COW2\%20Data/SystemMembership/2008/System2008.html.

${ }^{464} \mathrm{UN}$ country code is a three-digit country code defined in ISO 3166-1, part of the ISO 3166 standard, which was published by the International Organization for Standardization (ISO) to represent countries, dependent territories, and special areas of geographical interest. It is identical to the three-digit country code developed and maintained by the United Nations Statistics Divisions. See:

http://www.iarc.fr/en/publications/pdfs-online/epi/sp95/sp95-app1.pdf.

465 Teorell, Holmberg \& Rothstein, 2007.
} 
independence". ${ }^{466}$ As follows from the defining criteria, in contrast to the QoG country list; the COW state membership omits the smallest countries and the countries in the periods without existence of an effective sovereignty. Therefore, the COW list identifies a smaller sample of country-years for constructing the country dyads than the QoG country list. ${ }^{467}$ All together, the COW country list constitutes 199 countries. A more restricted country identification approach in the dyadic part of the data compilation was adopted to provide the researchers with a possibility to decide whether existing sovereignty is or is not critical for the conclusions of the researched question and to adopt the more appropriate system of country identification. So as to prevent occurrence of the possible mistakes that could be caused by a manual creation of the individual country dyad-years and by a continuous verification that both dyad members are included in the COW country list in that particular year; the list of dyad-years was generated by the Expected Utility Generation and Data Management Program (EUGene V 3.2). ${ }^{468}$

So as to make the QoG and COW country lists better combinable with each other and better usable for the purposes of this data compilation, they had to undergo certain adjustments. The coding of the historical nations in the QoG country list was slightly simplified and adjusted to the country coding of the COW country list. Some modifications were also carried out in the EUGene generated COW list of country-dyads. The dyads were expanded to include four artificial country codes denoting the different types of multilateral operations. Thanks to these plugged in artificial codes, the dyadic data can distinguish among the interventions led by the various international organizations dealing with the international peacekeeping of a multinational nature, or among the multilateral interventions outside any established institutional structure. A complete list of the countries identified by both country lists together with all the carried-out adjustments is to be found in the technical appendix of this chapter.

\section{i.5.1.4. Advantages of the adopted units of analysis}

Creating such a data structure offered several major advantages to the potential users of the data compilation. First of all, due to the fact that both the country-year and the directed country dyad-year data share the same object- and time-unit of analysis; the country-year data can be easily combined with the country dyadic ones in a way of being attached interchangeably to both sides of the dyad: to the intervener or the target state. The second major advantage of this data structure follows from its definitional variability. In the country-based data, it is possible to

\footnotetext{
${ }^{466}$ Small \& Singer, 1982: 20. Legal sovereignty is operationalized as a formal recognition by any two major states or membership in the United Nations.

${ }^{467}$ In comparison to the country-year data, the dyadic data omit at least one year of existence in case of 176 countries.

${ }^{468}$ Bennett \& Stam, 2000. EUGene V 3.2 is available at http://www.eugenesoftware.org.
} 
maintain a flexibility of choosing a preferred event definition that was used by any of the input datasets depending on the theoretical assumptions of the users of the data compilation. The users of the compilation can utilize the working name of the dataset that used the most convenient definition for their research purposes to filter out only the country-years or the country-dyad years, for which the event was identified. Afterwards, the users can easily add additional explanatory variables from the other datasets that are attached to the same country-year or country dyad-year so as to enrich a possible scope of the analysis. Therefore, the users can run the analysis based on more different operationalizations of the event so as to double-check the correctness of their results, and they can do so without having to engage into any extra time consuming data work. The list of the event definitions included into the compilation is provided below.

Table 23: Event definitions in the data compilation

\begin{tabular}{|c|c|c|c|}
\hline \multicolumn{4}{|c|}{ EVENT IDENTIFICATION } \\
\hline $\begin{array}{c}\text { Dataset } \\
\text { name }\end{array}$ & Event identification definitions + thresholds & $\begin{array}{c}\text { Covered } \\
\text { time frame }\end{array}$ & $\begin{array}{c}\text { Number of } \\
\text { identified events }\end{array}$ \\
\hline MEPV & $\begin{array}{l}\text { Interstate, internal, or communal political violence: } \\
\text { conflict intensity threshold = at least } 500 \text { directly related } \\
\text { conflict deaths over year. }\end{array}$ & 1946-2005 & $\begin{array}{l}324 \text { episodes of } \\
\text { armed conflict } \\
\text { (including } 28 \text { of } \\
\text { ongoing cases) } \\
\end{array}$ \\
\hline PITF & $\begin{array}{l}\text { Ethnic and revolutionary internal conflicts: mobilization } \\
\text { threshold = each party must mobilize minimum of } 1000 \\
\text { people + conflict intensity threshold = at least } 1000 \text { direct } \\
\text { conflict-related deaths over the full conflict and at least } \\
\text { one year with an annual conflict-related death toll } \\
\text { exceeding } 100 \text { fatalities. Adverse regime changes: index } \\
\text { threshold = at least a six point drop in the value of a state's } \\
\text { POLITY index score over a period of three years or less. } \\
\text { Genocides and politicides: definition = a coherent action } \\
\text { by the state or by a dominant social group against the } \\
\text { unarmed civilians causing a destruction of people's } \\
\text { existence, in whole or in part. }\end{array}$ & 1955-2005 & $\begin{array}{l}76 \text { episodes of } \\
\text { ethnic wars, } 64 \\
\text { episodes of } \\
\text { revolutionary } \\
\text { wars, } 112 \text { episodes } \\
\text { of adverse regime } \\
\text { change, } 41 \\
\text { episodes of } \\
\text { genocide and } \\
\text { politicide }\end{array}$ \\
\hline ACD & $\begin{array}{l}\text { Interstate and internal conflicts: conflict intensity threshold } \\
=\text { at least } 25 \text { battle-related deaths over year + conflict type } \\
\text { threshold = at least one party of the conflict is the } \\
\text { government. }\end{array}$ & 1946-2005 & $\begin{array}{l}250 \text { episodes of } \\
\text { armed conflict }\end{array}$ \\
\hline Regan & $\begin{array}{l}\text { Internal conflicts: conflict intensity threshold = at least } 200 \\
\text { fatalities over the entire conflict. Third party } \\
\text { interventions: definition = convention breaking military } \\
\text { and/or economic activities in the internal affairs of a } \\
\text { foreign country targeted at the government with the aim } \\
\text { of affecting the balance of power between the government } \\
\text { and the opposition forces. }\end{array}$ & 1946-1999 & $\begin{array}{l}\text { 150/138 episodes } \\
\text { of internal } \\
\text { conflicts and } 101 \\
\text { interventions }\end{array}$ \\
\hline
\end{tabular}




\begin{tabular}{|c|c|c|c|}
\hline MID & $\begin{array}{l}\text { Militarized interstate disputes: conflict intensity threshold = } \\
\text { use of military force with fewer than } 1000 \text { combatant } \\
\text { deaths per participant per year. }\end{array}$ & $1946-2001$ & $\begin{array}{l}2332 \text { episodes of } \\
\text { militarized } \\
\text { interstate disputes }\end{array}$ \\
\hline ICB & $\begin{array}{l}\text { International conflicts: definition = a pair of states, where } \\
\text { at least one of the states directed a hostile action against } \\
\text { the other. }\end{array}$ & $1946-2005$ & $\begin{array}{l}447 \text { episodes of } \\
\text { international crisis } \\
\text { and } 983 \text { crisis } \\
\text { actors } \\
\end{array}$ \\
\hline Mil Int & $\begin{array}{l}\text { Military interventions: definition = a purposeful } \\
\text { movement of regular troops or forces of one country } \\
\text { inside another because of some political issue or dispute. }\end{array}$ & $1946-2005$ & 447 interventions \\
\hline Peace & $\begin{array}{l}\text { Civil wars: conflict intensity threshold = organized military } \\
\text { opposition of the rebels against the government of an } \\
\text { internationally recognized state with at least } 1000 \text { battle } \\
\text { deaths for the entire war as long as the war caused } 1000 \\
\text { deaths in any single year + war type threshold = at least one } \\
\text { significant settlement or truce or a 'third-party' peace } \\
\text { operation. }\end{array}$ & 1946-1999 & $\begin{array}{l}124 \text { episodes of } \\
\text { civil wars with } \\
\text { third-party peace } \\
\text { operations }\end{array}$ \\
\hline
\end{tabular}

Due to the fact that the event occurrence is identified flexibly depending on the adopted definition in this data compilation; some of the variables seem to be providing conflicting information about the same characteristic of the same event. This is, however, a logical consequence of evaluating a characteristic of the same event that is operationalized in more different ways; given the characteristic is closely dependent on the definition. A typical example of such an inconsistency is represented by the data indicating conflict duration. In case that a softer definition of conflict is selected - for example 25 battle-related deaths per year, the conflict will be indicated as lasting longer; however, if a stricter definition is selected - for example 1000 battle-related deaths per year, the same conflict will be recorded as lasting much shorter. Therefore, the users of the compilation should take this fact into account when combining the variables vulnerable to the definitional changes.

\section{i.5.1.5. Multiple entries resolution}

After harmonizing the units of analysis in the input datasets, there appeared the cases of multiple information entries related to the same country-year or countrydyad year. A typical reason for their occurrence was either a simple fact that there were more conflicts or more interventions taking place in the same country-year or the country dyad-year; or that some countries were treated as two separate ones in the original dataset, but are treated as belonging to one country based on the country identification procedure applied in this data compilation. Before merging the input datasets together, the multiple entries had to be localized and replaced by the single entries. ${ }^{469}$ There are many possible options on how to aggregate the

\footnotetext{
469 Rahm, Erhard and Hong Hai Do, 2000. 'Data Cleaning: Problems and Current Approaches', IEEE Bulletin of the Technical Committee on Data Engineering, Vol 23 No. 4.
} 
multiple entries, and thus to solve the conflict among more values recorded for one observation. To carry out this replacement consistently, this study used the declarative aggregation functions by the means of the Structured Query Language (SQL) statements. ${ }^{470}$ This method uses the identifying variables and the SQL GROUP BY operator to group the multiple entries according to the assigned resolution functions. The country-year data were grouped by the COW ccode of the target state and the year; while the directed county dyad-year data were grouped by the COW ccode of the target state, the COW ccode of the intervener, and the year.

All the chosen resolution functions for each variable together with all the adjustments related to the data grouping are carefully recorded in the technical appendix, so that the future users get a clear picture of what the data are actually telling. There were some common methods applied when selecting the appropriate resolution functions for the variables. In general, the aggregate function of maximum was used for the binary variables to indicate the occurrence of the measured phenomena in a given country-year or a country dyad-year, regardless of in which month the event occurred or how many of these events actually took place. A typical step complementing in such a way aggregated multiple entries was to create an extra variable counting a frequency of occurrence of the event. Without plugging in this additional variable, the important information about the event's frequency would get lost in the aggregation process. The variable indicating a frequency of the event was usually created either by using an aggregation function sum in case of a binary variable to sum the positive records of that event occurrence; or by using an aggregation function count in case of a nonbinary variable to count all the cells identifying occurrence of the event.

Another often repeated type of data aggregation involved the variables indicating duration of the events. The multiple entries were merged in a way to code the event as ongoing as long as the country was experiencing it, regardless of the frequency of that event occurrence. Therefore, the variables indicating event beginning were aggregated by a function minimum to denote a day or a month, in which the first conflict or intervention began in particular country-year or country dyad-year. Similarly, an aggregate function of maximum was typically used to indicate the termination of the last conflict or intervention in particular countryyear or country dyad-year.

While aggregating the multiple entries in the ordinal variables, three following aggregate functions were typically applied interchangeably depending on the characteristics of the concept and a flexibility of its interpretation: maximum, average or sum. The most straightforward solution was to use the function maximum or average so as to indicate either the most intensive level or the average level of the

${ }_{470} \mathrm{SQL}$ is a database computer language used for managing data in relations database management systems. 
measured phenomenon as experienced in particular country-year or country dyadyear. However, in case that the variable was not only ordinal but also ordered gradually and proportionally; an alternative function sum was sometimes given preference. By summing up all the values recorded for the variable in a given country-year or country dyad-year, the resulting value provided a picture about the scale of the measured characteristics.

In some cases, when a variable was neither binary nor ordinal, and also did not indicate event duration; grouping of the multiple entries was rather problematic, since there was no straightforward way of how to group them without destroying their meaning. Such a variable had to be transformed first so as to maintain some sense even after being aggregated. A typical solution to this problem was to disaggregate the variable into the logical groups, and then to create the new binary variables out of them. To demonstrate this procedure, let's take an example of one variable originally indicating various types of interventions that took place in some target country. In this variable, individual values represented different types of non-military and military pressure; but a growing degree of the pressure of the intervention strategy did not correspond with a growing value in the variable. Therefore, the classical aggregation functions were impossible to be applied. There were two possible options of how to solve this problem - by transforming the variable into either an ordinal or a binary indicator. The individual intervention types were thus divided into three groups: no intervention, less aggressive intervention, and more aggressive intervention; and were assigned the respective values of 0,1 and 2. Afterwards, one option was to use an aggregation function sum to approximate an overall scale of intervention aggressiveness for particular country-year or country-dyad year. An alternative solution was to create two binary variables; one of which indicates presence or absence of the less aggressive intervention, and one indicating presence or absence of the more aggressive intervention in particular country-year or country dyad-year.

\section{i.5.2. Merging of the adjusted datasets}

After resolving the multiple entries, the transformed input datasets were merged together with the prepared list of country-years or country-dyad years. The merging procedure was a step by step process, carried out by the means of instance matching by a standard SQL equi-join on the identifying variables. The first identifying variable was utilized for merging of each input dataset without any exception. It was a time indicator: year. The second identifying variable that served as a country identifier varied by individual input dataset. There were three types of variables serving this purpose: either the numeric COW ccode, the 3-letter COW ccode, or the numeric UN ccode. In case of the dyadic data, the second country identifying variable was needed twice so as to identify both members of the dyad. 
To get an overview of the data losses resulting from the merging process of individual datasets, see the technical appendix of the chapter.

\section{i.6. Statistical evaluation}

A quality of the merged data from multiple sources is typically evaluated by assessing their 'consistency', 'correctness', and 'completeness'.

\section{i.6.1. 'Consistency' of the merged data}

A 'consistency' or a degree of data overlap of the merged data in this compilation varies depending on the data type being evaluated. 'Consistency' of the merged 'structural data' does not represent any major problem, given it is measured within the time frame that the variables were originally intended to cover; since tracing some characteristic consistently follows from the nature of this data type. In contrast to that a 'consistency' of the merged 'event data' suffered due to their definitional heterogeneity. Evaluation of the impacts of definitional differences on the identified event samples in the individual merged datasets and a degree of their mutual overlap was enabled by the fact that all the input datasets were transformed into a homogenous unit of analysis and the time period. The results of this evaluation are presented in the two following tables. The first presented table (table 23) indicates a number of country-years, in which the event was identified in each merged dataset; and also the number of country-years that were identified jointly for each given pair of the merged datasets.

Table 24: Event identification overlap in the data compilation (in country-years)

\begin{tabular}{|l|c|c|c|c|c|c|c|c|c|c|}
\hline \multicolumn{10}{|c|}{ 'CONSISTENCY' - Event identification overlap (in country-years) } \\
\hline & MEPV & $\begin{array}{c}\text { PITF } \\
\mathbf{1 2 3}\end{array}$ & $\begin{array}{c}\text { PITF } \\
\mathbf{4}\end{array}$ & $\mathbf{A C D}$ & $\begin{array}{c}\text { Regan } \\
\mathbf{1 2 3}\end{array}$ & $\begin{array}{c}\text { EUG } \\
\text { MID }\end{array}$ & $\begin{array}{c}\text { EUG } \\
\text { ICB }\end{array}$ & ICB & $\begin{array}{c}\text { Mil } \\
\text { Int }\end{array}$ & Peace \\
\hline MEPV & $\mathbf{7 5 4 9}$ & 1127 & 268 & 1367 & 1013 & 6878 & 5918 & 452 & 1663 & 800 \\
\hline PITF 123 & 1127 & $\mathbf{1 1 5 2}$ & 201 & 872 & 748 & 1059 & 887 & 131 & 535 & 602 \\
\hline PITF 4 & 268 & 201 & $\mathbf{2 6 9}$ & 215 & 176 & 264 & 252 & 43 & 147 & 157 \\
\hline ACD & 1367 & 872 & 215 & $\mathbf{1 4 3 8}$ & 774 & 1238 & 1059 & 239 & 670 & 659 \\
\hline Regan 123 & 1013 & 748 & 176 & 774 & $\mathbf{1 0 2 1}$ & 1010 & 879 & 126 & 443 & 639 \\
\hline EUG MID & 6878 & 1059 & 264 & 1238 & 1010 & $\mathbf{7 6 1 2}$ & 6479 & 483 & 1581 & 767 \\
\hline EUG ICB & 5918 & 887 & 252 & 1059 & 879 & 6479 & $\mathbf{6 4 7 9}$ & 444 & 1395 & 730 \\
\hline ICB & 452 & 131 & 43 & 239 & 126 & 483 & 444 & $\mathbf{4 9 0}$ & 284 & 134 \\
\hline Mil Int & 1663 & 535 & 147 & 670 & 443 & 1581 & 1395 & 284 & $\mathbf{1 7 3 6}$ & 383 \\
\hline Peace & 800 & 602 & 157 & 659 & 639 & 767 & 730 & 134 & 383 & $\mathbf{8 3 6}$ \\
\hline
\end{tabular}


The next table (table 24) also represents the event identification overlap between the individual pairs of the merged datasets, but this time presented in percentages. ${ }^{471}$ These results serve as a good indication of which datasets are worse and which better combinable with each other, and thus from which datasets is it more convenient to draw the variables for a joint analysis. On average, the 'event data' in the compilation achieve a $55 \%$ of identification overlap.

Table 25: Event identification overlap in the data compilation (in percentage)

\begin{tabular}{|c|c|c|c|c|c|c|c|c|c|c|}
\hline \multicolumn{11}{|c|}{ 'CONSISTENCY' - Event identification overlap (in percentage) } \\
\hline & MEPV & $\begin{array}{c}\text { PITF } \\
123 \\
\end{array}$ & $\begin{array}{c}\text { PITF } \\
4 \\
\end{array}$ & ACD & $\begin{array}{c}\text { Regan } \\
123 \\
\end{array}$ & $\begin{array}{l}\text { EUG } \\
\text { MID }\end{array}$ & $\begin{array}{l}\text { EUG } \\
\text { ICB }\end{array}$ & ICB & $\begin{array}{l}\text { Mil } \\
\text { Int }\end{array}$ & Peace \\
\hline MEPV & 100,0 & 14,9 & 3,6 & 18,1 & 13,4 & 91,1 & 78,4 & 6,0 & 22,0 & 10,6 \\
\hline PITF 123 & 97,8 & 100,0 & 17,4 & 75,7 & 64,9 & 91,9 & 77,0 & 11,4 & 46,4 & 52,3 \\
\hline PITF 4 & 99,6 & 74,7 & 100,0 & 79,9 & 65,4 & 98,1 & 93,7 & 16,0 & 54,6 & 58,4 \\
\hline ACD & 95,1 & 60,6 & 15,0 & 100,0 & 53,8 & 86,1 & 73,6 & 16,6 & 46,6 & 45,8 \\
\hline Regan 123 & 99,2 & 73,3 & 17,2 & 75,8 & 100,0 & 98,9 & 86,1 & 12,3 & 43,4 & 62,6 \\
\hline EUG MID & 90,4 & 13,9 & 3,5 & 16,3 & 13,3 & 100,0 & 85,1 & 6,3 & 20,8 & 10,1 \\
\hline EUG ICB & 91,3 & 13,7 & 3,9 & 16,3 & 13,6 & 100,0 & 100,0 & 6,9 & 21,5 & 11,3 \\
\hline ICB & 92,2 & 26,7 & 8,8 & 48,8 & 25,7 & 98,6 & 90,6 & 100,0 & 58,0 & 27,3 \\
\hline Mil Int & 95,8 & 30,8 & 8,5 & 38,6 & 25,5 & 91,1 & 80,4 & 16,4 & 100,0 & 22,1 \\
\hline Peace & 95,7 & 72,0 & 18,8 & 78,8 & 76,4 & 91,7 & 87,3 & 16,0 & 45,8 & 100,0 \\
\hline
\end{tabular}

\section{i.6.2. 'Correctness' of the merged data}

A 'correctness' of the merged data is ensured, if the merged data are based on a coherent unit of analysis, and if there are no multiple entries for any single unit of observation. All necessary steps to control for the 'correctness' were carried out:

- STEP 1 - Creation of a common unit of analysis

- STEP 2 - Multiple entries resolution

- STEP 3 - Merging of the adjusted datasets

The below table (table 25) provides a statistical overview of the data adjustments carried out in the individual steps of the merging process, and the associated data losses. A more detailed description is to be found in the technical appendix.

\footnotetext{
${ }^{471}$ Precisely, it indicates to what degree the datasets listed vertically identify the same events as the paired datasets listed horizontally.
} 
Extensiveness of the data losses can be derived by comparing the numbers of lost observations with the final number of observations in the merged datasets.

Table 26: Overview of the 'correctness' of the data compilation

\begin{tabular}{|c|c|c|c|c|c|}
\hline \multicolumn{6}{|c|}{ 'CORRECTNESS' } \\
\hline & \multicolumn{2}{|c|}{ STEP 1} & \multirow{2}{*}{$\begin{array}{c}\text { STEP 2 } \\
\text { Removed } \\
\text { multiple entries } \\
\text { (CD \& DD) }\end{array}$} & \multirow{2}{*}{$\begin{array}{c}\text { STEP } 3 \\
\text { Lost records } \\
\text { due to merging } \\
\text { (CD \& DD) }\end{array}$} & \multirow{2}{*}{$\begin{array}{c}\text { FINAL } \\
\text { Final number of } \\
\text { observations (CD \& } \\
\text { DD) }\end{array}$} \\
\hline $\begin{array}{c}\text { Dataset } \\
\text { name }\end{array}$ & $\begin{array}{l}\text { Adjusted } \\
\text { ccodes (CD } \\
\text { \& DD) }\end{array}$ & $\begin{array}{l}\text { Unit of analysis } \\
\text { transformation } \\
\text { (CD \& DD) }\end{array}$ & & & \\
\hline $\begin{array}{l}\text { EUGene } \\
\text { SV }\end{array}$ & $0 \& 0$ & $0 \& 0$ & $0 \& 0$ & $0 \& 0$ & 8380 \\
\hline $\begin{array}{l}\text { UN Pop } \\
1 / 2 / 3 / 4\end{array}$ & $112 / 140 / 11 / 0$ & Ccode_year & 1 & $784 / 540 / 198 / 198$ & $9800 / 5280 / 1914 / 1936$ \\
\hline UN SD & 0 & Ccode_year & 1 & 451 & 1417 \\
\hline FAO & 201 & 0 & 0 & 2340 & 11460 \\
\hline FDP & 94 & Ccode_year & 7 & 47 & 6089 \\
\hline MAR & 0 & 0 & 0 & 0 & 7937 \\
\hline QoG & 0 & 0 & 300 & 0 & 12000 \\
\hline DEM & 0 & 0 & 0 & 0 & 6871 \\
\hline MEPV & 88 & Ccode_year & 1 & 45 & 7549 \\
\hline $\begin{array}{l}\text { PITF } \\
1 / 2 / 3 / 4 \\
\end{array}$ & $6 / 6 / 6 / 3$ & Ccode_year & 358 & $1 / 1 / 1 / 0$ & $1152 / 1152 / 1152 / 269$ \\
\hline $\mathrm{ACD}$ & 0 & Ccode_year & 495 & 2 & 1438 \\
\hline $\begin{array}{l}\text { Regan } \\
1 / 2 / 3 / 4\end{array}$ & 0 & Ccode_year & $12004 / 12199 / 1259$ & 0 & $1021 / 1021 / 890$ \\
\hline $\begin{array}{l}\text { EUGene } \\
\text { MID }\end{array}$ & $0 \& 0$ & $\begin{array}{c}\text { Ccode_year \& } \\
\text { ccode_ccode_year }\end{array}$ & $1250172 \& 0$ & $0 \& 0$ & 7612 \\
\hline $\begin{array}{l}\text { EUGene } \\
\text { ICB }\end{array}$ & $0 \& 0$ & $\begin{array}{c}\text { Ccode_year \& } \\
\text { ccode_ccode_year }\end{array}$ & $1250172 \& 0$ & $0 \& 0$ & 6479 \\
\hline ICB II & $0 \& 0$ & $\begin{array}{c}\text { Ccode_year \& } \\
\text { ccode_ccode_year }\end{array}$ & $536 \& 87$ & $0 \& 7$ & 490 \\
\hline $\begin{array}{l}\text { ICB } \\
\text { Dyad }\end{array}$ & $0 \& 0$ & $\begin{array}{c}\text { Ccode_year \& } \\
\text { ccode_ccode_year }\end{array}$ & $536 \& 87$ & $0 \& 7$ & 490 \\
\hline Mil Int & $2 \& 893$ & $\begin{array}{c}\text { Ccode_year \& } \\
\text { ccode_ccode_year }\end{array}$ & $1631 \& 247$ & $32 \& 94$ & 1736 \\
\hline Peace & 54 & Ccode_year & 92 & 0 & 863 \\
\hline
\end{tabular}

${ }^{*}$ Ccode in the table refers to the COW ccode.

\section{i.6.3. 'Completeness' of the merged data}

After harmonizing the coding of the missing values in each of the input datasets and merging them all together; the entire compilation ended up as having $19,5 \%$ of the missing values. This result was artificially increased by some methodological 
and structural decisions, which are described together with a complete overview of 'completeness' of individual merged datasets in the technical appendix of this chapter.

Table 27: Overview of the 'completeness' of the data compilation (percentage of missing values)

\begin{tabular}{|c|}
\hline $\begin{array}{l}\text { 'COMPLETENESS' - Missing values } \\
\text { (in percentage) } \\
\end{array}$ \\
\hline Structural data (CD) \\
\hline Missing variables avg. $=26,1 \%$ \\
\hline Event data (CD) \\
\hline Missing variables avg. $=3,4 \%$ \\
\hline Dyadic structural and event data (DD) \\
\hline Missing variables avg. $=19,5 \%$ \\
\hline Total compilation average $=19,5 \%$ \\
\hline
\end{tabular}

\section{i.7. Attachment of the newly generated quantified JWT}

The last part of the data compilation is composed of the quantified JWT from the previous chapter. The newly generated variables together with their coding description are described in the following table (table 27).

Table 28: Coding of the variables quantifying the JWT

\begin{tabular}{|c|c|c|}
\hline \multicolumn{2}{|c|}{ QUANTIFIED JWT } \\
\hline Variable name & $\begin{array}{c}\text { Variable } \\
\text { description }\end{array}$ & \multicolumn{2}{|c|}{ Variable coding } \\
\hline JUST CAUSE INDEX \\
\hline JWT_CAUSE_X & Just cause index & $\begin{array}{c}\text { Just cause index approximates the JWT criterion of 'just } \\
\text { cause' that is used as a tool to evaluate a 'justice' of the } \\
\text { 'motives and means' of a military intervention waged into } \\
\text { the target state in particular year. It is a composite } \\
\text { indicator evaluating a severity of the crisis in the target } \\
\text { state (based on the number of battle deaths, genocide } \\
\text { deaths, displaced population, and internal violence), } \\
\text { together with a capability and willingness of the target } \\
\text { state to deal with the crisis on its own (based on the } \\
\text { existence of a state failure and existence of on ongoing } \\
\text { rebellion against the target state's government). }\end{array}$ \\
\hline
\end{tabular}




\begin{tabular}{|c|c|c|}
\hline JWT_CAUSE_X_w25 & $\begin{array}{l}\text { Just cause index } \\
\text { (after weight.) }\end{array}$ & $\begin{array}{l}\text { This variable represents a recalculated just cause index } \\
\text { ("JWT_CAUSE_X") weighted by a } 25 \% \text { importance within } \\
\text { the aggregate JWT. }\end{array}$ \\
\hline \multicolumn{3}{|c|}{ JUST INTENT INDEX } \\
\hline JWT_INTENT_X & Just intent index & $\begin{array}{l}\text { Just intent index approximates the JWT criterion of 'just } \\
\text { intent' that is used as a tool to evaluate a 'justice' of the } \\
\text { 'motives and means' of a military intervention waged into } \\
\text { the target state in particular year. It is composed of four } \\
\text { weighted components. One group of the components } \\
\text { evaluates the existence of a 'humanitarian' motivation of } \\
\text { the intervener (based on the 'humanitarianism' behind the } \\
\text { intervention, the intervener's utility form the intervention, } \\
\text { a joint history of the intervener with the target state, and a } \\
\text { similarity of their alliance portfolios); while the second } \\
\text { group controls for the other different motivations of the } \\
\text { intervener by capturing a possible economic motivation } \\
\text { (based on the trade importance and trade growth of the } \\
\text { target state, and the natural resources reserves in the } \\
\text { target state), and by capturing a possible political } \\
\text { motivation (based on the political, territorial, strategic, and } \\
\text { protective considerations behind the intervention). }\end{array}$ \\
\hline JWT_INTENT_X_30w & $\begin{array}{l}\text { Just intent index } \\
\text { (after weight.) }\end{array}$ & $\begin{array}{l}\text { This variable represents a recalculated just intent index } \\
\text { ("JWT_INTENT_X") weighted by a } 30 \% \text { importance within } \\
\text { the aggregate JWT. }\end{array}$ \\
\hline \multicolumn{3}{|c|}{ JUST AUTHORITY INDEX } \\
\hline JWT_AUTH_X & $\begin{array}{l}\text { Just authority } \\
\text { index }\end{array}$ & $\begin{array}{l}\text { Just authority index approximates the JWT criterion of } \\
\text { 'just authority' that is used as a tool to evaluate a 'justice' } \\
\text { of the 'motives and means' of a military intervention } \\
\text { waged into the target state in particular year. It is } \\
\text { composed of two weighted components. One of the } \\
\text { components evaluates a legitimacy of the intervener } \\
\text { (based on the democracy level of the intervener, and the } \\
\text { type of leadership of the intervention). The second } \\
\text { component evaluates a lack of legitimacy of the target } \\
\text { state, which provides the intervention with an increased } \\
\text { legitimacy (based on the democracy level, and existence of } \\
\text { the autocratization tendencies in the target state). }\end{array}$ \\
\hline JWT_AUTH_X_15w & $\begin{array}{l}\text { Just authority } \\
\text { index (after } \\
\text { weight.) }\end{array}$ & $\begin{array}{l}\text { This variable represents a recalculated just authority index } \\
\text { ("JWT_AUTH_X") weighted by a 15\% importance within } \\
\text { the aggregate JWT. }\end{array}$ \\
\hline \multicolumn{3}{|c|}{ LAST RESORT INDEX } \\
\hline
\end{tabular}




\begin{tabular}{|c|c|c|}
\hline JWT_LAST_X & Last resort index & $\begin{array}{l}\text { Last resort index approximates the JWT criterion of 'last } \\
\text { resort' that is used as a tool to evaluate a 'justice' of the } \\
\text { 'motives and means' of a military intervention waged into } \\
\text { the target state in particular year. It is expressed by an } \\
\text { urgency for a timely reaction by the intervener that is } \\
\text { calculated as a yearly change in the just cause index } \\
\text { ("JWT_CAUSE_X") that captures a severity of the crisis in } \\
\text { the target state and the expected propensity of the country } \\
\text { to manage the crisis on its own. }\end{array}$ \\
\hline JWT_LAST_X_10w & $\begin{array}{l}\text { Last resort index } \\
\text { (after weight.) }\end{array}$ & $\begin{array}{c}\text { This variable represents a recalculated last resort index } \\
\text { ("JWT_LAST_X") weighted by a } 10 \% \text { importance within } \\
\text { the aggregate JWT. }\end{array}$ \\
\hline \multicolumn{3}{|c|}{ PROPORTIONALITY INDEX } \\
\hline JWT_PROP_X & $\begin{array}{l}\text { Proportionality } \\
\text { index }\end{array}$ & $\begin{array}{l}\text { Proportionality index approximates the JWT criterion of } \\
\text { 'proportionality' that is used as a tool to evaluate a 'justice' } \\
\text { of the 'motives and means' of a military intervention } \\
\text { waged into the target state in particular year. It is } \\
\text { composed of two groups of the weighted components. } \\
\text { One group evaluates the extensiveness of a security threat } \\
\text { in the target state as perceived by the intervener (based on } \\
\text { the assessment of a military strength to be encountered by } \\
\text { the intervener in the target state - both internally and from } \\
\text { the other external parties, and on the aggregate battle } \\
\text { deaths on both sides), while the other group evaluates the } \\
\text { strategies used by the intervener in reaction to the } \\
\text { anticipated threat (based on the number of the waged } \\
\text { troops, on the most violent troop activity, and on the } \\
\text { aggregate troop activity of the intervener). }\end{array}$ \\
\hline JWT_PROP_X_10w & $\begin{array}{l}\text { Proportionality } \\
\text { index (after } \\
\text { weight.) }\end{array}$ & $\begin{array}{l}\text { This variable represents a recalculated proportionality } \\
\text { index ("JWT_PROP_X") weighted by a } 10 \% \text { importance } \\
\text { within the aggregate JWT. }\end{array}$ \\
\hline \multicolumn{3}{|c|}{ PROBABILITY OF SUCCESS INDEX } \\
\hline
\end{tabular}




\begin{tabular}{|c|c|c|}
\hline JWT_SUCC_X & $\begin{array}{l}\text { Probability of } \\
\text { success index }\end{array}$ & $\begin{array}{l}\text { Probability of success index approximates the JWT } \\
\text { criterion of 'probability of success' that is used as a tool to } \\
\text { evaluate a 'justice' of the 'motives and means' of a military } \\
\text { intervention waged into the target state in particular year. } \\
\text { It is composed of two weighted components. One } \\
\text { component evaluates a military strength of the target state } \\
\text { (based on the 'big power status' of the target state, on the } \\
\text { military opposition in the target state, and on the } \\
\text { probability of success of the intervener based on its } \\
\text { military capabilities), while the second component } \\
\text { evaluates a conflict complexity that decreases a probability } \\
\text { of intervener's success (based on the culture of political } \\
\text { violence, on the propensity of conflict to draw external } \\
\text { parties, and on the just cause index). }\end{array}$ \\
\hline JWT_SUCC_X_10w & $\begin{array}{l}\text { Probability of } \\
\text { success index } \\
\text { (after weight.) }\end{array}$ & $\begin{array}{l}\text { This variable represents a recalculated probability of } \\
\text { success index ("JWT_SUCC_X") weighted by a 10\% } \\
\text { importance within the aggregate JWT. }\end{array}$ \\
\hline \multicolumn{3}{|c|}{ AGGREGATE JWT INDEX } \\
\hline JWT_X & JWT index & $\begin{array}{l}\text { JWT index approximates a 'justice' of the 'motives and } \\
\text { means' of a military intervention waged into the target } \\
\text { state in particular year based on the quantified JWT. The } \\
\text { aggregate JWT index consists of the weighted JWT criteria } \\
\text { of 'just cause' ( } 25 \%) \text {, 'just intent' ( } 30 \%) \text {, 'just authority' } \\
(15 \%) \text {, 'last resort' (10\%), 'proportionality' (10\%), and } \\
\text { 'probability of success' (10\%). }\end{array}$ \\
\hline
\end{tabular}

\section{i.8. Conclusion}

The main goal of this data compiling initiative was to pool the empirical data about political conflicts and military interventions into one comprehensive data compilation that would be opened for the influences from the different social fields. An aspiration was to create such a data compilation that would allow for a holistic approach in researching either the individual phases of the conflict on its own, or the conflict dynamics within a multi-staged analysis; while creating a possibility to integrate a role of a possible intervener into the conflict. At the same time, the structure of the compilation was constructed with an attempt to allow the researchers to flexibly switch among the individual conflict definitions so as to confirm a validity of their hypotheses using the alternative operationalizations of the event. In addition to that the compilation was enriched by introducing a completely new set of variables quantifying the JWT that could generate a new stream of research exploring this normative concept based on the empirical evidence. All together, the aim was to introduce a data pool that would save a valuable time to the researchers that is typically spent on the data manipulation 
and merging. The whole initiative was carried out with a hope that the resulting output would make the quantitative approach accessible to a wider spectrum of researchers, encouraging thus a further empirical research in the sensitive field of conflict studies and conflict management. 


\section{BIBLIOGRAPHY}

Adelman, H. (1992). 'The ethics of humanitarian intervention: The case of the Kurdish refugees', Public Affairs Quarterly, 6(1): 61-88.

Alvarez, E. Jose (2007). The Schizophrenias of R2P. Panel Presentation at the 2007 Hague Joint Conference on Contemporary Issues International Criminal Law: Criminal Jurisdiction 100 Years After the 1907 Hague Peace Conference, 30 June 2007, available at: http://www.asil.org/pdfs/r2pPanel.pdf.

Amerasinghe, C.F. (2006). 'The Conundrum of Recourse to Force-To Protect Persons', International Organizations Law Review, 3: 7-53.

Annan, Kofi A. (1999). 'Two concepts of sovereignty,' The Economist, 18 September.

Anscombe, G.E. M. (2005). Human Life, Action, and Ethics: Essays by G.E.M. Anscombe (eds.) Geach, Mary \& Luke Gormally, Essex: Imprint Academic.

Aquinas, Thomas. Summa Theologica. Translated by Father Daniel J. Sullivan (1952), Chicago: Encyclopedia Britannica.

Arend, Anthony \& Robert Beck (1993). International Law and the Use of Force. London: Routledge.

Arrindell, W. A. \& J. van der Ende (1985). 'An Empirical-Test of the Utility of the Observations to-Variables Ratio in Factor and Components-Analysis', Applied Psychological Measurement, 9(2): 165-178.

Atwood, Susan J. (2003). 'From Just War to Just Intervention', New England Journal of Public Policy, 19 (1): 55-74.

Austin, Alex; Martina Fischer \& Norbert Ropers (2004). Transforming Ethnopolitical Conflict: The Berghof Handbook. Wiesbaden: VS Verlag für Sozialwissenschaften.

Bannon, L. Alicia (2006). 'The Responsibility To Protect: The U.N. World Summit and the Question of Unilateralism', The Yale Law Journal, 115(5): 1157-1165

Barbieri, Katherine; Omar Keshk \& Brian Pollins (2008). Correlates of War Project Trade Data Set Codebook, Version 2.0.

Barbour, Brian \& Brian Gorlick (2008). 'Embracing the 'Responsibility To Protect': A Repertoire of Measures Including Asylum for Potential Victims', International Journal of Refugee Law, 20(4): 533-566.

Barcalow, Emmett (1994). Moral Philosophy: Theory and Issues. California: Wadsworth Publishing Company. 
Bates, Robert H.; David L. Epstein, Jack A. Goldstone, Ted Robert Gurr, Barbara Harff, Colin H. Kahl, Kristen Knight, Marc A. Levy, Michael Lustik, Monty G. Marshall, Thomas M. Parris, Jay Ulfelder \& Mark R. Woodward (2003). Political Instability Task Force Report: Phase IV Findings. McLean, VA: Science Applications International Corporation.

Bauhaug, Halvard (2005). 'Dangerous Dyads Revisited: Democracies May Not Be That Peaceful After All', Conflict Management and Peace Science, 22: 95-111.

Beck, N, \& J. N. Katz (1997). 'What to do (and not to do) with time-series-crosssection data and/or the democratic peace', Paper presented at the annual meeting of the Political Methodology Group, Columbus, $\mathrm{OH}$.

Bederman, David J. (2001). International Law Frameworks. New York: Foundation Press.

Bellamy, A. J. (2003). 'Humanitarian intervention and the three traditions', Global Society, 17(1): 3-20.

Bellamy, Alex J. (2002). Kosovo and International Society. London: Palgrave Macmillan.

Bellamy, Alex J. (2004). 'Motives, outcomes, intent and the legitimacy of humanitarian intervention', Journal of Military Ethics, 3(3): 216-232.

Bellamy, Alex J. (2005). 'Responsibility To Protect or Trojan Horse? The Crisis in Darfur and Humanitarian Intervention After Iraq', Ethics $\mathcal{E}$ International Affairs, 19(2): 31-54.

Bellamy, Alex J. (2006). 'Whither the Responsibility to Protect? Humanitarian Intervention and the 2005 World Summit', Ethics \& International Affairs, 20(2): 143169.

Bellamy, Alex J. (2009). Responsibility to Protect: The Global Effort to End Mass Atrocities. Cambridge: Polity Press.

Bennett, D. Scott \& Allan Stam (2000). 'EUGene: A Conceptual Manual', International Interactions, 26:179-204, available at: http://www.eugenesoftware.org.

Benoit, K (1996). 'Democracies really are more Pacific (in general): Reexamining regime type and war involvement', Journal of Conflict Resolution, 40(4): 646-657.

Bercovitch, Jacob \& Paul F. Diehl (1997). 'Conflict Management of Enduring Rivalries: The Frequency, Timing, and Short-term Impact of Mediation', International Interactions, 22(4): 299-320.

Berdal, M. \& Malone, D. M. (eds.) (2000). Greed and Grievance. Boulder and London: Lynne Rienner. 
Betts, Richard K. (1994). 'The delusion of impartial intervention', Foreign Affairs, 73(6): 20-33.

Blomerg, S. Brock \& Gregory D. Hess (2002). 'The Temporal Links between Conflict and Economic Activity', Journal of Conflict Resolution, 46(1): 79-90.

Bloom, M. (1999). Failures of intervention: the unintended consequences of mixed messages and the exacerbation of ethnic conflict. PhD thesis, Columbia University.

Blume, Till; Julian Junk; Elisabeth Schöndorf \& Wolfgang Steibel (2006). Discourse at the Juncture: The Explanatory Power of Discourse Theory and Policy Analysis for Understanding Peace Operations and Humanitarian Intervention. Discussion paper, Workshop: 'Discourse, Communication and Policy Entrepreneurship in Peace Operations and Humanitarian Interventions', Collaborative Research Center, University of Konstanz, September 22-24.

Brecher, Michael \& Jonathan Wilkenfeld (1997, 2000). A Study of Crisis. MI: University of Michigan Press.

Brock, Lothar \& Harald Müller (2004). Ursachen der wechslenden Beteiligung demokratischer Staaten an Kriegen seit 1990. HSFK Kernprojekt IV/1. Available online: http://www.hsfk.de/downloads/Kernprojekt_IV-1.pdf.

Brownlie, Ian (2000). 'Kosovo Crisis Inquiry: Memorandum on the International Law Aspects', The International and Comparative Law Quarterly, 49(4): 878-905.

Brown, Michael E. \& Richard N. Rosecrance (1999). The Costs of Conflict: Prevention and Cure in the Global Arena. New York: Rowman \& Littlefield.

Brownlie, Ian (2003). Principles of Public International Law. Oxford: Oxford University Press.

Buchanan, Allen (1999). 'The Internal Legitimacy of Humanitarian Intervention', The Journal of Political Philosophy, 7(1): 71-87.

Buchanan, Allen. (2003). 'Reforming the International Law of Humanitarian Intervention'. In: J. Holzgrefe \& R. Keohane (eds), Humanitarian Intervention: Ethical, Legal, and Political Dilemmas, Cambridge: Cambridge University Press.

Bull, Hedley (1966). 'The Grotian Conception of International Society'. In: Herbert Butterfield \& Martin Wight (eds.), Diplomatic Investigations, London: Allen and Unwin.

Bull, Hedley (1979). 'Recapturing the just war for political theory', World Politics, 43: 588-99.

Bull, Hedley (1984). Intervention in World Politics. Oxford: Clarendon Press. 
Bulley, Dan (2010). 'The politics of ethical foreign policy: A responsibility to protect whom?', European Journal of International Relations, 16(3): 441-461.

Butler, J. Michael (2003). 'U.S. Military Intervention in Crisis, 1945-1994: An Empirical Inquiry of Just War Theory', Journal of Conflict Resolution, 47(2): 226-248.

Byers, Michael \& Simon Chesterman (2003). 'Changing the Rules about Rules? Unilateral Humanitarian Intervention and the Future of International Law'. In: Holzgrefe, J.L. \& Keohane, R. O. (eds.), Humanitarian Intervention - Ethical, Legal and Political Dilemmas, Cambridge University Press, Cambridge.

Cannizzaro, Enzo (2006). 'Contextualizing proportionality: jus ad bellum and jus in bello in the Lebanese war', International Review of the Red Cross, 88: 779-792.

Caplan, Richard (2000). 'Humanitarian Intervention: Which Way Forward?', Ethics and International Affairs, 14: 23-38.

Carey, S. C. (2005). Patterns of authority and the escalation of intrastate conflict. Paper presented at the general meeting of the European Consortium for Political Research, September 8-10, Budapest.

Cassese, Antonio (2000). 'Ex iniuria ius oritur: Are We Moving Towards International Legitimation of Forcible Humanitarian Countermeasures in the World Community?', European Journal of International Law, 10(1): 23-30.

Cattell, R. B. (1966). 'The scree test for the number of factors', Multivariate Behavioral Research, 1: 629-637.

Cederman, Lars-Erik; Min, Brian \& Andreas Wimmer (2009), 'Ethnic Power Relations dataset', http://hdl.handle.net/1902.1/11796UNF:5:k4xxXC2ASI204QZ4jqvUrQ==V1[Version ].

Cederman, Lars-Erik; Simon Hug \& Lutz F. Krebs (2007). Democratization and Civil War: Empirical Evidence. Paper prepared for presentation at the workshop Disaggregating the Study of Civil War and Transnational Violence at University of Essex, UK, November, 24-25.

Chapman, Geoffrey (1994). Catechism of the Catholic Church. Citta del Vaticano: Libreria Editrice Vaticana, paragraph 2309.

Chesterman, Simon (2001). Just War or Just Peace? Humanitarian Intervention and International Law. Oxford: Oxford University Press.

Chesterman, Simon. (2004). 'Humanitarian Intervention in Afghanistan'. In: J. Welsh (ed.), Humanitarian Intervention in International Relations, Oxford: Oxford University Press. Cushman, T. (ed.) (2006). A Matter of Principle: Humanitarian Arguments for War in Iraq. Berkeley, CA: University of California Press. 
Christopher, P. (1994). The Ethics of War and Peace: An Introduction to Legal and Moral Issues. New Jersey: Prentice Hall.

Clark, Ian (2005). Legitimacy in International Society. Oxford: Oxford University Press.

Cliff, N. \& R. Pennell (1967). 'The influence of communality factor strength and loading size on the sampling characteristics of factor loadings', Psychometrika, 32: 309-326.

Coady, C. A. J. (2002). 'The Ethics of Armed Humanitarian Intervention', Peaceworks No. 45, United States Institute of Peace.

Collier, Paul \& Anke Hoeffler (2000). Greed and grievance in civil war. World Bank Policy Research Paper 2355.

Collier, Paul \& Anke Hoeffler (2001). Data Issues in the Study of Conflict. Paper prepared for the Conference on Data Collection on Armed Conflict, Uppsala, 8-9 June.

Collier, Paul \& Anke Hoeffler (2002). 'On the Incidence of Civil War in Africa', Journal of Conflict Resolution, 46(1): 13-28.

Collier, Paul (2001). 'Economic causes of civil conflict and their implications for policy'. In: Crocker, C. A., Hampson, F. O. \& Aall, P. (eds.), Managing Global Chaos. US Institute of Peace, Washington DC.

Comrey, A. L. (1978). 'Common methodological problems in factor analytic studies', Journal of Consulting and Clinical Psychology, 46: 648-659.

Convention No. IV on the Laws and Customs of War on Land (1907), with annex of regulations, pmbl. 36 Stat. 2277. [In: Meron, Theodor (2000). 'The Humanization of Humanitarian Law', The American Journal of International Law, 94(2): 239-278.]

Convention on the Prevention and Punishment of the Crime of Genocide (1948), U.N. Doc. A/RES/3/260 A.

Cook, M. L. (2000). 'Immaculate war: Constraints on humanitarian intervention', Ethics \& International Affairs, 14: 55-65.

Correlates of War 2 Project. Colonial/Dependency Contiguity Data, 1816-2002. Version 3.0.

Correlates of War Project (2008). State System Membership List. Version 2008.1, available at: http://correlatesofwar.org.

Costello, Anna B. \& Jason W. Osborne (2005). 'Best Practices in Exploratory Factor Analysis: Four Recommendations for Getting the Most From Your Analysis', Practical Assessment, Research \& Evaluation, 10(7): 1-9. 
Counsens, Elizabeth M. \& Charles K. Cater (2001). Toward Peace in Bosnia: Implementing the Dayton Accords. Lynne Rienner, Boulder.

Cranna, Michael (1994) ed. The True Cost of Conflict. New York: The New Press.

Crawford, C. Neta (2003). 'Just War Theory and the U.S. Counterterror War', Perspectives on Politics, 1: 5-25.

Crawford, T.W. (2003). Pivotal Deterrence: Third Party Statecraft and the Pursuit of Peace. Ithaca, NY: Cornell University Press.

Curran, Charles (1979). 'Utilitarianism and Contemporary Moral Theology: Situating the Debates'. In: Charles Curran \& Richard McCormick (eds.), Readings in Moral Theology 1: Moral Norms and Catholic Tradition, New York: Paulist Press, 341362.

D'entrèves, P. Alexander (1963). 'Legality and Legitimacy', The Review of Metaphysics, 16(4): 687-702.

Damrosch, L. Fisler (1993) (Ed). Enforcing Restraint: Collection Intervention in Internal Conflicts. New York: Council to Foreign Relations Press.

Deininger, Klaus \& Lyn Squire (1996). 'A New Data Set Measuring Income Inequality', The World Bank Economic Review, 10(3): 565-591.

Don Hubert \& Thomas G. Weiss et al. (2001). The Responsibility to Protect: Supplementary Volume to the Report of the International Commission on Intervention and State Sovereignty. Canada: International Development Research Centre.

Doyle, W. Michael \& Nicholas Sambanis (2000). 'International Peacebuilding: A theoretical and Quantitative Analysis', American Political Science Review, 94(4): 779802.

Eberwien, Wolf-Dieter \& Sven Chojnacki (2001). Scientific Necessity and Political Utility: A Comparison of Data on Violent Conflicts. Arbeitsgrupp: Internationale Politik P01-304, available at: http://www.wz-berlin,de/ip.

Elbadawi, A. Ibrahim \& Nicholas Sambanis (2000). External Interventions and the Duration of Civil Wars, World Bank Policy Research Paper 2433.

Elbadawi, A. Ibrahim \& Nicholas Sambanis (2002). 'How Much War Will We See?: Explaining the Prevalence of Civil War', Journal of Conflict Resolution, 46(3): 307-334.

Ellingsen, Tanja (2000). 'Colorful Community or Ethnic Witches' Brew?', Journal of Conflict Resolution, 44(2): 228-249. 
Esty, D. C.; Goldstone, J.; Gurr, T. R.; Surko, P. T. \& A. N. Unger (1995). Working Papers: State Failure Task Force Report. Science Applications International Corporation, McLean, VA.

Esty, D. C.; Goldstone, J.; Gurr, T. R.; Surko, P. T.; Unger, A. N. \& R. S. Chen (1998). The State Failure Task Force Report: Phase II Findings. Science Applications International Corporation, McLean, VA.

Evans, Gareth (2006). 'From Humanitarian Intervention to the Responsibility To Protect', Wisconsin International Law Journal, 24(3): 101-120.

Evans, Gareth (2008). The Responsibility to Protect: Ending Mass Atrocity Crimes Once and For All. Washington D.C.: The Brookings Institution.

FAOSTAT, available at: http://faostat.fao.org/default.aspx.

Farer, J. Tom (2003). 'The Prospect for International Law and Order in the Wake of Iraq', The American Journal of International Law, 97(3): 621-628.

Fearon, D. James \& David D. Laitin (2003). 'Ethnicity, Insurgency, and Civil War', American Political Science Review, 97(1): 75-90.

Fearon, D. James (1991). 'Counterfactuals and hypothesis testing in political science', World Politics, 43: 169-195.

Finnemore, Martha (2003). The Purpose of Intervention: Changing Beliefs about the Use of Force. Ithaca, New York: Cornell University Press.

Flöter, Annegret; Lujala, Päivi \& Jan Ketil Rød (2007). The Gemstone Dataset. Mimeo, Department of Geography. Trondheim: Norwegian University of Science and Technology.

Floyd, F. J. \& K. F. Widaman (1995). 'Factor analysis in the development and refinement of clinical assessment instruments', Psychological Assessment, 7(3): 286299.

Fordman, O. Benjamin \& Chritpoher C. Sarver (2001). 'Militarized Interstate Disputes and United States Uses of Force', International Studies Quarterly, 45(3): 455466.

Fortna, Virginia Page (2003). 'Inside and Out: Peacekeeping and the Duration of Peace after Civil and Interstate Wars', International Studies Review, 5(4): 97-114.

Franck, M. Thomas (2001). 'When, if Ever, May States Deploy Military Force Without Prior Security Council Authorization?', Journal of Law and Policy 5: 51-68.

Frost, M. (1986). Toward a Normative Theory of International Relations: A Critical Analysis of the Philosophical and Methodological Assumptions in the Discipline with 
Proposals toward a Substantive Normative Theory. Cambridge: Cambridge University Press.

Galtung, Johan \& Carl Jacobsen (2000). Searching for Peace: the Road to Transcend. London: Pluto Press.

General Assembly Declaration (1970), GA Res 2625.

General Assembly Declaration (1974), GA Res 3314.

George, P. Robert (1999). In Defense of Natural Law. Oxford: Clarendon Press Oxford.

Ghosn, Faten; Glenn Palmer \& Stuart Bremer (2004). 'The MID3 Data Set, 19932001: Procedures, Coding Rules, and Description', Conflict Management and Peace Science, 21: 133-154.

Gibler, Douglas M. \& Meredith Sarkees (2004). 'Measuring Alliances: The Correlates of War Formal Interstate Alliance Data set, 1816-2000', Journal of Peace Research, 41(2): 211-222.

Gilmore, Elisabeth; Gleditsch, Nils Petter; Lujala, Päivi \& Jan Ketil Rød (2005). 'Conflict Diamonds: A New Dataset', Conflict Management and Peace Science, 22(3): 257-292.

Gleditsch, Kristian S. \& Michael D. Ward (2001). 'Measuring Space: A Minimum Distance Database', Journal of Peace Research, 38: 749-68.

Gleditsch, Nils Petter; Peter Wallensteen, Mikael Eriksson, Margareta Sollenberg \& Håvard Strand (2002). 'Armed Conflict 1946-2001: A New Dataset', Journal of Peace Research, 39(5): 615-637.

Global Centre for the Responsibility to Protect (2009). Implementing the Responsibility to Protect: The 2009 General Assembly Debate: An Assessment, available at:

http://globalr2p.org/media/pdf/GCR2P_General_Assembly_Debate_Assessment.p df.

Goertz, G. \& P.F. Diehl (1995). 'The Initiation and Termination of Enduring Rivalries: The Impact of Political Shocks', American Journal of Political Science, 39: 3052.

Gorsuch, R. L. (1974). Factor analysis. Philadelphia, PA: W. B. Saunders.

Gorsuch, R. L. (1983). Factor Analysis. Hillsdale, NJ: Lawrence Erlbaum.

Gray, Christine (2008). International Law and the Use of Force. Oxford: Oxford University Press. 
Greenwood, Christopher (2000). 'International Law and the NARO Intervention in Kosovo', International and Comparative Law Quarterly, 49(4): 926-934.

Grisez, Germain (1978). 'Against Consequentialism', The American Journal of Jurisprudence, 23: 21-72.

Grotius, Hugo (1625). De jure belli ac pacis libri tres, Paris ('The Law of War and Peace' - full text translated in English is available on-line at http://www.lonang.com/exlibris/grotius/index.html).

Guertin A. A.; Guertin, W. H. \& W. B. Ware (1981). 'Distortion as a function of the number of factors rotated under varying levels of common variance and error', Educational and Psychological Measurement, 41: 1-9.

Gurr, Ted Robert \& Barbara Harff (2004). Ethnic Conflict in World Politics, $2^{\text {nd }}$ edition. Westview Press.

Gurr, Ted Robert (2000). Peoples Versus States: Minorities at Risk in the New Century. Washington, DC: US Institute of Peace.

Haar, Barend ter (2000). Peace or Human Rights? The Dilemma of Humanitarian Intervention. The Hague: Netherlands Institute of International Relations Clingendael.

Haas, B. Ernst (1986). Why We Still Need the United Nations: The Collective Management of International Conflict, 1945-1985. Policy papers in International Affairs, Berkley: Institute of International Studies, University of California.

Haas, B. Ernst (1993). 'Collective conflict management: Evidence for a new world order?'. In Thomas G. Weiss (ed.) Collective security in a changing world, Boulder: Lynne Reinner.

Hair, J.F.; Anderson R. E. Jr.; Tatham R. L. \& W. C. Black (1998). Multivariate data analysis with readings ( $5^{\text {th }} \mathrm{ed}$ ). Englewood Cliffs, NJ: Prentice-Hall.

Hakstian A. R. \& V. J. Muller (1973). 'Some notes on the number of factors problems', Multivariate Behavioral Research, 8: 461-475.

Handrick, Steffen (2005). 'Das Kosovo und die internationale Gemeinschaft: Nation-building versus peace-building', Studien zur Internationalen Politik, 2.

Harbour, F. (1995). 'Basic moral values: A shared core', Ethics and International Affairs, 9: 155-170.

Harcourt, William Vernon, Sir (1863). Letters by Historicus on some questions of international law. (Reprinted from The Times with considerable additions) London: Macmillan. 
Harff, B. (2003). 'No lessons learned from the Holocaust? Assessing risks of genocide and political mass murder since 1955', American Political Science Review, 97(1): 57-73.

Hargrove, John Lawrence (1987). 'The Nicaragua Judgement and the Future of the Law of Force and Self-Defense', The American Journal of International Law, 81(1): 135-143.

Harhoff, Frederik (2001). 'Unauthorized Humanitarian Interventions - Armed Violence in the Name of Humanity?', Nordic Journal of International Law, 70 (1-2): 65-119.

Hart, H.L.A (1994). The Concept of Law. Oxford: Clarendon Press.

Hartzell, Caroline; Mathew Hoddie \& Donald Rothschild (2001). 'Stabilizing the Peace after Civil War', International Organization, 55: 183-208.

Heagerty, P.; M. D. Ward \& K. S. Gleditsch (2002). 'Windows of opportunity: Window subseries empirical variance estimators in international relations', Political Analyst, 10(3): 304-317.

Hegre, Havard; Tanja Ellingsen; Scott Gates \& Nils Petter Gleditsch (2001). 'Toward a Democratic Civil Peace? Democracy, Political Change, and Civil War, 1816-1992', American Political Science Review, 95(1): 33-48.

Hehir, J. Bryan (1995). 'Expanding Military Intervention: Promise or Peril?', Social Research, 62(1): 41-51.

Heldt, Birger (2004). 'UN-led or Non-UN-led Peacekeeping Operations?', IRI Review, 9(2): 113-138.

Henkin, Louis (1999). 'Kosovo and the Law of Humanitarian Intervention', The American Journal of International Law, 93(4): 824-828.

Herbst, Jeffrey (2000). 'Economic, political, and social incentives in the organization of rebellion in Africa', paper prepared for the World Bank conference on The Economics of Political Violence 2000, Princeton University, 18-19 March.

Herbst, Jeffrey (2004). 'African Militaries and Rebellion: The Political Economy of Threat and Combat Effectiveness', Journal of Peace Research, 41: 357-369.

Hermann, G. Magaret (1998). 'The US Use of Military Intervention to Promote Democracy: Evaluating the Record', International Interactions, 24(2): 91-114.

Hess, G. \& Blomberg, B. (2002). 'The temporal links between conflict and economic activity', Journal of Conflict Resolution, 46(1): 74-90.

Hewitt, J. Joseph (2003). 'Dyadic Processes and International Crises', Journal of Conflict Resolution, 47: 669-692. 
Hilpold, Peter (2001). 'Humanitarian Intervention: Is There a Need for a Legal Reappraisal?', European Journal of International Law, 12(3): 437-468.

Hoffmann, Stanley (1995). 'The Politics and Ethics of Military Intervention', Survival, 37(4): 318-332.

Hoffmann, Stanley (1997). The Ethics and Politics of Humanitarian Intervention. South Bend, IN: University of Notre Dame Press.

Hoffmann, Stanley (1998). World Disorders: Troubled Peace in the Post-Cold War Era, Lanham, Md.: Rowman and Littlefield.

Holbrook, Jon (2002). 'Humanitarian Intervention'. In: David Chandles (ed.) Rethinking Human Rights: Critical Approach to International Politics, Palgrave Macmillan.

Holzgrefe, J. L. \& Keohane, R. O. (2003). Humanitarian Intervention: Ethical, Legal, and Political Dilemmas (Eds). Cambridge: Cambridge University Press.

Hooker, B. (2000). 'Sidgwick and common-sense morality', Utilitas, 12(3): 347360 .

Hopkinson, N. (1993). The United Nations in the New World Order. London: HMSO.

Horowitz, D. L. (1985). Ethnic Groups in Conflict. Berkeley: University of California Press.

Hubert, Don \& Michael Bonser (2001). 'Humanitarian Military Intervention'. In: McRae, Rob \& Don Hubert (eds.), Human security and the new diplomacy: protecting people, promoting peace, Montreal and Kingston: McGill-Queen's University Press.

Hubert, Don \& Thomas G. Weiss et al. (2001). The Responsibility to Protect: Supplementary Volume to the Report of the International Commission on Intervention and State Sovereignty. Canada: International Development Research Centre.

Humphreys L. G. \& R. G. Montanelli (1974). 'An investigation of the parallel analysis criterion for determining the number of common factors', Multivariate Behavioral Research, 10: 193-205.

Huntington, S. (1997). The clash of civilizations and the remaking of the world order. New York: Simon \& Schuster.

Hurd, Ian (2002). 'Legitimacy, Power, and the Symbolic Life of the UN Security of the UN Security Council', Global Governance, 8(1): 35-51.

Independent International Commission of Kosovo (2000). The Kosovo report: conflict, international response, lessons learned. Oxford: Oxford University Press. 
International Commission on Intervention and State Sovereignty (2001). The Responsibility to Protect. Ottawa: International Development Research Center for International Commission on Intervention and State Sovereignty (ICISS).

International Court of Justice Report (1996). 'Legality of the Threat of Use of Nuclear Weapons', Advisory Opinion, p. 226, available at: http://www.un.org/law/icjsum/9623.htm.

International Monetary Fund (2009), available at: http://en.wikipedia.org/wiki/List_of_countries_by_GDP_(nominal)_per_capita.

International Standards Organization (1999). Information Technology-Database Language SQL. Standard No. ISO/IEC 9075.

Jackson, Robert H. (2000). The Global Covenant: Human Conduct in a World of States. Oxford: Oxford University Press.

Jaggers, Keith \& Ted Robert Gurr (1995). 'Tracking Democracy's Third Wave with the Polity III Data', Journal of Peace Research, 32(4): 469-482.

Janzekovic, John (2006). The Use of Force in Humanitarian Intervention. Hampshire: Ashgate

Johnson, J. Turner (1981). Just War Tradition and the Restraint of War: A Moral and Historical Inquiry. New Jersey: Princeton University Press.

Johnson, T. James (1999). Morality and contemporary warfare. New Haven, CT: Yale University Press.

Jokic, A. \& Wilkins, B. (2003). Humanitarian Intervention: Moral and Philosophical Issues (Eds). Peterborough, Ontario: Broadview.

Jones, Daniel M.; Stuart A. Bremer \& J. David Singer (1996). 'Militarized Interstate Disputes, 1816-1992: Rationale, Coding Rules, and Empirical Patterns', Conflict Management and Peace Science, 15(2): 163:213.

Kabia, John M. (2009). Humanitarian intervention and conflict resolution in West Africa: from ECOMOG to ECOMIL. Surrey: Ashgate Publishing Limited.

Kagan, S. (1989). The Limits of Morality. Oxford: Clarendon.

Kagan, S. (1998). Normative Ethics. Boulder, CO: Westview.

Kaiser, H. F. (1960). 'The application of electronic computers to factor analysis', Educational and Psychological Measurement, 20: 141-151.

Kalyvas, S. N. (2005). 'Warfare in civil wars'. In: Duyvesteyn I. \& J. Angstrom, Rethinking the nature of war, London: Frank Cass, pp. 88-108. 
Kim, Jae-On \& Charles W. Mueller (1978). Factor Analysis: Statistical methods and practical issues. Thousands Oaks, CA: Sage Publications.

Kisangani, Emizet F. \& Jeffrey Pickering (2007). International Military Intervention, 1989-2005 [Computer file], Manhattan, KS: Kansas State University [producer].

Kissinger, Henry (2001). Does America Need a Foreign Policy? Toward a Diplomacy for the 21st Century. New York: Simon and Schuster.

Knudsen, T. Brems (2009). The History of Humanitarian Intervention: The Rule or the Exception?, paper for the 50th ISA Annual Convention, New York.

Köchler, Hans (2000). 'The Use of Force in the New International Order: On the Problematic Nature of the Concept of Humanitarian Intervention', paper presented at the international conference Interventionism against International Law: From Iraq to Yugoslavia, November 20, Madrid.

Krain, Matthew (2005). 'International Intervention and the Severity of Genocides and Politicides', International Studies Quarterly, 49: 363-387.

Kurth, James (2006). 'Humanitarian Intervention After Iraq: Legal Ideals vs. Military Realities', Journal of World Affairs, 50(1): 87-101.

Kurtz, Paul (1995). Living Without Religion: Eupraxophy. Amherst, NY: Prometheus Books.

Lacina, Bethany \& Nils Petter Gleditsch (2005). 'Monitoring Trends in Global Combat: A New Dataset of Battle Deaths', European Journal of Population, 21(2-3): 145-166.

Lance, E. Charles; Butts M. Marcus \& Lawrence C. Michels (2006). 'The sources of four commonly reported cutoff criteria: What did they really say?', Organizational Research Methods 9(2): 202-220.

Lango, J. W. (2001). 'Is armed humanitarian intervention to stop mass killing morally obligatory?', Public Affairs Quarterly, 15(3): 173-191.

Laughland, John (2000). 'Human Rights and the Rule of law: Achieving Universal Justice?'. In: David Chandler (ed.), Rethinking Human Rights, London: Palgrave-Macmillan.

Lebow, R. N. (2000). 'What's so different about a counterfactual?', World Politics, 52: $580-81$.

Lepard, Brian (2002). Rethinking Humanitarian Intervention: A Fresh Legal Approach Based on Fundamental Ethical Principles in International Law and World Religions. University Park, PA: Pennsylvania State University Press. 
Lichbach, M. I. (1987). 'Deterrence or escalation? The puzzle of aggregate studies of repression and dissent', Journal of Conflict Resolution, 31(2): 266-297.

Linklater, Andrew (1998). The Transformation of Political Community. Cambridge: Polity.

Lischer, Sarah Kenyon (2007). 'Military Intervention and the Humanitarian Force Multiplier', Global Governance, 13: 99-118.

Lissitzyn, J. Oliver (1967). 'Treaties and Changed Circumstances (Rebus Sic Stantibus)', American Journal of International Law, 61(4): 895-922. [In Farer, Tom (1971). 'Humanitarian Law and Armed Conflicts: Toward the Definition of International Armed Conflict', Columbia Law Review, 71(1): 37-72.]

Luck, C. Edward (2008). ‘Der verantwortliche Souverän und die Schutzverantwortung' [The Responsible Sovereign and the Responsibility To Protect], Vereinte Nationen, 2: 51-58.

Lujala, Päivi; Jan Ketil Rød \& Nadia Thieme (2007). 'Fighting over Oil: Introducing A New Dataset', Conflict Management and Peace Science, 24(3): 239-256.

MacCallum, R. C. \& L. R. Tucker (1991). 'Representing Sources of Error in the Common- Factor Model - Implications for Theory and Practice', Psychological Bulletin, 109(3): 502-511.

MacCallum, R. C. (1983). 'A comparison of factor analysis programs in SPSS, BMDP and SAS', Psychometrika, 48: 223-231.

MacFarlane, S. Neil; Thielking, J. Carolin \& Thomas G. Weiss (2004). 'The Responsibility To Protect: Is Anyone Interested in Humanitarian Intervention?', Third World Quarterly, 25(5): 977-992.

Mandelbaum, Michael (1996). 'Foreign Policy as Social Work', Foreign Affairs, 75(1): 16-32.

Mansfield, E. D. \& J. Snyder (1995). 'Democratization and the danger of war', International Security, 20(1): 5-38.

Marshall, G. M. \& Jaggers, K. (2002). Polity IV Project: Political Regime Characteristics and Transitions, 1800-2002: Dataset Users' Manual. Maryland: University of Maryland.

Marshall, G. Monty (1999). Third World War: System, Process, and Conflict Dynamics. Lanham, MD: Rowman \& Littlefield Publishers.

Marshall, G. Monty (2002). 'Measuring the Societal Impact of War'. In: F. O. Hampson \& D. M. Malone (eds.), From Reaction to Prevention, Boulder: Lynne Rienner. 
Mason, A. \& N. Wheeler (1996). 'Realist objections to humanitarian intervention'. In: B. Holden (ed.), The Ethical Dimensions of Global Change, London: Macmillan.

Maull, W. Hanns \& Bernhard Stahl (2002). 'Durch den Balkan nach Europa? Deutschland und Frankreich in den Jugoslawien-Kriegen', Politische Vierteljahresschrift, 43(1): 82-111.

Meernik, James (1996). 'United States Military Intervention and the Promotion of Democracy', Journal of Peace Research, 33(4): 391-402.

Meron, Theodor (1983). 'On the Inadequate Reach of Humanitarian and Human Rights Law and the Need for a New instrument', The American Journal of International Law, 77(3): 589-606.

Meron, Theodor (2000). 'The Humanization of Humanitarian Law', The American Journal of International Law, 94(2): 239-278.

Miall, Hugh (2001). 'Data Requirements for Conflict Prevention', paper for the Uppsala Conference on Conflict Data, June 8-9.

Minorities at Risk Project (2005). Minorities at Risk Dataset. College Park, MD: Center for International Development and Conflict Management.

Moore, J., (1998a). Hard Choices: Moral Dilemmas in Humanitarian Intervention (ed). Boulder, CO: Rowman \& Littlefield.

Moore, W. H. (1998b). 'Repression and dissent: substitution, context, and timing', American Journal of Political Science, 42(3): 851-873.

Most, Benjamin A. \& Harvey Starr (1989). Inquiry, Logic and International Politics. Columbia: South Carolina Press.

Mueller, J. (2000). 'The banality of ethnic war', International Security, 25(1): 4270 .

Murphy, N. Craig (2000). 'Global Governance: Poorly Done and poorly Understood', International Affairs, 76(4): 789-803.

Nanda, P. Ved (2007). 'The Protection of Human Rights Under International Law: Will the U.N. Human Rights Council and the Emerging New Norm “Responsibility To Protect" Make a Difference?', Denver Journal of International Law and Policy, 35: 353-378.

Nardin, T. (2002). 'The moral basis of humanitarian intervention', Ethics $\mathcal{E}$ International Affairs, 16(1): 57-70.

Naumann, Felix \& Matthias Häussler (2002). ‘Declarative Data Merging with Conflict Resolution', IQ, 212-224. 
Nunnally, J. C. (1978). Psychomteric theory (2nd ed.). New York: McGraw-Hill.

O'Brien, V. William (1979). U.S. military intervention: Law and morality. Washington DC: Center for Strategic and International Studies, Georgetown University.

Orakhelashvili, Alexander (2007). The Interaction between Human Rights and Humanitarian Law: A Case of Fragmentation? International Law and Justice Colloquium New York University (NYU), 26 February.

Parekh, Bhikhu (1997). 'Rethinking Humanitarian Intervention', International Political Science Review, 18 (1): 55-74.

Paris, Roland (2000). 'Broadening the Study of Peace Operations', International Studies Review, 2(3): 27-44.

Parker, I. (1999). 'Qualitative data and the Subjectivity of Objective Facts'. In: Simpson, L. \& D. Dorling, Statistics in Society. London: Hodder.

Payandeh, Mehrdad (2010). 'With Great Power Comes Great Responsibility? The Concept of the Responsibility to Protect within the Process of International Lawmaking', The Yale Journal of International Law, 35(2): 469-516.

Pearson, Frederic S. \& Robert A. Baumann (1992). International Military Intervention, 1946-1988 [Computer file], St. Louis, MO: University of Missouri-St. Louis, Center for International Studies [producer].

Pettit, P. (1988). 'The consequentialist can recognize rights', The Philosophical Quarterly, 38(150): 42-55.

Pettit, P. (1991). 'Consequentialism'. In: P. Singer (ed.), A Companion to Ethics, Cambridge, MA: Blackwell.

Pfetsch, R. Frank \& Christoph Rohloff (2000). 'KOSIMO: A Databank on Political Conflict', Journal of Peace Research, 37(3): 379-389.

Phillips, L. Robert (1984). War and Justice. Norman: University of Oklahoma Press.

Pickering, Jeffrey \& Emizet F. Kisangani (2006). 'Political, Economic, and Social Consequences of Foreign Military Intervention', Political Research Quarterly, 59(3): 363-376.

Pogge, T. W. (1992). 'An institutional approach to humanitarian intervention', Public Affairs Quarterly, 6(1): 89-103.

Popovski, Vesselin \& Nicholas Turner (2008). Legality and Legitimacy in International Order. Policy Brief November 2008, United Nations University. 
Portmore, D. W. (2000). 'Commonsense morality and not being required to maximize the overall good', Philosophical Studies, 100(2): 193-213.

Rahm, Erhard \& Hong Hai Do (2000). 'Data Cleaning: Problems and Current Approaches', IEEE Bulletin of the Technical Committee on Data Engineering, 23(4): 313.

Raknerud, A. \& Hegre, R. (1997). 'The hazard of war: reassessing the evidence for the democratic peace', Journal of Peace Research, 34(4): 385-404.

Ramsbotham, Oliver \& Tom Woodhouse (1996). Humanitarian Intervention in Contemporary Conflict. United Kingdom: Blackwell Publishers.

Ramsey, Paul (1968). The just war: Force and political responsibility. Lanham, MD: University Press of America.

Rantner, S. R. (1995). The New UN Peacekeeping: Building Peace in Lands of Conflict after the Civil War. New York: St. Martin's Press.

Raubenheimer, J. E. (2004). 'An item selection procedure to maximize scale reliability and validity', South African Journal of Industrial Psychology, 30 (4): 59-64.

Regan, M. Patrick \& Aysegul Aydin (2004). Diplomacy and other Forms of Intervention: Combined Strategies and the Duration of Civil War. Binghamton, NY: Binghamton University.

Regan, M. Patrick (2000). Civil Wars and Foreign Powers: Interventions and Intrastate Conflict. MI: University of Michigan Press.

Regan, M. Patrick (2001). Data on Third Party Interventions in Intrastate Conflicts. Paper prepared for the Uppsala Conflict Data Project workshop, June 8-10.

Regan, M. Patrick (2002). 'Third-party Interventions and the Duration of Intrastate Conflicts', Journal of Conflict Resolution, 46(1): 55-73.

Reisman, W. Michael (1984). 'Coercion and Self-Determination: Construing Charter Article 2(4)', The American Journal of International Law, 78(3): 642-645.

Reisman, W. Michael (1990). 'Sovereignty and Human Rights in Contemporary International Law', American Journal of International Law, 84 (4): 866 - 876.

Reynal-Querrol, M. (2002). 'Ethnicity, political systems and civil wars', Journal of Conflict Resolution, 46(1): 29-54.

Reichberg, Gregory \& Henrik Syse (2002). 'Humanitarian Intervention: A Case of Offensive Force?', Security Dialogue, 33(3): 309-322.

Roberts, Adams (1993). 'Humanitarian War: Military Intervention and Human Rights', International Affairs, 69(3): 429-449. 
Roberts, Les \& Charles-Antoine Hofmann (2004). 'Assessing the Impact of Humanitarian Assistance in the Health Sector', Emerging Themes in Epidemiology, 1(1): 3 .

Robinson, G. (1998). Methods and Techniques in Human Geography. London: Hodder.

Rome Statute of the International Criminal Court (1998), Article 8, Sec. 2.

Rome Statute of the International Criminal Court (1998), Article 38, Sec. 1.

Roth, K. (2004). The War in Iraq: Justified as Humanitarian Intervention?, Kroc Institute Occasional Paper No. 25, Notre Dame: The Joan B. Kroc Institute.

Rothschild, D. \& M. Foley (1988). 'African states and the politics of inclusive coalitions'. In: Rothschild, D. \& Chazan, N. (eds.), The Precarious Balance: State and Society in Africa, Boulder, CO: Westview Press.

Rummel, R. J (1970). Applied factor analysis. Evanston, IL: Northwestern University Press.

Russett, B.; David J. Singer \& Melvin Small (1968). 'National Political Units in the Twentieth Century', American Political Science Review, 62(3): 932-951.

Russett, B.; Oneal, J. R \& M. Cox (2000). 'Clash of civilizations or realism and liberalism de'ja'vu?: some evidence', Journal of Peace Research, 37(5): 583-608.

Ryter, Marc-André (2003). Motives for Humanitarian Intervention and the International Community. Research Report No. 2(23). Helsinki: National Defense College.

Rytter, E. Jens, (2001). 'Humanitarian Intervention without the Security Council: From San Francisco to Kosovo - and Beyond', Nordic Journal of International Law (NJIL), 124: 128-130.

Sambanis, Nicholas (2001). 'Do ethnic and non-ethnic civil wars have the same causes? A theoretical and empirical inquiry (part 1)', Journal of Conflict Resolution, 45(3): 259-282.

Sambanis, Nicholas (2002). 'A Review of Recent Advances and Future Directions in the Quantitative Literature on Civil War', Defence and Peace Economics, 13(3): 215-243.

Schonemann, P. H. (1990). 'Facts, Fictions, and Common-Sense About Factors and Components', Multivariate Behavioral Research, 25(1): 47-51.

Seidman, Barry (2003). 'Planetary Humanism and War and Peace', Free Inquiry, 23(3). 
Seybolt, B. Taylor (1994). 'Measuring violence: An introduction to conflict datasets', SIPRI Yearbook 2002: Armaments, Disarmament and International Security, Oxford University Press: Oxford, pp. 81-96.

Seybolt, B. Taylor (2007). Humanitarian Military Interventions: The Conditions for Success and Failure. Oxford: Oxford University Press.

Simma, Bruno (1994). 'From Bilateralism to Community Interest in International Law', Recueil des cours, 250(4): 217-384.

Simma, Bruno (1999). 'NATO, the UN and the Use of Force: Legal Aspects', Journal of International Law, 10(1): 1-22.

Singer, J. David; Stuart Bremer \& John Stuckey (1972). 'Capability Distribution, Uncertainty, and Major Power War, 1820-1965'. In: Bruce Russett (ed.) Peace, War, and Numbers, Beverly Hills: Sage, pp. 19-48.

Small, Melvin \& David J. Singer (1982). Resort to Arms, International and Civil Wars, 1816-1980. Beverly Hills: Sage Publications.

Smith, Michael G. \& Moreen Dee (2003). Peacekeeping in East Timor - The Path to Independence. Boulder: Lynne Rienner.

Smith, Michael J. (2006). 'Humanitarian Intervention: An Overview of the Ethical Issues', Ethics \& International Affairs, 12(1): 63-79.

Smith, W. Thomas (2002). 'The New Law of War', International Studies Quarterly, 46(3): 355-374.

Smyser, W. R. (2003). The Humanitarian Conscience: Caring for Others in the Age of Terror. New York: Palgrave.

Snyder, J. (2000). From Voting to Violence: Democratization and Nationalist Conflict. New York: Norton Publishers.

Stahn, C. J., \& K. Kleffner (eds.) (2008). Jus Post Bellum: Towards a Law of Transition from Conflict to Peace. The Hague: T.M.C. Asser Press.

Steiger, J. H. (1990). 'Some Additional Thoughts on Components, Factors, and Factor- Indeterminacy', Multivariate Behavioral Research, 25(1): 41-45.

Stein, S. Mark (2004). 'Unauthorized Humanitarian Intervention', Social Philosophy and Policy, 21(1): 14-38.

Stinger, J. David \& Melvin Small (1972). The Wages of War, 1816-1965: A Statistical Handbook. New York: Wiley.

Stoddard, Abby (2003). 'Humanitarian NGOs: Challenges and Trends'. In: Joanna Macrae \& Adele Harmer (eds.), Humanitarian Action and the 'Global War on 
Terror': A Review of Trends and Issues, London: Overseas Development Institute, Humanitarian Policy Group.

Teorell, Jan; Sören Holmberg \& Bo Rothstein (2007). The Quality of Government Dataset, version 1July07. Göteborg University: The Quality of Government Institute.

Tesón, Fernando (1997, 2005). Humanitarian Intervention: An Inquiry into Law and Morality $\left(2^{\text {nd }}+3^{\text {rd }}\right.$ ed.). Irvington, New York: Transnational Publishers.

Tesón, Fernando (2003). 'The liberal case for humanitarian intervention'. In: J. Holzgrefe \& R. Keohane (eds.), Humanitarian Intervention: Ethical, Legal, and Political Dilemmas, Cambridge: Cambridge University Press.

The World Conference on Human Rights (1993). The Vienna Declaration and Programme of Action, UN Doc. A/Conf. 157/24.

Traub, Joel (2000). 'Inventing East Timor', Foreign Affairs, 79(4): 74-89.

Truxillo, Catherine. (2003). Multivariate Statistical Methods: Practical Research Applications Course Notes. Cary, N.C.: SAS Institute.

Tucker, L. R.; Koopman R. F. \& R. L. Linn (1969). 'Evaluation of factor analysis research procedures by means of simulated correlation matrices', Psychometrika, 34: 421-459.

Tzu, Mo (1967). 'Against Offensive War'. In: Burton Watson, Basic Writings of Mo Tzu, Hsun Tzu, and Han Fei Tzu (ed. and trans.), New York: Columbia University Press.

UN Charter (1945), Article 2(4).

UN Charter (1945), Article 39.

UN Charter (1945), Article 42.

UN Charter (1945), Article 51.

UN General Assembly Convention (1948), Convention on the Prevention and Punishment of the Crime of Genocide, available at the webpage of the UN: http://www.un.org/millennium/law/iv-1.htm.

UN General Assembly Letter (2009), Letter and Concept Note from Office of the President, UN Gen. Assembly, to Permanent Missions and Permanent Observer Missions to the United Nations (July 17, 2009), available at: http://www.un.org/ga/president/63/letters/ResponsibilitytoProtect170709.pdf.

UN General Assembly Resolution (2005), 2005 World Summit Outcome, UNGA Res. A/RES/60/1.

UN General Assembly Resolution (2009), A/RES/63/308. 
UN Population Division (2006), UN World Population Prospects (2006 Revision), available at: http://www.un.org/esa/population/unpop.htm.

UN Press Release (1999), SG/SM/6949.

UN Secretary General Report (2000), Report of the Secretary-General, We the Peoples: The Role of the United Nations in the Twenty-First Century, UN Doc. $\mathrm{A} / 54 / 2000$.

UN Secretary General Report (2005), Report of the Secretary-General, In Larger Freedom: Toward Development, Security and Human Rights for All, UN Doc. A/59/2005.

UN Secretary General Report (2009), Implementing the Responsibility to Protect, A/63/677.

UN Security Council Resolution (2006a), S/RES/1674.

UN Security Council Resolution (2006b), S/RES/1706.

UN Security Council Resolution (2011a), S/RES/1970.

UN Security Council Resolution (2011b), S/RES/1973.

UN Security Council Resolution (2011c), S/RES/1975.

UN Security Council Summit Statement (1992), Note by the President of the Security Council, UN Doc. S/23500.

UN Statistics Division, Demographic Statistics, available at: http://unstats.un.org/unsd/default.htm.

United States National Conference of Catholic Bishops (1983). The challenge of peace: God's promise and our response. Washington, DC: United States Catholic Conference.

Valentino, Benjamin; Paul Huth, \& Dylan Balch-Lindsay (2004). 'Draining the Sea: Mass Killing and Guerrilla Warfare', International Organization 58: 375-407.

Vattel, de Emmerich (1758). Principes de la loi naturelle appliqués à la conduite et aux affaires des nations et des souverains ('The Law of Nations or the Principles of Natural Law Applied to the Conduct and to the Affairs of Nations and of Sovereigns' - full text translated in English is available on-line at http://www.lonang.com/exlibris/vattel/).

Velicer, W. F. \& D. N. Jackson (1990). 'Component Analysis Versus Common Factor-Analysis - Some Further Observations', Multivariate Behavioral Research, 25(1): 97-114. 
Verlage, Christopher (2009). Responsibility to Protect: Ein neuer Ansatz in Völkerrecht zur Verhinderung von Völkermord, Kriegsverbrechen und Verbrechen gegen die Menschlichkeit. Tübingen: Mohr Siebeck Gmbh \& Co.

Verwey, Wil (1992). 'The Legality of Humanitarian Intervention after the Cold War'. In: E. Ferris (ed.), A Challenge to Intervene: A New Role for the United Nations?, Uppsala: Life and Peace Institute, pp.12-36.

Voon, Tanja (2002). 'Closing the Gap between Legitimacy and Legality of Humanitarian Intervention: Lessons from East Timor and Kosovo', UCLA Journal of International Law E Foreign Affairs, 31-98.

Walzer, Michael (1980). 'The Moral Standing of States. A Response to Four Critics', Philosophy and Public Affairs, 9: 209-29.

Walzer, Michael (1997, 2000). Just and Unjust Wars: A Moral Argument with Historical Illustrations ( $2^{\text {nd }}$ and $3^{\text {rd }}$ ed.). New York: Harper Collins.

Walzer, Michael (2004). 'The Politics of Rescue'. In: Arguing about War, New Haven: Yale University Press, pp. 67-81.

Walzer, Michael (2004). Arguing About War. New Haven: Yale University Press.

Weiss, D. (1976). 'Multivariate procedures'. In: Dunnette M. D. (ed.) Handbook of Industrial/Organizational Psychology. Chicago, IL: Rand McNally.

Weiss, G. Thomas (2004). 'The Humanitarian Impulse'. In: David M. Malone (ed.), The United Nations Security Council After the Cold War, Boulder, CO: Lynne Rienner, pp. 37-54.

Weiss, Thomas G. \& Don Hubert (2001). The Responsibility to Protect: Research, Bibliography, and Background. Ottawa: International Development Research Centre.

Welsh, Jennifer (2006). 'The Responsibility to Protect: Securing the Individual in International Society?’. In: Oliver Jütersonke and Keith Krause (eds.), From Rights to Responsibilities: Rethinking Interventions for Humanitarian Purposes, Geneva: Programme for Strategic and International Security Studies, pp. 23-44.

Welsh, M. Jennifer (2002). 'From Right to Responsibility: Humanitarian Intervention and International Society', Global Governance, 8: 503-521.

Welsh, M. Jennifer (2008). 'The Security Council and Humanitarian Intervention'. In: Vaughan Lowe et al. (eds.), The United Nations Security Council and War, Oxford: Oxford University Press.

Wheeler, Nicholas J. \& Alex Bellamy (2001), 'Humanitarian Intervention and World Politics'. In: Steve Smith \& John Baylis, The Globalization of World Politics, Oxford: Oxford University Press. 
Wheeler, Nicholas J. (2000). Saving Strangers: Humanitarian Intervention in International Society. Oxford: Oxford University Press.

Wheeler, Nicholas J. (2001). 'The Legality of NATO's Intervention in Kosovo'. In: Ken Booth (ed.), The Kosovo Tragedy: The Human Rights Dimensions, London: Frank Cass.

Wheeler, Nicholas. J. (2005). 'A Victory for Common Humanity? The Responsibility to Protect after the 2005 World Summit', Journal of International Relations and international Law, 2 (1): 95-106.

Widaman, K. F. (1993). ‘Common Factor-Analysis Versus Principal Component Analysis - Differential Bias in Representing Model Parameters', Multivariate Behavioral Research, 28(3): 263-311.

Williams, E. Robert Jr. \& Dan Caldwell (2006). 'Jus Post Bellum: Just War Theory and the Principles of Just Peace', International Studies Perspectives, 7(4): 309-320.

Winkelmann, Ingo (2010). 'Responsibility To Protect'. In: Rüdiger Wolfrum (ed.), Max Planck Encyclopedia of Public International Law, 22.

Wright, Quincy (1965). A Study of War. Chicago: The University of the Chicago Press (2nd ed.).

Yannis, Oran R. \& Marc A. Levy (1999). 'The Effectiveness of International Environmental Regimes'. In: Young, O. R. (ed.), The Effectiveness of International Environmental Regimes - Causal Connections and Behavioral Mechanisms, Cambridge: MIT Press.

Zwick, W. R. \& W. F. Velicer (1982). 'Factors influencing four rules for determining the number of components to retain', Multivariate Behavioral Research, 17: 253-269. 
TECHNICAL APPENDICES 


\section{LIST OF VARIABLES USED FOR THE QUANTIFICATION OF THE JWT}

\section{CRITERIA}

The below listed variables used for the construction of the JWT criteria are drawn from the data compilation that is described in the last chapter of this study.

\section{1. 'Just cause' index}

'Just cause' index is structured based on the QoG country list, which includes all the countries throughout the whole time spam of 1946-2005, regardless of the existing acknowledgment of their sovereignty by the international community in each listed country-year. ${ }^{472}$ This approach was adopted for the reason of maintaining a maximal continuity of information about the developments in the target state, and thus for a reason of leaving a flexibility for any future use of the index.

\subsection{Severity of humanitarian crisis}

\subsubsection{Battle deaths - target state ("battle_deaths_x")}

$=$ total battle-related fatalities (both civilians and combatants) killed in the course of combat in particular country-year (scale 17).

Input variable:

- Best battle deaths estimate ("b_deaths_best") from the ACD dataset (1946-2005) (originally labeled "bdeadbes") - This variable sums the best estimates of total battle-related fatalities of all conflicts in particular country-year, in which battle fatalities are defined as civilians and combatants killed in the course of combat.

\section{Adjustments:}

Variable ("b_deaths_best") was transformed into a scaled summed number of fatalities related to fighting in particular country-year, which is set on a range from 1 to 7 in the following way. Missing values (41 cases) were coded as 50 battle-related fatalities. Reason for choosing particularly the number 50 comes from the fact that the identification threshold of conflict in the ACD dataset starts with at least 25 battle-related deaths over year. The observation was identified as fulfilling this minimal threshold, but was attached unknown value for some reasons. Therefore, amount of 50 is set

\footnotetext{
472 The resulting sample had 12000 identified country-years.
} 
above this threshold, but not much so that the result remains strict on granting the basis for 'just cause'.

After the correction of missing values, the values that originally indicated the numbers of battle-related deaths were transformed into the below described scale:

- $1-100=1$

- $\quad 101-500=2$

- $501-1000=3$

- $\quad 1001-5000=4$

- $\quad 5001-10000=5$

- $\quad 10001-50000=6$

- $50000-500000=7$

The cases not identified by the ACD dataset as fulfilling the set threshold of existing crisis were attached the value 0 .

\subsubsection{Genocide deaths - target state ("genoc_deaths_x")}

$=$ level of annual deaths resulting from a genocide or politicide in particular country-year (scale 0-5).

Input variable:

- Level of civilian deaths ("genoc_deaths") from the PITF 4 dataset (1956-2005) (originally coded "deathmag") - This variable indicates a level of annual deaths resulting from a genocide or politicide in particular country-year. The scale ranges from 0 to 5 .

\section{Adjustments:}

Country-years not identified by the PITF 4 dataset as experiencing either a genocide or a politicide were attached the value 0 .

\subsubsection{Displaced population - target state ("refug_x")}

$=$ number of people both internally and externally displaced in particular country-year (scale 0-4).

Main input variables:

- Number of refugees ("refug") from the FDP dataset (1964-2005) (originally labeled "source") - This variable indicates a number of refugees (in thousands) originating in the country at the end of a designated year.

- Number of internally displaced persons ("idp") from the FDP 
dataset (1964-2005) (originally labeled "idp") - This variable indicates a number of internally displaced persons (in thousands) in the country at the end of the designated year.

- Interpolated migration ("migr_i") from the UN pop II dataset (1950-1979) (created from the variable originally labeled "Migration, international net per year") - This variable indicates a net migration (absolute number), which is interpolated among the original measurements taken once in five years.

\section{Reference variables:}

- Political violence score ("viol") from the MEPV dataset (19462004) (originally labeled "civtot") - This variable represents the summed magnitudes of all societal major episodes of political violence (MEPVs) in particular country-year. This indicator counts the magnitude scores for civil violence, civil warfare, ethnic violence, and ethnic warfare; which are individually evaluated on the scale ranging from 1 (lowest) to 10 (highest), where $10=$ extermination and annihilation, $9=$ total warfare, $8=$ technological warfare, $7=$ pervasive warfare, $6=$ extensive warfare, $5=$ substantial and prolonged warfare, $4=$ serious warfare, $3=$ serious political violence, $2=$ limited political violence, and $1=$ sporadic or expressive political violence.

- Conflict intensity ("intensity") from the ACD dataset (1946-2005) (originally labeled "int") - This variable indicates a maximum level of intensity reached by the most violent conflict in particular country-year. The intensity levels are divided into two categories: $1=$ minor conflict (between 25 and 999 battle-related deaths in a given year), and 2 = war (at least 1000 battle-related deaths in a given year).

\section{Adjustments:}

Values in the two FDP variables ("refug") and ("idp") were summed together to jointly indicate the number of people externally and internally displaced as a result of the violence. The limited time coverage of these two variables covering only years 1964-2005 was increased by combining them with the data from the UN pop II variable ("migr_i") that complemented the data for years 1950-1963. So as to make the values in the variable "migr_i" compatible with the summed FDP variables, they were divided by 1000 to transform them from the values indicating absolute numbers into values indicating the numbers of migrants in thousands as indicated in the FDP variables. Afterwards, all the positive values in the "migr_i" variable were set to 0 , since the aim was to approximate only amount of refugees fleeing out of the country. In the next step, the estimated number 
of refugees across border from the "migr_i" variable was multiplied by two to approximate also the people displaced within the borders of the country due to the existing violence.

So as to fill in the missing values in the summed ("refug") and ("idp") or in the variable ("migr $i$ "), the study utilized two additional reference variables: ("viol") and ("intensity"). The missing values were filled in based on the following methodology. To fill in the missing values for years 1950-2005, the study estimated the amount of forcibly displaced people based on the level of violence in the country. For this purpose, two reference variables were utilized: "viol" (MEPV dataset) and "intensity" (ACD dataset), while the preference was always given to the variable that indicated a stronger impulse for a potential forced displacement of population in particular country-year. The 10-point scale of violence magnitude in the variable "viol" was transformed into the estimated attached number of displaced people: $1=10,2=100,3=300,4=500,5=$ 1000 , and $6-10=5000$. Similarly, the 2-point scale in the variable "intensity" was transformed into two types of estimates of the displaced people: $1=$ 300 , and $2=1000$. If both reference variables were coded as 0 , the number of forcibly displaced people was set to 0 . If one of the values in the reference variables was missing, the existing one was applied. The values for years 1946-1949 that were not covered by any of the above listed main input variables were left constant as indicated in year 1950, unless there was some change in the level of violence recorded in some country-years 1946-1949 in comparison to the country-year 1950 recorded in the reference variables ("viol") and ("intensity"). In case that there was a record of change, the same method of data transformation was used as the one applied when filling in the missing values for years 1950-2005.

And finally, the values representing a number of people internally and externally displaced (in thousands) in particular country-year were transformed into the following scale:

- $0=0$

- $1=1-50$

- $\quad 2=51-500$

- $3=501-1000$

- $\quad 4=1001-10000$

1.1.4. Internal violence - target state ("viol_x")

= summed magnitude of all the societal major episodes of political violence in particular country-year (scale 0-10). 
Main input variables:

- Political violence score ("viol") from the MEPV dataset (19462004) (originally labeled "civtot") - This variable represents the summed magnitudes of all the societal major episodes of political violence (MEPVs) in particular country-year. It counts the magnitude scores for civil violence, civil warfare, ethnic violence, and ethnic warfare, which are individually evaluated on the scale ranging from 1 (lowest) to 10 (highest); where $10=$ extermination and annihilation, $9=$ total warfare, $8=$ technological warfare, $7=$ pervasive warfare, $6=$ extensive warfare, $5=$ substantial and prolonged warfare, $4=$ serious warfare, $3=$ serious political violence, $2=$ limited political violence, $1=$ sporadic or expressive political violence, $0=$ no violence.

\section{Reference variable:}

- Conflict intensity ("intensity") from the ACD dataset (1946-2005) (originally labeled "int") - This variable indicates a maximum level of intensity reached by the most violent conflict in particular country-year. The intensity levels are divided into two categories: $1=$ minor conflict (between 25 and 999 battle-related deaths in a given year), and 2 = war (at least 1000 battle-related deaths in a given year).

\section{Adjustments:}

Due to the fact that "viol" variable does not cover year 2005, the values for this missing year were filled in based on the information provided in the reference variable "intensity". If "intensity" was coded 1, "viol" was assigned the value 3; if "intensity" was coded 2, the value 6 was attached. The same approach as applied for the year 2005 was used for filling in the missing values that appeared in the time period covered by the main input variable.

\subsection{Necessity of external assistance controls}

\subsubsection{State failure - target state ("state_fail_x")}

= degree of a state failure (failure of state authority, collapse of democratic institutions, violent regime transition) in particular country-year (scale 0-12).

\section{Input variable:}

- $\quad$ PITF magnitude sum ("pitf_magn_sum") from the PITF dataset (1948-2005) (created from the original variable "avemag") - This variable indicates an averaged magnitude of the following three scores for particular country-year: a scaled failure of state authority ("pitf_scale"); a 
scaled collapse of democratic institutions defined as a six or more points drop in the value of a state's POLITY index score over a period of three years or less ("dem_collapse_scale"); and a scaled violence associated with regime transition ("violence_scale"). Each of these three magnitude scores is set on a scale ranging from 1 to 4 . The final variable thus indicates a degree of state failure on the scale of 0-12.

\section{Reference variable:}

- State failure dummy ("state_failure") from the QoG dataset (19462004) (originally labeled "p_sf") - This dummy variable indicates whether the country is in a condition of a complete collapse of central authority (sate failure) or disintegrates.

\section{Adjustments:}

The reference QoG variable "state_failure" was used to fill in the missing values for the period of 1946-1948 not covered by the PITF variable "pitf_magn_sum". In case that the QoG data identified presence of a state failure in particular country-year, the missing value was coded 1; otherwise 0 . In case that the QoG reference variable also indicated a missing value; such values were coded 0 , since coding of the reference variable is set to indicate a missing value in cases that the country did not possess an internationally accepted sovereignty in particular year. Assigning the 0 value to these cases is based on an assumption that there can be no state failure, if there is no functioning government that could fail.

\subsubsection{Rebellion - target state ("rebel_x")}

$=$ the most serious manifestation of the rebellion in particular country-year (scale $0-7$ ).

Main input variable:

- Rebellion index ("rebellion_x") from the MAR dataset (19462003) (created from variables originally labeled "rebel_mean" and "reb_mean") - This variable records the most serious manifestation of a rebellion that is coded as follows: $0=$ none reported, $1=$ political banditry or sporadic terrorism, 2 = campaigns of terrorism, 3 = local armed rebellions, 4 = small-scale guerrilla activity (conditions: fewer than 1000 armed fighters, less than six reported attacks per year, attacks in a small part of the area), 5 = intermediate guerrilla activity, $6=$ large-scale guerrilla activity (conditions: more than 1000 armed fighters, more than 6 attacks per year, attacks affecting a large part of the area), and $7=$ protracted civil war (condition: fought by rebel military units with base areas).

Reference variable: 
- Political violence score ("viol") from the MEPV dataset (19462004) (originally labeled "civtot") - This variable represents the summed magnitudes of all the societal major episodes of political violence (MEPVs) in particular country-year. This indicator counts the magnitude scores for civil violence, civil warfare, ethnic violence, and ethnic warfare, which are individually evaluated on the scale ranging from 1 (lowest) to 10 (highest); where $10=$ extermination and annihilation, $9=$ total warfare, $8=$ technological warfare, $7=$ pervasive warfare, $6=$ extensive warfare, $5=$ substantial and prolonged warfare, $4=$ serious warfare, $3=$ serious political violence, $2=$ limited political violence, and $1=$ sporadic or expressive political violence.

\section{Adjustments:}

Variable "rebellion_x" has a higher number of missing values, which had to be substituted. The missing values were replaced based on data from the reference variable "viol", adopting the following procedure:

- $\quad 0(\mathrm{MEPV})=0(\mathrm{MAR})$

- $\quad 1(\mathrm{MEPV})=1(\mathrm{MAR})$

- $2(\mathrm{MEPV})=2(\mathrm{MAR})$

- $3(\mathrm{MEPV})=3(\mathrm{MAR})$

- $\quad 4(\mathrm{MEPV})=4(\mathrm{MAR})$

- $5(\mathrm{MEPV})=5(\mathrm{MAR})$

- $6(\mathrm{MEPV})=6(\mathrm{MAR})$

- $\quad$ 7-10 $(\mathrm{MEPV})=7(\mathrm{MAR})$

\section{2. 'Just intent' index}

Construction of the 'just intent' index required capturing the dyadic relationships between the intervener and the target states. Therefore, all the data composing the index were structured based on the EUGene dyadic country list covering all the country dyads in years 1946-2005. Nevertheless, since the study overtook a definition of military intervention from the Mil Int dataset, the justice of the intent could have been evaluated only for the country dyad-years, in which the military intervention was identified based on this definition. The filtered out country dyadyears with the identified interventions were then merged by the ccode of the target country and the year, while simultaneously counting the number of interveners in a given target country-year. ${ }^{473}$ If the same intervener intervened more than once

\footnotetext{
${ }^{473}$ Grouping the dyadic Mil Int data by target country-year resulted in identification of 1695 countryyears. (Original Mil Int data in the dyadic form identify 3057 dyadic country-years.)
} 
into the same country-year, the intervener was counted just once. While merging the data, the values of all the variables indicating the intent of the intervener were summed (using the SUM operator) and then divided by number of interveners in particular country-year, so as to get the averaged value of intent of all the interveners in particular target country-year.

Missing values in the variables were removed based on the various simplifying assumptions that are described individually in the overview of each input variable. Nevertheless, there was one common formula applied for the binary variables that served as controls for the possible side-motivations of the intervener. Majority of missing values in this type of binary variables concerned the multilateral operations. Therefore, this study adopted an approach that if the operation was multilateral; geographical, historical or other ties are considered to be of a lower importance, and that the intervention was less probably waged just for the narrow national interests of the intervener. As a result of that, all the missing values in these binary variables were set to 0 . Due to this permissive and optimistic approach in case of the variables controlling the 'humanitarian intent' of multilateral operations; a much stricter approach was adopted in case of missing observations in the variables supporting the existence of the 'humanitarian intent' in such a type of operations. The exceptional adjustments of the missing variables are listed below.

\subsection{Humanitarian motivation}

\subsubsection{Humanitarian intervention ("hum_int_x")}

$=$ existence of an ongoing humanitarian intervention in particular target country-year (range 0-1).

- Humanitarian intervention dummy ("hum_int") from the Mil Int dyad dataset (1946-2005) (created from variable originally labeled "Humanitarian Intervention" 1946-1988 - Mil Int I, and "Humanitarian Intervention" 1989-2005 - Mil Int II) - This dummy variable codes whether some military intervention attempts to save lives, to relieve suffering, or to distribute foodstuffs so as to prevent starvation in the target state in particular directed country dyad-year. It is coded as follows: $0=$ no, $1=$ yes.

\section{Adjustments:}

The missing values were coded 0 , so as to be strict on awarding the explicit humanitarian intent, due to the permissive approach to the missing values in case of the control variables.

\subsubsection{Intervener's utility ("util_achb_x")}

$=$ average utility of the interveners from waging an intervention into the target state (range -1-2) 
- Utility $A$ of changing B Tau-b ("util_achb_t") from the EUGene dyad dataset (1946-2000) (originally labeled "wrTu1v2") - This variable indicates a state A's utility from the state B's desired outcome. It is a sum of the bilateral and multilateral expected utility components using Tau-b (without risk attitude) that is calculated based on the COW composite capability scores adjusted for distance (as is operationalized in The War Trap War and Reason), and based on the perceptions of probability of success. The utility ranges from -1 to +2 .

\section{Adjustments:}

The values of the variable were multiplied by -1 , so that the higher the number, the higher utility was perceived by the intervener.

\subsubsection{Joint history ("joint_hist_x")}

$=$ a strongest historical relationship of the interveners with the target state (range 0-3).

- Joint history ("joint_hist_type") from the Mil Int dyad dataset (1946-2005) (created from variable originally labeled "Colonial history") - This variable indicates the strongest shared historical relationship of the target state with any intervener in particular year. The variable is divided into following categories: $0=$ no relationship, $1=$ colony (since 1648), 2 = protectorate (since 1648), 3 = previously unified country or empire (since 1648).

\subsubsection{Alliance ("alliance_x")}

$=\mathrm{a}$ similarity of the alliance portfolio between the interveners and the target state in particular country-year (range -1-1).

- Global alliance portfolio II ("alliance_glob") from the EUGene dyad dataset (1946-2000) (originally labeled "s_un_glo") - This variable evaluates the unweighted S-score of the global alliance portfolios of state A vs. state B by using all the countries in the system. It ranks an order correlation for two states' alliance portfolios: 1 = defense pact, 2 = neutrality pact, $3=$ entente and $4=$ no alliance. The ranking is then recalculated into the range starting with -1 (representing a totally opposite alliance agreements) going till +1 (representing a complete agreement in the alliances formed), while taking into account both the presence and the absence of an alliance in the correlation calculation.

\section{Adjustments:}

The values of the variable "alliance_ $x$ " were multiplied by -1 ; so that the higher the number, the more security-strategic side motives were possibly 
associated with the intervention and not the other way round. The missing values were set to 0 ; since 0 represents a middle value and thus seemed to be the most appropriate.

\subsection{Economic side motivations}

\subsubsection{Trade importance - target state ("tot_trade_ $x$ ")}

$=\mathrm{a}$ total trade (both imports and exports) of the target country in particular country-year (mil. USD).

Main input variable:

- $\quad$ Total trade ("tot_trade") from the QoG dataset (19482000) (originally labeled "gle_trade") - This variable sums all the dyadic import and export figures of the country in millions of current USD.

\section{$\underline{\text { Reference variables: }}$}

- Imports ("imports") from the EUGene SV dataset (19462005) (originally labeled "imports") - This variable indicates imports in 1000 USD.

- $\quad$ Exports ("exports") from the EUGene SV dataset (19462005) (originally labeled "exports") - This variable indicates exports in 1000 USD.

\section{Adjustments:}

Variable "tot_trade" is not focused on the existing mutual relationship between the intervener and the target state as such, but rather evaluates the economic importance of the target state as a whole. Total trade variable (QoG) has less missing observations than the two EUGene SV reference variables. Therefore, each missing observation in the QoG variable was substituted by the summed value of Imports and Exports from the EUGene data for particular country-year, multiplied by 1000 . In case that the value was missing in both datasets, the amount of total trade was left constant as in the last recorded year. Afterwards, the values were transformed into the following scale:

$$
\begin{array}{ll}
\text { - } & 0-1000=1 \\
\text { - } & 1001-5000=2 \\
\text { - } & 5001-15000=3 \\
\text { - } & 15001-50000=4 \\
\text { - } & 50001-100000=5
\end{array}
$$




\section{- $10001-500000=6$}

2.2.2. Trade growth - target state ("trade_growth_x")

$=$ a growth in trade performance of the target state over last three years (mil. USD).

Main input variable:

- Total trade ("tot_trade") from the QoG dataset (19482000) (originally labeled "gle_trade") - This variable sums all the dyadic import and export figures of the country in millions of current USD.

\section{Reference variables:}

- Imports ("imports") from the EUGene SV dataset (19462005) (originally labeled "imports") - This variable indicates imports of the country in 1000 USD.

- Exports ("exports") from the EUGene SV dataset (19462005) (originally labeled "exports") - This variable indicates exports of the country in 1000 USD.

\section{Adjustments:}

In case that there were missing values in the variable "tot_trade", they were replaced by the summed value of "imports" and "exports" from the reference variables for particular country-year and multiplied by 1000. In case that there were missing values both in the main and the reference variables, the amount of total trade was left constant as in the last available recorded year. After having all the missing values filled-in, the yearly change was counted. The calculated yearly changes were always summed for the three previous years to indicate whether the economic performance of the target state has an increasing or a decreasing trend. For year 1946, the trade growth was set to 0; for year 1947, the trade change was expressed by a yearly change between the year 1946 and 1947; and for year 1948 by summing the yearly change for years 1947 and 1948. Further on, the trade change was always calculated by summing the three last years.

\subsubsection{Gemstones - target state ("gemstones_x")}

$=$ existence of the known gemstone or diamond sites in the target state (scale $0,1,2)$

Main input variables: 
- Gemstones presence dummies ("gemstones") from the Gemstone dataset ${ }^{474}$ (1946-2005) (originally coded “Gemstone 12"...-32") These 11 variables represent separate dummies for existence of a specific gemstone type in particular country. The following gemstones are recorded: ruby, sapphire, emerald, aquamarine, heliodor, moganite, goshenite, nephrite, jadeite, lapis lazuli, opal, tourmaline, periodit, topaz, pearl, garnet, zircon, spinel, amber, and quartz. This variable excludes the diamonds.

- Diamonds presence dummy ("diamonds") from the Diamond dataset ${ }^{475}$ (1946-2005) (originally labeled "RES") - This dummy variable indicates presence of the diamond deposits in particular country.

\section{Adjustments:}

Binary variables from the Gemstone dataset that indicate a presence of the different types of gemstones were grouped into a single dummy variable indicating a presence of at least one gemstone type in particular country. A similar procedure was then carried out with the variable from the Diamond dataset indicating a presence of the diamond sites in different countries. The two resulting binary variables were transformed into the scale of 0-2; where 0 indicates an absence of whatever sites with precious stones in the country, 1 = a presence of gemstones excluding the diamonds, $2=\mathrm{a}$ presence of the diamond sites in the country. The resulting scale thus indicates an increasing resource-strategic attractiveness of the country for any intervener:

$$
\begin{aligned}
& -\quad 0 \text { = no gemstones } \\
& \text { - } 1 \text { = gemstones other than diamonds } \\
& 2 \text { = diamonds }
\end{aligned}
$$

2.2.4. Oil and gas - target state ("oil_gas_x")

$=$ existence of known oil or gas reserves in the target state (scale $0,1,2,3)$.

Input variable:

- Oil and/or gas presence ("oil_gas") from the Petroleum Dataset v. 1.2476 (1945-2005) (originally labeled "RESINFO") - This variable indicates a presence of the oil and gas reserves in the country. It is divided

\footnotetext{
${ }^{474}$ Flöter, Lujala \& Rød, 2007.

475 Gilmore, Gleditsch, Lujala \& Rød, 2005.

476 Lujala, Rød \& Thieme, 2007.
} 
into two parts, separately tracing the oil and gas reserves located both offshore and onshore.

\section{Adjustments:}

First of all, the information contained in the variable "RESINFO" were transformed into the numerical values by weighting the economic importance of the sites in the following way: "gas"=1, "oil"=2, "oil and gas" $=3$. Afterwards, the data were grouped by the target country ccode to indicate the highest graded offshore and onshore hydrocarbon site in each country. Finally, values for both types of sites were joined together, choosing always the higher indicated value.

$$
\begin{array}{ll}
\bullet & 0=\text { no oil or gas } \\
\bullet & 1=\text { only gas } \\
- & 2 \text { = only oil } \\
- & 3=\text { both gas and oil }
\end{array}
$$

\subsection{Political side motivations}

\subsubsection{Political intervention ("pol_int_x")}

$=$ existence of an ongoing political intervention in the target country-year (range 0-1).

- Political protective intervention dummy ("pol_int") from the Mil Int dyad dataset (1946-2005) (created from variable originally labeled "Affect policies or conditions in target" 1946-1988 - Mil Int I, and "Affect policies or conditions in target" 1989-2005 - Mil Int II) This dummy variable indicates whether some international military intervention attempts to affect the domestic policies or conditions in the target state in particular directed country dyad-year. It is coded as follows: $0=$ no, 1 = yes.

\subsubsection{Territorial intervention ("territ_int_x")}

= existence of an ongoing territorial intervention in the target country-year (range 0-1).

- Territorial intervention dummy ("territ_int") from the Mil Int dyad dataset (1946-2005) (created from variable originally labeled “Territorial Intervention" 1946-1988 - Mil Int I, and "Territorial Intervention" 1989-2005 - Mil Int II) - This dummy variable codes whether there was an intervention with the main aim of acquisition or retention of the territory, delineation of frontiers, or specification of 
sovereign status in particular directed country dyad-year. It is coded: 0 = no, 1 = yes.

\subsubsection{Strategic intervention ("strat_int_x")}

$=$ existence of an ongoing strategic intervention in particular target country-year (range 0-1).

- Strategic intervention dummy ("strat_int") from the Mil Int dyad dataset (1946-2005) (created from variable originally labeled "Strategic Intervention" 1946-1988 - Mil Int I, and "Strategic Intervention" 1989-2005 - Mil Int II) - This dummy variable codes whether some military intervention attempts to restore a regional balance of powers or stability; or is led by the ideological motives in particular directed country dyad-year. It is coded as follows: $0=$ no, $1=$ yes.

\subsubsection{Protective intervention ("protect_int_x")}

$=$ existence of an ongoing protective intervention in particular target country-year (range 0-1).

- Military/diplomatic protective intervention dummy ("protect_int") from the Mil Int dyad dataset (1946-2005) (created from variable originally labeled "Military/Diplomatic Protective Intervention" 1946-1988 - Mil Int I, and "Military/Diplomatic Protective Intervention" 1989-2005 - Mil Int II) - This dummy variable codes whether some military intervention attempted to protect own military and/or diplomatic interests and property inside or outside the target state in particular directed country dyad-year. It is coded as follows: 0 $=$ no, 1 = yes.

\section{3. 'Just authority' index}

As in the case of 'just intent' index, 'just authority' index required information about characteristics of both the intervener and the target state. Therefore, the index was constructed based on the EUGene list of country dyads, while filtering out only the cases identified by the Mil Int dataset.

\subsection{Legitimacy of the intervener}

\subsubsection{Democracy level - intervener ("dem_a_x")}

$=$ an averaged level of democracy in the countries intervening into the target state in particular year (range 2-20).

- Polity IV score ("polity_IV") from the DEM dataset (1946-2004) (originally labeled "polity") - This variable indicates the Polity IV score 
(without PARREG) that is adjusted to create a positive value ranging from 2 to 20 .

\section{Adjustments:}

The missing values were replaced with a middle value between the last known and the next known value in the time row for a particular country. In case that the identified middle value was not a natural number, the number was rounded down. In case that there was no observation for the country prior to the missing value, such as in the case that the missing value was caused by the fact that the country was still not identified as recognized by the DEM dataset, the value was left constant as in the first year available. If the country was not covered by the DEM dataset at all, the middle value 10 was attached so that the country is placed in the middle of the scale, demonstrating no extremes to either side. The only exceptions to this rule represent the multilateral interventions and the interventions led by some international organization. These were attached the value 20, since such interventions required a support from domestic constituencies in more countries to be waged. After removing all the missing values, the polity scores of all intervening countries were summed together and divided by the number of interveners so as to get the averaged level of democracy in the countries intervening into the target state in particular year.

\subsubsection{International organization leadership ("io_int_x")}

$=$ presence of an intervention led by the international organization in particular target country-year (range 0-1).

Input variable:

- International organization leadership dummy ("io_int") from the Mil Int dyad dataset (1946-2005) (newly created from the variables originally labeled "Source of intervention" 1946-1988 - Mil Int I, and "Source of intervention" 1989-2005 - Mil Int II) - This dummy variable indicates a presence of some intervention led by the international organization in particular directed country dyad-year.

\section{Adjustments:}

The values were grouped into the target country-year observations using the MAXIMUM operator so as to indicate a presence of some intervention that was backed up by some international organization.

\subsubsection{UN leadership ("un_int_x")}


= presence of an intervention led by the $\mathrm{UN}$ in particular target country-year (range 0-1).

Input variable:

- COW ccode of the intervener ("ccode_a")

Adjustments:

This variable was created by filtering out all the interventions led by the $\mathrm{UN}$, which means the ones that were assigned the ccode for the intervener 1000. UN interventions were coded with the value 1; all the remaining observations were denoted by 0 . Afterwards, the values were grouped into the target country-year observations using the MAXIMUM operator so as to indicate a presence of the UN leadership in any military intervention in particular target country-year.

\subsection{Absence of legitimacy of the target state}

3.2.1. Democracy level - target state ("dem_b_x")

$=$ level of democracy in particular target country-year (range 220).

- Polity IV score ("polity_IV") from the DEM dataset (1946-2004) (originally labeled "polity") - This variable indicates the Polity IV score (without PARREG) that is adjusted to create a positive value ranging from 2 to 20 .

\section{Adjustments:}

The missing values were removed according to the procedure described in the previous variable.

\subsubsection{Autocratization - target state ("autocratiz_b_x")}

$=$ existing autocratization in the target state in particular year (scale 1, 0, -1).

Main input variables:

- Autocratization dummy ("autoc_0") from the DEM dataset (19462004) (originally labeled "caut") - This dummy variable indicates whether the country-year experiences an autocratization period.

- Democratization dummy ("dem_0") from the DEM dataset (19462004) (originally labeled "cdem") - This dummy variable indicates, whether the country-year experiences a democratization period.

Reference variable: 
- Polity IV score ("polity_IV") from the DEM dataset (1946-2004) (originally labeled "polity") - This variable indicates the Polity IV score (without PARREG) that is adjusted to create a positive value ranging from 2 to 20 .

\section{Adjustments:}

The variable "autocratiz_b_x" was created by merging the information from variables "autoc_0" and "dem_0". The missing values were filled in by referring to the movement on the Polity scale in the reference variable "polity_IV" that has been already cleaned of the missing values in the previous steps. The variable "autocratiz_b_x" was coded in a way that the higher the autocratization of the regime is, the higher is the legitimacy of the intervention:

- $-1=$ democratization

- $0=$ no regime change

- 1 = autocratization

\section{4. 'Last resort' index}

'Last resort' index was constructed by calculating a percentage change in the 'just cause' index from the previous to the current year. It means that it is composed of the following input variables:

- Battle deaths ("b_deaths_best_x")

- Genocide deaths ("genoc_deaths_x")

- Displaced population ("refug_x")

- Internal violence (“viol_x")

- State failure ("pitf_magn_sum_x")

- Rebellion ("rebel_x")

\section{5. 'Proportionality' index}

'Proportionality' index was built on the EUGene list of country dyads, again filtering out only the cases when an ongoing intervention was identified based on the definition adopted by the Mil Int dataset. The dyadic data were grouped by the ccode of the target country and the year using the SUM operator, while simultaneously counting the number of interveners in each target country-year. In some variables, the summed values were then divided by the number of interveners so as to get the averaged value for the interveners. However, in some cases; the information for the whole conflict was more relevant and the summed value was left without being averaged. 


\subsection{Security threat}

5.1.1. Aggregate battle deaths on both sides ("battle_deaths_1x" + "battle_deaths_2x")

$=\mathrm{a}$ total number of the battle-related fatalities suffered by the interveners and the target state in particular target country-year (abs. no.; scale 1, 2, 3-8).

Main input variables:

- Best battle deaths estimate ("b_deaths_best") from the ACD dataset (1946-2005) (originally labeled "bdeadbes") - This variable sums the best estimates of the total battle-related fatalities resulting of all conflicts in particular country-year. Battle fatalities are defined as civilians and combatants killed in the course of combat.

- Battle casualties of the target II ("b_deaths_bsum") from the Mil Int dyad dataset (1946-2005) (originally labeled "Number of battle casualties to the target" 1946-1988 - Mil Int I, and "Number of battle casualties to the target" 1989-2005 - Mil Int II) - This variable indicates a total number of battle-related fatalities suffered by the target state associated with interventions of the intervener in particular directed country dyad-year. Whenever possible, the number includes both people killed and those being wounded, if the targets are camps or villages. It is coded: $0=$ none, $X X X=$ number of casualties (at least), $1000=$ at least 1000 casualties.

- Battle casualties of the intervener II ("b_deaths_asum") from the Mil Int dyad dataset (1946-2005) (originally labeled "Number of battle casualties to the intervener" 1946-1988 - Mil Int I, and "Number of battle casualties to the intervener" 1989-2005 - Mil Int II) - This variable indicates a total number of battle-related fatalities suffered by the intervener in particular directed country dyad-year. It sums the levels of casualties suffered by the intervener that are evaluated as follows: $0=$ none, $X X X=$ number of casualties (at least), $1000=$ at least 1000 casualties.

Adjustments:

First of all, the missing values in the input variables were corrected. The missing values in the main input variable "b_deaths_best" were replaced by a value of 25 battle-related fatalities. Rationale behind this value is the fact that the identification threshold of conflict in the ACD dataset is a minimum of 25 battle-related deaths over year. The cases not identified by the ACD dataset as fulfilling the threshold of an existing crisis were attached the value 0 . The missing values in the Mil Int variables "b_deaths_bsum" and 
"b_deaths_asum" were set to 0 , since Mil Int dataset does not set any identification threshold based on fatalities.

While estimating the aggregate number of battle-related deaths, it was important to take into consideration that the ACD variable indicates something slightly different than the Mil Int variables. ACD variable provides an aggregate total of the battle-related deaths associated with all the interveners in particular target country-year. On the other hand, Mil Int variables are constructed based on a dyadic structure, referring to each intervener separately. Therefore, they had to be treated differently during the merging process. While the ACD variable was just grouped by the MAXIMUM operator, values in the Mil Int variables were summed together and then grouped using the SUM operator into the target country-years. As a result of this restructuring, they started to indicate the same thing. While choosing the preferred value between the ACD and the summed Mil Int variables, the higher estimate for each country-year was selected. The resulting output indicates a total amount of battle-related causalities of all conflict participants in the target country-year, indicating thus the overall conflict severity.

The input variable was constructed in two versions, one in absolute numbers and one scaled. The reason for keeping both of them is that the number of battle-related fatalities in the Mil Int dyad variables is not fully coherent. In fact, the indicated values are kept in absolute numbers only till the number 999; since then, they indicate just a level over 1000 fatalities. Therefore, so as to harmonize the coding, apart from keeping the value in the absolute numbers, the second version of this variable was transformed into the below described scale.

- $\quad 1-100($ ACD or Mil Int dyad $)=1$

- $101-500($ ACD or Mil Int dyad $)=2$

- $501-999$ (ACD or Mil Int dyad) = 3 (number 999 is set as a border value)

- $1000-5000($ ACD or Mil Int dyad $)=4$

- $5001-10000$ (ACD or Mil Int dyad) = 5

- $10001-50000($ ACD or Mil Int dyad $)=6$

- $50001-500000($ ACD or Mil Int dyad $)=7$

- $500001-1000000($ ACD or Mil Int dyad) $=8$

5.1.2. Battle deaths - interveners ("battle_deaths_a1x" + "battle_deaths_a2x") 
= $\mathbf{a}$ number of battle-related fatalities suffered by all interveners in particular target country-year (abs. no.; scale 1, 2, 3-8).

- Battle casualties of the intervener II ("b_deaths_asum") from the Mil Int dyad dataset (1946-2005) (originally labeled "Number of battle casualties to the intervener" 1946-1988 - Mil Int I, and "Number of battle casualties to the intervener" 1989-2005 - Mil Int II) - This variable indicates a total number of battle-related suffered by the interveners in particular directed country dyad-year. It sums the levels of casualties suffered by the interveners that are evaluated as follows: $0=$ none, $X X X=$ number of casualties (at least), $1000=$ at least 1000 casualties.

\section{Adjustments:}

The missing values were set to 0 . Afterwards, the casualties suffered by individual interveners in particular target country-year were summed but not divided by the number of interveners, so as to show a total number of lives lost and thus to depict how dangerous the conflict is to be intervened into. As in case of the previous variable, there were two versions of this variable created - one in absolute numbers and one scaled, using exactly the identical procedure a scale.

\subsubsection{International troops strength - target state ("int_strength_x")}

$=\mathrm{a}$ total number of foreign soldiers being present in the target country-year (scale $0,1,2-51$ ).

Main input variable:

- Troop number sum ("troop_no_sum”) from the Mil Int dyad dataset (1946-2005) (originally labeled "Amount of Troop Incursion" 19461988 - Mil Int I, and "Amount of Troop Incursion" 1989-2005 - Mil Int II) This variable sums the levels of troop incursion initiated by the intervener in particular directed country dyad-year. It is coded as follows: $0=$ none, 1 $=1-1000,2=1001-5000,3=5001-10000,4=10000+$.

\section{Adjustments:}

Before grouping the data, the missing values in the variable were replaced by the middle value on the scale, which is the value 2 . After summing the levels for all interveners, the resulting values were not divided by the number of interveners. Rather they were left as aggregates, indicating the total number of foreign soldiers being present in the target country-year. The summed scales do not represent equal ranges, but disadvantage the stronger international presence in relation to the weaker one.

\subsubsection{Intervention frequency - target state ("int_freq_ $\mathrm{x}$ ")}


$=\mathbf{a}$ number of interventions in particular target country-year (abs. no.).

Main input variable:

- Number of interventions ("int_freq") from the Mil Int dyad dataset (1946-2005) - This variable counts interventions in particular directed country dyad-year.

Adjustments:

The number of interventions repeatedly counts the same intervener, if he intervened more than once in particular target country-year, so as to depict the complexity of the conflict and its potential for drawing others, situation complicating interventions.

\subsubsection{Military strength of opposition - target state ("opp_strength_x")}

$=$ an average strength of opposition faced by the intervener in particular target country-year (range 0-4).

Main input variable:

- Military capability B ("mil_cap_b") from the EUGene dyad dataset (1946-2001) (originally labeled "cap_2") - This variable represents a COW Composite Indicator of National Capabilities (CINC) index for the country that is composed of six capability indicators: military personnel, military expenditures, energy production, iron/steel production, nominal urban population, and nominal total population.

Reference variables:

- Intervention supporting government dummy ("int_supp_gov") from the Mil Int dyad dataset (1946-2005) (created from variables originally labeled "Direction of Intervener Supporting Action" 1946-1988 - Mil Int I, and "Direction of Intervener Supporting Action" 1989-2005 - Mil Int II) - This dummy variable indicates a presence of an intervention supporting the government in particular country-year.

- Intervention supporting rebels dummy ("int_supp_reb") from the Mil Int dyad dataset (1946-2005) (created from variables originally labeled "Direction of Intervener Supporting Action" 1946-1988 - Mil Int I, and "Direction of Intervener Supporting Action" 1989-2005 - Mil Int II) - This dummy variable indicates a presence of an intervention supporting the opposition in particular country-year.

Adjustments: 
The missing values in the variable "mil_cap_b" were left constant as in the last available observation for a particular country. For example, the missing values for years 2002-2005 that fall out of the time coverage of the dataset were made constant as indicated in year 2001. The resulting values were grouped by the ccode of the target country and the year using the SUM operator.

Variable "mil_cap_b" was not sufficient on its own to capture the expected strength of the opposition that the intervener could face. For that purpose, the study utilized the reference dummy variables that indicate whether all interventions in particular target country-year supported just the government, supported just the rebels, or were mixed in their targeting. Different type of targeting was assigned a different multiplier effect that was used to adjust the military capability index:

- $\quad$ Supporting rebels $=0,5^{*}$ military capability of the target state index

- $\quad$ Supporting government $=1^{*}$ military capability of the target state index

- $\quad$ Mixed target $=1,5^{*}$ military capability of the target state index

And finally, the multiplied values were divided by the number of interveners in particular target country-year, so as to get the average strength of opposition that the interveners faced.

\subsubsection{Alliance risk score - target state ("risk_b_x")}

$=\mathbf{a}$ risk score indicating how vulnerable is the target state to a possible intervention by other states based on its alliance portfolio (range -1-1).

Main input variable:

- Tau-b risk score $B$ ("risk_b_t") from the EUGene dyad dataset (1946-2000) (originally labeled "riskT2") - This variable indicates a risk score (measured in Tau-b) for the target state in a relevant region based on the sum of other states' utilities toward the country. It shows whether the target state chooses to form an alliance portfolio that leaves it relatively vulnerable or relatively invulnerable to other states. The score ranges from -1 to +1 ; with -1 indicating a highly risk-averse actor, and a +1 indicating a highly risk-acceptant actor. An optimal security level is associated with the hypothetical alliance pattern that would leave the target state least vulnerable to defeat, i.e. in the best possible security position.

Adjustments: 
The missing values outside the time coverage of the variable were set constant as in the last recorded year.

\subsection{Force used}

\subsubsection{Most violent troop activity - intervener ("troop_act_x")}

$=$ an averaged level of violence employed by the interveners in particular target country-year (range 0-5).

\section{Input variables:}

- Type of troop activity ("troop_act") from the Mil Int dyad dataset (1946-2005) (originally labeled "Type of Troop Activity" 1946-1988 - Mil Int I, and "Type of Troop Activity" 1989-2005 - Mil Int II) - This variable indicates the most violent type of troop activity applied by the intervening forces in particular directed country dyad-year. It is coded as follows: $0=$ none, 1 = evacuation of troops or personnel (any nationality), 2 = transport or negotiate-observe, 3 = patrol, guard, defend, $4=$ intimidation, $5=$ combat.

- Intervention force type ("force_type_max") from the Regan 1 dataset (1946-1999) (originally labeled "clash") - This variable records the most intensive type of force employed by the intervening country in particular target country-year. It is coded as follows: $1=$ single incident border clash, 2 = air attack and 3 = more general use of force beyond that of a single incident.

\section{Adjustments:}

The two input variables indicate slightly different things. The variable "troop_act" indicates the most violent type of troop activity carried out by a particular intervener in a given country-year; while the variable "force_type_max" groups the most violent activity of all interveners, depicting the most violent one. Therefore, they had to be treated differently in the grouping process into the target country-years. Variable "troop_act" was grouped using the SUM operator, while MAXIMUM operator was used for the variable "force_type_max". Afterwards, the structure of the variables needed to be harmonized. The scale of the variable "force_type_max" was adjusted to become better combinable with the variable "troop_act" classification:

$$
\begin{array}{ll}
\text { - } & 0(\text { Regan } 1)=0(\text { Mil Int }) \\
\text { - } & 1(\text { Regan } 1)=1(\text { Mil Int }) \\
\text { - } & 2(\text { Regan } 1)=3(\text { Mil Int }) \\
\text { (Regan } 1)=5(\text { Mil Int })
\end{array}
$$


After finishing the harmonization of the two variables, the higher estimated level of troop activity from the two variables was always selected as a preferred value for each country-year. In case that some value was indicated as missing, the value from the second variable was used. The remaining missing values not covered by any of the two datasets were attached a value that indicates the most common type of a military intervention, which is the value 2 . Finally, the values were divided by the number of interveners so as to get the average of the most violent troop activity employed by all the interveners in particular target country-year.

\subsubsection{Aggregate violent troop activity - interveners ("troop_act_agr_x")}

= a sum of the most aggressive level of troop activity employed by all the interveners in particular target country-year (range 0 12).

\section{Input variables:}

- Type of troop activity ("troop_act") from the Mil Int dyad dataset (1946-2005) (originally labeled "Type of Troop Activity" 1946-1988 - Mil Int I, and "Type of Troop Activity" 1989-2005 - Mil Int II) - This variable indicates the most violent type of troop activity applied by the intervening forces in particular directed country dyad-year. It is coded as follows: $0=$ none, 1 = evacuation of troops or personnel (any nationality), $2=$ transport or negotiate-observe, 3 =patrol, guard, defend, $4=$ intimidation, $5=$ combat.

- Intervention force type ("force_type_max") from the Regan 1 dataset (1946-1999) (originally labeled "clash") - This variable records the most intensive type of force employed by the intervening country in particular target country-year. It is coded as follows: $1=$ single incident border clash, 2 = air attack and $3=$ more general use of force beyond that of a single incident.

\section{Adjustments:}

In contrast to the previous indicator "troop_act_x"; the indicator "troop_act_agr_x" was generated using the MAXIMUM operator in the grouping process for both variables, and the resulting values were not divided by the number of interveners. Otherwise, the carried out replacement of the missing variables, and the selection of the higher resulting value was identical.

\subsubsection{Troop number - interveners ("troop_no_ax")}

$=$ an average number of troops sent by the interveners to the target state in particular year (range 0-6). 
Main variable:

- Troop number sum ("troop_no_sum") from the Mil Int dyad dataset (1946-2005) (originally labeled "Amount of Troop Incursion" 19461988 - Mil Int I, and “Amount of Troop Incursion" 1989-2005 - Mil Int II) This variable sums the level of troop incursion initiated by the intervener in particular directed country dyad-year. It is coded as follows: $0=$ none, $1=1$ $1000,2=1001-5.000,3=5001-10000,4=10000+$.

\section{Adjustments:}

This variable is similar to the "int_strength_x" indicator that describes the security threat in the first part of this index. However, this one is not capturing the total amount of foreign troops in the target country-year; but rather an average number of troops sent by the interveners. The variable was constructed by summing the amounts of external troops in particular target country-year, while not taking into to the consideration which country actually sent them. The resulting number was then divided by the number of interveners. As a result of this procedure, if one intervener sent troops more than once in a given year, the resulting value could reach a higher value than 4 (= the maximum level indicated in the coding of the input variable). Allowing the inflated impact of the repeated military actions by one actor reflects a concern that the repeatedly deployed troops suggest a major military devotion to the conflict or the target state and thus an intensified security threat. The missing values were again set to the middle value of the range of $0-4$, which is the value 2 .

\section{6. 'Probability of success' index}

'Probability of success' index was built on the EUGene list of country dyads. It is composed only of two control groups of variables, one indicating the probability of success based on the military strength of the target state and the other based on the complexity of the ongoing conflict.

\subsection{Probability of success based on the military strength of the target state}

\subsubsection{Probability of success - intervener ("succ_a_x")}

$=$ an average probability of success of a military intervention waged by the interveners to the target state in particular year (range 0-1).

- Probability of success A vs. B (Tau) ("succ_a_t $t$ ") from the EUGene dyad dataset (1946-2000) (originally labeled "wrTp1win") - This variable represents a state A's perception of the probability of success vs. state B. It is computed by combining the Tau-b scores, distance data, national capability data, and regional risk attitude scores to produce the estimates 
of probability of success for state A in a military conflict against B, while taking into account the likely behavior of possible interveners.

\section{Adjustments:}

The values falling out of the time coverage of the input variable were left constant as in the last recorded year. The probability of success of the interventions led by some international organization or the multilateral interventions was set to the middle value of $50 \%$, as well as the probability of success of the recently established countries, which fall out of the time spam of the dataset and which thus have no recorded observations. The probabilities associated with individual interveners in particular target country-year were summed and then divided by the number of interveners so as to represent an averaged probability of success of the actual interveners.

\subsubsection{Military strength of opposition - target state ("opp_strength_x")}

$=$ an average strength of the opposition faced by the intervener in particular target country-year (range 0-4).

Input variable and adjustments:

The variable "opp_strength_x" is constructed in a same way as the identically labeled variable in the section 'proportionality' index (5.1.5).

6.1.3. Big power target state ("big_pow_b_x")

$=$ target state is a major power (binary 0,1$)$.

Input variable:

- Major power B ("big_pow_b") from the EUGene dyad dataset (19462005) (originally labeled "majpow2") - This dummy variable assigns a major power status to the target state.

\subsubsection{Risk score of the target state ("risk_b_x")}

= risk score of the target state indicating how vulnerable its alliance portfolio leaves it to a possible intervention by other states (range -1-1).

Input variable and adjustments:

The variable "risk_b_x" is constructed in a same way as the identically labeled variable in the section 'proportionality' index (5.1.6).

\subsection{Probability of success based on the conflict complexity}

\subsubsection{Political violence culture in the target state ("viol_cult_x")}


$=\mathbf{a}$ number of violent years relative to those peaceful ones in the target state since the year 1946 till the year of concern (range 0-1).

\section{Input variable:}

This variable counts the number of country-years identified by the ACD dataset as crossing the threshold of 25 battle-related deaths. The counting is done in a cumulative way, starting with the year 1946 till the year of concern. Afterwards, the number is divided by the number of years that passed since 1946 till the intervention year that is being evaluated. The resulting value ranges on the scale form $0-1$, where 0 means no occurrence of violence in any year, while 1 means that the violence was identified in each year previous to the year of concern.

\subsubsection{Just cause index ("just_cause_x")}

$=$ severity of the crisis in particular target country-year (range 0.4-7.3).

Input variable:

This variable is a product of factor analysis applied to the JWT criterion of 'just cause'.

\subsubsection{Intervention frequency - target state ("int_freq_ $x$ ")}

$=\mathrm{a}$ number of interventions in particular target country-year (abs. no.).

Input variable and adjustments:

The variable "int_freq_x" is constructed in a same way as the identically labeled variable in the section 'proportionality' index (5.1.4).

\section{RESULTS OF THE FACTOR ANALYSIS}

\section{Construction of the components}

\section{1. 'Just cause' index}

\begin{tabular}{|c|c|c|c|}
\hline variable name & $\begin{array}{c}\text { storage } \\
\text { type }\end{array}$ & $\begin{array}{l}\text { display } \\
\text { format }\end{array}$ & variable label \\
\hline battle_deaths_x & byte & $\div 8.0 \mathrm{~g}$ & Battle deaths - target state \\
\hline genoc_deaths_x & float & $\div 9.0 \mathrm{~g}$ & Genocide deaths - target state \\
\hline refug_x & float & $\div 9.0 \mathrm{~g}$ & Displaced population - target state \\
\hline viol_x & byte & $\div 8.0 \mathrm{~g}$ & Internal violence - target state \\
\hline state_fail_x & float & $\div 9.0 \mathrm{~g}$ & State failure - target state \\
\hline rebel_x & float & $\div 9.0 \mathrm{~g}$ & Rebellion - target state \\
\hline
\end{tabular}




\begin{tabular}{|c|c|c|c|c|c|}
\hline Variable & Obs & Mean & Std. Dev. & Min & Max \\
\hline battle_deaths_x & 12000 & .3744167 & 1.168693 & 0 & 7 \\
\hline genoc_deatths_x & 12000 & .0550417 & .4134273 & 0 & 5 \\
\hline refug_x & 12000 & .5312183 & .992765 & 0 & 4 \\
\hline viol_x & 12000 & .4505833 & 1.407322 & 0 & 10 \\
\hline state_fail_x & 12000 & .2985417 & 1.111997 & 0 & 12 \\
\hline rebel_x & 12000 & .4174361 & 1.135828 & 0 & 7 \\
\hline
\end{tabular}

- Sample is large enough to yield reliable estimates of the correlations among the variables: $n=12000$.

- There are no outliers among the cases, because the values are located within a limited scale: see the low standard deviations and the moderate minimal and maximal values.

\begin{tabular}{|c|c|c|c|c|c|c|}
\hline & battle x & enoc_ $\sim x$ & refug_x & viol_x & state_ $\sim x$ & rebel_ \\
\hline battle_dea x & 1.0000 & & & & & \\
\hline genoc_deat $\sim x$ & 0.3931 & 1.0000 & & & & \\
\hline refug_x & 0.4619 & 0.2741 & 1.0000 & & & \\
\hline viol_x & 0.7748 & 0.5118 & 0.4805 & 1.0000 & & \\
\hline state_fail_x & 0.6299 & 0.3585 & 0.4409 & 0.6776 & 1.0000 & \\
\hline rebel_x & 0.6324 & 0.3295 & 0.4070 & 0.7014 & 0.5595 & 1.0000 \\
\hline
\end{tabular}

- Data seem convenient for PCA, since there is some visible degree of collinearity among the variables so as to generate the components, and this degree is also not extreme. Variables that correlate with each other do so because they are - as expected based on the theory - measuring related characteristics.

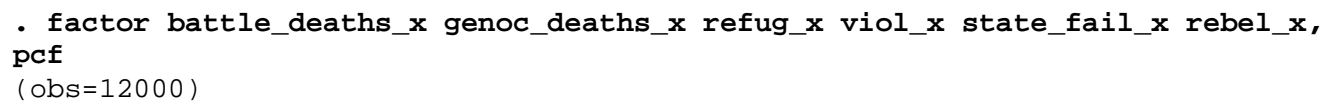

\begin{tabular}{|c|c|c|c|c|}
\hline Factor & Eigenvalue & Difference & Proportion & Cumulative \\
\hline Factor 1 & 3.61144 & 2.85798 & 0.6019 & 0.6019 \\
\hline Factor2 & 0.75346 & 0.10047 & 0.1256 & 0.7275 \\
\hline Factor3 & 0.65299 & 0.21494 & 0.1088 & 0.8363 \\
\hline Factor 4 & 0.43805 & 0.08816 & 0.0730 & 0.9093 \\
\hline Factor5 & 0.34989 & 0.15573 & 0.0583 & 0.9676 \\
\hline Factor 6 & 0.19417 & . & 0.0324 & 1.0000 \\
\hline
\end{tabular}


- 6 components were extracted, the same as the number of variables factored.

- $\quad$ Kaiser test of component retention $=$ retain 1 component:

- Only one component accounts for more than 1.0 unit of variance (have an eigenvalue $\lambda>1.0$ ) and was retained (Kaiser test).

$\circ \quad 1^{\text {st }}$ component has an eigenvalue $=3.61$. Since this is greater than 1.0 , it explains more variance than a single variable, in fact 3.61 times as much. This component explains $3.61 / 6^{*} 100=60.19 \%$ of variance.

- The remaining 5 components have eigenvalues lower than 1.0. Since they explain less variance than a single variable, they were dropped prior to rotation.

screeplot

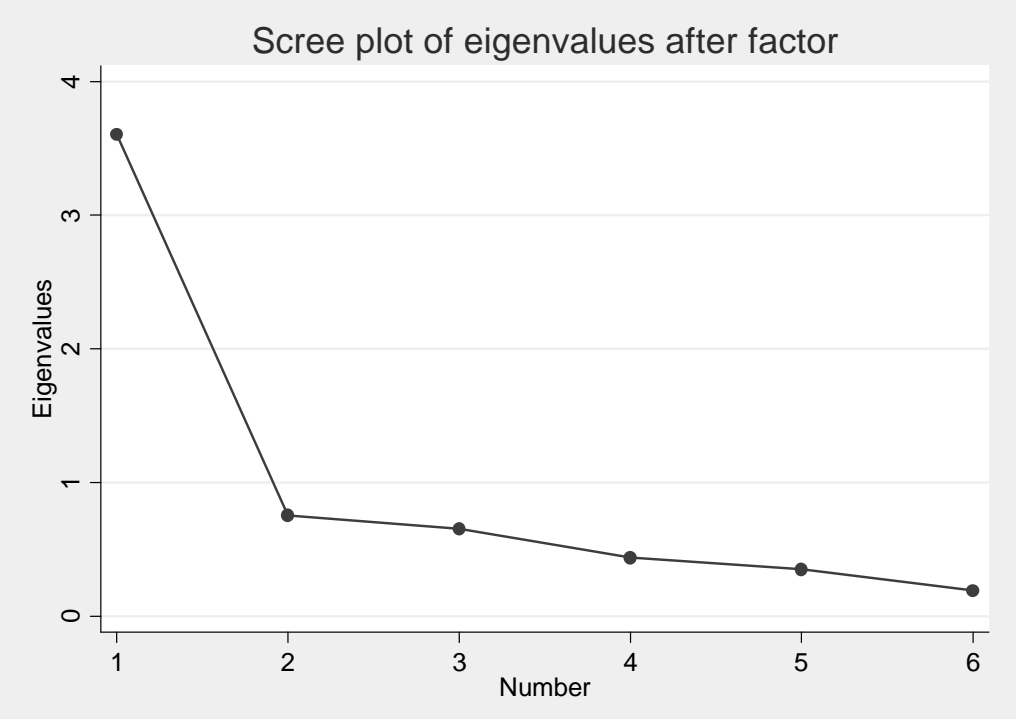

- $\quad$ Cattell screeplot test of component retention = retain 1 component (same result as Kaiser test).

- Components are retained till the point where the plot begins to level off, the additional components explain less variance than a single variable.

- Final decision: 1 retained component. 
- Cumulative variance explained: $60.19 \%$.

Factor loadings (pattern matrix) and unique variances

\begin{tabular}{r|c|c} 
Variable & Factor1 & Uniqueness \\
\hline battle_deaths_x & 0.8598 & 0.2608 \\
genoc_deathts_x & 0.5867 & 0.6558 \\
refug_x & 0.6417 & 0.5882 \\
viol_x & 0.9115 & 0.1692 \\
state_fail_x & 0.8040 & 0.3535 \\
rebel_x & 0.7993 & 0.3611
\end{tabular}

- The component matrix indicates the correlation of each variable with the retained component: products are component loadings.

- Loadings of variables in the pattern and component label:

$\circ$ $1^{\text {st }}$ component $=$ 'Just cause index' (just_cause_x)

- battle_deaths_x - component loading $=0.8598$ ('strong')

- genoc_deaths_x - component loading $=0.5867$ ('moderate')

- refug_x - component loading $=0.6417$ ('strong')

- viol_x - component loading $=0.9115$ ('strong')

- $\quad$ state_fail_x - component loading $=0.7993$ ('strong')

- Component interpretation:

\section{$\circ \quad 1^{\text {st }}$ component $=$ 'Just cause index'}

- All variables provide complementary information about the increasing complexity of the ongoing crisis.

- The retained component is stable, since it has mostly strong loadings and it was calculated based on a large amount of observations and variables.

rotate \& rotate, promax

- Orthogonal and oblique rotations with just one retained component produce exactly the same component loadings as unrotated component solution. Therefore, rotations are not necessary.

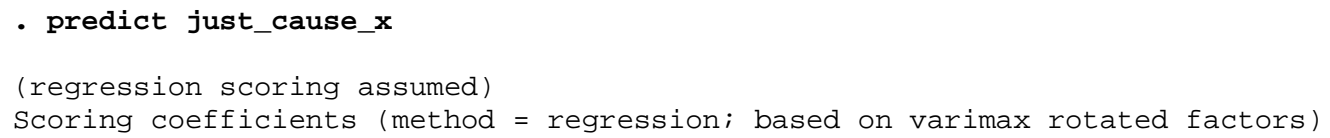




\begin{tabular}{r|c} 
Variable & Factor 1 \\
------------- & ------- \\
battle_deaths_x & 0.23807 \\
genoc_deaths_x & 0.16245 \\
refug_x & 0.17769 \\
viol_x & 0.25238 \\
state_fail_x & 0.22264 \\
rebel_x & 0.22134
\end{tabular}

- A new latent variable representing the 'just cause' index: just_cause_x was created based on the above stated component scores.

\section{2. 'Just intent' index}

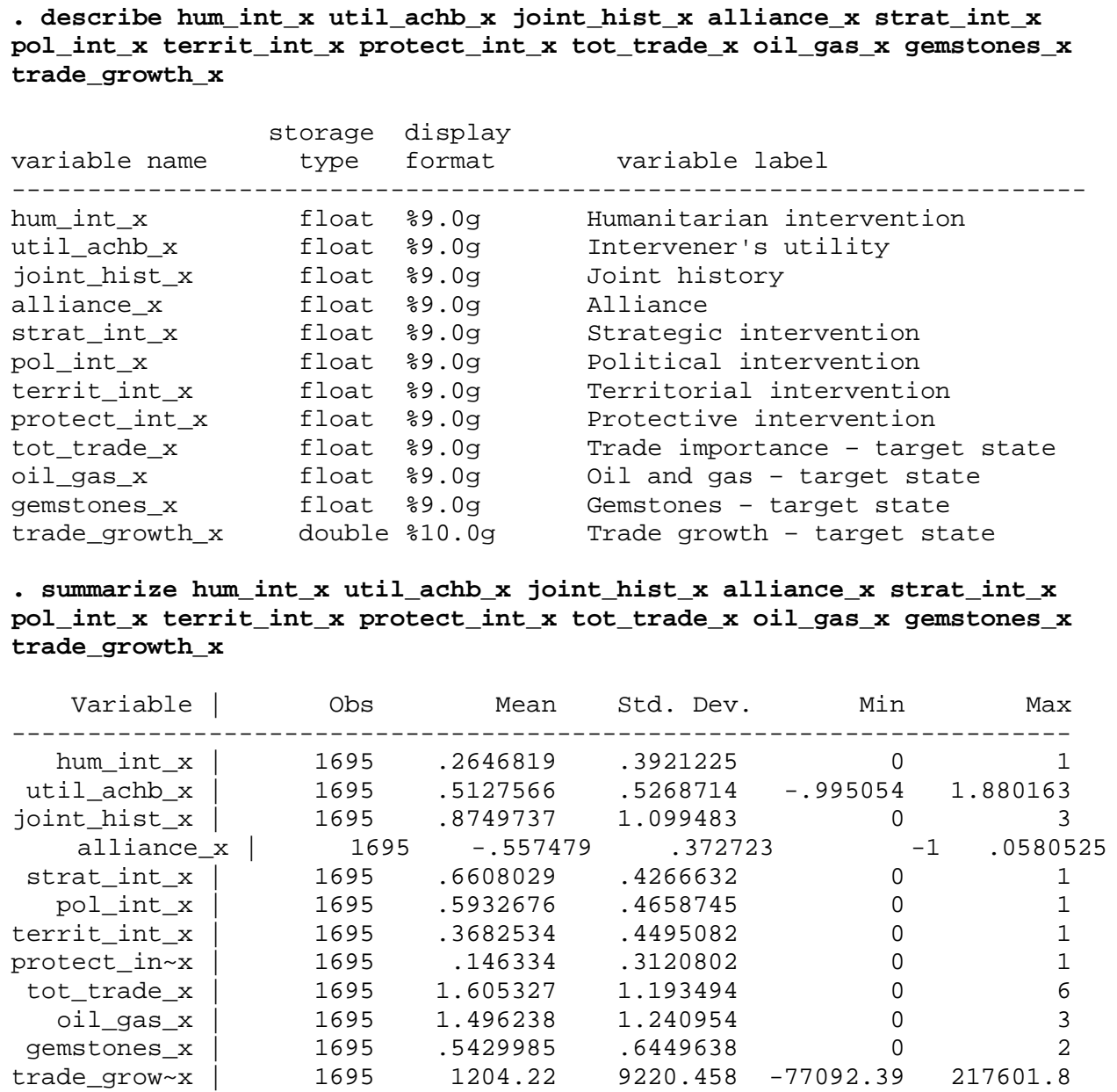

- Sample is large enough to yield reliable estimates of the correlations among the variables: $\mathrm{n}=1695$. 
- There are no outliers among the cases, because the values are mainly located within limited scales: see the low standard deviations and the moderate minimal and maximal values.

- The only higher standard deviation is visible in case of trade growth, which is not scaled but kept in absolute values. However, the reported deviations are defendable based on theory.

- Many of the variables were originally binary, which is not the most appropriate data structure for the PCA. However, during the data merging from the dyadic country-year data into target country-year data, the values assigned to individual interveners were summed and then divided by number of interveners in particular target country-year, so as to get the average intent of intervener. Therefore, even though the variables were originally binary, averaging set the value somewhere on the range of $0-1$.

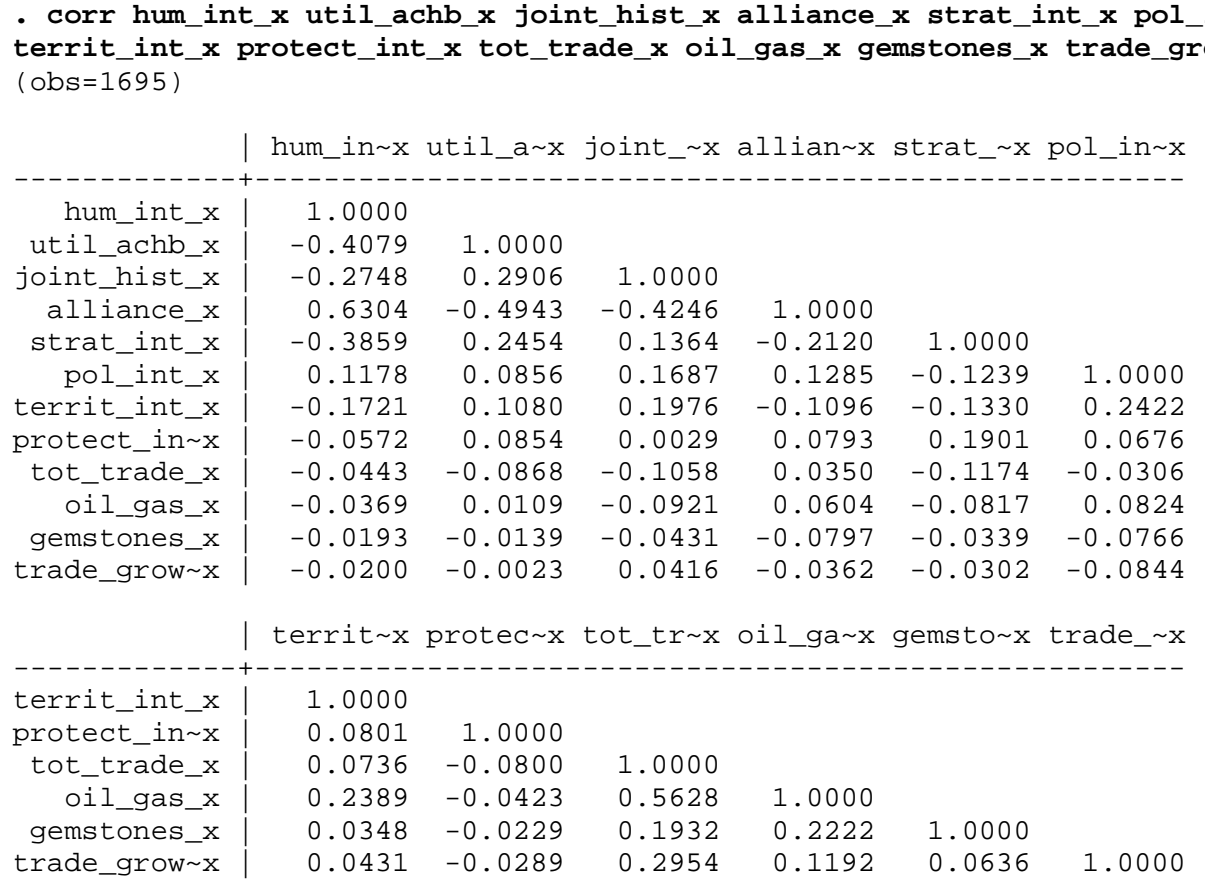

- Data seem convenient for PCA, since there is some visible degree of collinearity among the variables to facilitate calculation of the components. Also these correlations are not extreme. Variables that correlate with each other do so because they - as expected based on the theory - measure related characteristics. 


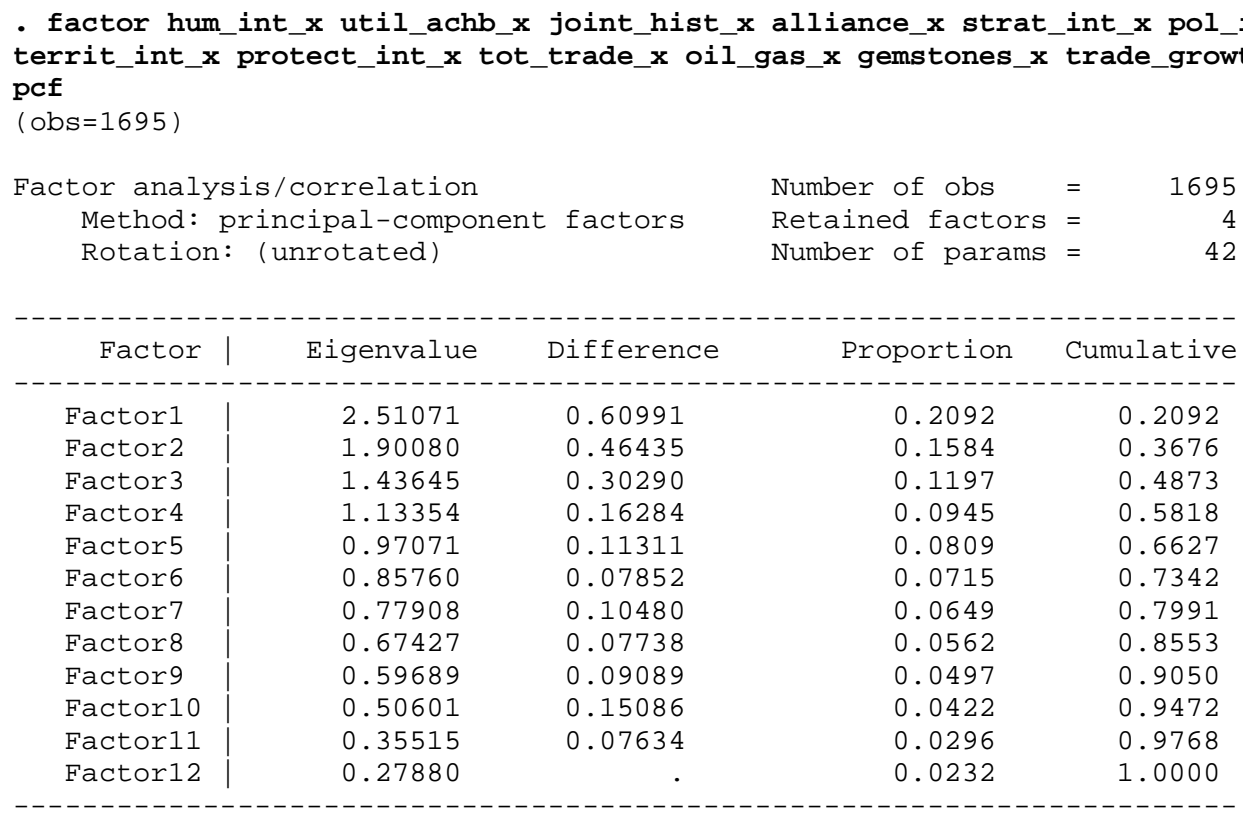

LR test: independent vs. saturated: $\operatorname{chi} 2(66)=3864.50$

Prob>chi2 $=0.0000$

- 12 components were extracted, the same as the number of variables factored.

- $\quad$ Kaiser test of component retention = retain 4 components:

- 4 components account for more than 1.0 unit of variance (have an eigenvalue $\lambda>1.0$ ) and were thus retained (Kaiser test).

$\circ \quad 1^{\text {st }}$ component has an eigenvalue $=2.51071$. Since this is greater than 1.0, it explains more variance than a single variable, in fact 2.51 times as much. This component explains $2.51 / 12^{*} 100=\mathbf{2 0 . 9 2} \%$ of variance.

$\circ 2^{\text {nd }}$ component has an eigenvalue $=\mathbf{1 . 9 0 0 8 0}$. This component explains $1.9 / 12^{*} 100=\mathbf{1 5 . 8 4} \%$ of variance.

$\circ 3^{\text {rd }}$ component has an eigenvalue $=1.43645$. This component explains $1.44 / 12 * 100=\mathbf{1 1 . 9 7} \%$ of variance.

$\circ 4^{\text {th }}$ component has an eigenvalue $=1.13354$. This component explains $1.13 / 12 * 100=\mathbf{9 . 4 5} \%$ of variance.

- The remaining 5 components have eigenvalues lower than 1.0. Due to the fact that they explain less variance than a single variable, they were dropped prior to rotation. 


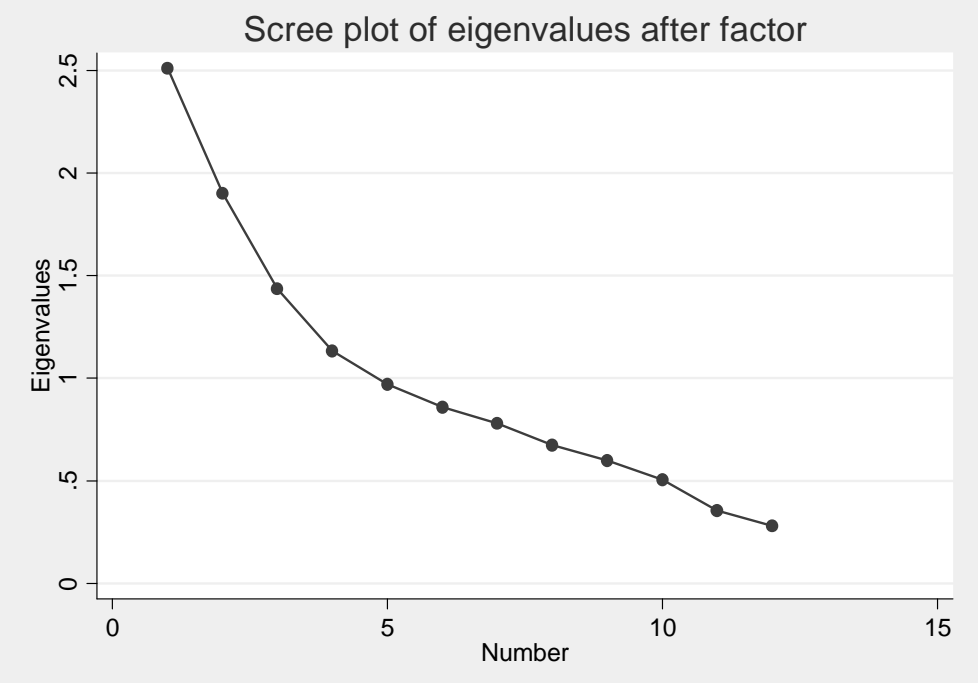

- Cattell screeplot test of component retention:

- Result is unclear. The curve is flattening gradually and it is difficult to determine from the graph, where the plot begins to level off. Retaining 4 components suggested by the Kaiser test are nevertheless a plausible possibility based on the graph $=\underline{\text { retain } 4}$ components.

- Final decision: 4 retained components.

- Cumulative variance explained: $58.18 \%$.

Factor loadings (pattern matrix) and unique variances

\begin{tabular}{|c|c|c|c|c|c|}
\hline Variable & Factor 1 & Factor 2 & Factor 3 & Factor 4 & Uniqueness \\
\hline hum_int_x & -0.7950 & -0.1550 & 0.1757 & -0.0664 & 0.3087 \\
\hline util_achb_x & 0.7081 & 0.0387 & 0.1000 & 0.0398 & 0.4855 \\
\hline joint_hist_x & 0.5989 & 0.0002 & 0.3340 & -0.2661 & 0.4589 \\
\hline alliance_x & -0.8213 & -0.1046 & 0.1400 & 0.2737 & 0.2201 \\
\hline strat_int_x & 0.5025 & -0.2002 & -0.3269 & 0.4742 & 0.3756 \\
\hline pol_int_x & -0.0289 & 0.0614 & 0.7951 & 0.0630 & 0.3593 \\
\hline territ_int_x & 0.2128 & 0.3955 & 0.6029 & 0.0285 & 0.4340 \\
\hline protect_int_x & 0.1123 & -0.1313 & 0.1698 & 0.8342 & 0.2455 \\
\hline tot_trade_x & -0.1505 & 0.7997 & -0.1812 & 0.0806 & 0.2985 \\
\hline oil_gas_x & -0.1004 & 0.7976 & 0.0532 & 0.2006 & 0.3107 \\
\hline gemstones_x & -0.0106 & 0.4315 & -0.2286 & 0.0446 & 0.7594 \\
\hline trade_growth_x & 0.0033 & 0.4299 & -0.2126 & -0.0872 & 0.7624 \\
\hline
\end{tabular}

- Unrotated patterns were rotated to clarify the component patterns: 
Factor analysis/correlation Method: principal-component factors Rotation: orthogonal varimax (Horst off)

\begin{tabular}{|c|c|c|c|c|}
\hline Factor & Variance & Difference & Proportion & Cumulative \\
\hline Factor 1 & 2.45339 & 0.58320 & 0.2044 & 0.2044 \\
\hline Factor2 & 1.87019 & 0.41259 & 0.1558 & 0.3603 \\
\hline Factor3 & 1.45761 & 0.25729 & 0.1215 & 0.4818 \\
\hline Factor 4 & 1.20031 & . & 0.1000 & 0.5818 \\
\hline
\end{tabular}

LR test: independent vs. saturated: $\operatorname{chi} 2(66)=3864.50$

Prob>chi2 $=0.0000$

Rotated factor loadings (pattern matrix) and unique variances

\begin{tabular}{|c|c|c|c|c|c|}
\hline Variable & Factor 1 & Factor2 & Factor3 & Factor 4 & Uniqueness \\
\hline hum_int_x & -0.8016 & -0.0969 & 0.0847 & -0.1795 & 0.3087 \\
\hline util_achb_x & 0.6771 & -0.0544 & 0.1587 & 0.1669 & 0.4855 \\
\hline joint_hist_x & 0.5900 & -0.1737 & 0.3804 & -0.1344 & 0.4589 \\
\hline alliance_x & -0.8710 & 0.0239 & 0.0483 & 0.1358 & 0.2201 \\
\hline strat_int_x & 0.4212 & -0.1099 & -0.3293 & 0.5714 & 0.3756 \\
\hline pol_int_x & -0.1134 & -0.0546 & 0.7867 & 0.0769 & 0.3593 \\
\hline territ_int_x & 0.1914 & 0.2632 & 0.6778 & 0.0275 & 0.4340 \\
\hline protect_in $\bar{x}$ & -0.0588 & -0.0112 & 0.1310 & 0.8566 & 0.2455 \\
\hline tot_trade_x & -0.0350 & 0.8312 & -0.0479 & -0.0840 & 0.2985 \\
\hline oil_gas_x & -0.0302 & 0.8078 & 0.1825 & 0.0510 & 0.3107 \\
\hline gemstones_x & 0.0633 & 0.4617 & -0.1487 & -0.0364 & 0.7594 \\
\hline trade_grow $\mathrm{x}$ & 0.0959 & 0.4313 & -0.1289 & -0.1606 & 0.7624 \\
\hline
\end{tabular}

Factor rotation matrix

\begin{tabular}{r|rrrr} 
& Factor1 & Factor2 & Factor3 & Factor4 \\
Factor1 & 0.9728 & -0.1170 & 0.0772 & 0.1845 \\
Factor2 & 0.1316 & 0.9619 & 0.1793 & -0.1592 \\
Factor3 & -0.1047 & -0.1620 & 0.9804 & 0.0390 \\
Factor4 & -0.1594 & 0.1868 & -0.0248 & 0.9691
\end{tabular}

- The pattern matrix indicates the correlation of each variable with the retained components: products are component loadings.

- Assignment of variables to individual patterns, loadings of variables in the pattern and the respective component labels:

○ $\quad 1^{\text {st }}$ component $=$ 'Humanitarian motivation' $($ hum_motive_x $)$

- hum_int_x - component loading $=-0.8016$ ('strong')

- util_achb_x - component loading $=0.6771$ ('strong') 
- joint_hist_ $\mathrm{x}$ - component loading $=0.5900$ ('moderate')

- alliance_ $x$ - component loading $=-0.8710$ ('strong')

$\circ \quad 2^{\text {nd }}$ component $=$ 'Economic motivation' (econ_motive $\left.\_x\right)$

- tot_trade_x - component loading $=0.8312$ ('strong')

- oil_gas_x - component loading $=0.8078$ ('strong')

- gemstones_x - component loading $=0.4617$ ('moderate')

- trade_growth_x - component loading $=0.4313$ ('moderate')

$\circ \quad 3^{\text {rd }}$ component $=$ 'Political motivation I' (pol_motive_1x)

- pol_int_x - component loading $=0.7867$ ('strong')

- territ_int_x - component loading $=0.6778$ ('strong')

$\circ \quad 4^{\text {th }}$ component $=$ 'Political motivation II' (pol_motive_2x)

- protect_int_x - component loading $=0.8566($ 'strong')

- strat_int_x - component loading $=0.5714$ ('moderate')

- Interpretation of the components:

$\circ \quad 1^{\text {st }}$ component interpretation $=$ 'Humanitarian motivation':

- Variables building the component relate to directly to humanitarian motives and mutual ties that encourage feelings of humanitarianism.

- The higher the utility the intervener has from changing the situation in the target state, the less humanitarian the motivation of the intervener is.

- If the target state shared the common history with the intervening state, the motives behind intervention do not tend to be humanitarian.

- The greater similarity of alliance portfolio between the intervener and the target state, the greater humanitarianism does the intervener show.

$\circ \quad 2^{\text {nd }}$ component interpretation $=$ 'Economic motivation' (control group of 'humanitarian motivation'):

- The component represents economic side motives of the interveners. The more economic importance the target country has the less humanitarian the motivations behind interventions tend to be. 
$\circ 3^{\text {rd }}$ and $4^{\text {th }}$ component interpretation= 'Political motivation $I^{\prime}$ and

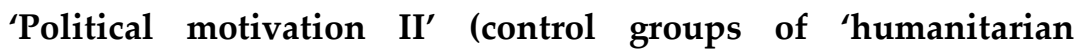
motivation'):

- These two components represent political side motives the intervener, which go against the humanitarian motivation.

- There is just one cross-loading variable: strat_int_x, but the second variable in the component is strong enough to make the component stable. The correctness of the assignment of the variable will be tested by oblique rotation yet.

- A component with fewer than three variables could be weak and unstable. Theoretically, the minimum of three strongly loading variables is indicated as being desirable to indicate a solid component. However, the number of variables can be reduced while still maintaining a strong component, if there is a large data set behind the calculation, which is the case.

- The retained components are stable, since they have mostly strong loadings and were calculated based on a large amount of observations and many variables.

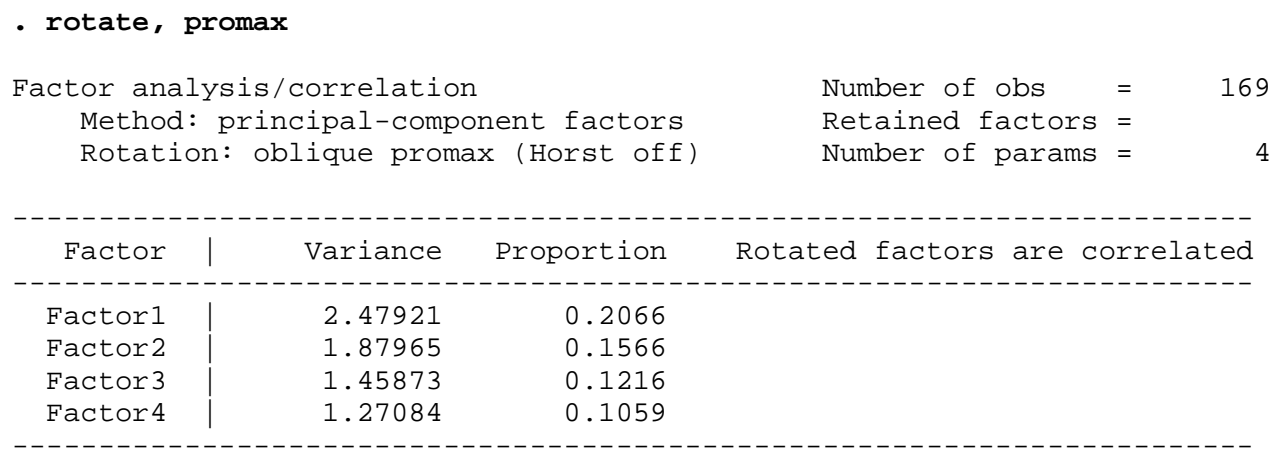

LR test: independent vs. saturated: $\operatorname{chi} 2(66)=3864.50$

Prob>chi2 $=0.0000$

Rotated factor loadings (pattern matrix) and unique variances

\begin{tabular}{r|rrr|r|r} 
Variable & Factor1 & Factor2 & Factor3 & \multicolumn{1}{c}{ Factor4 } & Uniqueness \\
hum_int_x & 0.7938 & -0.1065 & 0.0894 & -0.1367 & 0.3087 \\
util_achb_x & -0.6638 & -0.0413 & 0.1520 & 0.1292 & 0.4855 \\
joint_hist_x & -0.5973 & -0.1764 & 0.3601 & -0.1727 & 0.4589 \\
alliance_x & 0.8906 & 0.0352 & 0.0705 & 0.1931 & 0.2201 \\
strat_int_x & -0.3818 & -0.0800 & -0.3176 & 0.5422 & 0.3756 \\
pol_int_x & 0.1397 & -0.0334 & 0.7922 & 0.0995 & 0.3593 \\
territ_int_x & -0.1742 & 0.2801 & 0.6845 & 0.0442 & 0.4340 \\
protect_in x & 0.1378 & 0.0483 & 0.1670 & 0.8761 & 0.2455 \\
tot_trade_x & 0.0270 & 0.8291 & -0.0270 & -0.0429 & 0.2985 \\
oil_gas_x & 0.0396 & 0.8193 & 0.2086 & 0.0978 & 0.3107 \\
gemstones_x & -0.0704 & 0.4586 & -0.1385 & -0.0210 & 0.7594
\end{tabular}




trade_grow $\sim$ x $|-0.1137 \quad 0.4202-0.1252 \quad-0.1503| r .7624$

Factor rotation matrix

\begin{tabular}{r|rrrr} 
& Factor1 & Factor2 & Factor3 & Factor4 \\
Factor1 & -0.9835 & -0.1323 & 0.0972 & 0.2717 \\
Factor2 & -0.1220 & 0.9627 & 0.1667 & -0.2156 \\
Factor3 & 0.0863 & -0.1892 & 0.9799 & 0.0039 \\
Factor4 & 0.1024 & 0.1408 & -0.0504 & 0.9379
\end{tabular}

- Oblique rotation confirmed attaching the variable strategic intervention into the $4^{\text {th }}$ rather than $1^{\text {st }}$ component. Otherwise, the results of both types of rotations produce more or less the same results.

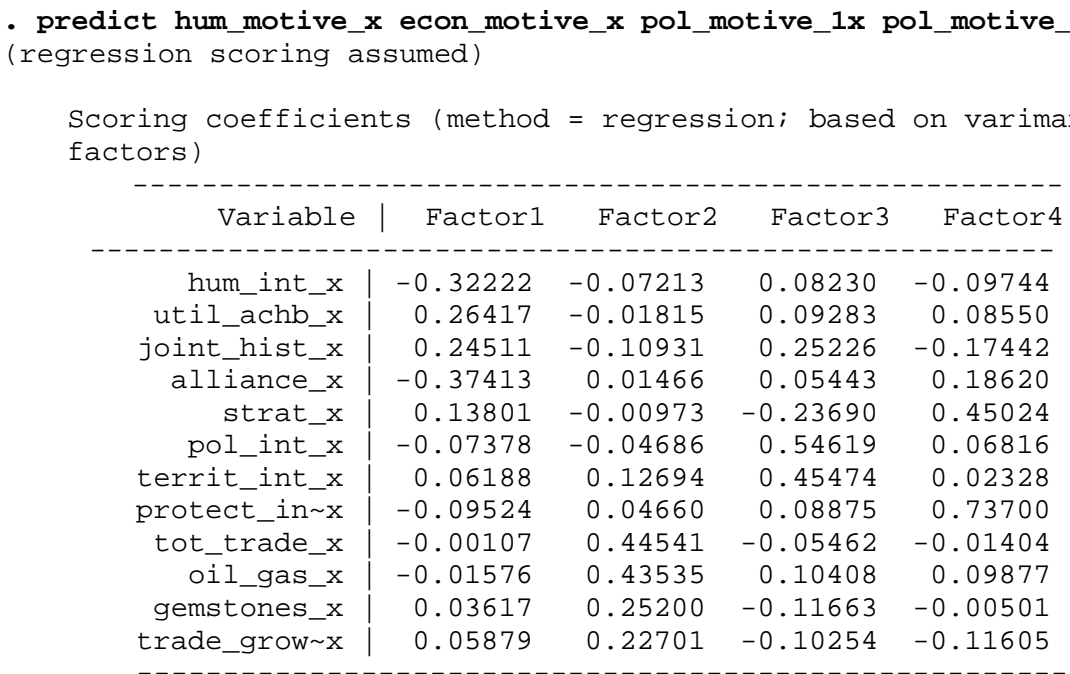

- Four new latent variables composing the 'just intent' index: hum_motive_x, econ_motive_x, pol_motive_1x and pol_motive_2x were created based on the above calculated component scores.

\section{3. 'Just authority' index}

\begin{tabular}{|c|c|c|c|}
\hline variable name & $\begin{array}{c}\text { storage } \\
\text { type }\end{array}$ & $\begin{array}{l}\text { display } \\
\text { format }\end{array}$ & variable label \\
\hline em_a_x & float & $\div 9.0 \mathrm{~g}$ & Democracy level - intervener \\
\hline lem_b_x & byte & $\div 8.0 \mathrm{~g}$ & Democracy level - target state \\
\hline cocratiz_b_x & byte & $\div 8.0 \mathrm{~g}$ & Autocratization - target state \\
\hline o_int_x & byte & $\div 8.0 \mathrm{~g}$ & International organization leadership \\
\hline
\end{tabular}




\begin{tabular}{|c|c|c|c|c|c|}
\hline Variable & Obs & Mean & Std. Dev. & Min & $\operatorname{Max}$ \\
\hline dem_a_x & 1695 & 13.44874 & 6.153513 & 2 & 20 \\
\hline dem_b_x & 1695 & 8.880236 & 5.617096 & 2 & 20 \\
\hline aurocratiz x & 1695 & -.0076696 & .1926946 & -1 & 1 \\
\hline io_int_x & 1695 & .3952802 & .4890551 & 0 & 1 \\
\hline un_int_x & 1695 & .3374631 & .4729839 & 0 & 1 \\
\hline
\end{tabular}

- Sample is large enough to yield reliable estimates of the correlations among the variables: $n=1695$.

- There are no outliers among the cases, because the values are located within limited ranges: see the low standard deviations and the moderate minimal and maximal values.

- Two of the variables were originally binary, which is not the most appropriate data structure for the PCA. However, during the data merging from the dyadic country-year data into target country-year data, the values assigned to individual interveners were summed and then divided by number of interveners in particular target country-year, so as to get the average authority behind the intervention. Therefore, even though the variables were originally binary, averaging set the value somewhere on the range of $0-1$.

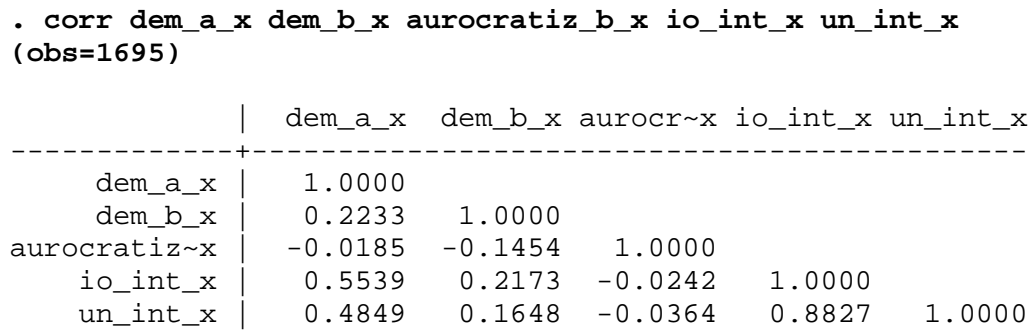

- There is some degree of collinearity among the variables to facilitate calculation of the components. In most of the cases, these correlations are not extreme. The only exception is correlation between variables io_int_x and un_int_x, which is rather high. This is caused by partially by a similar data structure division, but especially by the fact that one is a subset of the other and thus the correlation makes sense theoretically as well. ${ }^{477}$

\footnotetext{
${ }^{477}$ When one of the correlated variables was dropped, the patterns identified by the PCA were very similar. Both variables were thus retained due to their theoretical significance in the model.
} 


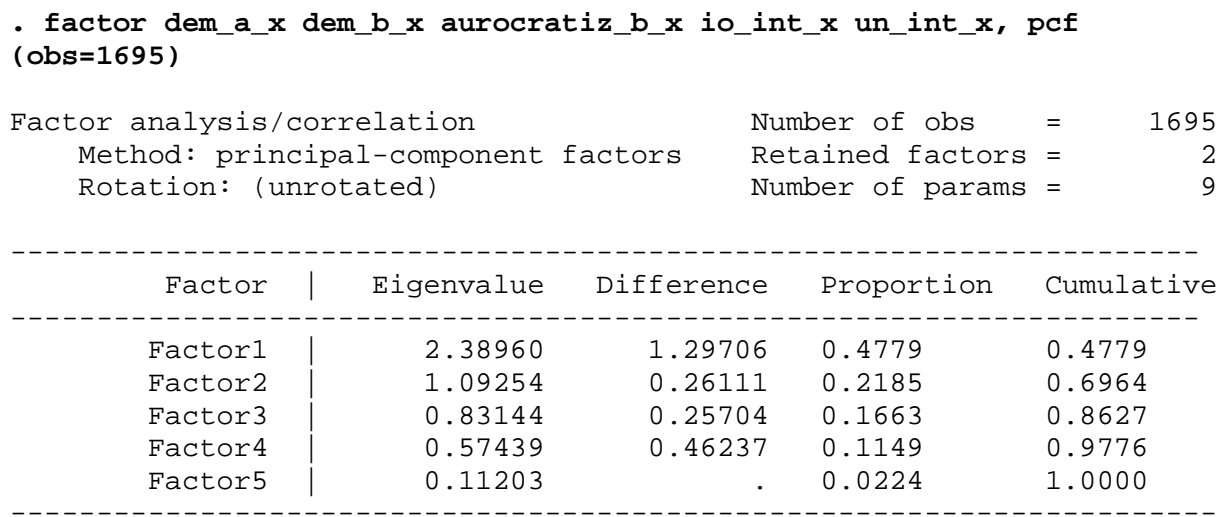

LR test: independent vs. saturated: $\operatorname{chi2}(10)=3331.56$

Prob>chi2 $=0.0000$

- 5 components were extracted, the same as the number of variables factored.

- $\underline{\text { Kaiser test }}$ of component retention = retain 2 components:

- 2 components account for more than 1.0 unit of variance (have an eigenvalue $\lambda>1.0$ ) and were thus retained (Kaiser test).

$\circ \quad 1^{\text {st }}$ component has an eigenvalue $=\mathbf{2 . 3 8 9 6 0}$. Since this is greater than 1.0, it explains more variance than a single variable, in fact 2.39 times as much. This component explains $2.39 / 5^{*} 100=\mathbf{4 7 . 7 9} \%$ of variance.

$\circ 2^{\text {nd }}$ component has an eigenvalue $=1.09254$. This component explains $1.09 / 5^{*} 100=\mathbf{2 1 . 8 5} \%$ of variance.

- The remaining 3 components have eigenvalues lower than 1.0. Due to the fact that they explain less variance than a single variable, they were dropped prior to rotation.

screeplot 


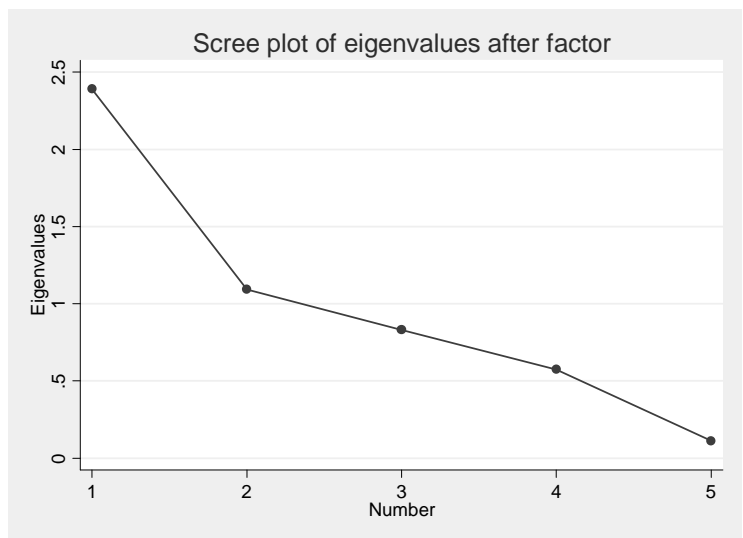

- Cattell screeplot test of component retention = retain 1 component $($ Kaiser test suggests 2).

- The data were run both with 1 and 2 components retained. After rotation, the data with 2 components had a cleaner structure and were better reflecting the theory. Therefore, two components were retained.

- Final decision: 2 retained components.

- Cumulative variance explained: $69.64 \%$.

Factor loadings (pattern matrix) and unique variances

\begin{tabular}{r|rr|r} 
Variable & Factor1 & Factor2 & Uniqueness \\
dem_a_x & 0.7477 & 0.0434 & 0.4390 \\
dem_b_x & 0.3818 & -0.5968 & 0.4980 \\
aurocratiz x & -0.0897 & 0.8311 & 0.3012 \\
io_int_x & 0.9310 & 0.1382 & 0.1141 \\
un_int_x & 0.8999 & 0.1570 & 0.1655
\end{tabular}

- Unrotated patterns were rotated to clarify the factor (component) patterns:

rotate

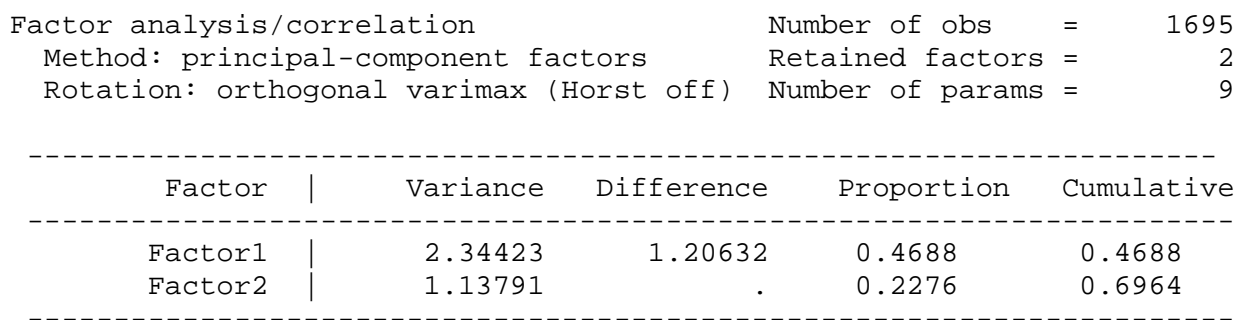


LR test: independent vs. saturated: $\operatorname{chi2}(10)=3331.56$

Prob>chi2 $=0.0000$

Rotated factor loadings (pattern matrix) and unique variances

\begin{tabular}{|c|c|c|c|}
\hline Variable & Factor 1 & Factor2 & Uniqueness \\
\hline dem_a_x & 0.7426 & -0.0972 & 0.4390 \\
\hline dem_b_x & 0.2635 & -0.6577 & 0.4980 \\
\hline aurocratiz $\mathrm{x}$ & 0.0674 & 0.8332 & 0.3012 \\
\hline io_int_x & 0.9404 & -0.0383 & 0.1141 \\
\hline un_int_x & 0.9134 & -0.0141 & 0.1655 \\
\hline
\end{tabular}

Factor rotation matrix

\begin{tabular}{r|rc} 
& Factor1 & Factor2 \\
Factor1 & 0.9824 & -0.1870 \\
Factor2 & 0.1870 & 0.9824
\end{tabular}

- The pattern matrix indicates the correlation of each variable with the retained components: products are component loadings.

- Assignment of variables to individual patterns, loadings of variables in the pattern and the respective component labels:

$\circ \quad 1^{\text {st }}$ component $=$ 'Legitimacy of the intervener' ('legit_a_x')

- dem_a_x - component loading $=0.7426$ ('strong')

- io_int_x - component loading =0.9404 ('strong')

- un_int_x - component loading $=0.9134$ ('strong')

$\circ 2^{\text {nd }}$ component $=$ 'Absence of legitimacy of the target state' ('legit_b_x')

- dem_b_x - component loading $=-0.6577$ ('strong')

- $\quad$ autocratiz_b_x - component loading $=0.8332$ ('strong')

- Interpretation of the components:

- $\quad 1^{\text {st }}$ component interpretation = 'Legitimacy of the intervener':

- Variables building the component describe legitimacy of the intervener. They thus indicate, whether the intervener had authority to make a 'just' decision to intervene.

- The higher degree of democracy and presence of international intervention increase legitimacy = authority of the intervener. 
$\circ 2^{\text {nd }}$ component interpretation $=$ 'Absence of legitimacy of the target state':

- The two variables describe lack of legitimacy of the government of the target state. It reflects, whether the sovereignty of the country can be justly questioned.

- The two variables logically go into opposite directions. The lower level of democracy of the target state increases authorization of some third party to intervene into domestic affairs of such a state. In contrast to that presence of regime autocratization in the target country increases the authority of any third-party intervention.

- $\quad$ There is no cross-loading variable with loading higher than 0.3.

- $\quad 2^{\text {nd }}$ component is based just on two observed variables, but their loadings are strong and calculated based on a large dataset. Therefore, component should be stable.

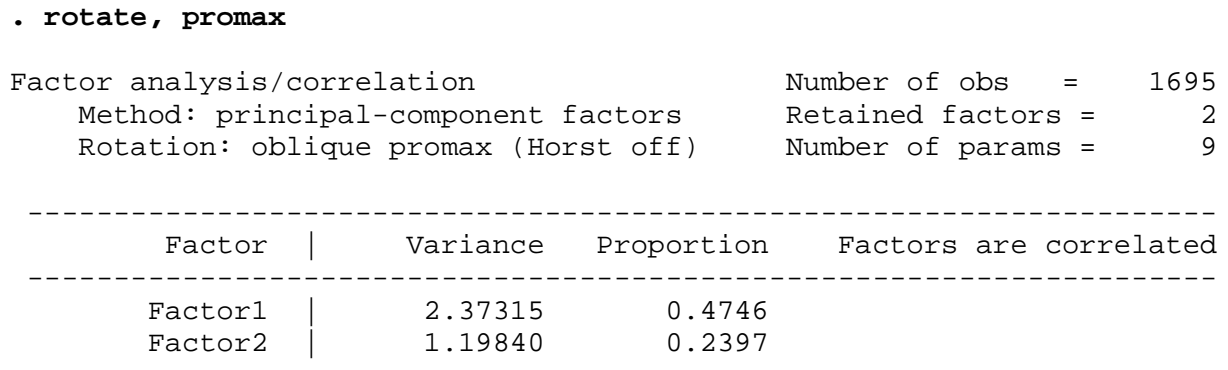

LR test: independent vs. saturated: $\operatorname{chi2}(10)=3331.56$

Prob>chi2 $=0.0000$

Rotated factor loadings (pattern matrix) and unique variances

\begin{tabular}{r|rr|r} 
Variable & Factor1 & Factor2 & Uniqueness \\
dem_a_x & 0.7405 & -0.0417 & 0.4390 \\
dem_b_x & 0.1985 & -0.6461 & 0.4980 \\
aurocratiz x & 0.1539 & 0.8492 & 0.3012 \\
io_int_x & 0.9465 & 0.0330 & 0.1141 \\
un_int_x & 0.9217 & 0.0555 & 0.1655
\end{tabular}

Factor rotation matrix

\begin{tabular}{r|rr} 
& Factor 1 & Factor 2 \\
Factor1 & 0.9936 & -0.2857 \\
Factor2 & 0.1126 & 0.9583
\end{tabular}


- Both orthogonal and oblique rotations produce similar results. As component correlation matrix suggests, there is just a little mutual correlation between the two components.

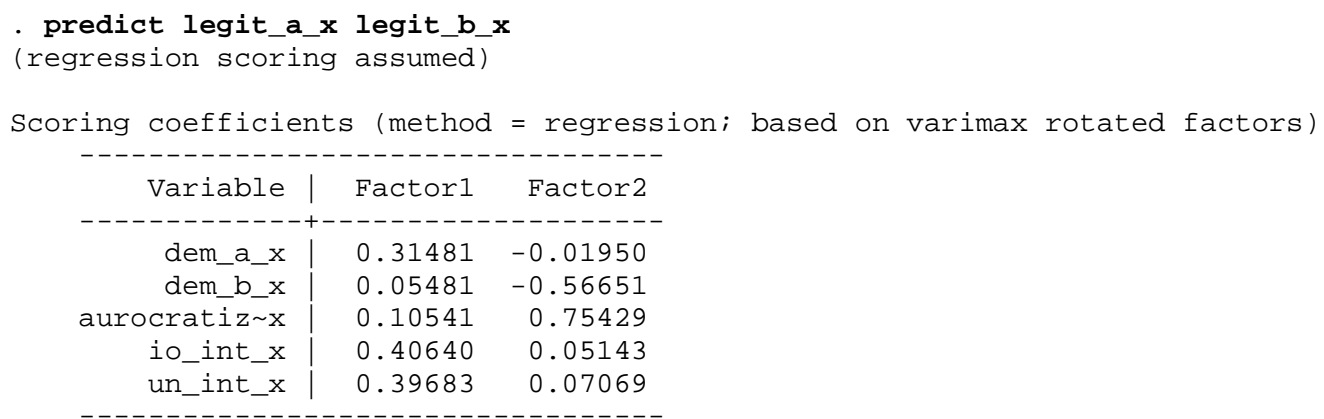

- Two new latent variables: legit_a_x and legit_b_x composing the 'just authority' index were created based on the above calculated component scores.

\section{4. 'Last resort' index}

'Last resort' index was calculated by counting a yearly change in the 'just cause' index (newly generated factor just_cause_x) from the previous to the current year.

\section{5. 'Proportionality' index}

\begin{tabular}{|c|c|}
\hline $\begin{array}{l}\text { variable } \\
\text { name }\end{array}$ & $\begin{array}{l}\text { display } \\
\text { format }\end{array}$ \\
\hline $\begin{array}{ll}\text { opp_strength_x } & \text { float } \\
\text { battle_deaths_1x } & \text { long } \\
\text { battle_deaths_2x } & \text { byte } \\
\text { battle_deaths_a1x } & \text { int } \\
\text { battle_deaths_a2x } & \text { byte } \\
\text { int_strength_x } & \text { byte } \\
\text { int_freq_x } & \text { byte } \\
\text { risk_b_x } & \text { float } \\
\text { troop_act_x } & \text { float } \\
\text { troop_act_agr_x } & \text { byte } \\
\text { troop_no_ax } & \text { float }\end{array}$ & 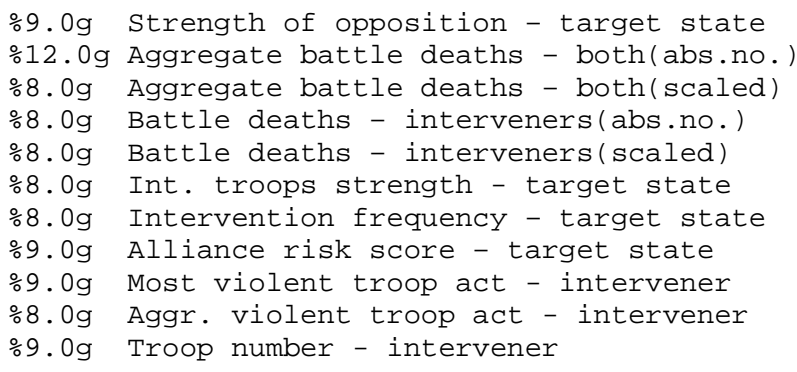 \\
\hline \multicolumn{2}{|c|}{$\begin{array}{l}\text { summarize opp_strength_x battle_deaths_1x battle_deaths_2x } \\
\text { battle_deaths_b1x battle_deaths_b2x int_strength_x int_freq_x risk_b_x } \\
\text { troop_act_x troop_act_agr_x troop_no_ax }\end{array}$} \\
\hline Variable & Std. Dev. \\
\hline
\end{tabular}




\begin{tabular}{rr|rrrrr} 
opp_streng x & $\mathbf{( 1 )}$ & 1695 & .0072785 & .0233198 & $3.50 e-06$ & .363988 \\
battle_de 1x & $\mathbf{( 2 )}$ & 1695 & 14439.41 & 87081.64 & 0 & 1505776 \\
battle_de 2x & $\mathbf{( 3 )}$ & 1695 & 2.093805 & 2.154056 & 0 & 8 \\
battle_d a1x & $\mathbf{( 4 )}$ & 1695 & 218.2 & 1192.709 & 0 & 23557 \\
battle_d a2x & $\mathbf{( 5 )}$ & 1695 & .8660767 & 1.205703 & 0 & 6 \\
int_streng x & $\mathbf{( 6 )}$ & 1695 & 3.515044 & 4.326913 & 0 & 51 \\
int_freq_x & $\mathbf{( 7 )}$ & 1695 & 1.80354 & 2.110241 & 1 & 37 \\
risk_b_x & $\mathbf{( 8 )}$ & 1695 & .5416336 & .2647924 & -.622892 & 5 \\
troop_act_x & $\mathbf{( 9 )}$ & 1695 & 3.19176 & 1.505224 & 0 & 12 \\
troop_ac r_x & $(\mathbf{1 0 )}$ & 1695 & 3.700885 & 1.644164 & 0 & 7 \\
troop_no_ax & $\mathbf{( 1 )}$ & 1695 & 1.870722 & 1.106529 & 0 & 5
\end{tabular}

- Sample is large enough to yield reliable estimates of the correlations among the variables: $\mathrm{n}=1695$.

- In most of the variables, there are no outliers among the cases, since the values are located within limited ranges: see the low standard deviations and the moderate minimal and maximal values.

- The only possible candidates for outliers are variables: battle_deaths_1x and battle_deaths_a1x that indicate fatalities in absolute values. For that reason, to limit possibility of outliers and consequences of imprecise information from the war zones, both variables were kept also as scales, depreciating the higher values. $^{478}$

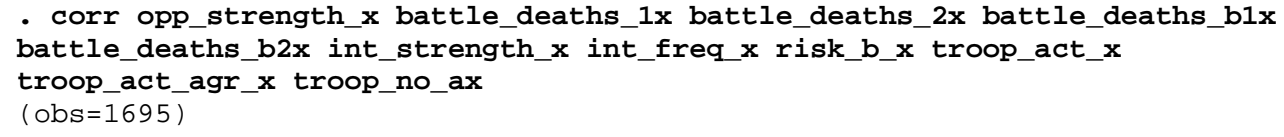

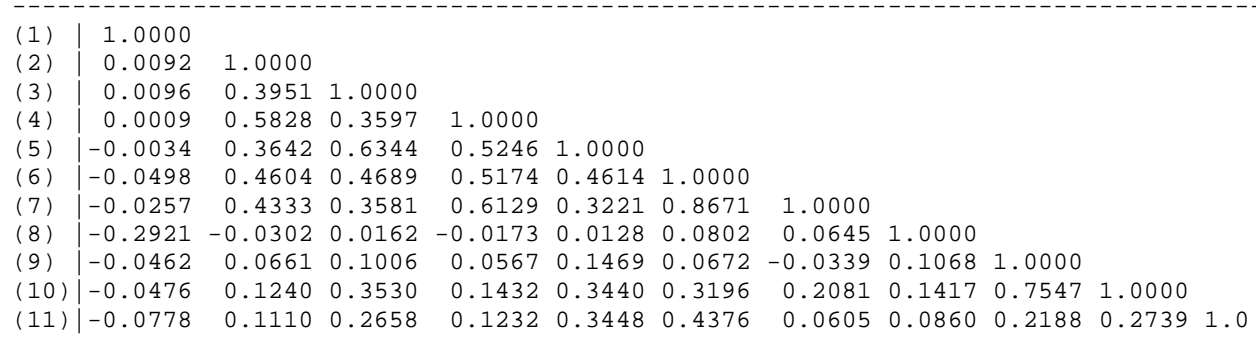

- There is some degree of collinearity among the variables to facilitate calculation of the components. In most of the cases, these correlations are not extreme. The only exception is correlation between variables int_strength_x and int_freq_x, which is rather high. This is caused correlation is, however, from the theoretical point of view very

\footnotetext{
478 PCA was run also without the two problematic variables indicating the absolute numbers of battle deaths. The discovered pattern and related loadings remained very similar in the data. Therefore, the values were kept in the model, having the scaled variables as controls.
} 
understandable, since the more interventions there are, the more international soldiers are present in the country.

- Many of the input variables were form divided data into similarly structured scales in their original. This could have provided artificial correlations. However, due to the fact that the scales were sometimes summed to provide a total value and sometimes divided by number of interveners to create an averaged value, the resulting data structure is different.

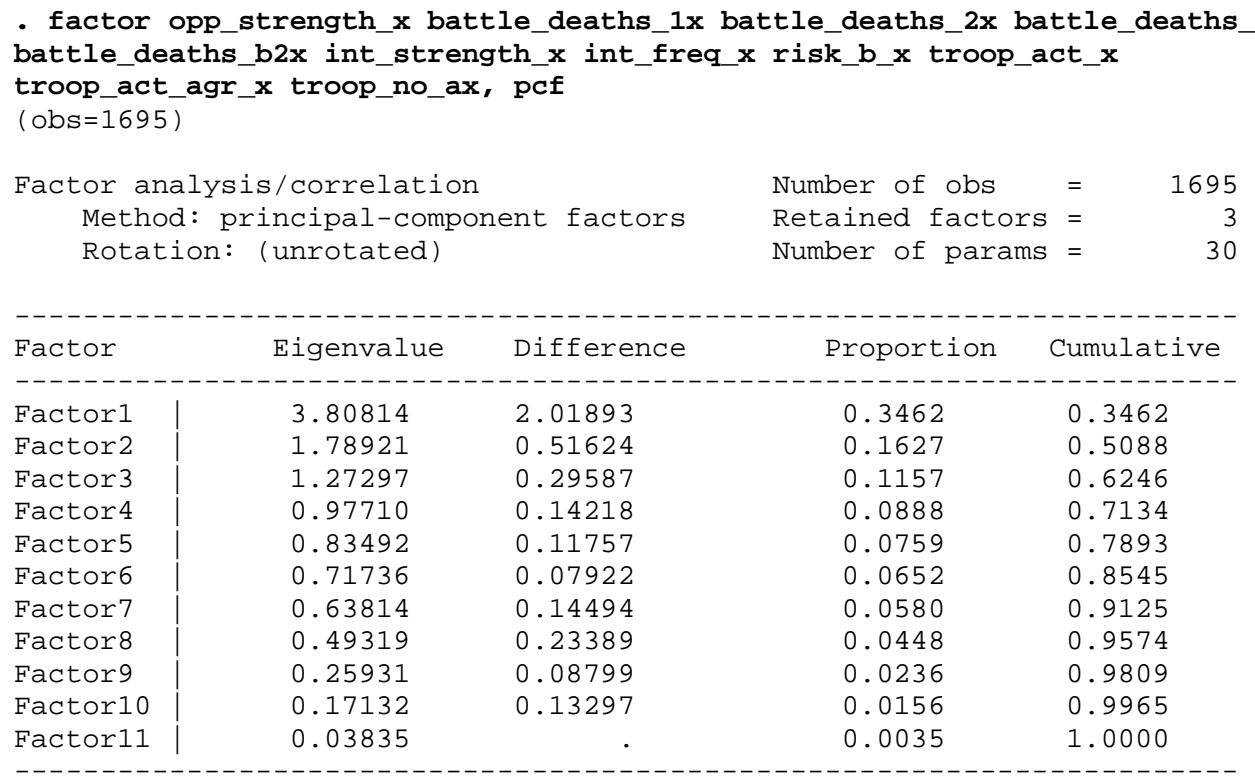

LR test: independent vs. saturated: chi2(55) $=9985.01$

Prob>chi2 $=0.0000$

- 11 components were extracted, the same as the number of variables factored.

- $\quad$ Kaiser test of component retention = retain 3 components:

- 3 components account for more than 1.0 unit of variance (have an eigenvalue $\lambda>1.0$ ) and were thus retained (Kaiser test).

$\circ 1^{\text {st }}$ component has an eigenvalue $=3.80814$. Since this is greater than 1.0, it explains more variance than a single variable, in fact 2.39 times as much. This component explains $3.81 / 11^{*} 100=\mathbf{3 4 . 6 2} \%$ of variance.

$\circ 2^{\text {nd }}$ component has an eigenvalue $=1.78921$. This component explains $1.79 / 11^{*} 100=\mathbf{1 6 . 2 7} \%$ of variance. 
$\circ 3^{\text {rd }}$ component has an eigenvalue $=1.27297$. This component explains $1.27 / 11^{*} 100=\mathbf{1 1 . 5 7} \%$ of variance.

- The remaining 8 components have eigenvalues lower than 1.0. Due to the fact that they explain less variance than a single variable, they were dropped prior to rotation.

screeplot

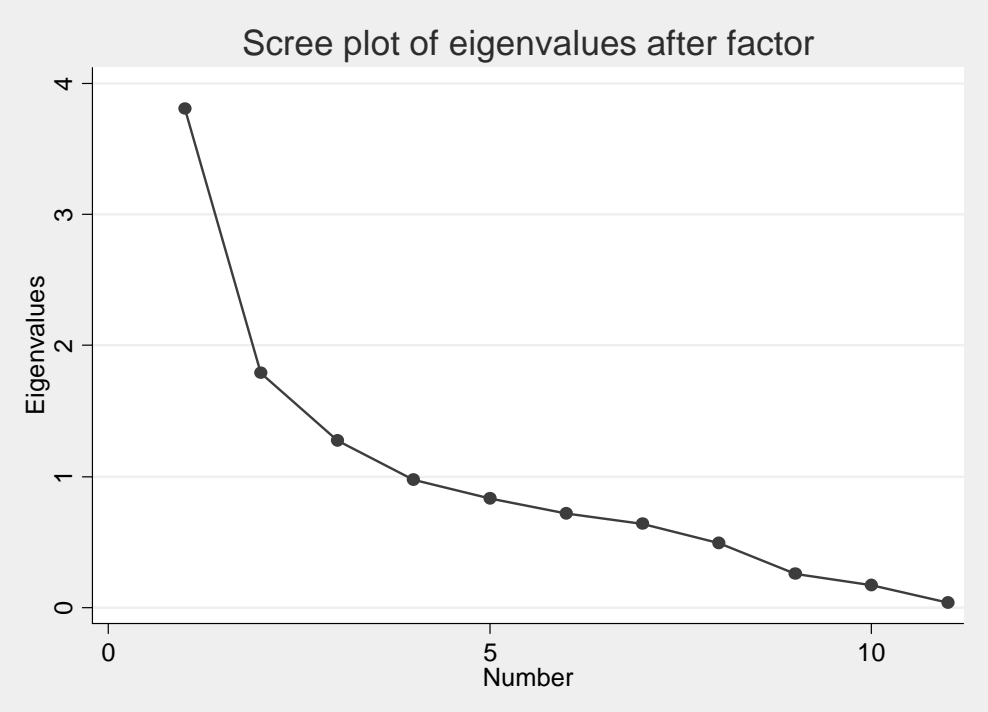

- $\quad$ Cattell screeplot test of component retention = retain 3 components (same result as Kaiser test).

- Components are retained till the point where the plot begins to level off, the additional components explain less variance than a single variable.

- Final decision: 4 retained components.

- Cumulative variance explained: $62.46 \%$.

Factor loadings (pattern matrix) and unique variances

\begin{tabular}{|c|c|c|c|c|}
\hline Variable & Factor 1 & Factor2 & Factor3 & Uniqueness \\
\hline opp_streng x & -0.0532 & -0.2299 & 0.7474 & 0.3857 \\
\hline battle_de $1 \mathrm{x}$ & 0.6451 & -0.2965 & 0.0436 & 0.4941 \\
\hline battle_de $2 \mathrm{x}$ & 0.7040 & 0.0157 & 0.1554 & 0.4800 \\
\hline battle_d a1x & 0.7302 & -0.3337 & -0.0049 & 0.3554 \\
\hline battle_d a $2 x$ & 0.7362 & 0.0351 & 0.1633 & 0.4301 \\
\hline int_streng x & 0.8459 & -0.1560 & -0.1694 & 0.2314 \\
\hline
\end{tabular}




\begin{tabular}{r|rrr|r} 
int_freq_x & 0.7416 & -0.3561 & -0.2135 & 0.2777 \\
risk_b_x & 0.0932 & 0.3341 & -0.7081 & 0.3783 \\
troop_act_x & 0.2835 & 0.8009 & 0.2288 & 0.2258 \\
troop_ac r_x & 0.5203 & 0.7168 & 0.1827 & 0.1822 \\
troop_no_ax & 0.4395 & 0.3430 & -0.0151 & 0.6890
\end{tabular}

- Unrotated patterns were rotated to clarify the component patterns:

rotate

Factor analysis/correlation

Method: principal-component factors

Rotation: orthogonal varimax (Horst off)

$\begin{array}{lr}\text { Number of obs } & 1695 \\ \text { Retained factors }= & 3 \\ \text { Number of params }= & 30\end{array}$

\begin{tabular}{|c|c|c|c|c|}
\hline Factor & Variance & Difference & Proportion & Cumulative \\
\hline Factor 1 & 3.47387 & 1.40101 & 0.3158 & 0.3158 \\
\hline Factor2 & 2.07286 & 0.74929 & 0.1884 & 0.5042 \\
\hline Factor3 & 1.32357 & . & 0.1203 & 0.6246 \\
\hline
\end{tabular}

LR test: independent vs. saturated: chi2(55) $=9985.01$

Prob>chi2 $=0.0000$

Rotated factor loadings (pattern matrix) and unique variances

\begin{tabular}{|c|c|c|c|c|}
\hline Variable & Factor 1 & Factor 2 & Factor3 & Uniqueness \\
\hline opp_streng x & -0.0272 & -0.0033 & -0.7833 & 0.3857 \\
\hline battle_de $1 \mathrm{x}$ & 0.7027 & 0.0152 & -0.1092 & 0.4941 \\
\hline battle_de $2 \mathrm{x}$ & 0.6234 & 0.3424 & -0.1189 & 0.4800 \\
\hline battle_d a $1 \mathrm{x}$ & 0.7997 & 0.0031 & -0.0714 & 0.3554 \\
\hline battle_d a $2 \mathrm{x}$ & 0.6445 & 0.3745 & -0.1194 & 0.4301 \\
\hline int_streng $\mathrm{x}$ & 0.8508 & 0.1560 & 0.1431 & 0.2314 \\
\hline int_freq_x & 0.8381 & -0.0725 & 0.1208 & 0.2777 \\
\hline risk_b_x & 0.0192 & 0.1212 & 0.7789 & 0.3783 \\
\hline troop_act_x & -0.0770 & 0.8758 & 0.0350 & 0.2258 \\
\hline troop_ac r_x & 0.1769 & 0.8847 & 0.0616 & 0.1822 \\
\hline troop_no_ax & 0.2684 & 0.4702 & 0.1337 & 0.6890 \\
\hline
\end{tabular}

Factor rotation matrix

\begin{tabular}{r|rrr} 
& Factor1 & Factor2 & Factor3 \\
Factor1 & 0.9147 & 0.4027 & 0.0345 \\
Factor2 & -0.3935 & 0.8677 & 0.3036 \\
Factor3 & -0.0923 & 0.2913 & -0.9522 \\
\hline
\end{tabular}

- The pattern matrix indicates the correlation of each variable with the retained components: products are component loadings.

- Assignment of variables to individual patterns, loadings of variables in the pattern and the respective component labels: 
○ $\quad 1^{\text {st }}$ component = 'Security threat in the target state $I^{\prime}$ (threat_1x)

- battle_deaths_1x - component loading $=0.7027$ ('strong')

- battle_deaths_2x - component loading $=0.6234$ ('strong')

- battle_deaths_a1x - component loading $=0.7997$ ('strong')

- battle_deaths_a2x - component loading $=0.6445$ ('strong')

- int_strength_x - component loading $=0.8508$ ('strong')

- int_freq_x - component loading $=0.8381$ ('strong')

$\circ \quad 2^{\text {nd }}$ component $=$ 'Force used by the intervener' (force_used_x)

- troop_act_x - component loading $=0.8758$ ('strong')

- troop_act_agr_x - component loading $=0.8847$ ('strong')

- troop_no_ax - component loading $=0.4702$ ('moderate')

$\circ \quad 3^{\text {rd }}$ component $=$ 'Security threat in the target state II' (threat_2x)

- opp_srength_x - component loading $=-0.7833$ ('strong')

- risk_b_x - component loading $=0.7789$ ('strong')

- Interpretation of the components:

$\circ \quad 1^{\text {st }}$ component interpretation $=$ 'Security threat in the target state $I^{\prime}$

- Variables building the component describe the increasing security threat in the target state as it could be perceived by the interveners. The higher the threat, the more violent means can be justifiably used by the interveners.

$\circ \quad 2^{\text {nd }}$ component interpretation $=$ 'Force used by the intervener'

- Variables building the component describe the increasingly violent type of military strategies employed by the interveners in the target state.

$\circ 3^{\text {rd }}$ component $=$ 'Security threat in the target state II'

- Same as in the $1^{\text {st }}$ component, variables building the factor describe the increasing security threat in the target state as it could be perceived by the interveners. Components 1 and 2 are complementary.

- The two variables in the component go in the opposite directions. The reason for that is clear, since variable 
opp_srength_x is partially calculated based on the military strength of the target state. The stronger the target state is, the stronger opposition the intervener can expect. Military strength of the target state is also related to the risk of potential intervention. The stronger the state, the less probable it is that it will be intervened into.

- There are just a couple of cross-loading variables with the loadings higher than 0.3 , however, their loading on the assigned components are strong.

- $\quad 3^{\text {rd }}$ component is based just on two observed variables, but their loadings are strong and calculated based on a large dataset. Therefore, the component should be stable.

- rotate, promax

Factor analysis/correlation

Method: principal-component factors

Number of obs $=1695$

Rotation: oblique promax (Horst off)

\begin{tabular}{|c|c|c|}
\hline Factor & Variance & Proportion Factors are correlated \\
\hline Factor 1 & 3.66141 & 0.3329 \\
\hline Factor2 & 2.35414 & 0.2140 \\
\hline Factor3 & 1.33788 & 0.1216 \\
\hline
\end{tabular}

test: independent vs. saturated: $\operatorname{chi2}(55)=9985.01$

Prob>chi2 $=0.0000$

Rotated factor loadings (pattern matrix) and unique variances

\begin{tabular}{|c|c|c|c|c|}
\hline Variable & Factor1 & Factor2 & Factor3 & Uniqueness \\
\hline opp_streng $\mathrm{x}$ & -0.0610 & 0.0381 & -0.7863 & 0.3857 \\
\hline battle_de $1 \mathrm{x}$ & 0.7206 & -0.0867 & -0.0997 & 0.4941 \\
\hline battle_de $2 \mathrm{x}$ & 0.5835 & 0.2659 & -0.1230 & 0.4800 \\
\hline battle_d a $1 \mathrm{x}$ & 0.8247 & -0.1160 & -0.0599 & 0.3554 \\
\hline battle_d a $2 \mathrm{x}$ & 0.6000 & 0.2961 & -0.1244 & 0.4301 \\
\hline int_streng $\sim x$ & 0.8613 & 0.0248 & 0.1504 & 0.2314 \\
\hline int_freq_x & 0.8854 & -0.2097 & 0.1364 & 0.2777 \\
\hline risk_b_x & 0.0328 & 0.0860 & 0.7773 & 0.3783 \\
\hline troop_act_x & -0.2244 & 0.9204 & 0.0010 & 0.2258 \\
\hline troop_ac r_x & 0.0383 & 0.8895 & 0.0312 & 0.1822 \\
\hline troop_no_ax & 0.2053 & 0.4412 & 0.1205 & 0.6890 \\
\hline
\end{tabular}

Factor rotation matrix

\begin{tabular}{r|rrr} 
& Factor1 & Factor2 & Factor3 \\
Factor1 & 0.9632 & 0.5427 & 0.0192 \\
Factor2 & -0.2658 & 0.8049 & 0.3520 \\
Factor3 & -0.0402 & 0.2399 & -0.9358
\end{tabular}


- Oblique and orthogonal rotations produce same data pattern with similar loadings.

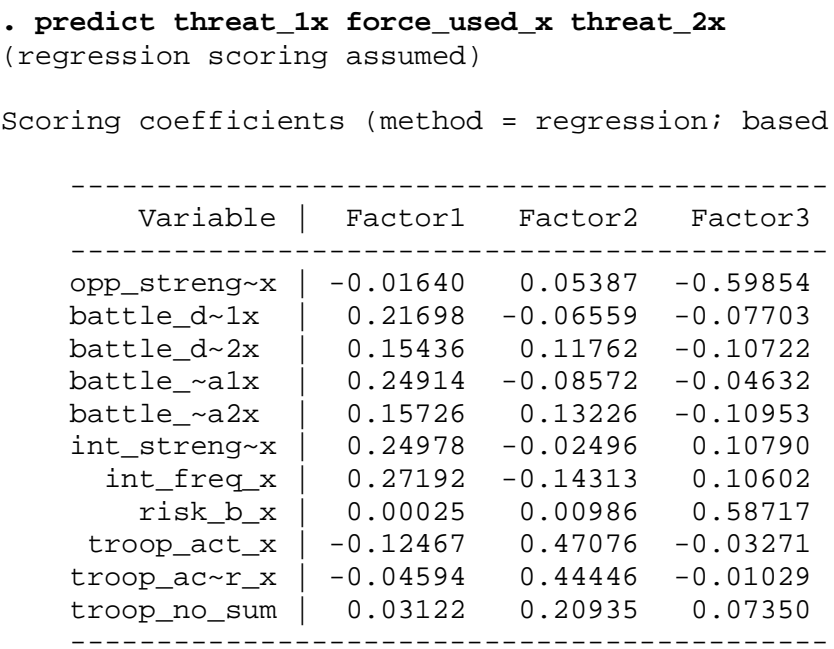

- Three new latent variables composing the 'proportionality' index: threat_1 $x$, force_used_ $x$ and threat_2x were created based on the above calculated component scores.

\section{6. 'Probability of success' index}

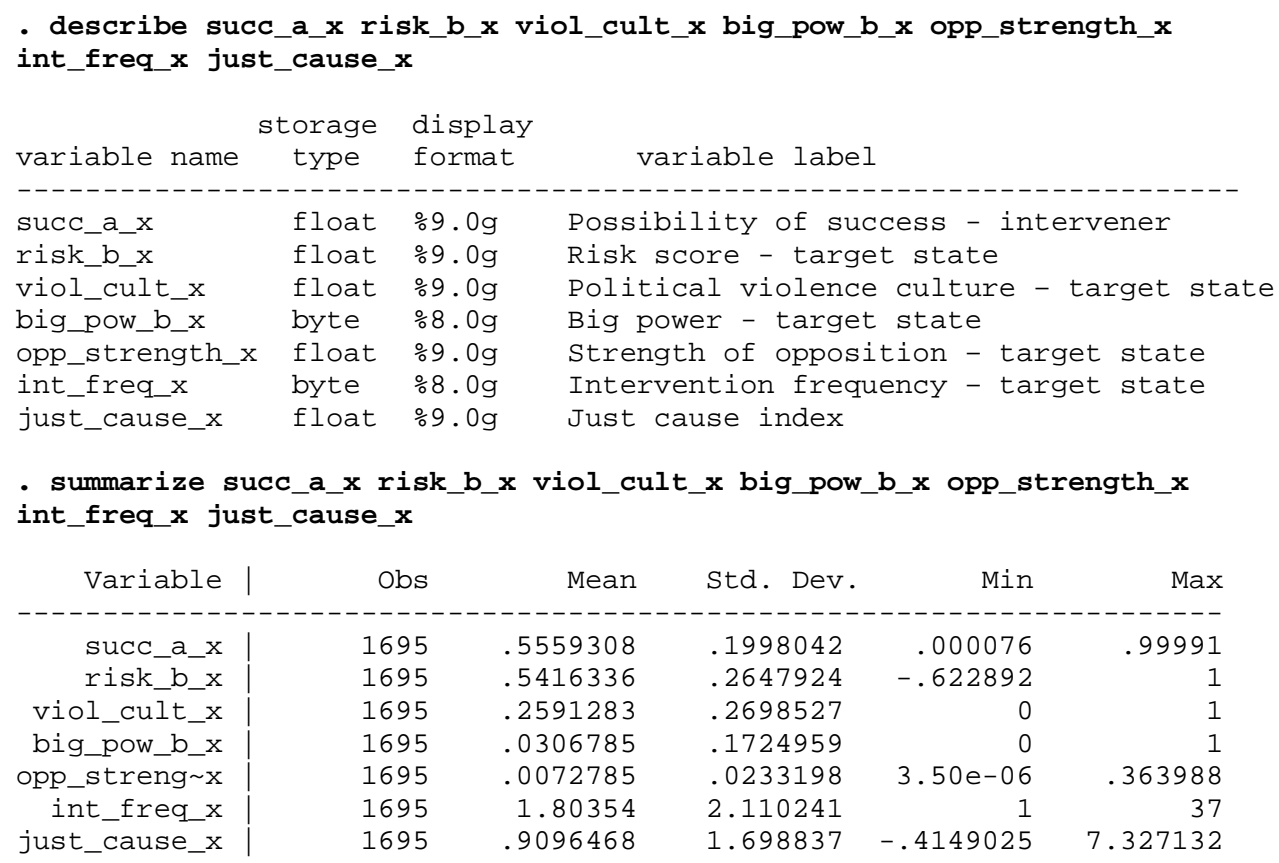


- Sample is large enough to yield reliable estimates of the correlations among the variables: $\mathrm{n}=1695$.

- There are no outliers among the cases, since the values are located within limited ranges: see the low standard deviations and the moderate minimal and maximal values.

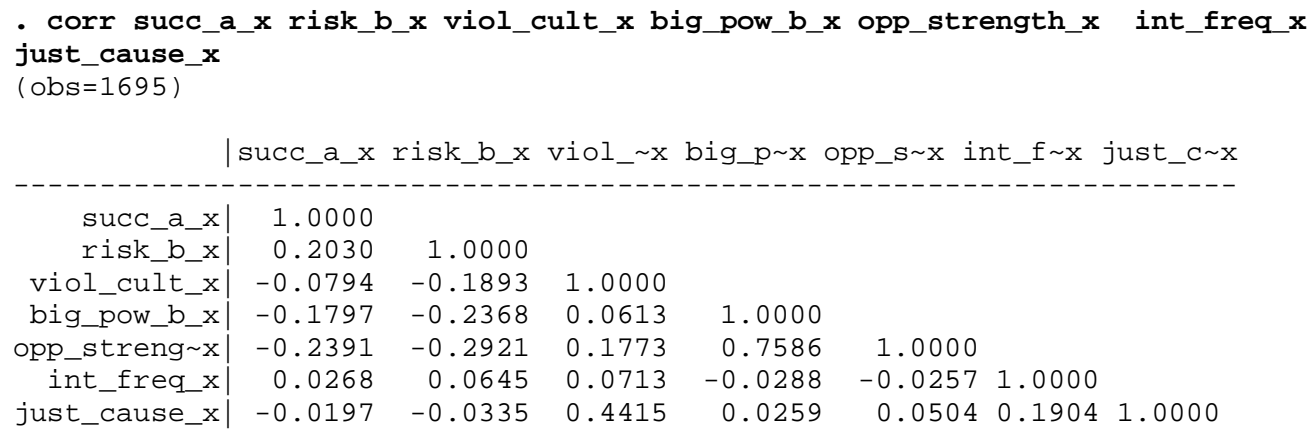

- There is some degree of collinearity among the variables to facilitate calculation of the components. In most of the cases, these correlations are not extreme.

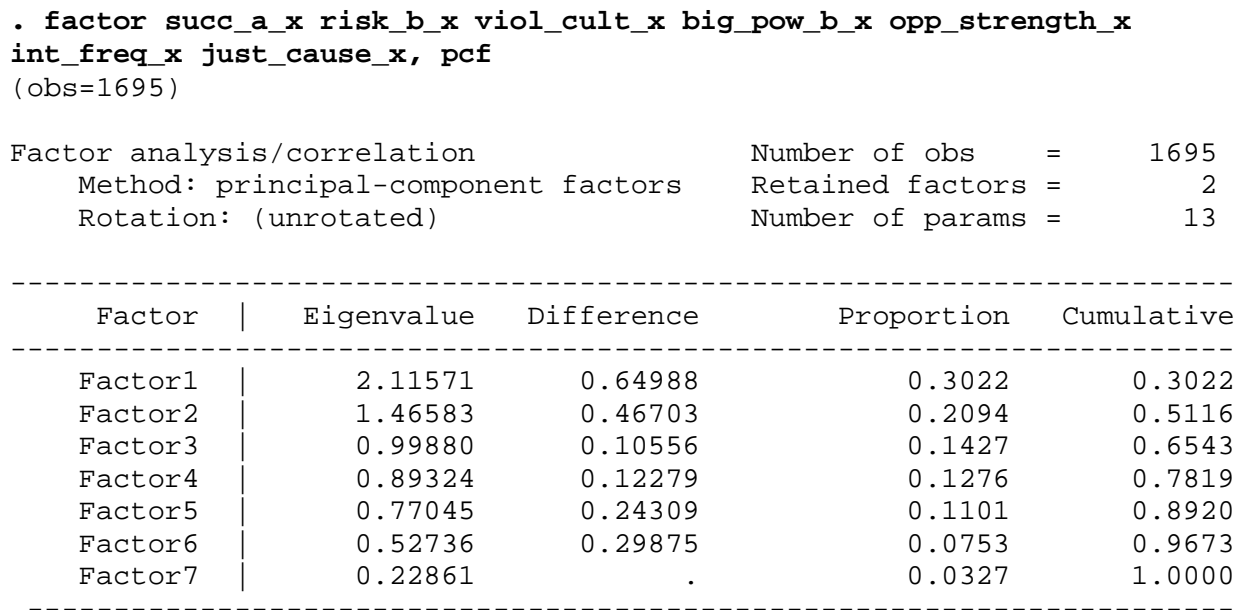

LR test: independent vs. saturated: $\operatorname{chi} 2(21)=2298.68$

Prob>chi2 $=0.0000$

- 7 components were extracted, the same as the number of variables factored.

- $\quad$ Kaiser test of component retention $=\underline{\text { retain } 2 \text { component: }}$ 
- 2 components account for more than 1.0 unit of variance (have an eigenvalue $\lambda>1.0$ ) and was thus retained (Kaiser test).

$\circ \quad 1^{\text {st }}$ component has an eigenvalue $=2.11571$. Since this is greater than 1.0, it explains more variance than a single variable, in fact 2.12 times as much. This component explains $2.12 / 7^{*} 100=\mathbf{3 0 . 2 2} \%$ of variance.

$\circ 2^{\text {nd }}$ component has an eigenvalue $=1.46583$. This component explains $1.47 / 7^{*} 100=\mathbf{2 0 . 9 4} \%$ of variance.

- The remaining 5 components have eigenvalues lower than 1.0. Due to the fact that they explain less variance than a single variable, they were dropped prior to rotation.

screeplot

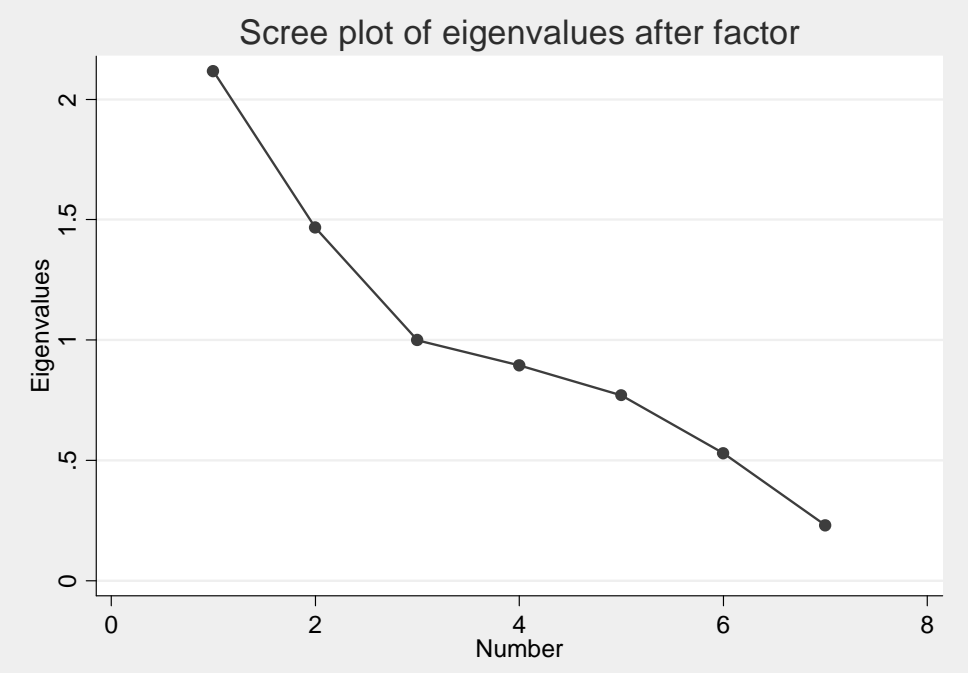

- Cattell screeplot test of component retention = retain 2 components (same result as Kaiser test).

- Components are retained till the point where the plot begins to level off, the additional components explain less variance than a single variable.

- Final decision: 2 retained components.

- Cumulative variance explained: $51.16 \%$.

Factor loadings (pattern matrix) and unique variances 


\begin{tabular}{r|rr|r} 
Variable & Factor1 & Factor2 & Uniqueness \\
\hline succ_a_x & -0.4483 & 0.0999 & 0.7890 \\
risk_b_x & -0.5541 & 0.0360 & 0.6917 \\
viol_cult_x & 0.4000 & 0.6885 & 0.3660 \\
big_pow_b_x & 0.8043 & -0.2750 & 0.2775 \\
opp_strength_x & 0.8626 & -0.1990 & 0.2162 \\
int_freq_x & -0.0174 & 0.4718 & 0.7771 \\
just_cause_x & 0.2375 & 0.8017 & 0.3009
\end{tabular}

- Unrotated patterns were rotated to clarify the component patterns:

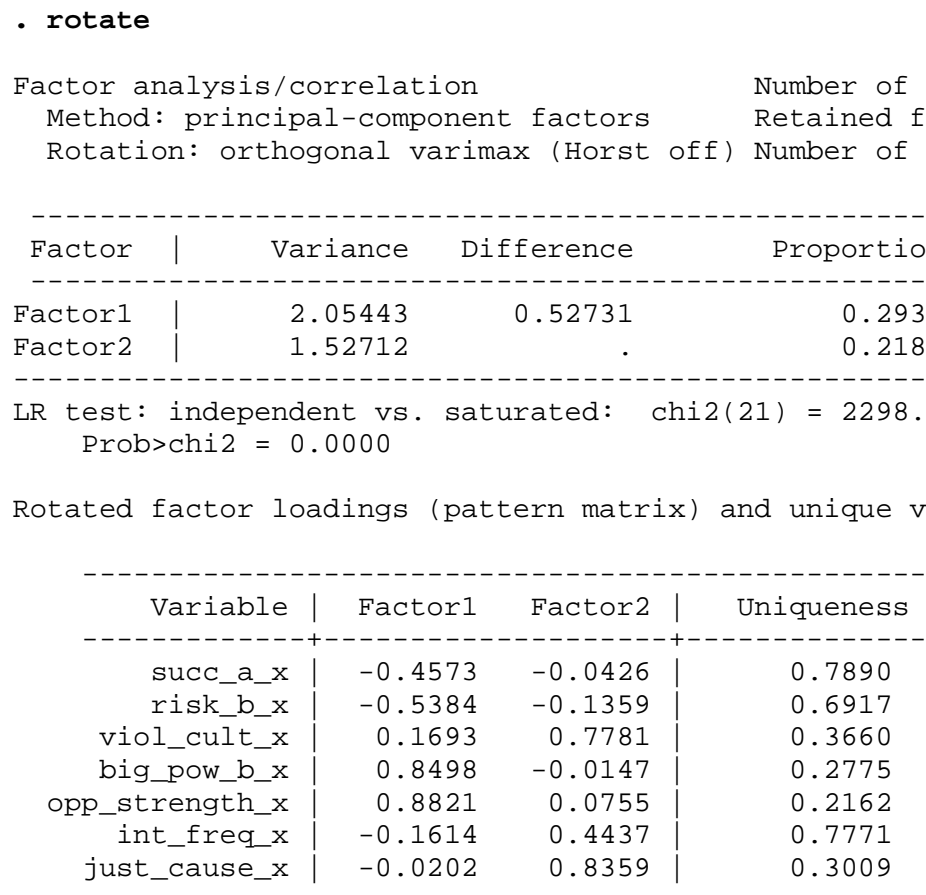

Factor rotation matrix

\begin{tabular}{|c|c|c|}
\hline & Factor 1 & Factor2 \\
\hline Factor 1 & 0.9517 & 0.3071 \\
\hline Factor 2 & -0.3071 & 0.9517 \\
\hline
\end{tabular}

- The pattern matrix indicates the correlation of each variable with the retained component: products are component loadings.

- Loadings of variables in the pattern and the respective component label:

$\circ \quad 1^{\text {st }}$ component $=$ 'Strength of the target state' (strength_b_x) 
- $\quad$ succ_a_x - component loading $=-0.4573$ ('moderate')

- risk_b_x - component loading $=-0.5384$ ('moderate')

- big_power_b_x - component loading $=0.8498$ ('strong')

- opp_strength_x - component loading $=0.8821$ ('strong')

$\circ \quad 2^{\text {nd }}$ component $={ }^{\text {CConflict }}$ complexity' (conf_complex_x $)$

- viol_cult_x - component loading $=0.7781$ ('strong')

- int_freq_x - component loading $=0.4437$ ('moderate')

- just_cause_x - component loading $=0.8359$ ('strong')

- Interpretation of the component:

$\circ 1^{\text {st }}$ component interpretation $=$ 'Military strength of the target state'

- Perceptions of the intervener about the military strength of the target state and thus about its expectations of success during the military operations waged into such country are influenced into both directions. High success of a mutual military confrontation is dependent on the fact whether the target state has alliance portfolio that leaves it vulnerable to external interventions. High success is on the other hand negatively correlated with the expected military strength of the opposition adjusted by the existence of the joint- or mixed-target intervention. And finally, the success is higher if the target state is not considered to be a big power.

○ $2^{\text {nd }}$ component interpretation $=$ 'Conflict complexity'

- All variables describing the conflict complexity go into one direction. The higher the conflict complexity, the lower is the possible success of the intervention.

- $\quad$ There are no cross-loading variables with the loadings higher than 0.3.

- Both components have at least two strongly loaded variables and accompanying moderate ones. The components were calculated based on a large data sample and should be stable.

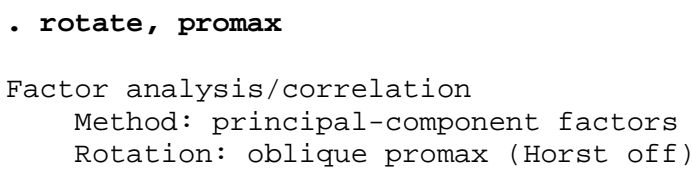




\begin{tabular}{|c|c|c|c|}
\hline Factor & Variance & Proportion & Rotated factors are correlated \\
\hline Factor 1 & 2.07090 & 0.2958 & \\
\hline Factor2 & 1.54730 & 0.2210 & \\
\hline
\end{tabular}

LR test: independent vs. saturated: $\operatorname{chi2}(21)=2298.68$

Prob $>$ chi2 $=0.0000$

Rotated factor loadings (pattern matrix) and unique variances

\begin{tabular}{r|rr|r} 
Variable & Factor1 & Factor2 & Uniqueness \\
\hline succ_a_x & -0.4567 & -0.0214 & 0.7890 \\
risk_b_x & -0.5334 & -0.1113 & 0.6917 \\
viol_cult_x & 0.1310 & 0.7729 & 0.3660 \\
big_pow_b_x & 0.8535 & -0.0544 & 0.2775 \\
opp_strength_x & 0.8813 & 0.0346 & 0.2162 \\
int_freq_x & -0.1842 & 0.4528 & 0.7771 \\
just_cause_x & -0.0620 & 0.8398 & 0.3009
\end{tabular}

Factor rotation matrix

\begin{tabular}{|c|c|c|}
\hline & Factor 1 & Factor2 \\
\hline Factor 1 & 0.9649 & 0.3541 \\
\hline Factor 2 & -0.2626 & 0.9352 \\
\hline
\end{tabular}

- Orthogonal and oblique rotations produced similar results.

\begin{tabular}{|c|c|c|}
\hline \multicolumn{3}{|c|}{ Scoring coefficients (method = regress } \\
\hline Variable & Factor 1 & Factor2 \\
\hline succ_a_x & -0.22258 & -0.00021 \\
\hline risk_b_x & -0.25678 & -0.05705 \\
\hline viol_cult_x & 0.03571 & 0.50505 \\
\hline big_pow_b_x & 0.41938 & -0.06181 \\
\hline opp_streng $\sim x$ & 0.42973 & -0.00402 \\
\hline int_freq_x & -0.10666 & 0.30380 \\
\hline just_cause_x & -0.06111 & 0.55496 \\
\hline
\end{tabular}

- Two new latent variables composing the 'probability of success' index were created based on the above calculated component scores: strength_b_x and conf_complex_x. 


\section{Statistical description, adjustments and weighting of the components}

\subsection{Description of the generated components}

The below presented variables are the output components from the PCA analysis that served as a starting point for the quantification of the JWT criteria.

\begin{tabular}{|c|c|c|c|c|c|}
\hline Variable & Obs & Mean & Std. Dev. & Min & $\operatorname{Max}$ \\
\hline just_cause_x & 12000 & $-8.56 e-09$ & 1 & -.4149025 & 7.327132 \\
\hline hum_motive_x & 1695 & $-3.52 e-10$ & 1 & -2.125517 & 1.989052 \\
\hline econ_motive_x & 1695 & $3.56 e-10$ & 1 & -1.872808 & 7.990421 \\
\hline pol_motive_1x & 1695 & $-5.22 e-10$ & 1 & -3.597034 & 2.113276 \\
\hline pol_motive_2x & 1695 & $-1.06 e-09$ & 1 & -3.848562 & 2.963233 \\
\hline legit_a_x & 1695 & $-3.80 e-09$ & 1 & -1.717106 & 1.936192 \\
\hline legit_b_x & 1695 & $-1.49 e-09$ & 1 & -4.970283 & 4.697333 \\
\hline last_resort_x & 12000 & .00287 & .3870606 & -5.947042 & 6.817963 \\
\hline threat_1x & 1695 & $5.79 e-10$ & 1 & -.8900204 & 15.32858 \\
\hline force_used_x & 1695 & $-3.57 e-10$ & 1 & -4.11881 & 2.829428 \\
\hline threat_ $2 \mathrm{x}$ & 1695 & $-2.23 e-10$ & 1 & -8.601045 & 2.48785 \\
\hline strength_b_x & 1695 & $3.64 e-10$ & 1 & -2.112912 & 9.183849 \\
\hline conf_complex_x & 1695 & $-5.51 e-10$ & 1 & -1.528818 & 6.642991 \\
\hline
\end{tabular}

Due to the fact that they are components, their standard deviations are equal to 1 . The only exception represents the last_resort_x component, which is not a component by itself, but a calculated yearly change of the component just_cause_x.

\subsection{Adjustment of the components to the positive values}

Each of the generated components was then transformed into a wholly positive range starting with 0 , meaning that the lowest possible value achieved by the component was 0 .

\begin{tabular}{|c|c|c|c|c|c|}
\hline Variable & Obs & Mean & Std. Dev. & Min & Max \\
\hline just_cause_x_adj & 12000 & .5 & 1 & .0850975 & 7.827132 \\
\hline hum_motive_x_adj & 1695 & 2.126 & 1 & .0004826 & 4.115052 \\
\hline econ_motive_x_adj & 1695 & 1.873 & 1 & .0001925 & 9.86342 \\
\hline pol_motive_1x_adj & 1695 & 3.598 & 1 & .0009665 & 5.711276 \\
\hline pol_motive_2x_adj & 1695 & 3.849 & 1 & .000438 & 6.812232 \\
\hline legit_a_x_adj & 1695 & 1.718 & 1 & .0008939 & 3.654192 \\
\hline legit_b_x_adj & 1695 & 4.971 & 1 & .000717 & 9.668333 \\
\hline last_resort_adj & 12000 & 5.95087 & .3870606 & .0009584 & 12.76596 \\
\hline threat_1x_adj & 1695 & .891 & 1 & .0009796 & 16.21958 \\
\hline
\end{tabular}




\begin{tabular}{r|rrrrr} 
force_used_x_adj & 1695 & 4.119 & 1 & .0001903 & 6.948428 \\
threat_2x_adj & 1695 & 8.602 & 1 & .0009553 & 11.08985 \\
strength_b_adj & 1695 & 2.113 & 1 & .0000883 & 11.29685 \\
conf_complex_adj & 1695 & 1.529 & 1 & .0001816 & 8.171991
\end{tabular}

Even after the data transformation into a positive range, the standard deviations remain unchanged for the components. No value in the data has now a negative number.

\subsection{Weighting of the adjusted components}

In case that the quantified JWT criterion was composed of more components; the components were weighted according to their relative importnace within the criterion, and the values were recalculated accordingly. The attached weights are indicated in the labels of the variables.

\begin{tabular}{|c|c|c|c|c|c|}
\hline Variable & Obs & Mean & Std. Dev. & Min & $\operatorname{Max}$ \\
\hline hum_motive_x_100w & 1695 & 51.65209 & 24.29543 & .0117257 & 99.97697 \\
\hline econ_motive_x_30w & 1695 & 5.696472 & 3.041363 & .0005855 & 29.99824 \\
\hline pol_motive_1x_10w & 1695 & 6.29902 & 1.7507 & .0016921 & 9.998733 \\
\hline pol_motive_2x_10w & 1695 & 5.649494 & 1.467782 & .0006429 & 9.998874 \\
\hline legit_a_x_60w & 1695 & 28.20246 & 16.41587 & .0146741 & 59.98674 \\
\hline legit_b_x_40w & 1695 & 20.56469 & 4.136932 & .0029661 & 39.99724 \\
\hline threat_1x_70w & 1695 & 3.845253 & 4.31566 & .0042277 & 69.99818 \\
\hline force_used_x_50w & 1695 & 29.63736 & 7.19528 & .0013693 & 49.99588 \\
\hline threat_2x_30w & 1695 & 23.26961 & 2.70514 & .0025843 & 29.9996 \\
\hline strength_b_60w & 1695 & 11.22245 & 5.311145 & .000469 & 59.9992 \\
\hline conf_complex_40w & 1695 & 7.474945 & 4.88878 & .000888 & 39.95107 \\
\hline
\end{tabular}

\subsection{Construction of the quantified JWT criteria out of the adjusted and weighted components}

The weighted components were combined together to create the quantified JWT criteria. In most of the criteria, the components were just summed, since their weights had the mutually complementing positive signs of increasing the 'humanitarianism' behind the military intervention. Nevertheless, some JWT criteria were constructed also of the control components, which had to be subtracted from the joint score, since they decreased the 'humanitarianism' behind the intervention. In the cases that the control components had a higher combined value that the summed positive ones within the JWT criterion, the resulting value for the criterion could have been negative. For those reasons, the newly generated JWT criteria including the control components had to be again re-adjusted into a positive scale starting with 0 . One exception is represented by the quantified JWT criterion of 'probability of success'. What makes this criterion different from the 
others is the fact that the criterion is built exclusively with control components and not the components increasing the possible success. Therefore, after summing the negative weighted values together, they were subtracted from the value 100 to become reversed and to show an increasing probability of success instead of a decreasing one. Only afterwards, the scale was adjusted into a distribution starting with 0 .

All the JWT criteria that needed any type of such an adjustment are kept recorded in their original form as well as in all stages of the adjustments, so that the next users of the data can make their own informed choices. All the combined JWT criteria that still needed some adjustment are presented in italics in the below summary together with the final quantified JWT criteria.

\begin{tabular}{|c|c|c|c|c|c|}
\hline Variable & Obs & Mean & Std. Dev. & Min & Max \\
\hline jwt_cause_x & 12000 & 6.387327 & 12.77466 & 1.087091 & 99.98891 \\
\hline$j w t$ intent_bef_adj & 1695 & 34.0071 & 24.59141 & -19.68492 & 82.54643 \\
\hline jwt_intent_x & 1695 & 53.6921 & 24.59141 & .0000786 & 102.2314 \\
\hline jwt_auth_x & 1695 & 48.76715 & 16.92912 & 3.779543 & 98.85175 \\
\hline jwt_last_x & 12000 & 46.61499 & 3.031965 & .0075072 & 99.99971 \\
\hline jwt_prop_bef_adj & 1695 & -2.522493 & 8.815597 & -41.25367 & 92.88819 \\
\hline jwt_prop_x & 1695 & 38.73151 & 8.815597 & .0003291 & 134.1422 \\
\hline jwt_succ_bef_adj_1 & 1695 & 18.69739 & 7.218617 & 8.38438 & 60.09357 \\
\hline jwt_succ_bef_adj_2 & 1695 & 81.30261 & 7.218617 & 39.90643 & 91.61562 \\
\hline jwt_succ_x & 1695 & 41.40261 & 7.218617 & .0064325 & 51.71562 \\
\hline
\end{tabular}

\subsection{Weighting of the JWT criteria}

Individual JWT criteria were weighted according to their relative relevance within the JWT as a whole. All the weights are complementary, contributing to the increased 'humanitarian' effect of military interventions.

\begin{tabular}{|c|c|c|c|c|c|}
\hline Variable & Obs & Mean & Std. Dev. & Min & $\operatorname{Max}$ \\
\hline jwt_cause_x_25w & 12000 & 1.597008 & 3.194015 & .2718027 & 24.99998 \\
\hline jwt_intent_x_30w & 1695 & 15.75596 & 7.216353 & .0000231 & 29.99983 \\
\hline jwt_auth_x_15w & 1695 & 7.400025 & 2.568858 & .5735154 & 14.99996 \\
\hline jwt_last_x_10w & 12000 & 4.661499 & .3031965 & .0007507 & 9.999971 \\
\hline jwt_prop_x_10w & 1695 & 2.88733 & .6571791 & .0000245 & 9.99994 \\
\hline jwt_succ_x_10w & 1695 & 8.005144 & 1.395711 & .0012437 & 9.999153 \\
\hline
\end{tabular}

\subsection{Aggregate JWT index}


The aggregate index summs the values of the individual weighted JWT criteria. The distribution of the values was adjusted so that the minimal value started close to 0 .

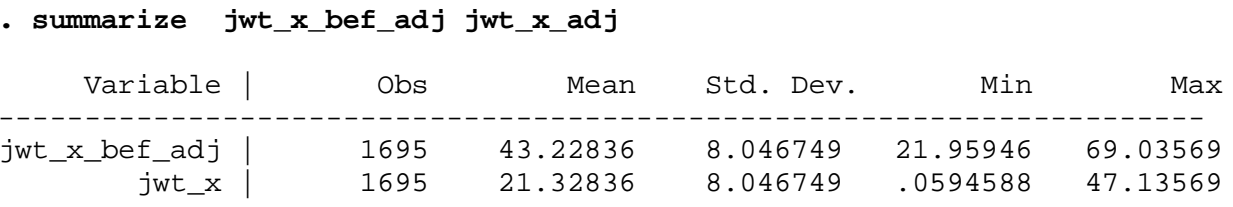




\section{Dependent variables}

\subsection{Dependent variable - battle deaths}

1.1.1. Immediate battle deaths change ("b_deaths_ch")

$=$ a yearly change in the number of battle-related fatalities (including both civilians and combatants killed in the course of combat) measured from the previous to the current target country-year (abs. num.).

Input variable:

- Best battle deaths estimate ("b_deaths_best") from the ACD datase $^{479}$ (1946-2005) (originally labeled "bdeadbes") - This variable sums the best estimates of total battle-related fatalities of all conflicts in particular country-year. Battle fatalities are defined as civilians and combatants killed in the course of combat.

Adjustments:

Missing values in the variable "b_deaths_best" (41 cases) were assigned the value 50. Reason for choosing particularly number 50 comes from the fact that the identification threshold of conflict in the ACD dataset starts with at least 25 battle-related deaths over year. The observation was identified as fulfilling this minimal threshold, but was attached unknown value for some reasons. Amount of 50 battle-related fatalities was thus set reasonably above this threshold. The cases not identified by the ACD dataset as fulfilling the set threshold of an existing crisis were attached the value 0 . After removing all the missing values, a yearly difference from the previous to the current year was calculated, assuming that there was a 0 change in year 1946.

\subsubsection{Lagged battle deaths change ("b_deaths_ch_lag")}

$=a$ yearly change in the number of battle-related fatalities (including both civilians and combatants killed in the course of combat lagged by one target country-year (abs. num.).

Input variable:

${ }^{479}$ Lacina \& Gleditsch, 2005. 
- Intermediate battle deaths change ("b_deaths_ch") $\uparrow$

Adjustments:

$2^{\text {nd }}$ dependent variable "b_deaths_ch" was lagged by one year, moving the values one year forward in the time frame, while keeping the year 2005 constant as in year 2004. By doing that, it is possible to test, whether the effects of independent variables on the dependent variable are not lagged.

\subsubsection{Lagged battle deaths change ("b_deaths_ch_lag2")}

$=$ a yearly change in the number of battle-related fatalities (including both civilians and combatants killed in the course of combat lagged by two target country-years (abs. num.).

Input variable:

- Intermediate battle deaths change ("b_deaths_ch") $\uparrow$

\section{Adjustments:}

$2^{\text {nd }}$ dependent variable "b_deaths_ch" was lagged by two years, moving the values one year forward in the time frame, while keeping the year 2005 and 2004 constant as in year 2003. By doing that, it is possible to test, whether the effects of independent variables on the dependent variable are not lagged in the longer run.

\subsection{Dependent variable - conflict deaths}

\subsubsection{Immediate crude mortality change ("deaths_ch")}

$=$ a yearly change in the number of deaths per year for both sexes combined measured from the current to the following target countryyear (in thousands).

Input variable:

- Interpolated deaths ("deaths_i") from the UN pop I dataset 480 (1950-2005) (newly created from the variable originally labeled "Deaths per year, both sexes combined in thousands) - This variable indicates a number of deaths for both sexes combined (in thousands), which is interpolated among the original measurements taken in the 5-year periods.

\section{Adjustments:}

Missing values in the input variable for years 1946-1949 were left constant as in the last available measurement in the year 1950. In case that no measurement was taken for a particular country at all, the value 
corresponding to the average crude mortality of 69,57 was adopted and kept constant throughout the whole time spam. This value was calculated by averaging all the available measurements. After removing all the missing values, a yearly difference from the previous to the current year was calculated, assuming that there was a 0 change in year 1946.

\subsubsection{Lagged crude mortality change ("deaths_ch_lag")}

$=a$ yearly change in the number of deaths per year for both sexes combined lagged by one target country-year (in thousands).

Input variable:

- Immediate crude mortality change ("deaths_ch") $\uparrow$

Adjustments:

$1^{\text {st }}$ dependent variable "deaths_ch" was lagged by one year, moving the values one year forward in the time frame, while keeping the year 2005 constant as in year 2004. By doing that, it is possible to test, whether the effects of independent variables on the dependent variable are not lagged.

\subsubsection{Lagged crude mortality change 2 ("deaths_ch_lag2")}

$=a$ yearly change in the number of deaths per year for both sexes combined lagged by two target country-years (in thousands).

Input variable:

- Immediate crude mortality change ("deaths_ch") $\uparrow$

\section{Adjustments:}

$1^{\text {st }}$ dependent variable "deaths_ch" was lagged by two years, moving the values two years forward in the time frame, while keeping the year 2005 and 2004 constant as in year 2003. By doing that, it is possible to test, whether the effects on the dependent variable are not lagged in the longer run.

\section{Independent variables}

\subsection{Control variables for the 'humanitarian motives and means'}

\subsubsection{Military intervention ("mil int")}

$=$ an ongoing military intervention in the target country-year regardless of the degree of humanitarianism entailed (binary variable).

Input variable and adjustments: 
Country-years identified by the Mil Int dataset ${ }^{481}$ as experiencing a military intervention were coded 1 ; the remaining observations were assigned the value 0 .

\subsubsection{Military intervention 1 ("mil int 1")}

$=$ an ongoing 'third-party' military intervention in the target country-year regardless of the degree of humanitarianism entailed (binary variable).

Main input variable:

- Military intervention ("mil_int") $\uparrow$

\section{Reference variables:}

- Domestic dispute dummy ("intern_c") from the Mil Int dataset ${ }^{482}$ (1946-2005) (newly created from the original variables "Domestic Dispute" 1946-1988 - Mil Int I, and "Domestic Dispute" 1989-2005 - Mil Int II) - This dummy variable indicates presence of a domestic dispute in particular country-year.

- Conflict frequency ("c_freq") from the ACD dataset ${ }^{483}$ (1946-2005) (newly created from the original variable "incomp") = This variable denotes a number of crises that occurred in particular country-year based on the UCDP-PRIO conflict definition.

\section{Adjustments:}

Control variable "mil_int" was taken and only the cases of the "thirdparty' military interventions were filtered out from the sample of military interventions using the two above listed reference variables. 'Third-party' interventions were identified as those taking place into the internal conflicts or into the conflicts, where the violence was already present in the year previous to the intervention. Nevertheless, the reference variables had to be adjusted first. The missing values in the reference variable "intern_c" (197 cases) were assumed to be a mixture of internal and international conflicts, where it was impossible to assign a simple yes or no label. These missing observations were coded as internal, since the violence was not perpetuated solely by the intervener. The second reference variable "c_freq" was converted from the variable indicating frequency of conflicts into a binary variable merely identifying existence of a violent conflict. Afterwards, the value was lagged by one year, indicating whether there

\footnotetext{
481 Pearson \& Baumann, 1992; and Kisangani \& Pickering, 2007.

482 Pearson \& Baumann, 1992; and Kisangani \& Pickering, 2007.

${ }^{483}$ Gleditsch, Wallensteen, Eriksson, Sollenberg \& Strand, 2002.
} 
was violence in the year previous to the military intervention. If there was a conflict identified in the year 1946, it was assumed that the conflict was ongoing also in the year 1945. After adjusting the reference variables, the military intervention was coded as being a 'third-party', if any of the two reference variables indicated a positive value.

\subsubsection{Military intervention 2 ("mil_int_2")}

$=$ an ongoing 'third-party' military intervention supporting the government of the target country-year regardless of the degree of humanitarianism entailed (binary variable).

Main input variable:

- Military intervention 1 ("mil_int_1") $\uparrow$

Reference variable:

- Intervention supporting government dummy ("int_supp_gov") from the Mil Int dataset ${ }^{484}$ (1946-2005) (newly created from the original variables "Direction of Intervener Supporting Action" 1946-1988 - Mil Int I, and "Direction of Intervener Supporting Action" 1989-2005 - Mil Int II) This dummy variable indicates a presence of some intervention supporting the government in particular country-year.

\section{Adjustments:}

This variable was built on the previous variable "mil_int_1". Nevertheless, one additional reference variable was taken into consideration, which is the targeting of the intervention. In case that the observed intervention was third party and the reference variables "int_supp_gov" was coded 1, the observation was coded 1 ; othervise, it was set to 0 .

\subsection{Variables approximating the 'humanitarian motives and means'}

Key independent variables approximating the 'humanitarian motives and means' were structured based on three possible definitions of the term. Each definition rests on a different identification procedure and results in a different sample of military interventions that are selected and awarded the JWT score (converted into merely positive numbers). ${ }^{485}$ All the remaining cases of military interventions not being covered by the appropriate definition are awarded JWT score of 0 . Therefore, if no crisis management happens, indicated 0 is less

\footnotetext{
484 Pearson \& Baumann, 1992; and Kisangani \& Pickering, 2007.

485 See the fourth chapter of this study for the description of the quantified JWT and its individual criteria. The JWT scores are used as the input data for approximating the humanitarian motives and means' of military interventions in this chapter.
} 
humanitarian than whatever positive value accorded to the identified sample of military interventions with the JWT scores of humanitarian motives and means'.

2.2.1. 'Humanitarian motives and means' of a military intervention ("jwt_...x")

$=$ a score of humanitarianism entailed in the military intervention being waged into the target country, if any, based on the JWT.

(= approximation of the existence of crisis management based on the $1^{\text {st }}$ definition)

Input variables:

- Quantified JWT criteria and the aggregate JWT score generated in the fourth chapter of this study: individual JWT criteria indexes ("jwt_cause_x", "jwt_intent_x", "jwt_auth_x", "jwt_last_x", "jwt_prop_x", and "jwt_succ_x") and the aggregate JWT index ("jwt_x").

\section{Adjustments:}

First definition of 'humanitarian motives and means' is the most simplistic of the three. It takes all the cases of military interventions that took place in the selected time period and awards them with the respective JWT scores, not distinguishing whether the intervener was a third- or a direct-party to the conflict, and not distinguishing among the types of targeting. A separate dependent variable was created for each individual JWT criterion as well as for the aggregate JWT index.

- 'Just cause' index ("jwt_cause_x") = a degree of 'just cause' (1st JWT criterion) entailed in the military intervention.

- 'Just intent' index ("jwt_intent_x") = a degree of 'just intent' $\left(2^{\text {nd }}\right.$ JWT criterion) entailed in the military intervention.

- 'Just authority' index ("jwt_auth_x") = a degree of 'just authority' (3rd JWT criterion) entailed in the military intervention.

- LLast resort' index ("jwt_last_x") $=$ a degree of 'last resort' $\left(4^{\text {th }}\right.$ JWT criterion) entailed in the military intervention.

- 'Proportionality' index ("jwt_prop_x") = a degree of 'proportionality' ( $5^{\text {th }}$ JWT criterion) entailed in the military intervention.

- 'Probability of success' index ("jwt_succ_x") = a degree of 'probability of success' ( $6^{\text {th }}$ JWT criterion) entailed in the military intervention. 
- JWT index ("jwt_x") = an aggregate degree of 'humanitarian motives and means' entailed in the military intervention based on the JWT.

2.2.2. 'Humanitarian motives and means' of a military intervention 1 ("jwt_....x1")

$=$ a degree of humanitarianism entailed in the 'third-party' military intervention being waged into the target country, if any; based on the JWT ('third-party' interventions are those being waged into the internal conflicts or those being waged into the ongoing conflicts of any type).

(= approximation of the existence of crisis management based on the $2^{\text {nd }}$ definition)

Main input variables:

- Quantified JWT criteria and the aggregate JWT score generated in the fourth chapter of this study: individual JWT criteria indexes ("jwt_cause_x", “jwt_intent_x", “jwt_auth_x", “jwt_last_x", “jwt _prop_x", and "jwt_succ_x") and the aggregate JWT index ("jwt_x").

Reference variables:

- Domestic dispute dummy ("intern_c") from the Mil Int dataset ${ }^{486}$ (1946-2005) (newly created from the original variables "Domestic Dispute" 1946-1988 - Mil Int I, and “Domestic Dispute" 1989-2005 - Mil Int II) - This dummy variable indicates presence of a domestic dispute in particular country-year.

- Conflict frequency ("c_freq") from the ACD dataset ${ }^{487}$ (1946-2005) (newly created from the original variable "incomp") = This variable denotes a number of crises that occurred in particular country-year based on the UCDP-PRIO conflict definition.

\section{Adjustments:}

Second definition of 'humanitarian motives and means' is more complex. It requires that the military intervention was a third party before assigning the JWT scores. 'third-party' interventions are identified as those taking place into the internal conflicts or into the conflicts, where the violence was already present in the year previous to the intervention, so as to ensure that the intervention was not an act of aggression initiating the crisis in the target state.

486 Pearson \& Baumann, 1992; and Kisangani \& Pickering, 2007.

${ }^{487}$ Gleditsch, Wallensteen, Eriksson, Sollenberg \& Strand, 2002. 
So as to filter out the 'third-party' military interventions from the sample of all military nterventions, the two reference variables were utilized in a same way as in case of the control variable on the effects of 'humanitarian motives and means' - the variable "mil_int_1". If the intervention was identified as being 'third-party' based on the information in the reference variables, it was assigned the JWT score.

- 'Just cause' index (“jwt_cause_x1") = a degree of 'just cause' (1 $1^{\text {st }} \mathrm{JWT}$ criterion) entailed in the 'third-party' military intervention.

- 'Just intent' index (“jwt _intent_x1") = a degree of 'just intent' $\left(2^{\text {nd }}\right.$ JWT criterion) entailed in the 'third-party' military intervention.

- 'Just authority' index ("jwt_auth_x1") = a degree of 'just authority' ( $3^{\text {rd }}$ JWT criterion) entailed in the 'third-party' military intervention.

- 'Last resort' index ("jwt_last_x1") = a degree of 'last resort' (4 $4^{\text {th }} \mathrm{JWT}$ criterion) entailed in the 'third-party' military intervention.

- 'Proportionality' index (“jwt_prop_x1") = a degree of 'proportionality' ( $5^{\text {th }}$ JWT criterion) entailed in the 'third-party' military intervention.

- 'Probability of success' index ("jwt_succ_x1") = a degree of 'probability of success' ( $6^{\text {th }}$ JWT criterion) entailed in the 'third-party' military intervention.

- JWT index ("jwt_x1") = an aggregate degree of 'humanitarian motives and means' entailed in the 'third-party' military intervention based on the JWT.

2.2.3. 'Humanitarian motives and means' of a military intervention 2 ("jwt_....x2")

$=$ a degree of humanitarianism entailed in the 'third-party' military intervention supporting the government of the target state, if any; that is evaluated based on the JWT ('third-party' interventions are those being waged into the internal conflicts or those being waged into the ongoing conflicts of any type).

Main input variables:

- Quantified JWT criteria and the aggregate JWT score generated in the fourth chapter of this study: individual JWT criteria indexes (“jwt_cause_x1", “jwt_intent_x1", "jwt_auth_x1", "jwt_last_x1", "jwt _prop_x1", and "jwt_succ_x1") and the aggregate JWT index ("jwt_x1").

$\underline{\text { Reference variable: }}$ 
- Intervention supporting government dummy ("int_supp_gov") from the Mil Int dataset ${ }^{488}$ (1946-2005) (newly created from the original variables "Direction of Intervener Supporting Action" 1946-1988 - Mil Int I, and "Direction of Intervener Supporting Action" 1989-2005 - Mil Int II) This dummy variable indicates a presence of some intervention supporting the government in particular country-year.

\section{Adjustments:}

Last definition of 'humanitarian motives and means' is the most complex. It includes not only the requirement that a military intervention must be 'third-party', but also that it must support the government of the target state. 'third-party' interventions were filtered out of the sample of military interventions by the same procedure as in the previous variable "jwt_....x1". Nevertheless, one additional reference variable had to be taken into consideration, which is the targeting of the intervention. In case that the observed intervention was third party and the reference variables "int_supp_gov" was coded 1, the JWT score was assigned. Otherwise, the JWT score was set to 0 .

- 'Just cause' index ("jwt_cause_x2") = a degree of 'just cause' (1 ${ }^{\text {st }}$ JWT criterion) entailed in the 'third-party' military intervention supporting the government of the target state.

- 'Just intent' index ("jwt _intent_x2") = a degree of 'just intent' (2 $2^{\text {nd }}$ JWT criterion) entailed in the military intervention supporting the government of the target state.

- 'Just authority' index ("jwt_auth_x2") = a degree of "just authority' ( $3^{\text {rd }}$ JWT criterion) entailed in the military intervention supporting the government of the target state.

- 'Last resort' index ("jwt_last_x2") $=$ a degree of 'last resort' $\left(4^{\text {th }}\right.$ JWT criterion) entailed in the military intervention supporting the government of the target state.

- 'Proportionality' index ("jwt_prop_x2") = a degree of 'proportionality' (5 $5^{\text {th }}$ JWT criterion) entailed in the military intervention supporting the government of the target state.

- 'Probability of success' index ("jwt_succ_x2") = a degree of 'probability of success' ( $6^{\text {th }}$ JWT criterion) entailed in the military intervention supporting the government of the target state.

488 Pearson \& Baumann, 1992; and Kisangani \& Pickering, 2007. 
- JWT index ("jwt_x2") = an aggregate degree of "humanitarian motives and means' of a military intervention based on the JWT.

\title{
2.3. Control independent variables - characteristics of the target country
}

\author{
2.3.1. Economic grievance level ("gdp_lev") \\ $=$ target state GDP per capita (in 1000 USD).
}

Input variable:

- GDP per capita (1946-2005) from the Ethnic Politics Armed Conflict replication dataset ${ }^{489}$ (originally labeled "gdpcap") - This variable indicates GDP per capita in 1000 USD.

Adjustments:

Missing values in the input variable were identified and estimated based on a simplifying assumption that economies tend to grow by $3 \%$ per annum. Therefore, if there were missing values at the beginning or at the end of the time frame for some country, missing values were extrapolated based on the assumed 3\% GDP growth from the last available measurement. In case that there were missing values in-between the existing observations, the missing values were interpolated in-between the last two available observations. In case that there was none measurement for a given country at all, the web-pages of International Monetary Fund (IMF) were consulted to find the country's GDP level for year 2009.490 Due to the fact that the IMF figure was calculated based on a different methodology than the ones recorded in the input variable, it was not possible just to incorporate the found IMF value into the input variable and to extrapolate it till the year 1946 based on the assumed 3\% growth. Instead, it was necessary to find another country in the IMF database that has a comparable level of GDP to the one that was missing in the input dataset, but that was available in the input dataset. Having identified such a similar country, its value indicated for year 2005 in the input dataset was taken as a basis for extrapolation of the missing GDP level values for the country absent in the input dataset and extrapolated by the assumed 3\% GDP growth from the year 2005 backwards.

\subsubsection{Economic grievance growth ("gdp_ch")}

\footnotetext{
489 'Replication data and publications', http://hdl.handle.net/1902.1/13825UNF:5:SmiRXYaARiznnVH0DtoDoQ== V1 [Version].

490 International Monetary Fund data for year 2009 are available at:

http://en.wikipedia.org/wiki/List_of_countries_by_GDP_(nominal)_per_capita.
} 
= an average growth of GDP per capita in the target state over the last three years (in 1000 USD).

Input variable:

- GDP per capita (1946-2005) from the Ethnic Politics Armed Conflict replication dataset ${ }^{491}$ (originally labeled "gdpcap") - This variable indicates GDP per capita in 1000 USD.

\section{Adjustments:}

The missing values in the input variable "gdpcap" were removed as in the case of the above described adjustments of the variable indicating economic grievance level ("gdp_lev"). Afterwards, the variable was transformed to indicate the averaged growth of economic grievance over the last three years. The resulting values always represent an averaged economic growth over last three years with the exception of years 1946 and 1947. Year 1946 indicates just a one year change, and year 1947 indicates an averaged change over the last two years. Since the year 1948, however, the indicated value always reports a three-year average.

\subsubsection{Political grievance level ("polity_lev")}

$=$ a polity scale evaluating the level of democracy in the target state (indicated on the scale of 2-20, with the score 20 reaching the highest quality of the democracy).

\section{$\underline{\text { Input variable: }}$}

- Polity IV score ("polity_IV") from the DEM dataset"92 (1946-2004) - (originally labeled "polity") - This variable indicates a Polity IV score (without PARREG) that is adjusted to create a positive value range of 2-20.

\section{Adjustments:}

First of all, the missing values from the input variable had to be removed. In case of the missing values at the very beginning of the time frame, which was usually the case since the country officially did not exist yet; the missing observations were assigned a value that was three points lower than the polity scale recorded in the first year of its existence, and this value was kept constant throughout its whole pre-sovereignty period. The upward jump in the polity scale then reflects a political change associated with the regime transition that follows from an assumption that the newly established regime represents an improvement in how citizens in the

491 'Replication data and publications', http://hdl.handle.net/1902.1/13825UNF:5:SmiRXYaARiznnVH0DtoDoQ== V1 [Version].

492 Cederman, Hug \& Krebs, 2007. 
country are represented by their government. In case that the missing values were located in the middle of the time frame having the existing observations both at the beginning and at the end of the missing time period, the polity scale was interpolated between the last existing and the first existing observations. In case that the missing values appeared only at the end of the time frame, the polity scale was left constant as in the last available measurement. And finally, in case that the country had none existing measurement throughout the whole time period at all, a middle polity value of 10 points was assigned to such country on a constant basis.

\subsubsection{Political grievance growth ("polity_ch")}

$=$ an average movement on the polity scale in the target state over the last three years (a positive sign denoting democratization, a negative sign denoting autocratization).

Input variable:

- Polity IV score ("polity_IV") from the DEM dataset ${ }^{493}$ (1946-2004) - (originally labeled "polity") - This variable indicates a Polity IV score (without PARREG) that is adjusted to create a positive value range of 2-20.

\section{Adjustments:}

The missing values in the input variable "polity" were removed as in the case of the above described adjustments of the variable indicating political grievance level ("polity_lev"). Afterwards, the variable was transformed to show the averaged political regime change over the last three years, and thus an overall trend of political democratization or autocratization within the target country. The resulting values always represent an average over last three years with the exception of years 1946 and 1947. Year 1946 indicates just a one year change, and year 1947 indicates an averaged change over the last two years. Since the year 1948, however, the indicated value always reports a three-year average.

\subsubsection{Ethnic fractionalization ("ethn_fract")}

Input variable:

- Ethnic fractionalization index from the Ethnic Power Relations (EPR) dataset ${ }^{494}$ (1946-2005) (originally labeled "elf") - This variable indicates ethnic fractionalization index based on the ESEG data (i.e. only ethno-politically relevant groups).

493 Cederman, Hug \& Krebs, 2007.

${ }^{494}$ Cederman, Min \& Wimmer, 2009. 


\section{Adjustments:}

The missing values had to be removed. In case that there was some existent measurement in the particular country, the measurement was kept constant as in the closest available year. If there were missing values inbetween the existing measurements, the values were interpolated. If no measurement was recorded for particular country at all, the average value of excluded population for all countries was added on a constant basis.

\subsubsection{Excluded population ("excl_pop")}

= a percentage of population excluded from the participation in central government of the target state.

Input variable:

- Excluded population ("excl_pop") from the Ethnic Power Relations (EPR) dataset ${ }^{495}$ (1946-2005) (originally labeled "exclpop") - This variable indicates a percentage of the excluded population from the political participation.

\section{Adjustments:}

The missing values had to be removed. In case that there was some existent measurement in the particular country, the measurement was kept constant as in the closest available year. If there were missing values inbetween the existing measurements, the values were interpolated. If no measurement was recorded for particular country at all, the average value of excluded population for all countries was added on a constant basis.

\subsubsection{Culture of violence ("viol_cult")}

$=$ an average number of battle deaths over the last three years in the target state (using the best guess estimate).

Input variable:

- Best battle deaths estimate ("b_deaths_best") from the ACD datase $^{496}$ (1946-2005) (originally labeled "bdeadbes") - This variable sums the best estimates of the total battle-related fatalities of all conflicts in particular country-year. Battle fatalities are defined as civilians and combatants killed in the course of combat.

Adjustments:

495 Cederman, Min \& Wimmer, 2009.

${ }^{496}$ Lacina \& Gleditsch, 2005. 
Missing values in the variable "b_deaths_best" (41 cases) were assigned the value 50 . Reason for choosing particularly number 50 comes from the fact that the identification threshold of conflict in the ACD dataset starts with at least 25 battle-related deaths over year. The observation was identified as fulfilling this minimal threshold, but was attached unknown value for some reasons. Amount of 50 battle-related fatalities was thus set reasonably above this threshold. The cases not identified by the ACD dataset as fulfilling the set threshold of an existing crisis were attached the value 0 . After removing all the missing values, the variable was transformed to indicate the average number of battle deaths over the last three years. For year 1946, the indicated value is just one year average, year 1947 is indicated as an average over two previous years; and since year 1948 forward, the generated values are always three-year averages.

\subsection{Control independent variables - characteristics of the conflict}

2.4.1. Existence of a conflict ("confl")

$=$ existence of a violent conflict based on the identification threshold of more than 25 battle-related deaths per year in the target country-year (binary).

Input variable:

- Conflict frequency ("c_freq") from the ACD dataset ${ }^{497}$ (1946-2005) (newly created variable from the original variable "incomp") = This variable denotes a number of crises that occurred in particular countryyear (based on the UCDP-PRIO conflict definition).

\section{Adjustments:}

Conflict frequency denoting variable was converted into a dummy variable identifying existence of a violent conflict.

2.4.2. Previous violence ("prev_confl")

$=$ existence of a violent conflict in the previous target country-year based on the identification threshold of more than 25 battle-related deaths per year (binary).

Input variable:

- Conflict frequency ("c_freq") from the ACD dataset ${ }^{498}$ (1946-2005)

(newly created variable from the original variable "incomp") $=$ This

497 Ibid.

498 Ibid. 
variable denotes a number of crises that occurred in particular countryyear (based on the UCDP-PRIO conflict definition).

\section{Adjustments:}

Conflict frequency denoting variable was converted into a dummy variable identifying existence of a violent conflict. Afterwards, the variable was lagged by one year to indicate whether the conflict was already ongoing in previous year.

\subsubsection{Internal conflict ("intern_confl”)}

$=$ existence of an internal conflict in particular target country-year (binary).

Input variable:

- Domestic dispute dummy ("intern_c") from the Mil Int dataset ${ }^{499}$ (1946-2005) (newly created from original variables "Domestic Dispute" 1946-1988 - Mil Int I, and “Domestic Dispute" 1989-2005 - Mil Int II) - This dummy variable indicates presence of a domestic dispute in particular country-year.

\section{Adjustments:}

The missing values (197 cases) were assumed to be of mixed type, where the distinction between internal and international conflict was blurred. These missing observations were assigned the value 1 , since the violence was not perpetuated solely by the intervener.

\subsection{Control independent variables - characteristics of the military intervention}

\subsubsection{Previous military intervention ("prev mil int")}

$=\mathbf{a}$ military intervention taking place in the previous target country-year regardless of the degree of humanitarianism entailed (binary variable).

\section{Adjustments:}

If the previous target country-year was identified by the Mil Int dataset 500 as experiencing a military intervention, the observations were coded 1; otherwise, the observations were assigned the value 0 .

\subsection{2. 'Third-party' military intervention ("third party int")}

\footnotetext{
499 Pearson \& Baumann, 1992; Kisangani \& Pickering, 2007.

500 Pearson \& Baumann, 1992; Kisangani \& Pickering, 2007.
} 
$=$ a presence of a 'third-party' military intervention in particular target country-year (binary variable).

Input variable and adjustments:

Country-years identified by the Mil Int dataset ${ }^{501}$ as experiencing a military intervention were coded 1; the remaining observations were assigned the value 0 .

\section{$\underline{\text { Reference variables: }}$}

- Domestic dispute dummy ("intern_c") from the Mil Int dataset ${ }^{502}$ (1946-2005) (newly created from the original variables "Domestic Dispute" 1946-1988 - Mil Int I, and "Domestic Dispute" 1989-2005 - Mil Int II) - This dummy variable indicates presence of a domestic dispute in particular country-year.

- Conflict frequency ("c_freq") from the ACD dataset ${ }^{503}$ (1946-2005) (newly created from the original variable "incomp") = This variable denotes a number of crises that occurred in particular country-year based on the UCDP-PRIO conflict definition.

\section{Adjustments:}

'Third-party' military interventions were filtered out from the sample of military interventions using the two above listed reference variables. 'Third-party' interventions were identified as those taking place into the internal conflicts or into the conflicts, where the violence was already present in the year previous to the intervention. Nevertheless, the reference variables had to be adjusted first. The missing values in the reference variable "intern_c" (197 cases) were assumed to be a mixture of internal and international conflicts, where it was impossible to assign a simple yes or no label. These missing observations were coded as internal, since the violence was not perpetuated solely by the intervener. The second reference variable "c_freq" was converted from the variable indicating frequency of conflicts into a binary variable merely identifying existence of a violent conflict. Afterwards, the value was lagged by one year, indicating whether there was violence in the year previous to the military intervention. If there was a conflict identified in the year 1946, it was assumed that the conflict was ongoing also in the year 1945. After adjusting the reference variables, the military intervention was coded as

\footnotetext{
501 Ibid.

502 Ibid.

${ }^{503}$ Gleditsch, Wallensteen, Eriksson, Sollenberg \& Strand, 2002.
} 
being a 'third-party', if any of the two reference variables indicated a positive value.

\subsubsection{Use of force by the intervener ("viol mil int")}

$=$ a presence of an aggressive troop activity by some intervener in particular target country-year (binary).

Input variable:

- Aggressive troop activity dummy ("agress_act") from the Mil Int dataset $^{504}$ (1946-2005) (newly created from the original variables "Type of Troop Activity" 1946-1988 - Mil Int I, and "Type of Troop Activity" 19892005 - Mil Int II) - This dummy variable indicates a presence of an aggressive troop activity by some intervener in particular country-year.

\subsubsection{Military intervention supporting the government ("int_supp_gov")}

$=\mathbf{a}$ presence of a military intervention supporting the government of the target state in particular year (binary).

Input variable:

- Intervention supporting government dummy ("int_supp_gov") from the Mil Int dataset50 (1946-2005) (newly created from the original variables "Direction of Intervener Supporting Action" 1946-1988 - Mil Int I, and "Direction of Intervener Supporting Action" 1989-2005 - Mil Int II) This dummy variable indicates a presence of some intervention supporting the government in particular country-year.

\subsubsection{Military intervention supporting the rebels ("int_supp_reb")}

$=$ a presence of a military intervention supporting the rebels in the target country-year (binary).

Input variable:

- Intervention supporting rebels dummy ("int_supp_reb") from the Mil Int dataset ${ }^{506}$ (1946-2005) (newly created from the original variables "Direction of Intervener Supporting Action" 1946-1988 - Mil Int I, and "Direction of Intervener Supporting Action" 1989-2005 - Mil Int II) - This dummy variable indicates a presence of some intervention supporting the opposition in particular country-year.

\subsubsection{Mixed targeting of military intervention ("mixed_target")}

\footnotetext{
504 Ibid.

505 Pearson \& Baumann, 1992; Kisangani \& Pickering, 2007.

506 Ibid.
} 
$=$ a presence of the mixed targeting of military interventions was mixed targeting both rebels and government (binary).

Input variables:

- Intervention supporting government dummy ("int_supp_gov") from the Mil Int dataset ${ }^{507}$ (1946-2005) (newly created from the original variables "Direction of Intervener Supporting Action" 1946-1988 - Mil Int I, and "Direction of Intervener Supporting Action" 1989-2005 - Mil Int II) This dummy variable indicates a presence of some intervention supporting the government in particular country-year.

- Intervention supporting rebels dummy ("int_supp_reb") from the Mil Int dataset ${ }^{508}$ (1946-2005) (newly created from the original variables “Direction of Intervener Supporting Action" 1946-1988 - Mil Int I, and "Direction of Intervener Supporting Action" 1989-2005 - Mil Int II) - This dummy variable indicates a presence of some intervention supporting the opposition in particular country-year.

\section{Adjustments:}

In case that there was an intervention supporting the government of the target state and the rebels in the same target country-year, the variable was assigned the value 1 ; otherwise, it was assigned the value 0 .

\section{Statistical description of the input variables}

\subsection{Main variables of concern}

. summarize deaths_ch deaths_ch_lag deaths_ch_lag2 b_deaths_ch
b_deaths_ch_lag b_deaths_ch_lag2 jwt_cause_x jwt_intent_x jwt_auth_x
jwt_last_x jwt_prop_x jwt_succ_x jwt_x jwt_cause_x1 jwt_intent_x1
jwt_auth_x1 jwt_last_x1 jwt_prop_x1 jwt_succ_x1 jwt_x1 jwt_cause_x2
jwt_intent_x2 jwt_auth_x2 jwt_last_x2 jwt_prop_x2 jwt_succ_x2 jwt_x2
V
Variable
| Obs

507 Ibid.

508 Ibid. 


\begin{tabular}{|c|c|c|c|c|c|}
\hline $\begin{array}{r}\text { jwt_prop_x } \\
\text { jwt_succ_x } \\
\text { jwt_x }\end{array}$ & $\begin{array}{l}12000 \\
12000 \\
12000\end{array}$ & $\begin{array}{l}5.470825 \\
5.848118 \\
3.012631\end{array}$ & $\begin{array}{l}13.89065 \\
14.67313 \\
8.020253\end{array}$ & $\begin{array}{l}0 \\
0 \\
0\end{array}$ & $\begin{array}{l}134.1422 \\
51.71562 \\
47.13569\end{array}$ \\
\hline $\begin{array}{r}\text { jwt_cause_x1 } \\
\text { jwt_intent_x1 } \\
\text { jwt_auth_x1 } \\
\text { jwt_last_x1 } \\
\text { jwt_prop_x1 } \\
\text { jwt_succ_x1 } \\
\text { jwt_x1 }\end{array}$ & $\begin{array}{l}12000 \\
12000 \\
12000 \\
12000 \\
12000 \\
12000 \\
12000\end{array}$ & $\begin{array}{r}2.171711 \\
5.066024 \\
4.046422 \\
4.015425 \\
3.32427 \\
3.471216 \\
2.073439\end{array}$ & $\begin{array}{r}9.986077 \\
17.78411 \\
13.9584 \\
13.22487 \\
11.12133 \\
11.47254 \\
7.129816\end{array}$ & $\begin{array}{l}0 \\
0 \\
0 \\
0 \\
0 \\
0 \\
0\end{array}$ & $\begin{array}{r}99.98891 \\
102.2314 \\
98.5947 \\
99.99971 \\
134.1422 \\
51.71562 \\
47.13569\end{array}$ \\
\hline $\begin{array}{r}\text { jwt_cause_x2 } \\
\text { jwt_intent_x2 } \\
\text { jwt_auth_x2 } \\
\text { jwt_last_x2 } \\
\text { jwt_prop_x2 } \\
\text { jwt_succ_x2 } \\
\text { jwt_x2 }\end{array}$ & $\begin{array}{l}12000 \\
12000 \\
12000 \\
12000 \\
12000 \\
12000 \\
12000\end{array}$ & $\begin{array}{r}1.04467 \\
2.583385 \\
1.891138 \\
1.926458 \\
1.603368 \\
1.717201 \\
1.048897\end{array}$ & $\begin{array}{l}7.298367 \\
13.02358 \\
9.585511 \\
9.388785 \\
7.890948 \\
8.369769 \\
5.294889\end{array}$ & $\begin{array}{l}0 \\
0 \\
0 \\
0 \\
0 \\
0 \\
0\end{array}$ & $\begin{array}{r}92.6641 \\
97.80616 \\
98.5947 \\
78.72822 \\
75.22523 \\
51.71562 \\
47.13569\end{array}$ \\
\hline
\end{tabular}

\subsection{Control variables}

\begin{tabular}{|c|c|c|c|c|c|}
\hline Variable & Obs & Mean & Std. Dev. & Min & $\operatorname{Max}$ \\
\hline polity_lev & 12000 & 10.41529 & 5.796502 & 1 & 20 \\
\hline polity_gr & 12000 & .0565694 & .6830917 & -5.333333 & 5.333333 \\
\hline gdp_lev & 12000 & 5.59136 & 7.553927 & .0278672 & 110.3153 \\
\hline gdp_gr & 12000 & .1225041 & .3888547 & -8.202377 & 11.31875 \\
\hline excl_pop & 12000 & .1543356 & .1921297 & 0 & .98 \\
\hline ethn_fract & 12000 & .4090667 & .2694655 & 0 & .9996 \\
\hline viol_cult & 12000 & 865.3349 & 8684.617 & 0 & 334266.7 \\
\hline confl & 12000 & .1198333 & .3247801 & 0 & 1 \\
\hline prev_confl & 12000 & .1190833 & .3239 & 0 & 1 \\
\hline intern_confl & 12000 & .062 & .2411656 & 0 & 1 \\
\hline mil_int & 12000 & .1446667 & .3517791 & 0 & 1 \\
\hline prev_mil_int & 12000 & .1429167 & .3500024 & 0 & 1 \\
\hline third_party_int & 12000 & .1541667 & .3611235 & 0 & 1 \\
\hline viol_mil_int & 12000 & .104 & .3052733 & 0 & 1 \\
\hline int_supp_gov & 12000 & .0553333 & .2286393 & 0 & 1 \\
\hline int_supp_reb & 12000 & .0614167 & .240103 & 0 & 1 \\
\hline mixed_target & 12000 & .015 & .1215575 & 0 & 1 \\
\hline
\end{tabular}

\subsection{Number of examined events}

- Mil Int dyad data - $\mathbf{1 7 3 6}$ country dyad-years with military intervention

- Target country-year grouped Mil Int dyad data - 1695 country-years (41 lost observations) 
- $1^{\text {st }}$ definition of 'humanitarian motives and means' ("jwt_...x") - 1695 country-years

- $2^{\text {nd }}$ definition of 'humanitarian motives and means' ("jwt_...1x") - 1036 country-years $(41+659$ lost observations due to the changes in the definition)

- $3^{\text {rd }}$ definition of 'humanitarian motives and means' ("jwt_...2x") - 494 country-years $(41+659+542$ lost observations due to the changes in the definition)

\section{RESULTS OF THE REGRESSION ANALYSIS}

Panel id variables were established:

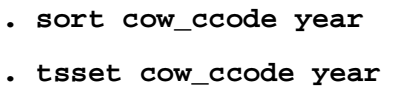

panel variable: cow_ccode, 2 to 990

time variable: year, 1946 to 2005

All the theoretially relevant variables were put into the regression model regardless of their final significance. Each model was built with the same variables so as to make the models mutually comparable.

\section{Hausman test}

The appropriate regression method was selected by testing all the definitions of 'humanitarian motives and means' of military interventions, including the control definition, on both dependent variables using the Hausman test. The tests were carried out using the following sequence of stata orders:

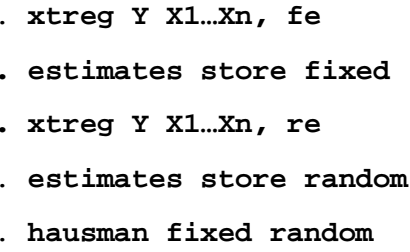

If the resulting p-value was significant $(\leq 0,05)$, the Hausman test suggested that the fixed effects method should be used; if insignificant $(>0,5)$, the random effects method should be used. 


\begin{tabular}{|c|c|c|c|c|c|c|c|c|c|}
\hline \multicolumn{10}{|c|}{ HAUSMAN TEST } \\
\hline \multirow{2}{*}{$\begin{array}{c}\text { Y1: } \\
\text { deaths_ch.... }\end{array}$} & \multicolumn{3}{|c|}{ Y1a: deaths_ch } & \multicolumn{3}{|c|}{ Y1b: deaths_ch_lag } & \multicolumn{3}{|c|}{ Y1c: deaths_ch_lag2 } \\
\hline & Chi 2 & $P>|t|$ & Result & Chi 2 & $P>|t|$ & Result & Chi 2 & $P>|t|$ & Result \\
\hline jwt_x & $-24,9$ & $?$ & Failed* & $-0,2$ & $?$ & Failed* & 12,4 & 0,72 & RE \\
\hline jwt_x1 & 70,1 & 0,00 & FE & 82,2 & 0,00 & FE & 103,0 & 0,00 & FE \\
\hline jwt_x2 & 43,8 & 0,00 & FE & 48,3 & 0,00 & FE & 51,6 & 0,00 & FE \\
\hline \multirow{2}{*}{$\begin{array}{c}\text { Y2: } \\
\text { b_deaths_ch.. }\end{array}$} & \multicolumn{3}{|c|}{ Y2a: b_deaths_ch } & \multicolumn{3}{|c|}{ Y2b: b_deaths_ch_lag } & \multicolumn{3}{|c|}{$\begin{array}{c}\text { Y2c: } \\
\text { b_deaths_ch_lag2 }\end{array}$} \\
\hline & Chi 2 & $P>|t|$ & Result & Chi 2 & $P>|t|$ & Result & Chi 2 & $P>|t|$ & Result \\
\hline jwt_x & 8,2 & 0,94 & RE & 45,9 & 0,00 & $\mathrm{FE}$ & 15,5 & 0,56 & RE \\
\hline jwt_x1 & 6,5 & 0,98 & RE & 51,0 & 0,00 & $\mathrm{FE}$ & 17,5 & 0,35 & RE \\
\hline jwt_x2 & 6,1 & 0,99 & RE & 55,9 & 0,00 & $\mathrm{FE}$ & 19,1 & 0,26 & RE \\
\hline \multirow{2}{*}{$\begin{array}{c}\text { Y1: } \\
\text { deaths_ch.... }\end{array}$} & \multicolumn{3}{|c|}{ Y1a: deaths_ch } & \multicolumn{2}{|c|}{ Y1b: deaths_ch_lag } & \multicolumn{4}{|c|}{ Y1c: deaths_ch_lag2 } \\
\hline & Chi 2 & $P>|t|$ & Result & Chi 2 & $P>|t|$ & Result & Chi 2 & $P>|t|$ & Result \\
\hline mil_int & 58,9 & 0,00 & $\mathrm{FE}$ & $-46,5$ & $?$ & Failed* & 15,3 & 0,50 & RE \\
\hline mil_int_1 & 226,1 & 0,00 & $\mathrm{FE}$ & 17,2 & 0,38 & RE & 29,6 & 0,02 & $\mathrm{FE}$ \\
\hline mil_int_2 & 57,9 & 0,00 & FE & 4,5 & 0,99 & RE & 25,9 & 0,05 & FE \\
\hline \multirow{2}{*}{$\begin{array}{c}\text { Y2: } \\
\text { b_deaths_ch.. }\end{array}$} & \multicolumn{3}{|c|}{ Y2a:b_deaths_ch } & \multicolumn{2}{|c|}{$\begin{array}{c}\text { Y2b: } \\
\text { b_deaths_ch_lag }\end{array}$} & \multicolumn{4}{|c|}{ Y2c: b_deaths_ch_lag2 } \\
\hline & Chi 2 & $P>|t|$ & Result & Chi 2 & $P>|t|$ & Result & Chi 2 & $P>|t|$ & Result \\
\hline mil_int & 6,0 & 0,99 & RE & 44,0 & 0,00 & FE & 13,9 & 0,61 & RE \\
\hline mil_int_1 & 6,7 & 0,98 & RE & 44,9 & 0,00 & FE & 14,5 & 0,57 & RE \\
\hline mil_int_2 & 6,6 & 0,98 & RE & 50,6 & 0,00 & FE & 15,6 & 0,48 & RE \\
\hline
\end{tabular}

${ }^{*}$ Chi2 $<0 \Rightarrow$ data fails to meet the asymptotic assumptions of the Hausman test $=>$ Hausman test failed $F E=$ fixed effects, $R E=$ random effects

\section{Regression results for all the definitions (using the aggregate JWT indexes)}

The significance level is indicated by the following marking:

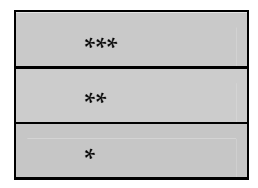

$$
\begin{aligned}
& 1 \% \text { significance level } \\
& 5 \% \text { significance level } \\
& 10 \% \text { significance level }
\end{aligned}
$$

\subsection{Control definition of the 'humanitarian motives and means' of military intervention}




\subsubsection{Dependent variable (Y1) - conflict deaths}

\begin{tabular}{|c|c|c|c|c|c|c|c|c|c|}
\hline \multirow{3}{*}{ Y1a: deaths_ch } & \multirow{2}{*}{\multicolumn{3}{|c|}{$\begin{array}{c}\text { Control definition } \\
1 \\
\text { Prob }>\text { F }=0.0000\end{array}$}} & \multirow{2}{*}{\multicolumn{3}{|c|}{$\begin{array}{l}\text { Control definition } 2 \\
\text { Prob }>\text { F }=0.0000\end{array}$}} & \multirow{2}{*}{\multicolumn{3}{|c|}{$\begin{array}{c}\text { Control definition } 3 \\
\text { Prob }>F=0.0000\end{array}$}} \\
\hline & & & & & & & & & \\
\hline & Coef. & $\begin{array}{c}\text { St. } \\
\text { Err. }\end{array}$ & $P>t$ & Coef. & $\begin{array}{c}\text { St. } \\
\text { Err. }\end{array}$ & $P>t$ & Coef. & St. Err. & $P>t$ \\
\hline mil_int & 0,001 & 0,058 & 0,99 & - & - & - & - & - & - \\
\hline mil_int_1 & - & - & - & ${ }^{*} 0,113$ & 0,064 & 0,08 & - & - & - \\
\hline mil_int_2 & - & - & - & - & - & - & 0,016 & 0,093 & 0,87 \\
\hline polity_lev & 0,003 & 0,003 & 0,26 & 0,003 & 0,003 & 0,28 & 0,003 & 0,003 & 0,26 \\
\hline polity_gr & $-0,056$ & 0,013 & 0,00 & $-0,056$ & 0,013 & 0,00 & $-0,056$ & 0,013 & 0,00 \\
\hline gdp_lev & 0,003 & 0,002 & 0,17 & 0,003 & 0,002 & 0,17 & 0,003 & 0,002 & 0,17 \\
\hline gdp_gr & 0,001 & 0,023 & 0,97 & 0,001 & 0,023 & 0,96 & 0,001 & 0,023 & 0,97 \\
\hline excl_pop & 0,432 & 0,080 & 0,00 & 0,432 & 0,080 & 0,00 & 0,432 & 0,080 & 0,00 \\
\hline ethn_fract & $-0,193$ & 0,143 & 0,18 & $-0,199$ & 0,143 & 0,16 & $-0,194$ & 0,143 & 0,17 \\
\hline viol_cult & 0,112 & 0,031 & 0,01 & 0,114 & 0,040 & 0,01 & 0,061 & 0,042 & 0,15 \\
\hline confl & 0,105 & 0,042 & 0,01 & 0,108 & 0,042 & 0,01 & 0,105 & 0,042 & 0,01 \\
\hline prev_confl & $-0,131$ & 0,076 & 0,08 & $-0,134$ & 0,076 & 0,08 & $-0,132$ & 0,076 & 0,08 \\
\hline intern_confl & $-0,078$ & 0,069 & 0,26 & $-0,138$ & 0,077 & 0,07 & $-0,082$ & 0,073 & 0,26 \\
\hline prev_mil_int & 0,114 & 0,040 & 0,01 & 0,104 & 0,035 & 0,00 & 0,114 & 0,035 & 0,00 \\
\hline third_party_int & 0,226 & 0,076 & 0,00 & 0,200 & 0,077 & 0,01 & 0,226 & 0,076 & 0,00 \\
\hline viol_mil_int & $-0,131$ & 0,054 & 0,02 & $-0,139$ & 0,050 & 0,01 & $-0,131$ & 0,049 & 0,01 \\
\hline int_supp_gov & $-0,088$ & 0,067 & 0,19 & $-0,098$ & 0,065 & 0,13 & $-0,096$ & 0,083 & 0,24 \\
\hline int_supp_reb & 0,246 & 0,061 & 0,00 & 0,229 & 0,059 & 0,00 & 0,248 & 0,059 & 0,00 \\
\hline mixed_target & 0,311 & 0,103 & 0,00 & 0,325 & 0,101 & 0,00 & 0,309 & 0,101 & 0,00 \\
\hline _cons & 0,183 & 0,070 & 0,01 & 0,188 & 0,070 & 0,01 & 0,184 & 0,070 & 0,01 \\
\hline
\end{tabular}

\begin{tabular}{|c|c|c|c|c|c|c|c|c|c|}
\hline \multirow{3}{*}{ Y1b: deaths_ch_lag } & \multicolumn{3}{|c|}{ Control definition 1} & \multicolumn{3}{|c|}{ Control definition 2} & \multicolumn{3}{|c|}{ Control definition 3} \\
\hline & \multicolumn{3}{|c|}{ Prob $>F=0.0000$} & \multicolumn{3}{|c|}{ Prob $>F=0.0000$} & \multicolumn{3}{|c|}{ Prob $>F=0.0000$} \\
\hline & Coef. & St. Err. & $P>t$ & Coef. & St. Err. & $P>t$ & Coef. & St. Err. & $P>t$ \\
\hline mil_int & 0,004 & 0,058 & 0,95 & - & - & - & - & - & - \\
\hline mil_int_1 & - & - & - & $* * 0,140$ & 0,065 & 0,03 & - & - & - \\
\hline mil_int_2 & - & - & - & - & - & - & $-0,027$ & 0,094 & 0,77 \\
\hline polity_lev & 0,005 & 0,003 & 0,06 & 0,005 & 0,003 & 0,06 & 0,005 & 0,003 & 0,06 \\
\hline polity_gr & $-0,060$ & 0,013 & 0,00 & $-0,060$ & 0,013 & 0,00 & $-0,060$ & 0,013 & 0,00 \\
\hline gdp_lev & 0,002 & 0,002 & 0,37 & 0,002 & 0,002 & 0,37 & 0,002 & 0,002 & 0,36 \\
\hline
\end{tabular}




\begin{tabular}{|l|r|r|r|r|r|r|r|r|l|}
\hline gdp_gr & 0,004 & 0,024 & $\mathbf{0 , 8 6}$ & 0,004 & 0,024 & $\mathbf{0 , 8 5}$ & 0,004 & 0,024 & $\mathbf{0 , 8 6}$ \\
\hline excl_pop & 0,470 & 0,080 & $\mathbf{0 , 0 0}$ & 0,470 & 0,080 & $\mathbf{0 , 0 0}$ & 0,470 & 0,080 & $\mathbf{0 , 0 0}$ \\
\hline ethn_fract & $-0,219$ & 0,143 & $\mathbf{0 , 1 3}$ & $-0,226$ & 0,143 & $\mathbf{0 , 1 2}$ & $-0,217$ & 0,143 & $\mathbf{0 , 1 3}$ \\
\hline viol_cult & 0,185 & 0,052 & $\mathbf{0 , 0 0}$ & 0,175 & 0,070 & $\mathbf{0 , 0 1}$ & 0,183 & 0,069 & $\mathbf{0 , 0 1}$ \\
\hline confl & 0,061 & 0,042 & $\mathbf{0 , 1 5}$ & 0,065 & 0,042 & $\mathbf{0 , 1 2}$ & 0,061 & 0,042 & $\mathbf{0 , 1 5}$ \\
\hline prev_confl & 0,007 & 0,076 & $\mathbf{0 , 9 3}$ & 0,004 & 0,076 & $\mathbf{0 , 9 6}$ & 0,009 & 0,076 & $\mathbf{0 , 9 1}$ \\
\hline intern_confl & 0,066 & 0,069 & $\mathbf{0 , 3 4}$ & $-0,008$ & 0,077 & $\mathbf{0 , 9 2}$ & 0,074 & 0,073 & $\mathbf{0 , 3 2}$ \\
\hline prev_mil_int & 0,105 & 0,040 & $\mathbf{0 , 0 1}$ & 0,095 & 0,035 & $\mathbf{0 , 0 1}$ & 0,107 & 0,035 & $\mathbf{0 , 0 0}$ \\
\hline third_party_int & 0,074 & 0,076 & $\mathbf{0 , 3 3}$ & 0,043 & 0,077 & $\mathbf{0 , 5 8}$ & 0,074 & 0,076 & $\mathbf{0 , 3 3}$ \\
\hline viol_mil_int & $-0,115$ & 0,054 & $\mathbf{0 , 0 3}$ & $-0,124$ & 0,050 & $\mathbf{0 , 0 1}$ & $-0,114$ & 0,050 & $\mathbf{0 , 0 2}$ \\
\hline int_supp_gov & $-0,125$ & 0,067 & $\mathbf{0 , 0 6}$ & $-0,136$ & 0,065 & $\mathbf{0 , 0 4}$ & $-0,109$ & 0,083 & $\mathbf{0 , 1 9}$ \\
\hline int_supp_reb & 0,285 & 0,062 & $\mathbf{0 , 0 0}$ & 0,265 & 0,059 & $\mathbf{0 , 0 0}$ & 0,284 & 0,059 & $\mathbf{0 , 0 0}$ \\
\hline mixed_target & 0,284 & 0,104 & $\mathbf{0 , 0 1}$ & 0,300 & 0,102 & $\mathbf{0 , 0 0}$ & 0,285 & 0,102 & $\mathbf{0 , 0 1}$ \\
\hline _cons & 0,175 & 0,070 & $\mathbf{0 , 0 1}$ & 0,182 & 0,070 & $\mathbf{0 , 0 1}$ & 0,175 & 0,070 & $\mathbf{0 , 0 1}$ \\
\hline
\end{tabular}

\begin{tabular}{|l|c|c|c|c|c|c|c|c|c|}
\hline \multirow{2}{*}{ Y1c: deaths_ch_lag2 } & \multicolumn{2}{|c|}{ Control definition $\mathbf{1}$} & \multicolumn{2}{c|}{ Control definition $\mathbf{2}$} & \multicolumn{2}{c|}{ Control definition 3} \\
\cline { 2 - 11 } & \multicolumn{2}{|c|}{ Prob $>$ F $=0.0000$} & \multicolumn{2}{c|}{ Prob $>$ F $=0.0000$} & \multicolumn{2}{c|}{ Prob $>$ F = 0.0000 } \\
\cline { 2 - 11 } & Coef. & St. Err. & P>t & Coef. & St. Err. & P>t & Coef. & St. Err. & P>t \\
\hline mil_int & $-\mathbf{0 , 0 1 5}$ & $\mathbf{0 , 0 5 8}$ & $\mathbf{0 , 8 0}$ & - & - & - & - & - & - \\
\hline mil_int_1 & - & - & - & $* * \mathbf{0 , 1 5 0}$ & $\mathbf{0 , 0 6 5}$ & $\mathbf{0 , 0 2}$ & - & - & - \\
\hline mil_int_2 & - & - & - & - & - & - & $-\mathbf{0 , 0 6 7}$ & $\mathbf{0 , 0 9 4}$ & $\mathbf{0 , 4 7}$ \\
\hline polity_lev & 0,007 & 0,003 & $\mathbf{0 , 0 1}$ & 0,007 & 0,003 & $\mathbf{0 , 0 1}$ & 0,007 & 0,003 & $\mathbf{0 , 0 1}$ \\
\hline polity_gr & $-0,065$ & 0,013 & $\mathbf{0 , 0 0}$ & $-0,065$ & 0,013 & $\mathbf{0 , 0 0}$ & $-0,065$ & 0,013 & $\mathbf{0 , 0 0}$ \\
\hline gdp_lev & 0,001 & 0,002 & $\mathbf{0 , 6 7}$ & 0,001 & 0,002 & $\mathbf{0 , 6 8}$ & 0,001 & 0,002 & $\mathbf{0 , 6 4}$ \\
\hline gdp_gr & 0,004 & 0,024 & $\mathbf{0 , 8 7}$ & 0,004 & 0,024 & $\mathbf{0 , 8 6}$ & 0,004 & 0,024 & $\mathbf{0 , 8 8}$ \\
\hline excl_pop & 0,464 & 0,080 & $\mathbf{0 , 0 0}$ & 0,464 & 0,080 & $\mathbf{0 , 0 0}$ & 0,465 & 0,080 & $\mathbf{0 , 0 0}$ \\
\hline ethn_fract & $-0,263$ & 0,144 & $\mathbf{0 , 0 7}$ & $-0,272$ & 0,144 & $\mathbf{0 , 0 6}$ & $-0,261$ & 0,144 & $\mathbf{0 , 0 7}$ \\
\hline viol_cult & 0,112 & 0,031 & $\mathbf{0 , 0 1}$ & 0,114 & 0,040 & $\mathbf{0 , 0 1}$ & 0,061 & 0,042 & $\mathbf{0 , 1 5}$ \\
\hline confl & 0,046 & 0,043 & $\mathbf{0 , 2 8}$ & 0,050 & 0,043 & $\mathbf{0 , 2 4}$ & 0,045 & 0,043 & $\mathbf{0 , 2 9}$ \\
\hline prev_confl & 0,083 & 0,077 & $\mathbf{0 , 2 8}$ & 0,081 & 0,076 & $\mathbf{0 , 2 9}$ & 0,089 & 0,077 & $\mathbf{0 , 2 5}$ \\
\hline intern_confl & 0,183 & 0,069 & $\mathbf{0 , 0 1}$ & 0,103 & 0,077 & $\mathbf{0 , 1 8}$ & 0,201 & 0,074 & $\mathbf{0 , 0 1}$ \\
\hline prev_mil_int & 0,114 & 0,040 & $\mathbf{0 , 0 1}$ & 0,097 & 0,036 & $\mathbf{0 , 0 1}$ & 0,109 & 0,035 & $\mathbf{0 , 0 0}$ \\
\hline third_party_int & $-0,022$ & 0,076 & $\mathbf{0 , 7 8}$ & $-0,057$ & 0,078 & $\mathbf{0 , 4 7}$ & $-0,024$ & 0,076 & $\mathbf{0 , 7 6}$ \\
\hline viol_mil_int & $-0,136$ & 0,054 & $\mathbf{0 , 0 1}$ & $-0,152$ & 0,050 & $\mathbf{0 , 0 0}$ & $-0,143$ & 0,050 & $\mathbf{0 , 0 0}$ \\
\hline int_supp_gov & $-0,135$ & 0,067 & $\mathbf{0 , 0 5}$ & $-0,152$ & 0,065 & $\mathbf{0 , 0 2}$ & $-0,102$ & 0,083 & $\mathbf{0 , 2 2}$ \\
\hline
\end{tabular}




\begin{tabular}{|l|l|l|l|l|r|r|r|r|r|}
\hline int_supp_reb & 0,339 & 0,062 & $\mathbf{0 , 0 0}$ & 0,310 & 0,059 & $\mathbf{0 , 0 0}$ & 0,328 & 0,059 & $\mathbf{0 , 0 0}$ \\
\hline mixed_target & 0,228 & 0,104 & $\mathbf{0 , 0 3}$ & 0,252 & 0,102 & $\mathbf{0 , 0 1}$ & 0,241 & 0,102 & $\mathbf{0 , 0 2}$ \\
\hline _cons & 0,183 & 0,070 & $\mathbf{0 , 0 1}$ & 0,191 & 0,070 & $\mathbf{0 , 0 1}$ & 0,182 & 0,070 & $\mathbf{0 , 0 1}$ \\
\hline
\end{tabular}

2.1.2. Dependent variable (Y2) - battle deaths

\begin{tabular}{|c|c|c|c|c|c|c|c|c|c|}
\hline \multirow{3}{*}{ Y2a: b_deaths_ch } & \multicolumn{3}{|c|}{ Control definition 1} & \multicolumn{3}{|c|}{ Control definition 2} & \multicolumn{3}{|c|}{ Control definition 3} \\
\hline & \multicolumn{3}{|c|}{ Prob $>F=0.0000$} & \multicolumn{3}{|c|}{ Prob $>F=0.0000$} & \multicolumn{3}{|c|}{ Prob $>F=0.0000$} \\
\hline & Coef. & $\begin{array}{l}\text { St. } \\
\text { Err. }\end{array}$ & $P>t$ & Coef. & $\begin{array}{l}\text { St. } \\
\text { Err. }\end{array}$ & $P>t$ & Coef. & $\begin{array}{l}\text { St. } \\
\text { Err. }\end{array}$ & $P>t$ \\
\hline mil_int & 307 & 487 & 0,53 & - & - & - & - & - & - \\
\hline mil_int_1 & - & - & - & -153 & 545 & 0,78 & - & - & - \\
\hline mil_int_2 & - & - & - & - & - & - & -145 & 789 & 0,85 \\
\hline polity_lev & -10 & 24 & 0,69 & -9 & 24 & 0,71 & -9 & 24 & 0,70 \\
\hline polity_gr & 100 & 108 & 0,36 & 100 & 108 & 0,36 & 99 & 108 & 0,36 \\
\hline gdp_lev & 6 & 17 & 0,75 & 5 & 17 & 0,76 & 6 & 17 & 0,75 \\
\hline gdp_gr & -17 & 198 & 0,93 & -18 & 198 & 0,93 & -18 & 198 & 0,93 \\
\hline excl_pop & -699 & 673 & 0,30 & -696 & 673 & 0,30 & -694 & 673 & 0,30 \\
\hline ethn_fract & -2 & 1208 & 1,00 & 40 & 1207 & 0,97 & 38 & 1207 & 0,98 \\
\hline viol_cult & 138 & 91 & 0,13 & 289 & 160 & 0,07 & 182 & 68 & 0,01 \\
\hline confl & 2697 & 358 & 0,00 & 2703 & 358 & 0,00 & 2707 & 357 & 0,00 \\
\hline prev_confl & -1159 & 642 & 0,07 & -1185 & 641 & 0,07 & -1179 & 643 & 0,07 \\
\hline intern_confl & 845 & 580 & 0,15 & 937 & 648 & 0,15 & 895 & 619 & 0,15 \\
\hline prev_mil_int & -911 & 340 & 0,01 & -793 & 298 & 0,01 & -804 & 295 & 0,01 \\
\hline third_party_int & -798 & 641 & 0,21 & -741 & 652 & 0,26 & -778 & 640 & 0,22 \\
\hline viol_mil_int & 692 & 456 & 0,13 & 818 & 419 & 0,05 & 804 & 418 & 0,05 \\
\hline int_supp_gov & -148 & 566 & 0,79 & -42 & 549 & 0,94 & 24 & 698 & 0,97 \\
\hline int_supp_reb & -498 & 518 & 0,34 & -372 & 499 & 0,46 & -409 & 497 & 0,41 \\
\hline mixed_target & 2630 & 874 & 0,00 & 2492 & 856 & 0,00 & 2528 & 858 & 0,00 \\
\hline _cons & 162 & 590 & 0,78 & 142 & 590 & 0,81 & 145 & 590 & 0,81 \\
\hline
\end{tabular}

\begin{tabular}{|l|r|r|r|r|r|r|r|r|c|}
\hline \multirow{2}{*}{ Y2b: b_deaths_ch_lag } & \multicolumn{3}{|c|}{ Control definition 1} & \multicolumn{3}{c|}{ Control definition 2} & \multicolumn{2}{c|}{ Control definition 3} \\
\cline { 2 - 10 } & \multicolumn{2}{|c|}{ Prob $>$ F $=0.0000$} & \multicolumn{2}{c|}{ Prob $>$ F $=0.0000$} & \multicolumn{3}{c|}{ Prob $>$ F = 0.0000 } \\
\cline { 2 - 10 } & Coef. & St. Err. & P>t & Coef. & St. Err. & P>t & Coef. & St. Err. & P>t \\
\hline mil_int & -187 & 463 & 0,69 & - & - & - & - & - & - \\
\hline mil_int_1 & - & - & - & $*-926$ & 519 & 0,07 & - & - & - \\
\hline
\end{tabular}




\begin{tabular}{|l|r|r|r|r|r|r|r|r|r|}
\hline mil_int_2 & - & - & - & - & - & - & $*-1286$ & 750 & $\mathbf{0 , 0 9}$ \\
\hline polity_lev & -14 & 23 & $\mathbf{0 , 5 4}$ & -13 & 23 & $\mathbf{0 , 5 6}$ & -14 & 23 & $\mathbf{0 , 5 2}$ \\
\hline polity_gr & 146 & 103 & $\mathbf{0 , 1 6}$ & 146 & 103 & $\mathbf{0 , 1 6}$ & 144 & 103 & $\mathbf{0 , 1 6}$ \\
\hline gdp_lev & -3 & 17 & $\mathbf{0 , 8 7}$ & -3 & 17 & $\mathbf{0 , 8 8}$ & -1 & 17 & $\mathbf{0 , 9 5}$ \\
\hline gdp_gr & -25 & 189 & $\mathbf{0 , 8 9}$ & -27 & 189 & $\mathbf{0 , 8 9}$ & -29 & 189 & $\mathbf{0 , 8 8}$ \\
\hline excl_pop & -1221 & 641 & $\mathbf{0 , 0 6}$ & -1223 & 641 & $\mathbf{0 , 0 6}$ & -1208 & 641 & $\mathbf{0 , 0 6}$ \\
\hline ethn_fract & -658 & 1149 & $\mathbf{0 , 5 7}$ & -629 & 1148 & $\mathbf{0 , 5 8}$ & -624 & 1148 & $\mathbf{0 , 5 9}$ \\
\hline viol_cult & 289 & 160 & $\mathbf{0 , 0 7}$ & 263 & 88 & $\mathbf{0 , 0 0}$ & 182 & 68 & $\mathbf{0 , 0 1}$ \\
\hline confl & 1029 & 340 & $\mathbf{0 , 0 0}$ & 996 & 340 & $\mathbf{0 , 0 0}$ & 1016 & 340 & $\mathbf{0 , 0 0}$ \\
\hline prev_confl & 2727 & 611 & $\mathbf{0 , 0 0}$ & 2766 & 610 & $\mathbf{0 , 0 0}$ & 2832 & 612 & $\mathbf{0 , 0 0}$ \\
\hline intern_confl & 3470 & 552 & $\mathbf{0 , 0 0}$ & 3956 & 617 & $\mathbf{0 , 0 0}$ & 3815 & 589 & $\mathbf{0 , 0 0}$ \\
\hline prev_mil_int & 560 & 323 & $\mathbf{0 , 0 8}$ & 573 & 284 & $\mathbf{0 , 0 4}$ & 505 & 281 & $\mathbf{0 , 0 7}$ \\
\hline third_party_int & -2843 & 610 & $\mathbf{0 , 0 0}$ & -2648 & 620 & $\mathbf{0 , 0 0}$ & -2873 & 609 & $\mathbf{0 , 0 0}$ \\
\hline viol_mil_int & -185 & 434 & $\mathbf{0 , 6 7}$ & -189 & 399 & $\mathbf{0 , 6 4}$ & -284 & 397 & $\mathbf{0 , 4 8}$ \\
\hline int_supp_gov & -902 & 538 & $\mathbf{0 , 0 9}$ & -875 & 522 & $\mathbf{0 , 0 9}$ & -249 & 664 & $\mathbf{0 , 7 1}$ \\
\hline int_supp_reb & -620 & 493 & $\mathbf{0 , 2 1}$ & -537 & 475 & $\mathbf{0 , 2 6}$ & -803 & 473 & $\mathbf{0 , 0 9}$ \\
\hline mixed_target & -242 & 832 & $\mathbf{0 , 7 7}$ & -288 & 815 & $\mathbf{0 , 7 2}$ & -23 & 816 & $\mathbf{0 , 9 8}$ \\
\hline _cons & 705 & 561 & $\mathbf{0 , 2 1}$ & 671 & 561 & $\mathbf{0 , 2 3}$ & 676 & 561 & $\mathbf{0 , 2 3}$ \\
\hline
\end{tabular}

\begin{tabular}{|c|c|c|c|c|c|c|c|c|c|}
\hline \multirow{3}{*}{ Y2c: b_deaths_ch_lag2 } & \multicolumn{3}{|c|}{ Control definition 1} & \multicolumn{3}{|c|}{ Control definition 2} & \multicolumn{3}{|c|}{ Control definition 3} \\
\hline & \multicolumn{3}{|c|}{ Prob $>F=0.0000$} & \multicolumn{3}{|c|}{ Prob $>F=0.0000$} & \multicolumn{3}{|c|}{ Prob $>F=0.0000$} \\
\hline & Coef. & St. Err. & $P>t$ & Coef. & St. Err. & $P>t$ & Coef. & St. Err. & $P>t$ \\
\hline mil_int & -141 & 474 & 0,77 & - & - & - & - & - & - \\
\hline mil_int_1 & - & - & - & 494 & 531 & 0,35 & - & - & - \\
\hline mil_int_2 & - & - & - & - & - & - & -34 & 768 & 0,97 \\
\hline polity_lev & -7 & 23 & 0,78 & -7 & 23 & 0,76 & -7 & 23 & 0,77 \\
\hline polity_gr & -7 & 105 & 0,95 & -7 & 105 & 0,95 & -7 & 105 & 0,95 \\
\hline gdp_lev & -1 & 17 & 0,97 & -1 & 17 & 0,97 & 0 & 17 & 0,98 \\
\hline gdp_gr & -23 & 193 & 0,91 & -21 & 193 & 0,91 & -22 & 193 & 0,91 \\
\hline excl_pop & 304 & 656 & 0,64 & 303 & 656 & 0,65 & 303 & 656 & 0,64 \\
\hline ethn_fract & -156 & 1176 & 0,90 & -198 & 1176 & 0,87 & -170 & 1176 & 0,89 \\
\hline viol_cult & 138 & 91 & 0,13 & 182 & 68 & 0,01 & 289 & 160 & 0,07 \\
\hline confl & 243 & 349 & 0,49 & 252 & 349 & 0,47 & 238 & 348 & 0,50 \\
\hline prev_confl & 1149 & 626 & 0,07 & 1151 & 624 & 0,07 & 1165 & 626 & 0,06 \\
\hline intern_confl & 1721 & 565 & 0,00 & 1453 & 632 & 0,02 & 1725 & 603 & 0,00 \\
\hline
\end{tabular}




\begin{tabular}{|l|r|r|r|r|r|r|r|r|r|}
\hline prev_mil_int & 2 & 331 & $\mathbf{1 , 0 0}$ & -88 & 291 & $\mathbf{0 , 7 6}$ & -46 & 287 & $\mathbf{0 , 8 7}$ \\
\hline third_party_int & -1507 & 624 & $\mathbf{0 , 0 2}$ & -1629 & 635 & $\mathbf{0 , 0 1}$ & -1518 & 623 & $\mathbf{0 , 0 2}$ \\
\hline viol_mil_int & 51 & 444 & $\mathbf{0 , 9 1}$ & -37 & 408 & $\mathbf{0 , 9 3}$ & -3 & 407 & $\mathbf{1 , 0 0}$ \\
\hline int_supp_gov & -169 & 551 & $\mathbf{0 , 7 6}$ & -256 & 534 & $\mathbf{0 , 6 3}$ & -193 & 680 & $\mathbf{0 , 7 8}$ \\
\hline int_supp_reb & 208 & 505 & $\mathbf{0 , 6 8}$ & 83 & 486 & $\mathbf{0 , 8 6}$ & 158 & 485 & $\mathbf{0 , 7 5}$ \\
\hline mixed_target & -836 & 852 & $\mathbf{0 , 3 3}$ & -718 & 834 & $\mathbf{0 , 3 9}$ & -777 & 836 & $\mathbf{0 , 3 5}$ \\
\hline _cons & 238 & 575 & $\mathbf{0 , 6 8}$ & 266 & 575 & $\mathbf{0 , 6 4}$ & 243 & 575 & $\mathbf{0 , 6 7}$ \\
\hline
\end{tabular}

\subsection{Definitions of the 'humanitarian motives and means' of military intervention}

2.2.1. Dependent variable (Y1) - conflict deaths

\begin{tabular}{|c|c|c|c|c|c|c|c|c|c|}
\hline \multirow{3}{*}{ Y1a: deaths_ch } & \multicolumn{3}{|c|}{ HMI definition 1} & \multicolumn{3}{|c|}{ HMI definition 2} & \multicolumn{3}{|c|}{ HMI definition 3} \\
\hline & \multicolumn{3}{|c|}{ Prob $>F=0.0000$} & \multicolumn{3}{|c|}{ Prob $>F=0.0000$} & \multicolumn{3}{|c|}{ Prob $>F=0.0000$} \\
\hline & Coef. & St. Err. & $P>t$ & Coef. & St. Err. & $P>t$ & Coef. & St. Err. & $P>t$ \\
\hline jwt_x & 0,004 & 0,003 & 0,16 & - & - & - & - & - & - \\
\hline jwt_x1 & - & - & - & $* * 0,006$ & 0,003 & 0,024 & - & - & - \\
\hline jwt_x2 & - & - & - & - & - & - & $* * *-0,012$ & 0,003 & 0,00 \\
\hline polity_lev & 0,003 & 0,003 & 0,25 & 0,003 & 0,003 & 0,24 & 0,003 & 0,003 & 0,30 \\
\hline polity_gr & $-0,056$ & 0,013 & 0,00 & $-0,056$ & 0,013 & 0,00 & $-0,057$ & 0,013 & 0,00 \\
\hline gdp_lev & 0,003 & 0,002 & 0,16 & 0,003 & 0,002 & 0,17 & 0,003 & 0,002 & 0,13 \\
\hline gdp_gr & 0,001 & 0,023 & 0,98 & 0,001 & 0,023 & 0,98 & 0,002 & 0,023 & 0,93 \\
\hline excl_pop & 0,431 & 0,080 & 0,00 & 0,426 & 0,080 & 0,00 & 0,440 & 0,080 & 0,00 \\
\hline ethn_fract & $-0,199$ & 0,143 & 0,16 & $-0,197$ & 0,143 & 0,17 & $-0,189$ & 0,143 & 0,19 \\
\hline viol_cult & 0,061 & 0,042 & 0,15 & 0,114 & 0,040 & 0,01 & 0,111 & 0,031 & 0,01 \\
\hline confl & 0,096 & 0,043 & 0,03 & 0,099 & 0,042 & 0,02 & 0,112 & 0,043 & 0,01 \\
\hline prev_confl & $-0,143$ & 0,076 & 0,06 & $-0,165$ & 0,077 & 0,03 & $-0,065$ & 0,078 & 0,40 \\
\hline intern_confl & $-0,111$ & 0,072 & 0,13 & $-0,188$ & 0,084 & 0,03 & 0,046 & 0,076 & 0,55 \\
\hline prev_mil_int & 0,097 & 0,037 & 0,01 & 0,108 & 0,035 & 0,00 & 0,114 & 0,035 & 0,00 \\
\hline third_party_int & 0,242 & 0,077 & 0,00 & 0,239 & 0,076 & 0,00 & 0,166 & 0,077 & 0,03 \\
\hline viol_mil_int & $-0,160$ & 0,053 & 0,00 & $-0,141$ & 0,050 & 0,00 & $-0,134$ & 0,049 & 0,01 \\
\hline int_supp_gov & $-0,110$ & 0,067 & 0,10 & $-0,100$ & 0,065 & 0,12 & 0,065 & 0,077 & 0,40 \\
\hline int_supp_reb & 0,216 & 0,062 & 0,00 & 0,220 & 0,059 & 0,00 & 0,211 & 0,059 & 0,00 \\
\hline mixed_target & 0,335 & 0,102 & 0,00 & 0,326 & 0,101 & 0,00 & 0,369 & 0,102 & 0,00 \\
\hline _cons & 0,184 & 0,070 & 0,01 & 0,186 & 0,070 & 0,01 & 0,180 & 0,070 & 0,01 \\
\hline
\end{tabular}




\begin{tabular}{|c|c|c|c|c|c|c|c|c|c|}
\hline \multirow{3}{*}{ Y1b: deaths_ch_lag } & \multicolumn{3}{|c|}{ HMI definition 1} & \multicolumn{3}{|c|}{ HMI definition 2} & \multicolumn{3}{|c|}{ HMI definition 3} \\
\hline & \multicolumn{3}{|c|}{ Prob $>F=0.0000$} & \multicolumn{3}{|c|}{ Prob $>F=0.0000$} & \multicolumn{3}{|c|}{ Prob $>F=0.0000$} \\
\hline & Coef. & St. Err. & $P>t$ & Coef. & St. Err. & $P>t$ & Coef. & St. Err. & $P>t$ \\
\hline jwt_x & $* 0,005$ & 0,003 & 0,06 & - & - & - & - & - & - \\
\hline jwt_x1 & - & - & - & $* * * 0,008$ & 0,003 & 0,00 & - & - & - \\
\hline jwt_x2 & - & - & - & - & - & - & $* * *-0,015$ & 0,003 & 0,00 \\
\hline polity_lev & 0,006 & 0,003 & 0,05 & 0,006 & 0,003 & 0,05 & 0,005 & 0,003 & 0,07 \\
\hline polity_gr & $-0,059$ & 0,013 & 0,00 & $-0,059$ & 0,013 & 0,00 & $-0,061$ & 0,013 & 0,00 \\
\hline gdp_lev & 0,002 & 0,002 & 0,36 & 0,002 & 0,002 & 0,37 & 0,002 & 0,002 & 0,30 \\
\hline gdp_gr & 0,004 & 0,024 & 0,86 & 0,004 & 0,024 & 0,86 & 0,006 & 0,024 & 0,81 \\
\hline excl_pop & 0,468 & 0,080 & 0,00 & 0,462 & 0,080 & 0,00 & 0,479 & 0,080 & 0,00 \\
\hline ethn_fract & $-0,226$ & 0,143 & 0,12 & $-0,224$ & 0,143 & 0,12 & $-0,213$ & 0,143 & 0,14 \\
\hline viol_cult & 0,183 & 0,069 & 0,01 & 0,286 & 0,063 & 0,00 & 0,115 & 0,041 & 0,01 \\
\hline confl & 0,048 & 0,043 & 0,26 & 0,053 & 0,043 & 0,21 & 0,069 & 0,042 & 0,10 \\
\hline prev_confl & $-0,009$ & 0,077 & 0,91 & $-0,038$ & 0,078 & 0,62 & 0,089 & 0,078 & 0,25 \\
\hline intern_confl & 0,021 & 0,073 & 0,77 & $-0,081$ & 0,085 & 0,34 & 0,220 & 0,077 & 0,00 \\
\hline prev_mil_int & 0,084 & 0,037 & 0,02 & 0,098 & 0,035 & 0,01 & 0,107 & 0,035 & 0,00 \\
\hline third_party_int & 0,097 & 0,077 & 0,21 & 0,091 & 0,076 & 0,23 & $-0,001$ & 0,078 & 0,99 \\
\hline viol_mil_int & $-0,153$ & 0,054 & 0,00 & $-0,127$ & 0,050 & 0,01 & $-0,117$ & 0,050 & 0,02 \\
\hline int_supp_gov & $-0,154$ & 0,067 & 0,02 & $-0,140$ & 0,065 & 0,03 & 0,066 & 0,077 & 0,39 \\
\hline int_supp_reb & 0,245 & 0,062 & 0,00 & 0,252 & 0,060 & 0,00 & 0,242 & 0,059 & 0,00 \\
\hline mixed_target & 0,315 & 0,103 & 0,00 & 0,303 & 0,102 & 0,00 & 0,355 & 0,103 & 0,00 \\
\hline _cons & 0,176 & 0,070 & 0,01 & 0,179 & 0,070 & 0,01 & 0,171 & 0,070 & 0,02 \\
\hline
\end{tabular}

\begin{tabular}{|c|c|c|c|c|c|c|c|c|c|}
\hline \multirow{3}{*}{ Y1c: deaths_ch_lag2 } & \multicolumn{3}{|c|}{ HMI definition 1} & \multicolumn{3}{|c|}{ HMI definition 2} & \multicolumn{3}{|c|}{ HMI definition 3} \\
\hline & \multicolumn{3}{|c|}{ Prob $>F=0.0000$} & \multicolumn{3}{|c|}{ Prob $>F=0.0000$} & \multicolumn{3}{|c|}{ Prob $>F=0.0000$} \\
\hline & Coef. & St. Err. & $P>t$ & Coef. & St. Err. & $P>t$ & Coef. & St. Err. & $P>t$ \\
\hline jwt_x & $* * * 0,007$ & 0,003 & 0,01 & - & - & - & - & - & - \\
\hline jwt_x1 & - & - & - & $* * * 0,011$ & 0,003 & 0,00 & - & - & - \\
\hline jwt_x2 & - & - & - & - & - & - & $* * *-0,015$ & 0,003 & 0,00 \\
\hline polity_lev & 0,008 & 0,003 & 0,01 & 0,008 & 0,003 & 0,01 & 0,007 & 0,003 & 0,01 \\
\hline polity_gr & $-0,064$ & 0,013 & 0,00 & $-0,064$ & 0,013 & 0,00 & $-0,066$ & 0,013 & 0,00 \\
\hline gdp_lev & 0,001 & 0,002 & 0,65 & 0,001 & 0,002 & 0,68 & 0,001 & 0,002 & 0,56 \\
\hline gdp_gr & 0,004 & 0,024 & 0,88 & 0,004 & 0,024 & 0,88 & 0,006 & 0,024 & 0,82 \\
\hline
\end{tabular}




\begin{tabular}{|l|r|r|r|r|r|r|r|r|r|}
\hline excl_pop & 0,461 & 0,080 & $\mathbf{0 , 0 0}$ & 0,453 & 0,080 & $\mathbf{0 , 0 0}$ & 0,473 & 0,080 & $\mathbf{0 , 0 0}$ \\
\hline ethn_fract & $-0,275$ & 0,144 & $\mathbf{0 , 0 6}$ & $-0,271$ & 0,144 & $\mathbf{0 , 0 6}$ & $-0,259$ & 0,144 & $\mathbf{0 , 0 7}$ \\
\hline viol_cult & 0,116 & 0,033 & $\mathbf{0 , 0 1}$ & 0,291 & 0,065 & $\mathbf{0 , 0 0}$ & 0,185 & 0,071 & $\mathbf{0 , 0 1}$ \\
\hline confl & 0,028 & 0,043 & $\mathbf{0 , 5 2}$ & 0,035 & 0,043 & $\mathbf{0 , 4 1}$ & 0,054 & 0,043 & $\mathbf{0 , 2 0}$ \\
\hline prev_confl & 0,062 & 0,077 & $\mathbf{0 , 4 2}$ & 0,023 & 0,078 & $\mathbf{0 , 7 6}$ & 0,171 & 0,078 & $\mathbf{0 , 0 3}$ \\
\hline intern_confl & 0,119 & 0,073 & $\mathbf{0 , 1 0}$ & $-0,018$ & 0,085 & $\mathbf{0 , 8 3}$ & 0,344 & 0,077 & $\mathbf{0 , 0 0}$ \\
\hline prev_mil_int & 0,076 & 0,037 & $\mathbf{0 , 0 4}$ & 0,098 & 0,035 & $\mathbf{0 , 0 1}$ & 0,109 & 0,035 & $\mathbf{0 , 0 0}$ \\
\hline third_party_int & 0,009 & 0,077 & $\mathbf{0 , 9 1}$ & 0,000 & 0,076 & $\mathbf{1 , 0 0}$ & $-0,101$ & 0,078 & $\mathbf{0 , 1 9}$ \\
\hline viol_mil_int & $-0,197$ & 0,054 & $\mathbf{0 , 0 0}$ & $-0,160$ & 0,050 & $\mathbf{0 , 0 0}$ & $-0,146$ & 0,050 & $\mathbf{0 , 0 0}$ \\
\hline int_supp_gov & $-0,182$ & 0,067 & $\mathbf{0 , 0 1}$ & $-0,161$ & 0,065 & $\mathbf{0 , 0 1}$ & 0,060 & 0,077 & $\mathbf{0 , 4 4}$ \\
\hline int_supp_reb & 0,275 & 0,063 & $\mathbf{0 , 0 0}$ & 0,286 & 0,060 & $\mathbf{0 , 0 0}$ & 0,287 & 0,059 & $\mathbf{0 , 0 0}$ \\
\hline mixed_target & 0,280 & 0,103 & $\mathbf{0 , 0 1}$ & 0,261 & 0,102 & $\mathbf{0 , 0 1}$ & 0,310 & 0,103 & $\mathbf{0 , 0 0}$ \\
\hline cons & 0,185 & 0,070 & $\mathbf{0 , 0 1}$ & 0,190 & 0,070 & $\mathbf{0 , 0 1}$ & 0,179 & 0,070 & $\mathbf{0 , 0 1}$ \\
\hline
\end{tabular}

\subsubsection{Dependent variable (Y2) - battle deaths}

\begin{tabular}{|c|c|c|c|c|c|c|c|c|c|}
\hline \multirow{3}{*}{ Y2a:b_deaths_ch } & \multicolumn{3}{|c|}{ HMI definition 1} & \multicolumn{3}{|c|}{ HMI definition 2} & \multicolumn{3}{|c|}{ HMI definition 3} \\
\hline & \multicolumn{3}{|c|}{ Prob $>F=0.0000$} & \multicolumn{3}{|c|}{ Prob $>F=0.0000$} & \multicolumn{3}{|c|}{ Prob $>F=0.0000$} \\
\hline & Coef. & St. Err. & $P>t$ & Coef. & St. Err. & $P>t$ & Coef. & St. Err. & $P>t$ \\
\hline jwt_x & $* * * 119$ & 22 & 0,00 & - & - & - & - & - & - \\
\hline jwt_x1 & - & - & - & $* * * 96$ & 22 & 0,00 & - & - & - \\
\hline jwt_x2 & - & - & - & - & - & - & $* * * 96$ & 27 & 0,00 \\
\hline polity_lev & -6 & 24 & 0,82 & -7 & 24 & 0,77 & -7 & 24 & 0,77 \\
\hline polity_gr & 108 & 108 & 0,32 & 108 & 108 & 0,32 & 107 & 108 & 0,32 \\
\hline gdp_lev & 6 & 17 & 0,72 & 5 & 17 & 0,77 & 3 & 17 & 0,84 \\
\hline gdp_gr & -20 & 198 & 0,92 & -20 & 198 & 0,92 & -29 & 198 & 0,89 \\
\hline excl_pop & -743 & 673 & 0,27 & -797 & 673 & 0,24 & -753 & 673 & 0,26 \\
\hline ethn_fract & -152 & 1205 & 0,90 & -33 & 1206 & 0,98 & -3 & 1206 & 1,00 \\
\hline viol_cult & 292 & 163 & 0,07 & 285 & 112 & 0,01 & 184 & 69 & 0,01 \\
\hline confl & 2398 & 361 & 0,00 & 2612 & 358 & 0,00 & 2655 & 358 & 0,00 \\
\hline prev_confl & -1572 & 644 & 0,02 & -1738 & 653 & 0,01 & -1724 & 659 & 0,01 \\
\hline intern_confl & -231 & 612 & 0,71 & -948 & 712 & 0,18 & -144 & 647 & 0,82 \\
\hline prev_mil_int & -1367 & 312 & 0,00 & -908 & 296 & 0,00 & -808 & 295 & 0,01 \\
\hline third_party_int & -235 & 646 & 0,72 & -569 & 641 & 0,38 & -289 & 655 & 0,66 \\
\hline viol_mil_int & -138 & 451 & 0,76 & 639 & 419 & 0,13 & 831 & 417 & 0,05 \\
\hline
\end{tabular}




\begin{tabular}{|l|r|r|r|r|r|r|r|r|r|}
\hline int_supp_gov & -794 & 562 & $\mathbf{0 , 1 6}$ & -258 & 548 & $\mathbf{0 , 6 4}$ & -1288 & 650 & $\mathbf{0 , 0 5}$ \\
\hline int_supp_reb & -1414 & 525 & $\mathbf{0 , 0 1}$ & -824 & 501 & $\mathbf{0 , 1 0}$ & -106 & 499 & $\mathbf{0 , 8 3}$ \\
\hline mixed_target & 3311 & 865 & $\mathbf{0 , 0 0}$ & 2762 & 855 & $\mathbf{0 , 0 0}$ & 2038 & 864 & $\mathbf{0 , 0 2}$ \\
\hline _cons & 170 & 589 & $\mathbf{0 , 7 7}$ & 200 & 589 & $\mathbf{0 , 7 4}$ & 177 & 589 & $\mathbf{0 , 7 6}$ \\
\hline
\end{tabular}

\begin{tabular}{|c|c|c|c|c|c|c|c|c|c|}
\hline \multirow{3}{*}{ Y2b: b_deaths_ch_lag } & \multicolumn{3}{|c|}{ HMI definition 1} & \multicolumn{3}{|c|}{ HMI definition 2} & \multicolumn{3}{|c|}{ HMI definition 3} \\
\hline & \multicolumn{3}{|c|}{ Prob $>F=0.0000$} & \multicolumn{3}{|c|}{ Prob $>F=0.0000$} & \multicolumn{3}{|c|}{ Prob $>F=0.0000$} \\
\hline & Coef. & St. Err. & $P>t$ & Coef. & St. Err. & $P>t$ & Coef. & St. Err. & $P>t$ \\
\hline jwt_x & -28 & 21 & 0,17 & - & - & - & - & - & - \\
\hline jwt_x1 & - & - & - & $* * *-65$ & 21 & 0,00 & - & - & - \\
\hline jwt_x2 & - & - & - & - & - & - & $* * *-67$ & 26 & 0,01 \\
\hline polity_lev & -15 & 23 & 0,51 & -16 & 23 & 0,49 & -15 & 23 & 0,50 \\
\hline polity_gr & 144 & 103 & 0,16 & 140 & 103 & 0,17 & 140 & 103 & 0,17 \\
\hline gdp_lev & -3 & 17 & 0,86 & -2 & 17 & 0,88 & -1 & 17 & 0,94 \\
\hline gdp_gr & -24 & 189 & 0,90 & -24 & 189 & 0,90 & -17 & 189 & 0,93 \\
\hline excl_pop & -1212 & 641 & 0,06 & -1154 & 641 & 0,07 & -1183 & 641 & 0,07 \\
\hline ethn_fract & -635 & 1148 & 0,58 & -635 & 1147 & 0,58 & -654 & 1147 & 0,57 \\
\hline viol_cult & 260 & 178 & 0,14 & 280 & 166 & 0,01 & 259 & 85 & 0,00 \\
\hline confl & 1097 & 344 & 0,00 & 1088 & 341 & 0,00 & 1060 & 340 & 0,00 \\
\hline prev_confl & 2837 & 613 & 0,00 & 3120 & 621 & 0,00 & 3120 & 627 & 0,00 \\
\hline intern_confl & 3722 & 583 & 0,00 & 4694 & 678 & 0,00 & 4163 & 615 & 0,00 \\
\hline prev_mil_int & 630 & 297 & 0,03 & 566 & 281 & 0,05 & 497 & 281 & 0,08 \\
\hline third_party_int & -2986 & 616 & 0,00 & -2998 & 610 & 0,00 & -3198 & 623 & 0,00 \\
\hline viol_mil_int & -30 & 429 & 0,94 & -141 & 399 & 0,72 & -273 & 397 & 0,49 \\
\hline int_supp_gov & -782 & 535 & 0,14 & -820 & 521 & 0,12 & -97 & 619 & 0,88 \\
\hline int_supp_reb & -439 & 500 & 0,38 & -390 & 477 & 0,41 & -884 & 474 & 0,06 \\
\hline mixed_target & -360 & 824 & 0,66 & -340 & 814 & 0,68 & 162 & 822 & 0,84 \\
\hline _cons & 708 & 561 & 0,21 & 678 & 561 & 0,23 & 693 & 561 & 0,22 \\
\hline
\end{tabular}

\begin{tabular}{|l|r|r|r|r|r|r|r|r|r|}
\hline \multirow{2}{*}{ Y2c: b_deaths_ch_lag2 } & \multicolumn{3}{|c|}{ HMI definition 1 } & \multicolumn{3}{c|}{ HMI definition 2 } & \multicolumn{3}{c|}{ HMI definition 3} \\
\cline { 2 - 10 } & \multicolumn{2}{|c|}{ Prob $>$ F = 0.0000 } & \multicolumn{3}{|c|}{ Prob > F =0.0000 } & \multicolumn{3}{c|}{ Prob $>$ F =0.0000 } \\
\cline { 2 - 10 } & Coef. & St. Err. & P>t & Coef. & St. Err. & P>t & Coef. & St. Err. & P>t \\
\hline jwt_x & -16 & 21 & 0,44 & - & - & - & - & - & - \\
\hline jwt_x1 & - & - & - & -1 & 21 & 0,95 & - & - & - \\
\hline jwt_x2 & \multicolumn{1}{|c|}{-} & - & - & - & - & - & $*-48$ & 27 & 0,07 \\
\hline
\end{tabular}




\begin{tabular}{|l|r|r|r|r|r|r|r|r|r|}
\hline polity_lev & -7 & 23 & $\mathbf{0 , 7 5}$ & -7 & 23 & $\mathbf{0 , 7 7}$ & -8 & 23 & $\mathbf{0 , 7 4}$ \\
\hline polity_gr & -8 & 105 & $\mathbf{0 , 9 4}$ & -7 & 105 & $\mathbf{0 , 9 5}$ & -11 & 105 & $\mathbf{0 , 9 2}$ \\
\hline gdp_lev & -1 & 17 & $\mathbf{0 , 9 7}$ & -1 & 17 & $\mathbf{0 , 9 8}$ & 0 & 17 & $\mathbf{0 , 9 8}$ \\
\hline gdp_gr & -22 & 193 & $\mathbf{0 , 9 1}$ & -22 & 193 & $\mathbf{0 , 9 1}$ & -17 & 193 & $\mathbf{0 , 9 3}$ \\
\hline excl_pop & 309 & 656 & $\mathbf{0 , 6 4}$ & 304 & 656 & $\mathbf{0 , 6 4}$ & 331 & 656 & $\mathbf{0 , 6 1}$ \\
\hline ethn_fract & -146 & 1176 & $\mathbf{0 , 9 0}$ & -170 & 1175 & $\mathbf{0 , 8 9}$ & -153 & 1175 & $\mathbf{0 , 9 0}$ \\
\hline viol_cult & 251 & 186 & $\mathbf{0 , 1 5}$ & 278 & 159 & $\mathbf{0 , 0 7}$ & 220 & 118 & $\mathbf{0 , 0 5}$ \\
\hline confl & 280 & 353 & $\mathbf{0 , 4 3}$ & 239 & 349 & $\mathbf{0 , 4 9}$ & 264 & 349 & $\mathbf{0 , 4 5}$ \\
\hline prev_confl & 1214 & 628 & $\mathbf{0 , 0 5}$ & 1171 & 636 & $\mathbf{0 , 0 7}$ & 1431 & 642 & $\mathbf{0 , 0 3}$ \\
\hline intern_confl & 1863 & 597 & $\mathbf{0 , 0 0}$ & 1743 & 694 & $\mathbf{0 , 0 1}$ & 2216 & 630 & $\mathbf{0 , 0 0}$ \\
\hline prev_mil_int & 29 & 304 & $\mathbf{0 , 9 2}$ & -45 & 288 & $\mathbf{0 , 8 8}$ & -45 & 287 & $\mathbf{0 , 8 7}$ \\
\hline third_party_int & -1591 & 631 & $\mathbf{0 , 0 1}$ & -1521 & 625 & $\mathbf{0 , 0 2}$ & -1762 & 638 & $\mathbf{0 , 0 1}$ \\
\hline viol_mil_int & 126 & 440 & $\mathbf{0 , 7 7}$ & 1 & 408 & $\mathbf{1 , 0 0}$ & -14 & 407 & $\mathbf{0 , 9 7}$ \\
\hline int_supp_gov & -112 & 548 & $\mathbf{0 , 8 4}$ & -209 & 534 & $\mathbf{0 , 7 0}$ & 405 & 634 & $\mathbf{0 , 5 2}$ \\
\hline int_supp_reb & 299 & 512 & $\mathbf{0 , 5 6}$ & 167 & 489 & $\mathbf{0 , 7 3}$ & 16 & 486 & $\mathbf{0 , 9 7}$ \\
\hline mixed_target & -889 & 843 & $\mathbf{0 , 2 9}$ & -785 & 833 & $\mathbf{0 , 3 5}$ & -544 & 842 & $\mathbf{0 , 5 2}$ \\
\hline cons & 241 & 574 & $\mathbf{0 , 6 8}$ & 243 & 574 & $\mathbf{0 , 6 7}$ & 229 & 574 & $\mathbf{0 , 6 9}$ \\
\hline
\end{tabular}

\section{Regression results for all the definitions (distinguishing among individual IWT criteria)}

The significance level is indicated by the following marking:

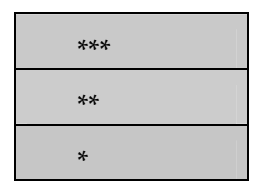

$$
\begin{aligned}
& 1 \% \text { significance level } \\
& 5 \% \text { significance level } \\
& 10 \% \text { significance level }
\end{aligned}
$$




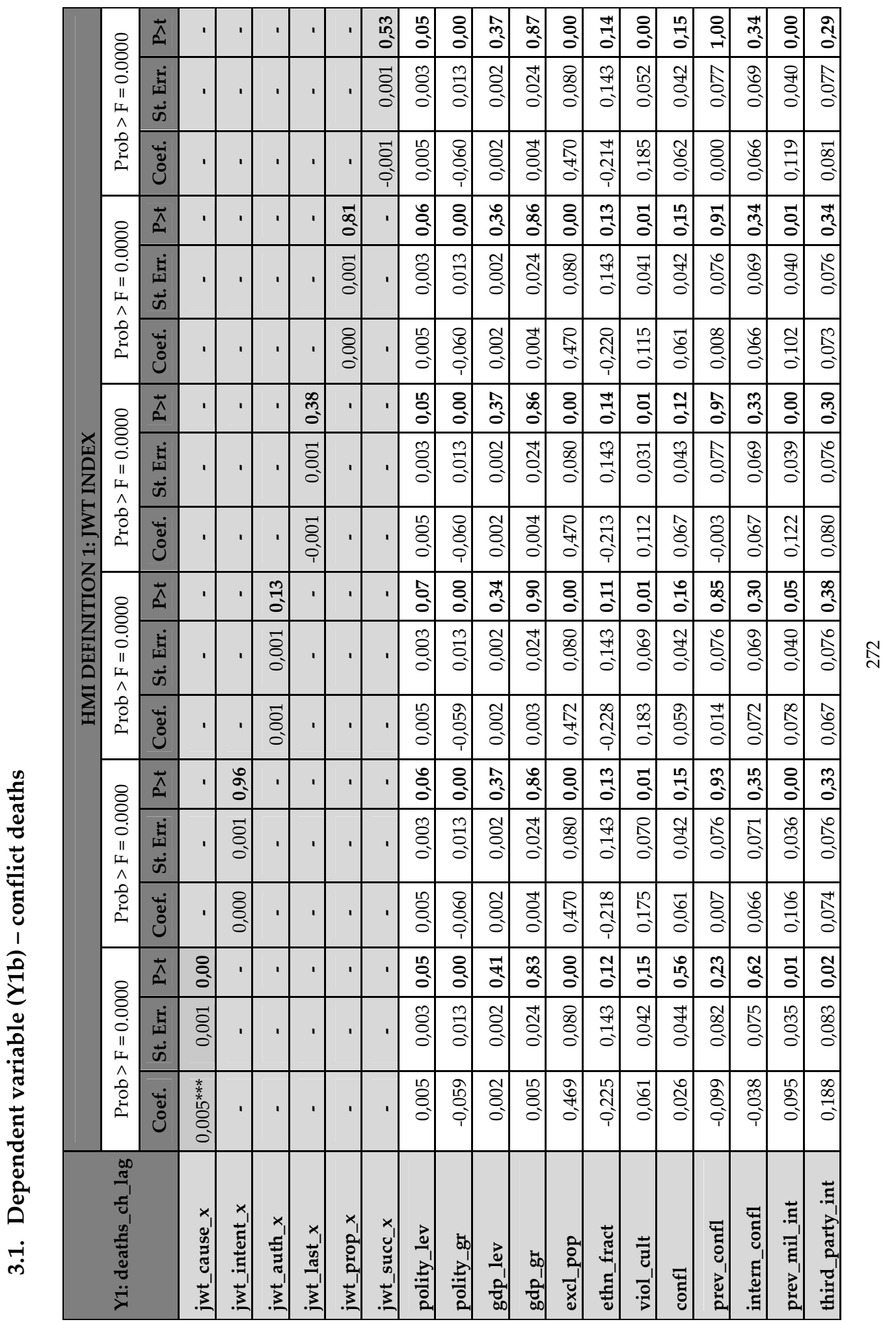




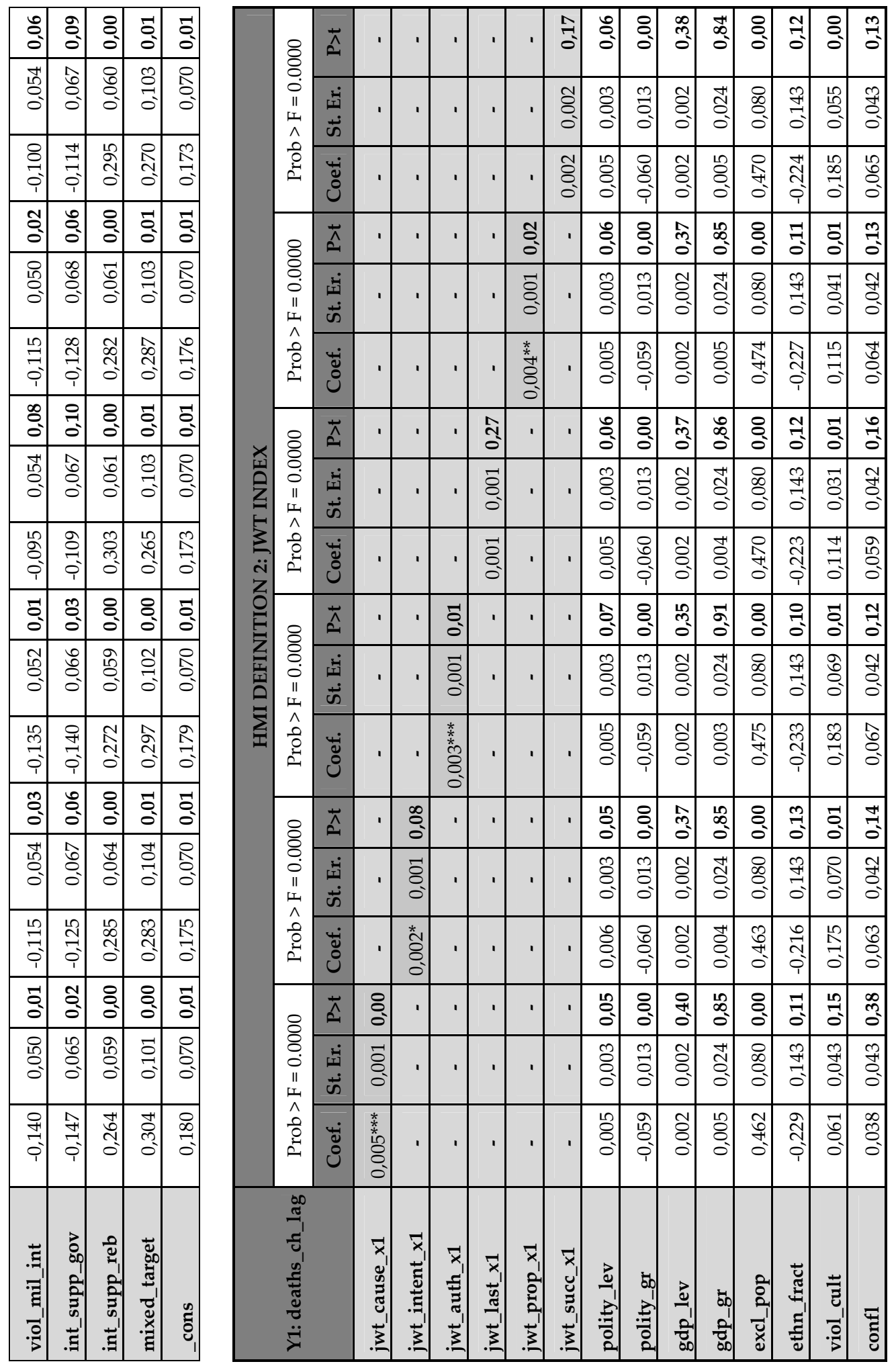




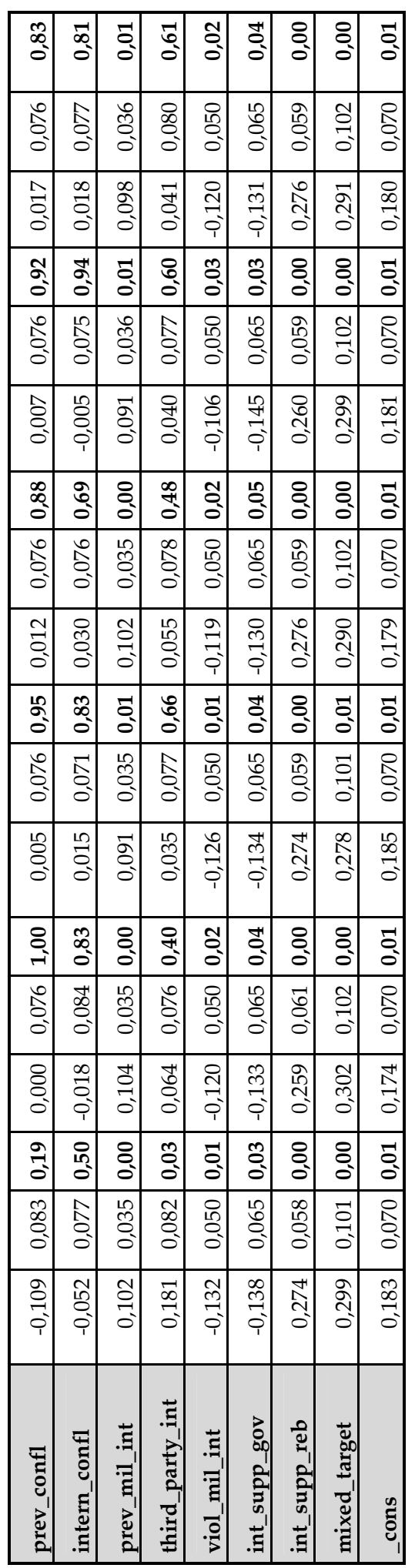

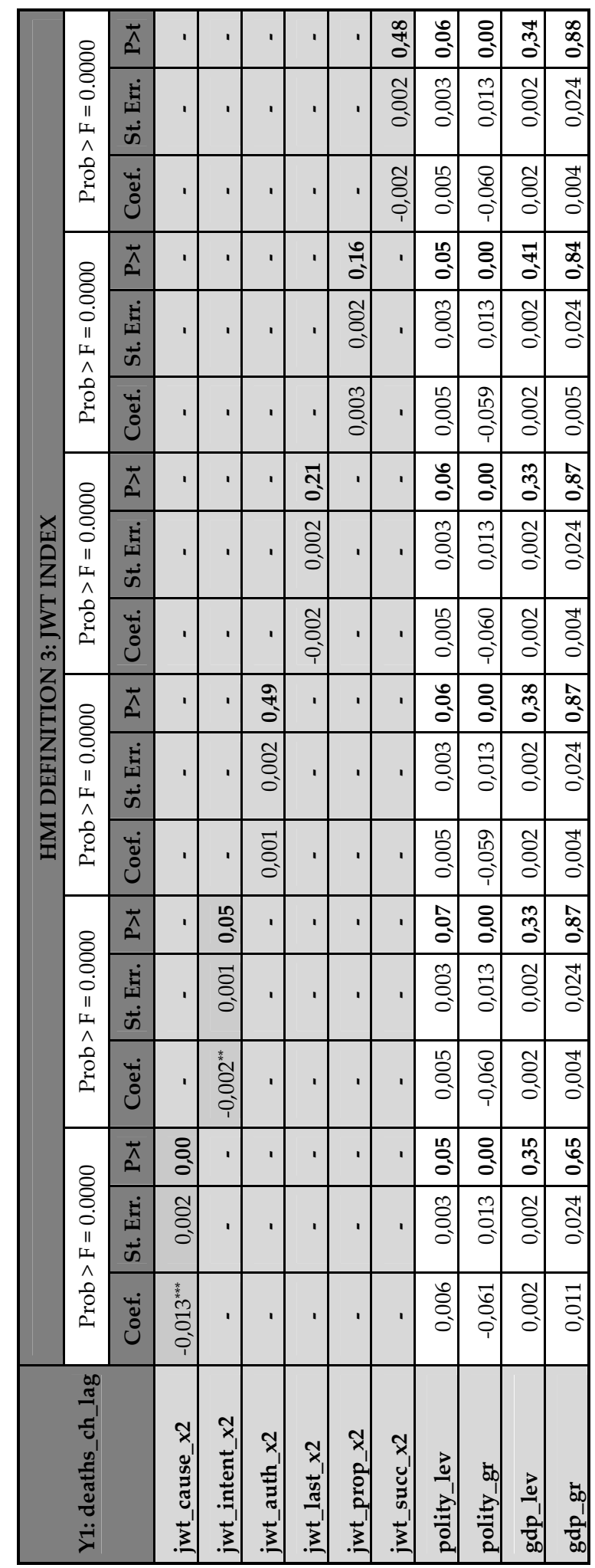




\begin{tabular}{|c|c|c|c|c|c|c|c|c|c|c|c|c|}
\hline ঃ & $\begin{array}{l}n \\
0 \\
0\end{array}$ & $\begin{array}{l}8 \\
8 \\
0\end{array}$ & $\begin{array}{l}10 \\
0 \\
0\end{array}$ & $\begin{array}{l}+ \\
0 \\
0\end{array}$ & 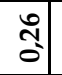 & $\begin{array}{l}8 \\
8 \\
0\end{array}$ & \begin{tabular}{l|} 
\\
尺े. \\
0 \\
0
\end{tabular} & $\begin{array}{l}9 \\
0 \\
0\end{array}$ & \begin{tabular}{l}
0 \\
\multirow{2}{*}{} \\
0
\end{tabular} & $\begin{array}{l}8 \\
8 \\
0\end{array}$ & $\begin{array}{l} \\
0 \\
0 \\
0\end{array}$ & $\begin{array}{l}-1 \\
0 \\
0\end{array}$ \\
\hline$\infty$ & 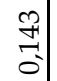 & $\begin{array}{l}\sharp \\
\stackrel{2}{0} \\
0 \\
0\end{array}$ & \begin{tabular}{l}
7 \\
\multirow{2}{0}{} \\
0
\end{tabular} & $\begin{array}{l}0 \\
5 \\
0 \\
0\end{array}$ & $\begin{array}{l}N \\
\hat{0} \\
0\end{array}$ & $\begin{array}{l}10 \\
8 \\
0 \\
0\end{array}$ & 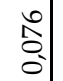 & $\begin{array}{l}0 \\
\stackrel{2}{0} \\
0\end{array}$ & $\begin{array}{l}0 \\
0 \\
0 \\
0\end{array}$ & $\begin{array}{l}0 \\
\grave{z} \\
0\end{array}$ & 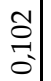 & 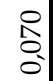 \\
\hline-1 & 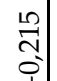 & $\begin{array}{l}10 \\
0 \\
0 \\
0\end{array}$ & $\begin{array}{l}8 \\
8 \\
0\end{array}$ & $\begin{array}{l}8 \\
8 \\
0\end{array}$ & $\begin{array}{l}0 \\
0 \\
0\end{array}$ & $\begin{array}{l}\text { 音 } \\
\text { - }\end{array}$ & $\begin{array}{l}8 \\
8 \\
0 \\
0\end{array}$ & $\begin{array}{l}10 \\
\stackrel{7}{0} \\
0\end{array}$ & $\begin{array}{l}\infty \\
\infty \\
0 \\
0\end{array}$ & 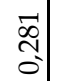 & $\begin{array}{c}\infty \\
\infty \\
\sim \\
0\end{array}$ & 今a \\
\hline 8 & $\begin{array}{l}\text { సี } \\
0\end{array}$ & $\begin{array}{l}5 \\
0 \\
0\end{array}$ & \begin{tabular}{l|}
2 \\
2 \\
0
\end{tabular} & $\begin{array}{l} \\
\text { જे }\end{array}$ & $\begin{array}{l}1 \\
0 \\
0 \\
0\end{array}$ & $\begin{array}{l} \\
8 \\
0\end{array}$ & $\begin{array}{l}\text { N } \\
\tilde{3} \\
0\end{array}$ & $\begin{array}{l} \\
\\
0 \\
0\end{array}$ & $\begin{array}{l}0 \\
0 \\
0\end{array}$ & $\begin{array}{l}8 \\
8 \\
0\end{array}$ & $\begin{array}{l} \\
0 \\
0\end{array}$ & $\begin{array}{l}0 \\
0 \\
0\end{array}$ \\
\hline$\infty$ & $\begin{array}{l}\stackrel{2}{2} \\
\stackrel{6}{0}\end{array}$ & \begin{tabular}{l}
9 \\
\multirow{3}{0}{} \\
0
\end{tabular} & \begin{tabular}{l}
7 \\
\multirow{2}{0}{} \\
0
\end{tabular} & $\begin{array}{l}0 \\
0 \\
0 \\
0\end{array}$ & $\begin{array}{l}0 \\
\hat{0} \\
0\end{array}$ & $\begin{array}{l}10 \\
\\
0 \\
0\end{array}$ & $\begin{array}{l}0 \\
5 \\
0 \\
0\end{array}$ & $\begin{array}{l}0 \\
\stackrel{2}{0} \\
0 \\
0\end{array}$ & $\begin{array}{l}\overrightarrow{8} \\
0 \\
0\end{array}$ & 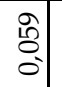 & $\begin{array}{c}\delta \\
0 \\
0 \\
0\end{array}$ & $\begin{array}{l}\text { R } \\
0 \\
0 \\
0\end{array}$ \\
\hline 3 & $\begin{array}{l}\text { הి } \\
\text { in } \\
\end{array}$ & $\begin{array}{l}10 \\
\vdots \\
0\end{array}$ & $\begin{array}{l}1 \\
8 \\
0 \\
0\end{array}$ & $\begin{array}{l}\overline{8} \\
0 \\
0\end{array}$ & $\begin{array}{l}\tilde{c} \\
0 \\
0\end{array}$ & 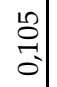 & $\begin{array}{l}12 \\
\hat{0} \\
0 \\
0\end{array}$ & $\begin{array}{l}20 \\
0 \\
0 \\
1\end{array}$ & $\begin{array}{l}0 \\
2 \\
0 \\
1\end{array}$ & 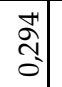 & \begin{tabular}{l}
$\infty$ \\
\multirow{2}{0}{} \\
\end{tabular} & $\begin{array}{l}\Omega \\
\\
0 \\
0\end{array}$ \\
\hline 8 & 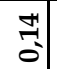 & $\begin{array}{l}5 \\
0 \\
0\end{array}$ & $\begin{array}{l}\text { 足 } \\
0\end{array}$ & \begin{tabular}{l|l}
2 \\
0 \\
0
\end{tabular} & 官 & $\begin{array}{l}0 \\
0 \\
0\end{array}$ & 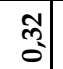 & $\begin{array}{l}\text { s. } \\
0 \\
0\end{array}$ & 吉 & $\begin{array}{l}8 \\
0 \\
0\end{array}$ & $\begin{array}{l}8 \\
\vdots \\
0\end{array}$ & $\begin{array}{l}-5 \\
8 \\
0\end{array}$ \\
\hline $\begin{array}{l}8 \\
\$ \\
0 \\
0\end{array}$ & \begin{tabular}{l}
$\stackrel{2}{7}$ \\
\hdashline \\
0
\end{tabular} & $\begin{array}{l}\overrightarrow{8} \\
0\end{array}$ & $\begin{array}{l}\text { ?ै } \\
0 \\
0\end{array}$ & $\begin{array}{l}2 \\
0 \\
0 \\
0\end{array}$ & $\begin{array}{l}0 \\
0 \\
0 \\
0\end{array}$ & 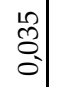 & $\begin{array}{l}0 \\
0 \\
0 \\
0\end{array}$ & 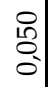 & $\begin{array}{l}\overrightarrow{8} \\
0 \\
0\end{array}$ & $\begin{array}{l}0 \\
\text { ถે } \\
0\end{array}$ & $\begin{array}{l}0 \\
0 \\
0\end{array}$ & $\begin{array}{l}R \\
0 \\
0 \\
0\end{array}$ \\
\hline 实 & 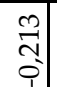 & $\begin{array}{l}\text { 吾 } \\
0 \\
0\end{array}$ & $\begin{array}{l}\tilde{3} \\
8 \\
0\end{array}$ & $\begin{array}{l}0 \\
0 \\
0 \\
0\end{array}$ & $\begin{array}{l}0 \\
8 \\
0\end{array}$ & $\begin{array}{l}\text { 童 } \\
\text { - }\end{array}$ & 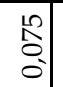 & $\begin{array}{l}0 \\
\stackrel{7}{0} \\
\mathbf{1}\end{array}$ & $\begin{array}{l}0 \\
8 \\
0\end{array}$ & $\begin{array}{l}\text { స̃ } \\
\text { ลे } \\
0\end{array}$ & $\begin{array}{l}\hat{~} \\
\text { సે } \\
0\end{array}$ & $\begin{array}{l}\text { N } \\
\text { - } \\
0\end{array}$ \\
\hline $\begin{array}{l}8 \\
0 \\
0\end{array}$ & 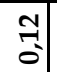 & $\begin{array}{l}5 \\
0 \\
0\end{array}$ & $\begin{array}{l}+ \\
5 \\
0\end{array}$ & $\begin{array}{l}\mathrm{s} \\
\mathrm{o}\end{array}$ & $\begin{array}{l}10 \\
8 \\
0\end{array}$ & $\begin{array}{l}8 \\
8 \\
0\end{array}$ & $\begin{array}{l}0 \\
3 \\
0\end{array}$ & $\begin{array}{l}\mathrm{S} \\
0 \\
0\end{array}$ & $\begin{array}{l}10 \\
0 \\
0\end{array}$ & $\begin{array}{l}8 \\
0 \\
0\end{array}$ & $\begin{array}{c}5 \\
0 \\
0\end{array}$ & $\begin{array}{l}5 \\
0 \\
0\end{array}$ \\
\hline$\triangleright$ & $\begin{array}{l}\vec{q} \\
\stackrel{9}{4} \\
0\end{array}$ & $\begin{array}{l}8 \\
\vdots \\
0\end{array}$ & $\begin{array}{l}\text { ఫี } \\
0 \\
0\end{array}$ & $\begin{array}{l}0 \\
5 \\
0 \\
0\end{array}$ & $\begin{array}{l}-1 \\
5 \\
0\end{array}$ & \begin{tabular}{l}
1 \\
\hdashline \\
8 \\
0
\end{tabular} & $\begin{array}{l}0 \\
5 \\
0 \\
0\end{array}$ & 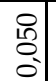 & $\begin{array}{l}0 \\
5 \\
0\end{array}$ & $\begin{array}{l}0 \\
8 \\
0 \\
0\end{array}$ & $\begin{array}{l}8 \\
\stackrel{2}{0} \\
0\end{array}$ & $\begin{array}{l}\text { R } \\
\text { Oे } \\
0\end{array}$ \\
\hline 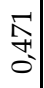 & $\begin{array}{l}\text { ה̃ } \\
\text { in }\end{array}$ & $\begin{array}{l}m \\
\infty \\
0 \\
0\end{array}$ & \begin{tabular}{l}
1 \\
\multirow{8}{0}{} \\
0
\end{tabular} & $\begin{array}{l}0 \\
8 \\
0 \\
0\end{array}$ & 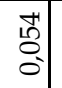 & $\begin{array}{l}1 \\
0 \\
0\end{array}$ & $\begin{array}{l}+1 \\
5 \\
0\end{array}$ & $\begin{array}{l}m \\
\stackrel{2}{7} \\
\vdots \\
i\end{array}$ & $\begin{array}{l} \\
\text { กิ } \\
0 \\
0\end{array}$ & $\begin{array}{l}\text { సे } \\
0 \\
0\end{array}$ & $\begin{array}{l}\text { त̂. } \\
\text { o }\end{array}$ & $\begin{array}{l}\hat{A} \\
\vdots \\
0\end{array}$ \\
\hline 8 & $\stackrel{m}{0}$ & $\begin{array}{l}5 \\
0 \\
0\end{array}$ & $\begin{array}{l}10 \\
\text { 웅 }\end{array}$ & \begin{tabular}{l|l}
$\infty$ \\
$\infty$ \\
0
\end{tabular} & $\begin{array}{l}0 \\
0 \\
0\end{array}$ & $\begin{array}{l}0 \\
8 \\
0\end{array}$ & $\begin{array}{l}\hat{\tilde{m}} \\
0\end{array}$ & $\begin{array}{l}\text { s. } \\
0 \\
0\end{array}$ & सُ & $\begin{array}{l}8 \\
0 \\
0\end{array}$ & $\begin{array}{l} \\
8 \\
0\end{array}$ & $\begin{array}{l}5 \\
0 \\
0\end{array}$ \\
\hline$\infty$ & $\begin{array}{c}\stackrel{9}{+} \\
\stackrel{4}{6}\end{array}$ & $\begin{array}{l}\mathbb{N} \\
\hat{0} \\
0\end{array}$ & $\begin{array}{l}\text { Iี } \\
\text { కొ }\end{array}$ & $\begin{array}{l}0 \\
0 \\
0 \\
0\end{array}$ & $\begin{array}{l}+1 \\
\vdots \\
0 \\
0\end{array}$ & $\begin{array}{l}10 \\
\Upsilon \\
0 \\
0\end{array}$ & $\begin{array}{l}1 \\
5 \\
0 \\
0\end{array}$ & $\begin{array}{l} \\
0 \\
0 \\
0 \\
0\end{array}$ & $\begin{array}{l}1 \\
5 \\
0 \\
0\end{array}$ & $\begin{array}{l}0 \\
\text { ถి } \\
0 \\
0\end{array}$ & 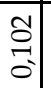 & $\begin{array}{l}R \\
0 \\
0 \\
0\end{array}$ \\
\hline \begin{tabular}{l}
$\circ$ \\
\multirow{2}{*}{} \\
0
\end{tabular} & 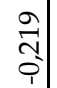 & 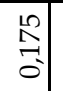 & $\begin{array}{l}\vec{b} \\
0 \\
0\end{array}$ & 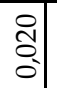 & $\begin{array}{l}\overline{1} \\
0 \\
0\end{array}$ & $\begin{array}{l}\infty \\
0 \\
0 \\
0\end{array}$ & $\begin{array}{l}\mid \\
0 \\
0 \\
0\end{array}$ & $\begin{array}{l}10 \\
\stackrel{2}{0} \\
\mathbf{9}\end{array}$ & $\begin{array}{l}\text { f } \\
\text { Oे } \\
0 \\
0\end{array}$ & 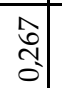 & \begin{tabular}{l|} 
\\
0 \\
0 \\
0
\end{tabular} & 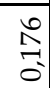 \\
\hline ঃ & $\begin{array}{l}10 \\
\stackrel{10}{6}\end{array}$ & $\begin{array}{l}0 \\
0 \\
0\end{array}$ & $\begin{array}{l}0 \\
0 \\
0\end{array}$ & $\begin{array}{l}8 \\
8 \\
0\end{array}$ & $\begin{array}{l}8 \\
0 \\
0\end{array}$ & $\begin{array}{l} \\
8 \\
0\end{array}$ & $\begin{array}{l}0 \\
0 \\
0\end{array}$ & $\begin{array}{l}\mathrm{a} \\
0 \\
0\end{array}$ & $\begin{array}{l}3 \\
7 \\
0\end{array}$ & $\begin{array}{l}0 \\
8 \\
0\end{array}$ & $\begin{array}{l} \\
\\
0\end{array}$ & 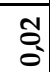 \\
\hline 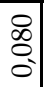 & $\begin{array}{l}\mid \mathfrak{a} \\
\stackrel{9}{6} \\
0\end{array}$ & $\begin{array}{l}\text { H' } \\
0 \\
0 \\
0\end{array}$ & \begin{tabular}{l}
3 \\
\multirow{3}{*}{} \\
0 \\
0
\end{tabular} & $\begin{array}{l} \\
0 \\
0 \\
0\end{array}$ & $\begin{array}{l}0 \\
5 \\
0 \\
0\end{array}$ & $\begin{array}{l}10 \\
\text { \% } \\
0 \\
0\end{array}$ & $\begin{array}{l} \\
0 \\
0 \\
0\end{array}$ & $\begin{array}{l}\text { के } \\
\text { के } \\
0\end{array}$ & $\begin{array}{l}0 \\
0 \\
0 \\
0\end{array}$ & $\begin{array}{l}0 \\
\text { ถે̊ } \\
0\end{array}$ & $\begin{array}{l}\overrightarrow{0} \\
\overrightarrow{0}\end{array}$ & $\begin{array}{l}\text { R } \\
\text { O } \\
0\end{array}$ \\
\hline 공 & 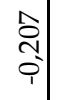 & $\begin{array}{l}+ \\
8 \\
0\end{array}$ & $\begin{array}{l}8 \\
8 \\
0\end{array}$ & $\begin{array}{c}\hat{\mathrm{n}} \\
\mathrm{N} \\
0\end{array}$ & 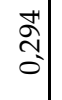 & $\begin{array}{l}0 \\
0 \\
0 \\
0\end{array}$ & $\begin{array}{l}0 \\
\infty \\
-1 \\
1\end{array}$ & 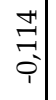 & $\begin{array}{l}7 \\
0 \\
0 \\
0\end{array}$ & 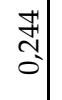 & 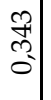 & $\begin{array}{l}18 \\
6 \\
0\end{array}$ \\
\hline ひ & 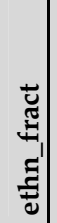 & 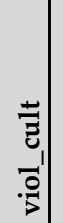 & है. & $\begin{array}{l}\bar{u} \\
0 \\
0 \\
0 \\
0 \\
0 \\
0 \\
0\end{array}$ & 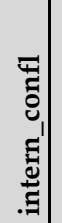 & 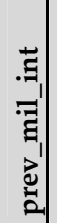 & 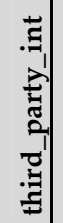 & 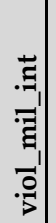 & $\begin{array}{l}0 \\
0 \\
0 \\
0 \\
0 \\
\vdots \\
. \\
. \\
.\end{array}$ & 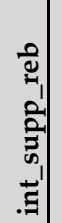 & 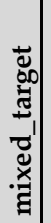 & $\Xi$ \\
\hline
\end{tabular}

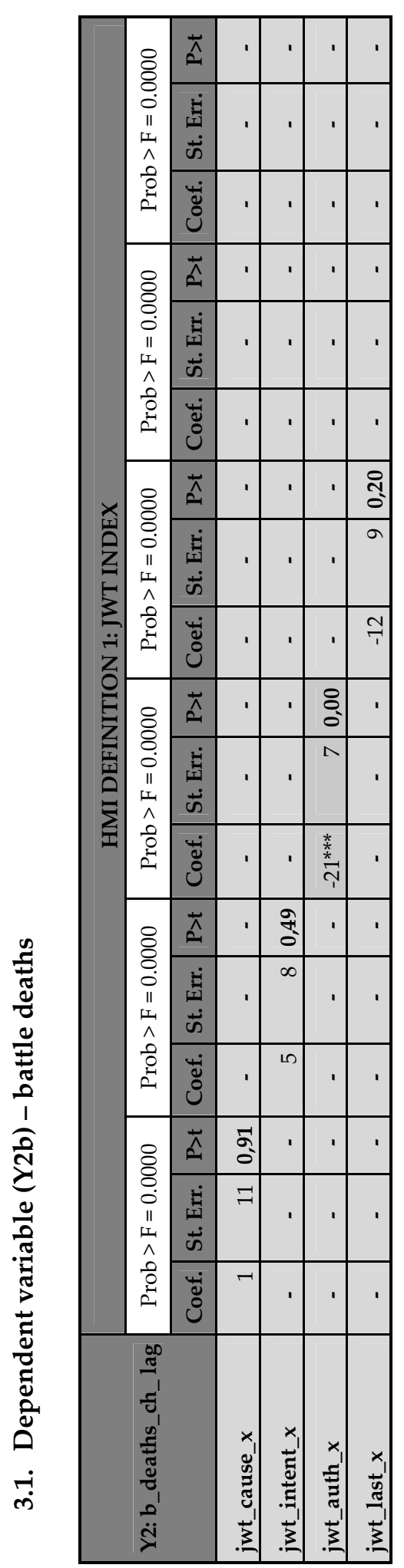




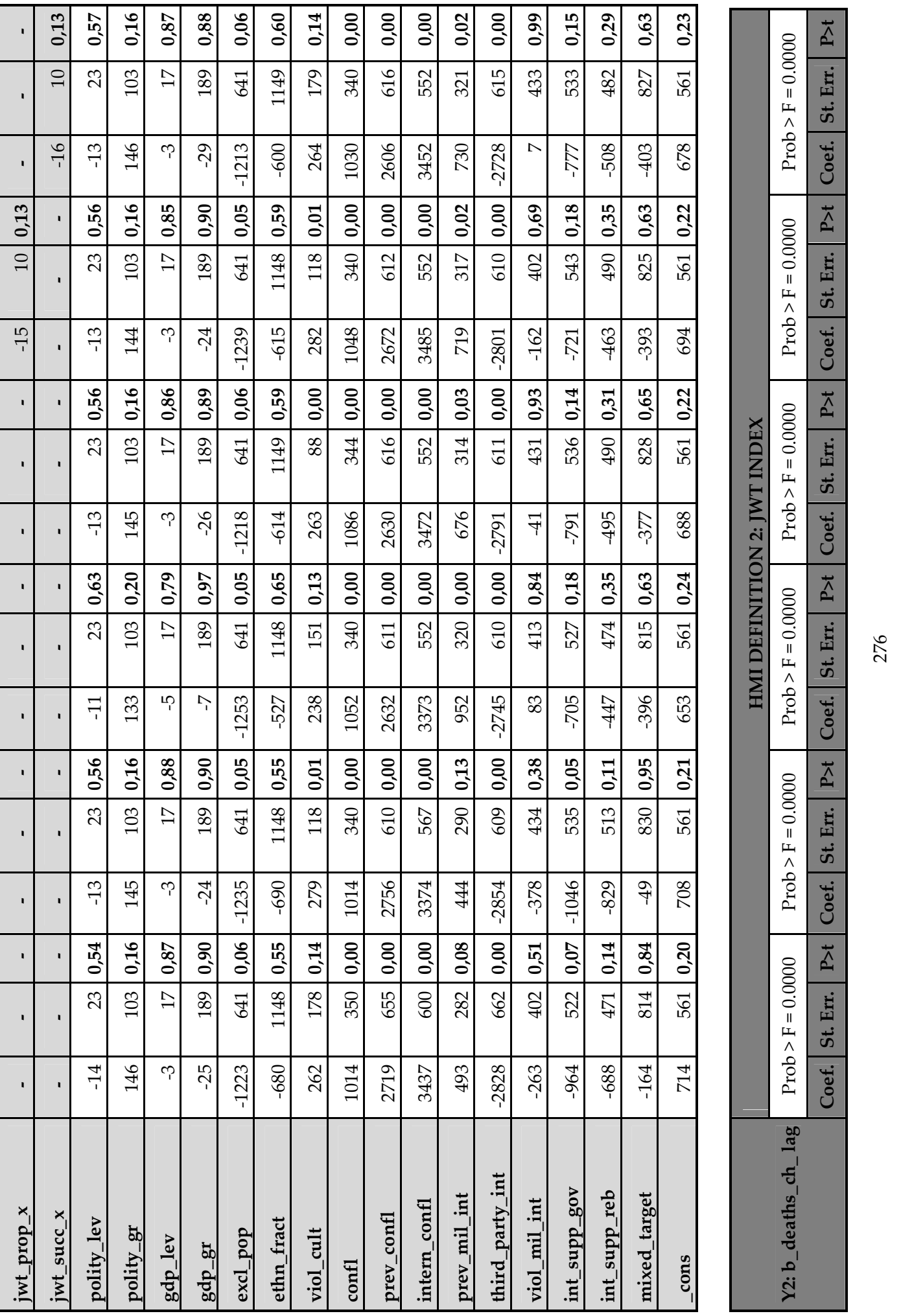




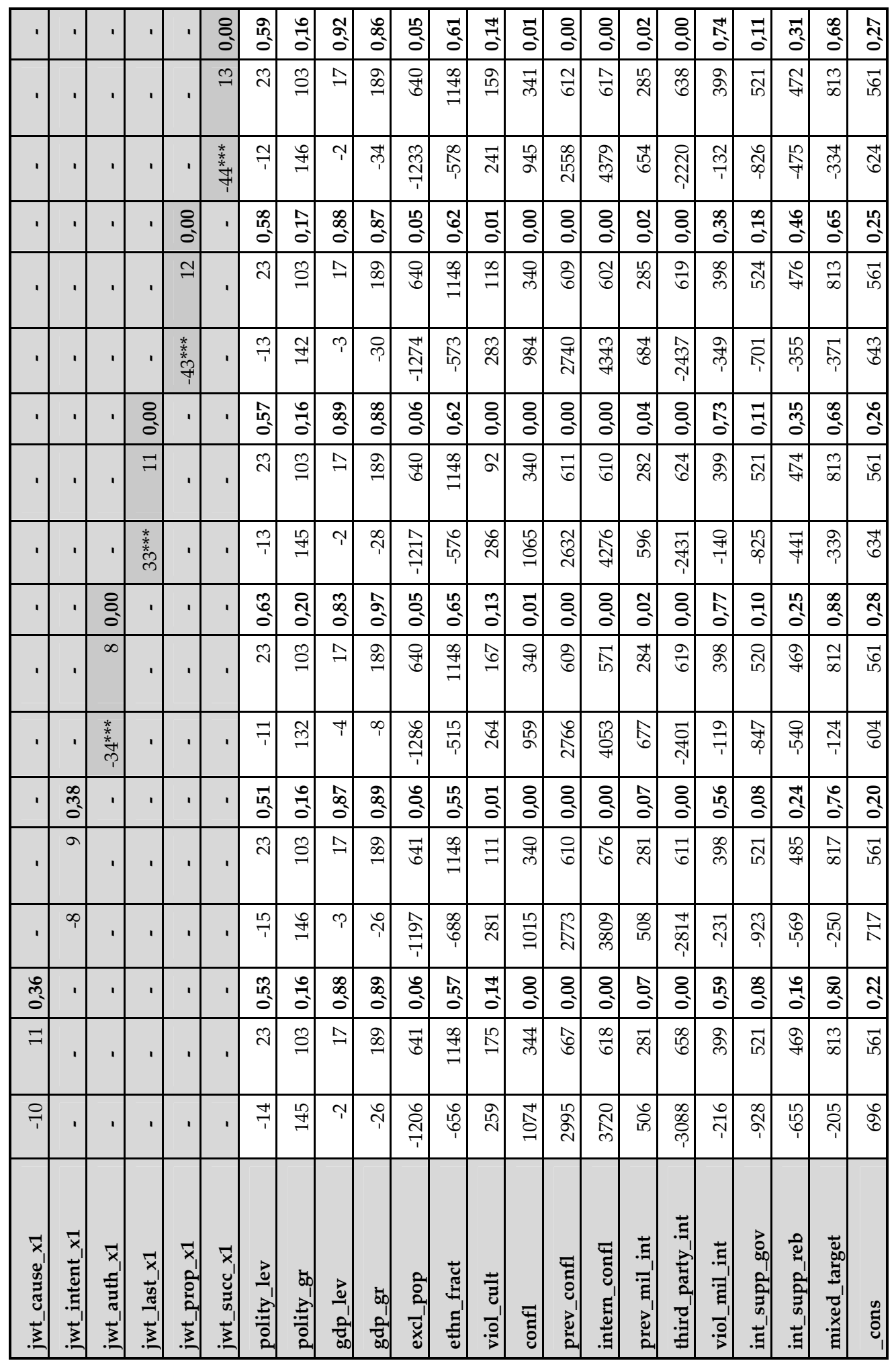




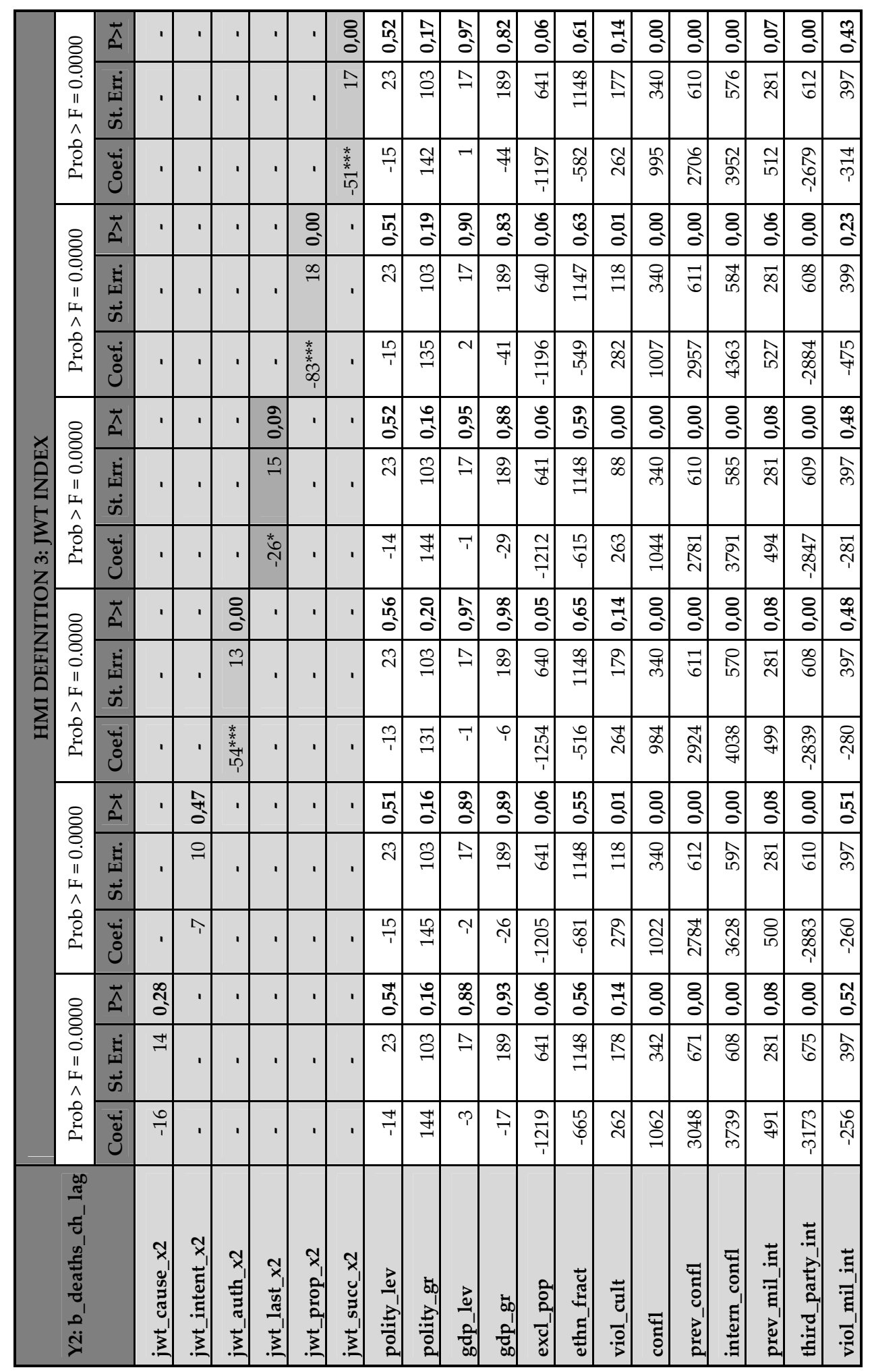




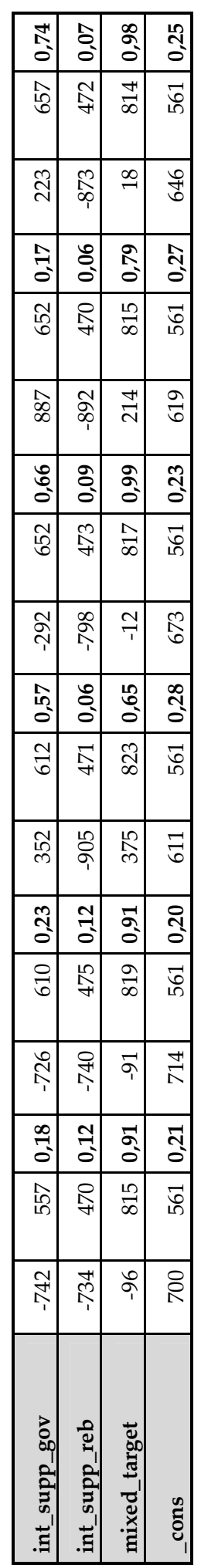




\section{Sample of military interventions selected as candidates for being awarded the label 'humanitarian'}

Selection procedure:

- 'Humanitarian motives and means' $=$ jwt_x.. $>23,57$ (since the maximum achieved JWT score equals 47,14)

- 'Humanitarian outcomes' = b_deaths_ch_lag $<0$ u deaths_ch_lag $<0$

Sample of the cases fulfilling both conditions (using the additional criteria associated with the individual HMI definitions):

\begin{tabular}{|l|r|r|r|r|l|}
\hline \multicolumn{7}{|c|}{ SAMPLE OF THE CANDIDATES FOR A 'LEGITIMATE HMI' } \\
\hline \multicolumn{7}{|c|}{ CONFLICT DEATHS (Y1) } \\
\hline Name & COW ccode & Year & JWT_X & \multicolumn{1}{l|}{ JWT_X1 } & JWT_X2 \\
\hline El Salvador & 92 & 1982 & $-0,02$ & $-0,02$ & - \\
\hline El Salvador & 92 & 1983 & $-0,02$ & $-0,02$ & - \\
\hline Moldova & 359 & 1992 & $-0,06$ & $-0,06$ & - \\
\hline Liberia & 450 & 1990 & $-1,05$ & $-1,05$ & $-1,05$ \\
\hline Sierra Leone & 451 & 1991 & $-0,33$ & - & - \\
\hline Congo & 484 & 1997 & $-0,69$ & - & - \\
\hline Congo, Dem. Rep. & 490 & 1993 & $-0,37$ & - & - \\
\hline Congo, Dem. Rep. & 490 & 1996 & $-0,59$ & - & - \\
\hline Congo, Dem. Rep. & 490 & 1997 & $-0,59$ & $-0,59$ & - \\
\hline Congo, Dem. Rep. & 490 & 1998 & $-0,59$ & $-0,59$ & $-0,59$ \\
\hline Congo, Dem. Rep. & 490 & 1999 & $-0,59$ & $-0,59$ & $-0,59$ \\
\hline Uganda & 500 & 1976 & $-0,13$ & - & - \\
\hline Uganda & 500 & 1978 & $-0,13$ & $-0,13$ & - \\
\hline Uganda & 500 & 1979 & $-0,13$ & $-0,13$ & $-0,13$ \\
\hline Uganda & 500 & 1980 & $-0,10$ & $-0,10$ & - \\
\hline Uganda & 500 & 1981 & $-0,10$ & $-0,10$ & - \\
\hline Uganda & 500 & 1994 & $-0,54$ & - & - \\
\hline Uganda & 500 & 1996 & $-0,85$ & $-0,85$ & - \\
\hline Uganda & 500 & 1998 & $-0,85$ & $-0,85$ & - \\
\hline Rwanda & 517 & 1990 & $-4,08$ & $-4,08$ & $-4,08$ \\
\hline Rwanda & 517 & 1991 & $-4,08$ & $-4,08$ & $-4,08$ \\
\hline
\end{tabular}




\begin{tabular}{|c|c|c|c|c|c|}
\hline Rwanda & 517 & 1993 & $-4,08$ & $-4,08$ & $-4,08$ \\
\hline Rwanda & 517 & 1994 & $-4,08$ & $-4,08$ & $-4,08$ \\
\hline Somalia & 520 & 1992 & $-0,97$ & $-0,97$ & - \\
\hline Somalia & 520 & 1993 & $-0,97$ & $-0,97$ & - \\
\hline Somalia & 520 & 1994 & $-0,97$ & $-0,97$ & - \\
\hline Zambia & 551 & 1987 & $-0,20$ & $-0,20$ & - \\
\hline Iraq & 645 & 1991 & $-1,12$ & $-1,12$ & - \\
\hline Iraq & 645 & 1992 & $-1,12$ & $-1,12$ & - \\
\hline Iraq & 645 & 1993 & $-1,12$ & $-1,12$ & - \\
\hline Iraq & 645 & 1994 & $-1,12$ & $-1,12$ & - \\
\hline Iraq & 645 & 1996 & $-0,13$ & $-0,13$ & - \\
\hline Iraq & 645 & 1997 & $-0,13$ & $-0,13$ & - \\
\hline Iraq & 645 & 2003 & $-0,35$ & - & - \\
\hline Iraq & 645 & 2005 & $-0,35$ & $-0,35$ & - \\
\hline Afghanistan & 700 & 1979 & $-0,92$ & $-0,92$ & $-0,92$ \\
\hline Afghanistan & 700 & 1980 & $-5,86$ & $-5,86$ & $-5,86$ \\
\hline Afghanistan & 700 & 1981 & $-5,86$ & $-5,86$ & $-5,86$ \\
\hline Afghanistan & 700 & 1982 & $-5,86$ & $-5,86$ & $-5,86$ \\
\hline Afghanistan & 700 & 1983 & $-5,86$ & $-5,86$ & $-5,86$ \\
\hline Afghanistan & 700 & 1984 & $-5,86$ & $-5,86$ & $-5,86$ \\
\hline Afghanistan & 700 & 1985 & $-5,10$ & $-5,10$ & $-5,10$ \\
\hline Afghanistan & 700 & 1986 & $-5,10$ & $-5,10$ & $-5,10$ \\
\hline Afghanistan & 700 & 1987 & $-5,10$ & $-5,10$ & $-5,10$ \\
\hline Afghanistan & 700 & 1988 & $-5,10$ & $-5,10$ & $-5,10$ \\
\hline Afghanistan & 700 & 1989 & $-5,10$ & $-5,10$ & - \\
\hline Tajikistan & 702 & 1992 & $-0,05$ & - & - \\
\hline Cambodia & 811 & 1970 & $-1,02$ & $-1,02$ & - \\
\hline Cambodia & 811 & 1971 & $-1,02$ & $-1,02$ & - \\
\hline Cambodia & 811 & 1972 & $-1,02$ & $-1,02$ & - \\
\hline Cambodia & 811 & 1973 & $-1,02$ & $-1,02$ & - \\
\hline Cambodia & 811 & 1974 & $-1,02$ & $-1,02$ & - \\
\hline Cambodia & 811 & 1975 & $-1,82$ & $-1,82$ & - \\
\hline Cambodia & 811 & 1976 & $-1,82$ & $-1,82$ & - \\
\hline Cambodia & 811 & 1977 & $-1,82$ & $-1,82$ & - \\
\hline Cambodia & 811 & 1978 & $-1,82$ & $-1,82$ & - \\
\hline Cambodia & 811 & 1979 & $-1,82$ & $-1,82$ & - \\
\hline
\end{tabular}




\begin{tabular}{|c|c|c|c|c|c|}
\hline \multicolumn{6}{|c|}{ BATTLE DEATHS (Y2) } \\
\hline Name & COW ccode & Year & JWT_X & JWT_X1 & JWT_X2 \\
\hline Cuba & 40 & 1958 & -4500 & -4500 & -4500 \\
\hline Dominican Republic & 42 & 1965 & -3276 & -3276 & -3276 \\
\hline Guatemala & 90 & 1987 & -500 & -500 & -500 \\
\hline Guatemala & 90 & 1992 & -1200 & -1200 & - \\
\hline El Salvador & 92 & 1983 & -3000 & -3000 & - \\
\hline El Salvador & 92 & 1989 & -4800 & -4800 & - \\
\hline Nicaragua & 93 & 1979 & -7000 & -7000 & - \\
\hline Nicaragua & 93 & 1985 & -1000 & -1000 & - \\
\hline Nicaragua & 93 & 1987 & -3300 & -3300 & - \\
\hline Nicaragua & 93 & 1988 & -2900 & -2900 & - \\
\hline Costa Rica & 94 & 1948 & -2000 & -2000 & -2000 \\
\hline Peru & 135 & 1995 & -395 & -395 & - \\
\hline Peru & 135 & 1997 & -62 & -62 & - \\
\hline Bolivia & 145 & 1967 & -82 & -82 & - \\
\hline United Kingdom & 200 & 1979 & -41 & -41 & -41 \\
\hline Hungary & 310 & 1956 & -2854 & -2854 & -2854 \\
\hline Bosnia and Herzegovina & 346 & 1993 & -23575 & -23575 & -23575 \\
\hline Bosnia and Herzegovina & 346 & 1994 & -950 & -950 & -950 \\
\hline Bosnia and Herzegovina & 346 & 1995 & -1250 & -1250 & -1250 \\
\hline Greece & 350 & 1949 & -38500 & -38500 & - \\
\hline Cyprus & 352 & 1974 & -4350 & -4350 & - \\
\hline Moldova & 359 & 1992 & -650 & -650 & - \\
\hline Georgia & 372 & 1993 & -2049 & -2049 & -2049 \\
\hline Azerbaijan & 373 & 1993 & -60 & -60 & -60 \\
\hline Azerbaijan & 373 & 1994 & -6320 & -6320 & - \\
\hline Guinea-Bissau & 404 & 1998 & -150 & - & - \\
\hline Equatorial Guinea & 411 & 1979 & -185 & -185 & -185 \\
\hline Mali & 432 & 1985 & -5 & - & - \\
\hline Sierra Leone & 451 & 2000 & -400 & -400 & -400 \\
\hline Nigeria & 475 & 1969 & -26612 & -26612 & -26612 \\
\hline Nigeria & 475 & 1970 & -2420 & -2420 & -2420 \\
\hline Chad & 483 & 1983 & -185 & -185 & -185 \\
\hline Chad & 483 & 1987 & -4250 & -4250 & -4250 \\
\hline Chad & 483 & 1988 & -1920 & -1920 & - \\
\hline
\end{tabular}




\begin{tabular}{|c|c|c|c|c|c|}
\hline Chad & 483 & 1992 & -400 & -400 & -400 \\
\hline Congo & 484 & 1997 & -5383 & - & - \\
\hline Congo, Dem. Re. & 490 & 1961 & -423 & -423 & - \\
\hline Congo, Dem. Re. & 490 & 1965 & -14983 & -14983 & -14983 \\
\hline Congo, Dem. Re. & 490 & 1967 & -778 & -778 & -778 \\
\hline Congo, Dem. Re. & 490 & 1978 & -593 & -593 & -593 \\
\hline Congo, Dem. Re. & 490 & 2000 & -47134 & -47134 & -47134 \\
\hline Congo, Dem. Re. & 490 & 2001 & -900 & -900 & -900 \\
\hline Uganda & 500 & 1979 & -3098 & -3098 & -3098 \\
\hline Uganda & 500 & 1989 & -300 & -300 & - \\
\hline Uganda & 500 & 1996 & -250 & -250 & - \\
\hline Uganda & 500 & 1998 & -300 & -300 & - \\
\hline Rwanda & 517 & 1993 & -200 & -200 & -200 \\
\hline Rwanda & 517 & 1994 & -700 & -700 & -700 \\
\hline Rwanda & 517 & 1998 & -1400 & -1400 & -1400 \\
\hline Somalia & 520 & 1964 & -350 & - & - \\
\hline Somalia & 520 & 1978 & -520 & - & - \\
\hline Somalia & 520 & 1983 & -376 & -376 & - \\
\hline Somalia & 520 & 1992 & -3050 & -3050 & - \\
\hline Somalia & 520 & 1993 & -350 & -350 & - \\
\hline Ethiopia (-1992) & 530 & 1964 & -349 & -349 & - \\
\hline Ethiopia (-1992) & 530 & 1978 & -18300 & -18300 & -18300 \\
\hline Ethiopia (-1992) & 530 & 1983 & -376 & -376 & -376 \\
\hline Angola & 540 & 1976 & -2967 & -2967 & -2967 \\
\hline Angola & 540 & 1991 & -2559 & -2559 & - \\
\hline Angola & 540 & 1994 & -19300 & -19300 & - \\
\hline Angola & 540 & 1995 & -725 & -725 & -725 \\
\hline Angola & 540 & 2000 & -2250 & -2250 & -2250 \\
\hline Mozambique & 541 & 1988 & -17500 & -17500 & -17500 \\
\hline Mozambique & 541 & 1992 & -1000 & -1000 & - \\
\hline Zimbabwe & 552 & 1978 & -610 & -610 & -610 \\
\hline Zimbabwe & 552 & 1979 & -9397 & -9397 & -9397 \\
\hline Comoros & 581 & 1989 & -27 & -27 & - \\
\hline Morocco & 600 & 1976 & -150 & -150 & -150 \\
\hline Morocco & 600 & 1977 & -50 & -50 & -50 \\
\hline Sudan & 625 & 1971 & -38 & -38 & -38 \\
\hline
\end{tabular}




\begin{tabular}{|c|c|c|c|c|c|}
\hline Sudan & 625 & 1997 & -3500 & -3500 & - \\
\hline Sudan & 625 & 1998 & -1500 & -1500 & - \\
\hline Sudan & 625 & 2004 & -2753 & -2753 & - \\
\hline Iran & 630 & 1982 & -5000 & -5000 & - \\
\hline Iran & 630 & 1983 & -15550 & -15550 & - \\
\hline Iran & 630 & 1984 & -750 & -750 & - \\
\hline Iran & 630 & 1988 & -34225 & -34225 & - \\
\hline Turkey & 640 & 1974 & -1450 & -1450 & - \\
\hline Iraq & 645 & 1969 & -500 & -500 & - \\
\hline Iraq & 645 & 1974 & -217 & -217 & -217 \\
\hline Iraq & 645 & 1975 & -8075 & -8075 & -8075 \\
\hline Iraq & 645 & 1983 & -15615 & -15615 & - \\
\hline Iraq & 645 & 1984 & -25 & -25 & - \\
\hline Iraq & 645 & 1987 & -36 & -36 & - \\
\hline Iraq & 645 & 1988 & -32225 & -32225 & - \\
\hline Iraq & 645 & 1991 & -39322 & -39322 & - \\
\hline Iraq & 645 & 1992 & -400 & -400 & - \\
\hline Iraq & 645 & 1996 & -1500 & -1500 & - \\
\hline Iraq & 645 & 2003 & -500 & - & - \\
\hline Iraq & 645 & 2005 & -1400 & -1400 & - \\
\hline Egypt & 651 & 1948 & -6970 & - & - \\
\hline Egypt & 651 & 1967 & -2703 & - & - \\
\hline Egypt & 651 & 1970 & -2130 & -2130 & -2130 \\
\hline Egypt & 651 & 1973 & -5225 & - & - \\
\hline Syria & 652 & 1966 & -300 & - & - \\
\hline Lebanon & 660 & 1976 & -54500 & -54500 & -54500 \\
\hline Lebanon & 660 & 1978 & -3500 & -3500 & -3500 \\
\hline Lebanon & 660 & 1982 & -23000 & -23000 & -23000 \\
\hline Lebanon & 660 & 1986 & -5700 & -5700 & -5700 \\
\hline Jordan & 663 & 1948 & -6970 & - & - \\
\hline Israel & 666 & 1948 & -6804 & -6804 & - \\
\hline Israel & 666 & 1949 & -33 & -33 & - \\
\hline Israel & 666 & 1967 & -1153 & -1153 & - \\
\hline Israel & 666 & 1973 & -2317 & -2317 & - \\
\hline Israel & 666 & 1974 & -398 & -398 & - \\
\hline Yemen, North & 678 & 1964 & -7034 & -7034 & -7034 \\
\hline
\end{tabular}




\begin{tabular}{|c|c|c|c|c|c|}
\hline Yemen, North & 678 & 1968 & -7033 & -7033 & -7033 \\
\hline Yemen, North & 678 & 1970 & -867 & -867 & -867 \\
\hline Yemen, North & 678 & 1979 & -63 & -63 & - \\
\hline Yemen, South & 680 & 1979 & -163 & -163 & - \\
\hline Kuwait & 690 & 1991 & -8474 & -8474 & -8474 \\
\hline Oman & 698 & 1975 & -500 & -500 & -500 \\
\hline Afghanistan & 700 & 1980 & -5000 & -5000 & -5000 \\
\hline Afghanistan & 700 & 1984 & -15000 & -15000 & -15000 \\
\hline Afghanistan & 700 & 1985 & -5000 & -5000 & -5000 \\
\hline Afghanistan & 700 & 1986 & -15000 & -15000 & -15000 \\
\hline Afghanistan & 700 & 1987 & -15000 & -15000 & -15000 \\
\hline Afghanistan & 700 & 1988 & -15000 & -15000 & -15000 \\
\hline Afghanistan & 700 & 1989 & -8000 & -8000 & - \\
\hline Afghanistan & 700 & 1992 & -4000 & -4000 & - \\
\hline Afghanistan & 700 & 1994 & -5000 & -5000 & - \\
\hline Afghanistan & 700 & 1996 & -2000 & -2000 & - \\
\hline Afghanistan & 700 & 1998 & -5000 & -5000 & - \\
\hline Afghanistan & 700 & 2001 & -1000 & -1000 & -1000 \\
\hline China & 710 & 1950 & -5180 & -5180 & - \\
\hline China & 710 & 1959 & -67000 & -67000 & - \\
\hline China & 710 & 1967 & -13 & - & - \\
\hline China & 710 & 1969 & -62 & - & - \\
\hline Taiwan & 713 & 1950 & -720 & -720 & - \\
\hline Korea, North & 731 & 1951 & -388992 & -388992 & -388992 \\
\hline Korea, North & 731 & 1952 & -25096 & -25096 & -25096 \\
\hline Korea, North & 731 & 1953 & -25096 & -25096 & -25096 \\
\hline Korea, South & 732 & 1950 & -251962 & -251962 & -251962 \\
\hline Korea, South & 732 & 1952 & -37645 & - & - \\
\hline Korea, South & 732 & 1953 & -37644 & -37644 & -37644 \\
\hline India & 750 & 1948 & -3700 & -3700 & - \\
\hline India & 750 & 1971 & -5612 & -5612 & - \\
\hline India & 750 & 1991 & -1434 & -1434 & - \\
\hline India & 750 & 1993 & -2229 & -2229 & - \\
\hline Pakistan (1972-) & 770 & 1948 & -3750 & - & - \\
\hline Pakistan (1972-) & 770 & 1971 & -55612 & -55612 & - \\
\hline Pakistan (1972-) & 770 & 1984 & -38 & - & - \\
\hline
\end{tabular}




\begin{tabular}{|c|c|c|c|c|c|}
\hline Pakistan (1972-) & 770 & 1987 & -50 & - & - \\
\hline Myanmar & 775 & 1969 & -243 & -243 & - \\
\hline Myanmar & 775 & 1970 & -1000 & -1000 & - \\
\hline Thailand & 800 & 1976 & -414 & -414 & -414 \\
\hline Thailand & 800 & 1978 & -667 & -667 & -667 \\
\hline Thailand & 800 & 1979 & -48 & -48 & -48 \\
\hline Thailand & 800 & 1980 & -507 & -507 & -507 \\
\hline Cambodia & 811 & 1975 & -60000 & -60000 & - \\
\hline Cambodia & 811 & 1978 & -37 & -37 & - \\
\hline Cambodia & 811 & 1979 & -29079 & -29079 & - \\
\hline Cambodia & 811 & 1986 & -2472 & -2472 & - \\
\hline Cambodia & 811 & 1987 & -750 & -750 & - \\
\hline Laos & 812 & 1961 & -1667 & -1667 & -1667 \\
\hline Laos & 812 & 1973 & -1682 & -1682 & -1682 \\
\hline Laos & 812 & 1988 & -168 & -168 & -168 \\
\hline Vietnam & 816 & 1968 & -29933 & -29933 & - \\
\hline Vietnam & 816 & 1969 & -29744 & -29744 & - \\
\hline Vietnam & 816 & 1970 & -7594 & -7594 & - \\
\hline Vietnam & 816 & 1974 & -75476 & -75476 & - \\
\hline Vietnam & 816 & 1975 & -10690 & -10690 & - \\
\hline Vietnam & 816 & 1977 & -878 & -878 & - \\
\hline Vietnam & 816 & 1979 & -31360 & -31360 & - \\
\hline Vietnam & 816 & 1987 & -1890 & -1890 & - \\
\hline Vietnam, South & 817 & 1964 & -4770 & -4770 & -4770 \\
\hline Vietnam, South & 817 & 1968 & -29933 & -29933 & -29933 \\
\hline Vietnam, South & 817 & 1969 & -29744 & -29744 & -29744 \\
\hline Vietnam, South & 817 & 1970 & -7594 & -7594 & -7594 \\
\hline Vietnam, South & 817 & 1974 & -75643 & -75643 & - \\
\hline Vietnam, South & 817 & 1975 & -10690 & -10690 & - \\
\hline Malaysia & 820 & 1957 & -107 & -107 & -107 \\
\hline Malaysia & 820 & 1958 & -141 & -141 & -141 \\
\hline Malaysia & 820 & 1959 & -12 & -12 & -12 \\
\hline Malaysia & 820 & 1960 & -13 & -13 & -13 \\
\hline Malaysia & 820 & 1966 & -61 & -61 & -61 \\
\hline Malaysia & 820 & 1975 & -100 & -100 & -100 \\
\hline Philippines & 840 & 1989 & -600 & -600 & -600 \\
\hline
\end{tabular}


TECHNICAL APPENDIX - TECHNICAL APPENDUM TECHNICALITIES OF THE DATA COMPILATION

\section{Variables included into the data compilation}

There are 587 variables included in the data compilation. Out of this amount, 163 variables were newly created by transforming the coding of the origina input variables.

The variables can be divided into the following four categories:

- Country-year data $(C D)$ - structural data $(S D)=>74$ variables

- Country-year data (CD) - conflict event data (ED) => 89 variables

- Country-year data (CD) - intervention event data (ED) $\Rightarrow 204$ variables

- Directed dyad-year data (DD) - structural, conflict event and intervention event data $(S D \& E D)=>220$ variables

\begin{tabular}{|c|c|c|c|}
\hline \multicolumn{4}{|c|}{ GENERAL DESCRIPTION OF THE INCLUDED VARIABLES } \\
\hline $\begin{array}{l}\text { Original dataset } \\
\text { name }\end{array}$ & $\begin{array}{c}\text { Number of variables (CD \& } \\
\text { DD) }\end{array}$ & $\begin{array}{l}\text { Number of new variables } \\
\text { (CD \& DD) }\end{array}$ & Data type \\
\hline EUGene SV & $18 \& 37$ & $0 \& 0$ & $\mathrm{SV}(\mathrm{CD} \& \mathrm{DD})$ \\
\hline UN Pop & 12 & 7 & $\mathrm{SV}(\mathrm{CD})$ \\
\hline UN SD & 2 & 1 & SV (CD) \\
\hline UN FAO & 1 & 0 & $\mathrm{SV}(\mathrm{CD})$ \\
\hline FDP & 3 & 0 & $\mathrm{SV}(\mathrm{CD})$ \\
\hline DEM & 14 & 0 & $\mathrm{SV}(\mathrm{CD})$ \\
\hline MAR & 7 & 3 & SV/ED (CD) \\
\hline QoG & 17 & 0 & $\mathrm{SV}(\mathrm{CD})$ \\
\hline MEPV & 3 & 0 & $\mathrm{ED}(\mathrm{CD})$ \\
\hline PITF & 23 & 16 & $\mathrm{ED}(\mathrm{CD})$ \\
\hline ACD & 14 & 7 & $\mathrm{ED}(\mathrm{CD})$ \\
\hline Regan & 50 & 9 & $\mathrm{ED}(\mathrm{CD})$ \\
\hline EUGene MID & $27 \& 54$ & $3 \& 0$ & $\mathrm{ED}(\mathrm{CD} \& \mathrm{DD})$ \\
\hline EUGene ICB & $22 \& 40$ & $0 \& 0$ & $\mathrm{ED}(\mathrm{CD} \& \mathrm{DD})$ \\
\hline ICB II & $31 \& 30$ & $19 \& 18$ & $\mathrm{ED}(\mathrm{CD} \& \mathrm{DD})$ \\
\hline ICB Dyad & $21 \& 20$ & $6 \& 5$ & $\mathrm{ED}(\mathrm{CD} \& \mathrm{DD})$ \\
\hline Mil Int & $39 \& 39$ & $34 \& 34$ & $\mathrm{ED}(\mathrm{CD} \& \mathrm{DD})$ \\
\hline Peace & 64 & 1 & $\mathrm{ED}(\mathrm{CD})$ \\
\hline
\end{tabular}




\section{Common identification procedure}

\subsection{Country coding}

The main country coding system applied in this data compilation is based on the Correlates of War (COW) country code (COW ccode) which has been developed by the COW Project to represent the world countries, the dependent territories, and the special areas of geographical interest. A precise description of this coding system is to be found in the COW State System Membership List (Version 2008.1) that is available online at: http://correlatesofwar.org. The COW ccode was selected as a key identification code for countries in this data compilation. Nevertheless, due to the extensive variety of country coding systems applied in the individual input datasets, one supplementary coding system was added aside the COW ccode system so as to ensure a greater flexibility of the data for the other potential enlargements of the compilation in the future. The additionally included country code system is the so-called UN country code (UN ccode) that was introduced by the United Nations Statistics Division. This system is almost identical with the three-digit and 3-letter country codes published by the International Organization for Standardization (ISO-3166-1 numeric, ISO-3166-1 alpha3). Nevertheless, the UN ccode includes five extra 'non-ISO' ccodes: Tibet (UN ccode 994), Zanzibar (UN ccode 995), pre-1971 Pakistan (UN ccode 997), Vietnam North (UN ccode 998), and Vietnam South (UN ccode 999).

\subsection{Country identification}

\subsubsection{Country-year data}

Sample of countries in the country-year part of the data was identified based on the Quality of Government (QoG) project country list. ${ }^{1}$ The original QoG country list covers all countries in the world recognized by the United Nations as of the year 2002 plus an addition of 13 historical nations. Among the historical nations belong: Taiwan, Tibet, Zanzibar, pre-1972 Pakistan (including Bangladesh), North and South Yemen, East and West Germany, pre-1992 Yugoslavia, the USSR, Czechoslovakia and Ethiopia pre-1993 (including Eritrea). Problematic identification of the countries that experienced some type of a territorial transformation was governed by the following two principles. First of all, whenever two countries merged into one; this newly created country was considered to represent a new case. There were just two exceptions to this rule:

\footnotetext{
1 Teorell, Holmberg \& Rothstein, 2007.
} 
Tanzania and Zanzibar, and China and Tibet (since they were not considered as being the separate countries before their occupation). Secondly, whenever a country splited up; all the new countries were considered to represent new cases. The only exception to this rule constituted Indonesia and East Timor.

Nevertheless, the QoG country list had to be slightly adjusted to simplify and unify the coding of the historical nations in the QoG country list, making it thus better combinable with the COW country list. As a result of these adjustments, the QoG country list that originally covered 204 countries ended up as covering a sample of only 200 countries. See an overview of the carried out adjustments:

- While Ethiopia is throughout the whole period of 1946-2005 coded as one country in the COW country list (COW ccode 530), it is divided into pre1992 Ethiopia (UN ccode 230, COW ccode 530) and post-1993 Ethiopia (UN ccode 231, COW ccode 530) in the QoG country list. So as to unify this distortion, Ethiopia was attached COW ccode 530 and UN ccode 230 for the entire period of its existence.

- Similarly, Pakistan is throughout the whole period of 1946-2005 coded as one country (COW ccode 770) in the COW country list, but it is treated as two countries in the QoG country list: pre-1971 Pakistan (UN ccode 997) and post-1972 Pakistan (UN ccode 586). The QoG country list was thus again adjusted according to the COW coding, by assigning to Pakistan a homogenous coding (COW ccode of 770, UN ccode 586).

- Additionally, while the QoG country list distinguishes between Serbia and Montenegro (UN ccode 891), and Yugoslavia (UN ccode 890); the COW country list codes the country under a common COW ccode 345. Here again, coding of the both countries was unified by a single code (COW ccode 345 , UN ccode 890).

- The final adjustment of the QoG country list concerned the USSR (UN ccode 810). The USSR that is originally included in the QoG country list was omitted from the country sample, since it is not treated as a country in most of the input datasets. Just Russia (COW ccode 365) was kept in both country lists.

\subsubsection{Directed country dyad-year data}

Country sample identification process in the directed country dyad-year part of the data compilation was based on the COW country list, ${ }^{2}$ which sets two criteria for identifying a country. First of all, the country has to have a population greater than 
500000; and must be sufficiently unencumbered by legal, military, economic, or political constraints to exercise a fair degree of sovereignty and independence. The second COW criterion is operationalized as a formal recognition of the country by any two major states or its membership in the United Nations. So as to avoid a possible mistake, the individual country dyads were generated by the Expected Utility Generation and Data Management Program (EUGene v.3.2). ${ }^{3}$ This software serves mainly as a computational tool for the creation of the expected utility data that enables application of the rational choice theory to the study of international conflict. Its ability to combine a number of original quantitative datasets and to transform them into various levels of analysis was repeatedly utilized during building of this data compilation. It can be downloaded from the following webpage: http://www.eugenesoftware.org.

Also the EUGene generated list of country dyads had to undergo certain adjustments. The sample of the dyads was expanded by including four artificial ccodes for interveners that did not intervene as single countries but formed the various types of multilateral operations. As a result of these modifications, instead of the EUGene generated sample of 199 countries composing 1258552 dyad-years, the country sample was increased to cover 203 entities composed into 1291832 dyads. See the list of the carried out adjustments:

- A new artificial ccode 1000 (UN) was added to represent the United Nations as the intervener.

- Next artificial ccode 2000 (NATO) was added to represent the North Atlantic Treaty Organization as the intervener.

- Other artificial ccode $3000(\mathrm{IO})$ was included to represent the interventions led by the international organizations dealing with international peacekeeping of a multinational nature other than the UN and the NATO. These institutions are, for example, ECOWAS, CEMAC, EU, COMESA, OAU, AU, ECOMOG, CIS, SADC, OAS, or Arab League.

- The last created artificial ccode was created to denote the multilateral operations carried out outside any established institutional structure. Interveners in such types of operations were assigned the ccode 4000 (Multilat).

\subsection{Country coding lists and their time coverage of the data compilation}

The following table represents the harmonized QoG and COW country lists together with their respective time coverage, which were used as a basis for

\footnotetext{
${ }^{3}$ Bennett \& Stam, 2000.
} 
country identification in both parts of the new data compilation. The table indicates individual country codes in both the COW and the UN versions, which were applied coherently in the whole data compilation.

\begin{tabular}{|c|c|c|c|c|c|c|}
\hline \multicolumn{5}{|c|}{ COUNTRY LISTS } & \multirow{2}{*}{$\begin{array}{c}\begin{array}{c}\text { Country-year } \\
\text { data }\end{array} \\
\begin{array}{c}\text { QoG - year } \\
\text { coverage }\end{array}\end{array}$} & \multirow{2}{*}{$\begin{array}{c}\text { Country dyad- } \\
\text { year data }\end{array}$} \\
\hline Country name & $\begin{array}{l}\text { COW } \\
\text { Ccode }\end{array}$ & $\begin{array}{l}\text { Cow } \\
\text { Ccode }\end{array}$ & $\begin{array}{c}\text { UN } \\
\text { Ccode }\end{array}$ & $\begin{array}{c}\text { UN } \\
\text { Ccode }\end{array}$ & & \\
\hline Albania & 339 & ALB & 8 & ALB & $1946-2005$ & 1946-2005 \\
\hline Algeria & 615 & ALG & 12 & DZA & $1946-2005$ & 1962-2005 \\
\hline Andorra & 232 & AND & 20 & AND & $1946-2005$ & 1993-2005 \\
\hline Angola & 540 & ANG & 24 & AGO & $1946-2005$ & 1975-2005 \\
\hline Antigua and Barbuda & 58 & $\mathrm{AAB}$ & 28 & ATG & $1946-2005$ & 1981-2005 \\
\hline Argentina & 160 & ARG & 32 & ARG & $1946-2005$ & 1946-2005 \\
\hline Armenia & 371 & ARM & 51 & ARM & $1946-2005$ & 1991-2005 \\
\hline Australia & 900 & AUL & 36 & AUS & $1946-2005$ & 1946-2005 \\
\hline Austria & 305 & AUS & 40 & AUT & 1946-2005 & 1955-2005 \\
\hline Azerbaijan & 373 & AZE & 31 & AZE & 1946-2005 & 1991-2005 \\
\hline Bahamas & 31 & BHM & 44 & BHS & $1946-2005$ & 1946-2005 \\
\hline Bahrain & 692 & $\mathrm{BAH}$ & 48 & BHR & 1946-2005 & 1971-2005 \\
\hline Bangladesh & 771 & BNG & 50 & BGD & $1946-2005$ & 1971-2005 \\
\hline Barbados & 53 & BAR & 52 & $\mathrm{BRB}$ & $1946-2005$ & 1966-2005 \\
\hline Belarus & 370 & BLR & 112 & BLR & 1946-2005 & 1991-2005 \\
\hline Belgium & 211 & BEL & 56 & BEL & $1946-2005$ & 1946-2005 \\
\hline Belize & 80 & BLZ & 84 & BLZ & 1946-2005 & 1946-2005 \\
\hline Benin & 434 & $\mathrm{BEN}$ & 204 & BEN & $1946-2005$ & $1960-2005$ \\
\hline Bhutan & 760 & $\mathrm{BHU}$ & 64 & BTN & 1946-2005 & 1971-2005 \\
\hline Bolivia & 145 & BOL & 68 & BOL & 1946-2005 & 1946-2005 \\
\hline Bosnia and Herzegovina & 346 & $\mathrm{BOS}$ & 70 & $\mathrm{BIH}$ & $1946-2005$ & 1992-2005 \\
\hline Botswana & 571 & BOT & 72 & BWA & 1946-2005 & 1966-2005 \\
\hline Brazil & 140 & BRA & 76 & BRA & $1946-2005$ & 1946-2005 \\
\hline Brunei Darussalam & 835 & BRU & 96 & BRN & 1946-2005 & 1984-2005 \\
\hline Bulgaria & 355 & BUL & 100 & BGR & 1946-2005 & 1946-2005 \\
\hline Burkina Faso & 439 & $\mathrm{BFO}$ & 854 & BFA & $1946-2005$ & $1960-2005$ \\
\hline Burundi & 516 & BUI & 108 & BDI & 1946-2005 & 1962-2005 \\
\hline
\end{tabular}




\begin{tabular}{|c|c|c|c|c|c|c|}
\hline Cambodia & 811 & CAM & 116 & KHM & 1946-2005 & 1953-2005 \\
\hline Cameroon & 471 & $\mathrm{CAO}$ & 120 & CMR & 1946-2005 & $1960-2005$ \\
\hline Canada & 20 & CAN & 124 & CAN & 1946-2005 & 1946-2005 \\
\hline Cape Verde & 402 & CAP & 132 & $\mathrm{CPV}$ & 1946-2005 & $1975-2005$ \\
\hline Central African Rep. & 482 & CEN & 140 & CAF & 1946-2005 & 1960-2005 \\
\hline Colombia & 100 & COL & 170 & COL & $1946-2005$ & 1946-2005 \\
\hline Comoros & 581 & $\mathrm{COM}$ & 174 & $\mathrm{COM}$ & 1946-2005 & $1975-2005$ \\
\hline Congo & 484 & $\mathrm{CON}$ & 178 & COG & 1946-2005 & $1960-2005$ \\
\hline Congo, Democratic Rep. & 490 & DRC & 180 & COD & 1946-2005 & 1960-2005 \\
\hline Costa Rica & 94 & COS & 188 & CRI & 1946-2005 & 1946-2005 \\
\hline Cote d'Ivoire & 437 & CDI & 384 & CIV & 1946-2005 & $1960-2005$ \\
\hline Croatia & 344 & $\mathrm{CRO}$ & 191 & HRV & 1946-2005 & 1992-2005 \\
\hline Cuba & 40 & CUB & 192 & CUB & 1946-2005 & 1946-2005 \\
\hline Cyprus & 352 & CYP & 196 & CYP & 1946-2005 & 1960-2005 \\
\hline Czech Republic & 316 & CZR & 203 & CZE & 1946-2005 & 1993-2005 \\
\hline Czechoslovakia & 315 & CZE & 200 & CSK & 1946-2005 & 1946-1992 \\
\hline Denmark & 390 & DEN & 208 & DNK & 1946-2005 & 1946-2005 \\
\hline Djibouti & 522 & DJI & 262 & DJI & 1946-2005 & $1977-2005$ \\
\hline Dominica & 54 & DMA & 212 & DMA & $1946-2005$ & 1978-2005 \\
\hline Dominican Republic & 42 & $\mathrm{DOM}$ & 214 & DOM & 1946-2005 & 1946-2005 \\
\hline East Timor & 860 & ETM & 626 & TLS & 1946-2005 & $2002-2005$ \\
\hline Ecuador & 130 & ECU & 218 & ECU & 1946-2005 & 1946-2005 \\
\hline Egypt & 651 & EGY & 818 & EGY & $1946-2005$ & $1946-2005$ \\
\hline El Salvador & 92 & SAL & 222 & SLV & 1946-2005 & 1946-2005 \\
\hline Equatorial Guinea & 411 & EQG & 226 & GNQ & 1946-2005 & 1968-2005 \\
\hline Eritrea & 531 & ERI & 232 & ERI & 1946-2005 & 1993-2005 \\
\hline Estonia & 366 & EST & 233 & EST & 1946-2005 & 1991-2005 \\
\hline Ethiopia (-1992) & 530 & ETH & 230 & ETH & 1946-2005 & 1946-2005 \\
\hline Ethiopia* & 530 & ETH & 231 & ETH & 1946-2005 & - \\
\hline Fiji & 950 & FIJ & 242 & FJI & 1946-2005 & 1970-2005 \\
\hline Finland & 375 & FIN & 246 & FIN & 1946-2005 & 1946-2005 \\
\hline France & 220 & FRN & 250 & FRA & 1946-2005 & 1946-2005 \\
\hline Gabon & 481 & GAB & 266 & GAB & 1946-2005 & 1960-2005 \\
\hline Gambia & 420 & GAM & 270 & GMB & 1946-2005 & 1965-2005 \\
\hline
\end{tabular}




\begin{tabular}{|c|c|c|c|c|c|c|}
\hline Georgia & 372 & GRG & 268 & GEO & 1946-2005 & 1991-2005 \\
\hline Germany & 255 & GMY & 276 & DEU & 1946-2005 & 1990-2005 \\
\hline Germany, East & 265 & GDR & 278 & DDR & 1946-2005 & 1954-1990 \\
\hline Germany, West & 260 & GFR & 280 & DEU & 1946-2005 & $1955-1990$ \\
\hline Ghana & 452 & GHA & 288 & GHA & 1946-2005 & 1957-2005 \\
\hline Greece & 350 & GRC & 300 & GRC & 1946-2005 & 1946-2005 \\
\hline Grenada & 55 & GRN & 308 & GRD & 1946-2005 & 1974-2005 \\
\hline Guatemala & 90 & GUA & 320 & GTM & 1946-2005 & 1946-2005 \\
\hline Guinea & 438 & GUI & 324 & GIN & 1946-2005 & 1958-2005 \\
\hline Guinea-Bissau & 404 & GNB & 624 & GNB & 1946-2005 & 1974-2005 \\
\hline Guyana & 110 & GUY & 328 & GUY & 1946-2005 & 1966-2005 \\
\hline Haiti & 41 & HAI & 332 & HTI & 1946-2005 & 1946-2005 \\
\hline Honduras & 91 & $\mathrm{HON}$ & 340 & HND & 1946-2005 & 1946-2005 \\
\hline Hungary & 310 & HUN & 348 & HUN & 1946-2005 & 1946-2005 \\
\hline Chad & 483 & $\mathrm{CHA}$ & 148 & TCD & 1946-2005 & 1960-2005 \\
\hline Chile & 155 & $\mathrm{CHL}$ & 152 & $\mathrm{CHL}$ & 1946-2005 & 1946-2005 \\
\hline China & 710 & $\mathrm{CHN}$ & 156 & $\mathrm{CHN}$ & 1946-2005 & 1946-2005 \\
\hline Iceland & 395 & ICE & 352 & ISL & 1946-2005 & 1946-2005 \\
\hline India & 750 & IND & 356 & IND & 1946-2005 & 1947-2005 \\
\hline Indonesia & 850 & INS & 360 & IDN & 1946-2005 & 1949-2005 \\
\hline Iran & 630 & IRN & 364 & IRN & 1946-2005 & 1946-2005 \\
\hline Iraq & 645 & IRQ & 368 & IRQ & 1946-2005 & 1946-2005 \\
\hline Ireland & 205 & IRE & 372 & IRL & 1946-2005 & 1946-2005 \\
\hline Israel & 666 & ISR & 376 & ISR & 1946-2005 & 1946-2005 \\
\hline Italy & 325 & ITA & 380 & ITA & 1946-2005 & 1946-2005 \\
\hline Jamaica & 51 & JAM & 388 & JAM & 1946-2005 & $1962-2005$ \\
\hline Japan & 740 & JPN & 392 & JPN & 1946-2005 & $1952-2005$ \\
\hline Jordan & 663 & JOR & 400 & JOR & 1946-2005 & 1946-2005 \\
\hline Kazakhstan & 705 & KZK & 398 & KAZ & 1946-2005 & 1991-2005 \\
\hline Kenya & 501 & KEN & 404 & KEN & 1946-2005 & 1963-2005 \\
\hline Kiribati & 946 & KIR & 296 & KIR & 1946-2005 & 1999-2005 \\
\hline Korea, North & 731 & PRK & 408 & PRK & 1946-2005 & 1948-2005 \\
\hline Korea, South & 732 & ROK & 410 & KOR & 1946-2005 & 1949-2005 \\
\hline Kuwait & 690 & KUW & 414 & KWT & 1946-2005 & 1961-2005 \\
\hline
\end{tabular}




\begin{tabular}{|c|c|c|c|c|c|c|}
\hline Kyrgyzstan & 703 & KYR & 417 & KGZ & 1946-2005 & 1991-2005 \\
\hline Laos & 812 & LAO & 418 & LAO & 1946-2005 & 1953-2005 \\
\hline Latvia & 367 & LAT & 428 & LVA & 1946-2005 & 1991-2005 \\
\hline Lebanon & 660 & LEB & 422 & LBN & 1946-2005 & 1946-2005 \\
\hline Lesotho & 570 & LES & 426 & LSO & 1946-2005 & 1966-2005 \\
\hline Liberia & 450 & LBR & 430 & LBR & 1946-2005 & 1946-2005 \\
\hline Libya & 620 & LIB & 434 & LBY & 1946-2005 & 1951-2005 \\
\hline Liechtenstein & 223 & LIE & 438 & LIE & 1946-2005 & 1990-2005 \\
\hline Lithuania & 368 & LIT & 440 & LTU & 1946-2005 & 1991-2005 \\
\hline Luxembourg & 212 & LUX & 442 & LUX & 1946-2005 & 1946-2005 \\
\hline Macedonia & 343 & MAC & 807 & MKD & 1946-2005 & 1993-2005 \\
\hline Madagascar & 580 & MAG & 450 & MDG & 1946-2005 & 1960-2005 \\
\hline Malawi & 553 & MAW & 454 & MWI & 1946-2005 & 1964-2005 \\
\hline Malaysia & 820 & MAL & 458 & MYS & 1946-2005 & 1957-2005 \\
\hline Maldives & 781 & MAD & 462 & MDV & 1946-2005 & 1965-2005 \\
\hline Mali & 432 & MLI & 466 & MLI & 1946-2005 & 1960-2005 \\
\hline Malta & 338 & MLT & 470 & MLT & 1946-2005 & 1964-2005 \\
\hline Marshall Islands & 983 & MSI & 584 & MHL & 1946-2005 & 1991-2005 \\
\hline Mauritania & 435 & MAA & 478 & MRT & 1946-2005 & 1960-2005 \\
\hline Mauritius & 590 & MAS & 480 & MUS & 1946-2005 & 1968-2005 \\
\hline Mexico & 70 & MEX & 484 & MEX & 1946-2005 & 1946-2005 \\
\hline Micronesia & 987 & FSM & 583 & FSM & 1946-2005 & 1991-2005 \\
\hline Moldova & 359 & MLD & 498 & MDA & 1946-2005 & 1991-2005 \\
\hline Monaco & 221 & MNC & 492 & $\mathrm{MCO}$ & 1946-2005 & 1993-2005 \\
\hline Mongolia & 712 & MON & 496 & MNG & 1946-2005 & 1946-2005 \\
\hline Morocco & 600 & MOR & 504 & MAR & 1946-2005 & 1956-2005 \\
\hline Mozambique & 541 & MZM & 508 & $\mathrm{MOZ}$ & 1946-2005 & 1975-2005 \\
\hline Myanmar & 775 & MYA & 104 & MMR & 1946-2005 & 1948-2005 \\
\hline Namibia & 565 & NAM & 516 & NAM & 1946-2005 & 1990-2005 \\
\hline Nauru & 970 & NAU & 520 & NRU & 1946-2005 & 1999-2005 \\
\hline Nepal & 790 & NEP & 524 & NPL & 1946-2005 & 1946-2005 \\
\hline Netherlands & 210 & NTH & 528 & NLD & 1946-2005 & 1946-2005 \\
\hline New Zealand & 920 & NEW & 554 & NZL & 1946-2005 & 1946-2005 \\
\hline Nicaragua & 93 & NIC & 558 & NIC & 1946-2005 & 1946-2005 \\
\hline
\end{tabular}




\begin{tabular}{|c|c|c|c|c|c|c|}
\hline Niger & 436 & NIR & 562 & NER & $1946-2005$ & 1960-2005 \\
\hline Nigeria & 475 & NIG & 566 & NGA & $1946-2005$ & 1960-2005 \\
\hline Norway & 385 & NOR & 578 & NOR & $1946-2005$ & 1946-2005 \\
\hline Oman & 698 & OMA & 512 & OMN & $1946-2005$ & 1971-2005 \\
\hline Pakistan $(-1971)^{*}$ & 770 & PAK & 997 & $P A K$ & $1946-2005$ & - \\
\hline Pakistan (1972-) & 770 & PAK & 586 & PAK & $1946-2005$ & $1947-2005$ \\
\hline Palau & 986 & PAL & 585 & PLW & 1946-2005 & 1994-2005 \\
\hline Panama & 95 & PAN & 591 & PAN & $1946-2005$ & 1946-2005 \\
\hline Papua New Guinea & 910 & PNG & 598 & PNG & $1946-2005$ & $1975-2005$ \\
\hline Paraguay & 150 & PAR & 600 & PRY & $1946-2005$ & 1946-2005 \\
\hline Peru & 135 & PER & 604 & PER & $1946-2005$ & 1946-2005 \\
\hline Philippines & 840 & PHI & 608 & PHL & $1946-2005$ & 1946-2005 \\
\hline Poland & 290 & POL & 616 & POL & $1946-2005$ & 1946-2005 \\
\hline Portugal & 235 & POR & 620 & PRT & $1946-2005$ & 1946-2005 \\
\hline Qatar & 694 & QAT & 634 & QAT & $1946-2005$ & 1971-2005 \\
\hline Romania & 360 & $\mathrm{ROM}$ & 642 & ROU & 1946-2005 & 1946-2005 \\
\hline Russia iii & 365 & RUS & 643 & RUS & $1946-2005$ & 1946-2005 \\
\hline Rwanda & 517 & RWA & 646 & RWA & 1946-2005 & $1962-2005$ \\
\hline Samoa & 990 & WSM & 882 & WSM & 1946-2005 & 1976-2005 \\
\hline San Marino & 331 & SNM & 674 & SMR & 1946-2005 & $1992-2005$ \\
\hline Sao Tome and Principe & 403 & STP & 678 & STP & 1946-2005 & 1975-2005 \\
\hline Saudi Arabia & 670 & SAU & 682 & SAU & 1946-2005 & 1946-2005 \\
\hline Senegal & 433 & SEN & 686 & SEN & 1946-2005 & 1960-2005 \\
\hline Serbia and Montenegro* & 345 & $S C G$ & 981 & $Y U G$ & $1946-2005$ & - \\
\hline Seychelles & 591 & SEY & 690 & SYC & $1946-2005$ & 1976-2005 \\
\hline Sierra Leone & 451 & SIE & 694 & SLE & 1946-2005 & 1961-2005 \\
\hline Singapore & 830 & SIN & 702 & SGP & 1946-2005 & 1965-2005 \\
\hline Slovakia & 317 & SLO & 703 & SVK & 1946-2005 & 1993-2005 \\
\hline Slovenia & 349 & SLV & 705 & SVN & 1946-2005 & $1992-2005$ \\
\hline Solomon Islands & 940 & SOL & 90 & SLB & 1946-2005 & 1978-2005 \\
\hline Somalia & 520 & $\mathrm{SOM}$ & 706 & $\mathrm{SOM}$ & 1946-2005 & 1960-2005 \\
\hline South Africa & 560 & SAF & 710 & ZAF & 1946-2005 & 1946-2005 \\
\hline Spain & 230 & SPN & 724 & ESP & 1946-2005 & 1946-2005 \\
\hline Sri Lanka & 780 & SRI & 144 & LKA & 1946-2005 & 1948-2005 \\
\hline
\end{tabular}




\begin{tabular}{|c|c|c|c|c|c|c|}
\hline St Kitts and Nevis & 60 & SKN & 659 & KNA & $1946-2005$ & 1983-2005 \\
\hline St Lucia & 56 & SLU & 662 & LCA & $1946-2005$ & 1979-2005 \\
\hline $\begin{array}{l}\text { St Vincent \& } \\
\text { Grenadines }\end{array}$ & 57 & SVG & 670 & VCT & $1946-2005$ & 1979-2005 \\
\hline Sudan & 625 & SUD & 736 & SDN & $1946-2005$ & 1956-2005 \\
\hline Suriname & 115 & SUR & 740 & SUR & $1946-2005$ & 1975-2005 \\
\hline Swaziland & 572 & SWA & 748 & SWZ & $1946-2005$ & 1968-2005 \\
\hline Sweden & 380 & SWD & 752 & SWE & $1946-2005$ & 1946-2005 \\
\hline Switzerland & 225 & SWZ & 756 & CHE & $1946-2005$ & 1946-2005 \\
\hline Syria & 652 & SYR & 760 & SYR & $1946-2005$ & $\begin{array}{l}\text { 1946-1958; } \\
\text { 1961-2005 }\end{array}$ \\
\hline Taiwan & 713 & TAW & 158 & TWN & $1946-2005$ & 1949-2005 \\
\hline Tajikistan & 702 & TAJ & 762 & TJK & $1946-2005$ & 1991-2005 \\
\hline Tanzania & 510 & TAZ & 834 & TZA & $1946-2005$ & 1961-2005 \\
\hline Thailand & 800 & THI & 764 & THA & $1946-2005$ & 1946-2005 \\
\hline Tibet & 711 & n.a. & 994 & XTI & $1946-2005$ & - \\
\hline Togo & 461 & TOG & 768 & TGO & $1946-2005$ & 1960-2005 \\
\hline Tonga & 955 & TON & 776 & TON & $1946-2005$ & 1999-2005 \\
\hline Trinidad and Tobago & 52 & TRI & 780 & TTO & 1946-2005 & $1962-2005$ \\
\hline Tunisia & 616 & TUN & 788 & TUN & $1946-2005$ & 1956-2005 \\
\hline Turkey & 640 & TUR & 792 & TUR & $1946-2005$ & 1946-2005 \\
\hline Turkmenistan & 701 & TKM & 795 & TKM & 1946-2005 & 1991-2005 \\
\hline Tuvalu & 947 & TUV & 798 & TUV & $1946-2005$ & 2000-2005 \\
\hline Uganda & 500 & UGA & 800 & UGA & 1946-2005 & $1962-2005$ \\
\hline Ukraine & 369 & UKR & 804 & UKR & $1946-2005$ & 1991-2005 \\
\hline United Arab Emirates & 696 & UAE & 784 & ARE & 1946-2005 & $1971-2005$ \\
\hline United Kingdom & 200 & UKG & 826 & GBR & $1946-2005$ & 1946-2005 \\
\hline $\begin{array}{l}\text { United States of } \\
\text { America }\end{array}$ & 2 & USA & 840 & USA & $1946-2005$ & 1946-2005 \\
\hline Uruguay & 165 & URU & 858 & URY & $1946-2005$ & 1946-2005 \\
\hline Uzbekistan & 704 & UZB & 860 & UZB & 1946-2005 & 1991-2005 \\
\hline Vanuatu & 935 & VAN & 548 & VUT & $1946-2005$ & 1981-2005 \\
\hline Venezuela & 101 & VEN & 862 & VEN & 1946-2005 & 1946-2005 \\
\hline Vietnam & 816 & DRV & 704 & VNM & 1946-2005 & 1954-2005 \\
\hline Vietnam, South & 817 & RVN & 999 & VDR & 1946-2005 & 1954-1975 \\
\hline Yemen & 679 & YEM & 887 & YEM & $1946-2005$ & 1990-2005 \\
\hline
\end{tabular}




\begin{tabular}{|l|c|c|c|c|c|c|}
\hline Yemen, North & $\mathbf{6 7 8}$ & YAR & 886 & YEM & $1946-2005$ & $1946-1990$ \\
\hline Yemen, South & $\mathbf{6 8 0}$ & YPR & 720 & YMD & $1946-2005$ & $1967-1990$ \\
\hline Yugoslavia & $\mathbf{3 4 5}$ & YUG & 890 & YUG & $1946-2005$ & $1946-2005$ \\
\hline Zambia & $\mathbf{5 5 1}$ & ZAM & 894 & ZMB & $1946-2005$ & $1964-2005$ \\
\hline Zanzibar & $\mathbf{5 1 1}$ & ZAN & 995 & EAZ & $1946-2005$ & $1963-1964$ \\
\hline Zimbabwe & $\mathbf{5 5 2}$ & ZIM & 716 & ZWE & $1946-2005$ & $1965-2005$ \\
\hline United Nations* & $\mathbf{1 0 0 0}$ & UN & 1000 & UN & - & $1946-2005$ \\
\hline $\begin{array}{l}\text { North Atlantic Treaty } \\
\text { Organization* }\end{array}$ & $\mathbf{2 0 0 0}$ & NATO & 2000 & NATO & - & $1946-2005$ \\
\hline $\begin{array}{l}\text { Other international } \\
\text { organizations* }\end{array}$ & $\mathbf{3 0 0 0}$ & IO & 3000 & IO & - & $1946-2005$ \\
\hline Multilateral operations* & $\mathbf{4 0 0 0}$ & Multilat & 4000 & Multilat & - & $1946-2005$ \\
\hline
\end{tabular}

* Adjustment to the original country code

\subsection{Country coding adjustments}

The below table identifies the extensiveness of the carried out ccode adjustments.

\begin{tabular}{|l|c|c|c|}
\hline \multicolumn{4}{|c|}{ COUNTRY CODING ADJUSTMENTS } \\
\hline $\begin{array}{c}\text { Original dataset } \\
\text { name }\end{array}$ & $\begin{array}{c}\text { Original identifying } \\
\text { variable }\end{array}$ & $\begin{array}{c}\text { Ccode adjustments } \\
\text { (CD \& DD) }\end{array}$ & $\begin{array}{c}\text { Saved records by ccode } \\
\text { adjustments (CD \& } \\
\text { DD) }\end{array}$ \\
\hline EUGene SV & COW ccode & 0 \& 0 & 0 \& 0 \\
\hline UN Pop 1/2/3/4 & UN ccode & $2 / 2 / 2 / 0$ & $112 / 140 / 11 / 0$ \\
\hline UN SD & UN ccode & 0 & 0 \\
\hline UN FAO & UN ccode & 4 & 201 \\
\hline FDP & COW ccode & 5 & 04 \\
\hline DEM & COW ccode & 0 & 0 \\
\hline MAR & COW ccode & 0 & 88 \\
\hline QoG & COW ccode & 0 & $6 / 6 / 6 / 3$ \\
\hline MEPV & COW ccode & $3 / 3 / 3 / 2$ & 0 \\
\hline PITF 1/2/3/4 & COW ccode & 0 & 0 \\
\hline ACD & COW ccode & 0 & $0 \& 0$ \\
\hline Regan & COW ccode & $0 \& 0$ & $0 \& 0$ \\
\hline EUGene MID & COW ccode & $0 \& 0$ & $0 \& 0$ \\
\hline EUGene ICB & COW ccode & & 0 \\
\hline ICB II & & & 0 \\
\hline
\end{tabular}




\begin{tabular}{|l|c|c|c|} 
ICB Dyad & COW ccode & $0 \& 0$ & $0 \& 0$ \\
\hline Mil Int & COW ccode & $2 \& 14$ & $2 \& 893$ \\
\hline Peace & Country abbreviation & 5 & 54 \\
\hline
\end{tabular}

\subsubsection{Detailed description of the country coding adjustments in individual input datasets}

Most of the input datasets required some ccode adjustments to become compatible with the QoG and COW country lists used for the data compilation. In general, if some input dataset used a ccode for a certain territory with a limited sovereignty, and this ccode did not exist in the QoG or COW country list; it was changed in to the ccode of the country that possessed official sovereignty over particular part of the territory in that time. Otherwise, the carried out depended on the circumstances, and they are described below:

\section{EUGene SV (CD E DD)}

None

$\&$

None - unifying ccode for the dyadic data

\section{UN Pop (CD)}

Instead of two keeping two different countries: Montenegro (UN ccode 499) and Serbia (UN ccode 688), which do not exist in COW system membership list, the averaged values of these two countries were applied under a joint label Serbia and Montenegro (UN ccode 891).

\section{UN SD (CD)}

Instead of two keeping two different countries: Montenegro (UN ccode 499) and Serbia (UN ccode 688), which do not exist in COW system membership list, the summed values for these two countries were used under a joint label Serbia and Montenegro (UN ccode 891).

\section{UN FAO (CD)}

The missing years for Korea (UN ccode 408), Korea (UN ccode 410), and Micronesia (UN ccode 583), which were lost due to the wrong setting of the data download setting, were recovered. Montenegro (UN ccode 499) and Serbia (UN ccode 688) were again transformed under a joint label Serbia and Montenegro (UN ccode 891) by summing the values for individual countries. 


\section{$F D P(C D)$}

COW ccodes for three countries were corrected: Bulgaria (COW ccode 335) was corrected to (COW ccode 355), Namibia (COW ccode 561) was corrected to (COW ccode 565), and Pakistan (COW ccode 769) was corrected to (COW ccode 770). Former Yugoslavia not covered in the original COW country list was attached COW ccode 345. A missing ccode for one year in case of East Timor (COW ccode 860) was added.

\section{$\operatorname{DEM}(C D)$}

None

$\operatorname{MAR}(C D)$

None

QoG (CD)

None - unifying ccode for the country-year data

$\operatorname{MEPV}(C D)$

COW ccodes for five countries were corrected: Yugoslavia (COW ccode 347) was corrected to (COW ccode 345), Serbia and Montenegro from (COW ccode 347) to (COW ccode 345), Ethiopia from (COW ccode 529) to (COW ccode 530), Pakistan from (COW ccode 769) to (COW ccode 770), and Vietnam from (COW ccode 818) to (COW ccode 816).

\section{PITF (CD)}

COW ccodes for three countries were corrected: Yugoslavia (COW ccode 347) was corrected to (COW ccode 345), Ethiopia from (COW ccode 529) to (COW ccode 530), and Pakistan from (COW ccode 769) to (COW ccode 770).

$A C D(C D)$

None

Regan (CD)

None

EUGene MID (CD E DD)

None

$\&$

None

EUGene ICB (CD \& DD) 
None

$\&$

None

ICB II (CD E DD)

None

$\&$

None

ICB Dyad (CD E DD)

None

$\&$

None

Mil Int $(C D \mathcal{E} D D)$

COW ccodes of the Mil Int I and Mil Int II datastes were unified. An artificial COW ccode for the UN was set to 1000 (originally coded 1 in Mil Int I and 1014 in Mil Int II dataset). COW ccode of Sikkim (part of India) was changed from 761 to 760 (India). A missing time indication in case of the Dhofar Rebellion (COW ccode 680) was added.

$\&$

COW ccodes of the Mil Int I and Mil Int II datasets were unified. First of all, the artificial ccodes for the cases, when the intervener was a non-state actor were created. When the intervener was the UN, the ccode was set to 1000 (originally coded 1 in the Mil Int I, and 1014 in the Mil Int II dataset). Interventions led by the NATO were coded with an artificial ccode 2000 (originally coded 1060 in the Mil Int II). The remaining types of non-state interventions were grouped into two additional categories. Interventions led by the organizations dealing with international peacekeeping of a multinational nature other than the UN and the NATO were coded with an artificial ccode 3000. Such organizations are, for example: ECOWAS, CEMAC, EU, COMESA, OAU, AU, ECOMOG, CIS, SADC, OAS, Arab League (originally coded with a four-digit ccode starting with a number 2 in the Mil Int II dataset). And finally, multilateral operations carried out outside the institutional structure were attached an artificial ccode 4000 (originally coded with a four-digit code starting with a number 3 in Mil Int II dataset). Afterwards, COW ccodes for some target countries were also adjusted. COW ccode for Sikkim 
was changed from 761 (part of India) to 750 (India), for Bangladesh from 749 to 771, for Anguilla from 61 to 200 (British oversee territory), for Tibet from 709 to 710 (China), for the United Arab Emirates from 695 to 696, for the Commonwealth from 204 to 200 (Great Britain), for Hyderabad from 755 (part of India) to 750 (India), for Junagadh from 753 (part of India) to 750 (India), for Western Sahara from 601 (part of Morocco) to 600 (Morocco), for Kashmir from 754 to 770 (Pakistan - since India was intervener and Pakistan the target state in that particular case). And finally, a missing year in case of the Dhofar Rebellion (COW ccode 680 - target, and COW ccode 40 -intervener) was added.

\section{Peace (CD)}

Peacebuilding dataset did not have any numerical ccodes in its original version. Therefore, identification of the actors was carried out based on the comparison of the provided alphabetical state abbreviations with the abbreviations from the Quality of Government (QoG) dataset. Differences in the state abbreviations were corrected. Burma BRM was changed to MMR, Cambodia CAM was changed to KHM, Guatemala GUA was changed to GTM, Romania ROM was changed to ROU, and Sri Lanka SRI was changed to LKA.

\section{Unit of analysis transformation}

After transforming the input datasets into a homogenous country coding rules, there appeared to be the multiple information entries. These were replaced by applying the declarative aggregation functions in a form of SQL GROUP BY operators. SQL can be applied both to numerical types of the data as well as to the non-numeric ones, and it allows for implementing a wide range of the data transformations and the query processing tasks. The ANSI/ISO SQL99 standard defines five types of aggregate functions for the GROUP BY approach: average, maximum, minimum, sum and count. In addition to that, typical database systems supply three supplementary built-in aggregate functions: first, standard deviation and variance. ${ }^{4}$ The concrete choices of operator used for individual variables are listed in the coding table at the end of this technical appendix.

The following table provides an overview of the original unit of analysis, which variables were used to group the data in the desired unit of analysis, and the number of removed multiple entries due to the carried out grouping.

\begin{tabular}{|l|c|}
\hline \multicolumn{2}{|c|}{ UNIT OF ANALYSIS TRANSFORMATION } \\
\hline ORIGINAL DATA STRUCTURE & NEW DATA STRUCTURE \\
\hline
\end{tabular}

${ }^{4}$ International Standards Organization, 1999; Naumann \& Häussler, 2002. 


\begin{tabular}{|c|c|c|c|c|}
\hline Dataset name & $\begin{array}{c}\text { Original unit of } \\
\text { analysis (CD \& DD) }\end{array}$ & $\begin{array}{l}\text { Desired unit of } \\
\text { analysis }\end{array}$ & $\begin{array}{l}\text { Unit of analysis } \\
\text { transformation } \\
\text { (CD \& DD) }\end{array}$ & $\begin{array}{c}\text { Removed } \\
\text { multiple entries } \\
\text { (CD \& DD) }\end{array}$ \\
\hline EUGene SV & $\begin{array}{l}\text { Country-year \& } \\
\text { directed country } \\
\text { dyad-year }\end{array}$ & CD \& DD & $0 \& 0$ & $0 \& 0$ \\
\hline UN Pop & $\begin{array}{l}\text { Country- } \\
\text { 5year/country-year }\end{array}$ & $\mathrm{CD}$ & Ccode_year & 1 \\
\hline UN SD & Country-year & $\mathrm{CD}$ & Ccode_year & 1 \\
\hline UN FAO & Country constant & $\mathrm{CD}$ & 0 & 0 \\
\hline FDP & Country-year & $\mathrm{CD}$ & Ccode_year & 7 \\
\hline DEM & Country-year & $\mathrm{CD}$ & 0 & 0 \\
\hline MAR & $\begin{array}{l}\text { Communal group- } \\
\text { various time periods }\end{array}$ & $\mathrm{CD}$ & 0 & 0 \\
\hline QoG & Country-year & $\mathrm{CD}$ & 0 & 0 \\
\hline MEPV & Country-year & $\mathrm{CD}$ & Ccode_year & 1 \\
\hline PITF & State failure-year & $\mathrm{CD}$ & Ccode_year & 358 \\
\hline ACD & Conflict-year & $\mathrm{CD}$ & Ccode_year & 495 \\
\hline Regan $1 / 2 / 3 / 4$ & $\begin{array}{l}\text { Conflict- } \\
\text { month/conflict } \\
\text { constant }\end{array}$ & $\mathrm{CD}$ & Ccode_year & $12004 / 12199 / 1259$ \\
\hline EUGene MID & $\begin{array}{l}\text { Directed country } \\
\text { dyad-year }\end{array}$ & CD \& DD & \begin{tabular}{|l|} 
Ccode_year \& \\
ccode_ccode_year
\end{tabular} & $1250172 \& 0$ \\
\hline EUGene ICB & $\begin{array}{l}\text { Directed country } \\
\text { dyad-year }\end{array}$ & CD \& DD & \begin{tabular}{|l|}
$\begin{array}{l}\text { Ccode_year \& } \\
\text { ccode_ccode_year }\end{array}$ \\
\end{tabular} & $1250172 \& 0$ \\
\hline ICB II & Actor-year & CD \& DD & $\begin{array}{l}\text { Ccode_year \& } \\
\text { ccode_ccode_year }\end{array}$ & $536 \& 87$ \\
\hline ICB Dyad & Crisis dyad-year & CD \& DD & \begin{tabular}{|l|}
$\begin{array}{l}\text { Ccode_year \& } \\
\text { ccode_ccode_year }\end{array}$ \\
\end{tabular} & $536 \& 87$ \\
\hline Mil Int & Intervention constant & CD \& DD & \begin{tabular}{|l|}
$\begin{array}{l}\text { Ccode_year \& } \\
\text { ccode_ccode_year }\end{array}$ \\
\end{tabular} & $1631 \& 247$ \\
\hline Peace & $\begin{array}{l}\text { Peacebuilding } \\
\text { constant }\end{array}$ & $\mathrm{CD}$ & Ccode_year & 92 \\
\hline
\end{tabular}

\subsection{Detailed description of the unit of analysis transformation in the individual input datasets}

\section{EUGene SV (CD \& DD)}

EUGene software was set to download the data already in the country-year format that covers all the existing countries in a desired time spam according to the COW country list. Therefore, no additional changes were needed. 
\&

Similarly, EUGene software was set to download the dyadic data directly in a proper country dyad-year format including all the existing countries in the desired time spam according to the COW country list. After carrying out some alterations of adding the relevant non-state actors to the list (artificial ccodes 1000, 2000, 3000, and 4000), the adjusted EUGene generated country-dyad list was used as a merging muster for the dyadic part of the data compilation.

\section{UN Pop (CD)}

UN Pop variables were downloaded individually. Most of them included values that were in their original form captured in the 5-year intervals. They were transformed either into the 5-year constant values or interpolated into the yearly values. The original variables were kept in the compilation as well so as to enable the future users applying some alternative adjustments. One variable was grouped by COW ccode_year to remove a multiple entry for one country-year.

\section{UN SD (CD)}

The included variable was originally recorded in the 5-year intervals. It was transformed into the 5-year constant values, while keeping the original variable in the compilation to allow the future users applying an alternative adjustment.

\section{UN FAO (CD)}

The FAO variable originally covered a shorter time period. Due to the fact that the variable was time constant (area of the countries does not change much), it was extended in the time-constant values to cover the whole time frame of the data compilation.

\section{$F D P(C D)$}

Observations were grouped by COW ccode_year to remove the multiple entries.

\section{$\operatorname{DEM}(C D)$}

\section{QoG (CD)}

Observations were grouped by COW ccode_year to remove the multiple entries. The dataset was used as a merging muster for the first part of the data compilation that is based on the country-year data structure.

\section{$\operatorname{MEPV}(C D)$}

A multiple entry was corrected by grouping the records by COW ccode_year. 


\section{PITF (CD)}

Each of the PITF datasets (PITF 1, 2, 3 and 4) originally gathered information about four different types of state failure. Since the number of events identified by the individual datasets was low, and most of the variables included in PITF 1, 2 and 3 datasets traced the similar characteristics describing some type of a state failure, these three datasets were joined together, and grouped by $\mathrm{COW}$ ccode_year. Bringing the three datasets together required the following steps. If the country experienced at least one of the PITFs events (PITF 1, 2, or 3) in some year; the given country-year observation was added into the identified sample by grouping the information about all the identified PITF events for that country-year into one record. Nevertheless, so as not to lose the information about the types of the PITF event that took place in each country-year; new dummy variables were created indicating occurrence of each type of PITF in individual country-years. Moreover, due to the fact that there were cases when two or more state failures of the same type occurred simultaneously in one country-year, variables indicating a frequency of occurrence of the different types of PITF were added, so that this information was not lost by the grouping of the data. The last of the PITF datasets (PITF 4) dealing with the genocides and the politicides was treated individually, since such types of event require from the theoretical point of view a different methodological approach during the conflict analysis. PITF 4 was again grouped by COW ccode_year.

\section{$A C D(C D)$}

Data in this dataset were originally organized into the conflict-year data structure, which means that the individual values described the situation of all countries involved in the conflict jointly together. Due to the fact that the ACD dataset was intended to be included only in the country-year part and not the dyadic part of the data compilation; the focus was put only on the countries hosting the conflicts and not on the external interveners. Therefore, so as to transfer this type of data into the target country-year unit of analysis, a following procedure was applied.

In case that just one country was listed as a conflict participant in some conflictyear observation, it was a simple internal conflict taking place within the country's territory, and no adjustment was necessary. In case that there were more countries involved as participants in some conflict; the Mil Int dyad dataset was consulted to distinguish the country hosting the conflict from the intervening country, and just the target country of the conflict was kept for the purpose of this data compilation. Nevertheless, before removing the information about the intervener from the data compilation, number of its casualties had to be identified and subtracted from the number of casualties that was originally attached to the whole conflict. This final 
decreased number was then attached to the identified target. If there were more countries in the conflict, and the Mil Int dyad dataset indicated existence of mutual dyads, it meant that the participating countries both intervened into each other's territory in the same year; all these countries were kept in the compilation and the casualties were attached to them based on the proportions indicated in the Mil Int dataset.

In case that the conflict dyad was not listed in the Mil Int dataset, the carried out adjustments had to be based on several simplifying assumptions that were formulated according to the typical behavior of the countries in the international arena. A first assumption is that the weak developing states do not usually challenge the strong developed ones on their home territory. Therefore, such disproportional conflicts usually take place just within the territories of those developing ones. A second assumption is that the developing countries tend to have much less developed armies, strategies and weapons than the developed ones do; and thus tend to suffer much more casualties. Therefore, if there were two types of countries participating in the conflict - a developed and a developing one, the casualties were assigned to the developing country only. To put it into an example, if two developing countries and one developed country were listed together as the participants in some conflict, and the Mil Int dataset did not keep record of this conflict dyads composed of these participants; the developed country was neglected and not included as a target, and the causalities were divided equally only among the two developing ones. The actual proportions attached to individual conflict actors in the above described process are presented in the following table. After transforming all the ACD data in this way, the data were grouped by COW ccode_year.

\begin{tabular}{|l|c|c|c|}
\hline \multicolumn{3}{|c|}{ ADJUSTMENTS OF THE ACD DATASET } \\
\hline \multicolumn{1}{|c|}{ Participating countries in the conflict } & COW ccode & Year & $\begin{array}{c}\text { Proportion of } \\
\text { causalities }\end{array}$ \\
\hline France, Thailand & 220,800 & 1946 & $\mathbf{0 - 9 0}$ \\
\hline Albania, United Kingdom & 339,200 & 1946 & $\mathbf{9 0 - 0}$ \\
\hline Hyderabad, India & 755,750 & 1948 & $\mathbf{9 0 - 0}$ \\
\hline Egypt, United Kingdom & 651,200 & 1951 & $\mathbf{9 0 - 0}$ \\
\hline Egypt, United Kingdom & 651,200 & 1952 & $\mathbf{9 0 - 0}$ \\
\hline Hungary, Russia (Soviet Union) & 310,365 & 1956 & $\mathbf{9 0 - 0}$ \\
\hline Egypt, France, Israel, United Kingdom & $651,220,66,200$ & 1956 & $\mathbf{8 0 - 0 - 0 - 0}$ \\
\hline China, Myanmar & 710,775 & 1969 & $\mathbf{0 - 9 0}$ \\
\hline France, Tunisia & 220,616 & 1961 & $\mathbf{0 - 9 0}$ \\
\hline Indonesia, Netherlands & 850,210 & 1962 & $\mathbf{9 0 - 0}$ \\
\hline
\end{tabular}




\begin{tabular}{|c|c|c|c|}
\hline Panama, United States of America & 95,2 & 1989 & $90-0$ \\
\hline Argentina, United Kingdom & 160,200 & 1982 & $90-0$ \\
\hline India, Pakistan & 750,770 & 1948 & $50-50$ \\
\hline India, Pakistan & 750,770 & 1964 & $50-50$ \\
\hline India, Pakistan & 750,770 & 1965 & $50-50$ \\
\hline India, Pakistan & 750,770 & 1971 & $50-50$ \\
\hline India, Pakistan & 750,770 & 1984 & $50-50$ \\
\hline India, Pakistan & 750,770 & 1987 & $50-50$ \\
\hline India, Pakistan & 750,770 & 1989 & $50-50$ \\
\hline India, Pakistan & 750,770 & 1990 & $50-50$ \\
\hline India, Pakistan & 750,770 & 1991 & $50-50$ \\
\hline India, Pakistan & 750,770 & 1992 & $50-50$ \\
\hline India, Pakistan & 750,770 & 1996 & $50-50$ \\
\hline India, Pakistan & 750,770 & 1997 & $50-50$ \\
\hline India, Pakistan & 750,770 & 1998 & $50-50$ \\
\hline India, Pakistan & 750,770 & 1999 & $50-50$ \\
\hline India, Pakistan & 750,770 & 2000 & $50-50$ \\
\hline India, Pakistan & 750,770 & 2001 & $50-50$ \\
\hline India, Pakistan & 750,770 & 2002 & $50-50$ \\
\hline India, Pakistan & 750,770 & 2003 & $50-50$ \\
\hline Egypt, Iraq, Israel, Jordan, Lebanon, Syria & $\begin{array}{c}651,645,666,663,660 \\
652\end{array}$ & 1948 & 33-33-33 \\
\hline Egypt, Iraq, Israel, Jordan, Lebanon, Syria & \begin{tabular}{|c|}
$651,645,666,663,660$ \\
652
\end{tabular} & 1949 & $33-33-33$ \\
\hline China, Taiwan & 710,713 & 1949 & $20-80$ \\
\hline China, Taiwan & 710,713 & 1950 & $20-80$ \\
\hline China, Taiwan & 710,713 & 1954 & $20-80$ \\
\hline China, Taiwan & 710,713 & 1958 & $20-80$ \\
\hline Peoples Republic of Korea , Republic of Korea & 731,732 & 1949 & $60-40$ \\
\hline Peoples Republic of Korea , Republic of Korea & 731,732 & 1950 & $60-40$ \\
\hline Peoples Republic of Korea , Republic of Korea & 731,732 & 1951 & $60-40$ \\
\hline Peoples Republic of Korea , Republic of Korea & 731,732 & 1952 & $60-40$ \\
\hline Peoples Republic of Korea , Republic of Korea & 731,732 & 1953 & $60-40$ \\
\hline Honduras, Nicaragua & 91,93 & 1957 & $90-0$ \\
\hline Egypt, Israel & 651,666 & 1967 & $90-0$ \\
\hline Egypt, Israel & 651,666 & 1969 & $90-0$ \\
\hline Egypt, Israel & 651,666 & 1970 & $90-0$ \\
\hline Egypt, Israel & 651,666 & 1973 & $90-0$ \\
\hline Israel, Jordan & 666,663 & 1967 & $50-0$ \\
\hline Israel, Syria & 666,652 & 1967 & $66-0$ \\
\hline Israel, Syria & 666,652 & 1973 & $50-0$ \\
\hline
\end{tabular}




\begin{tabular}{|c|c|c|c|}
\hline Cameroon, Nigeria & 471,475 & 1996 & $33-0$ \\
\hline China, Russia (Soviet Union) & 710,365 & 1969 & $20-80$ \\
\hline El Salvador, Honduras & 92,91 & 1969 & $95-5$ \\
\hline Ethiopia, Somalia & 530,520 & 1960 & $50-50$ \\
\hline Ethiopia, Somalia & 530,520 & 1964 & $50-50$ \\
\hline Ethiopia, Somalia & 530,520 & 1973 & $50-50$ \\
\hline Ethiopia, Somalia & 530,520 & 1983 & $50-50$ \\
\hline Ethiopia, Somalia & 530,520 & 1987 & $50-50$ \\
\hline China, India & 710,750 & 1962 & $50-50$ \\
\hline China, India & 710,750 & 1967 & $50-50$ \\
\hline Algeria, Morocco & 615,600 & 1963 & $90-10$ \\
\hline Indonesia, Malaysia & 850,820 & 1963 & 33-0 \\
\hline Indonesia, Malaysia & 850,820 & 1964 & $33-0$ \\
\hline Indonesia, Malaysia & 850,820 & 1965 & $33-0$ \\
\hline Indonesia, Malaysia & 850,820 & 1966 & 33-0 \\
\hline Democratic Rep. of Vietnam, Rep. of Vietnam & 816,817 & 1965 & $50-50$ \\
\hline Democratic Rep. of Vietnam, Rep. of Vietnam & 816,817 & 1966 & $50-50$ \\
\hline Democratic Rep. of Vietnam, Rep. of Vietnam & 816,817 & 1967 & $50-50$ \\
\hline Democratic Rep. of Vietnam, Rep. of Vietnam & 816,817 & 1968 & $50-50$ \\
\hline Democratic Rep. of Vietnam, Rep. of Vietnam & 816,817 & 1969 & $50-50$ \\
\hline Democratic Rep. of Vietnam, Rep. of Vietnam & 816,817 & 1970 & $50-50$ \\
\hline Democratic Rep. of Vietnam, Rep. of Vietnam & 816,817 & 1971 & $50-50$ \\
\hline Democratic Rep. of Vietnam, Rep. of Vietnam & 816,817 & 1972 & $50-50$ \\
\hline Democratic Rep. of Vietnam, Rep. of Vietnam & 816,817 & 1973 & $50-50$ \\
\hline Democratic Rep. of Vietnam, Rep. of Vietnam & 816,817 & 1974 & $50-50$ \\
\hline Democratic Rep. of Vietnam, Rep. of Vietnam & 816,817 & 1975 & $50-50$ \\
\hline Cambodia, Thailand & 811,800 & 1966 & $50-50$ \\
\hline Cambodia, Thailand & 811,800 & 1977 & $50-50$ \\
\hline Cambodia, Thailand & 811,800 & 1978 & $50-50$ \\
\hline $\begin{array}{l}\text { Peoples Republic of Yemen, Yemen (Arab Rep. } \\
\text { of Yemen) }\end{array}$ & 678,680 & 1972 & $50-50$ \\
\hline $\begin{array}{l}\text { Peoples Republic of Yemen, Yemen (Arab Rep. } \\
\text { of Yemen) }\end{array}$ & 678,680 & 1978 & $50-50$ \\
\hline $\begin{array}{l}\text { Peoples Republic of Yemen, Yemen (Arab Rep. } \\
\text { of Yemen) }\end{array}$ & 678,680 & 1979 & $50-50$ \\
\hline Cyprus, Turkey/Ottoman Empire & 352,640 & 1974 & $75-25$ \\
\hline Iran, Iraq & 630,645 & 1974 & $50-50$ \\
\hline Iran, Iraq & 630,645 & 1980 & $50-50$ \\
\hline Iran, Iraq & 630,645 & 1981 & $50-50$ \\
\hline Iran, Iraq & 630,645 & 1982 & $50-50$ \\
\hline Iran, Iraq & 630,645 & 1983 & $50-50$ \\
\hline
\end{tabular}




\begin{tabular}{|l|c|c|c|}
\hline Iran, Iraq & 630,645 & 1984 & $\mathbf{5 0 - 5 0}$ \\
\hline Iran, Iraq & 630,645 & 1985 & $\mathbf{5 0 - 5 0}$ \\
\hline Iran, Iraq & 630,645 & 1986 & $\mathbf{5 0 - 5 0}$ \\
\hline Iran, Iraq & 630,645 & 1987 & $\mathbf{5 0 - 5 0}$ \\
\hline Iran, Iraq & 630,645 & 1988 & $\mathbf{5 0 - 5 0}$ \\
\hline Cambodia, Democratic Republic of Vietnam & 811,816 & 1975 & $\mathbf{5 0 - 5 0}$ \\
\hline Cambodia, Democratic Republic of Vietnam & 811,816 & 1976 & $\mathbf{5 0 - 5 0}$ \\
\hline Cambodia, Democratic Republic of Vietnam & 811,816 & 1977 & $\mathbf{5 0 - 5 0}$ \\
\hline Burkina Faso, Mali & 439,432 & 1985 & $\mathbf{9 5 - 5}$ \\
\hline Laos, Thailand & 812,800 & 1986 & $\mathbf{6 6 - 3 3}$ \\
\hline Laos, Thailand & 812,800 & 1987 & $\mathbf{6 6 - 3 3}$ \\
\hline Laos, Thailand & 812,800 & 1988 & $\mathbf{6 6 - 3 3}$ \\
\hline Chad, Libya & 483,620 & 1987 & $\mathbf{5 0 - 5 0}$ \\
\hline Iraq, Kuwait & 645,690 & 1990 & $\mathbf{3 0 - 7 0}$ \\
\hline Iraq, Kuwait & 645,690 & 1991 & $\mathbf{7 0 - 3 0}$ \\
\hline China, Democratic Republic of Vietnam & 710,816 & 1978 & $\mathbf{3 0 - 7 0}$ \\
\hline China, Democratic Republic of Vietnam & 710,816 & 1979 & $\mathbf{3 0 - 7 0}$ \\
\hline China, Democratic Republic of Vietnam & 710,816 & 1980 & $\mathbf{3 0 - 7 0}$ \\
\hline China, Democratic Republic of Vietnam & 710,816 & 1981 & $\mathbf{3 0 - 7 0}$ \\
\hline China, Democratic Republic of Vietnam & 710,816 & 1983 & $\mathbf{3 0 - 7 0}$ \\
\hline China, Democratic Republic of Vietnam & 710,816 & 1984 & $\mathbf{3 0 - 7 0}$ \\
\hline China, Democratic Republic of Vietnam & 710,816 & 1986 & $\mathbf{3 0 - 7 0}$ \\
\hline China, Democratic Republic of Vietnam & 710,816 & 1987 & $\mathbf{3 0 - 7 0}$ \\
\hline China, Democratic Republic of Vietnam & 710,816 & 1988 & $\mathbf{3 0 - 7 0}$ \\
\hline Chad, Nigeria & 483,475 & 1983 & $\mathbf{5 0 - 5 0}$ \\
\hline Ecuador, Peru & 130,135 & 1995 & $\mathbf{7 5 - 2 5}$ \\
\hline Eritrea, Ethiopia & 531,530 & 1998 & $\mathbf{5 0 - 5 0}$ \\
\hline Eritrea, Ethiopia & 531,530 & 1999 & $\mathbf{5 0 - 5 0}$ \\
\hline Eritrea, Ethiopia & 531,530 & 2000 & $\mathbf{5 0 - 5 0}$ \\
\hline & & & \\
\hline
\end{tabular}

\section{Regan (CD)}

The original structure of the Regan datasets (Regan 1, 2, and 3) was incoherent. They were not only structured based on the different units of analysis, but the datasets also used different identifying variables. It was impossible to merge the Regan datasets individually with the prepared country-year list structuring the data compilation. First of all, all three Regan datasets had to be merged together. Regan 1 and Regan 2 datasets were originally based on the country-event-month unit of analysis and both included the Regan conflict identification number as an event identifying variable. Nevertheless, only Regan 1 dataset included also the 
COW ccode that serves as a target country identifying variable in the data compilation. Therefore, so as to identify the COW ccodes also in the Regan 2 dataset; Regan 1 and Regan 2 datasets were merged using the "Regan conflict number" \& "Months since the beginning of the conflict" as identifying variables. Unfortunately, there were some inconsistencies in the Regan's coding and identification of the events, which were reflected by a higher frequency of interventions identified by the Regan 2 dataset in comparison to those identified in the Regan 1 dataset for the same conflicts. As a result of the merging process, 347 observations (in conflict-months) were lost from the Regan 2 dataset. The lost observations concerned conflicts with the following Regan identification numbers: $600,610,615,630,784,786,787,793,799,805,826,827,835,838,840,841,845,847$, $850,853,857,858,859,863,864,865,870,872,874,881,882,887,888,889,892,894$, 896, 901, 903, 904, 907, 908, 910, 913, 919, 930, 934, 936, 937, 947, 949, 952, 953, 964, 966, 967, 977, 979, 982, 984, 986, 987, 991, 992, and 993. Afterwards, the merged Regan $1+2$ data were grouped by COW ccode_year to adjust the monthly time-unit of analysis into the yearly one. The final step was to attach the originally conflictconstant data in the Regan 3 dataset. Regan 3 data were extended into the countryyear unit of analysis, grouped by COW ccode_year, and when merged with the Regan 1+2 data. Even though, some Regan data also provided information about the identity of the intervener; the data were not transformed into a dyadic form, since the intervener identifying variable contained too many missing values.

\section{MID EUGene (CD \& DD)}

MID data were generated by the EUGene software with the directed country dyadyear unit of analysis. The software was set to generate all dyads from all countries without dyads $i$ versus $i$ without using any sampling. While identifying the conflict events, no exclusions in the sample were applied in case of a both-way conflict (target versus initiator and initiator versus target). In the sample, state A was coded as a conflict initiator rather than as a revisionist state. Joiners on the initiating side of the conflict were coded as initiators, while joiners on the target side were coded as targets. In case that more MIDs occurred in particular country dyad-year, the output was set to include the most serious MID (measured by the highest hostility level). In such a way created dyadic data were then transformed also into the target country-year unit of analysis so as to have MID data flexibly available for both parts of the data compilation. During the process of grouping the dyadic data by COW ccode_year, an extra variable counting the frequency of the dyadic conflict occurrence was generated.

ICB EUGene (CD E DD) 
ICB data were again generated by the EUGene software. This time, the data were downloaded in the crisis dyad-year unit of analysis. The software was set to generate a sample covering all the dyads from all existing countries without dyads $i$ versus $i$, while not applying any sampling option. The conflict events were identified based on the ICB Dyad dataset in a way that all dyad-years with an ongoing conflict as well as all the joiners were kept in the conflict event sample. The originators and joiners of the interventions (regardless of side they took in the conflict) were coded as initiators. After generating the ICB data in the dyadic form, the data were transformed also to the country-year unit of analysis. As in the case of MID EUGene data; while grouping the data by COW ccode_year, a new variable counting the number of dyadic events in each year was created.

\section{$I C B(C D \& D D)$}

ICB data were included in two versions into this data compilation. Even though, EUGene software allows for generating the ICB data in the preferred unit of analysis; the time coverage of the ICB data available in the EUGene data store is limited, because the software does not allow downloading the most recent version of the data. While the EUGene gathers ICB II data for years 1946-2001, and ICB Dyad data for years 1946-1995; the last updated existing version of the ICB data covers the period 1946-2005 in case of the ICB II data and 1946-2001 in case of the ICB Dyad data. Moreover, while merging the data manually, the most preferred version of the data grouping can be selected and applied. As a result of that the second version of the data provides an alternative option for the researchers to choose a better version depending on their theoretical assumptions.

The most recent ICB data were adjusted in a following way. The originally conflict-constant observations in the ICB II dataset were extended into countryyear units of analysis. Due to the fact that ICB II dataset in its original form did not distinguish between the intervener and the target state in the conflicts, the data had to be merged with the ICB Dyad dataset to be able to identify the roles of individual conflict participants. This merging process was not straightforward and had to be divided into two steps. In the first step, two linking pairs of the identifying variables had to be selected: "actnuma" from the ICB Dyad dataset that identifies an actor-level sequence ICB number for state A (it is set to the value 9999 if the state A was not considered a crisis-actor), and an identical variable "cracno" from the actor-level ICB II dataset. Second selected linking pair was the variable "statea" from the ICB Dyad dataset that indicates the COW ccode of the actor, and an identical variable "cracid" from the ICB II dataset. Therefore, the two datasets were merged together by linking the variable "actnuma" (ICB Dyad) with "cracno" (ICB II), and the variable "statea" (ICB Dyad) with "cracid" (ICB II). There were 
825 matches, and 393 records were not joined. Out of these 393 not joined records, 373 records showed the value 9999 in the variable "actnuma", since the state A was not considered to be a crisis actor.

In the second step of the merging process, 393 "cracno" records from the ICB II dataset that failed to be linked with the variable "actnuma" from the ICB Dyad dataset in the first step of the merging process were linked to the complementary variable "actnumb" from the ICB Dyad dataset in the second step of the merging process. Variable "actnumb" from the ICB Dyad dataset indicates an actor-level sequence ICB number for state B that is again identical with the variable "cracno" from the actor-level ICB II dataset. Similarly as in the first step, the second linking pair for the purposes of merging was composed of the variable "stateb" from the ICB Dyad dataset, and an identical variable "cracid" from the ICB II dataset. Therefore, the second part of the merging process was based on pairing the variable "actnumb" (ICB Dyad) with "cracno" (ICB II), and the variable "stateb" (ICB Dyad) with "cracid" (ICB II). There were 373 matches out of 393. All together, 20 records from the ICB II dataset were lost due to this merging process. These losses concerned the last records in the ICB II dataset that were no more covered by the ICB Dyad dataset that has a shorter time coverage (ICB II covers period 1946-2005, ICB Dyad covers period 1946-2001). The lost records included conflicts with the following ICB numbers: 428, 429, 430, 431, 432, 433, and 434.

Thanks to all these adjustments, both datasets were restructured into a dyadic form. So as to transform the data into the final directed country dyad-year unit of analysis, the data were grouped by COW ccode_ccode_year. So as to generate also the country-year unit of analysis version of the ICB data, the dyadic data were grouped using $\mathrm{COW}$ ccode_year, while creating a variable counting a frequency of the merged dyads in each country-year.

\section{Mil Int (CD $\mathcal{E} D D)$}

The Mil Int dataset covering the period 1946-1988 and the Mil Int dataset covering the period 1989-2005 were joined together, since both these datasets traced the development of the same variables (with a couple of exceptions) and followed the same coding. Due to the fact that Mil Int data are country-event-constant, they had to be extended into the country-event-year observations. After doing that, the data were merged by COW ccode_year to get the country-year unit of analysis, and by COW ccode_ccode_year to get the directed country dyad-year unit of analysis.

\section{Peacebuilding (CD)}

Peacebuilding data did not have any numerical ccodes. Therefore, the alphabetical country abbreviations from the QoG dataset had to be used to attach the 
peacebuilding data with the numerical ccodes. Afterwards, the data were grouped by COW ccode_year to remove the multiple observations for a single country-year.

\subsection{Lost records in the process of merging}

The below described data losses include observations that failed to be matched with the prepared QoG or COW country lists. These failures do not include cases of multiple entries for a single country-year or country dyad year that were removed by grouping the entries by some function into one record. Instead, they include lost cases that occurred because of one of the two following reasons:

- Differences in the country identification procedure applied by individual input datasets (Most of these discrepancies occurred, because a country that was identified as existing in some input dataset, has not qualified to become included into the QoG or COW country lists.)

- Merging of the sub-parts of input datasets (Some datasets - e.g.: PITF $1+2+3$, ICB II + ICB Dyad - had to be merged together to gain the necessary identifying variables to attach the data to the QoG or COW country list.)

\subsubsection{Lost records in a summary}

\begin{tabular}{|l|c|}
\hline \multicolumn{2}{|c|}{ LOST RECORDS IN THE MERGING PROCESS } \\
\hline Original dataset name & Lost records by merging (CD \& DD) \\
\hline EUGene SV & 0 \& 0 \\
\hline UN Pop 1/2/3/4 & $784 / 540 / 198 / 198$ \\
\hline UN SD & 451 \\
\hline FAO & 2340 \\
\hline FDP & 47 \\
\hline DEM & 0 \\
\hline MAR & 0 \\
\hline QoG & 0 \\
\hline MEPV & 45 \\
\hline PITF 1/2/3 & $1 / 1 / 1 / 0$ \\
\hline ACD & 2 \\
\hline Regan & 0 \\
\hline EUGene MID & $0 \& 0$ \\
\hline EUGene ICB & $0 \& 0$ \\
\hline ICB II & $0 \& 7$ \\
\hline ICB Dyad & $0 \& 7$ \\
\hline
\end{tabular}




\begin{tabular}{|l|c|}
\hline Mil Int & $32 \& 94$ \\
\hline Peace & 0 \\
\hline
\end{tabular}

\subsubsection{Detailed description of the data losses in individual datasets}

\section{EUGene (CD $\mathcal{E} D D)$}

0 lost cases

$\&$

0 lost cases

\section{UN Pop (CD)}

UN Pop I - 784 lost cases - UN ccode notation: 254 French Guiana, 312 Guadeloupe, 316 Guam, 344 Hong Kong, 474 Martinique, 530 Netherlands Antilles, 533 Aruba, 540 New Caledonia, 630 Puerto Rico, 638 Reunion, 830 Channel Island, 850 Virgin Islands

UN Pop II - 540 lost cases - UN ccode notation: 254 French Guiana, 258 French Polynesia, 275 Occupied Palestinian Territories, 312 Guadeloupe, 316 Guam, 344 Hong Kong, 446 Macao, 474 Martinique, 499 Montenegro, 530 Netherlands Antilles, 533 Aruba, 540 New Caledonia, 630 Puerto Rico, 638 Reunion, 688 Serbia, 732 Western Sahara, 830 Channel Island, 850 Virgin Islands

UN Pop III - 198 lost cases - UN ccode notation: 533 Aruba, 254 French Guiana, 258 French Polynesia, 312 Guadeloupe, 316 Guam, 830 Channel Islands, 312 Guadeloupe, 316 Guam, 344 Hong Kong, 446 Macao, 474 Martinique, 530 Netherlands Antilles, 540 New Caledonia, 275 Occupied Territories of Palestine, 630 Puerto Rico, 638 Reunion, 732 Western Sahara, 850 Virgin Islands

UN Pop VI - 198 lost cases - UN ccode notation: 533 Aruba, 254 French Guiana, 258 French Polynesia, 312 Guadeloupe, 316 Guam, 830 Channel Islands, 312 Guadeloupe, 344 Hong Kong, 446 Macao, 474 Martinique, 530 Netherlands Antilles, 540 New Caledonia, 275 Occupied Territories of Palestine, 630 Puerto Rico, 638 Reunion, 732 Western Sahara, 850 Virgin Islands

\section{UN SD (CD)}

451 lost cases - UN ccode notation: 16 American Samoa, 660 Anguilla, 533 Aruba, 60 Bermuda, 92 British Virgin Islands, 136 Cayman Islands, 184 Cook Islands, 254 French Guiana, 258 French Polynesia, 184 Faeroe Islands, 238 Falkland Islands, 292 Gibraltar, 304 Greenland, 316 Guam, 336 Holy See, 830 Channel Islands, 344 Hong Kong, 446 Macao, 833 Isle of Man, 474 Martinique, 500 Montserrat, 530 
Netherlands Antilles, 540 New Caledonia, 570 Niue, 574 Norfolk Island, 612 Pitcairn, 630 Puerto Rico, 638 Reunion, 653+656 Saint Helena, 666 Saint Pierre and Miquelon, 796 Turks Caicos Islands, 850 Virgin Islands, 876 Wallis and Futuna Islands

\section{FAO (CD)}

2340 lost cases - UN ccode notation: 16 American Samoa, 58 Belgium-Luxembourg, 60 Bermuda, 86 British Indian Ocean Territory, 92 British Virgin islands, 136 Cayman Islands, 162 Christmas Islands, 166 Cocos Islands, 75 Mayotte, 184 Cook Islands, 234 Faeroe Islands, 238 Falkland Islands, 254 French Guiana, 258 French Polynesia, 275 Occupied Palestinian Territories, 292 Gibraltar, 304 Greenland, 312 Guadeloupe, 316 Guam, 474 Martinique, 500 Montserrat, 530 Netherlands, Antilles, 533 Aruba, 540 New Caledonia, 570 Niue, 574 Norfolk Island, 580 Northern Mariana Islands, 582 Pacific Islands, 612 Pitcairn, 630 Puerto Rico, 638 Reunion, 654 Saint Helena, 660 Anguilla, 666 Saint Pierre and Miquelon, 732 Western Sahara, 772 Tokelau, 796 Turks and Caicos Islands, 830 Channel Islands, 833 Isle of Man, 850 United States of Virgin Islands, 876 Wallis and Futuna Islands

FDP (CD)

47 lost cases - COW ccode notation: 667 Palestine, and missing ccode for Former USSR

\section{$\operatorname{DEM}(C D)$}

0 lost cases

\section{MAR (CD)}

0 lost cases

QoG (CD)

0 lost cases - unifying ccode for structural variables and country-year data MEPV (CD)

45 lost cases - COW ccode notation: 364 SSSR

\section{PITF (CD)}

0 lost cases (during the merge of PITF 1+2+3); 1 lost case - COW ccode notation: 364 SSSR (in the process of merging with the QoG country list)

$A C D(C D)$

2 lost cases - COW ccode notation: 755 Hyderabad 


\section{$\operatorname{Regan}(C D)$}

Regan 1 - 0 lost cases

Regan 2 - 347 lost cases (during the merge of Regan 1+2+3) - Regan event identification number notation: $600,610,615,630,784,786,787,793,799,805,826$, $827,835,838,840,841,845,847,850,853,857,858,859,863,864,865,870,872,874$, $881,882,887,888,889,892,894,896,901,903,904,907,908,910,913,919,930,934$, 936, 937, 947, 949, 952, 953, 964, 966, 967, 977, 979, 982, 984, 986, 987, 991, 992, and 993; 0 lost cases (merge with the QoG country list)

Regan 3 - 165 lost cases (during the merge of Regan 1+2+3) - Regan event identification number notation: $818,830,838,840,844,847,849,872,878,884,885$, $893,910,919,933,947,953,954,957,972,973,974,985,988,989$, and 990; 0 lost cases (merge with the QoG country list)

\section{EUGene MID (CD \& DD)}

0 lost cases

$\&$

0 lost cases

\section{EUGene ICB (CD E DD)}

0 lost cases

$\&$

0 lost cases

\section{$I C B(C D \& D D)$}

20 lost cases (during the merge of ICB II+ICB Dyad) - ICB conflict number notation: $428,429,430,431,432,433$, and 434; 0 lost cases (merge with the QoG country list)

\section{Mil Int (CD \& DD)}

32 lost cases - COW ccode notation: $1000 \mathrm{UN}$ (the UN as a target state does not make a sense)

$\&$

94 lost cases - COW ccode notation in country dyads: 812 with 220, 750 with 750, 651 with 652,761 with 750, 710 with 710, 698 with 200, 265 with 365, 835 with 200, 200 with 200, 935 with 200, 935 with 900, 935 with 910, 255 with 315, 670 with 316, and 344 with $345+32$ cases with the UN as a target state (COW ccode 1000) 


\section{Peace (CD)}

0 lost cases

\section{4. 'Completeness'}

The coding of the missing observations in individual input datasets was harmonized by designating all the missing values with -999. An overview of the completeness of the merged input datasets is presented in the three following three tables that were divided according to the data type being described.

\begin{tabular}{|c|c|c|c|c|c|}
\hline \multicolumn{6}{|c|}{ CD/SD - 'COMPLETENESS' } \\
\hline Dataset & Variables & Country-years & Observations & Missing observations & Missing observations ( $\%$ ) \\
\hline EUGene SV & 18 & 8380 & 150840 & 34417 & 22,8 \\
\hline UN Pop I & 6 & 9800 & 58800 & 15400 & 26,2 \\
\hline UN Pop II & 3 & 5280 & 15840 & 4224 & 26,7 \\
\hline UN Pop III & 2 & 1914 & 3828 & 1392 & 36,4 \\
\hline UN Pop IV & 2 & 1936 & 3872 & 1408 & 36,4 \\
\hline UN SD & 1 & 1417 & 1417 & 0 & 0,0 \\
\hline FAO & 1 & 11460 & 11460 & 0 & 0,0 \\
\hline FDP & 3 & 6089 & 18267 & 1397 & 7,6 \\
\hline MAR & 7 & 7937 & 55559 & 26074 & 46,9 \\
\hline QoG & 17 & 12000 & 204000 & 71919 & 35,3 \\
\hline DEM & 14 & 6871 & 96194 & 5574 & 5,8 \\
\hline TOTAL & 74 & 73084 & 620077 & 161805 & \\
\hline \multicolumn{6}{|c|}{ Missing observations avg. $=\mathbf{2 6 , 1} \%$ (measured proportionally) } \\
\hline
\end{tabular}

\begin{tabular}{|l|r|r|r|r|r|}
\hline \multicolumn{7}{|c|}{ CD/ED - 'COMPLETENESS' } \\
\hline Dataset & Variables & Country-years & Observations & Missing observations & $\begin{array}{c}\text { Missing observations } \\
\text { (\%) }\end{array}$ \\
\hline MEPV & 3 & 7549 & $\mathbf{2 2 6 4 7}$ & 352 & $\mathbf{1 , 6}$ \\
\hline PITF 123 & 23 & 1152 & $\mathbf{2 6 4 9 6}$ & 3032 & $\mathbf{1 1 , 4}$ \\
\hline PITF 4 & 3 & 269 & $\mathbf{8 0 7}$ & 0 & $\mathbf{0 , 0}$ \\
\hline ACD & 14 & 1438 & $\mathbf{2 0 1 3 2}$ & 41 & $\mathbf{0 , 2}$ \\
\hline Regan 1 & 41 & 1021 & $\mathbf{4 1 8 6 1}$ & 389 & $\mathbf{0 , 9}$ \\
\hline Regan 2 & 3 & 1021 & $\mathbf{3 0 6 3}$ & 0 & $\mathbf{0 , 0}$ \\
\hline Regan 3 & 6 & 890 & $\mathbf{5 3 4 0}$ & 0 & $\mathbf{0 , 0}$ \\
\hline EUGene MID & 27 & 7612 & $\mathbf{2 0 5 5 2 4}$ & 0 & $\mathbf{0 , 0}$ \\
\hline
\end{tabular}




\begin{tabular}{|l|r|r|r|r|r|}
\hline EUGene ICB & 22 & 6479 & $\mathbf{1 4 2 5 3 8}$ & 164 & $\mathbf{0 , 1}$ \\
\hline ICB II & 31 & 490 & $\mathbf{1 5 1 9 0}$ & 175 & $\mathbf{1 , 2}$ \\
\hline ICB Dyad & 21 & 490 & $\mathbf{1 0 2 9 0}$ & 648 & $\mathbf{6 , 3}$ \\
\hline Mil Int & 39 & 1736 & $\mathbf{6 7 7 0 4}$ & 11821 & $\mathbf{1 7 , 5}$ \\
\hline Peace & 64 & 836 & 53504 & 4091 & $\mathbf{7 , 6}$ \\
\hline TOTAL & $\mathbf{2 9 7}$ & $\mathbf{3 0 9 8 3}$ & $\mathbf{6 1 5 0 9 6}$ & $\mathbf{2 0 7 1 3}$ & \\
\hline \multicolumn{7}{|c|}{ Missing observations avg. $=\mathbf{3 , 4 \%}$ (measured proportionally) } \\
\hline
\end{tabular}

\begin{tabular}{|l|r|r|r|r|r|}
\hline \multicolumn{7}{|c|}{ Dataset } & Variables & $\begin{array}{c}\text { Country-dyad } \\
\text { years }\end{array}$ & Observations & $\begin{array}{c}\text { Missing } \\
\text { observations }\end{array}$ & $\begin{array}{c}\text { Missing } \\
\text { observations (\%) }\end{array}$ \\
\hline EUGene SV dyad & 37 & 1258552 & $\mathbf{4 6 5 6 6 4 2 4}$ & 9925276 & $\mathbf{2 1 , 3}$ \\
\hline EUGene MID dyad & 54 & 1258552 & $\mathbf{6 7 9 6 1 8 0 8}$ & 7921152 & $\mathbf{1 1 , 7}$ \\
\hline EUGene ICB dyad & 40 & 1258552 & $\mathbf{5 0 3 4 2 0 8 0}$ & 14380960 & $\mathbf{2 8 , 6}$ \\
\hline ICB dyad & 50 & 754 & $\mathbf{3 7 7 0 0}$ & 1142 & $\mathbf{2 1 , 0}$ \\
\hline Mil Int dyad & 39 & 3057 & $\mathbf{1 1 9 2 2 3}$ & 25939 & 32254469 \\
\hline TOTAL & 220 & 3779467 & $\mathbf{1 6 5 0 2 7 2 3 5}$ & 320 \\
\hline \multicolumn{7}{|c|}{ Missing observations avg. = 19,5\% (measured proportionally) } \\
\hline
\end{tabular}

Based on the records in the above tables, some input datasets seem to have a relatively high proportion of the missing values. Nevertheless, the higher proportions of the missing values were not caused by a bad quality of the data itself, but rather by some of the methodological and structural decisions. First of all, the number of missing observations in the UN Pop 1/2/3 and UN SD datasets was artificially increased, since the datasets contained some variables with the measurements recorded only in the 5-year intervals. Even though, there were new variables created that interpolated the middle values or alternatively that kept the values within the five-year intervals constant; the original variables with the missing middle values were still left in the data compilation, so as to allow the future users applying a different methodological approach. This artificially increased the percentage of the missing observations in theses datasets.

Secondly, a higher number of the missing observations in the MAR, QoG, and partially in the Mil Int datasets was influenced by the fact that these datasets were originally created as data compilations in themselves; and therefore, individual variables within these datasets covered a different time spam. Regardless of this fact, each of these input datasets was treated as one block for the purposes of this data compilation. Therefore, in case that some variable covered a shorter time 
frame than the rest of the input dataset, the years not covered by the variable were denoted as missing. Similarly, data downloaded by the EUGene software (EUGene SV, EUGene SV dyad, EUGene ICB dyad and EUGene MID dyad) report an artificially higher amount of the missing observations, since each of these input datasets was downloaded in the time frame of 1946-2005, regardless of their actual time coverage of these datasets.

For this reason, while considering the completeness of the merged datasets; it is necessary to treat the variables individually. It is always better to check the number of the missing observations in each variable alone, and then to consult the coding table, which it to be found at the end of this technical appendix, so as to gain the information about the structure and the real original time coverage of the variable. The following table provides a complete list of the missing values in the individual variables. The list is divided by the data types and by the input datasets, with the yellow fields providing the information about a total number of missing variables in each merged dataset.

\begin{tabular}{|l|l|l|l|l|l|}
\hline \multicolumn{7}{|c|}{ MISSING OBSERVATIONS } \\
\hline Variable name & No. of obs. & Variable name & No. of obs. & Variable name & No. of obs. \\
\hline STRUCTURAL DATA (SD-CD) & Tot_MID & 0 & Risk_A_t & 465925 \\
\hline EUGene SV & $\mathbf{3 4 4 1 7}$ & Peace_yrs_B & 0 & Risk_B_t & 465925 \\
\hline Mil_cap & 768 & Peace_dys_B & 0 & Risk_A_s & 184006 \\
\hline Mil_personal & 856 & B_init & 0 & Risk_B_s & 184006 \\
\hline Mil_exp & 1217 & EUGene ICB & $\mathbf{1 6 4}$ & Uncert_t & 463498 \\
\hline Energy_consum & 802 & ICB_c & 0 & Uncert_s & 182978 \\
\hline Iron_steel & 769 & ICB_c_freq & 0 & Util_AchB_t & 466064 \\
\hline Urb_pop & 769 & New_ICB_c & 0 & Util_Asq_t & 466064 \\
\hline Tot_pop & 769 & C_beg_yr_AB & 0 & Succ_A_t & 468346 \\
\hline Major_power & 0 & C_beg_mth_AB & 0 & Util_BchB_t & 466064 \\
\hline Region & 0 & C_end_yr_AB & 0 & Util_Bsq_t & 466064 \\
\hline Polity_III & 2766 & C_end_mth_AB & 0 & Succ_B_t & 468346 \\
\hline Polity_III_lg & 2867 & C_dur_dys_AB & 0 & Util_AchB_s & 184145 \\
\hline Polity_III_adj & 1026 & C_dur_yrs_AB & 0 & Util_Asq_s & 184145 \\
\hline Dem_score & 1276 & C_beg_yr_B & 82 & Succ_A_s & 185034 \\
\hline Autoc_score & 1276 & C_beg_mth_B & 82 & Util_BchB_s & 184145 \\
\hline Democratiz & 2946 & C_end_yr_B & 0 & Util_Bsq_s & 184145 \\
\hline Regime_dur & 988 & C_end_mth_B & 0 & Succ_B_s & 185034 \\
\hline
\end{tabular}




\begin{tabular}{|c|c|c|c|c|c|}
\hline Imports & 7661 & ICB_B_no & 0 & EUGene MID dyad & 7921152 \\
\hline Exports & 7661 & Stability_B_I & 0 & MID_ongo & 146688 \\
\hline UN Pop & 22424 & Stability_B_II & 0 & MID_ongo_no & 146688 \\
\hline Deaths_5yr_o & 7700 & Internal_c_B & 0 & MID_init & 146688 \\
\hline Deaths_5yr_c & 0 & B_c_joiner & 0 & MID_init_no & 146688 \\
\hline Deaths_i & 0 & New_ICB_freq & 0 & MID_ref_no & 146688 \\
\hline Life_exp_5yr_o & 7700 & ICB_freq & 0 & Host_A & 146688 \\
\hline Life_exp_5y_c & 0 & Peace_yrs & 0 & Host_B & 146688 \\
\hline Life_exp_i & 0 & Peace_dys & 0 & Host_MID & 146688 \\
\hline Migr_5yr_o & 4224 & ICB II & 75 & Ref_no_kMID & 146688 \\
\hline Migr_5yr_c & 0 & Trig_type & 0 & A_init_kMID & 146688 \\
\hline Migr_i & 0 & C_freq & 0 & B_init_kMID & 146688 \\
\hline Migr_rate_o & 1392 & Ext_trigent & 0 & Join_A_init & 146688 \\
\hline Migr_rate_c & 0 & Int_trigent & 0 & Join_A_targ & 146688 \\
\hline Deaths_1yr & 0 & C_manage & 0 & Join_kMID_A_init & 146688 \\
\hline Migr_5yr000_o & 1408 & Mil_manage & 0 & Join_kMID_A_targ & 146688 \\
\hline UN SD & 0 & Viol_centr & 0 & Beg_A_mth & 146688 \\
\hline Migr_5yr000_c & 0 & Viol_use & 0 & Beg_A_dy & 146688 \\
\hline FAO & 0 & Viol_intens & 0 & Beg_A_yr & 146688 \\
\hline Land_area & 0 & Glob_org_act & 0 & Beg_B_mth & 146688 \\
\hline FDP & 1397 & Reg_org_act & 0 & Beg_B_dy & 146688 \\
\hline Refug & 548 & Satisf_A & 0 & Beg_B_yr & 146688 \\
\hline IDP & 426 & Satisf_B & 0 & End_A_mth & 146688 \\
\hline Refug_hosted & 423 & Satisf_AB & 0 & End_A_dy & 146688 \\
\hline MAR & 26074 & Dissatisf_AB & 0 & End_A_yr & 146688 \\
\hline Group_ident & 4615 & C_escal & 0 & End_B_mth & 146688 \\
\hline Ethn_diff_x & 2980 & C_deescal & 0 & End_B_dy & 146688 \\
\hline Aggr_diff_x & 3611 & Distance & 0 & End_B_yr & 146688 \\
\hline Advant_lost & 6238 & Actors_no & 1 & A_supp_i_kMID & 146688 \\
\hline Com_conflict_x & 3207 & Int_syst & 0 & A_supp_t_kMID & 146688 \\
\hline Protest_x & 2753 & C_scale & 0 & A_revis_kMID & 146688 \\
\hline Rebellion_x & 2670 & Protracted_c & 0 & B_revis_kMID & 146688 \\
\hline QoG & 71919 & Viol_actor & 0 & Revis_type_A & 146688 \\
\hline Region_1 & 57 & Power_dif & 2 & Revis_type_A2 & 146688 \\
\hline Colonial_origin & 57 & C_mil_sec & 0 & Revis_type_B & 146688 \\
\hline Pop_000 & 5355 & C_pol_dipl & 0 & Revis_type_B2 & 146688 \\
\hline
\end{tabular}




\begin{tabular}{|c|c|c|c|c|c|}
\hline Urban_pop_1 & 5355 & C_econ_dev & 0 & |Fatal_level_A & 146688 \\
\hline Literacy_i & 5205 & C_cult_status & 0 & Fatal_exact_A & 146688 \\
\hline Ethn_fract & 720 & C_gravity & 0 & Fatal_level_B & 146688 \\
\hline Relig_fract & 540 & Econ_actor & 72 & Fatal_exact_B & 146688 \\
\hline Cult_diversity & 2713 & ICB Dyad & 648 & Top_act_A & 146688 \\
\hline Power_res_x & 5205 & Mutual_c & 0 & Top_act_B & 146688 \\
\hline GDP_pc & 3736 & A_side_c & 0 & Top_act_MID & 146688 \\
\hline Tot_trade & 4367 & B_side_c & 0 & Outcome & 146688 \\
\hline Gini_mean & 9892 & Stab_A & 0 & Settle & 146688 \\
\hline Gini_x & 11317 & Stab_B & 0 & Fatal_MID & 146688 \\
\hline State_failure & 4533 & Beg_yr_A & 102 & Mutual_MID & 146688 \\
\hline Dem_x & 3770 & Beg_mth_A & 102 & Allies_A & 146688 \\
\hline Polity_IV_score & 4534 & End_yr_A & 61 & Allies_B & 146688 \\
\hline Regime_dur_pIV & 4563 & End_mth_A & 61 & New_MID & 146688 \\
\hline DEM & 5574 & Beg_yr_B & 88 & Tot_MID & 146688 \\
\hline Pop_log & 84 & Beg_mth_B & 88 & Peace_yrs & 146688 \\
\hline GDP_log & 147 & End_yr_B & 73 & Peace_dys & 146688 \\
\hline Onset_COW & 1490 & End_mth_B & 73 & MID_role_A & 146688 \\
\hline Peace_COW & 716 & Beg_yr_AB & 0 & MID_role_B & 146688 \\
\hline Onset_ADC & 910 & Beg_mth_AB & 0 & EUGene ICB dyad & 14380960 \\
\hline Peace_ACD & 0 & End_yr_AB & 0 & ICB_C & 359524 \\
\hline Onset_type_ADC & 913 & End_mth_AB & 0 & ICB_ref_no & 359524 \\
\hline Dem_0 & 0 & Dur_dys_AB & 0 & New_ICB_c & 359524 \\
\hline Autoc_0 & 0 & Dur_yrs_AB & 0 & New_ICB_no & 359524 \\
\hline Dem_0-3after & 387 & Ongo_AB & 0 & ICB_dyad_no & 359524 \\
\hline Autoc_0-3after & 387 & Mil Int & 11821 & One_side & 359524 \\
\hline Anoc & 180 & Int_descr & 0 & Beg_yr_AB & 359524 \\
\hline Polity_IV & 180 & Int_beg & 0 & Beg_mth_AB & 359524 \\
\hline Polity_IV_sq & 180 & Int_end & 80 & Beg_dy_AB & 359524 \\
\hline \multicolumn{2}{|c|}{ EVENT DATA (ED-CD) } & Int_no & 0 & End_yr_AB & 359524 \\
\hline MEPV & 352 & Prev_int & 490 & End_mth_AB & 359524 \\
\hline Viol & 115 & Align_B & 490 & End_dy_AB & 359524 \\
\hline Viol_neighb & 118 & Power_size_A & 490 & Dur_dys_AB & 359524 \\
\hline Viol_reg & 119 & Power_size_B & 490 & Dur_yrs_AB & 359524 \\
\hline PITF 123 & 3032 & Joint_hist_type & 0 & Beg_yr_A & 359524 \\
\hline PITF_1 & 0 & Joint_hist & 0 & Beg_mth_A & 359524 \\
\hline
\end{tabular}




\begin{tabular}{|c|c|c|c|c|c|}
\hline PITF_2 & 0 & IO_int & 0 & Beg_dy_A & 359524 \\
\hline PITF_3 & 0 & Neutral_int & 0 & Beg_yr_B & 359524 \\
\hline PITF_1_freq & 0 & Int_supp_gov & 0 & Beg_mth_B & 359524 \\
\hline PITF_2_freq & 0 & Int_supp_reb & 0 & Beg_dy_B & 359524 \\
\hline PITF_3_freq & 0 & Troop_act_type & 108 & End_yr_A & 359524 \\
\hline PITF_123_freq & 0 & Agress_act & 0 & End_mth_A & 359524 \\
\hline PITF_beg_mth & 0 & Troop_no_max & 211 & End_dy_A & 359524 \\
\hline PITF_beg_yr & 0 & Troop_no_sum & 211 & End_yr_B & 359524 \\
\hline PITF_end_mth & 0 & Air_incurs & 352 & End_mth_B & 359524 \\
\hline PITF_end_yr & 0 & Naval_incurs & 474 & End_dy_B & 359524 \\
\hline Opp_force & 149 & Navy_size & 1360 & A_ref_no & 359524 \\
\hline Fatalites & 147 & Outside_firing & 265 & B_ref_no & 359524 \\
\hline Area_affected & 132 & Intern_c & 197 & Stab_A_I & 359524 \\
\hline PITF_magn_avg & 2 & Pol_int & 8 & Stab_B_I & 359524 \\
\hline PITF_magn_sum & 2 & Social_int & 430 & Stab_A_II & 359524 \\
\hline PITF_magn_max & 2 & Pursuit_int & 151 & Stab_B_II & 359524 \\
\hline PITF_scale & 866 & Econ_int & 470 & Intern_c_A & 359524 \\
\hline Dem_collapse & 866 & Strat_int & 182 & Intern_c_B & 359524 \\
\hline Viol_scale & 866 & Hum_int & 214 & A_joiner & 359524 \\
\hline PITF 4 & 0 & Territ_int & 240 & B_joiner & 359524 \\
\hline PITF_4 & 0 & Protect_int & 673 & New_ICB_freq & 359524 \\
\hline Genoc_deaths & 0 & Contiguity & 148 & ICB_freq & 359524 \\
\hline ACD & 41 & Contiq_int & 33 & Peace_yrs & 359524 \\
\hline C_freq & 0 & C_deaths_max & 943 & Peace_dys & 359524 \\
\hline C_issue_ter & 0 & C_deaths_sum & 943 & ICB dyad & 1142 \\
\hline C_issue_gov & 0 & B_deaths_Amax & 514 & Mutual_c & 0 \\
\hline Extrasyst_c & 0 & B_deaths_Asum & 514 & A_side_c & 0 \\
\hline Interst_c & 0 & B_deaths_Bmax & 570 & B_side_c & 0 \\
\hline Intern_c & 0 & B_deaths_Bsum & 570 & Stab_A & 0 \\
\hline Spread_c & 0 & Peace & 4091 & Stab_B & 0 \\
\hline Intensity & 0 & C_beg_yr & 0 & Beg_yr_A & 191 \\
\hline Cum_intensity & 0 & C_end_yr & 84 & Beg_mth_A & 191 \\
\hline 1st_b_death & 0 & C_beg_dec & 0 & End_yr_A & 187 \\
\hline 1st25_b_deaths & 0 & C_reoc_2 & 0 & End_mth_A & 187 \\
\hline B_deaths_low & 0 & C_reoc_5 & 57 & Beg_yr_B & 106 \\
\hline B_deaths_high & 0 & C_reoc_10 & 366 & Beg_mth_B & 106 \\
\hline
\end{tabular}




\begin{tabular}{|c|c|c|c|c|c|}
\hline B_deaths_best & 41 & Viol_reoc_2 & 0 & End_yr_B & 0 \\
\hline Regan 1 & 389 & Viol_reoc_5 & 57 & End_mth_B & 0 \\
\hline C_beg_date & 0 & Viol_reoc_10 & 362 & Beg_yr_AB & 0 \\
\hline C_end_date & 0 & War_10bef & 0 & Beg_mth_AB & 0 \\
\hline C_end & 0 & Democr_2aft & 123 & End_yr_AB & 0 \\
\hline C_dur_mths & 0 & Democr_5aft & 189 & End_mth_AB & 0 \\
\hline C_int & 0 & Democr_10aft & 515 & C_dur_dys & 0 \\
\hline Bef_int & 0 & Democr_5bef & 0 & C_dur_yrs & 0 \\
\hline Int_mth & 0 & Democr_10bef & 0 & Ongo_c & 0 \\
\hline Int_freq & 0 & Polity_2aft & 0 & Trig_type & 0 \\
\hline Int & 0 & Polity_5aft & 53 & Trigent & 0 \\
\hline Force_type_max & 0 & Polity_10aft & 395 & Extern_trig & 0 \\
\hline Force_type_sum & 0 & Peacebuild & 0 & Intern_trig & 0 \\
\hline Force_freq & 0 & Rebel_vict & 0 & Manage & 0 \\
\hline Force & 0 & Gov_vict & 0 & Mil_manage & 0 \\
\hline Bef_force & 0 & Treaty & 0 & Viol_centr & 0 \\
\hline IO_int & 0 & Truce & 0 & Viol_use & 0 \\
\hline Target_clash & 0 & C_dur_mths & 0 & Viol_intens & 0 \\
\hline Int_neut & 0 & UN_int_0 & 0 & Glob_org_act & 0 \\
\hline Int_opp & 0 & UN_int_1 & 0 & Reg_org_act & 0 \\
\hline Int_gov & 0 & UN_int_01 & 0 & Satisf_A & 0 \\
\hline Mil_int & 0 & UN_int_2 & 0 & Satisf_B & 0 \\
\hline Bef_mil_int & 0 & UN_int_3 & 0 & Satisf_AB & 0 \\
\hline Mil_int_freq & 0 & UN_int_4 & 0 & Dissatisf_AB & 0 \\
\hline Mil_int_gov & 0 & UN_int_type & 0 & C_escal & 0 \\
\hline Mil_int_opp & 0 & NonUN_int_type & 0 & C_deescal & 0 \\
\hline Mil_int_neut & 0 & All_int_type & 0 & Distance & 0 \\
\hline Mil_int_type & 0 & Many_patries & 0 & Actors_no & 1 \\
\hline Econ_int & 0 & Parties_no & 0 & Syst_pol & 0 \\
\hline Econ_int_gov & 0 & 1_party & 0 & Protract_c_sc & 0 \\
\hline Econ_int_neut & 0 & 2_parties & 0 & Protract_c & 0 \\
\hline Econ_int_pos & 0 & Size_gov_army & 3 & Viol_actor & 0 \\
\hline Econ_pos_freq & 0 & Battle_deaths & 199 & Pow_dif & 2 \\
\hline Econ_int_neg & 0 & War_deaths & 5 & C_pol_dipl & 0 \\
\hline Econ_neg_freq & 0 & War_deaths_1 & 5 & C_econ_dev & 0 \\
\hline Relig_c & 0 & Refug_idp & 0 & C_cult_stat & 0 \\
\hline
\end{tabular}




\begin{tabular}{|c|c|c|c|c|c|}
\hline Ethn_c & 0 & Hum_cost & 5 & C_mil_sec & 0 \\
\hline Ideol_c & 0 & Hum_cost_1 & 5 & Issue_grav & 0 \\
\hline Ethn_relig_c & 0 & Life_exp_bef & 0 & Econ_actor & 171 \\
\hline Size_opp & 370 & Life_exp_aft & 0 & Mil Int dyad & 25939 \\
\hline War_deaths & 0 & GDPpc_bef & 16 & Int_descr & 0 \\
\hline War_deaths_avg & 0 & GDPr_bef & 44 & Beg_date_int & 0 \\
\hline Largest_ethn & 19 & GDPr_aft & 64 & End_date_int & 168 \\
\hline Regan 2 & 0 & GDPr_PPP & 18 & Int_freq & 0 \\
\hline GDP & 0 & Peace_gini & 158 & Prev_int & 985 \\
\hline Gemstones & 0 & Transfers & 55 & Targ_align & 985 \\
\hline Opiates & 0 & Transfers_adj & 2 & Pow_size_A & 985 \\
\hline Regan 3 & 0 & Pop_bef & 0 & Pow_size_B & 985 \\
\hline Dif_c_link & 0 & Pop_5aft & 249 & B_deaths_Amax & 1233 \\
\hline C_beg_mth & 0 & Pop_10aft & 527 & B_deaths_Asum & 1233 \\
\hline C_beg_yr & 0 & Pop_growth & 392 & B_deaths_Bmax & 1345 \\
\hline C_end_mth & 0 & Inf_deaths & 0 & B_deaths_Bsum & 1345 \\
\hline C_end_yr & 0 & Illit_bef & 30 & C_deaths_max & 2018 \\
\hline No_borders & 0 & Illit_aft & 30 & C_deaths_sum & 2018 \\
\hline EUGene MID & 0 & Cult_fract & 27 & IO_int & 0 \\
\hline MID_ongo & 0 & Water_access & 29 & Int_neutr & 0 \\
\hline MID_ongo_freq & 0 & State_area & 27 & Int_supp_gov & 0 \\
\hline MID_init & 0 & Borders_no & 0 & Int_supp_reb & 0 \\
\hline Host_A & 0 & \multicolumn{2}{|c|}{ DYADIC DATA (DD) } & Troop_act & 276 \\
\hline Host_B & 0 & EUGene SV & 9925276 & Agress_act & 0 \\
\hline Host_MID & 0 & Mil_cap_A & 146688 & Troop_no_max & 499 \\
\hline B_init_kMID & 0 & Mil_cap_B & 146688 & Troop_no_sum & 499 \\
\hline B_target_kMID & 0 & Big_pow_A & 0 & Air_incurs & 893 \\
\hline B_revis_kMID & 0 & Big_pow_B & 0 & Naval_icurs & 1153 \\
\hline B_revis & 0 & Reg_A & 0 & Navy_size & 2590 \\
\hline B_beg_mth & 0 & Reg_B & 0 & Outside_firing & 682 \\
\hline B_beg_yr & 0 & Dir_contig & 0 & Intern_c & 505 \\
\hline B_end_mth & 0 & Col_contig & 0 & Pol_int & 15 \\
\hline B_end_yr & 0 & Distance & 0 & Social_int & 890 \\
\hline Fatal_A & 0 & Tau_reg & 182978 & Pursuit_int & 338 \\
\hline Fatal_B & 0 & Tau_glob & 182978 & Econ_int & 1096 \\
\hline Fatal_MID & 0 & Alliance_reg & 182978 & Strat_int & 457 \\
\hline
\end{tabular}




\begin{tabular}{|l|l|l|l|l|l|} 
Top_act_A & 0 & Alliance_glob & 182978 & Hum_int & 462 \\
\hline Top_act_B & 0 & Dem_A & 496057 & Territ_int & 530 \\
\hline Top_act_MID & 0 & Dem_B & 496057 & Protect_int & 1313 \\
\hline Mutual_MID & 0 & Dem_A_lg & 507763 & Contiquity & 378 \\
\hline Allies_A & 0 & Dem_B_lg & 507763 & Contiq_int & 63 \\
\hline Allies_B & 0 & Democr_A & 519207 & Joint_hist_type & 0 \\
\hline New_MID & 0 & Democr_B & 519207 & Joint_hist & 0 \\
\hline
\end{tabular}

\section{Coding table - data compilation}

The coding table that provides relevant information about all the variables included into the data compilation is available on the web pages of the Maastricht Graduate School of Governance. The users of the data compilation can find there the original source of the variable, its original form, and all the carried out adjustments including the grouping operator used (if applicable). The table also indicates the newly assigned name and coding of the merged variables. The table is divided by the data types: country-year 'structural data' (CD-SD); country year 'crisis-event data' (CD-ED); country year 'intervention-event data' (CD-ED); and dyadic structural, crisis and intervention data (DD).

\section{6. $\quad$ Coding table - quantified JWT}

The following table presents the variables quantifying the JWT and its constituting criteria. Apart from the main JWT indexes, the table also includes the intermediate variables describing the various forms of the progressive adjustments. 


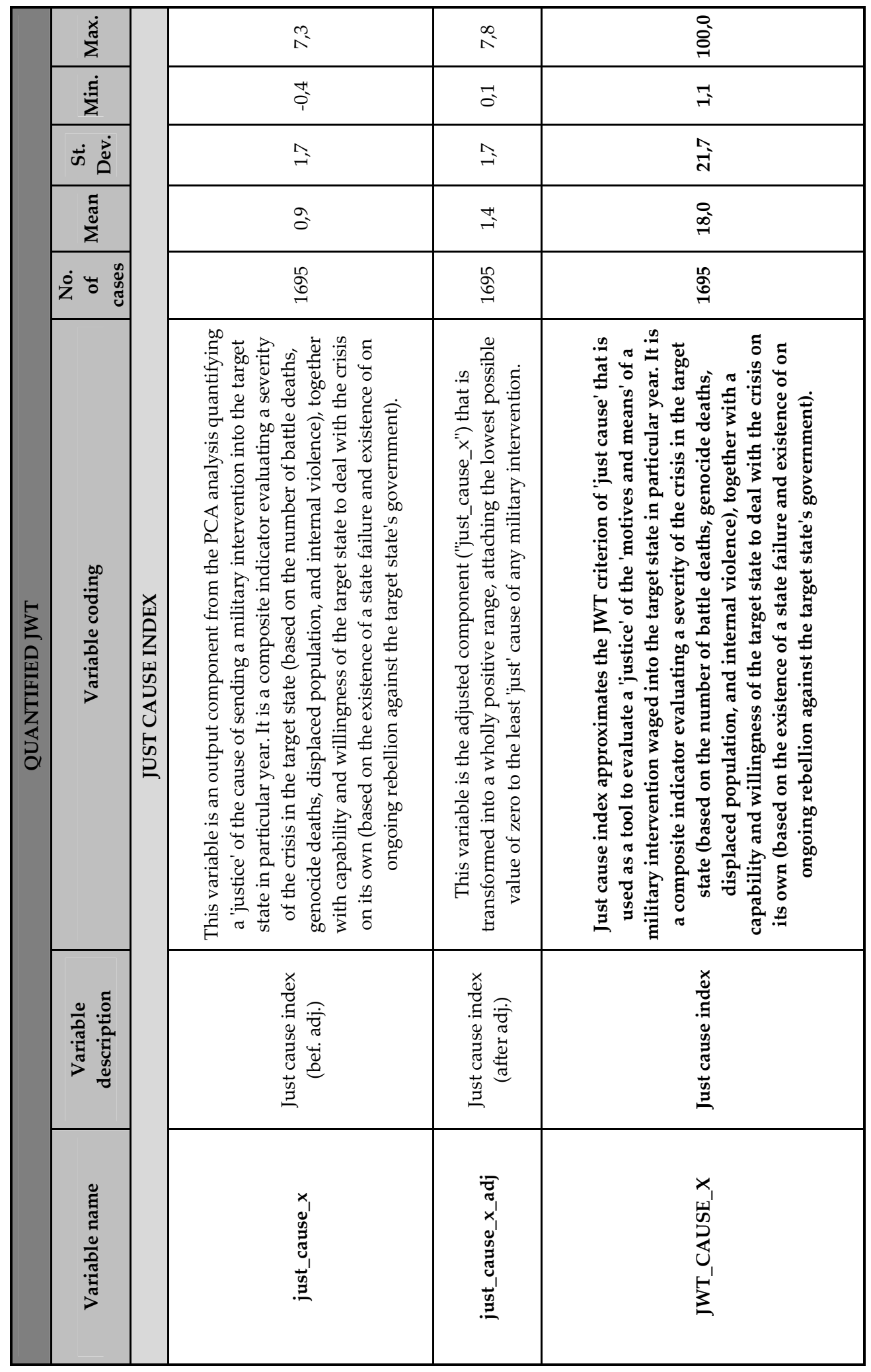




\begin{tabular}{|c|c|c|c|c|c|}
\hline $\begin{array}{l}\text { 오 } \\
\stackrel{2}{n}\end{array}$ & & $\stackrel{\circ}{i}$ & $\begin{array}{l}0 \\
\infty\end{array}$ & $\vec{\sim}$ & $\begin{array}{c}\circ \\
\overbrace{}^{\prime}\end{array}$ \\
\hline $\mathscr{O}^{2}$ & & $\vec{i}$ & $\stackrel{9}{\rightarrow}$ & $\vec{p}^{0}$ & $\infty^{\infty}$ \\
\hline स゙ & & $\stackrel{\circ}{-}$ & $\stackrel{\circ}{-}$ & $\stackrel{\circ}{-}$ & $\stackrel{\circ}{-}$ \\
\hline$\stackrel{L}{+}$ & & O̊. & ㅇ. & O̊. & ᄋ̊ \\
\hline 용 & & مू & $\stackrel{2}{\sigma}$ & $\begin{array}{l}\mathscr{L} \\
\sigma \\
-1\end{array}$ & $\underset{\sigma}{\mathscr{L}}$ \\
\hline 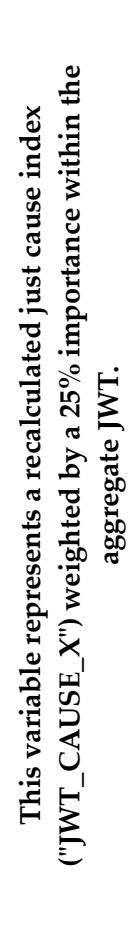 & 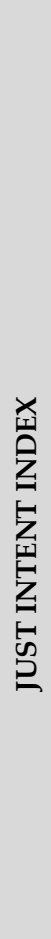 & 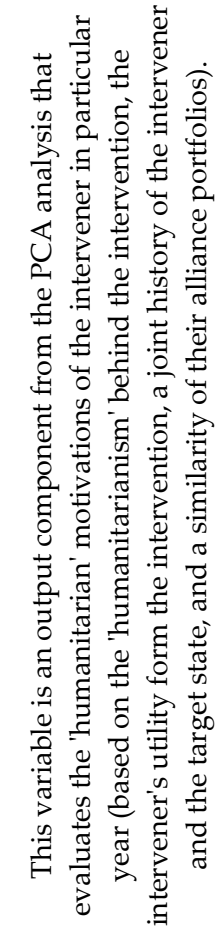 & 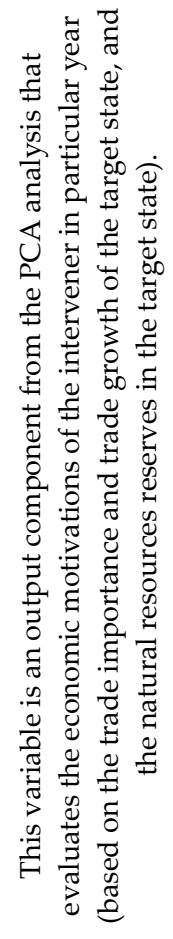 & 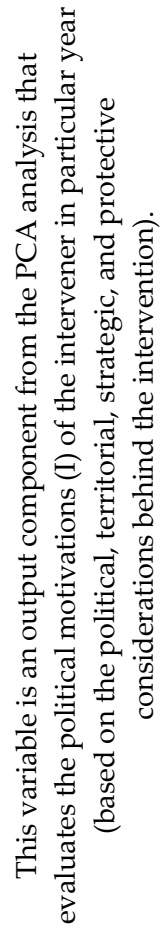 & 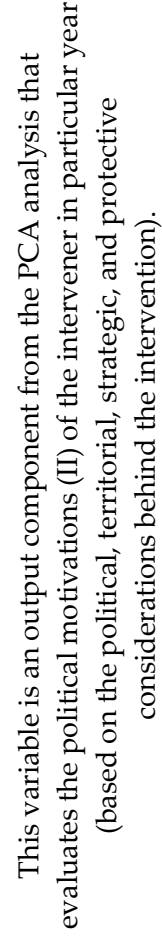 \\
\hline 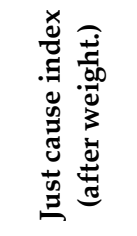 & & 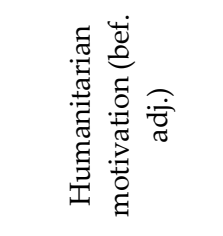 & 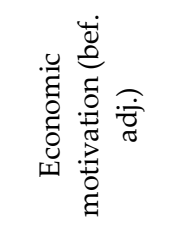 & 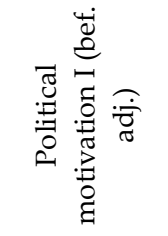 & 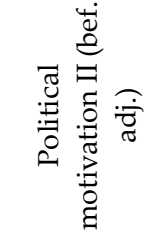 \\
\hline 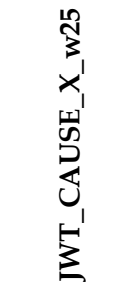 & & 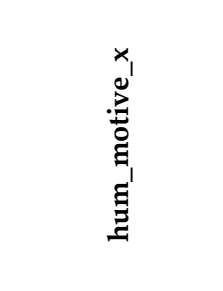 & 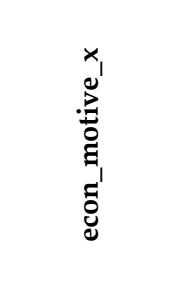 & 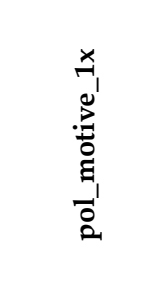 & 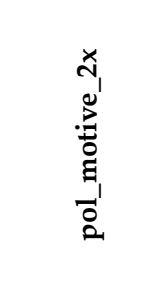 \\
\hline
\end{tabular}

กै 


\begin{tabular}{|c|c|c|c|c|c|c|}
\hline F & ڤે & $\widehat{\widehat{~}}$ & $\overbrace{}^{\infty}$ & $\stackrel{\circ}{\circ}$ & $\begin{array}{l}\text { वे. } \\
\text { iे }\end{array}$ & $\stackrel{0}{\circ}$ \\
\hline$\stackrel{\circ}{\circ}$ & $\stackrel{\circ}{\circ}$ & $\stackrel{\circ}{\circ}$ & ᄋ. & ᄋ & $\stackrel{\circ}{\circ}$ & $\stackrel{\circ}{\circ}$ \\
\hline$\stackrel{\circ}{-}$ & $\stackrel{\circ}{\rightarrow}$ & $\stackrel{0}{-}$ & $\stackrel{\circ}{-}$ & $\stackrel{\mathscr{N}}{\stackrel{N}{N}}$ & $\begin{array}{c}\circ \\
n^{\prime}\end{array}$ & $\hat{~}$ \\
\hline$\vec{i}$ & $\stackrel{q}{\rightarrow}$ & $\ddot{n}^{0}$ & $\stackrel{\infty}{\infty}^{\infty}$ & $\widehat{\bar{n}}$ & $\hat{\circ}$ & $\overbrace{0}^{n}$ \\
\hline 음 & $\underset{-10}{\text { gి }}$ & 음 & 믐 & $\underset{\sim}{2}$ & 음 & 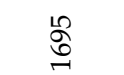 \\
\hline 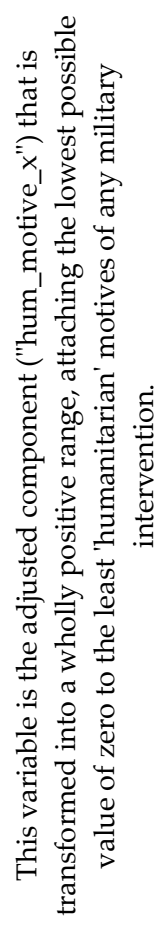 & 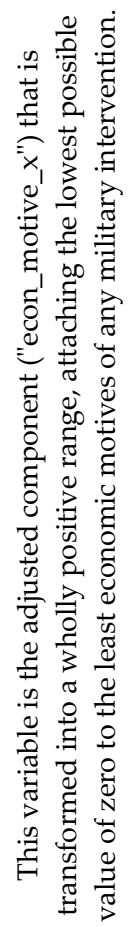 & 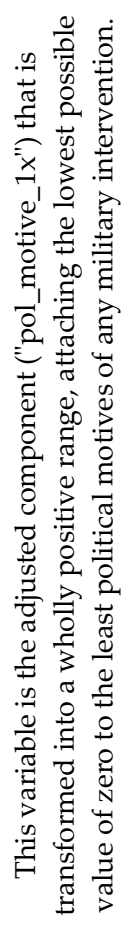 & 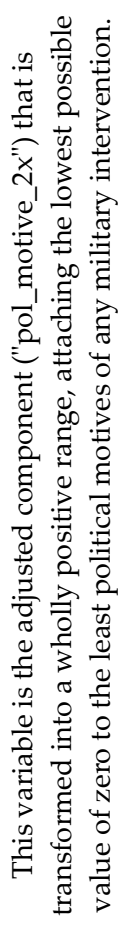 & 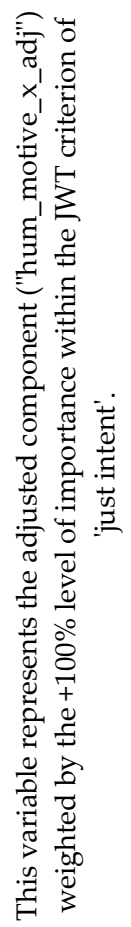 & 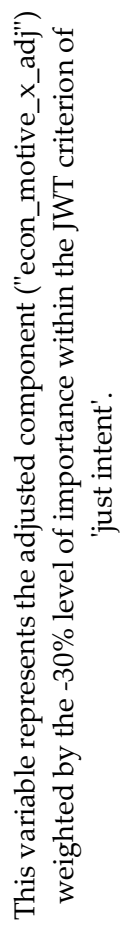 & 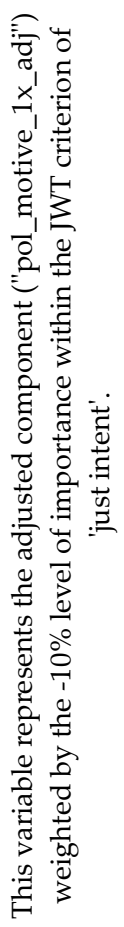 \\
\hline 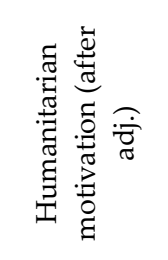 & 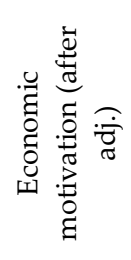 & 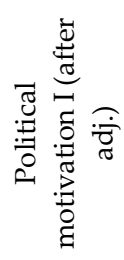 & 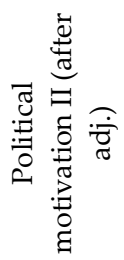 & 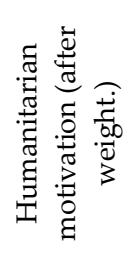 & 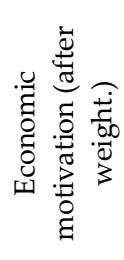 & 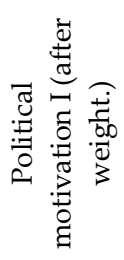 \\
\hline 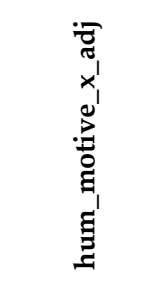 & 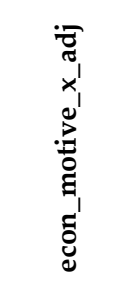 & 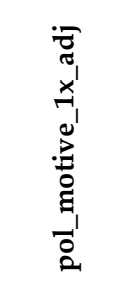 & 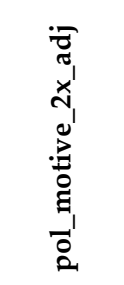 & 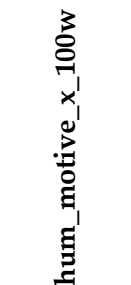 & 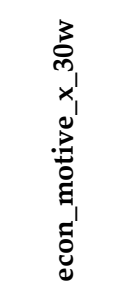 & 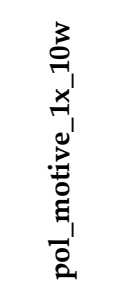 \\
\hline
\end{tabular}




\begin{tabular}{|c|c|c|}
\hline$\stackrel{0}{\circ}$ & $\begin{array}{l}\text { In } \\
\text { s. }\end{array}$ & $\begin{array}{l}\text { ָ̃ } \\
\text { Sิ }\end{array}$ \\
\hline 8 & $\frac{\widehat{\sigma}}{\overline{1}}$ & 8 \\
\hline 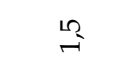 & I & $\stackrel{0}{\stackrel{N}{ }}$ \\
\hline i̊ & $\begin{array}{l}\text { Pे } \\
\text { di }\end{array}$ & $\hat{\tilde{n}}$ \\
\hline 兽 & مِ & : \\
\hline 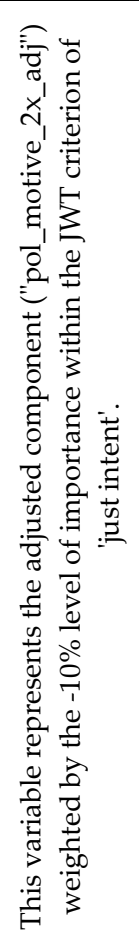 & 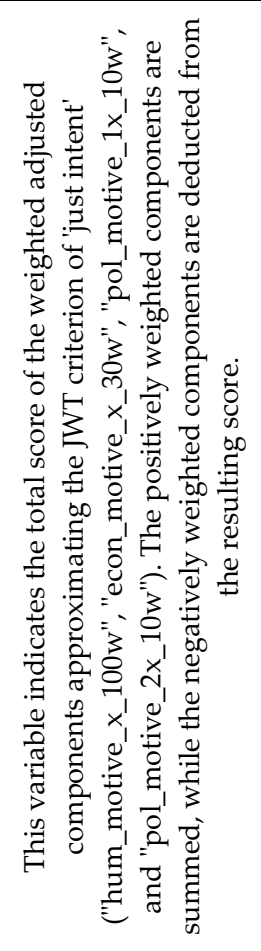 & 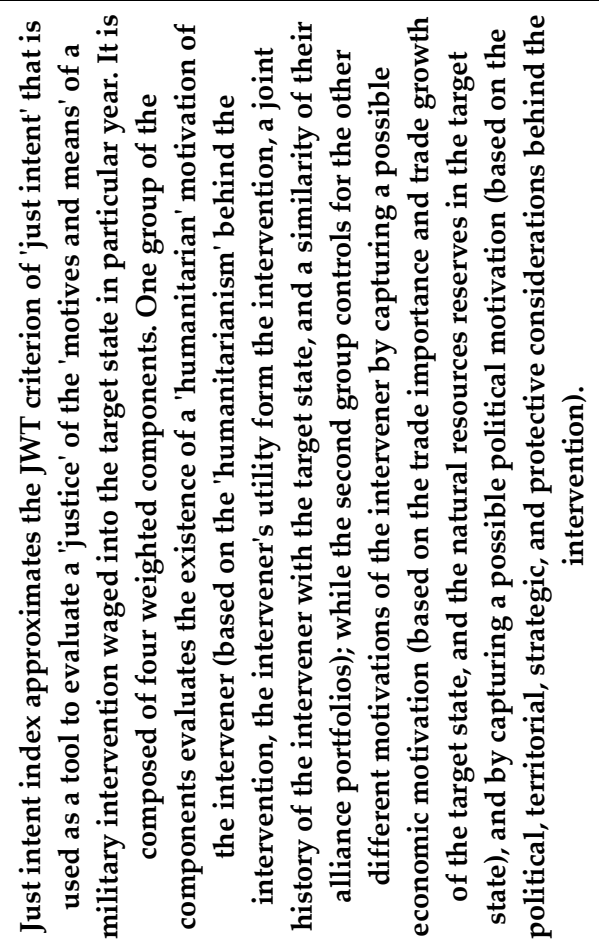 \\
\hline 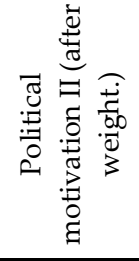 & 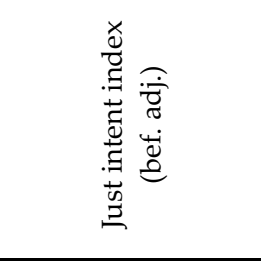 & 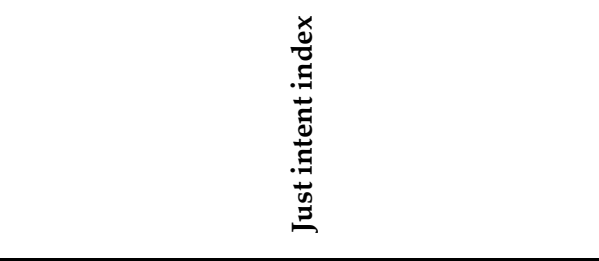 \\
\hline 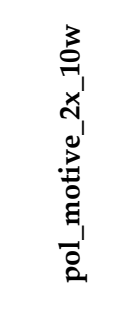 & 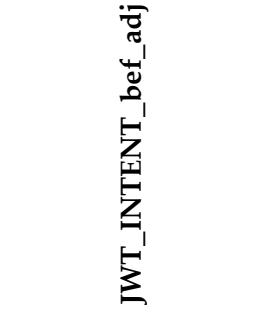 & 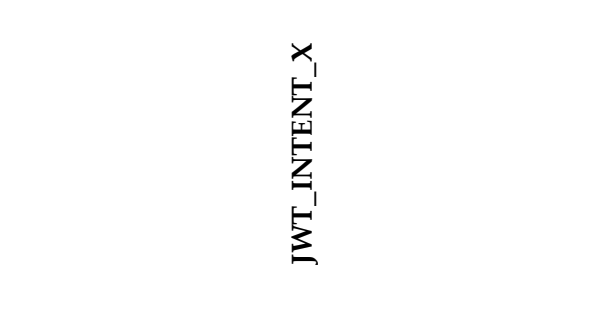 \\
\hline
\end{tabular}




\begin{tabular}{|c|c|c|c|c|c|c|}
\hline $\begin{array}{l}\text { Oे } \\
\text { ò }\end{array}$ & & $\stackrel{q}{\rightarrow}$ & $\stackrel{\curvearrowright}{\digamma}$ & $\widehat{\widehat{m}}$ & $\hat{\sigma}$ & $\stackrel{0}{8}$ \\
\hline O̊ & & $\stackrel{-}{\Im}$ & $\begin{array}{l}\text { 오 } \\
\text { ip }\end{array}$ & : & : & : \\
\hline 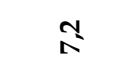 & & $\stackrel{\circ}{\rightarrow}$ & $\stackrel{\circ}{\rightarrow}$ & $\stackrel{\circ}{\rightarrow}$ & $\stackrel{\circ}{\rightarrow}$ & $\underset{\sigma}{*}$ \\
\hline $\begin{array}{l}\infty \\
\stackrel{\infty}{n}\end{array}$ & & ᄋ̊ & ᄋ & 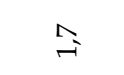 & 온 & $\begin{array}{l}\text { ते } \\
\text { ì }\end{array}$ \\
\hline 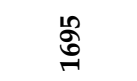 & & ஜू & 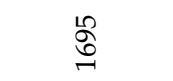 & $\underset{-}{\stackrel{2}{6}}$ & 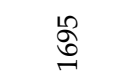 & 足 \\
\hline 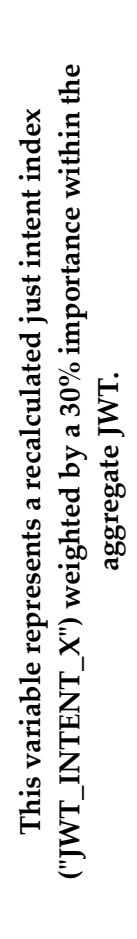 & 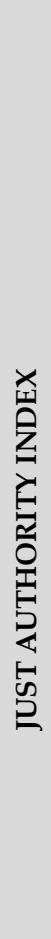 & 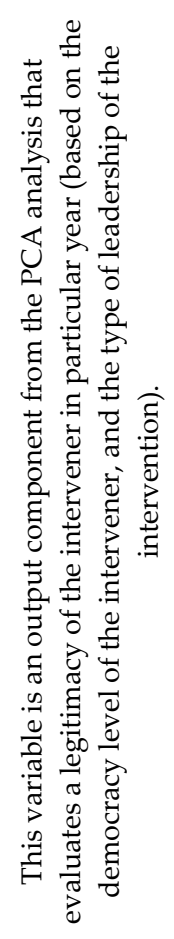 & 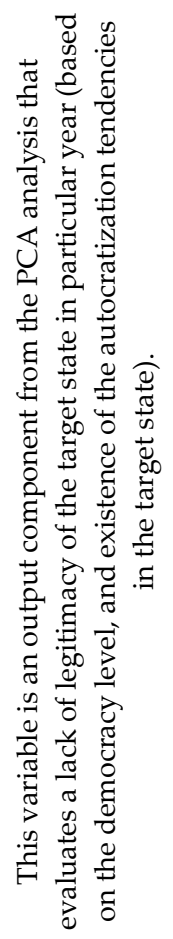 & 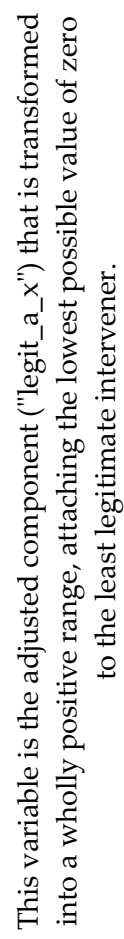 & 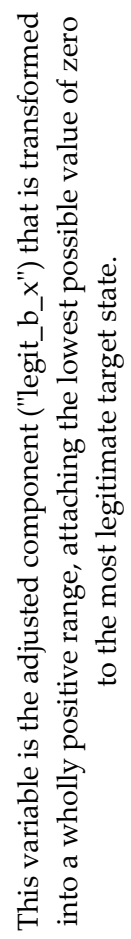 & 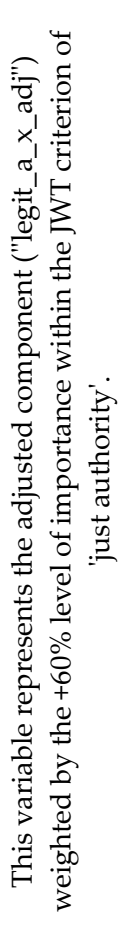 \\
\hline 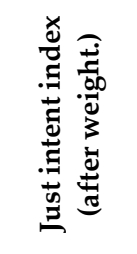 & & 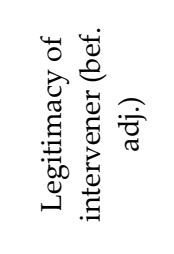 & 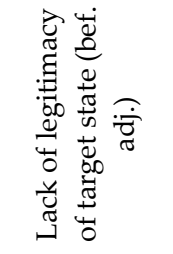 & 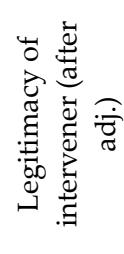 & 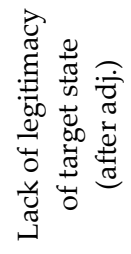 & 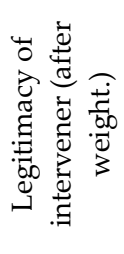 \\
\hline 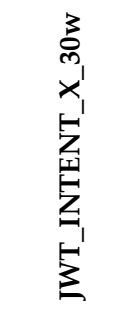 & & 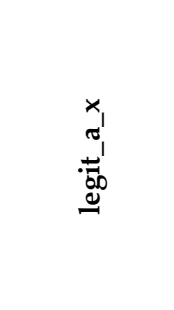 & 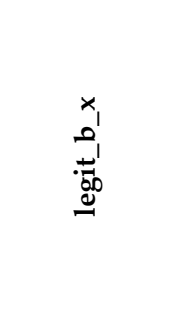 & 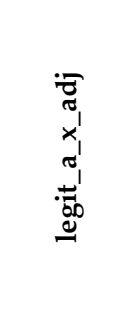 & 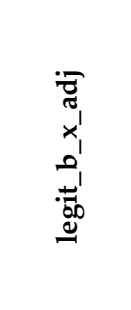 & 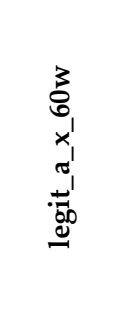 \\
\hline
\end{tabular}




\begin{tabular}{|c|c|c|c|c|c|}
\hline$\stackrel{\circ}{\circ}$ & $\begin{array}{l}\text { ळे } \\
\text { ळे }\end{array}$ & $\begin{array}{l}\text { 오 } \\
\text { in }\end{array}$ & & $\overbrace{}^{\infty}$ & $\begin{array}{l}\infty \\
\stackrel{\sim}{\sim}\end{array}$ \\
\hline$\stackrel{0}{8}$ & $\stackrel{\infty}{m}$ & $\stackrel{0}{0}$ & & $\frac{\sigma}{\varphi_{p}}$ & 8 \\
\hline F & g్ & 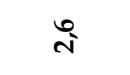 & & $\stackrel{\infty}{\sigma^{\prime}}$ & $\stackrel{\infty}{0}$ \\
\hline ¿̊. & $\begin{array}{l}\infty \\
\infty \\
\infty\end{array}$ & ボ & & ㅇ. & ᄋ़ \\
\hline 요 & ஜூ & 용 & & 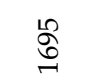 & 吕 \\
\hline 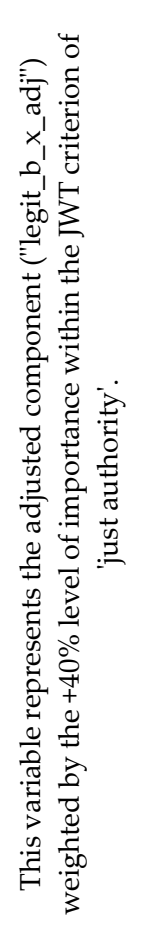 & 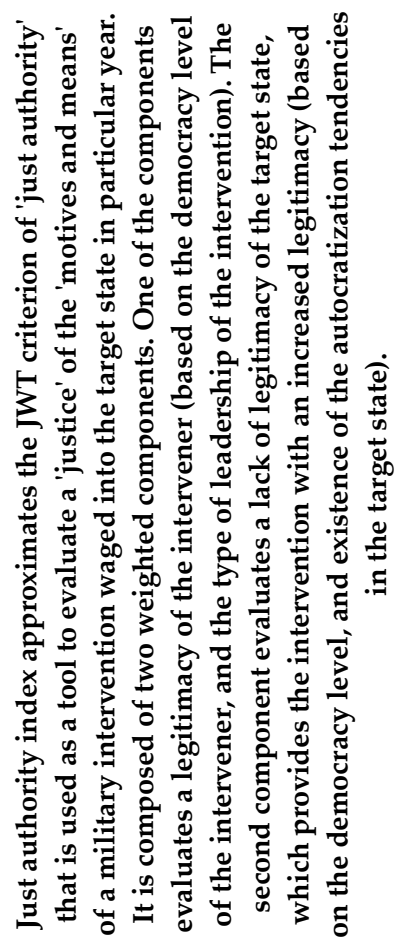 & 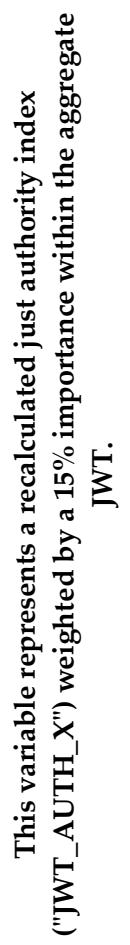 & 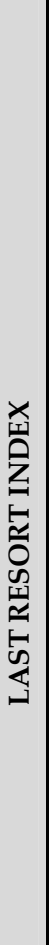 & 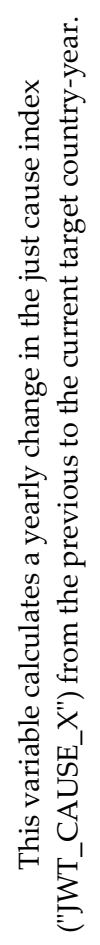 & 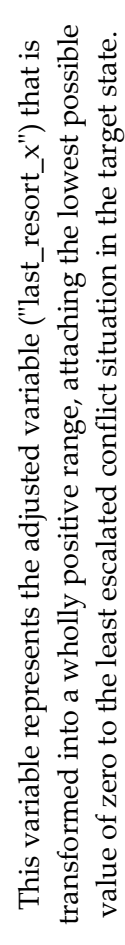 \\
\hline 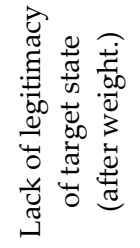 & 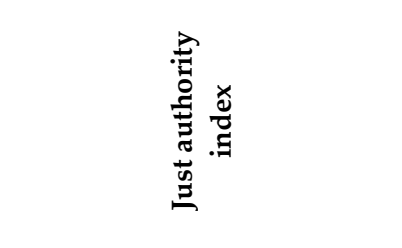 & 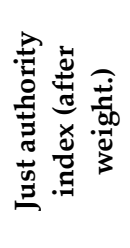 & & 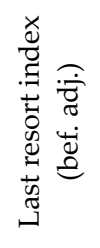 & 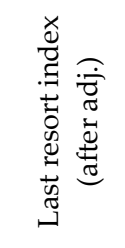 \\
\hline $\begin{array}{l}3 \\
a_{1}^{3} \\
\times 1 \\
x_{1} \\
0 \\
a_{0} \\
\stackrel{0}{0}\end{array}$ & 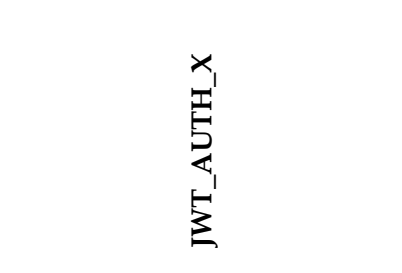 & 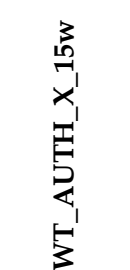 & & 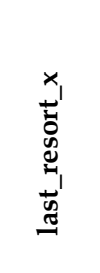 & 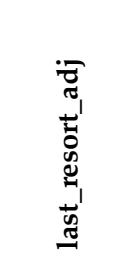 \\
\hline
\end{tabular}




\begin{tabular}{|c|c|c|c|c|}
\hline @े & $\stackrel{\circ}{\circ}$ & & s? & $\stackrel{\infty}{i}$ \\
\hline 8 & 8 & & $\hat{\bar{i}}$ & $\vec{f}$ \\
\hline : & $\stackrel{\circ}{\circ}$ & & $\stackrel{\circ}{\rightarrow}$ & $\stackrel{\circ}{\rightarrow}$ \\
\hline 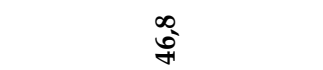 & 今 & & 8 & 8 \\
\hline 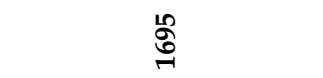 & ڤ్ & & 잉 & مి \\
\hline 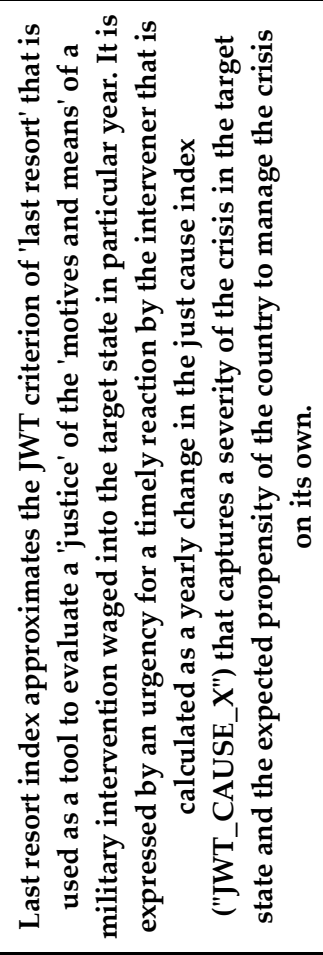 & 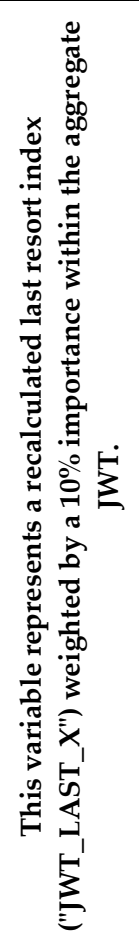 & 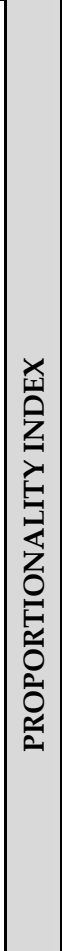 & 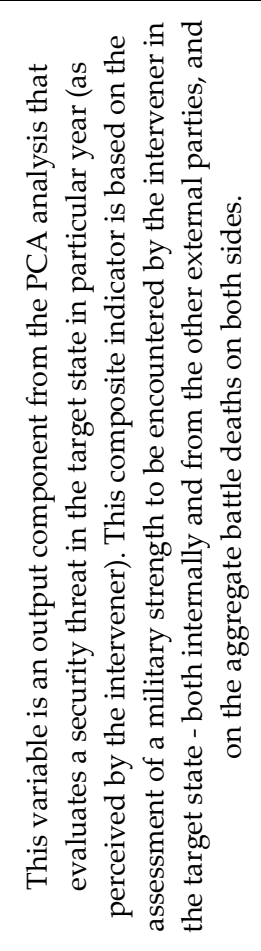 & 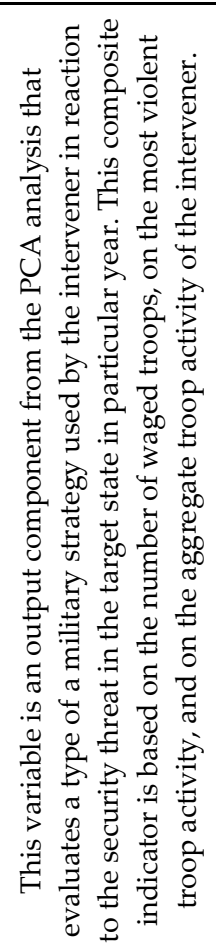 \\
\hline 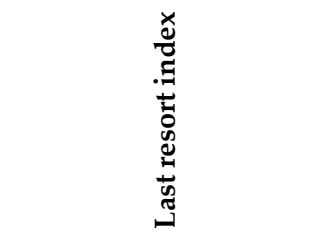 & 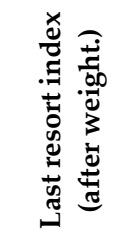 & & 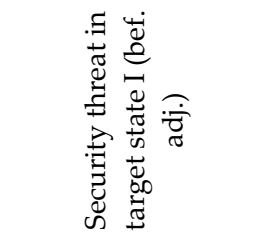 & 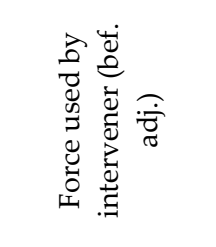 \\
\hline 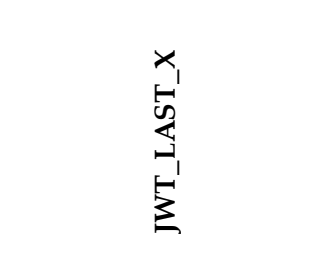 & 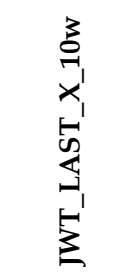 & & 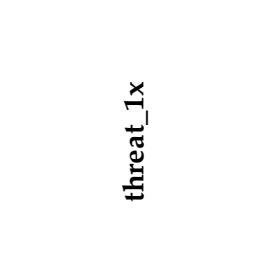 & 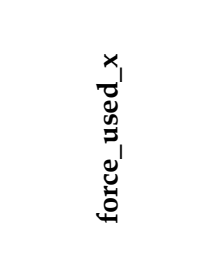 \\
\hline
\end{tabular}




\begin{tabular}{|c|c|c|c|c|c|}
\hline 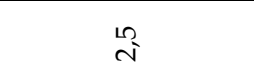 & $\underset{\sigma}{ }$ & જे & $\Xi$ & $\stackrel{0}{8}$ & $\begin{array}{l}0 \\
\text { in }\end{array}$ \\
\hline $\begin{array}{l}0 \\
\infty \\
\infty\end{array}$ & $\stackrel{0}{8}$ & ᄋ & 8 & $\stackrel{0}{0}$ & ㅇ. \\
\hline$\stackrel{\circ}{\rightarrow}$ & $\stackrel{\circ}{\rightarrow}$ & $\stackrel{\circ}{\rightarrow}$ & $\stackrel{\circ}{\rightarrow}$ & $\stackrel{m}{+}$ & $\cong$ \\
\hline ᄋ & $\hat{\sigma}$ & F & $\begin{array}{l}\infty \\
\infty\end{array}$ & $\stackrel{\infty}{\infty}$ & ते \\
\hline$\underset{్}{\operatorname{Ln}}$ & $\underset{\sim}{\stackrel{10}{\sigma}}$ & $\underset{\sim}{\stackrel{2}{6}}$ & 묘 & $\underset{\sim}{\stackrel{2}{\sigma}}$ & $\underset{\sim}{\stackrel{2}{\sigma}}$ \\
\hline 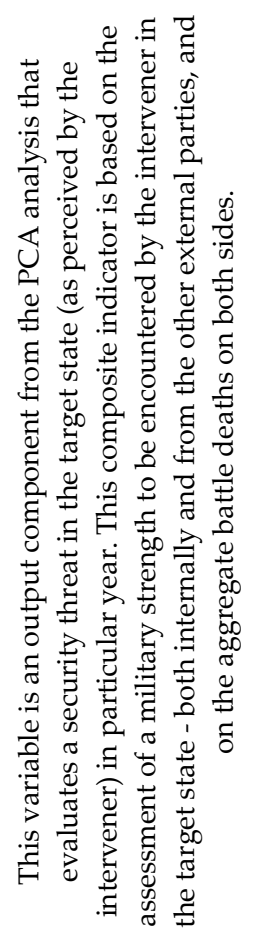 & 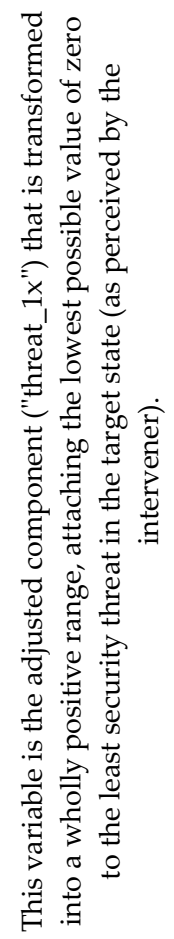 & 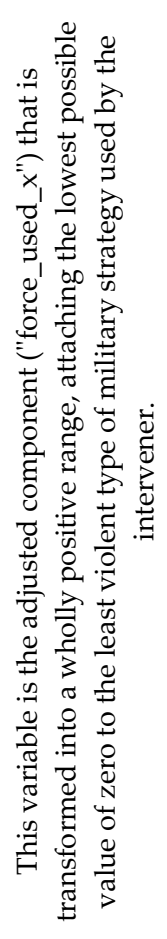 & 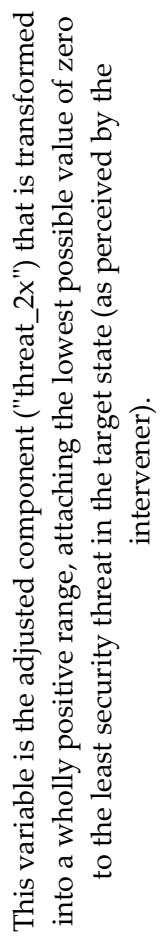 & 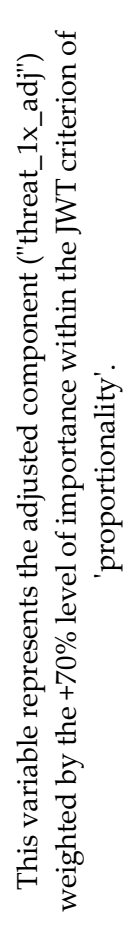 & 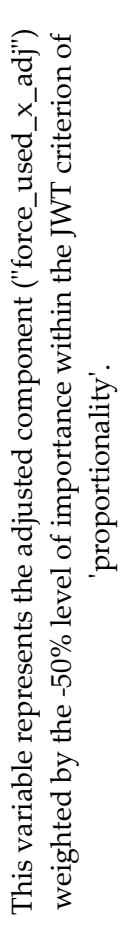 \\
\hline 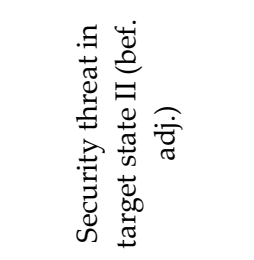 & 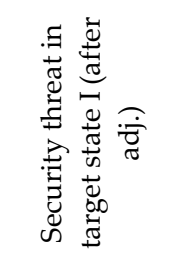 & 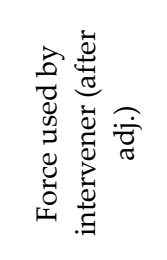 & 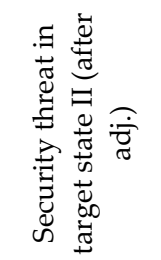 & 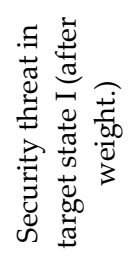 & 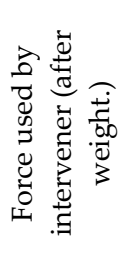 \\
\hline 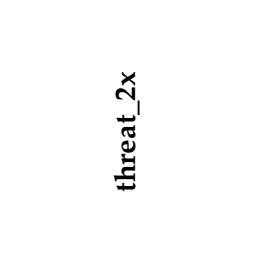 & 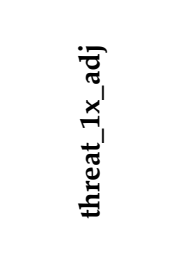 & 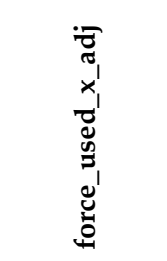 & 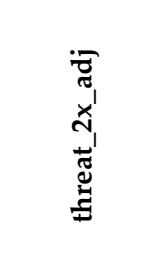 & 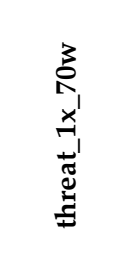 & 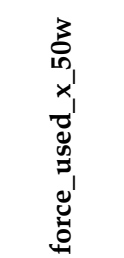 \\
\hline
\end{tabular}




\begin{tabular}{|c|c|c|c|}
\hline $\begin{array}{l}\text { ○े } \\
\text { ळे }\end{array}$ & ๙ે & क्ञ & $\stackrel{\circ}{\circ}$ \\
\hline$\stackrel{0}{\circ}$ & $\stackrel{M}{F}$ & ᄋ & ᄋ \\
\hline$\hat{\mathrm{v}}$ & $\stackrel{\infty}{\infty} \infty^{\infty}$ & $\stackrel{\infty}{\infty} \underset{\infty}{\infty}$ & $\hat{\sigma}$ \\
\hline$\tilde{\vartheta}^{2}$ & 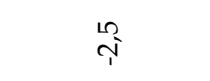 & 今్ & ेे \\
\hline 음 & 응 & 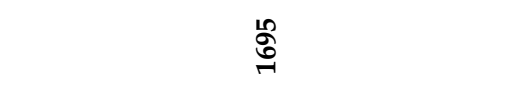 & ڤ్ \\
\hline 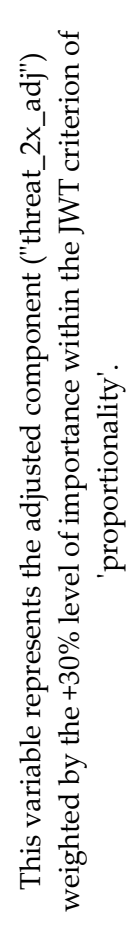 & 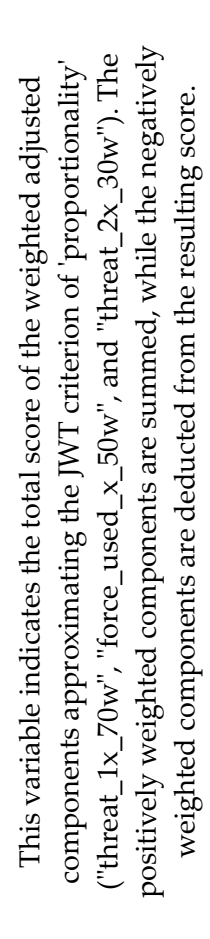 & 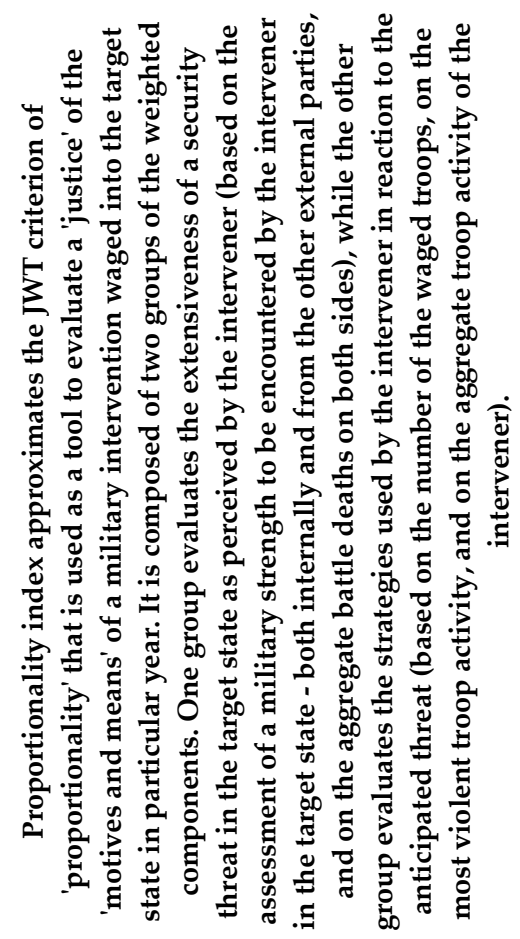 & 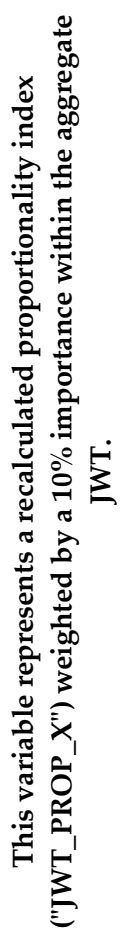 \\
\hline 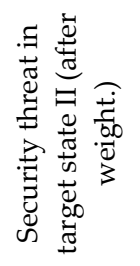 & 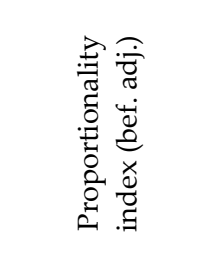 & 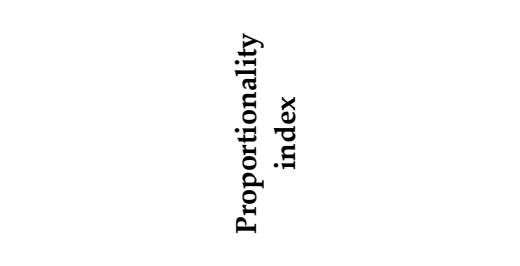 & 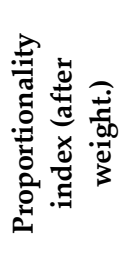 \\
\hline 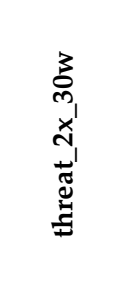 & 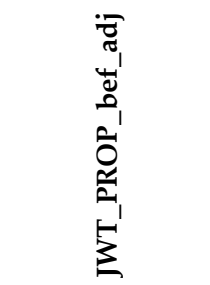 & $\begin{array}{l}x_{1} \\
\vdots \\
0 \\
\frac{1}{a} \\
5 \\
5 \\
\vdots\end{array}$ & 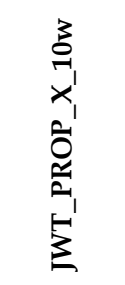 \\
\hline
\end{tabular}




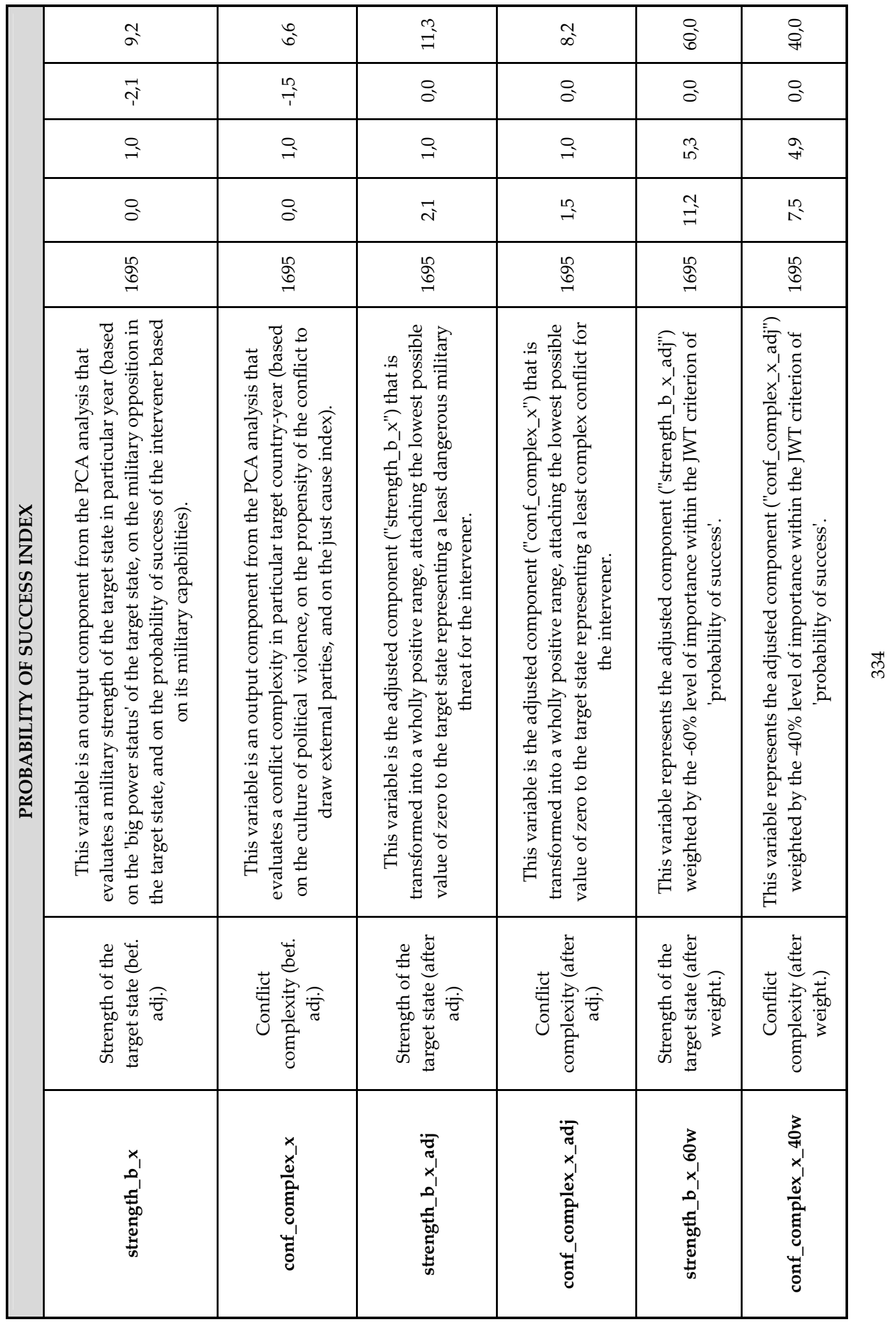




\begin{tabular}{|c|c|c|}
\hline : & $\begin{array}{l}0 \\
\dot{\sigma}\end{array}$ & $\hat{5}$ \\
\hline$\underset{\infty}{+1}$ & बे & O̊ \\
\hline$\cong$ & $\stackrel{\simeq}{\simeq}$ & $\mathfrak{N}$ \\
\hline$\stackrel{\wedge}{\infty}$ & $\underset{\infty}{\infty}$ & 焉 \\
\hline 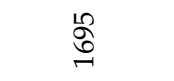 & 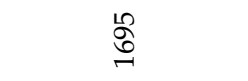 & 용 \\
\hline 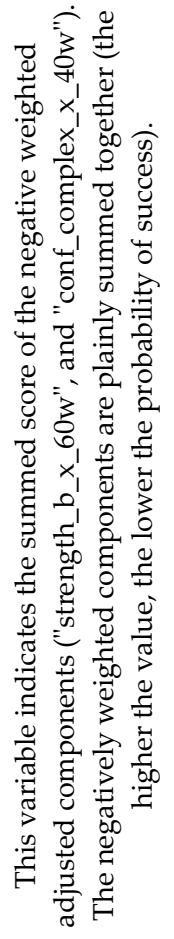 & 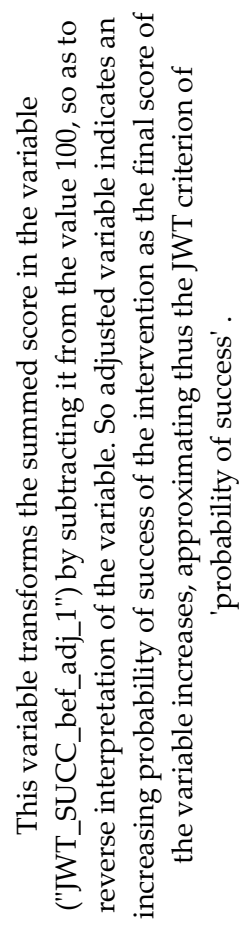 & 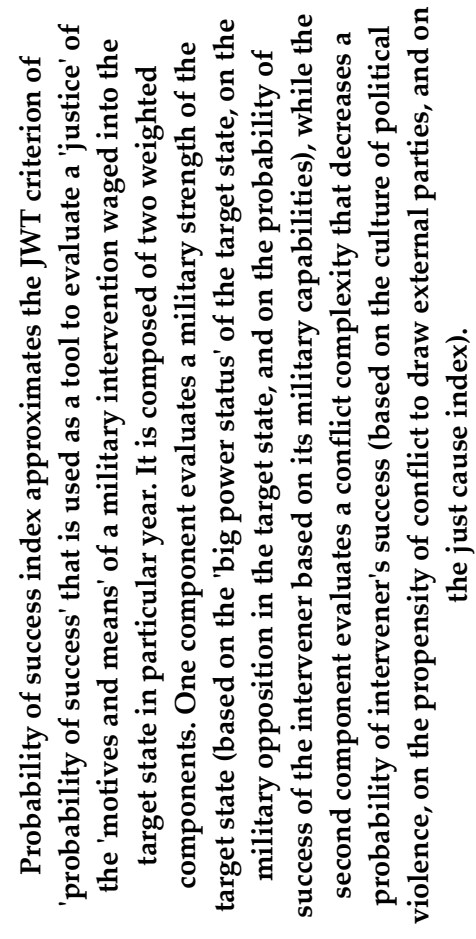 \\
\hline 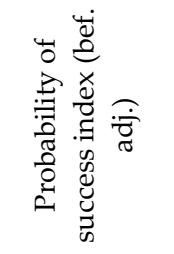 & 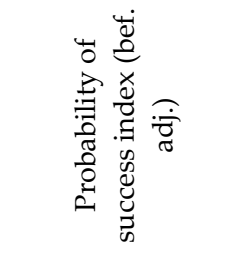 & 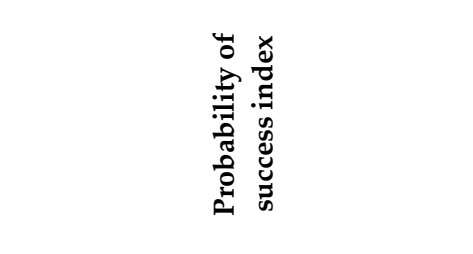 \\
\hline 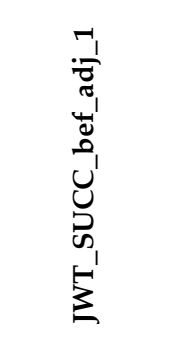 & 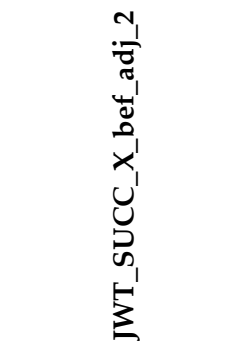 & $\begin{array}{l}x_{1} \\
u^{\prime} \\
\underbrace{\prime} \\
\omega_{1} \\
n^{\prime}\end{array}$ \\
\hline
\end{tabular}




\begin{tabular}{|c|c|c|c|}
\hline$\stackrel{\circ}{\stackrel{\circ}{\circ}}$ & & ồ & F \\
\hline$\stackrel{\circ}{\circ}$ & & $\begin{array}{l}\stackrel{0}{\mathrm{~N}} \\
\text { }\end{array}$ & 5 \\
\hline$\stackrel{+}{-}$ & & $\begin{array}{l}\circ \\
\infty\end{array}$ & $\begin{array}{l}\text { ○ } \\
\infty\end{array}$ \\
\hline ○' & & $\begin{array}{l}\text { İ } \\
\text { I }\end{array}$ & $\tilde{n}$ \\
\hline 믐 & & $\underset{\sim}{\stackrel{2}{\sigma}}$ & 농 \\
\hline 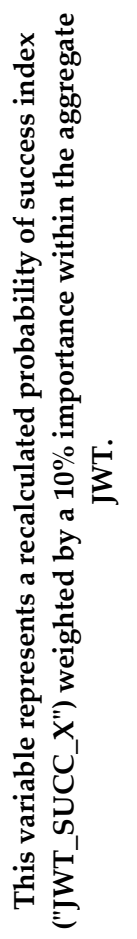 & 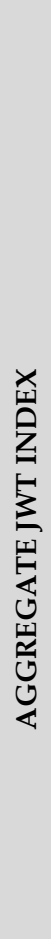 & 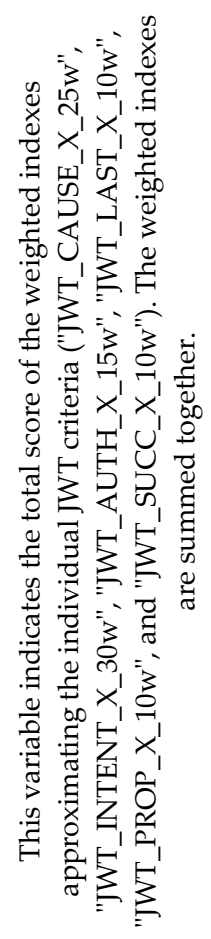 & 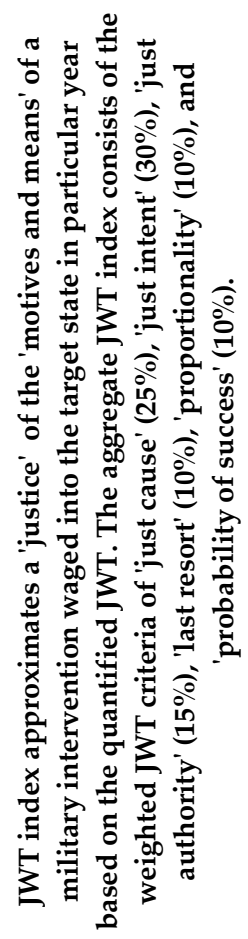 \\
\hline 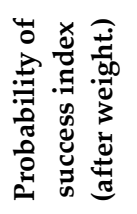 & & 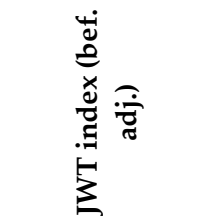 & 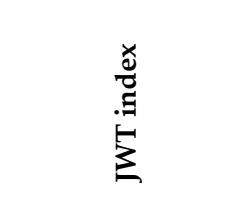 \\
\hline 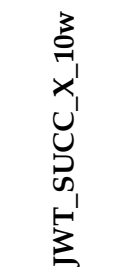 & & 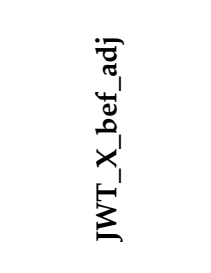 & $\begin{array}{l}x_{1} \\
-1 \\
\underline{2}\end{array}$ \\
\hline
\end{tabular}




\section{SAMENVATTING}

\section{De legitimiteit van "Humanitaire Militaire Interventies"}

Het rechtvaardigen van "Humanitaire Militaire Interventies" (HMI) en het verdedigen van het onderliggende concept in internationale discussies zijn bijzonder problematisch. Ondanks de zwakke rechtsstatus van het concept "humanitaire militaire interventies" (HMI) zelf, kan het concept niet eenvoudigweg genegeerd worden en kunnen de acties zelf niet als strikt illegaal bekeken worden. Als HMI inderdaad legitimiteit zouden hebben of krijgen, dan zou die legitimiteit de illegaliteit in vraag stellen. Het zou druk uitoefenen op het onderliggend normatieve kader en zou HMI stap voor stap in het internationale rechtssysteem verder kunnen introduceren. Het is daarom van belang dat om te bestuderen of de argumenten voor HMI en dus de legitimiteit van het concept zelf niet zo overtuigend zijn, dat het concept de voor onderstelde illegaliteit zou kunnen overstijgen en de interveniërende landen een legitem recht op interventie zou kunnen verstreken. Dit is wat deze studie beoogt te doen: de studie gaat na in hoeverre de meer dan 1000 HMI's na de Tweede Wereldoorlog empirisch gesproken aanspraak op een robuuste legitimiteit kunnen maken door na te gaan in hoeverre humanitaire motieven en humanitaire resultaten bij de interventies een rol hebben gespeeld.

Er zijn sterke en valide argumenten om HMI zowel te verdedigen als te veroordelen als een legitieme actie. Aan de ene kant kan worden beargumenteerd dat het respect voor territoriale integriteit en het afzien van het gebruik van geweld in het internationale politieke verkeer zo belangrijk zijn voor het bewaren van de vrede en de internationale stabiliteit, dat HMI niet eens als legitiem laat staan als legaal zouden kunnen beschouwd worden. Aan de andere kant, is het duidelijk dat het garanderen van het internationale recht en de verdediging van de mensenrechten vragen om de mogelijkheid om op te kunnen treden tegen inbreuken op deze principes ook buiten de territoriale grenzen van een land. De vraag is welke van de beweegredenen zou moeten overwegen: vrede en stabiliteit of mensenrechten en internationaal recht?

Deze studie neemt radicaal afstand van het moeilijke morele en legale debat over de legitimiteit van HMI. Als een alternatief voor het wegen en herwegen van het morele gewicht van diverse argumenten, wil deze studie aan de discussie zelf bijdragen door het aandragen van empirische gegevens die zouden moetent toelaten om de "humanitaire" lading van elk van de 1114 humanitaire militaire interventies in the periode 1946 - 2005. De originaliteit van deze benadering is gelegen in de systematische evaluatie van het "humanitaire gehalte" van de "motieven en middelen" voor de interventies en de "resultaten van de interventies. 
Op basis van deze evaluatie wordt nagegaan in welke mate het humanitaire karakter van de motieven en middelen ook leiden tot het bereiken van humanitair gunstige resultaten. Op deze manier wordt een index ontwikkeld die toelaat om te beoordelen welke van de onderzochte interventies het predicaat "legitieme humanitaire militaire interventie" verdienen.

De resultaten van de studie laten toe om te besluiten dat er sprake is van een empirische associatie tussen "humanitaire motieven en middelen" en "humanitaire resultaten". Dat suggereert dat het mogelijk is om humanitair acceptabele resultaten te boeken met militaire middelen. Dat was speciaal het geval als de acties ondernomen werden door een "derde partij" en als ze ondernomen werden om een regering in een derde land te ondersteunen. Bij het gebruik van meer specifieke testen om de "Just-War-Criteria" te beoordelen blijken de "just cause"en "just tintent" (rechtvaardige reden en rechtvaardige intentie) het meeste gewicht te hebben; naarmate zij meer aanwezig zijn, zijn de humanitaire resultaten ook beter. Dit verantwoordt de keuze voor een definitie van "legitieme humanitaire militaire interventies" die gebruik maakt van humanitaire motieven en middelen en van humanitaire resultaten.

De resultaten van de studie leiden tot de volgende definitie van een "legitieme humanitaire militaire interventie": "een militaire interventie door een derde land of een groep van derde landen ingegeven door humanitaire doelstellingen om ernstige inbreuken op de mensenrechten of andere elementen van het internationale humanitaire recht te voorkomen of the beëindigen, bij voorkeur om een zittende regering in een land bij te staan en gericht op het verminderen van het lijden van de bevolking in het betrokken land. Deze definitie heeft enerzijds elementen van de "just war" theorie door het vragen naar rechtvaardige reden voor de interventie (ernstige inbreuken op...) en het vragen naar een rechtvaardige intentie en anderzijds door erop aan te dringen dat er sprake is van een humanitair acceptabel resultaat (minder lijden van de bevolking). Het element in de definitie dat vraagt naar acties om een zittende regering bij te staan, is het meest problematische. Ondanks de hierboven besproken empirische associatie van acties ten behoeve van zittende regeringen met goede humanitaire resultaten, is aan de definitie toch de woorden "bij voorkeur toegevoegd"; het zou moreel te verdragend zijn om het als een noodzakelijke conditie op te leggen.

Het zou immers impliceren dat, als de inbreuken op de mensenrechten door een regering zelf zouden gepleegd worden, de internationale gemeenschap lijdzaam toe zou moeten zien en niet in zou kunnen grijpen. Dit betekent niet dat het gemakkelijke overwegingen zouden zijn: in de voorgestelde definitie wordt dit echter aan het oordeel van de politici overgelaten. Die kunnen in hun oordeelsvorming meewegen dat de empirische resultaten in deze studie aangeven dat humanitaire militaire interventies ten behoeve van rebellen groeperingen een 
groter risico inhouden met betrekking tot het eindelijk resultaat. Het is moeilijk om in deze omstandigheden te garanderen dat het menselijk lijden voor de bevolking inderdaad afneemt door de interventie. Overigens is deze overweging in het algemeen van belang: een van de resultaten van deze studie is dat ze laat zien dat het bereiken van een netto positief resultaat in termen van lijden van de bevolking geen eenvoudige zaak is.

De studie heeft ook, uit het geheel van 1114 interventies een aantal kandidaten geselecteerd die aan de voorgestelde definitie voldoen en als dusdanig het predicaat "legitiem" zouden verdienen. Zij voldoen zowel aan de criteria met betrekking tot de "humanitaire motieven en middelen" als met betrekking tot "humanitaire resultaten". Elk van de geselecteerde interventies heeft een hoger dan gemiddelde score op de Just War indicatoren en resulteerde in een aanzienlijk lager gevechts- en civiele doden. Van de 1114 interventies in de periode 1946 2005 voldeden 18 aan alle vereisten van de definitie. Als niet het totale aantal doden maar alleen de afname van de gevechtsdaden als criterium wordt genomen, zouden 81 interventies aan de definitie voldoen.

Op basis van de empirische studie is het mogelijk om enkele algemene conclusies te trekken met betrekking tot de legitimiteit van HMI. Die legitimiteit is te verdedigen op basis van de "Just War Theory" gecombineerd met de vereisten opgelegd in het kader van de zogenaamde "consequentialist approach". Ervan uitgaande dat op basis van de geldende internationale rechtsregels een HMI nog steeds als illegaal kan worden bestempeld, bevestigt deze studie de spanning die er bestaat tussen de formele illegaliteit en de legitimiteit. De vraag of de bevindingen van deze studie overtuigend genoeg zijn om het recht om te interveniëren of beter de plicht om te beschermen ook formeel in het internationale recht in te schrijven, moeten we ontbeantwoord laten. De empirische argumenten zijn aangedragen in deze studie: zij kunnen een rol spelen bij het toekomstige debat.

In het licht van het voorgaande dient ook nog opgemerkt te worden dat de coëfficiënten van het aantal gespaarde levens niet erg groot zijn. Toch lijken er argumenten aanwezig om de "verantwoordelijkheid om te beschermen" een belangrijke plaats in deze context te geven. Vooral het feit dat het aantoonbaar mogelijk is dat een humanitaire militaire interventie inderdaad het menselijk lijden van de bevolking doet afnemen, is daarbij van aanzienlijk belang. Het is dus niet automatisch zo dat het inbrengen van meer troepen en wapens in een conflictzone, tot meer ellende leidt.; toch bieden te resultaten geen grond voor al te overdreven optimisme: in veel gevallen is er nog steeds sprake van een aanzienlijke hoeveelheid menselijke verliezen ondanks de goed bedoelde motieven van de interveniërende staten. 
In weerwil van de significante en positieve resultaten, biedt de studie nog geen overtuigend antwoord op de gestelde morele vragen. Een humanitaire militaire interventie, ook als die ingegeven wordt door het verantwoordelijkheid om te beschermen, blijft een hachelijke onderneming die aanzienlijke risico's inhoudt. In alle gevallen zal een uiterst zorgvuldige politieke afweging plaats dienen te vinden waarin de potentiële korte- en lange termijn risico's tegen elkaar afgewogen worden in het licht van elke nieuwe humanitaire crisis. 


\section{CURRICULUM VITAE}

Lenka Eisenhamerová,

Born: 5.11.1980 in Beroun, Czech Republic

EMPLOYMENT

2011 - present

2011 - present

2007-2010

2002

Republic

2006

$2005-2006$

$2000-2005$

$1995-1999$

\section{EDUCATION}

2007 - present
University of New York in Prague, Czech Republic Lecturer

Bank Institute University, Czech Republic

Lecturer

Maastricht Graduate School of Governance, the

Netherlands

Research Fellow

Referent in the State Environmental Fund, Czech

Preparation and implementation of ISPA and World Bank projects

\section{SELECTED PUBLICATIONS}

Eisenhamerová, Lenka (2005). Development Policy versus Common Agricultural Policy of the EU. In: István Tarrósy \& Gerald Rosskogler (eds.) "Social, economic and political cohesion in the Danube region in light of EU enlargement". Proceedings of the 2nd DRC Summer School, Eisenstadt 2005 and the 1st DRC Winter Seminar, Pécs.

Eisenhamerová Lenka (2010). 'Actorness' of the EC/EU in International Crisis Management: Four case studies. Saarbrücken: VDM Verlag. 


\section{MGSoG DISSERTATION SERIES}

Sonila Tomini

Informal Payments for Health Care Services in Albania

MGSoG Dissertation Series, nr 25 (2011)

Jinjing Li

Dynamic Microsimulation in Public Policy Evaluation

MGSoG Dissertation Series, nr 24 (2011)

Aziz Atamanov

Rural Nonfarm Employment and International Migration as Alternatives to Agricultural

Employment:

The Case of Kyrgyztan

MGSoG Dissertation Series, nr 23 (2011)

Frieda Vandeninden

Poverty Alleviation: Aid and Social Pensions

MGSoG Dissertation Series, nr 22 (2011)

Juliana Nyasha Tirivayi

The Welfare Effects of Integrating AIDS Treatment with Food Transfers:

Evidence from Zambia

MGSoG Dissertation Series, nr 21 (2011)

Agnieska Ewa Sowa

Who's Left Behind? Social Dimensions of Health Transition and Utilization of Medical Care in Poland

MGSoG Dissertation Series, nr 20 (2011)

Emmanaouil Sfakianakis

The Role of Private Actors in the Provision of Public Goods with Applications to Infrastructure and Financial Stability

MGSoG Dissertation Series, nr 19 (2011)

Siu Hing Lo

White Collars Green Sleeves

An Interonganizational Compariso of Deteminants of Energie-Related Behaviors among Office Workers

MGSoG Dissertation Series, nr 18 (2011) 


\section{Treena $\mathrm{Wu}$}

Constraints to Human Capital Investment in Developing Countries:

Using the Asian Financial Crisis in Indonesia as a Natural Experiment

MGSoG Dissertation Series, nr 17 (2011)

Henry Espinoza Peña

Impact Evaluation of a Job-Training Programme for Disadvantaged Youths:

The Case of Projoven

MGSoG Dissertation Series, nr 16 (2011)

Florian Tomini

Between Family and Friends

Understanding the Interdependency of Private Transfers

MGSoG Dissertation Series, nr 15 (2010)

Michał Polalowski

The Institutional Transformation of Social Policy in East Central Europe:

Poland and Hungary in comparative and historical perspective

MGSoG Dissertation Series, nr 14 (2010)

Maha Ahmed

Defining, Measuring and Adressing Vulnerability:

The Case of Post Conflict Environments

MGSoG Dissertation Series, nr 13 (2010)

Pascal Beckers

Local Space and Economic Success

The role of spatial segregation of migrants in the Netherlands

MGSoG Dissertation Series, nr 12 (2011)

Victor Cebotari

Complicting Demands in Ethnically Diverse Societies

Ethnopolitical Contention and Identity Values in Europe

MGSoG Dissertation Series, nr 11 (2010)

Dennis Gyllensporre

Competing and Complementary Perspectives on the EU as a Crisis Management Actor:

An Examination of the Common Security and Defence Policy through the Lenses of Idealism and Realism

MGSoG Dissertation Series, nr 10 (2010) 
Judit Vall Castello

Business Cycle and Policy Effects on Labour Market Transitions of Older and Disabled Workers in Spain

MGSoG Dissertation Series, nr. 9 (2010)

Keetie Roelen

False Positives or Hidden Dimentions: the definition and measurement of child poverty

MGSoG Dissertation Series, nr. 8 (2010)

Denisa Maria Sologon

Earning Dynamics in Europe

MGSoG Dissertation Series, nr. 7 (2010)

Melissa Siegel

Money and Mobility: Migration and Remittances

MGSoG Dissertation Series, nr. 6 (2010)

Jessica S. Hagen-Zanker

Modest Expectations: Causes and effects of migration on migrant households in source countries

MGSoG Dissertation Series, nr. 5 (2010)

Mirtha R. Muniz Castillo

Human Development and Autonomy in Project Aid: Experiences from four

bilateral projects in Nigaragua and El Salvador

MGSoG Dissertation Series, nr. 4 (2009)

Christiane Arndt

Governance Indicators

MGSoG Dissertation Series, nr. 3 (2009)

Britta Augsburg

Microfinance - Greater Good or Lesser Evil?

MGSoG Dissertation Series, nr. 2 (2009)

Geranda Notten

Measuring and Managing Poverty Risks

MGSoG Dissertation Series, nr. 1 (2008) 